TEMPERATURE AND DISSOLVED OXYGEN IN THE OLDMAN RIVER FOLLOWING CONSTRUCTION OF THE OLDMAN RIVER DAM 


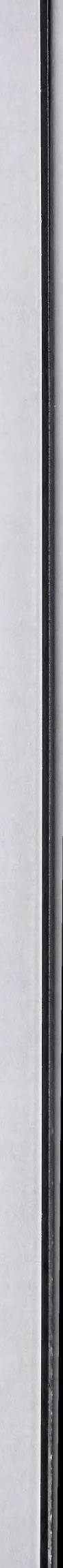




\title{
TEMPERATURE AND DISSOLVED OXYGEN IN THE OLDMAN RIVER FOLLOWING CONSTRUCTION OF THE OLDMAN RIVER DAM
}

\author{
Prepared for: \\ The Oldman River Environmental Monitoring Committee \\ Prepared by: \\ R.R.O. Hazewinkel, M.Sc. \\ Regional Services, Northern Region \\ Alberta Environment \\ And \\ K.A. Saffran, M.Sc., P.Biol. \\ Environmental Monitoring \& Evaluation Branch \\ Alberta Environment
}

July 2007 
ISBN: 0-7785-2449-3 (Printed Edition)

ISBN: 0-7785-2450-7 (On-Line Edition)

Web Site: http://www3.gov.ab.ca/env/info/infocentre/publist.cfm

Any comments, questions, or suggestions regarding the content of this document may be directed to:

Environmental Monitoring and Evaluation Branch

Alberta Environment

$12^{\text {th }}$ Floor, Oxbridge Place

$9820-106^{\text {th }}$ Street

Edmonton, Alberta T5K 2J6

Phone: (780) 427-6278

Fax: (780) 422-6712

Additional copies of this document may be obtained by contacting:

Information Centre

Alberta Environment

Main Floor, Oxbridge Place

$9820-106^{\text {th }}$ Street

Edmonton, Alberta T5K 2J6

Phone: (780) 427-2700

Fax: (780) 422-4086

Email: env.infocent@gov.ab.ca 


\section{SUMMARY}

The intent of this report is to summarise and interpret water temperature and dissolved oxygen data that have been collected at sites along the Oldman River during the summer months of 1991-2001, following the construction of the Oldman River Dam. The effects of the impoundment of the Oldman River on water temperature and dissolved oxygen in the $327 \mathrm{~km}$ from the Oldman River Dam to the confluence of the Oldman and Bow rivers are assessed. Predictions made prior to the impoundment of the Oldman River are evaluated and compared with post impoundment records. As well, the pre-impoundment implementation of the WQRRS model is examined as the basis for the establishment of current minimum flows.

Post-impoundment flows have resulted in an improvement in dissolved oxygen levels relative to historic conditions. Prior to impoundment, diel ( $24 \mathrm{~h})$ minima often fell to critically low levels from downstream of Monarch to the confluence of the Bow and Oldman rivers. Under the existing (post-impoundment) flow regime, the incidence of dissolved oxygen levels falling below the $5 \mathrm{mg} \cdot \mathrm{L}^{-1}$ Alberta Surface Water Quality Acute Guideline (Alberta Environment, 1999) is far less frequent. Under the present flow management regime, it is unlikely that dissolved oxygen levels have fallen below the guideline upstream of Lethbridge. Downstream of Lethbridge to the confluence of the Bow and Oldman rivers, submerged aquatic vegetation and other sources of biological and chemical oxygen demand continue to depress nocturnal dissolved oxygen concentrations, resulting in levels that may approach and occasionally fall below guidelines. Minimum flows that permit the effective dilution of oxygen consuming processes will continue to be a principal means by which the severe oxygen deficits that occurred prior to impoundment are avoided. Periodic scouring flows with sufficient current velocities to reduce accumulated vegetation and sediment nutrient content could also mitigate oxygen depletion. Recent wastewater treatment plant upgrades in Lethbridge have substantially reduced nutrient loading from that source. A continued effort to reduce nutrient loading from both point and diffuse sources in the basin will be part of any long-term solution.

As predicted prior to reservoir construction, thermal processes within the reservoir govern water temperatures immediately downstream of the dam. This has resulted in a shift in peak summer temperatures from mid-July through mid-August in the pre-impoundment period to earlythrough mid-September in the post-impoundment period. Average mid-summer postimpoundment temperatures can be more than $6^{\circ} \mathrm{C}$ below historic temperatures, while average temperatures from mid-September to mid-November can exceed historic temperatures by more than $2^{\circ} \mathrm{C}$. These changes are evident at least as far as Monarch and possibly as far as Lethbridge although substantial change in the post-impoundment water management regime, as well as the lack of a continuous historic record at these locations, precludes conclusive analysis.

Temperature and oxygen requirements for recruitment and survival of several fish species are used to interpret continuous monitoring records, as an aid to fish habitat suitability assessment. However, as habitat suitability is contingent on many factors besides water temperature and dissolved oxygen, assessment is left to fisheries resource managers. 


\section{TABLE OF CONTENTS}

SUMMARY.

LIST OF TABLES

LIST OF FIGURES.

LIST OF APPENDICES

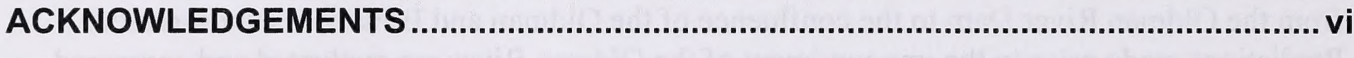

...iii

iv

. v

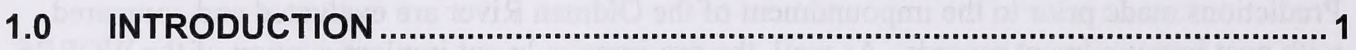

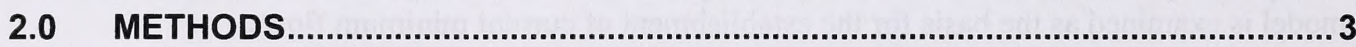

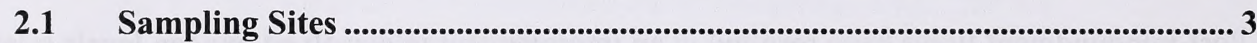

2.2 Dissolved Oxygen ................................................................................................... 3

2.3 Temperature ............................................................................................................... 7

2.4 Discharge ….................................................................................................................. 7

$2.5 \quad$ Air Temperature.................................................................................................... 8

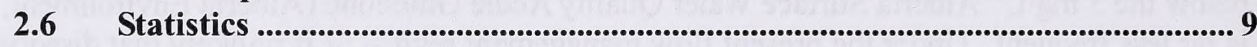

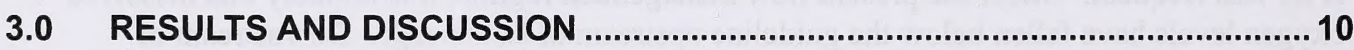

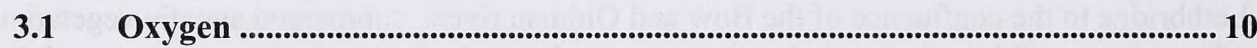

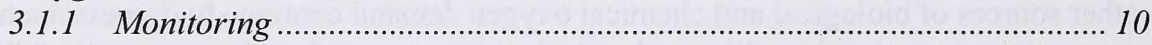

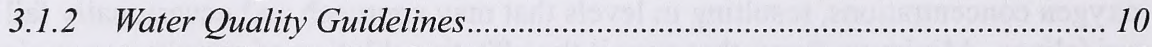

3.1.2.1 Historic Conditions.................................................................. 10

3.1.2.2 Post-impoundment Conditions................................................... 12

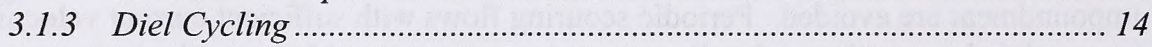

$3.2 \quad$ Water Temperature......................................................................................................... 18

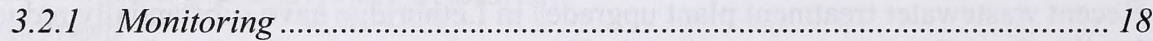

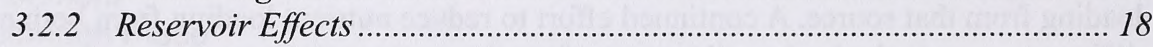

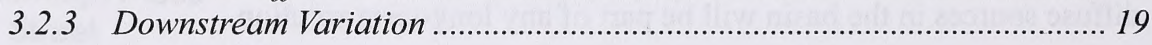

3.2.4 Model Predictions .............................................................................. 24

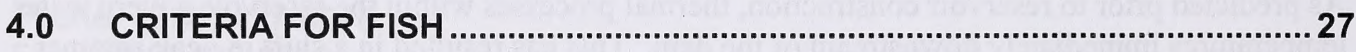

4.1 Oxygen Criteria............................................................................................................. 27

4.2 Temperature Criteria ..................................................................................................... 28

4.2.1 Chronic and Acute Temperatures .......................................................... 28

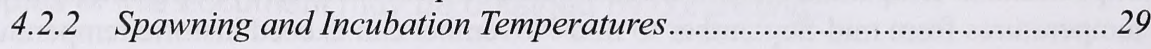

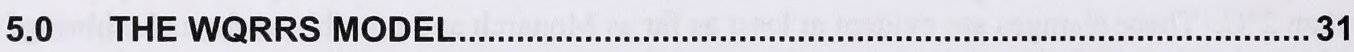

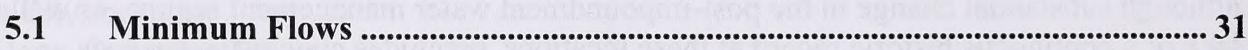

5.2 Post-impoundment Simulations.................................................................................. 32

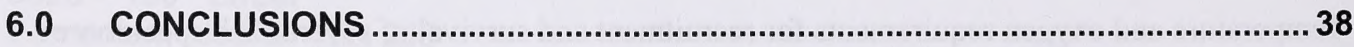

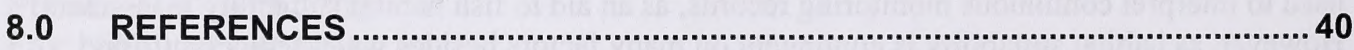




\section{LIST OF TABLES}

Table 2.1 Location and description of sampling sites on the Oldman River...................... 3

Table 2.2 ENVIRODAT location codes taken to correspond with post-impoundment monitoring sites

Table 2.3 Frequency and duration of sampling at seven sites during the post-impoundment period, Datasonde

Table 2.4 Frequency and duration of sampling at eight sites during the post-impoundment period, temperature logger.

Table 2.5 WSC hydrometric stations corresponding to inflows and withdrawals used in flow calculations

Table 2.6 Meteorological stations used for air temperature data. All data are from Environment Canada, except where noted. 8

Table 3.1 Incidences of daily minimum dissolved oxygen below $5 \mathrm{mg} \cdot \mathrm{L}^{-1}$ approximately 8 $\mathrm{km}$ downstream of the Lethbridge wastewater treatment plant, and corresponding daily mean flows at Hwy. 3

Table 3.2 Pearson Correlation matrix for dissolved oxygen and equilibrium dissolved oxygen near Monarch, u/s Lethbridge, and d/s Lethbridge 16

Table 3.3 Comparison of reservoir temperature with water temperature in the Oldman River $100 \mathrm{~m}$ downstream of the outflow and near Brocket ......................................... 20

Table 3.4 Dates during which the spillway was operated................................................. 21

Table 4.1 Chronic temperature criteria for spawning and incubation of six fish species in the Oldman River.................................................................................... 30

Table 5.1 Minimum flow requirements $\left(\mathrm{m}^{3} \cdot \mathrm{s}-1\right)$ in the Oldman River.............................. 31

Table 5.2 Dissolved oxygen criteria for walleye and sauger, used in establishing minimum flows downstream of Lethbridge. Criteria from Taylor and Barton (1992), for comparison

Table 5.3 Comparison of biomass $\left(\mathrm{g} \cdot \mathrm{m}^{-2}\right)$ values for macrophytes and benthic algae used in the simulation of post impoundment conditions in river reaches A-I for 1982-1986 with actual pre- and post-impoundment values 35 


\section{LIST OF FIGURES}

Figure 2.1 Map of Datasonde and thermograph sites along the Oldman River, downstream of the Oldman Reservoir .

Figure 3.1 Daily average water temperatures in the Oldman River near Brocket and Fort Macleod for pre-impoundment, transition, and post-impoundment years............ 22

Figure 3.2 Water level ( $\mathrm{m}$ above sea level) in the Oldman Reservoir, 1991-2001 .............. 26 


\section{LIST OF APPENDICES}

APPENDIX A Dissolved oxygen, air temperature, and flow figures

44

APPENDIX B Water temperature, air temperature, and flow figures and water temperature tables

APPENDIX C Observed water temperature and dissolved oxygen levels evaluated against sport fish criteria (Taylor and Barton 1992)

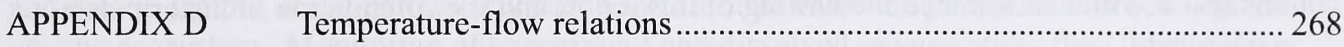




\section{ACKNOWLEDGEMENTS}

D. Allan, C. Beers, L. Boucher, D. Brymer, A. DiMaria, R. Eade, T. Grieef, C. Robertshaw, and R. Walker conducted field analyses, data collection, and preliminary data analyses, and compiled the post-impoundment time-series data. D. LeClair, O. Mahler, C. Runions, R. Tchir, and R. Walker provided and/or compiled historic data, meteorological data, and discrete data. B. Halbig and M. Raven provided technical and editorial assistance. M. Bryski, S. Figliuzzi, W. Koning, D. McDonald, D. Magowan, A. Sosiak, and D. Trew reviewed the report and provided comments. P. Mitchell initiated the writing of this report and the compilation of historic data. 


\section{$1.0 \quad$ INTRODUCTION}

The suitability of stream and river habitat for the support of aquatic life, while based on a wide variety of chemical, physical, and biological criteria, is often gauged using temperature and dissolved oxygen. These two variables have a fundamental and well-documented influence on biological processes at all trophic levels. Both can be recorded using automated sampling equipment to provide continuous records over long periods, allowing for rigorous monitoring of basic ecosystem processes. Because dissolved oxygen can itself be influenced by many biotic and abiotic factors, it is a particularly useful indicator of base-line processes that occur in the aquatic ecosystem. Monitoring of temperature and dissolved oxygen along the Oldman River mainstem has been extensive during the period following the construction of the Oldman River Dam in 1991, permitting a detailed analysis of the effects of impoundment on this system.

Temperature and dissolved oxygen are affected by changes in flow and are often the basis for the development of minimum flows on regulated rivers. Low flows permit greater temperature variability. This increased variability can stress sensitive populations of aquatic organisms, causing failures in recruitment for fish and invertebrate species, as well as major shifts in aquatic plant communities. Low flows also cause an upstream shift in the thermal zonation of a river, restricting habitat availability for species that have a lower tolerance for high temperatures. This can be especially significant where structures such as weirs and dams inhibit the migration of aquatic organisms.

Low flows also reduce the dilution of municipal, industrial, and agricultural effluent and runoff to the river, magnifying the effects of these discharges on aquatic life. Aquatic plant communities thrive under effluent-derived nutrient loads, causing large diel $(24 \mathrm{~h})$ variation in dissolved oxygen concentrations. Coupled with the effect of reduced dilution of effluent-derived oxygen demand, respiration by aquatic plants and other organisms can cause nocturnal dissolved oxygen concentrations to fall to levels that can be detrimental to other aquatic life. In addition, low flows permit the establishment of 'weedy' plant communities that would otherwise be kept in check by scouring and reduced bed stability. The decay of organic material derived from these plant communities further increases oxygen demand.

The Oldman River Dam was constructed to resolve water supply shortages within the Oldman Basin. Prior to impoundment, the abstraction of water from the river, primarily for irrigation purposes, was limited by naturally available flows. Natural flows were deemed insufficient to satisfy irrigation requirements while maintaining sufficient flow to protect aquatic life and to satisfy municipal requirements. The diversion of water from the Oldman River for irrigation purposes often caused historical mid-summer flows downstream of the Lethbridge Northern Headworks Diversion (LNHD) to approach $1 \mathrm{~m}^{3} \cdot \mathrm{s}^{-1}$. By comparison, average flows $45 \mathrm{~km}$ upstream of the LNHD weir were $49.3 \mathrm{~m}^{3} \cdot \mathrm{s}^{-1}$ and $23.4 \mathrm{~m}^{3} \cdot \mathrm{s}^{-1}$ during July and August of 1966 through 1990. During July and August of 1993 through 1999, after the reservoir had attained present operating levels, average flows upstream of the LNHD weir were $75.1 \mathrm{~m}^{3} \cdot \mathrm{s}^{-1}$ and 42.1 $\mathrm{m}^{3} \cdot \mathrm{s}^{-1}$, respectively. Average daily flows downstream of the weir did not fall below $12 \mathrm{~m}^{3} \cdot \mathrm{s}^{-1}$.

The situation with regard to historically low flows has been greatly improved following the construction of the Oldman River Dam and the accompanying implementation of more 
conservative water management practices. Preliminary analyses of the effects of postimpoundment flows on temperature and dissolved oxygen for 1991-1993 were reported in Golder Associates (1995). The present analysis includes further post-impoundment data that have been collected to date, as well as a more extensive set of pre-impoundment data. Current conditions are compared with predicted conditions and the bases for these predictions are examined. Current minimum flows are also examined relative to their water quality-based objectives. 


\section{$2.0 \quad$ METHODS}

\subsection{Sampling Sites}

Data collection following the construction of the Oldman River Dam occurred at 11 sites along the Oldman River mainstem, from directly downstream of the Oldman Reservoir to the confluence of the Bow and Oldman rivers (Figure 2.1). The location of each site, including the river distance in relation to the Oldman Reservoir, the site location code, and the site coordinates, is given in Table 2.1. Sampling sites were located to permit monitoring of changes caused by major withdrawals, such as the LNHD, and inputs, such as major tributaries and industrial and municipal effluent discharges. The data treated in this report relate to dissolved oxygen and water temperature, and were collected on a half-hourly or hourly basis during April through October of 1991-2001. The frequency and duration of sampling are given in Tables 2.2 and 2.3 .

Table 2.1 Location and description of sampling sites on the Oldman River

\begin{tabular}{|c|c|c|c|c|}
\hline SITE DESCRIPTION & $\begin{array}{l}\text { ENVIRODAT IDENTIFICATION \# } \\
\text { (NAQUADAT) }\end{array}$ & LATITUDE & LONGITUDE & RIVER km \\
\hline $100 \mathrm{~m} \mathrm{~d} / \mathrm{s}$ of Oldman Reservoir & AB05AB0020 (00AL05AB0101) & $49^{\circ} 33^{\prime} 40^{n}$ & $113^{\circ} 54^{\prime} 00^{\prime \prime}$ & 0.00 \\
\hline Near Brocket & $A B 05 A B 0050(00 A L 05 A B 0151)$ & $49^{\circ} 33^{\prime} 27^{\prime \prime}$ & $113^{\circ} 49^{\prime} 20^{\prime \prime}$ & 6.41 \\
\hline Downstream of the LNHD & AB05AB0110 (00ALO5AB0271) & $49^{\circ} 41^{\prime} 38^{\prime \prime \prime}$ & $113^{\circ} 34^{\prime} 08^{\prime \prime}$ & 52.05 \\
\hline Near Ft. Macleod & AB05AB0140 (00AL05AB0301) & $49^{\circ} 43^{\prime} 15^{\prime \prime}$ & $113^{\circ} 27^{\prime} 00^{\prime \prime}$ & 65.59 \\
\hline d/s Ft. Macleod at Rocky Coulee & AB05AB0290 (00AL05AB0442) & $49^{\circ} 51^{\prime} 08^{\prime \prime}$ & $113^{\circ} 14^{\prime} 50^{\prime \prime}$ & 100.63 \\
\hline Near Monarch at Hwy. 3 Bridge & AB05AC0020 (00AL05AC0051) & $49^{\circ} 47^{\prime} 25^{\prime \prime}$ & $113^{\circ} 07^{\prime} 25^{\prime \prime}$ & 115.02 \\
\hline $\mathrm{d} / \mathrm{s}$ of Belly River Confluence & AB05AD0270 (00AL05AD0611) & $49^{\circ} 42^{\prime} 33^{\prime \prime}$ & $112^{\circ} 58^{\prime} 21^{\prime \prime}$ & 137.66 \\
\hline Above Lethbridge at Hwy. 3 & AB05AD0340 (00AL05AD0701) & $49^{\circ} 41^{\prime} 05^{\prime \prime}$ & $112^{\circ} 51^{\prime} 00^{\prime \prime}$ & 168.31 \\
\hline Below Lethbridge at Pavan Park & AB05AD0570 (00AL05AD0782) & $49^{\circ} 45^{\prime} 15^{\prime \prime}$ & $112^{\circ} 51^{\prime} 08^{\prime \prime}$ & 179.36 \\
\hline Below Picture Butte at Hwy. 845 & AB05AD0750 (00AL05AD1002) & $49^{\circ} 51^{\prime} 30^{\prime \prime}$ & $112^{\circ} 37^{\prime} 24^{\prime \prime}$ & 213.72 \\
\hline Hwy. $36, \mathrm{u} / \mathrm{s}$ of Expanse Coulee & AB05AG0010 (00ALO5AG0001) & $49^{\circ} 57^{\prime} 40^{n}$ & $112^{\circ} 05^{\prime} 05^{\prime \prime}$ & 280.88 \\
\hline Bow River Confluence & AB05AG0240 (O0AL05AG0912) & $49^{\circ} 56^{\prime} 02^{\prime \prime}$ & $111^{\circ} 41^{\prime} 48^{\prime \prime}$ & 327.00 \\
\hline
\end{tabular}

\subsection{Dissolved Oxygen}

Historic (pre-1991) dissolved oxygen data were compiled from ENVIRODAT (formerly NAQUADAT; VMV codes 100922, 8101, 8102), from DACQ (archive; station code FINCASTL), from the Long-Term River Network (LTRN) sites near Lethbridge and Hwy. 36, and from miscellaneous hard copy. The ENVIRODAT data were obtained using azide-Winkler titrations, according to 'Standard Methods' (Greenberg et al. 1992), and using dissolved oxygen probes. Changing monitoring objectives have made necessary the establishment of many monitoring sites in the Oldman basin that do not directly correspond with existing automated water quality data logging (Hydrolab Corp. Datasondes I, IIH, and H2O) and thermograph sites. The location codes of these sampling sites are shown in Table 2.4, along with the corresponding Datasonde and thermograph sites. The LTRN site at Lethbridge was taken to correspond with the monitoring site upstream of Lethbridge, while the LTRN site at Hwy. 36 was taken to 
correspond with the monitoring site near the confluence of the Bow and Oldman rivers. Data available for the period of 1989-1991, collected at Fincastle using a remotely operated flowthrough monitor or robot monitor (Cleary 1962), are the most extensive continuous preimpoundment data that are presented in this report. Additional continuous data were collected in 1985 and again in 1988 to calibrate the WQRRS model. Only the 1985 data were used in the final calibration and appear as figures in HydroQual (1990); the numerical values are unavailable. The data collected in July and August of 1988 (upstream and downstream of Monarch, upstream and downstream of Lethbridge, and upstream and downstream of Fincastle) were transcribed from hard copy; these are currently stored in data files of the Water Quality Section, AENV.

Table 2.2 ENVIRODAT location codes taken to correspond with post-impoundment monitoring sites

\begin{tabular}{|c|c|}
\hline SAMPLING SITE & CORRESPONDING ENVIRODAT LOCATION CODE \\
\hline $100 \mathrm{~m} \mathrm{~d} / \mathrm{s}$ of Oldman Reservoir & AB05AA0070; AB05AA0080; AB05AA0420; AB05AB0010 \\
\hline Near Brocket & AB05AB0040; AB05AB0060; AB05AB0070 \\
\hline $\mathrm{d} / \mathrm{s}$ of the LNHD Diversion & n $/ a$ \\
\hline Near Ft. Macleod & AB05AB0130; АВ05AB0150; AB05AB0160 \\
\hline Near Rocky Coulee & $\ln / \mathrm{a}$ \\
\hline Near Monarch & AB05AB0300; AB05AC0010; AB05AC0030; AB05AC0040 \\
\hline d/s of the Belly River Confluence & n $/ a$ \\
\hline Above Lethbridge at Hwy. 3 & $\begin{array}{l}\text { AB05AD0010; AB05AD0260; AB05AD0300; AB05AD0310; AB05AD0320; } \\
\text { AB05AD0330; AB05AD0370; AB05AD0380; AB05AD0390 }\end{array}$ \\
\hline Below Lethbridge & $\begin{array}{l}\text { AB05AD0410; AB05AD0420; AB05AD0 430; AB05AD0440; AB05AD0450; } \\
\text { AB05AD0460; AB05AD0470; AB05AD0480; AB05AD0490; AB05AD0500; } \\
\text { AB05AD0510; AB05AD0520; AB05AD0530; AB05AD0540; AB05AD0550; } \\
\text { AB05AD0560; AB05AD0580; AB05AD0590; AB05AD0600; AB05AD0610; } \\
\text { AB05AD0620; AB05AD0630; AB05AD0640; AB05AD0650; AB05AD0660; } \\
\text { AB05AD0670;AB05AD0680; AB05AD0690; AB05AD0700; AB05AD0730 }\end{array}$ \\
\hline Below Picture Butte at Hwy. 845 & AB05AD0740; AB05AD0760; AB05AD0770; AB05AD0780; AB05AD0790 \\
\hline Hwy. 36 & $\begin{array}{l}\text { AB05AG0010; AB05AG0020; AB05AG0070; AB05AG0080; AB05AG009 } \\
\text { AB05AG0100; AB05AG0110; AB05AG0120 }\end{array}$ \\
\hline Bow River Confluence & $\begin{array}{l}\text { AB05AG0160; AB05AG0170; AB05AG0190; AB05AG0200; AB05AG0210; } \\
\text { AB05AG0220; AB05AG0230 }\end{array}$ \\
\hline
\end{tabular}

Post-impoundment (1991-present) data were collected using temperature compensated, calibrated dissolved oxygen probes (Hydrolab Corp. Datasondes I, IIH, and H2O). Datasondes were deployed in clear, weed-free channels at depths of $0.2 \mathrm{~m}$ to $1.0 \mathrm{~m}$ to permit periodic retrieval. Datasondes were retrieved at approximately bi-weekly intervals, and calibrated units re-deployed in their place. Samples for azide-Winkler analysis were obtained in duplicate at the deployment and retrieval of Datasondes. Samples were fixed in situ and titrated within $24 \mathrm{~h}$. While a certain amount of drift from calibration values is unavoidable, data that varied by more than $0.5 \mathrm{mg} \cdot \mathrm{L}^{-1}$ from the values obtained using azide-Winkler analyses were rejected. 


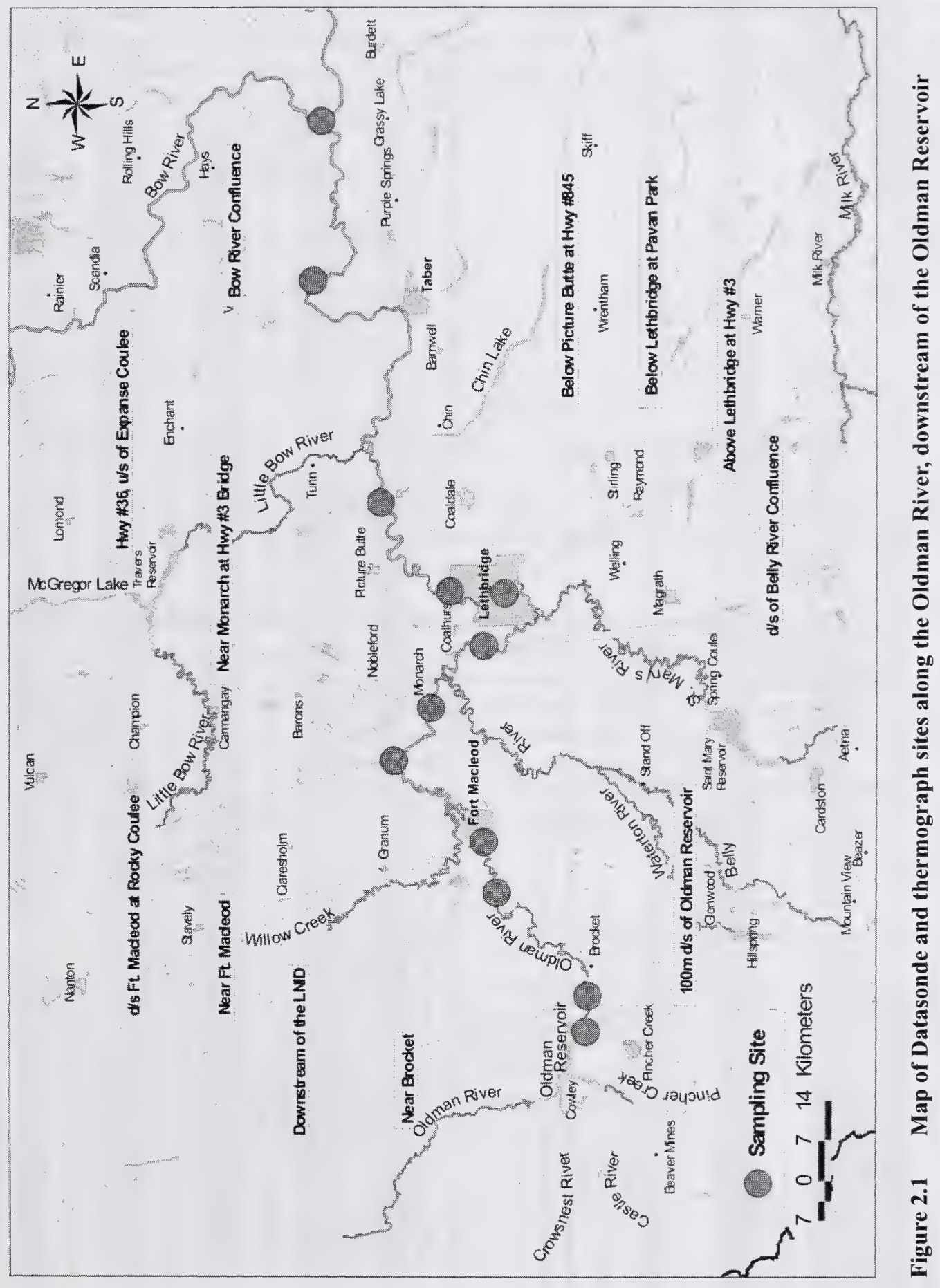




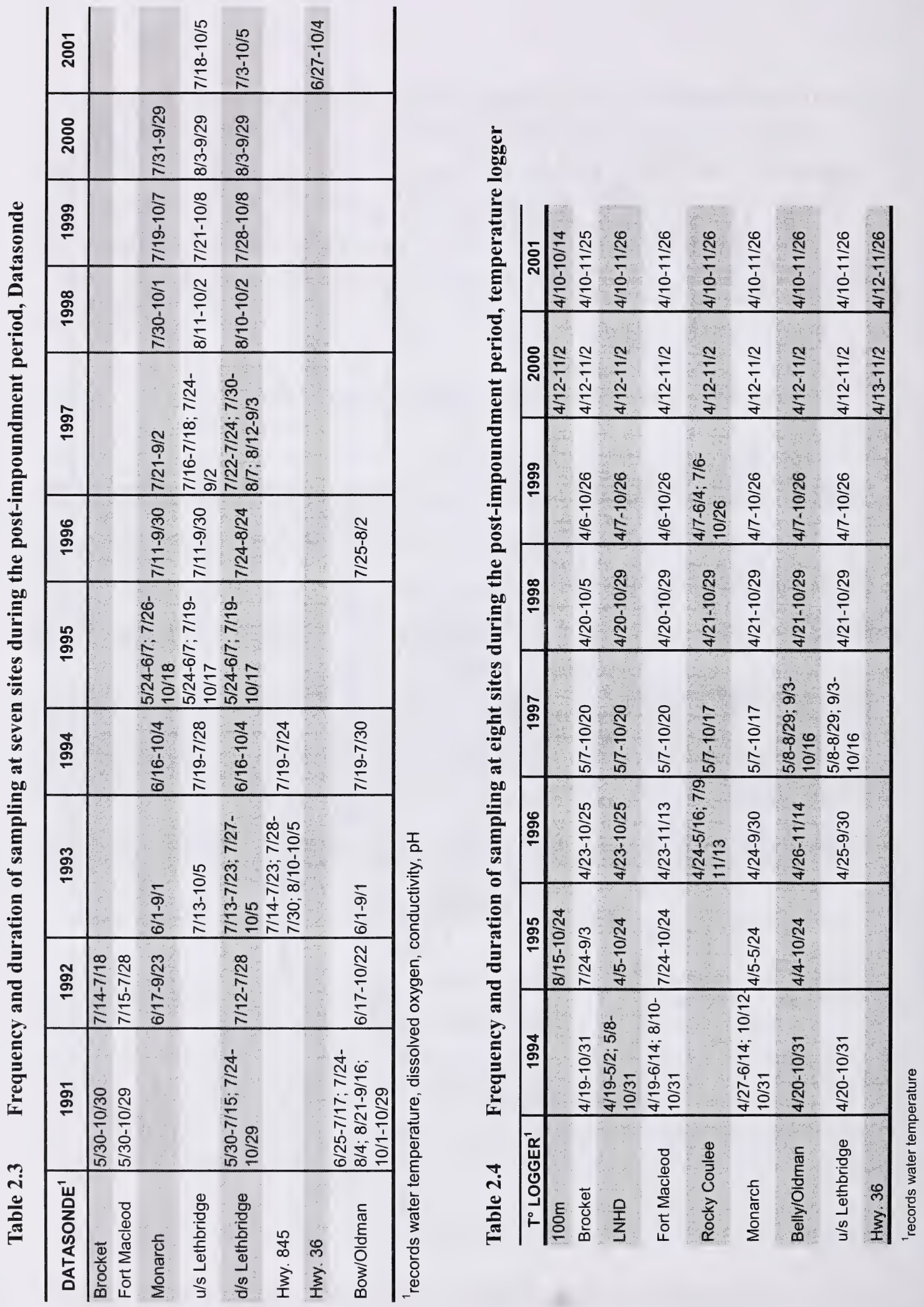


Equilibrium solubility of oxygen in water, used for baseline evaluation of recorded levels, was determined by the method of Benson and Krause (1980), in Mortimer (1981). Values for atmospheric pressure used in the solubility model were approximated from the elevations of the sampling sites, which were determined from 1:100,000 scale NTS maps. Water temperature was recorded concurrently with dissolved oxygen using the Datasonde probes.

\section{$2.3 \quad$ Temperature}

Continuous temperature data for the period prior to the construction of the Oldman River Dam exist for sites near Brocket, Fort Macleod, and Fincastle. Data from Brocket and Fort Macleod, recorded in 1985, were transcribed from thermograph tapes (Ryan Instruments) and are currently stored in data files of the Water Quality Section, AENV. Additional data from Brocket are compiled in the Water Resources Data Acquisition System (DACQ). These data are derived from real-time water temperature monitoring undertaken in 1988-1993 at the Water Survey of Canada (WSC) hydrometric station near Brocket. The WSC data were recorded by a Handar 560 datalogger (Handar, Inc.) at a resolution of $0.4^{\circ} \mathrm{C}$ (cf. $0.01^{\circ} \mathrm{C}$ for thermographs/Datasondes). Water temperature data from the robot monitor near Fincastle exist for 1989-1991. In addition, data collected at numerous monitoring sites along the Oldman mainstem were compiled from ENVIRODAT (sample codes 100925, 2061, 2062), from the Long-Term River Network (LTRN) sites near Lethbridge and Hwy. 36, and from the Water Survey of Canada (WSC) monitoring site near Brocket.

Post-impoundment data were collected at half-hourly or hourly intervals using temperature loggers (Ryan Instruments, Tempmentor and RTM 2000, and Vemco miniloggers) and Datasondes (Hydrolab Corp.). Datasondes were retrieved and re-deployed as outlined previously. Thermographs were deployed to a minimum depth of $0.3 \mathrm{~m}$, generally in the deepest channel. Periodic (bimonthly) field measurements were used to verify data from the recording instrument; data that varied from the field values by more than $0.5^{\circ} \mathrm{C}$ were rejected. Thermographs deployed in 1999 near Monarch and downstream of the Belly River had a range of $-4^{\circ} \mathrm{C}$ to $20.6^{\circ} \mathrm{C}$; therefore peak diurnal temperatures at these sites were truncated at $20.6^{\circ} \mathrm{C}$.

\subsection{Discharge}

Discharge data recorded at WSC hydrometric stations were retrieved as daily mean flows from the Hydat database. Flows for 2001 are from preliminary data and may be subject to minor revision. As there are only four hydrometric stations along the Oldman mainstem between the dam and the confluence of the Oldman and Bow rivers, discharge at several monitoring sites was estimated using additional tributary inflow and withdrawal data, as shown in Table 2.5. Because flooding during June of 1995 dislodged the hydrometric station at Brocket, discharge data for June 1, 1995 through March 19, 1996 were obtained from the reservoir outflow (DACQ). 


\subsection{Air Temperature}

Air temperature data were obtained as daily maximum, average, and minimum temperatures from the Meterologic Services of Canada. Meterologic stations corresponding to monitoring sites along the Oldman River are shown in Table 2.6.

Table 2.5 WSC hydrometric stations corresponding to inflows and withdrawals used in flow calculations

\begin{tabular}{|c|c|}
\hline SAMPLING SITE & WSC HYDROMETRIC STATIONS USED IN ESTIMATES OF \\
\hline $100 \mathrm{~m} \mathrm{~d} / \mathrm{s}$ of Oldman Reservoir & 05AA024 (Brocket) or ROLDOUT on DACQ (reservoir outflow) \\
\hline Near Brocket & 05AA024 \\
\hline$d / s$ of the LNHD Diversion & $\begin{array}{l}\text { 05AA024+05AA004(Pincher ck.)+05AB013(Beaver ck.)-(05AB016 or } 05 A B 019 ; \\
\text { LNID canal) }\end{array}$ \\
\hline Near Ft. Macleod & 05AA024+05AA004+05AB013-(05AB016 or 05AB019) \\
\hline Near Rocky Coulee & $\begin{array}{l}\text { 05AA024+05AA004+(05AB002 or 05AB046; Willow } C k .)+05 A B 013-(05 A B 016 \text { or } \\
\text { 05AB019) }\end{array}$ \\
\hline Near Monarch & (05AA024+05AA004+(05AB002 or 05AB046)+05AB013-(05AB016 or 05AB019) \\
\hline $\mathrm{d} / \mathrm{s}$ of the Belly River Confluence & $\begin{array}{l}\text { 05AA024+05AA004+(05AB002 or 05AB046)+05AB013+05AD028 } \\
\text { (Waterton R.) +05AD041(Belly R. nr Glenwood) }-(05 A B 016 \text { or 05AB019) }\end{array}$ \\
\hline Above Lethbridge at Hwy. 3 & 05AD007(Hwy. 3) \\
\hline Below Lethbridge at Pavan Park & $05 A D 007$ \\
\hline Below Picture Butte at Hwy. 845 & 05AD007 \\
\hline Hwy. 36 & 05AG006(Fincastle)-05AG003(Expanse Coulee) \\
\hline Bow River Confluence & 05AG006 \\
\hline
\end{tabular}

Table 2.6 Meteorological stations used for air temperature data. All data are from Environment Canada, except where noted.

\begin{tabular}{|c|c|}
\hline SAMPLING SITE & ENVIRONMENT CANADA METEOROLOGICAL STATION \\
\hline $100 \mathrm{~m} \mathrm{~d} / \mathrm{s}$ of Oldman Reservoir & Pincher Creek AUT (3035206) 1995; ZPC $2000-2001$ \\
\hline Near Brocket & $\begin{array}{l}\text { Pincher Creek A (3035202) 1991-1993; Pincher Creek AUT (3035206) 1994-1997; } \\
\text { ZPC1 1998-2001 }\end{array}$ \\
\hline$d / s$ of the LNHD Diversion & Pincher Creek AUT (3035206) 1994-1997; ZPC $1998-2001$ \\
\hline Near Ft. Macleod & Monarch (3034596) 1991-1997; ZPC $1998-2001$ \\
\hline Near Rocky Coulee & $\begin{array}{l}\text { Monarch (3034596) 1996-1997; LETH } 1998-1999 \text {; Lethbridge A (3033880) } 2000 \text { - } \\
2001\end{array}$ \\
\hline Near Monarch & $\begin{array}{l}\text { Monarch (3034596) 1992-1997; LETH } 1998-1999 \text {; Lethbridge A (3033880) 2000- } \\
2001\end{array}$ \\
\hline d/s of the Belly River Confluence & Lethbridge A (3033880) 1994-1997, 2000-2001; LETH $1998-1999$ \\
\hline Above Lethbridge at Hwy. 3 & Lethbridge A (3033880) 1993-1997, 2000-2001; LETH ${ }^{1} 1998-1999$ \\
\hline Below Lethbridge & Lethbridge A (3033880) 1991-1997, 2000-2001; LETH ${ }^{1} 1998-1999$ \\
\hline Below Picture Butte at Hwy. 845 & Picture Butte West (303N1G3) 1993-1994 \\
\hline Hwy. 36 & Vauxhall (3036682) 2000-2001 \\
\hline Bow River Confluence & Taber (3036360) 1991-1996 \\
\hline
\end{tabular}

${ }^{1}$ from DACQ, Alberta Environment 


\subsection{Statistics}

All statistical analyses were carried out using SYSTAT 10 (SPSS Inc.). 


\subsection{RESULTS AND DISCUSSION}

\subsection{Oxygen}

\subsubsection{Monitoring}

Efforts to monitor dissolved oxygen focus primarily on the Lethbridge area, where depressed nocturnal oxygen levels are frequently caused by a high net rate of oxygen consumption. Prior to 1991, continuous monitoring of dissolved oxygen occurred at the most downstream site on the Oldman River, near the confluence with the Bow River at Fincastle. These data were collected since the late 1970's using a robot monitor; few of these data are presently stored in an accessible format. The available data are presented as daily maximum, minimum, and average values in Figures 1 and 2 of Appendix A. Water temperature and flow data are included for comparison.

Data collected from post-impoundment monitoring consist of continuous records for April through October of 1991-2001. These data are presented as daily maximum, minimum, and average values in Figures 3-43 of Appendix A, along with curves showing the equilibrium solubility of oxygen in water (after Benson and Krause 1980, in Mortimer 1981). Water temperature and discharge are also included in these figures to permit comparison with general trends in oxygen data.

Data that were collected in the form of one-time measurements or occasional diel (24 h) surveys are presented collectively for each of the pre- and post-impoundment periods (Figures $44-47$ of Appendix A).

\subsubsection{Water Quality Guidelines}

The predominant concern with respect to dissolved oxygen management is the maintenance of acceptable levels of dissolved oxygen relative to the Alberta Surface Water Quality Guidelines (Alberta Environment 1999). The current ASWQ guidelines specify a one-day (acute) minimum level of $5 \mathrm{mg} \cdot \mathrm{L}^{-1}$, and a 7-day mean (chronic) level of $6.5 \mathrm{mg} \cdot \mathrm{L}^{-1}$. The chronic guideline can be increased to $8.3 \mathrm{mg} \cdot \mathrm{L}^{-1}$ from mid-May to the end of June for the protection of emergent mayfly species, and to $9.5 \mathrm{mg} \cdot \mathrm{L}^{-1}$ for the protection of embryonic and larval stages of fish species (mostly salmonids) that develop in gravel beds. The Canadian Water Quality (CWQ) guidelines (CCME 1999) also identify minimum dissolved oxygen levels for the protection of aquatic life. As these guidelines relate to specific biota and life stages, the CWQ guidelines, as well as the ASWQ chronic guidelines and further requirements that are specific to several sport fish species commonly found in the Oldman River, are addressed in section 4.1. The following sections specifically address the $5 \mathrm{mg} \cdot \mathrm{L}^{-1}$ acute guideline, relative to post-impoundment and historic dissolved oxygen conditions.

\subsubsection{Historic Conditions}

Pre-impoundment data are insufficient to permit definite conclusions about the extent of the oxygen deficit that occurred between April and October in the Oldman River downstream of 
Lethbridge to the confluence with the Bow River. Continuous monitoring data from 1989 and 1990 near the confluence of the Bow and Oldman rivers suggest that dissolved oxygen approached critical levels during late July through September; however, the data set is incomplete so this can not be confirmed. Flows were very low at the confluence of the Bow and Oldman rivers during these years relative to later years; the variability that is characteristic of the 1989 and 1990 data may have resulted in dissolved oxygen levels that fell below $5 \mathrm{mg} \cdot \mathrm{L}^{-1}$. Nocturnal dissolved oxygen levels at the Bow-Oldman confluence on July 21 and 221988 (Figure 47, Appendix A) also approached $5 \mathrm{mg} \cdot \mathrm{L}^{-1}$, further suggesting that critically low nocturnal dissolved oxygen levels occurred with relative frequency at this site during the preimpoundment period.

Nocturnal dissolved oxygen levels directly downstream of Lethbridge were also very low in July and August 1988 , consistently falling below $5 \mathrm{mg} \cdot \mathrm{L}^{-1}$ at the monitoring site directly downstream of the wastewater treatment plant outfall and at Pavan Park (Figure 46, Appendix A). On July 13-15, nocturnal dissolved oxygen levels directly downstream of the WWTP outfall (at the old rifle range) approached $0.5 \mathrm{mg} \cdot \mathrm{L}^{-1}$. The recovery of this severe deficit to $3 \mathrm{mg} \cdot \mathrm{L}^{-1} 5 \mathrm{~km}$ downstream (Pavan Park) may reflect a more thorough dilution of oxygen consuming processes, or may be a function of the position of the Datasonde relative to areas of dense aquatic plant growth. Mean daily flows at Lethbridge during this period were $5.64 \mathrm{~m}^{3} \cdot \mathrm{s}^{-1}, 5.1 \mathrm{~m}^{3} \cdot \mathrm{s}^{-1}$, and 4.9 $\mathrm{m}^{3} \cdot \mathrm{s}^{-1}$, well below the current minimum flow of $20 \mathrm{~m}^{3} \cdot \mathrm{s}^{-1}$.

The nocturnal oxygen deficits that occurred directly downstream of the wastewater treatment plant outfall on August $17-19,1988$, were slightly below $5 \mathrm{mg} \cdot \mathrm{L}^{-1}$ and were therefore not as acute as on July 13-15; however, dissolved oxygen levels near Pavan Park remained in the 3 $\mathrm{mg} \cdot \mathrm{L}^{-1}$ range. Flows during August $17-19,1988$ were $5.99 \mathrm{~m}^{3} \cdot \mathrm{s}^{-1}, 5.64 \mathrm{~m}^{3} \cdot \mathrm{s}^{-1}$, and $4.9 \mathrm{~m}^{3} \cdot \mathrm{s}^{-1}$. In addition to the depressed nocturnal dissolved oxygen levels that occurred during the three-day periods in July and August of 1988, diel $(24 \mathrm{~h})$ dissolved oxygen fluctuations at both sites exceeded $10 \mathrm{mg} \cdot \mathrm{L}^{-1} \cdot$ day $^{-1}$, approaching $15 \mathrm{mg} \cdot \mathrm{L}^{-1} \cdot$ day $^{-1}$ near Pavan Park. In contrast, diel fluctuations near Monarch and the confluence of the Bow and Oldman rivers were on the order of 5-6 $\mathrm{mg} \cdot \mathrm{L}^{-1} \cdot$ day $^{-1}$. Diel dissolved oxygen data from Monarch, also collected in July and August of 1988, indicate that dissolved oxygen levels did not frequently fall below critical levels at this site (Figure 45, Appendix A).

Surveys conducted in 1984 and 1985 (calibration figures in HydroQual 1990) indicate that diel dissolved oxygen minima downstream of Lethbridge were below $5 \mathrm{mg} \cdot \mathrm{L}^{-1}$ throughout most of the July and August period, although the exact values and their origin are not given in the Hydroqual report. Flows during July and August of both years were very low relative to postimpoundment flows; this was typical of the pre-1991 period, indicating that the depressed oxygen levels that occurred in 1984 and 1985 probably occurred in other years as well.

There are a few instances in the ENVIRODAT record (all in December, January, and February) of dissolved oxygen spot measurements falling below the $5 \mathrm{mg} \cdot \mathrm{L}^{-1}$ ASWQ guideline during years in which periodic sampling took place. However, because the dissolved oxygen regime is highly variable, an accurate evaluation of the dissolved oxygen deficit cannot be drawn from periodic monitoring. In addition, periodic sampling often does not coincide with the period of maximum nocturnal oxygen deficit. Some inference as to the magnitude of diel dissolved 
oxygen variation, and therefore aquatic plant density, can be drawn from the amount of scatter that is observed in the data points. The scatter is greatest directly downstream of Lethbridge; the pattern that is typical of sites upstream of Lethbridge recurs with further downstream distance, as indicated by data from sites near Hwy. 845 and the confluence of the Bow and Oldman rivers.

Because few data exist that describe the extent of pre-impoundment oxygen deficits downstream of Lethbridge, HydroQual used WQRRS to model dissolved oxygen conditions for July and August of 1982-1986 (HydroQual 1990). These post hoc predictions indicated that the frequency of daily dissolved oxygen minima falling below the $5 \mathrm{mg} \cdot \mathrm{L}^{-1}$ ASWQ guideline approached $50 \%$ (i.e. one of every two days; total duration of about $10 \%$ of the time in July and August). Similar predictions were extended to the reach directly downstream of the confluence of the Belly and Oldman rivers (upstream of Lethbridge), where frequencies of $20 \%$ of daily minima (i.e. one of every five days; $5 \%$ total duration) were predicted. Given the very low historic flows that were typical of these reaches during July and August, these values are plausible, but cannot be verified.

\subsubsection{Post-impoundment Conditions}

Upstream of Lethbridge, post-impoundment dissolved oxygen levels generally did not fall below the $5 \mathrm{mg} \cdot \mathrm{L}^{-1}$ guideline during the April-October monitoring period. The exception occurred in the beginning of July 2001 (Figure 41, Appendix A), apparently because of the Datasonde having been located within a dense macrophyte community. Following the clearing of the macrophytes from around the instrument on July 10 , dissolved oxygen remained above $5 \mathrm{mg} \cdot \mathrm{L}^{-1}$.

Downstream of Lethbridge, post-impoundment dissolved oxygen levels fell below the $5 \mathrm{mg} \cdot \mathrm{L}^{-1}$ guideline on September 13-14 and 16 of 1991, on July 26-30, August 3-6, and August 21 of 1994, on August 19-21 of 1997, on August 5 and September 14 of 2000, and on July 22 and August $4,7,8$, and 12-18 of 2001. Dissolved oxygen levels were probably below the $5 \mathrm{mg} \cdot \mathrm{L}^{-1}$ guideline more frequently in 1994, 1997, and possibly 1992 and 1996; however, the monitoring record during the critical mid-summer period is not complete for these years. The same is true of the remaining sites between the confluence of the Bow and Oldman rivers and the site downstream of Lethbridge. At Hwy. 36, dissolved oxygen fell below $5 \mathrm{mg} \cdot \mathrm{L}^{-1}$ on July 10,11 , 15, and 24, and on August 7 and 16 of 2001. At the confluence of the Bow and Oldman Rivers, the only recorded instances of dissolved oxygen levels falling below the $5 \mathrm{mg} \cdot \mathrm{L}^{-1}$ guideline occur on June 24 and 28 of 1992. Based on data from 1993, there appears to be little difference between dissolved oxygen levels downstream of Lethbridge and dissolved oxygen levels at Highway 845 (near Picture Butte). It is therefore likely that when dissolved oxygen levels fall below $5 \mathrm{mg} \cdot \mathrm{L}^{-1}$ downstream of Lethbridge, they also do so near Highway 845. There is not enough overlap between dissolved oxygen monitoring at the confluence of the Bow and Oldman Rivers and downstream of Lethbridge to permit comparison of the two sites.

Based on WQRRS modelling, HydroQual (1990) extended the following prediction to postimpoundment dissolved oxygen conditions downstream of Lethbridge:

Provided that discharge at Lethbridge is in excess of $20 \mathrm{~m}^{3} \cdot \mathrm{s}^{-1}$, dissolved oxygen should not fall below $5 \mathrm{mg} \cdot \mathrm{L}^{-1}$ during the critical July and August period. 
When dissolved oxygen levels fell to $4.99 \mathrm{mg} \cdot \mathrm{L}^{-1}$ and $4.92 \mathrm{mg} \cdot \mathrm{L}^{-1}$ near the confluence of the Bow and Oldman Rivers in 1992, flows at this site were very close to $20 \mathrm{~m}^{3} \cdot \mathrm{s}^{-1}\left(20.8 \mathrm{~m}^{3} \cdot \mathrm{s}^{-1}\right.$ and $19.1 \mathrm{~m}^{3} \cdot \mathrm{s}^{-1}$, respectively). At this time, flows at Lethbridge were below $20 \mathrm{~m}^{3} \cdot \mathrm{s}^{-1}\left(15.8 \mathrm{~m}^{3} \cdot \mathrm{s}^{-1}\right.$ and $15.0 \mathrm{~m}^{3} \cdot \mathrm{s}^{-1}$, respectively). However, flows downstream of Lethbridge were above $20 \mathrm{~m}^{3} \cdot \mathrm{s}^{-1}$ during all instances of dissolved oxygen falling below $5 \mathrm{mg} \cdot \mathrm{L}^{-1}$ at this site (Table 3.1). Flows during August of 1997 in particular were more than twice the IFN minimum flows prescribed for Lethbridge $\left(20 \mathrm{~m}^{3} \cdot \mathrm{s}^{-1}\right.$ in August $)$.

Data from transect studies conducted downstream of the Lethbridge wastewater treatment plant (WWTP) in 1996 and 1997 indicate that the nitrogen derived from the WWTP is not completely mixed across the width of the river near the Datasonde monitoring site, southwest of Diamond City (AENV unpublished data). The association of diurnal dissolved oxygen with the chemical indicators of the effluent plume was generally positive. Greater productivity within the mixing zone may cause this association to be reversed nocturnally, such that dissolved oxygen levels would be lowest where the effluent plume is most concentrated. Failure to meet the $5 \mathrm{mg} \cdot \mathrm{L}^{-1}$ dissolved oxygen guideline could therefore be more frequent within the effluent plume. HydroQual (1990) do not indicate whether the value of $20 \mathrm{~m}^{3} \cdot \mathrm{s}^{-1}$, proposed to maintain sufficiently elevated levels of dissolved oxygen downstream of Lethbridge, is intended to apply within the mixing zone. The value was, however, derived from a model element taken to be approximately $20 \mathrm{~km}$ downstream of the WWTP out-fall (reach 2, element 6), a distance that probably approximates the edge of the mixing zone. Because of the one-dimensionality of the WQRRS model, lateral and longitudinal mixing of influents was assumed instantaneous, so it is not meaningful to analyse model output relative to lateral mixing. It is likely that the IFN guideline of $20 \mathrm{~m}^{3} \cdot \mathrm{s}^{-1}$ does not provide insurance against dissolved oxygen levels falling below 5 $\mathrm{mg} \cdot \mathrm{L}^{-1}$ within the mixing zone. Whether or not this is in fact the case, conditions may have changed following the recent (1999) upgrades to the Lethbridge wastewater treatment plant, discussed in the section 3.1.3. 
Table 3.1 Incidences of daily minimum dissolved oxygen below $5 \mathrm{mg} \cdot \mathrm{L}^{-1}$ approximately $8 \mathbf{~ k m}$ downstream of the Lethbridge wastewater treatment plant, and corresponding daily mean flows at Hwy. 3

\begin{tabular}{|c|c|c|c|c|}
\hline \multicolumn{3}{|c|}{ DATE } & $\begin{array}{l}\text { DISSOLVED OXYGEN } \\
(\mathrm{mg} / \mathrm{L})\end{array}$ & $\begin{array}{c}\text { DISCHARGE (AB05AD007) } \\
\left(\mathrm{m}^{3} / \mathrm{s}\right)\end{array}$ \\
\hline \multirow[t]{4}{*}{1991} & Sept. 1 & 12 & 4.57 & 21.8 \\
\hline & Sept. 1 & 13 & 3.61 & 21.6 \\
\hline & Sept. 1 & 14 & 4.85 & 24.4 \\
\hline & Sept. 1 & 16 & 4.66 & 21.9 \\
\hline \multirow[t]{10}{*}{1994} & July 2 & 26 & 4.99 & 28.6 \\
\hline & July 2 & 27 & 4.96 & 26.6 \\
\hline & July 2 & 28 & 4.97 & 26.9 \\
\hline & July 2 & 29 & 4.88 & 25.9 \\
\hline & July 3 & 30 & 4.81 & 26.6 \\
\hline & Aug. 3 & & 4.76 & 27.8 \\
\hline & Aug. 4 & & 4.73 & 27.8 \\
\hline & Aug. 5 & & 4.81 & 31.8 \\
\hline & Aug. 6 & & 4.97 & 33.0 \\
\hline & Aug. 2 & 21 & 4.94 & 27.3 \\
\hline \multirow[t]{3}{*}{1997} & Aug. 1 & 19 & 4.68 & 46.0 \\
\hline & Aug. 2 & 20 & 4.87 & 43.6 \\
\hline & Aug. 2 & 21 & 3.96 & 41.4 \\
\hline \multirow[t]{2}{*}{2000} & Aug. 5 & & 4.69 & 27.3 \\
\hline & Sept. 1 & 14 & 3.73 & 22.9 \\
\hline \multirow[t]{11}{*}{2001} & July 2 & 22 & 4.67 & 23.3 \\
\hline & Aug. 4 & & 4.83 & 22.2 \\
\hline & Aug. 7 & & 4.65 & 21.3 \\
\hline & Aug. 8 & & 4.66 & 21.0 \\
\hline & Aug. 1 & 12 & 4.90 & 23.7 \\
\hline & Aug. 1 & 13 & 4.65 & 23.1 \\
\hline & Aug. 1 & 14 & 4.76 & 22.9 \\
\hline & Aug. 1 & 15 & 4.49 & 22.2 \\
\hline & Aug. 1 & 16 & 4.42 & 21.7 \\
\hline & Aug. 1 & 17 & 4.79 & 22.2 \\
\hline & Aug. 1 & 18 & 4.65 & 22.5 \\
\hline
\end{tabular}

\subsubsection{Diel Cycling}

Occurrences of dissolved oxygen falling below the $5 \mathrm{mg} \cdot \mathrm{L}^{-1}$ guideline were always accompanied by diel dissolved oxygen fluctuations in excess of $6 \mathrm{mg} \cdot \mathrm{L}^{-1} \cdot$ day $^{-1}$. These large diel cycles appear to occur only below Lethbridge, with the exception of early July upstream of Lethbridge prior to the clearing of macrophytes from immediately around the Datasonde, and of late September of 1999 near Monarch. In the latter instance, measurements may have been exaggerated as the recording instrument was located in a shallow riffle. Large diel fluctuations such as those in excess of $6 \mathrm{mg} \cdot \mathrm{L}^{-1} \cdot$ day $^{-1}$ are due to high levels of primary productivity, which result from nutrient loading by municipal and industrial wastewater inflows, as well as from non-point inflows such as runoff from farming operations. The amplitude of these diel fluctuations can provide an estimate of net photosynthetic rate (Odum 1956, Chapra and Di Toro 1991) and, by extension, of the productivity of a reach. 
The establishment of communities of primary producers is reflected in seasonal changes in the amplitude of diel dissolved oxygen cycling. The amplitude of diel cycles shows an early-season increase that is concomitant with the establishment of aquatic plant communities. The increase typically occurs in mid-June, depending on the magnitude and duration of peak spring flows. The amplitude of diel dissolved oxygen cycles fluctuates throughout the summer because of variations in the density of aquatic plant communities, the intensity of irradiance, and water flow. It then decreases in late October in association with a significant drop in water temperature.

There is also a general increase in the amplitude of diurnal dissolved oxygen cycles with downstream distance. This reflects the increasing productivity of the river. The amplitude of diel cycles is minimal near Monarch, the furthest upstream site at which dissolved oxygen was monitored during the 1993-1999 period. It is greater upstream of Lethbridge and attains a maximum downstream of Lethbridge. The amplitude appears to diminish slightly with downstream distance from Lethbridge, although it remains elevated relative to levels measured upstream of Lethbridge.

Significant reductions in the amplitude of diel dissolved oxygen cycles that take place over a relatively brief period may be due to the removal of aquatic plants, chiefly macrophytes, because of elevated current velocities (scouring). Macrophyte scouring is most pronounced at mean cross-sectional velocities that exceed $1 \mathrm{~m} \cdot \mathrm{s}^{-1}$ (Chambers et al. 1991a, Charlton et al. 1986). Current velocities downstream of Lethbridge are typically well below $1 \mathrm{~m} \cdot \mathrm{s}^{-1}$ during midsummer, allowing aquatic plant communities to become well established. Substantial decreases in the amplitude of diel dissolved oxygen fluctuations appear only to occur when flows are in excess of $100 \mathrm{~m}^{3} \cdot \mathrm{s}^{-1}$. For example, in 1993, the amplitude of diurnal dissolved oxygen fluctuations decreased substantially following a twofold increase in flow in mid-August, and again in mid-September. In 1995, the amplitude of diurnal fluctuations increased steadily as flows decreased to $110 \mathrm{~m}^{3} \cdot \mathrm{s}^{-1}$ following a spate of $4100 \mathrm{~m}^{3} \cdot \mathrm{s}^{-1}$. Peak flows during August $\left(330 \mathrm{~m}^{3} \cdot \mathrm{s}^{-1}\right)$ and September $\left(270 \mathrm{~m}^{3} \cdot \mathrm{s}^{-1}\right)$ of 1993 , and during June of 1995 translate to $0.842 \mathrm{~m} \cdot \mathrm{s}^{-1}, 0.783 \mathrm{~m} \cdot \mathrm{s}^{-1}$, and $2.108 \mathrm{~m} \cdot \mathrm{s}^{-1}$, respectively, by the following generalised channel velocity equation: Velocity $=0.10204^{*}(\text { Discharge })^{0.364}$ (Andy DeBoer, AENV). These values are consistent with the $1 \mathrm{~m} \cdot \mathrm{s}^{-1}$ values reported in the literature.

In practice, it is difficult to separate the effect of scouring flows from the dilution of oxygen producing and consuming processes and the decrease in photosynthetic activity resulting from increased turbidity that accompany increased flow volume. The changes in the amplitude of diel dissolved oxygen cycles that occurred in 1993 and 1995 may have been due to scouring. However, similar changes that occurred in mid-August of 1991 (associated with an increase in flow from $88 \mathrm{~m}^{3} \cdot \mathrm{s}^{-1}$ to $107 \mathrm{~m}^{3} \cdot \mathrm{s}^{-1}$ ) and in mid-June of 1994 (associated with a decrease in flow from $199 \mathrm{~m}^{3} \cdot \mathrm{s}^{-1}$ to $\sim 50 \mathrm{~m}^{3} \cdot \mathrm{s}^{-1}$ ) did not involve flow velocities anywhere near $1 \mathrm{~m} \cdot \mathrm{s}^{-1}$. Because the density of aquatic plant communities varies considerably from season to season, there does not appear to be any change in flow regime that can be said universally to effect a given change in the amplitude of dissolved oxygen cycles. This is evident in the widely varying flows at which dissolved oxygen concentrations downstream of Lethbridge fall below the $5 \mathrm{mg} \cdot \mathrm{L}^{-1}$ ASWQ guideline (Table 3.1). While cycles with an amplitude greater than $6 \mathrm{mg} \cdot \mathrm{L}^{-1} \cdot \mathrm{day}^{-1}$, associated with dissolved oxygen levels below $5 \mathrm{mg} \cdot \mathrm{L}^{-1}$, do not appear to occur when flows exceed 
$50 \mathrm{~m}^{3} \cdot \mathrm{s}^{-1}$, this value is clearly not practical as a minimum flow. Minimum flow values must therefore be applied in conjunction with appropriate controls over aquatic plants, if the $5 \mathrm{mg} \cdot \mathrm{L}^{-1}$ guideline is to be observed. In addition, minimum flows to mid-September should be equal to minimum flows for July and August. Based on general trends, dissolved oxygen levels are lowest during the July through mid-September period. While water temperatures in September are lower than in July and August, aquatic plant communities can remain dense, and continue to drive down nocturnal dissolved oxygen levels.

Diel dissolved oxygen cycles are driven toward equilibrium solubility. Near Brocket, where the dissolved oxygen regime is driven primarily by turbulent re-aeration, dissolved oxygen levels can remain above equilibrium levels for extended periods during high flows. Further downstream however, diel dissolved oxygen cycles tend to oscillate about equilibrium levels. As a result, the broad seasonal trend for dissolved oxygen is to track changes in the equilibrium solubility curve. The photosynthetic production of oxygen results in large diurnal excursions of dissolved oxygen levels above equilibrium levels. This occurs most prominently downstream of Lethbridge, where dissolved oxygen levels can exceed saturation by as much as $8 \mathrm{mg} \cdot \mathrm{L}^{-1}$. By comparison, upstream of Lethbridge, diel dissolved oxygen cycles do not exceed saturation levels by more than

$2 \mathrm{mg} \cdot \mathrm{L}^{-1}$.

Maximum diurnal oxygen levels vary substantially with the intensity of solar irradiance, aquatic plant community density, and flow. As a result, the predictive relationship between maximum dissolved oxygen and equilibrium solubility, and therefore temperature, is relatively weak. Minimum diurnal dissolved oxygen levels are far less variable, and more predictable with respect to equilibrium solubility. Table 3.2 shows a Pearson correlation matrix (SYSTAT 8.0) of summary statistics (minimum, maximum, average) for equilibrium solubility and dissolved oxygen. A Pearson correlation coefficient of 0 indicates that neither variable can be predicted from the other using a linear equation, while a correlation coefficient of 1 or -1 indicates perfect linear predictability. The sample dates used in the correlation analysis correspond for all three sites, to permit legitimate lateral comparison.

Table 3.2 Pearson Correlation matrix for dissolved oxygen and equilibrium dissolved oxygen near Monarch, u/s Lethbridge, and d/s Lethbridge

\begin{tabular}{c|c|c|c|c}
\hline SITE & & Min. Eq. DO & Avg. Eq. DO & Max. Eq. DO \\
\hline \multirow{3}{*}{ Monarch } & Min. DO & 0.89 & 0.90 & 0.88 \\
& Avg. DO & 0.82 & 0.86 & 0.88 \\
& Max. DO & 0.61 & 0.67 & 0.71 \\
\hline \multirow{4}{*}{ u/s Lethbridge } & & Min. Eq. DO & Avg. Eq. DO & Max. Eq. DO \\
& Min. Do & 0.92 & 0.92 & 0.92 \\
& Avg. DO & 0.90 & 0.90 & 0.91 \\
& Max. DO & 0.74 & 0.75 & 0.76 \\
\hline \multirow{4}{*}{ d/s Lethbridge } & & Min. Eq. DO & Avg. Eq. DO & Max. Eq. DO \\
& Min. Do & 0.77 & 0.75 & 0.72 \\
& Avg. DO & 0.56 & 0.63 & 0.67 \\
& Max. DO & -0.02 & 0.08 & 0.15 \\
\hline
\end{tabular}


There is a notable difference in the strength of the correlation of the equilibrium solubility of oxygen in water with maximum diel dissolved oxygen levels and minimum diel dissolved oxygen levels. This is especially true downstream of Lethbridge, where there is a very limited correlation between maximum diel dissolved oxygen levels and equilibrium levels. This is again a result of the dense aquatic plant communities downstream of Lethbridge. The relatively high predictability of minimum dissolved oxygen levels upstream of Lethbridge suggests that instances of dissolved oxygen levels that fall below the critical $5 \mathrm{mg} \cdot \mathrm{L}^{-1}$ guideline should be rare, as equilibrium levels typically remain well above this value. Conversely, downstream of Lethbridge the correlation of minimum dissolved oxygen with equilibrium dissolved oxygen is only moderate. Therefore, instances of dissolved oxygen levels that fall below the $5 \mathrm{mg} \cdot \mathrm{L}^{-1}$ guideline can not be predicted from water temperature, as minimum dissolved oxygen levels are far more variable relative to equilibrium levels. This again indicates that maintenance of acceptable levels of dissolved oxygen depends on the control of excessive aquatic plant density.

Nutrient loading from municipal effluent and from run-off captured in storm drains is probably the principal cause of the dense aquatic plant communities immediately downstream of Lethbridge. This is consistent with observations from other prairie rivers that rooted aquatic plant density and abundance tend to increase downstream of large urban centres, particularly in relation to nutrient loading from wastewater treatment plants (Anderson et al. 1986, Charlton and Bayne 1986, Charlton et al. 1986, Sosiak 1990, Carr and Chambers 1998a). Effluent from the Lethbridge wastewater treatment plant has been the most significant source of biologically available (dissolved) phosphorus to the Oldman River, historically contributing as much as $83 \%$ of total inputs along the Oldman River mainstem (Cross and Anderson 1989). An upgrade to the Lethbridge wastewater treatment plant including the implementation of biological nutrient removal was recently completed (December 1999). Preliminary data indicate that these upgrades have resulted in a substantial reduction of nutrient levels in the receiving waters downstream of the facility.

The immediate effect on aquatic plants of the reduced open water nutrient load downstream of Lethbridge is not predictable. At several sites along the Bow River downstream of Calgary, the rooted aquatic plant communities showed a significant five-year decline following a reduction in phosphorus loading from both of the Calgary WWTPs; however, the trend was not universal, possibly as a result of nutrients retained in the sediments (Sosiak 1990). Rooted aquatic plants, the most conspicuous of the aquatic plants downstream of Lethbridge, appear to derive most of their nutrients from the sediments (Chambers et al. 1989, Chambers et al. 1991b, Carr and Chambers 1998b). They also contribute decayed organic matter to the sediment nutrient pool, and increase the rate of sediment deposition, resulting in continued regeneration of the sediment nutrient pool (Chambers and Prepas 1994). Nutrients that have accumulated in the sediment therefore may be recycled for an indefinite period. While continued reduction of nutrient loading is the appropriate solution to excessive aquatic plant growth downstream of Lethbridge, a water management strategy aimed at flushing riverbed nutrient stores might enhance the process. 


\subsubsection{Monitoring}

Water temperature monitoring has focused primarily on the segment of the Oldman River from the dam to Lethbridge, as prior to impoundment the effect of the reservoir was predicted not to extend beyond this section (HydroQual 1990). Pre-impoundment water temperatures are presented as daily maximum, minimum, and average values in Figures 1-5 of Appendix B. Data collected since 1991 are presented as daily maximum, minimum, and average values in Figures 6-91 of Appendix B. Daily mean discharge and daily minimum, maximum and average air temperatures are also presented for comparison. Non-continuous data are included in composite figures for all years through 2001 (Figures 92-95 of Appendix B).

\subsubsection{Reservoir Effects}

The degree of association between water temperatures downstream of the Oldman Reservoir, and temperatures measured in Cell I (the reservoir sampling cell that is nearest the dam) at the approximate elevation of the diversion tunnels is highly variable. Excluding periods during which the spillway was operated, the range of variation can approach $3^{\circ} \mathrm{C}$ (Table 3.3$)$. This variation probably reflects processes that are internal to the reservoir, as the temperature difference between the reservoir outlet and the site near Brocket, $6.41 \mathrm{~km}$ downstream of the reservoir, did not exceed $0.33^{\circ} \mathrm{C}$ during the brief period of overlap that occurred between August 15 and September 3, 1995. The causes of this variation are discussed in more detail in Mitchell (2001).

Variation in mean daily temperature near Brocket tended to be slight during April through midMay, and from August through October of 1993-2001. Mean daily temperature variation during the post-impoundment period was generally less than $2^{\circ} \mathrm{C}$, whereas pre-impoundment daily mean temperature variation was often on the order of $2-3^{\circ} \mathrm{C}$, and could be as much as $4-5^{\circ} \mathrm{C}$ over several days. However, there was often considerable day-to-day variation during the mid-May through July period of 1993-2001. During this early summer period, flows can be high and highly variable. Whereas higher flows during summer months might normally be expected to correspond with cooler downstream temperatures, flows in excess of about $170 \mathrm{~m}^{3} \cdot \mathrm{s}^{-1}$ during the mid-May through June period tend to accompany sharp temperature increases.

These sharp temperature increases coincide with the operation of the spillway and are caused by the release of relatively warm epilimnetic water over the crest of the Oldman River Dam. This occurs when outflows approach the capacity of the diversion tunnels $\left(200 \mathrm{~m}^{3} \cdot \mathrm{s}^{-1}\right)$, as flows greater than $170 \mathrm{~m}^{3} \cdot \mathrm{s}^{-1}$ are necessary for proper spillway operation. The spillway is also occasionally operated at flows of less than $170 \mathrm{~m}^{3} \cdot \mathrm{s}^{-1}$, in order to permit inspection and maintenance of the diversion tunnels. The periods during which the spillway was operated are shown in Table 3.4. The sharp increases in temperature that accompany the operation of the spillway were less conspicuous downstream of the LNHD and near Fort Macleod than near Brocket, but were still discernable. Downstream of the Belly River, water temperature was not noticeably affected by spillway releases. 
A unique pattern of diel variation arises from the release of water from the hypolimnion of a reservoir. This pattern relates to the changing amplitude of diel temperature variation downstream of the release. The amplitude of diel temperature variation does not increase consistently with increasing distance from the reservoir, but rather is punctuated by nodes of maximum or minimum amplitude. These nodes occur at intervals of approximately 12 hours of travel time, at average flows. These nodes occur as a result of differing magnitudes of net heat exchange over a given distance for different periods during the day.

The amplitude of diel temperature variation is greatest at the first node, approximately 12 hours of travel time from the source, when the initial water temperature at the reservoir release is less than mean equilibrium temperature. The magnitude of the difference between daily maximum and minimum water temperature at this first node can be substantially greater than that 24 hours of travel time downstream. Conversely, the amplitude of diel temperature variation is least, relative to all further nodes, at 24 hours of travel time (Lowney 2000, Polehn and Kinsel 1997). When initial water temperature is greater than mean equilibrium temperature, the reverse is true. The precise spacing, in terms of travel time, of the minimum or maximum nodes or antinodes varies with the duration of diel heating and cooling cycles, but the nodes/antinodes can be expected to have a periodicity of 24 hours travel time.

The effects of a release of water at a constant temperature, and of accompanying nodal behaviour, on aquatic biota have apparently not been investigated. It may be advantageous to consider this thermal behaviour in the design of monitoring programs, particularly when the data being collected are to be used in the calibration of water quality models. This is of particular importance when the model to be calibrated is non-hydrodynamic, as with WQRRS. The application of such a steady-state model may be inappropriate downstream of major reservoirs. This specific problem relating to the application of non-hydrodynamic models downstream of major reservoirs has apparently not been extensively studied.

\subsubsection{Downstream Variation}

Post-impoundment temperatures near Brocket increased gradually from March through midSeptember, decreased relatively quickly through October and November, and reached a seasonal minimum during the December-March period. Water temperatures increased from a seasonal minimum of $0-2^{\circ} \mathrm{C}$ at a rate of approximately $2-2.5^{\circ} \mathrm{C} \cdot \mathrm{month}^{-1}$. In mid-September, water temperatures reached a maximum of around $14-15^{\circ} \mathrm{C}$, after which point they decreased through early October and November at a rate of approximately $6^{\circ} \mathrm{C} \cdot \mathrm{month}^{-1}$. This seasonal pattern was consistent throughout the post-impoundment monitoring period. Daily mean values of existing data for pre-impoundment, transition (1991 and 1992) and post-impoundment water temperatures near Brocket and Fort Macleod are shown in Figure 3.1. 
Table 3.3 Comparison of reservoir temperature with water temperature in the Oldman River 100m downstream of the outflow and near Brocket

\begin{tabular}{|c|c|c|c|c|}
\hline DATE & $\begin{array}{c}\text { RESERVOIR } \\
\text { TEMPERATURE }\left({ }^{\circ} \mathrm{C}\right)\end{array}$ & $\begin{array}{c}\text { ELEVATION } \\
\text { ( } m \text { above sea level) }\end{array}$ & $\begin{array}{r}\text { TEMPERATURE }\left({ }^{\circ} \mathrm{C} \text { ) IN T }\right. \\
\text { (difference in p } \\
100 \mathrm{~m} \mathrm{~d} / \mathrm{s} \text { of the Outflow }\end{array}$ & $\begin{array}{l}\text { OLDMAN RIVER } \\
\text { ntheses) } \\
\text { near Brocket }\end{array}$ \\
\hline $6 / 19 / 91$ & 9.88 & 1060.973 & & $11.85(1.97)$ \\
\hline $7 / 10 / 91$ & 8.80 & 1061.125 & & $11.60(2.80)$ \\
\hline 7/23/91 & 10.18 & 1059.815 & & $11.45(1.27)$ \\
\hline $8 / 7 / 91$ & 12.87 & 1055.515 & & $14.20(1.33)$ \\
\hline $8 / 20 / 91$ & 15.00 & 1050.200 & & $16.10(1.10)$ \\
\hline $9 / 4 / 91$ & 15.90 & 1058.800 & & $16.75(0.85)$ \\
\hline $9 / 17 / 91$ & 14.57 & 1052.340 & & $14.69(0.12)$ \\
\hline $10 / 4 / 91$ & 12.69 & 1053.350 & & $12.97(0.28)$ \\
\hline $5 / 13 / 92$ & 9.99 & 1053.780 & & $10.50(0.51)$ \\
\hline $5 / 28 / 92$ & 8.81 & 1053.070 & & $9.85(1.04)$ \\
\hline $6 / 10 / 92$ & 11.94 & 1053.860 & (2) & $12.33(0.39)$ \\
\hline $6 / 24 / 92$ & 11.18 & 1056.690 & & $12.03(0.85)$ \\
\hline $7 / 9 / 92$ & 11.64 & 1056.820 & & $11.90(0.26)$ \\
\hline $7 / 22 / 92$ & 11.42 & 1055.341 & & $12.20(0.78)$ \\
\hline $8 / 5 / 92$ & 11.93 & 1054.188 & & $12.94(1.01)$ \\
\hline $9 / 2 / 92$ & 12.66 & 1055.300 & & $12.92(0.26)$ \\
\hline $9 / 29 / 92$ & 11.79 & 1052.793 & & $11.16(-0.63)$ \\
\hline $10 / 27 / 92$ & 9.49 & 1062.374 & & $8.93(-0.56)$ \\
\hline $5 / 18 / 93$ & 6.48 & 1068.723 & & $6.61(0.13)$ \\
\hline $6 / 15 / 93$ & 7.52 & 1057.113 & & $11.93(4.41)$ \\
\hline $6 / 29 / 93$ & 9.40 & 1054.766 & & $9.45(0.05)$ \\
\hline $7 / 13 / 93$ & 10.07 & 1057.979 & & $11.33(1.26)$ \\
\hline $7 / 28 / 93$ & 8.97 & 1045.549 & & $12.43(3.46)$ \\
\hline $8 / 10 / 93$ & 10.83 & 1061.099 & & $11.08(0.25)$ \\
\hline $8 / 25 / 93$ & 11.51 & 1051.582 & & $11.47(-0.04)$ \\
\hline 9/9/93 & 11.65 & 1049.765 & & $11.98(0.33)$ \\
\hline $9 / 21 / 93$ & 10.70 & 1052.664 & & $10.68(-0.02)$ \\
\hline $5 / 17 / 94$ & 6.33 & 1065.051 & & $6.51(0.18)$ \\
\hline $6 / 20 / 94$ & 9.83 & 1064.751 & & $11.50(1.67)$ \\
\hline $7 / 12 / 94$ & 11.60 & 1056.237 & & $12.21(0.61)$ \\
\hline $8 / 10 / 94$ & 12.97 & 1052.392 & & $13.61(0.64)$ \\
\hline $9 / 13 / 94$ & 13.63 & 1050.302 & & $15.38(1.75)$ \\
\hline $10 / 12 / 94$ & 12.22 & 1056.771 & & $11.50(-0.72)$ \\
\hline $8 / 22 / 95$ & 13.29 & 1051.866 & $14.00(0.71)$ & $14.40(1.11)$ \\
\hline $9 / 13 / 95$ & 14.39 & 1059.588 & $14.20(-0.19)$ & \\
\hline $5 / 15 / 96$ & 5.68 & 1054.828 & & $6.50(0.82)$ \\
\hline$6 \longdiv { 4 / 9 6 }$ & 7.11 & 1052.842 & & $8.10(0.99)$ \\
\hline $7 / 28 / 96$ & 11.75 & 1052.002 & & $12.60(0.85)$ \\
\hline $8 / 27 / 96$ & 13.80 & 1052.998 & & $13.90(0.10)$ \\
\hline 9/17/96 & 14.26 & 1049.702 & & $14.10(-0.16)$ \\
\hline
\end{tabular}

Outlined areas indicate periods during which the spillway was operated. 
Table 3.4 Dates during which the spillway was operated

\begin{tabular}{c|l}
\hline YEAR & \multicolumn{1}{|c}{ PERIOD OF SPILLWAY OPERATION } \\
\hline 1991 & \\
1992 & \\
1993 & $6 / 2-6 / 6 ; 6 / 9-6 / 19 ; 7 / 14-7 / 23 ; 7 / 28-7 / 29$ \\
1994 & $4 / 18-4 / 21 ; 9 / 9-9 / 14$ \\
1995 & $5 / 20-5 / 22 ; 5 / 25-6 / 19$ \\
1996 & $6 / 4-6 / 11$ \\
1997 & $5 / 30-6 / 9$ \\
1998 & $5 / 25-6 / 4 ; 6 / 15-6 / 27$ \\
1999 & \\
2000 & \\
2001 & $6 / 6-6 / 24$ \\
\hline
\end{tabular}

Prior to impoundment, the seasonal pattern of water temperature variation was markedly different. Water temperatures increased sharply from freezing in late March to early April. The pattern of increase that occurred from mid-April to July approximated that of post-impoundment temperatures. In early July, the pre-impoundment pattern diverged from the post-impoundment pattern and increased to a seasonal maximum of $18-22^{\circ} \mathrm{C}$ that persisted, with considerable variation, throughout the July-August period. Temperatures then decreased through SeptemberNovember at a rate of approximately $6^{\circ} \mathrm{C} \cdot$ month $^{-1}$. During 1985 and 1989-1990, mean monthly temperatures near Brocket were $11.1^{\circ} \mathrm{C}$ (June), $17.6^{\circ} \mathrm{C}$ (July) and $17.0^{\circ} \mathrm{C}$ (August). During 1993-1999, mean monthly temperatures near Brocket for the same months were $9.7^{\circ} \mathrm{C}, 11.4^{\circ} \mathrm{C}$ and $13.1^{\circ} \mathrm{C}$, a difference of $1.4^{\circ} \mathrm{C}, 6.2^{\circ} \mathrm{C}$ and $3.9^{\circ} \mathrm{C}$ over pre-impoundment temperatures.

Although flows were very low downstream of Fort Macleod during July and August of 1985, there was only a moderate difference in mean temperatures for each month relative to those recorded during the same month near Brocket. Mean temperatures for July 4 (the beginning of the temperature record) to July 31 and for August of 1985 were $19.9^{\circ} \mathrm{C}$ and $16.8^{\circ} \mathrm{C}$ downstream of Fort Macleod, and $18.9^{\circ} \mathrm{C}$ and $14.3^{\circ} \mathrm{C}$ near Brocket, a respective difference of $1.0^{\circ} \mathrm{C}$ and $2.5^{\circ} \mathrm{C}$. In contrast, mean monthly temperatures for June, July, and August of 1995-1999 for Fort Macleod were $11.9^{\circ} \mathrm{C}, 15.5^{\circ} \mathrm{C}$, and $16.3^{\circ} \mathrm{C}$, while those for the same period near Brocket were $9.5^{\circ} \mathrm{C}, 11.5^{\circ} \mathrm{C}$, and $13.4^{\circ} \mathrm{C}$, a respective difference of $2.4^{\circ} \mathrm{C}, 4.0^{\circ} \mathrm{C}$, and $2.9^{\circ} \mathrm{C}$. The rate of temperature change between Brocket and Fort Macleod was greater during the postimpoundment period.

The seasonal temperature regime near Fort Macleod was such that post-impoundment daily mean temperatures attained a seasonal maximum of $17-20^{\circ} \mathrm{C}$ between mid-July and late-August, a shift of about $4-5^{\circ} \mathrm{C}$ relative to maximum seasonal temperatures near Brocket, which occurred in mid-September. While the post-impoundment temperature regime near Fort Macleod continued to approach the historic conditions, in July there remained a mean difference of $4.4^{\circ} \mathrm{C}$ over 1985 temperatures. In August, the difference was only $0.5^{\circ} \mathrm{C}$. 

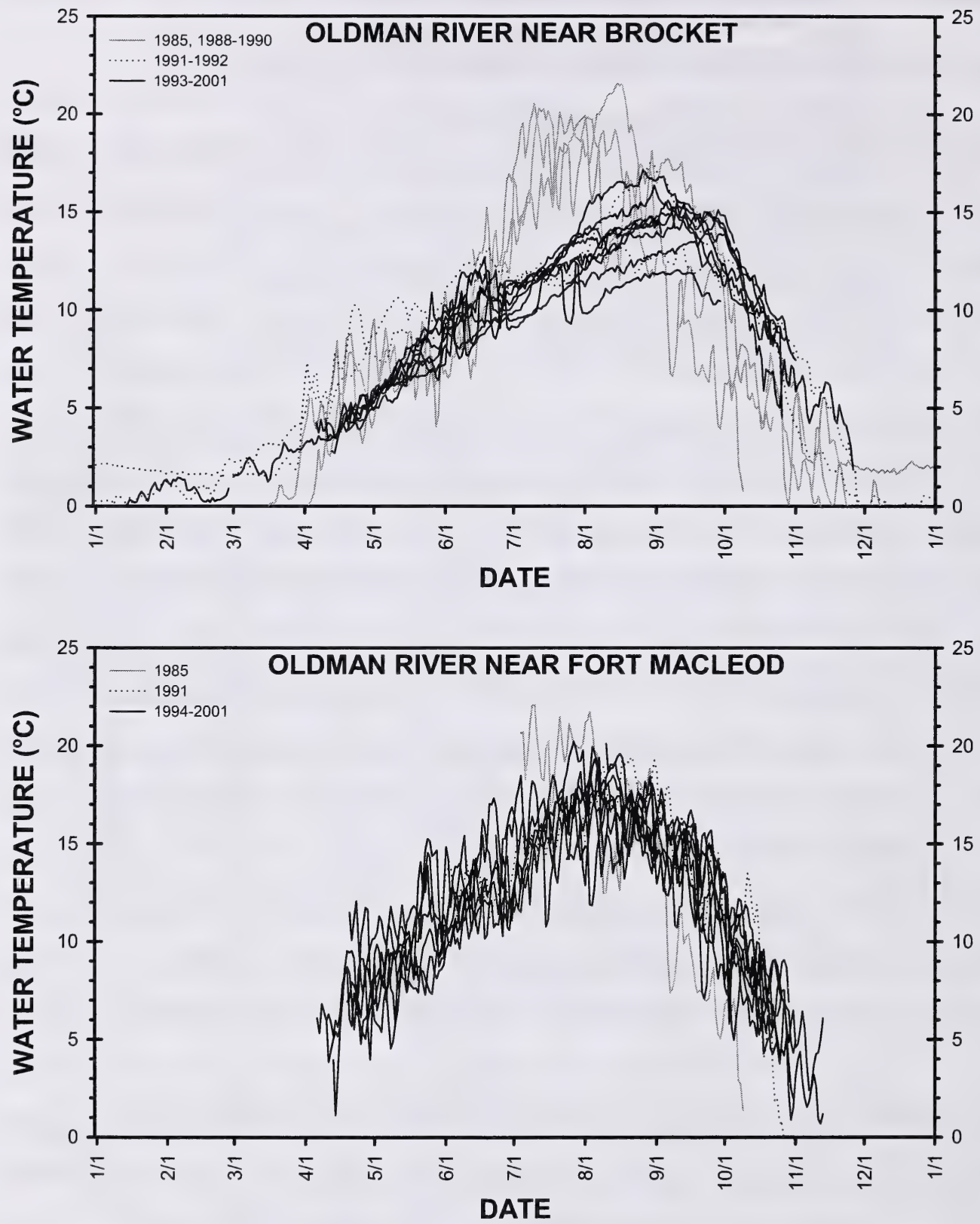

Figure 3.1 Daily average water temperatures in the Oldman River near Brocket and Fort Macleod for pre-impoundment, transition, and post-impoundment years 
Historic data between Fort Macleod and the confluence of the Oldman and Bow Rivers are limited to relatively few point measurements. It is therefore difficult to evaluate the extent of the temperature effect imposed on the Oldman River by the reservoir. However, based on the assumption that the maximum difference between the reservoir site and the confluence of the Oldman and Bow Rivers was historically small (less than $4^{\circ} \mathrm{C}$, HydroQual 1990), a reasonable approximation of the extent of this effect can be achieved. Figures 96-111 of Appendix B provide a monthly summary of mean daily water temperatures for all sites along the Oldman mainstem, as a function of downstream distance. There is a general increasing trend in water temperature with downstream distance, beginning in April and ending in early September. The trend then reverses, decreasing through October. The rate of increase is minimal in April, and appears to approach a maximum in July, when the downstream temperature differential is greatest.

Tables 1-56 of Appendix B show a matrix of pair-wise mean comparisons that were derived using the Tukey method of post-hoc analysis of variance for the monthly summaries presented in Figures 96-111 (Appendix B). These pair-wise comparisons indicate the probability that daily mean water temperatures for two sites, compared over one month, differ significantly. Values below 0.05 represent a difference at a $95 \%$ significance level. The probability that the daily mean water temperatures over one month for any two adjacent sites differ significantly decreases with downstream distance. Therefore, the difference between Brocket and downstream of the LNHD (a distance of $45.6 \mathrm{~km}$ ) is typically significant during all months except September, while the difference between Monarch and upstream of Lethbridge (a distance of $53.3 \mathrm{~km}$ ) is generally only significant in May, June, and July. The probability that adjacent sites differ significantly tends to be greatest upstream of Rocky Coulee. Downstream of the Belly River, differences become essentially undetectable.

It is difficult to isolate the downstream water temperature changes attributable to the hypolimnetic release from those that would occur in an unregulated river. Although the comparisons presented in Tables 1-56 (Appendix B) indicate that water temperature can vary significantly among the upstream sites, sufficient data do not exist to allow similar comparison with pre-impoundment conditions. The significance of inter-site differences are therefore an indication of the extent of post-impoundment changes to the thermal regime, but taken alone are not beyond question.

The nodal effect, discussed in section 3.2.2 that is caused by the release of hypolimnetic water of a constant temperature provides an additional indication of downstream thermal effects of the reservoir. Comparison among sites reveals that this effect, evinced by varying amplitude of diel temperature cycling between sites, is at times quite distinct in the reach between the LNHD and the Belly River, but is generally not discernable downstream of Lethbridge. This is due in part to the thermal signature of inflows from major tributaries like the Belly and St. Mary Rivers, and in part to the variability of flows and net heat exchange. This evidence, along with the pair-wise comparisons, suggests that the effect of the reservoir, which is at a maximum during June, July, and August, probably causes a measurable deviation from the historic temperature regime as far as the Belly River and does not extend past Lethbridge. While it is difficult to account for the influence of the Belly and St. Mary rivers on the temperature regime between Monarch and 
Lethbridge, it is unlikely that river temperatures within this reach deviate substantially from preimpoundment temperatures.

\subsubsection{Model Predictions}

Several predictions relating to changes in the water temperature regime following impoundment were presented by HydroQual (1990), based on modelling of the Oldman River downstream of the reservoir following its completion. These predictions are assessed based on data from the 1993-2001 monitoring period, as follows:

1. The water temperature differential between upper (below the dam out-fall) and lower (near the confluence with the Bow River) reaches in the Oldman River would approach $15^{\circ} \mathrm{C}$ following reservoir development. In contrast, the temperature differential under simulated pre-reservoir conditions did not exceed $4^{\circ} \mathrm{C}$.

This prediction is accurate. The downstream water temperature differential between Brocket and the confluence with the Bow River sometimes approaches $15^{\circ} \mathrm{C}$, but generally does not exceed this value. The difference is typically on the order of $8^{\circ} \mathrm{C}$ to $11^{\circ} \mathrm{C}$, two to three times the (simulated) pre-impoundment value of $4^{\circ} \mathrm{C}$. The largest temperature differential generally occurs during July and August, when water temperatures near the confluence of the Oldman and Bow Rivers are at a maximum.

2. Daily average water temperature upstream of the LNHD would not exceed $15^{\circ} \mathrm{C}$ following reservoir development. Under simulated historic conditions, water temperature would exceed $22^{\circ} \mathrm{C}$.

Daily average water temperature near Brocket occasionally exceeds $15^{\circ} \mathrm{C}$, but rarely exceeds $16^{\circ} \mathrm{C}$. Water temperature consistently exceeded $16^{\circ} \mathrm{C}$ in late August and early September of 1991, and again in 2001; in both cases, water levels in the reservoir were considerably below the full supply level. Provided that the reservoir operates at or near full supply level, this prediction is accurate.

3. The Oldman River downstream of the reservoir would be cooled substantially during summer months and warmed during fall and winter months, as compared to historic conditions. The cooling effect would extend as far downstream as the Belly River during summer months, and could extend as far downstream as Lethbridge.

Although this prediction appears to be accurate, it is difficult to gauge accurately the extent of the influence of the reservoir on the Oldman River. The greatest difference between postimpoundment temperatures and pre-impoundment temperatures occurs during mid-June through late-August, when the river directly downstream of the reservoir is substantially cooler than under historic conditions (Figure 3.2). Near Brocket, this translates to a decrease in mean monthly temperatures over pre-impoundment temperatures of $0.1^{\circ} \mathrm{C}$ in May, $1.4^{\circ} \mathrm{C}$ in June, $3.2^{\circ} \mathrm{C}$ in July and $6.9^{\circ} \mathrm{C}$ in August. In September, there is a reversal of the cooling effect, such that river temperatures downstream of the reservoir are on average $2.3^{\circ} \mathrm{C}$ warmer than under 
historic conditions. In October, the difference is $5.0^{\circ} \mathrm{C}$. These conditions probably continue through late-November, although there are insufficient data during the November-December period to support any conclusions to this effect. Post-impoundment winter temperatures do not differ substantially from historic temperatures, although the river is probably warmed sufficiently to reduce ice formation directly downstream of the reservoir. The direct warming or cooling effect of the reservoir extends at least as far as Monarch and probably as far as Lethbridge. This effect is most pronounced through Fort Macleod although its magnitude varies substantially with the time of year and with flow.

4. Seasonal warming and cooling of the Oldman River would be delayed relative to historic conditions.

The change in the temperature regime downstream of the reservoir can be described as a general forward shift in the seasonal temperature cycle, such that warming and cooling are delayed by two to six weeks, relative to historic conditions. The delay is most significant in early

September, as peak post-impoundment temperatures occur about six weeks later than in the historic condition. This delay is carried through at least until late October, and possibly until late November. While there appears to be a slight delay of one to two weeks in early season (AprilMay) warming, this delay is within the range of historic variability.

5. Water temperature at the reservoir outlet would vary substantially from year to year, depending upon water level elevations in the reservoir. Low water levels would generally result in warmer outlet temperatures.

This prediction is accurate, to the extent that reservoir levels vary as predicted by Hydroqual. Year-to-year variation in reservoir water level, to the extent to that it has occurred during the 1993-2000 period, does not appear to have a significant effect on outflow temperatures. While there is a certain degree of year-to-year variation in outflow temperature during the 1993-2000 period, it is unlikely that this is due to water level variation. The outflow temperature variation that occurred during the 1993-2000 period was primarily a function of reservoir heating and the various factors affecting heat transfer within the reservoir. However, the variation in water level that was modelled by HydroQual (1990) for 1982 to 1986 is greater than that observed during the 1993-2000 period. Figure 3.2 shows reservoir elevations for 1991 to 2001. After attaining spill level in 1993, reservoir elevations from 1993 to 2000 ranged between $1110 \mathrm{~m}$ and $1120 \mathrm{~m}$. In contrast, those modelled for the 1982-1986 period ranged between $1070 \mathrm{~m}$ and $1120 \mathrm{~m}$, and were particularly low in 1984-1985 (HydroQual 1990). The variation predicted for 1984 and 1985 is similar to that which occurred during 1991 and 1992, prior to the reservoir attaining spill level, and in 2001. During these years, outflow temperatures varied considerably from those recorded in 1993-2000, indicating that the variation in reservoir elevation characteristic of 1991, 1992, and 2001 was sufficient to have caused significant outflow temperature variation.

Based on natural flows near Brocket, 1982 through 1985 were particularly dry years, during which yearly natural flows (total volume) remained below the first quartile of historic (1912-1995) flows. The same is true of 2001. It is likely that during a succession of years 
in which naturally available flows fall below the historical median, as in 1982-1985, reservoir elevations could fall to the levels predicted for 1984-1985. Although the current reservoir operating plan is a refinement of that upon which the 1982-1986 model is based, the predictions of the model appear to be borne out in the 2001 reservoir elevations. The current operating plan was evaluated using the Water Resource Management Model (WRMM; Alberta Environment 1987), based on an irrigation demand of $90 \%$ of the expansion limit established in the Water Management Policy for the South Saskatchewan River Basin (Alberta Environment 1990). Although the reservoir was expected to attain spill level in $80 \%$ of model years under the $90 \%$ irrigation demand, at the expansion limit this figure could drop to $70 \%$ (Alberta Environment 1994). It is therefore likely that the substantial year-to-year variability in water level, and therefore in outlet temperature, that was projected to occur for the 1982-1986 period and that occurred in 2001 will occur more frequently under full allocation of irrigation resources.

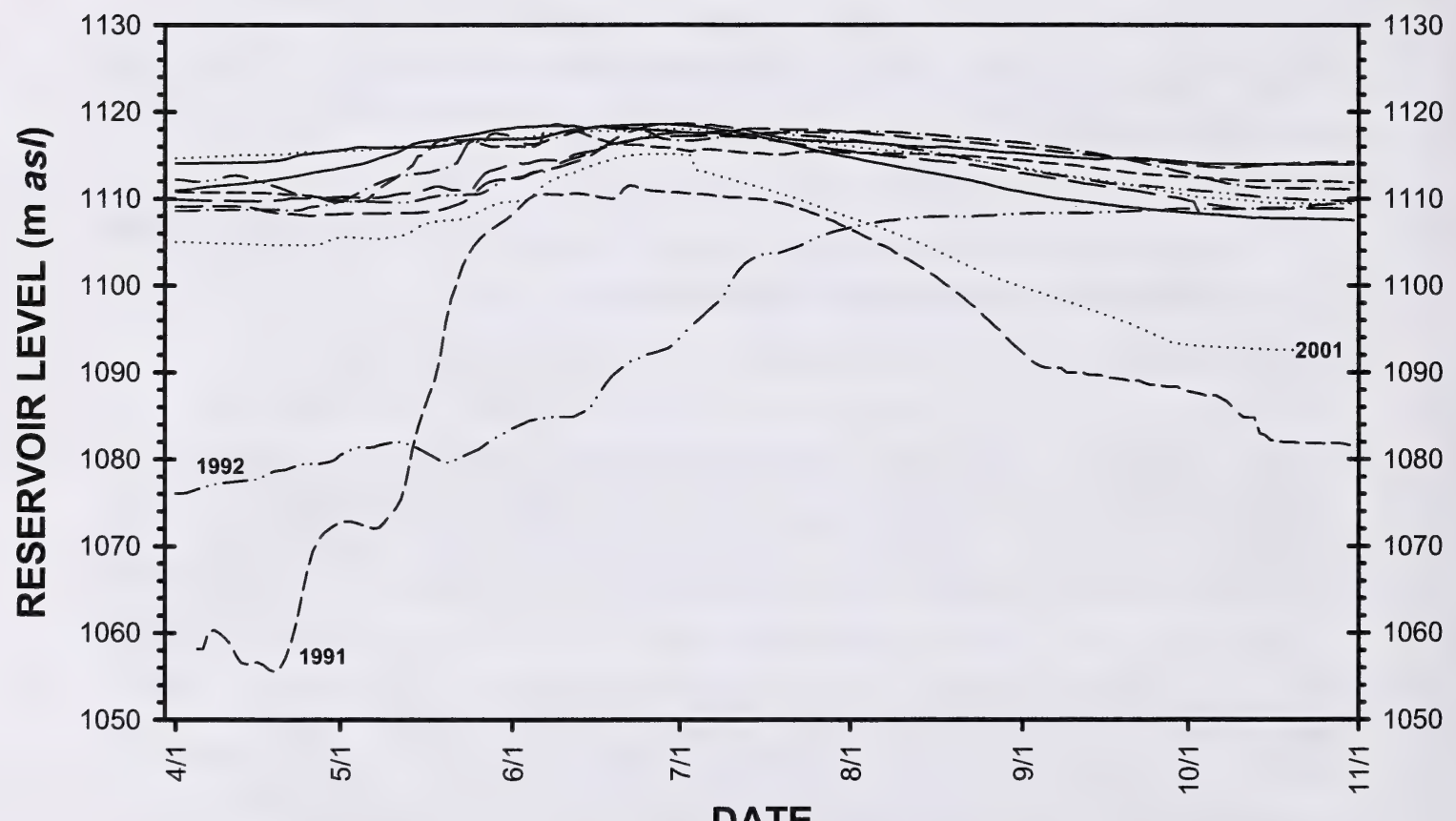

Figure 3.2 Water level ( $m$ above sea level) in the Oldman Reservoir, 1991-2001 


\subsection{CRITERIA FOR FISH}

Flow management on the Oldman River has been based primarily on the habitat and water quality requirements of the fish species that have been identified as priority management species. Priority management species were identified for the coldwater and coolwater zones of the Oldman River, and for the transitional zone that is defined by the overlap of the coldwater and coolwater zones. These zones are defined based on the potential suitability of habitat for trout and mountain whitefish (Prosopium williamsoni; coldwater) and northern pike (Esox lucius), walleye (Stizostedion vitreum vitreum), and goldeye (Hiodon alosides; coolwater) (Radford 1975, Allen 1985). Because the Oldman Reservoir has a cooling effect on downstream reaches during the summer, the coldwater zone has expanded from where it historically extended to the LNHD; it now extends downstream to Fort Macleod. The transition zone extends approximately to Rocky Coulee, after which the coolwater zone extends the remaining distance to the mouth (Dominion Ecological Consulting 1990). Priority management species, as identified by the Alberta Fish and Wildlife Division and by the Local Advisory Committee, are brown trout (Salmo trutta) and rainbow trout (Oncorhynchus mykiss) for the coldwater zone, and walleye and sauger (Stizostedion canadense) for the coolwater zone (Dominion Ecological Consulting 1990).

It is beyond the scope of this report to evaluate fully the suitability of post-impoundment temperature and dissolved oxygen conditions as they relate to fish populations. Water quality guidelines and species specific criteria are therefore presented as they apply to the conditions recorded during the 1991-2001 period, with no further discussion of the implications of recorded conditions having exceeded or failed to meet these criteria. A suitable assessment of the significance of post-impoundment changes on fish populations would require a far more detailed analysis than is presented here.

The criteria used for evaluation of oxygen and temperature data for 1991-2001 are expressed as chronic and acute criteria. Acute criteria are defined as levels at which mortality could result from short-term exposure. The risk of mortality varies with the duration and the intensity of exposure; however, the acute value should be considered the limit beyond which the probability of mortality is significant. Chronic criteria define the incipient limits of exposure beyond which long term exposure would result in eventual decline in the population due to physiological impairment, recruitment failure, mortality from cumulative stress, etc. These criteria are evaluated over a period of weeks or months and generally define the limits of optimal conditions. For a more comprehensive discussion of acute versus chronic criteria and how these criteria are derived, refer to Taylor and Barton (1992).

\subsection{Oxygen Criteria}

The Alberta surface water quality (ASWQ) dissolved oxygen guidelines (Alberta Environment, 1999) are designed to confer protection to a broad range of the aquatic biota. These guidelines (Shaw 1997) were developed based on a broad review of the available literature on acute and chronic effects of depressed dissolved oxygen levels on (primarily) fish and aquatic invertebrates, with reference to guidelines established by the United States Environmental Protection Agency and to the Canadian Water Quality Guideline. While evaluation of postimpoundment dissolved oxygen conditions has been restricted to the $5 \mathrm{mg} \cdot \mathrm{L}^{-1}$ acute guideline in

Temperature and Dissolved Oxygen in the Oldman River Following Construction of the Oldman River Dam 
this report, chronic guidelines have also been established for the protection of aquatic biota from persistent stresses. The chronic guideline of $6.5 \mathrm{mg} \cdot \mathrm{L}^{-1}$, based on a 7-day mean, can be increased to $8.3 \mathrm{mg} \cdot \mathrm{L}^{-1}$ from mid-May to the end of June for the protection of the emergence of mayfly species. The guideline can also be increased to $9.5 \mathrm{mg} \cdot \mathrm{L}^{-1}$ to ensure sufficient inter-gravel oxygen concentrations during the early growth and development of some salmonids (embryonic and larval stages). Because of the species and life stage specificity of these guidelines, they cannot be applied in the same manner as the $5 \mathrm{mg} \cdot \mathrm{L}^{-1}$ acute guideline. They are therefore presented on a monthly basis for each year at each site in Tables 1-9 of Appendix C, along with the Canadian Environmental Quality (CEQ) guidelines (CCME 1999). Dissolved oxygen levels are also evaluated based on the individual requirements of several fish species present in the Oldman River, as well as on the requirements of the more sensitive early life stages of these species. The values used in the evaluation are from Taylor and Barton (1992), and represent the currently accepted criteria for Alberta fish species. The evaluations are shown as frequency of criteria exceedance (i.e., failure to meet).

Acute criteria are assessed based on daily minimum values, while chronic criteria are assessed based on the 7-day mean or the 7-day mean of minimum (specified) values for a given day and for the following six days. A failure to meet the specified criterion is presented as a percent of the days sampled during a given month. Frequency values for which monthly data are incomplete are printed in grey. These values do not represent conditions over that entire month. They may over-represent or under-represent actual conditions. When monthly data are insufficient to permit the calculation of chronic criteria (less than seven consecutive values), the associated columns are shaded.

Dissolved oxygen criteria for adult salmonids, whitefish, and non-salmonids were normally satisfied at all locations in most years. Acute criteria for walleye and non-salmonid fry and early life stages were occasionally not satisfied from Lethbridge to the Bow confluence, while early life stage criteria for salmonids were usually not satisfied for part of the measurement season at all locations.

\subsection{Temperature Criteria}

\subsubsection{Chronic and Acute Temperatures}

Exposure to water temperatures that approach or exceed the tolerance of fish species also increases stress and mortality within fish populations. Water temperatures are therefore also evaluated based on the requirements of individual fish species, as specified in Taylor and Barton (1992). These evaluations are presented on a monthly basis for each site in Tables 10-31 of Appendix C. The ASWQ and CEQ guidelines are not evaluated, since these apply to thermal inputs affecting ambient conditions, and consequently are not relevant to this situation. Speciesspecific temperature guidelines are therefore presented for fry and adults only, as percent frequencies of failure to meet (i.e., exceed) the applied criterion over the sample period.

Acute criteria are assessed based on daily minimum values, while chronic criteria are assessed based on the 7-day mean values for a given day and for the following six days. As with the previous set of tables, values are printed in grey for months having an incomplete data set. 
Columns are shaded for months during which evaluation of the criteria is not possible. For chronic criteria, two columns are presented for each month. The first is an indication of whether water temperatures met minimum values; the second as an indication of whether water temperatures exceeded maximum values.

Chronic temperature criteria for Walleye were generally satisfied at all sites, with few exceptions. The lowermost locations at which chronic temperature criteria were most frequently satisfied for other species are as follows: brown trout (adult) and cutthroat trout - Rocky Coulee; cutthroat trout (all life stages), rainbow trout (all life stages), and mountain whitefish (all life stages) - Fort Macleod; bull trout (all life stages) and brown trout fry - Brocket. Acute temperature criteria for walleye were not exceeded at any sampling location. Acute temperature criteria were most frequently satisfied for brown trout (all life stages), rainbow trout (all life stages), and mountain whitefish fry upstream of Rocky Coulee. Acute temperature criteria were generally satisfied for all species upstream of Fort Macleod.

\subsubsection{Spawning and Incubation Temperatures}

A complete evaluation of temperature criteria is not possible in all cases, since the period during which data were collected does not coincide with the incubation and hatching period for fall spawners. For these species (mountain whitefish, bull trout, and brown trout), only spawning temperatures are evaluated. Spawning and incubation temperatures are evaluated for spring spawners, which include rainbow trout, cutthroat trout, and walleye. Evaluation of spawning and incubation criteria over the appropriate spawning period (Taylor and Barton 1992) is illustrated by sampling site in Figures 1-22 of Appendix C. These figures show the period for which data have been collected, the period during which temperatures fell within the appropriate range for spawning, and the period during which spawning was followed by temperatures conducive to potentially successful incubation. The period for spawning with successful incubation is given only if temperatures meet spawning criteria, and if the appropriate number of temperature units were achieved following spawning. The full range of the incubation period is not shown. The specific temperature criteria necessary for spawning and incubation, as given in Taylor and Barton (1992) are shown in Table 4.1. Spawning criteria specify a seven-day period during which temperatures fall within the required range. In the analyses shown in Figures 1-22, the seven-day period was taken to be a given day plus the previous six days. Incubation criteria specify that the temperature range that is favourable to incubation should occur over a specific period of temperature units. These were calculated as degree-days, the sum of daily average temperatures over consecutive days during which water temperatures fell within the specified range, although as discussed in Taylor and Barton (1992), degree-days are not strictly equivalent to temperature units. While there is no figure for July 14 and 15 of 1993 at the site near Highway 845 , temperatures during these two days did not meet the spawning or incubation criteria for cutthroat trout.

The temperature regime at Brocket generally provides conditions suitable only for spring spawners. Although water temperatures to upstream of Lethbridge were generally suitable for walleye spawning and incubation, water temperatures downstream of Brocket are not frequently

Temperature and Dissolved Oxygen in the Oldman River Following Construction of the Oldman River Dam 
suitable for other spring spawners. Water temperatures were occasionally suitable for mountain whitefish and bull trout downstream of Brocket, and for Brown trout at all sites.

Table 4.1 Chronic temperature criteria for spawning and incubation of six fish species in the Oldman River

\begin{tabular}{l|c|c|c|c}
\hline \multirow{2}{*}{ SPECIES } & \multicolumn{2}{c|}{ SPAWNING } & \multicolumn{2}{c}{ INCUBATION } \\
& Period & $\begin{array}{c}\text { Temperature } \\
\text { Criteria }\end{array}$ & Period & $\begin{array}{c}\text { Temperature } \\
\text { Criteria }^{2}\end{array}$ \\
\hline Rainbow Trout & $04 / 01-06 / 15$ & 7 days $5^{\circ} \mathrm{C} \leq \mathrm{T} \leq 10^{\circ} \mathrm{C}$ & $04 / 15-08 / 15$ & $320 \mathrm{TU} 7^{\circ} \mathrm{C} \leq \mathrm{T} \leq 14^{\circ} \mathrm{C}$ \\
Walleye & $04 / 15-06 / 01$ & 5 days $5^{\circ} \mathrm{C} \leq \mathrm{T} \leq 12^{\circ} \mathrm{C}$ & $04 / 15-07 / 01$ & $170 \mathrm{TU} 6^{\circ} \mathrm{C} \leq \mathrm{T} \leq 18^{\circ} \mathrm{C}$ \\
Cutthroat Trout & $05 / 15-07 / 15$ & 7 days $7^{\circ} \mathrm{C} \leq \mathrm{T} \leq 10^{\circ} \mathrm{C}$ & $05 / 15-08 / 15$ & 310 TU $7^{\circ} \mathrm{C} \leq \mathrm{T} \leq 12^{\circ} \mathrm{C}$ \\
Bull Trout & $08 / 15-11 / 15$ & 7 days $1^{\circ} \mathrm{C} \leq \mathrm{T} \leq 9^{\circ} \mathrm{C}$ & & \\
Mountain Whitefish & $09 / 15-11 / 15$ & 7 days $1^{\circ} \mathrm{C} \leq \mathrm{T} \leq 6^{\circ} \mathrm{C}$ & & \\
Brown Trout & $09 / 15-11 / 15$ & 7 days $5^{\circ} \mathrm{C} \leq \mathrm{T} \leq 11^{\circ} \mathrm{C}$ & & \\
\hline
\end{tabular}

${ }^{1}$ daily maximum and minimum temperatures

${ }^{2}$ subsequent to a successful spawning event 


\subsection{THE WQRRS MODEL}

The Water Quality for River-Reservoir Systems (WQRRS) model (Smith 1978) was employed in the Oldman River basin to simulate post-impoundment conditions downstream of the Oldman Reservoir. The modelling exercise had two distinct components: the analysis of management alternatives relative to water quality predictions, and the establishment of water quality-based minimum flows. These approaches differed in their respective treatment of the model flows. Post-impoundment simulations were based on historic conditions in the basin, relative to the availability of natural flows. Reservoir and tributary inflows, as well as consumptive demands, were modelled based on provisional operational plans using the Water Resource Management Model (WRMM; Alberta Environment 1987), and fed into the WQRRS input deck. Historic conditions were simulated in a similar manner. By comparison, minimum flows were established using an artificial hydrologic regime in which constant flows were assumed.

\section{$5.1 \quad$ Minimum Flows}

Existing minimum flows, presently under evaluation for the South Saskatchewan River Basin Water Management Review, were derived from modelling of dissolved oxygen conditions in the Oldman River using the WQRRS model. It was concluded from the initial modelling exercise that a flow greater than $20 \mathrm{~m}^{3} \cdot \mathrm{s}^{-1}$ would preclude critically low concentrations of dissolved oxygen $\left(<5 \mathrm{mg} \cdot \mathrm{L}^{-1}\right)$ downstream of Lethbridge (HydroQual 1990). Further modelling was undertaken to expand the scope of the initial exercise, resulting in the existing minimum flows presented in Table 5.1 (Alberta Environment 1993). It appears from briefing notes prepared for meetings held in November and December of 1990 (HydroQual 1990b; unpublished) that HydroQual revised the variables that describe aquatic plant biomass to reflect a more conservative (higher) estimate in the expanded model.

Table 5.1 Minimum flow requirements $\left(\mathrm{m}^{3} \cdot \mathrm{s}-1\right)$ in the Oldman River

\begin{tabular}{l|c|c|c|c|c|c|c|c|c|c|c|c}
\hline \multicolumn{1}{c|}{ REACH } & JAN & FEB & MAR & APR & MAY & JUN & JUL & AUG & SEP & OCT & NOV & DEC \\
\hline $\begin{array}{l}\text { d/s of the LNHD } \\
\text { Diversion }\end{array}$ & 6.5 & 6.5 & 6.5 & 8.5 & 8.5 & 8.5 & 8.5 & 8.5 & 8.5 & 8.5 & 6.5 & 6.5 \\
$\begin{array}{l}\text { d/s of } \\
\text { Lethbridge }\end{array}$ & 11.5 & 11.5 & 11.5 & 15 & 20 & 20 & 20 & 20 & 15 & 15 & 11.5 & 11.5 \\
\hline
\end{tabular}

Exceedence analyses for continuous flow models, also provided in the briefing notes, indicate that under the revised biomass estimates, the $20 \mathrm{~m}^{3} \cdot \mathrm{s}^{-1}$ minimum flow that was initially proposed in HydroQual (1990) was not adequate to prevent dissolved oxygen concentrations from falling below $5 \mathrm{mg} \cdot \mathrm{L}^{-1}$ downstream of Lethbridge. Dissolved oxygen targets therefore appear to have been revised and dissolved oxygen criteria for Walleye and Sauger, the target management species in that reach (Alberta Environment, 1993), adopted in place of the $5 \mathrm{mg} \cdot \mathrm{L}^{-1}$ ASWQG. These criteria are presented with criteria from Taylor and Barton (1992) in Table 5.2. Hydroqual ran the revised simulations at constant flows of $10,15,20$, and $25 \mathrm{~m}^{3} \cdot \mathrm{s}^{-1}$; the $20 \mathrm{~m}^{3} \cdot \mathrm{s}^{-1}$ minimum flow was adopted as adequately protective of the target management species (Walleye and 
Sauger) downstream of Lethbridge. Although the process by which minimum flows were established downstream of the LNHD is not well documented, it appears that the $5 \mathrm{mg} \cdot \mathrm{L}^{-1}$ objective was observed in this case.

Table 5.2 Dissolved oxygen criteria for walleye and sauger, used in establishing minimum flows downstream of Lethbridge. Criteria from Taylor and Barton (1992), for comparison

\begin{tabular}{|c|c|c|}
\hline \multicolumn{3}{|c|}{$\mathrm{DO}_{2}$ - ACUTE } \\
\hline & Hydroqual, $1990^{3}$ & Taylor and Barton, 1992 \\
\hline Early Life & $<5.0 \mathrm{mg} / \mathrm{L}$ & $<5.0 \mathrm{mg} / \mathrm{L}$ \\
\hline Fry & \multirow{2}{*}{$<3.0 \mathrm{mg} / \mathrm{L}$} & $<5.0 \mathrm{mg} / \mathrm{L}$ \\
\hline Adult & & $<3.0 \mathrm{mg} / \mathrm{L}$ \\
\hline \multicolumn{3}{|c|}{$\mathrm{DO}_{2}$ - CHRONIC } \\
\hline & Hydroqual, $1990^{3}$ & Taylor and Barton, 1992 \\
\hline Early Life & $<6.0 \mathrm{mg} / \mathrm{L}^{1}$ & $<6.0 \mathrm{mg} / \mathrm{L}^{1}$ \\
\hline Fry & \multirow{2}{*}{$\begin{array}{l}<5.0 \mathrm{mg} / \mathrm{L}^{1} \\
<4.0 \mathrm{mg} / \mathrm{L}^{2}\end{array}$} & $\begin{array}{l}<6.0 \mathrm{mg} / \mathrm{L}^{1} \\
<5.0 \mathrm{mg} / \mathrm{L}^{2} \\
\end{array}$ \\
\hline Adult & & $\begin{array}{l}<5.0 \mathrm{mg} / \mathrm{L}^{1} \\
<5.0 \mathrm{mg} / \mathrm{L}^{2}\end{array}$ \\
\hline $\begin{array}{l}{ }^{1} 7 \text {-day me } \\
{ }^{2} 7 \text {-day me } \\
{ }^{3} \text { From EP }\end{array}$ & & \\
\hline
\end{tabular}

\subsection{Post-impoundment Simulations}

Post-impoundment flows were simulated for the 1982-1986 period using the Water Resource Management Model, a water balance simulation model that approximates the consumptive demands and water supply in the South Saskatchewan River Basin (Alberta Environment 1987). The reservoir operating scenarios employed in the model were the provisional OD04/OD05 scenarios, resulting from a process that involved the evaluation of model output relative to provisional flow requirements followed by many iterations of revision and re-evaluation. The operating scenarios were evaluated based on adherence to criteria such as apportionment requirements, consumptive demands, and minimum flows. The optimal operational plan was considered to be one in which desired flow targets were most frequently met or exceeded.

Minimum in-stream flow targets used during the development of the provisional operating scenario OD04/OD05 (Alberta Environment 1989) were derived based on adherence to the $5 \mathrm{mg} \cdot \mathrm{L}^{-1}$ Alberta Surface Water Quality Objective (Alberta Environment 1977). These minimum targets were established through empirical analyses of the limited dissolved oxygen data that were available prior to impoundment and, to some extent, on preliminary water quality modelling (e.g., Hamilton and Cross 1985; Alberta Forestry, Lands, and Wildlife 1988). These 
preliminary targets were at best crude estimates of flows intended to amend the often critically low levels of dissolved oxygen in the reach that extends downstream of Lethbridge to the confluence with the Bow River.

Desired targets were to be met on a contingency basis; while a failure to meet these targets implied a potential weakness in the operating scenario, observance of the desired targets was not critical. The desired targets were derived by the method of Tessman (after Bietz et al. 1985), modified to allow for its general application to Alberta rivers (Allan 1986). This method, by which minimum flows for the protection of fish populations were derived in relation to naturally occurring flows, has since been superseded by the use of the Instream Flow Incremental Methodology (IFIM). The IFIM also relates the protection of fish populations to naturally occurring flows, but does so in a manner that is more rigorous with respect to its consideration of the biology of various fish species and their life stages.

The water balance obtained from the WRMM was input to the WQRRS model, along with meteorological data from 1982-1986 and output from the Laterally Averaged Reservoir Model (LARM), which simulated reservoir conditions over the same period. The model was run at hourly time-steps for the May-September period of these years for nine water quality zones, designated $a$ through $i$ (HydroQual 1990). Dissolved oxygen conditions, initially simulated only for July and August of 1984 and 1985, were later expanded to include the spring and fall periods of 1982 through 1986, for which temperature modelling had already been conducted.

Comparison of the dissolved oxygen regime that is predicted by the WQRRS model with actual values recorded during the 1991-2001 period suggests that the WQRRS model does not accurately reflect post-impoundment dissolved oxygen conditions. The model exaggerates the symmetry of maximum and minimum diel values for dissolved oxygen. Significant increases in predicted maximum diel dissolved oxygen levels are followed by roughly equivalent decreases in minimum diel dissolved oxygen levels. In contrast, the relation between maximum and minimum diel dissolved oxygen levels, relative to equilibrium levels, is very weak in productive reaches. The relative symmetry that is typical of the dissolved oxygen regime predicted by the model is not reflected in the actual data.

The discrepancy between values predicted using the WQRRS model and actual values reflects in part the decision to input epilithic algal and macrophyte biomass as state variables. The decision to override the WQRRS module that simulates the community dynamics of aquatic plants was based on the concern that this module could not predict these variables with sufficient accuracy. Hamilton and others (1986) found that it was difficult to achieve acceptable model calibration for nutrient and dissolved oxygen predictions while at the same time generating a prediction for the density of aquatic plant populations that reflected actual measurements. Concerns were also raised as to the capacity of the model to predict macrophyte development accurately (Hamilton and Cross 1985). Values reflecting density of epilithic algae and macrophyte populations were therefore defined at weekly intervals for specific river segments. These values were derived from a limited data set available for July and August of 1985-1986. Missing variables were interpolated from existing data, or assumed zero (HydroQual 1990). There is no constituent in the WQRRS model that accounts for the productivity of phytoplankton, although this has been 
shown by Charlton et al. (1986) to be a significant component of net productivity in the Oldman River, especially in downstream reaches.

The decision to input model constituents that describe population dynamics of aquatic plants as static variables has three principal implications with regard to the accuracy of dissolved oxygen predictions:

1. An increase in flow can disrupt phytobenthic populations (scour). The consumption of oxygen due to the decay of detritus generated by scour, and the reduced generation and consumption of oxygen resulting from the removal of phytobenthos are not addressed when plant biomass is held as constant.

2. Under the less variable flow regime projected for the post-impoundment period, the density and distribution of the phytobenthos, particularly macrophytes, was expected to increase (HydroQual 1990). The state variables describing the density of the phytobenthos were input based on pre-impoundment data. Therefore, a postimpoundment increase in the net rates of oxygen generation and consumption due to the expected increase in the density and distribution of the phytobenthos was not accounted for in the model output.

3. Changes in the post-impoundment temperature regime, with emphasis on warmer fall and winter water temperatures, may extend the growing season for aquatic plant communities and result in an increase in standing stocks. A change in the oxygen regime generated by an increase in standing stocks is not reflected in the model.

Because of the inter-relatedness between the dissolved oxygen regime and the trophic status of the river, the predictive capacity of the WQRRS model in relation to dissolved oxygen is contingent on the degree to which actual levels of primary productivity are reflected in the model. Users of the WQRRS model are advised to be judicious in modifications of code which allow a model constituent to be held constant. This is particularly important when the constituents being modified describe the distribution and density of aquatic plants, which can directly affect the accuracy of computation for other constituent variables (Smith 1978). Values that describe the density of aquatic plants should therefore reflect predicted conditions in a manner that allows for a reasonable margin of tolerance. It was assumed during the configuration of the model that the data from which estimates of algal biomass were derived represented a conservative (i.e. worst case) approximation of post-impoundment biomass, as they were collected during 1985 when flows were exceptionally low.

The model variables reflecting aquatic plant density and distribution are presented in Table 5.3, along with actual pre- and post-impoundment data. The data are arranged with reference to the water quality zones defined in the model (A-I). The values are the revised estimates (unpublished) that were presumably used in the derivation of current minimum flows. They represent a more conservative scenario than was initially employed in the 1984-1985 simulations (HydroQual 1990). Actual values for pre- and post-impoundment biomass have been converted 


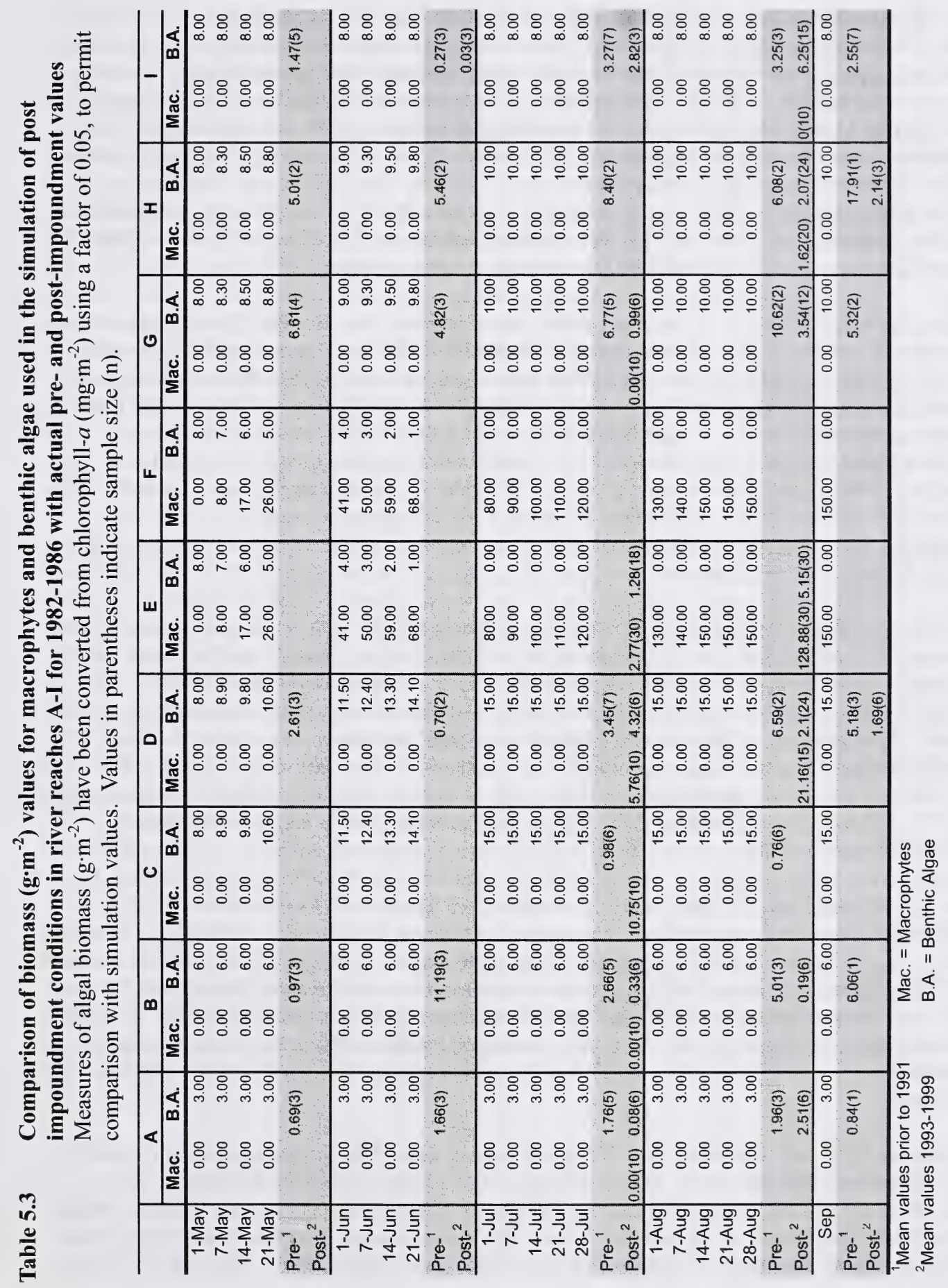


by the same factor that was applied by HydroQual $\left(0.05 \mathrm{mg} \mathrm{chl}-\mathrm{a} \cdot \mathrm{m}^{-2} / \mathrm{g}\right.$ biomass $\left.\cdot \mathrm{m}^{-2}\right)$. The distribution of macrophytes represented in the model input set does not extend as far upstream as the actual post-impoundment distribution. Post-impoundment data indicate that the macrophyte community extends upstream of the Lethbridge wastewater treatment plant to downstream of Lethbridge in July, and includes a patch near Taber in August. In contrast, the simulated distribution of macrophytes extends $35 \mathrm{~km}$ downstream of Lethbridge only. Simulated values directly downstream of Lethbridge are considerably higher than post-impoundment values in both July and August. However, the August post-impoundment value approaches the simulated value. It therefore remains possible that simulated values could be exceeded given suitable conditions such as those afforded by the relatively warm summer of 1998 .

The distribution of benthic algae represented in the model input set is roughly similar to the postimpoundment distribution. However, while the model distribution assumes peak biomass to occur around the Lethbridge area, the actual post-impoundment distribution has two additional peaks directly downstream of the reservoir and near the mouth. The post impoundment peak downstream of the reservoir is probably due to several flow-related factors, including an extended ice-free season and increased bed stability resulting from the more constant flow regime, which in turn permits algal growth. The values for benthic algal biomass presented in the model are consistently higher than the actual post-impoundment values, and represent a plausible 'worst case' scenario. Values for the two zones (e and f) downstream of Lethbridge have been omitted in the model.

In deriving static variables of algal biomass from the existing data, it was necessary to convert measures of chlorophyll- $a \cdot \mathrm{m}^{-2}$ to measures of biomass $\cdot \mathrm{m}^{-2}$. The conversion of values for algal biomass from chlorophyll- $a$ is generally considered a crude measure that yields inexact values. HydroQual applied a multiplying factor of 0.05 in estimating biomass $\mathrm{m}^{-2}$ from $\mathrm{mg}$ chlorophyll$a \cdot \mathrm{m}^{-2}$. Charlton et al. (1986) also used this value in order to compare macrophyte biomass with epilithic algal biomass. Charlton et al. (1986) apparently derived this value from Marker (1976b), although the same author considers such a conversion to be very unreliable (Marker 1976a, 1976b). The values derived by Wetzel and Westlake (1969), for which they report a threefold margin of error, were 0.06 for high chlorophyll (non-nutrient limited) phytoplankton populations, and of 0.12 for low chlorophyll (nutrient limited) phytoplankton populations, based on Strickland (1960). By these values, the conversion factor of 0.05 assumes very high chlorophyll per unit biomass. Epilithic algae in the Oldman River tend to be highly productive per unit chlorophyll- $a \cdot \mathrm{m}^{-2}$, suggesting that they have a low chlorophyll content (Charlton et al. 1986). If the aim of the modelling exercise was to provide a conservative (worst case) estimate for post-impoundment conditions, the conversion factor of 0.05 was not appropriate. While the revised estimates constitute an attempt to compensate for the shortfall, the estimates of algal biomass used in configuring the model should be considered poor approximations of actual biomass.

Photosynthesis and respiration rates for aquatic plants, as well as oxygen equivalency ratios for photosynthesis and respiration, can be defined by the user for calibrating the model. These variables are adjusted such that the simulated dissolved oxygen regime reflects recorded values. The calibration values, along with the data used in the calibration, are presented in HydroQual (1990), as well as in unpublished briefing notes from December of 1990. The WQRRS model 
was calibrated using relatively few data, the majority of which were not collected during the critical periods of maximal and minimal diel concentrations. Where continuous data are available, there is a considerable discrepancy with predicted values. This does not present a significant concern in relation to reaches where diel variation is small. However, in very productive reaches such as downstream of Lethbridge, in which rate variables define the diel oxygen regime, the lack of suitable calibration data is a potential source of error.

The model output retains the relative distribution pattern of aquatic plants; however, values reflecting the absolute density of aquatic plants become less representative. As calibration of the model entails a cut-to-fit process of adjusting rate variables such that model output reflects actual values, these rate variables are contingent on the accuracy of estimates of density and distribution and are therefore equally subject to uncertainty. Although a passable calibration can be achieved, the contingent nature of the rate variables will result in weakened predictive capacity. Rate variables are adjusted to compensate for density variables, the result being a relationship that is only meaningful in the calibration condition. This is a fundamental weakness in the manner in which the WQRRS model was applied, as the model must be calibrated over the entire length of the river, where the ratio of a given rate variable to density variables can be expected to vary tremendously.

The relative variation in rate and density variables is a reflection of community composition. If communities were uniform in composition along the length of the elements to be modelled, then suitable adjustments to the rate coefficients in relation to biomass could be made. This is an assumption that is reflected in the division within the WQRRS model of benthic algae from macrophytes, in which all components of either group are taken to be identical. However, rate variables relating to global physiological processes within these two somewhat arbitrary groups can be expected to change with community composition and physiology. To the extent that the model represents heterogeneity within the benthic community, it is only between macrophytes and algae. Because of the heterogeneity within these arbitrary groups, a rate adjustment that is appropriate for a single model element may not be appropriate for any other element. This further implies an erroneous assumption that community composition remains constant over time.

The objections raised here with respect to the WQRRS model are common to many model applications, and derive in part from a lack of suitable data with which to populate and calibrate the model. Extensive study of the Oldman River following the construction of the Oldman Reservoir has largely mitigated the deficiencies encountered with pre-impoundment model calibration. Given the intensive management regimes presently imposed on the river and the increasing volume of post-impoundment data, development of a more current model would be appropriate. 


\subsection{CONCLUSIONS}

Critically low dissolved oxygen levels that historically occurred downstream of Lethbridge largely have been amended by the increased minimum flows afforded by the Oldman Reservoir. This also appears to be true of the severity of critically low dissolved oxygen levels, which has been lessened following impoundment. Prior to the construction of the reservoir, nocturnal dissolved oxygen levels downstream of Lethbridge were often driven well below $5 \mathrm{mg} \cdot \mathrm{L}^{-1}$ by biological and chemical oxygen consuming processes. The frequency of pre-impoundment nocturnal dissolved oxygen levels that fell below $5 \mathrm{mg} \cdot \mathrm{L}^{-1}$ is not known; however, HydroQual (1990) have proposed a value of 50\% in July and August based on post-hoc simulations for 1984 and 1985. In the absence of a continuous monitoring record, it would be difficult to devise a similar estimate for 1993-2001. However, the available data indicate that the frequency of critically low nocturnal dissolved oxygen levels has decreased substantially during July and August of the post-impoundment period. Downstream of Lethbridge, consideration should be given to extending minimum flows for July and August into mid-September, as aquatic plant density and the attendant risk of a critical dissolved oxygen deficit are greatest during these periods.

The present minimum flow regime is not likely completely to eliminate dissolved oxygen levels that fall below $5 \mathrm{mg} \cdot \mathrm{L}^{-1}$ in the reach directly downstream of Lethbridge; critically low dissolved oxygen levels in this reach still occurred when flows were more than twice the minimum flows. Efforts to mitigate conditions of dissolved oxygen deficit downstream of Lethbridge should therefore include the control of processes that drive down dissolved oxygen levels, in addition to the maintenance of sufficient flow. A major component of these processes is respiration by the aquatic plant community, which is most dense directly downstream of Lethbridge. These plants may exploit the abundant nutrient supply that has accumulated in the riverbed, probably as result of nutrient loading in the open water. Recent upgrades to the Lethbridge wastewater treatment plant (WWTP) in the form of biological nutrient removal will help to reduce nutrient loading to the open water; however, the response of aquatic plants to this change may be contingent on the rate with which sediment nutrients are depleted. This may only occur over a period of many years, as in the Bow River downstream of Calgary (Sosiak 1990). Periodic scouring flows that remove accumulated vegetation and reduce sediment nutrient content could be investigated as a potential mechanism for reducing oxygen consumption and achieving acceptable dissolved oxygen levels. The upgrades to the WWTP at Lethbridge may also reduce other chemical and biological oxygen demanding processes; the relative contribution of these processes to the nocturnal oxygen deficit is not known.

The Oldman Reservoir has caused substantial changes in the downstream temperature regime relative to pre-impoundment temperatures. These changes extend through Monarch, and probably to Lethbridge. Mid-summer water temperatures are considerably cooler than in the past, and autumn temperatures are slightly warmer, tracking the seasonal warming and cooling that takes place within the reservoir. To the extent that reservoir levels have varied in the 19931996 period (when reservoir temperature data were collected), the relationship between reservoir level and outflow temperature is weak. However, substantial variation in reservoir levels beyond that which has occurred during 1993 to 2000 results in a significant change in seasonal outflow temperature variation, as found in 1991, 1992, and 2001. Greater water level, and therefore 
water temperature, variation could result from increased irrigation demand and decreased natural supply.

Isolation of the effect of air temperature from the water temperature to flow relationship, explored in Appendix D, suggests that water temperature is only slightly sensitive to air temperature at flows greater than about $40 \mathrm{~m}^{3} \cdot \mathrm{s}^{-1}$. At flows of less than $40 \mathrm{~m}^{3} \cdot \mathrm{s}^{-1}$, the sensitivity of water temperature to air temperature appears to increase geometrically. Downstream of Lethbridge, where water temperature would be most likely to raise concern under the current flow regime, flows rarely fell below $20 \mathrm{~m}^{3} \cdot \mathrm{s}^{-1}$ during July and August. Therefore, the value of the slope coefficient $a$ in the regression model is subject to considerable error. The empirical model that is presented is probably not sufficiently robust to be of value in application to a water management strategy in the Oldman River.

Although the implication of post-impoundment temperature and oxygen regimes for sport fish is not addressed in detail, the data have been summarised in a way that should facilitate further study.

Monitoring for dissolved oxygen and temperature should continue in the basin, to ensure that current instream flow needs remain protective under changing nutrient loads. As well, irrigation pressure will increase the frequency with which flow approaches IFN minima, raising the likelihood that water quality guidelines will not be met. Continued monitoring will also be valuable to future modelling efforts. Continuous monitoring of dissolved oxygen levels is not necessary upstream of Lethbridge, where guideline exceedences are rare. Monitoring efforts should focus on the reach from Lethbridge to the confluence of the Bow and Oldman rivers. Continued monitoring will also be valuable to future modelling efforts.

Present minimum flows, established using the WQRRS model, have largely been effective in mitigating the critically low dissolved oxygen levels that often occurred prior to the construction of the Oldman dam. However, shifting nutrient loads from both point and non-point sources, as well as post-impoundment shifts in aquatic plant and algal community distribution and composition provide a compelling rationale for renewed water quality modelling efforts. The Oldman River system is well suited to further model implementation, as the data collected following the construction of the Oldman dam include an extensive suite of continuously and non-continuously monitored parameters along the entire mainstem. Given the deficiencies of the WQRRS model outlined in chapter 5, and the increasing demands that continued economic development and population growth place on surface waters, an updated surface water quality model would prove an asset to future resource management decisions in the basin. 


\subsection{REFERENCES}

Alberta Environment. 1999. Surface water quality guidelines for use in Alberta. Environmental Sciences Division, Environmental Service. 25 pp.

Alberta Environment. 1994. Oldman River Dam and reservoir operational strategy. Water Resources Services. 21 pp. + app.

Alberta Environment. 1993. Oldman River instream flow needs summary. Water Resources Services, Planning division. $18 \mathrm{pp}$.

Alberta Environment. 1990. Water management policy for the South Saskatchewan River basin. $3 \mathrm{pp}$.

Alberta Environment, 1987. Water resources management model; computer program description. Water Resources Management Services, Planning Division.

Alberta Environment. 1977. Alberta surface water quality objectives. Water Quality Branch, Standards and Approvals Division, Alberta Environment. Edmonton, Alberta. 17 pp.

Alberta Environment. 1989. Oldman River reservoir operational plan; Water supply, flow regulation, and inter-provincial apportionment. Water Resources Management Services, Planning Division. 39 pp. + app.

Alberta Forestry, Lands, and Wildlife. 1988. Oldman River Dam - Operational planning phase II: Minimum in-stream flow values for fish and modelling run evaluations. Fish and Wildlife Division. 13 pp. + app.

Allan, J.H. 1986. Environmental conditions and instream flow needs for fish in Alberta: a user's guide to assessment methods. Alberta Energy and Natural Resources, Fish and Wildlife Division. $52 \mathrm{pp}$.

Allan, J.H. 1985. Phase I fisheries overview, ecological component, Oldman River Dam, environmental mitigation/opportunities plan. Alberta Environment, Planning Division. $61 \mathrm{pp}$.

Anderson, R.S., A.M. Anderson, A.M. Akena, J.S. Livingstone, A. Masuda, P.A. Mitchell, T.B. Reynoldson, D.O. Trew, and M. Vukadinovic. 1986. North Saskatchewan River: characterisation of water quality in the vicinity of Edmonton. Alberta Environment.

Benson, B.B., and D. Krause. 1980. The concentration and isotopic fractionation of gases dissolved in fresh water in equilibrium with the atmosphere: I. Oxygen. Limnology and Oceanography. 25, 662-671. 
Bietz, B.F., J.A. Martin, and J. Englert. 1985. Instream flow needs for fish in Alberta: a user's guide to assessment methods. Alberta Energy and Natural Resources, Fish and Wildlife Division. 76 pp.

Canadian Council of Ministers of the Environment. 1999. Canadian environmental quality guidelines. Canadian Council of Ministers of the Environment, Winnipeg. 2 vol.

Carr, G.M., and P.A. Chambers. 1998a. Spatial and temporal patterns in nutrients and algal abundance in Alberta rivers. National Water Research Institute. 69 pp. + app.

Carr, G.M., and P.A. Chambers. 1998b. Macrophyte growth and sediment phosphorus and nitrogen in a Canadian prairie river. Freshwater Biology. 39(3), 525-536.

Chambers, P.A., and E.E. Prepas. 1994. Nutrient dynamics in riverbeds: the impact of nutrient loading from a sewage treatment plant and aquatic macrophytes. ASLO and SWS general meeting abstracts. ASLO/SWS, USA.

Chambers, P.A., E.E. Prepas, H.R. Hamilton, and M.L. Bothwell. 1991a. Current velocity and its effect on aquatic macrophytes in flowing water. Ecol. Appl. 1(3), 249-257.

Chambers, P.A., E.E. Prepas, M.L. Bothwell, and H.R. Hamilton. 1991b. Towards prairie river restoration: manipulating nutrients and current flow to control aquatic weed growth in flowing waters. National Hydrology Research Institute. 55 pp. + app.

Chambers, P.A., E.E. Prepas, M.L. Bothwell, and H.R. Hamilton. 1989. Roots versus shoots in nutrient uptake by aquatic macrophytes in flowing waters. Canadian Journal of Fisheries and Aquatic Sciences. 46(3): 435-439.

Chapra, S.C., and D.M. Di Toro. 1991. Delta method for estimating primary production and respiration in streams. Journal of Environmental Engineering. 117(5), 640-655.

Charlton, S.E.D., and D. Bayne. 1986. Phosphorus removal: the impact upon water quality in the Bow River downstream of Calgary, Alberta, Bow River data base 1980-85. Alberta Environment. 34 pp. + app.

Charlton, S.E.D., H.R. Hamilton, and P.M. Cross. 1986. The limnological characteristics of the Bow, Oldman, and South Saskatchewan rivers (1979-1982). Part II. The primary producers. Alberta Environment, Environmental Protection Services, Edmonton. 110 pp. + app.

Cleary, E.J. 1962. Introducing the ORSANCO robot monitor. Proc. Water Quality Meas. Instrum. Publ. No. 108, U.S. Public Health Serv., Washington, D.C.

Cross, P.M., and A.M. Anderson. 1989. An overview of water quality in the Oldman River basin (1984-1985). Alberta Environment, Water Quality Control Branch. 94 pp. 
DeBoer, A. 2000. Personal Communication. Hydrologist, Alberta Environment, Hydrology Section.

Dominion Ecological Consulting. 1990. A strategy for fisheries mitigation in the Oldman River basin. Volume II. Downstream and reservoir components. prep. for Alberta Public Works, Supply, and Services. 178 pp. + app.

Greenberg, A.E., L.S. Clesceri, and A.D. Eaton (eds). 1992. Standard methods for the examination of water and wastewater. $18^{\text {th }}$ ed. Amer. Public Health Assoc., Amer. Water Works Assoc., and Water Env. Fed.

Golder Associates. 1995. Interim report on limnology of the Oldman Reservoir and its effects on Oldman River water quality (1991-1993). prep. for Alberta Environment, Surface Water Assessment Branch.42 pp. + app.

Gu, R., S. McCutcheon, and C. Chen. 1999. Development of weather dependent flow requirements for river temperature control. Environmental Management, 24(4), 529540 .

Hamilton, H.R., M.V. Thompson, G. Macdonald, V. Chiu, B. Taylor. 1986. Implementation of WQRRS for the Highwood River. Prep. for Alberta Environment, Planning Division. 53 pp. + app.

Hamilton, H.R. and P.M. Cross. 1985. The implementation of WQRRS for water quality modelling on the Bow, Oldman, South Saskatchewan, and Red Deer rivers. Internal technical report. Alberta Environment, Water Quality Control Branch. 44 pp. + app.

HydroQual Canada Ltd. 1990a. Data summary on Oldman River water quality projections. prep. for Alberta Environment, Planning Division. 160 pp. + app.

HydroQual Canada Ltd. 1990b. Re-evaluation of dissolved oxygen in the lower Oldman River. Briefing notes (unpublished) for meetings held 21 November and 18 December, 1990. Prepared for Planning Division, Alberta Environment.

Lowney, C.L. 2000. Stream temperature variation in regulated rivers: Evidence for a spatial pattern in daily minimum and maximum magnitudes. Water Resources Research 36(10), 2947-2955.

Marker, A.F.H. 1976a. The benthic algae of some streams in southern England. I. Biomass of the epilithon in some small streams. J. Ecol. 64, 343-358.

Marker, A.F.H. 1976b. The benthic algae of some streams in southern England. II. The primary production of the epilithon in a small chalk-stream. J. Ecol. 64, 359-373. 
Mitchell, P. 2001. Limnological Assessment of the Oldman River Reservoir. Alberta Environment, Water Quality Section. 55 pp. + app.

Mortimer, C.H. 1981. The oxygen content of air-saturated fresh waters over ranges of temperature and atmospheric pressure of limnological interest. International Association of Theoretical and Applied Limnology. Communications, 22.

Odum, H.T. 1956. Primary production in flowing waters. Limnology and Oceanography. 1(2), 102-117.

Polehn, R.A. and W.C. Kinsel. 1997. Transient temperature solution for stream flow from a controlled temperature source. Water Resources Research, 33(1), 261-265.

Radford, D.S. 1975. Oldman River flow regulation: A preliminary study of the fish resources. Alberta Parks, Recreation, and Wildlife, Fish and Wildlife Division. 86 pp.

Shaw, J. 1997. Alberta water quality guideline for the protection of freshwater aquatic life. Dissolved oxygen. Standards and Guidelines Branch, Alberta Environment. 80 pp.

Sinokrot, B.A. and H.G. Stefan. 1993. Stream temperature dynamics: measurements and modelling. Water Resources Research, 29(7), 2299-2312.

Smith, D.J. 1978. Water quality for river - reservoir systems. Documentation. U.S. Army Corps of Engineers, Hydrologic Engineering Centre; 371 pp.

Sosiak, A.J. 1990. An evaluation of nutrients and biological conditions in the Bow River, 1986 to 1988. $32 \mathrm{pp}$.

Strickland J.D.H. 1960. Measuring the production of marine phytoplankton. Bull. Fish. Res. Bd. Canada, 122, 1-172.

Taylor, B.R., and B.A. Barton. 1992. Temperature and dissolved oxygen criteria for Alberta fishes in flowing waters. Alberta Fish and Wildlife Division, Alberta Environment. 72 pp.

Wetzel, R.G. and D.F. Westlake. 1969. Primary production in aquatic environments. R.A. Volenweider, ed. Blackwell Scientific Publications. Oxford, England. 
APPENDIX A

DISSOLVED OXYGEN, AIR TEMPERATURE, AND FLOW FIGURES 

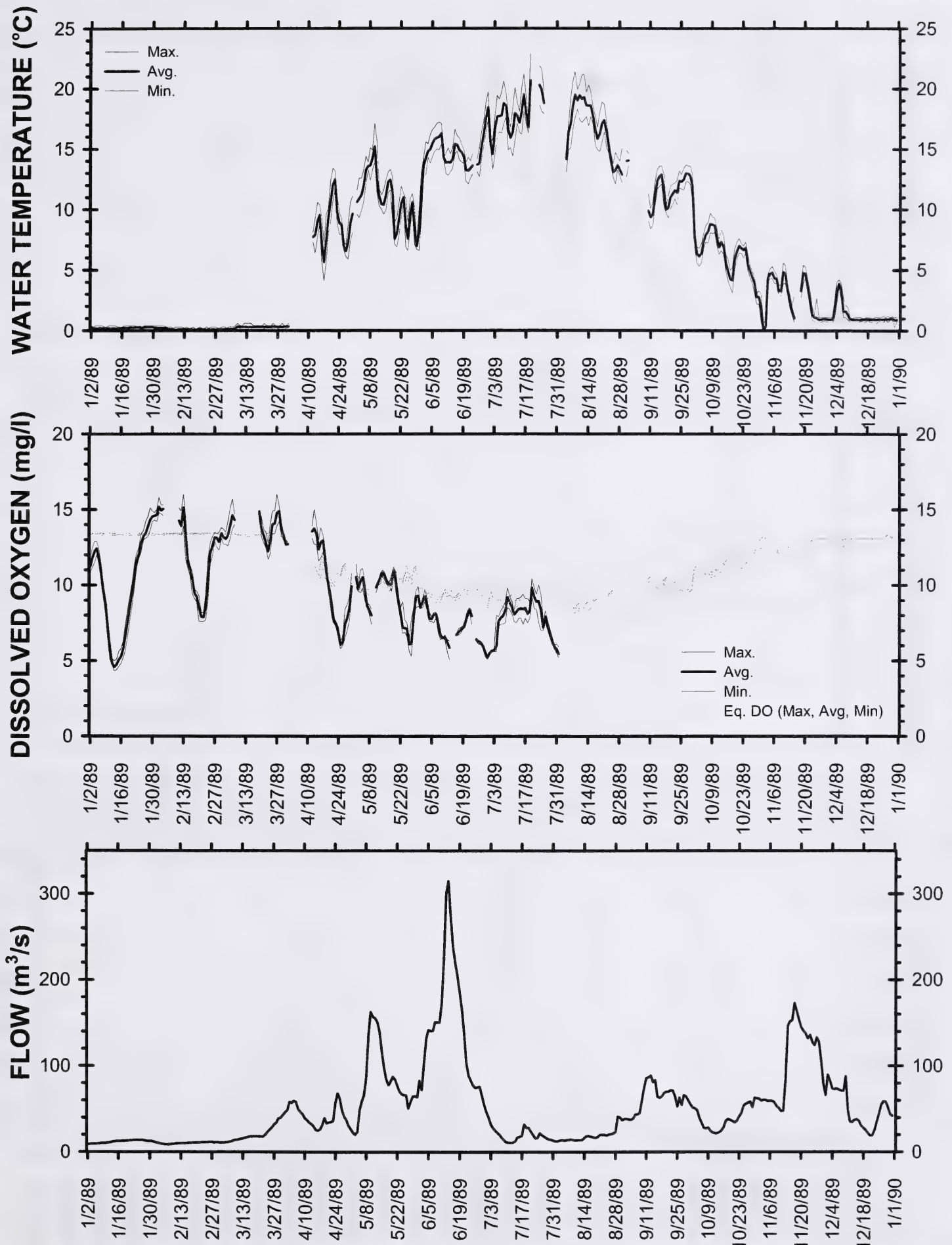

Figure 1. Daily water temperature, dissolved oxygen and flow in the Oİdman River at the Bow River confluence. January-December, 1989. 

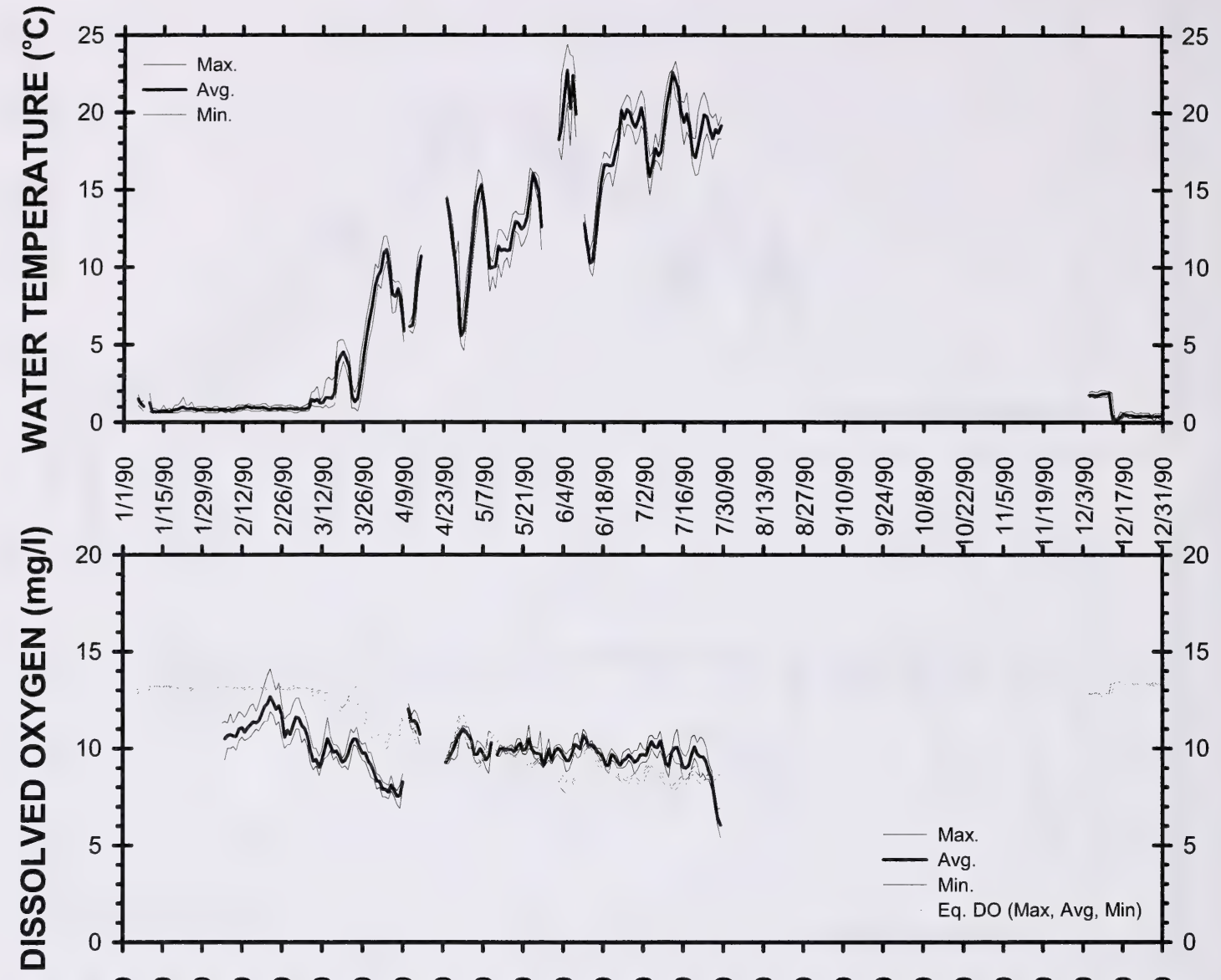

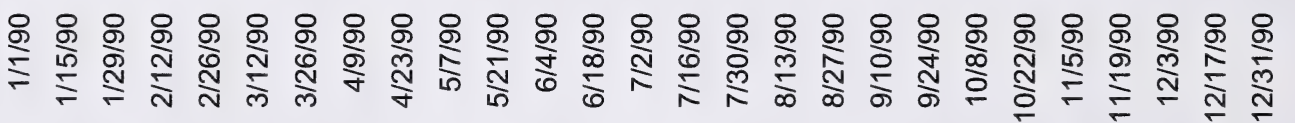

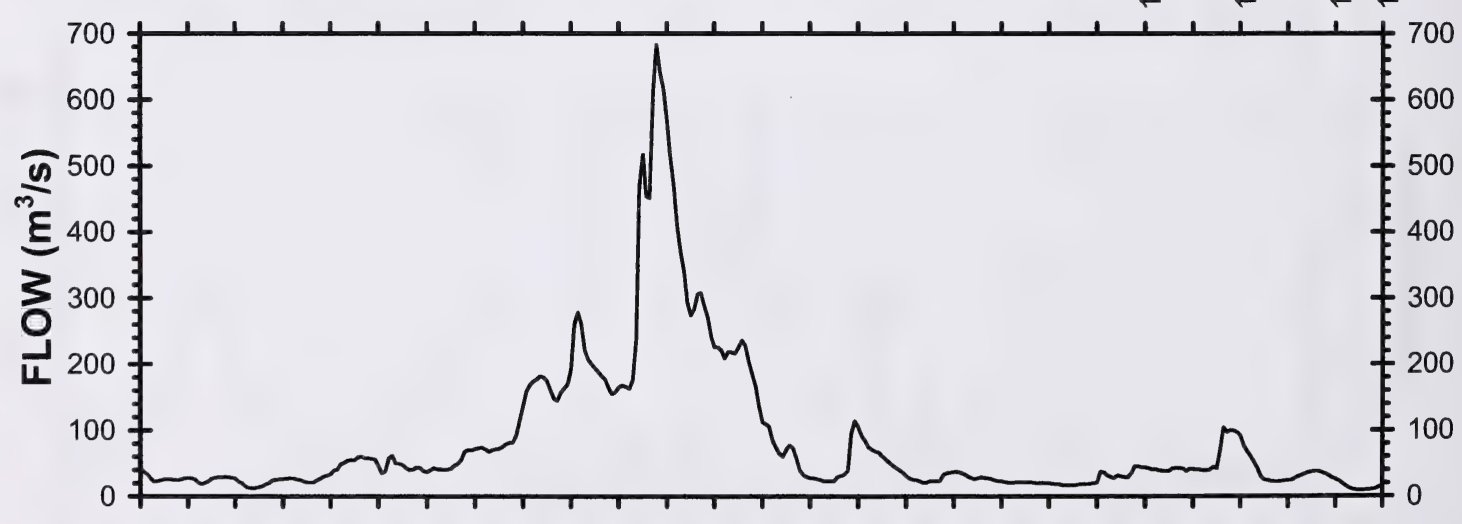

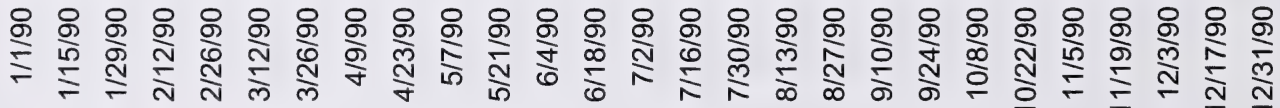

Figure 2. Daily water temperature, dissolved oxygen and flow in the Oİdman River at the Bow River confluence. January-December 1990. 


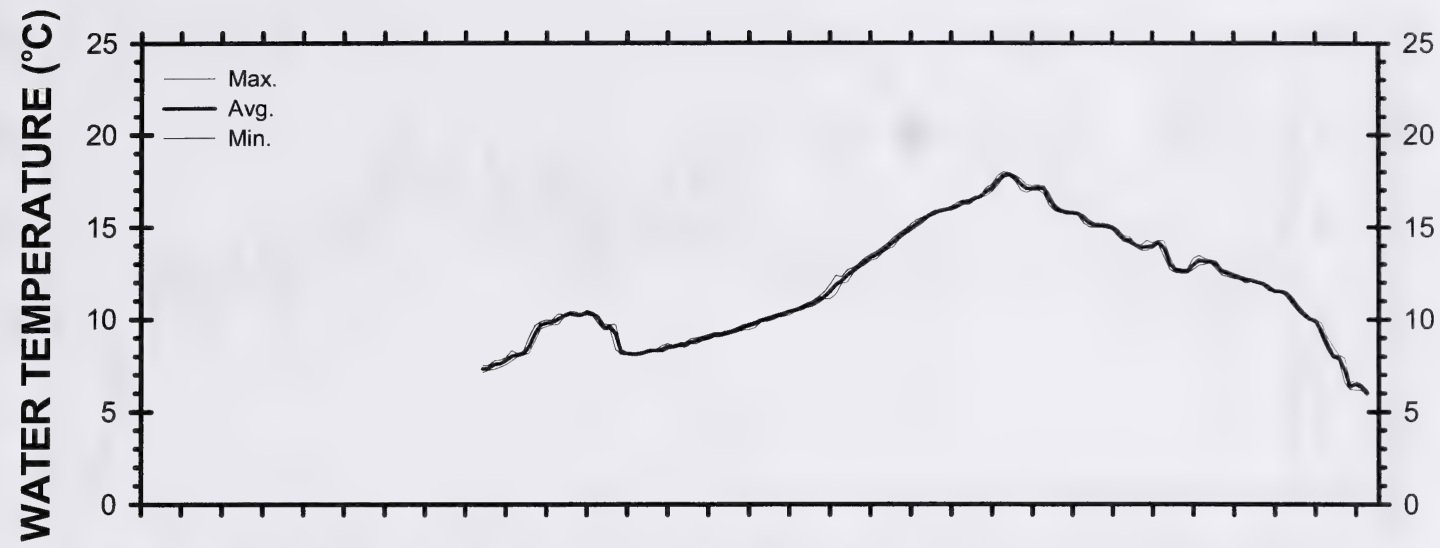

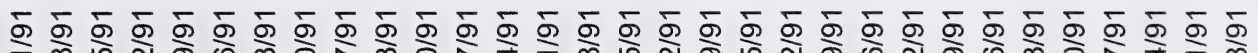

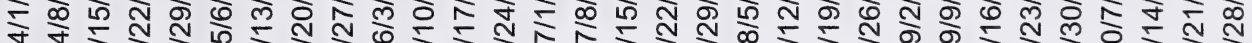

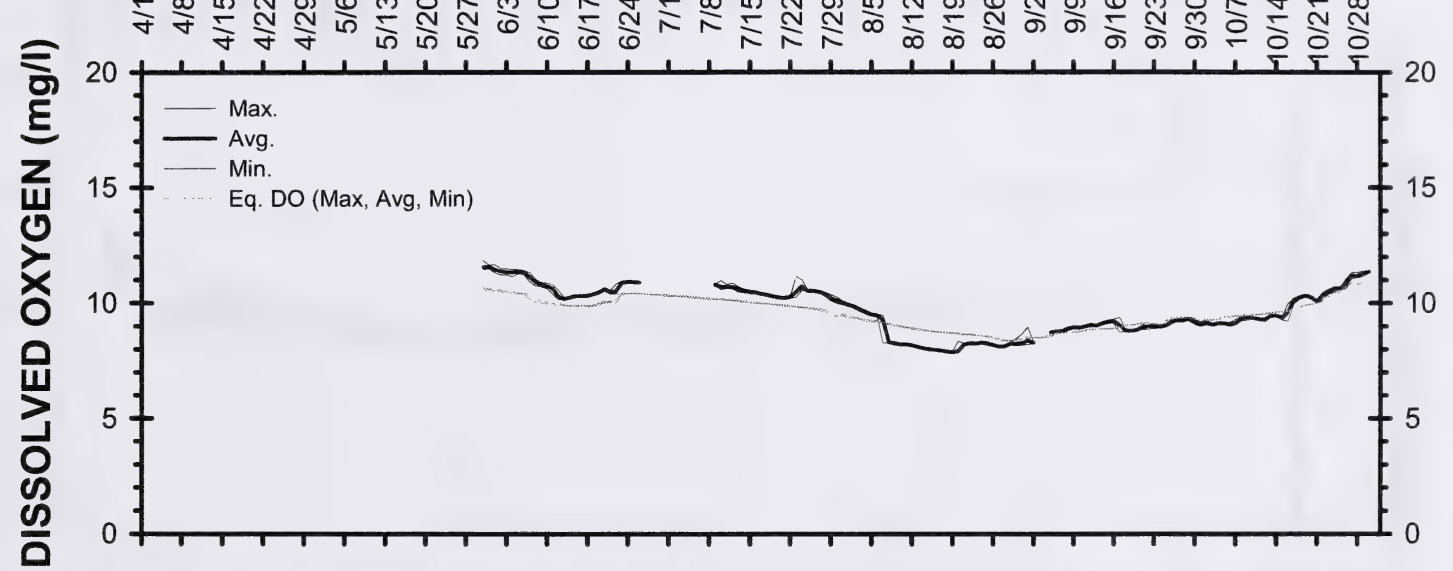

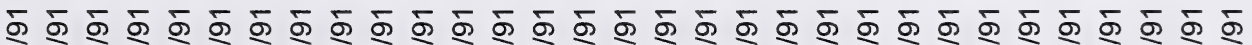

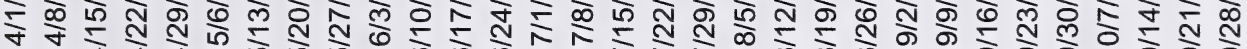

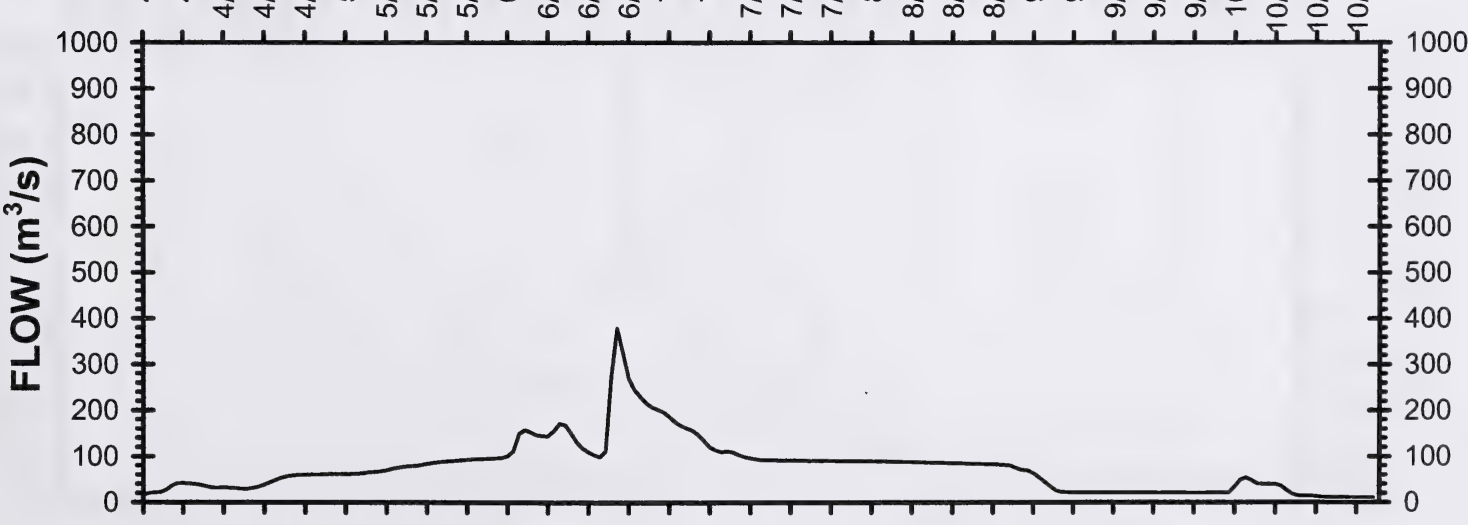

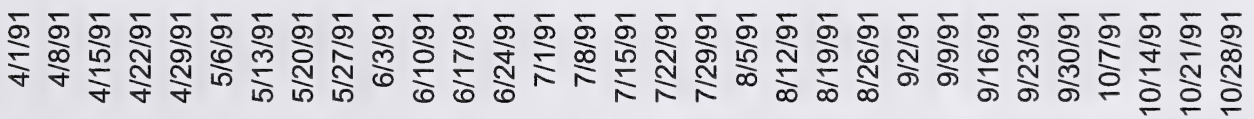

Figure 3. Daily water temperature (Datasonde), dissolved oxygen and flow in the Oldman River near Brocket. April-October 1991. 


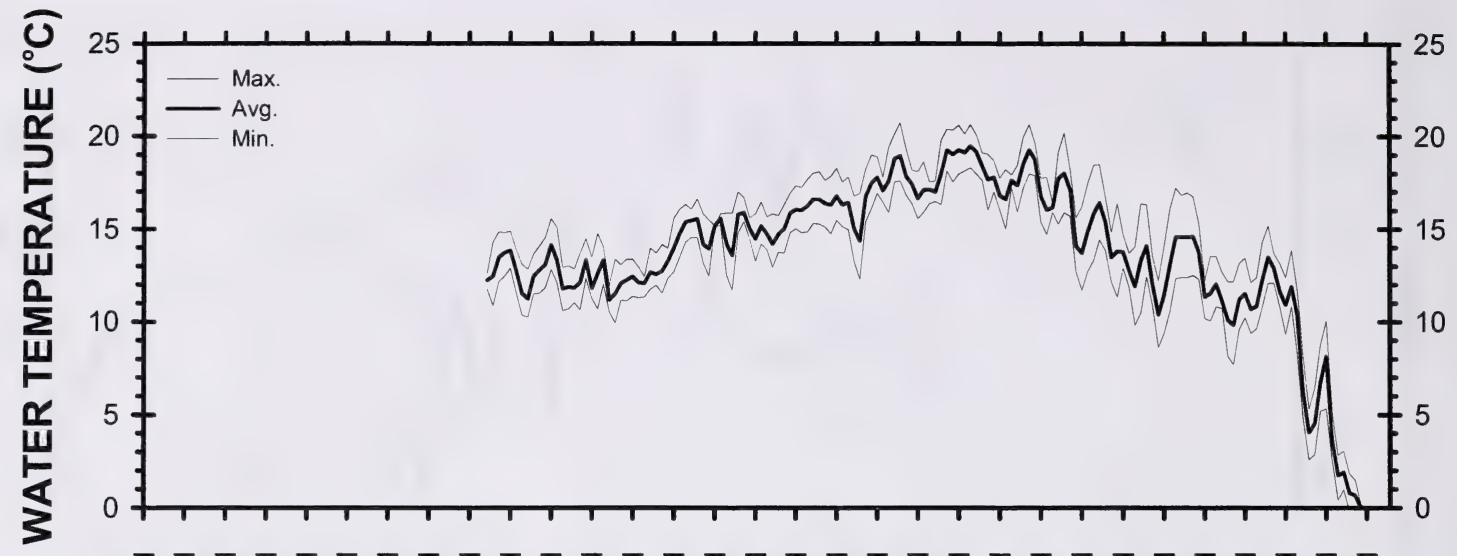

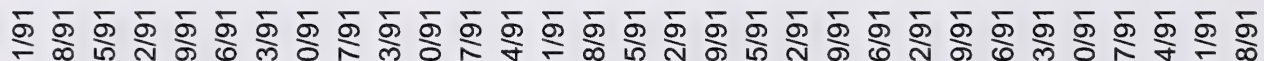

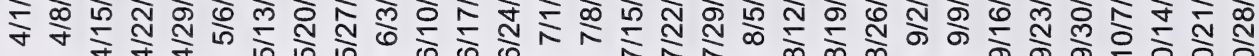

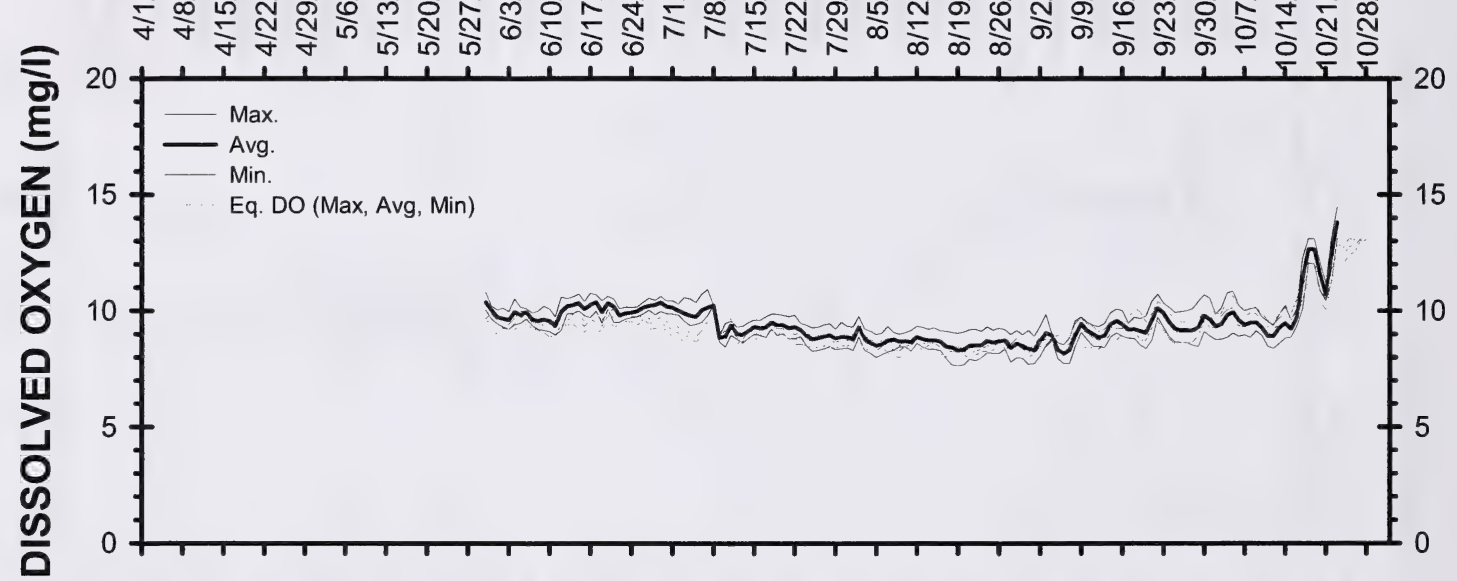

б б

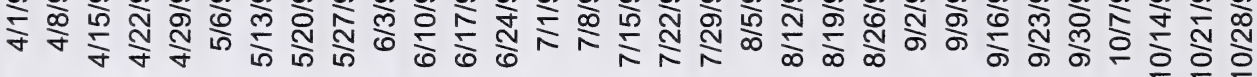

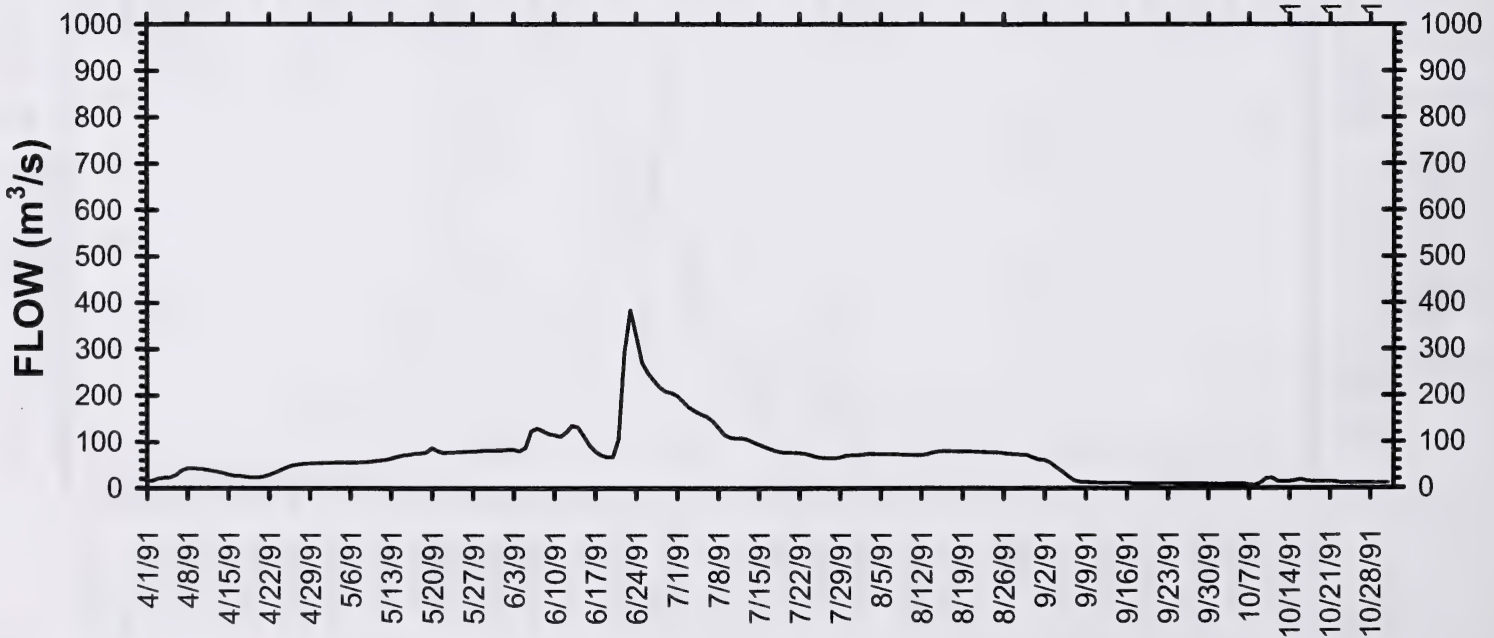

Figure 4. Daily water temperature (Datasonde), dissolved oxygen and flow in the Oldman River near Fort Macleod. April-October 1991. 


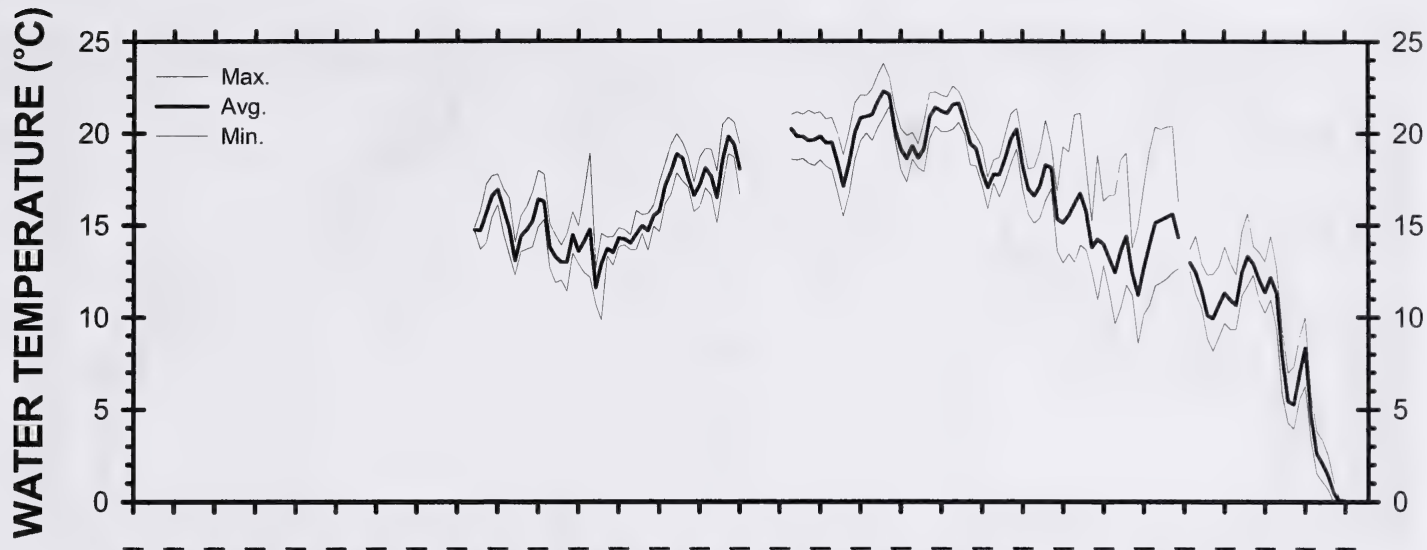

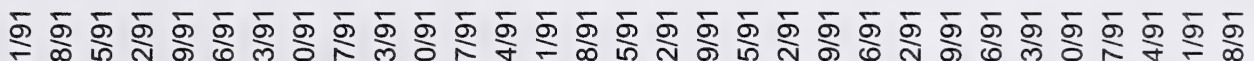

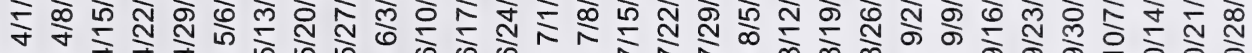

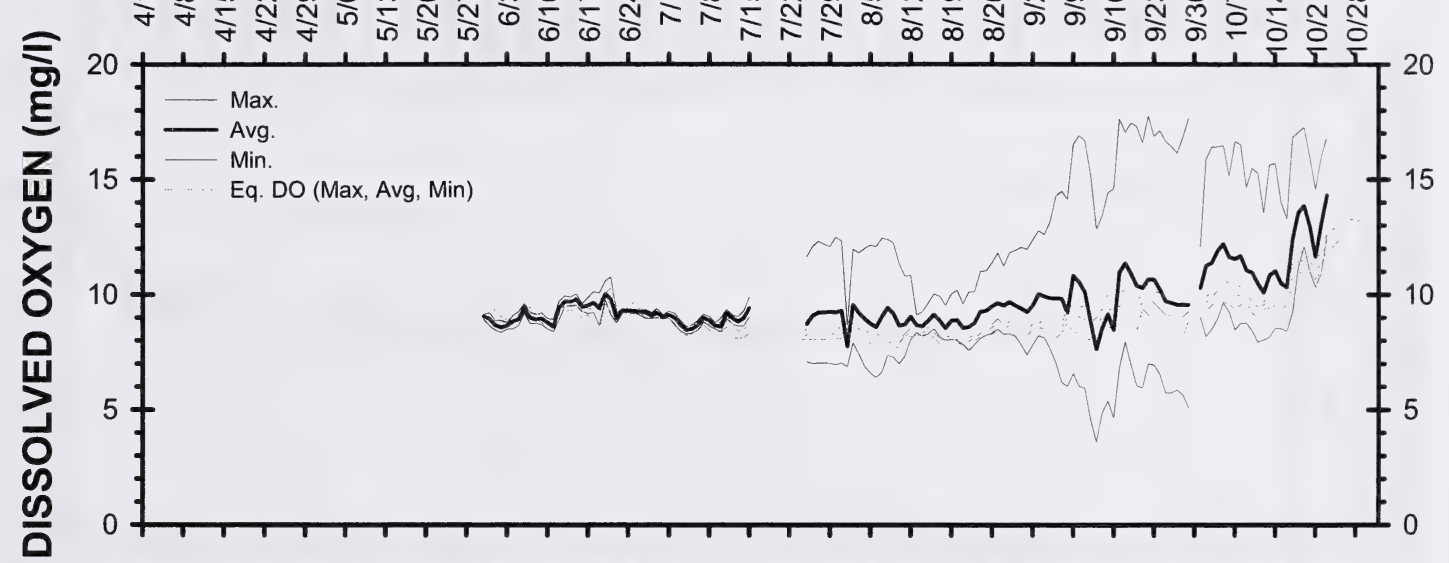

б

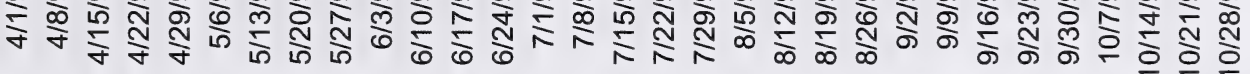

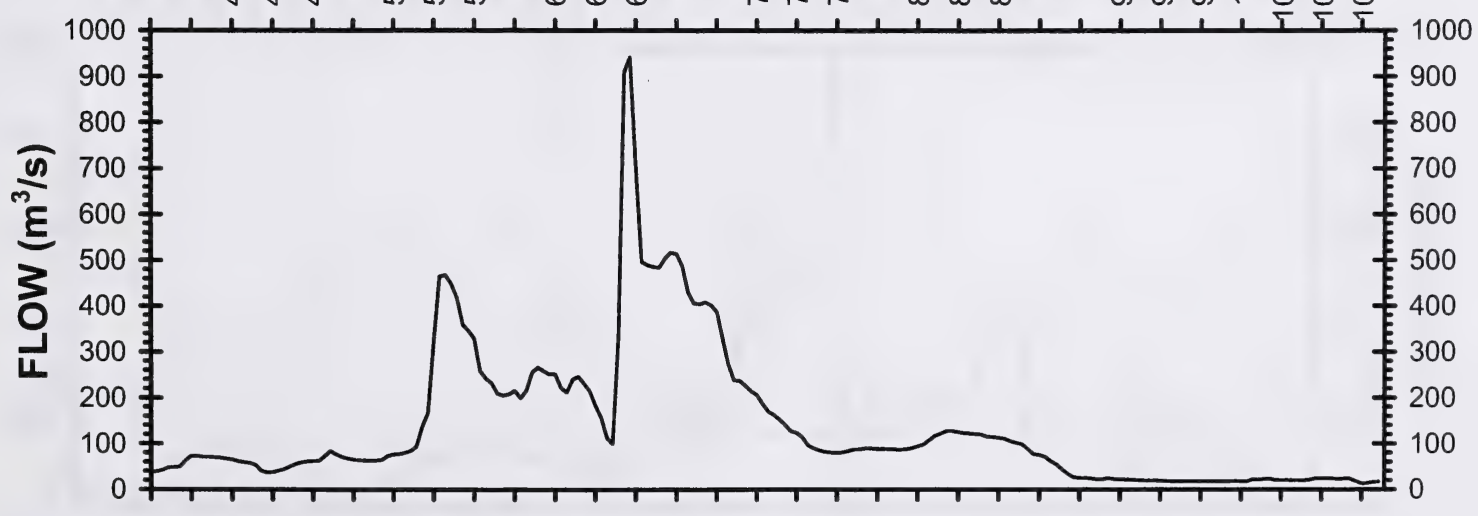

б চু

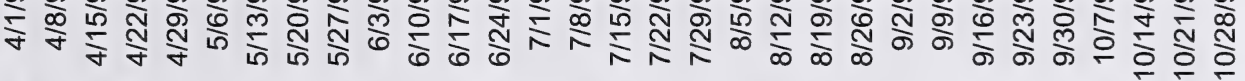

Figure 5. Daily water temperature (Datasonde), dissolved oxygen and flow in the Oldman River downstream of Lethbridge. April-October 1991. 


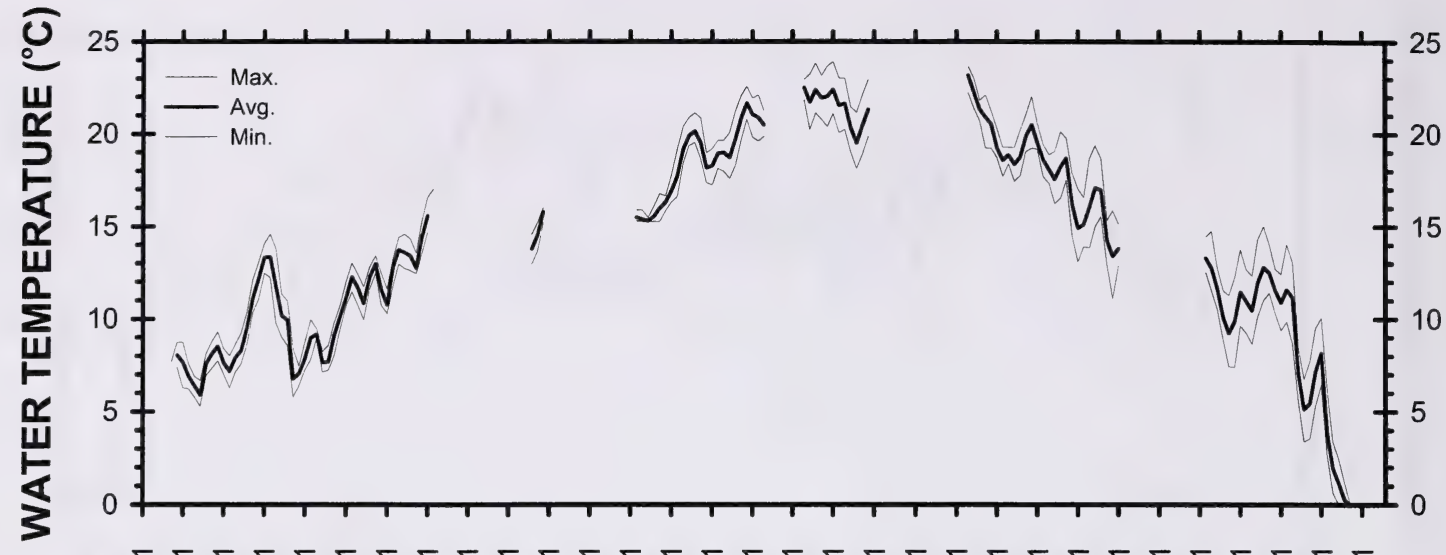

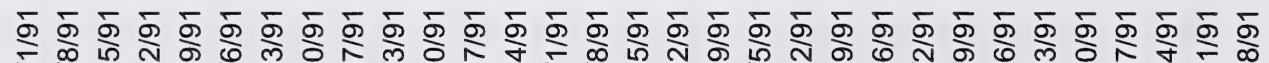

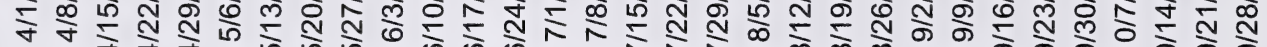

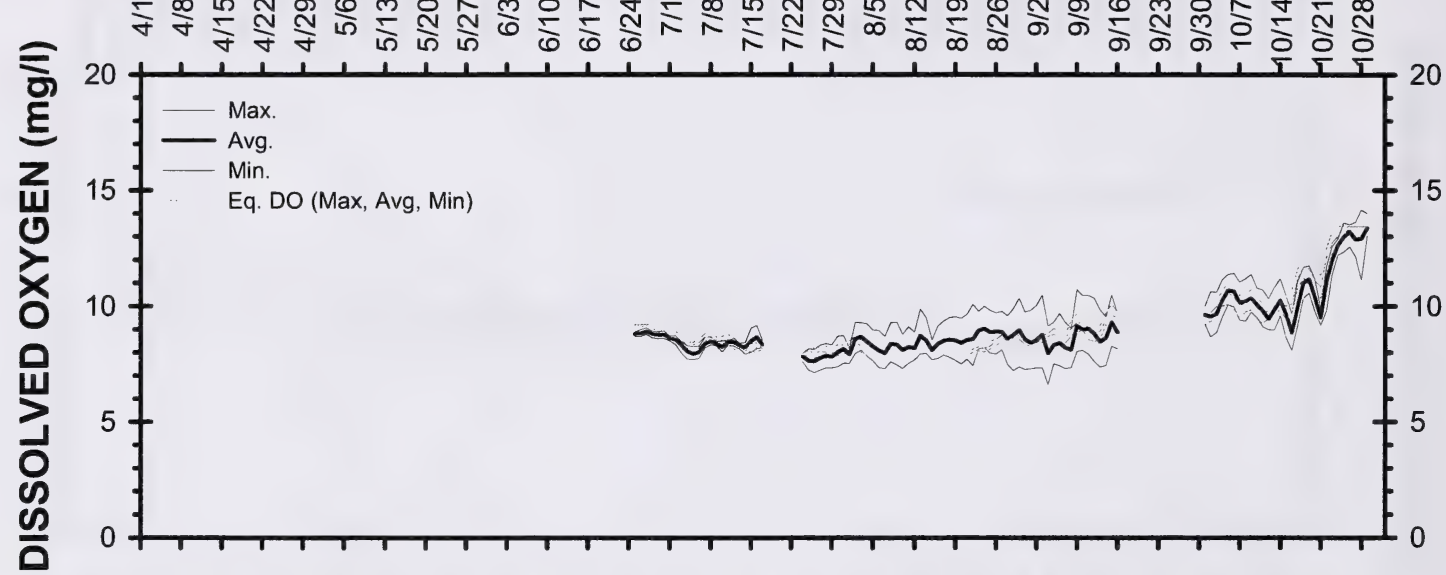

চু চু

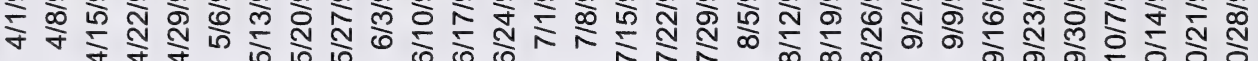

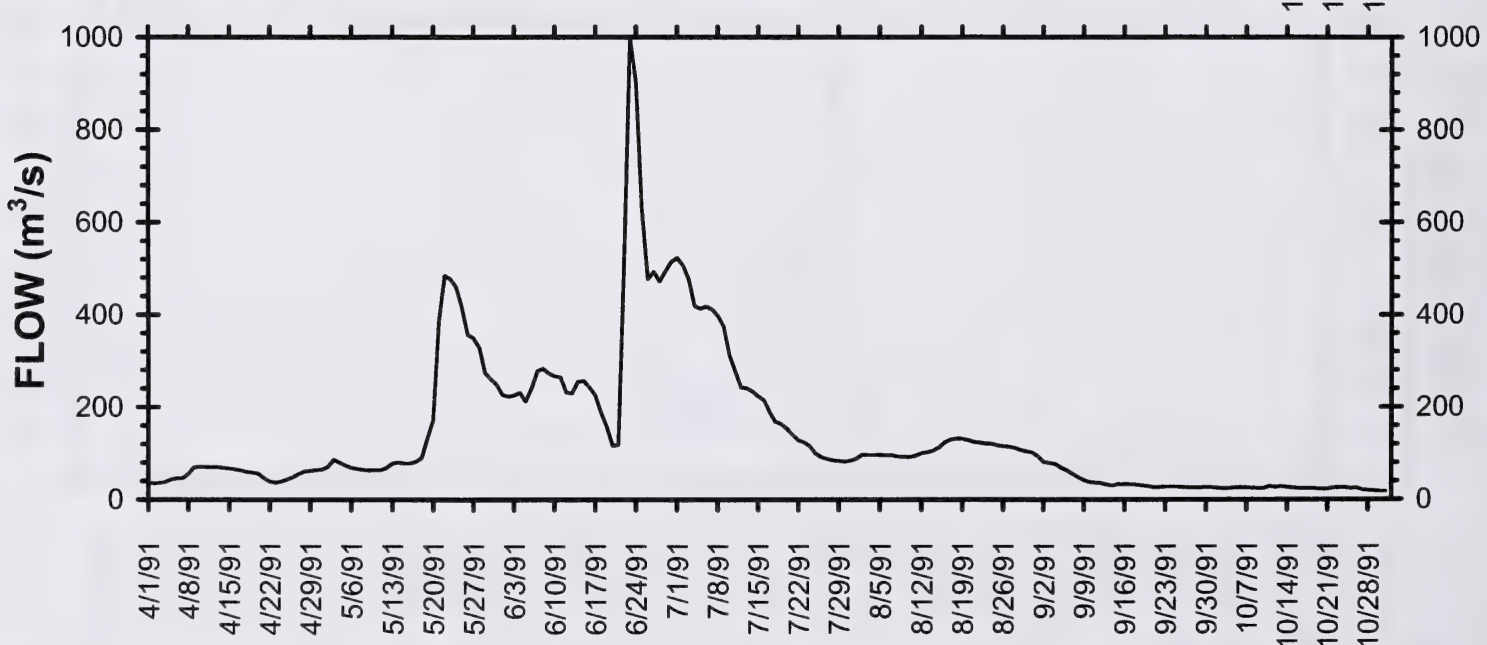

Figure 6. Daily water temperature (Datasonde), dissolved oxygen and fiow in the Oldman River at the Bow River confluence. April-October 1991. 

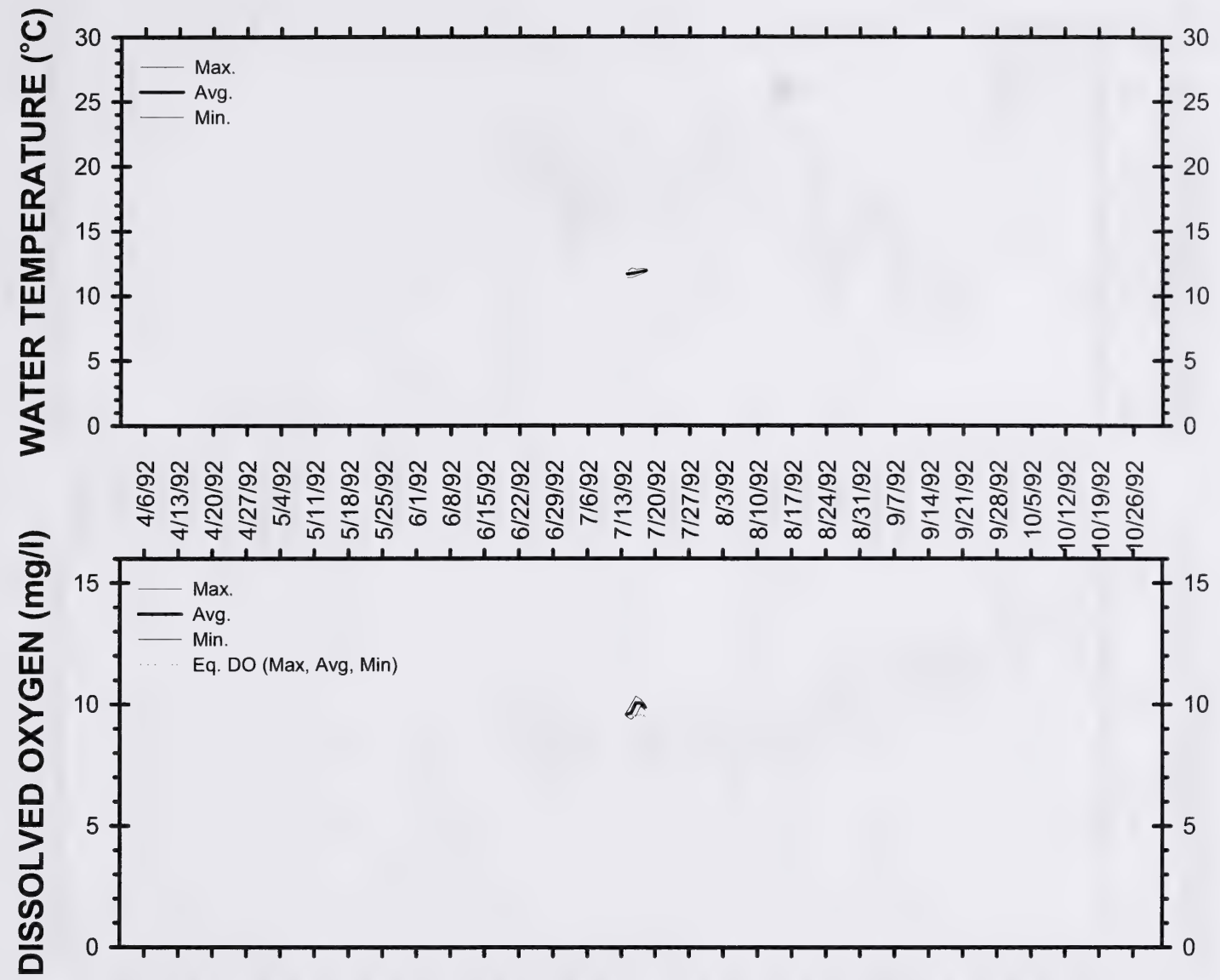

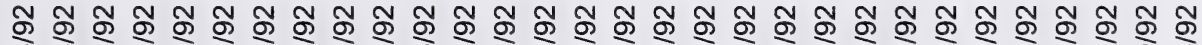

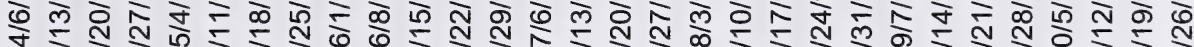

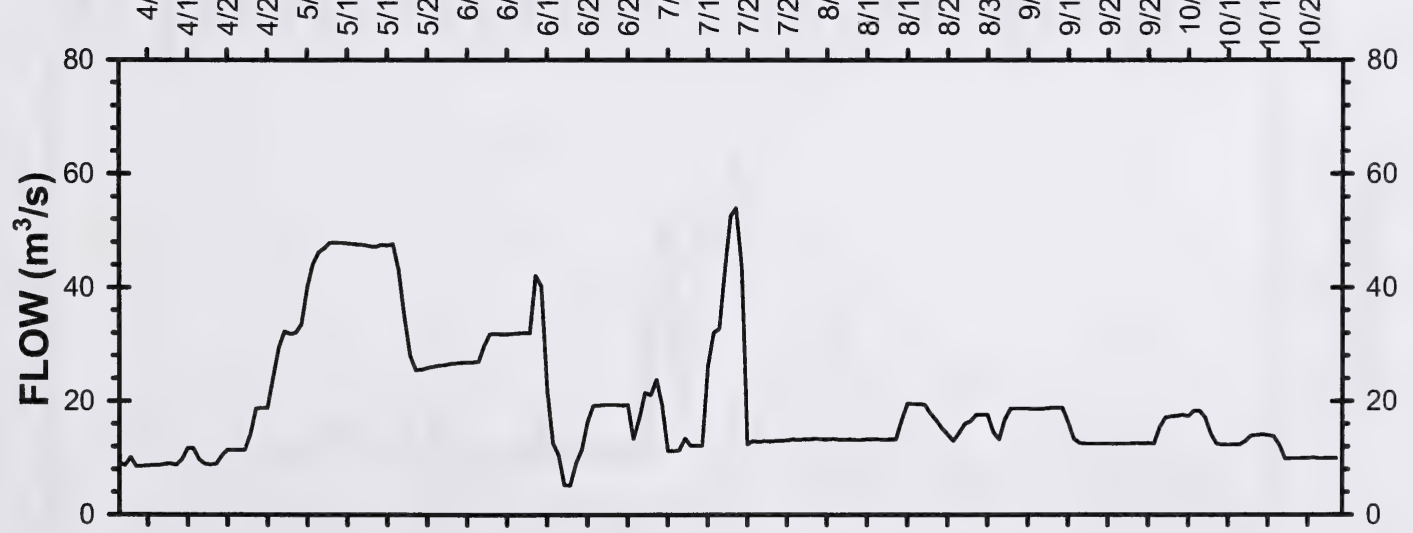

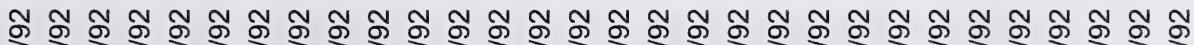

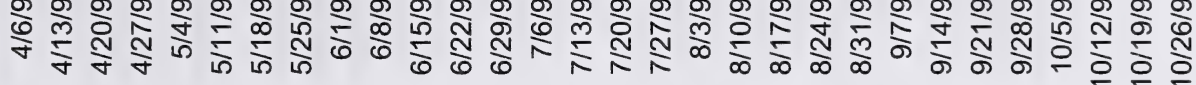

Figure 7. Daily water temperature (Datasonde), dissolved oxygen and flow in the Oldman River near Brocket. April-October 1992. 

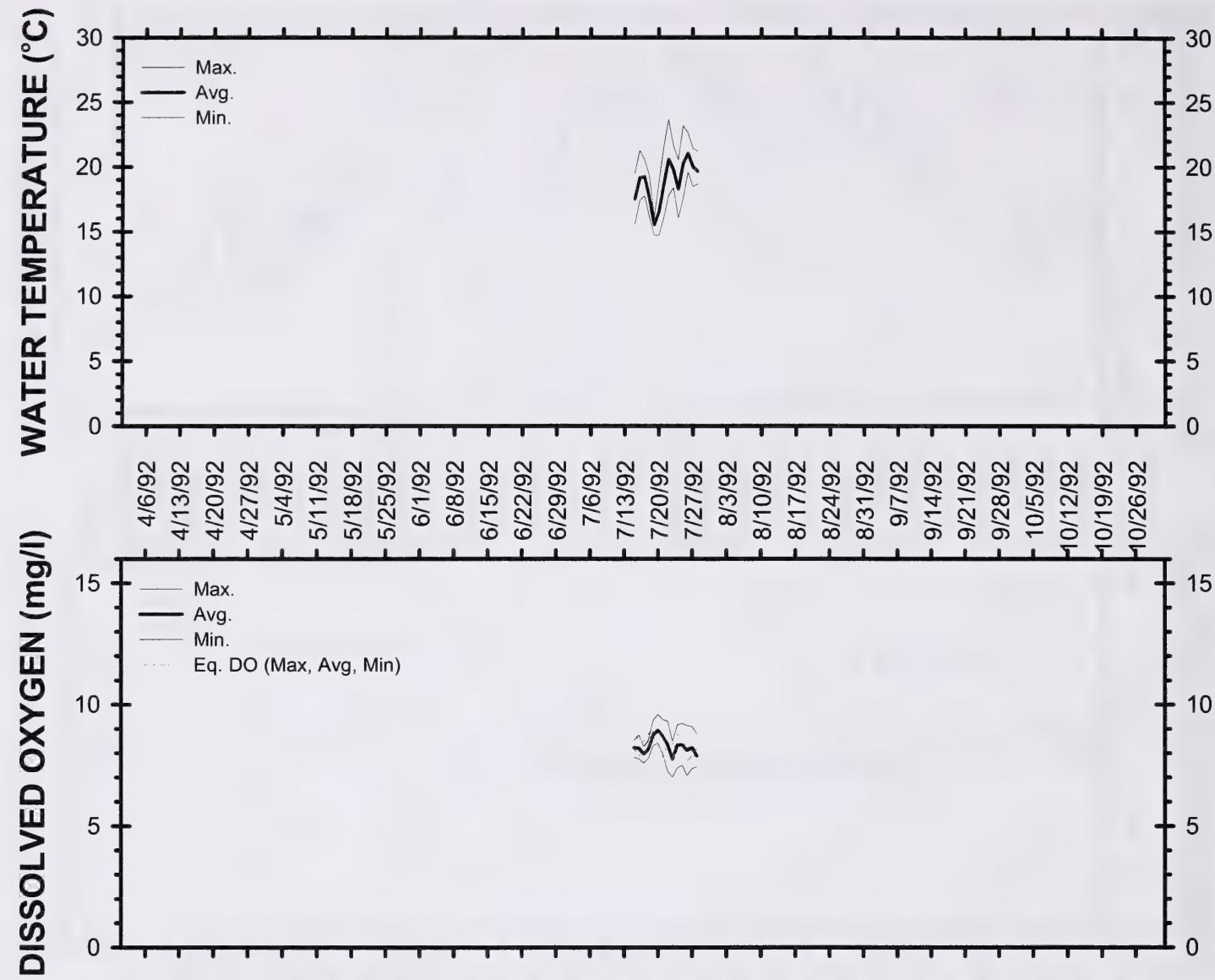

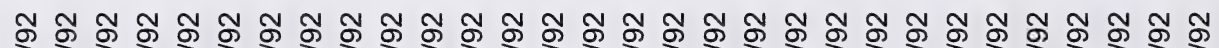
守

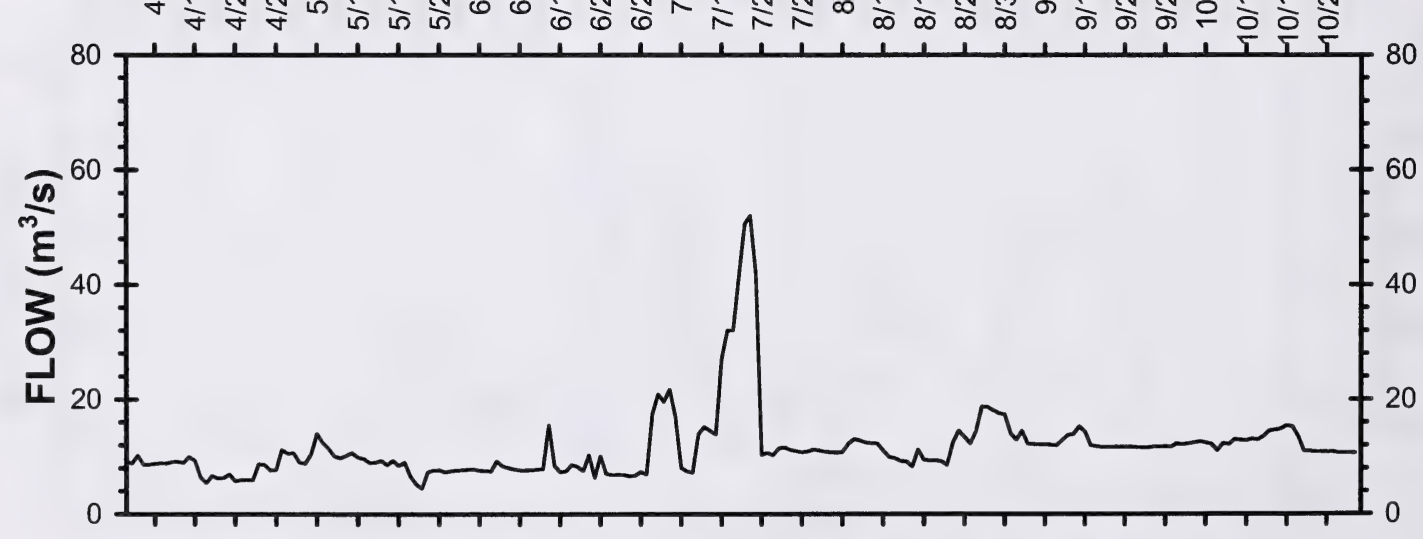

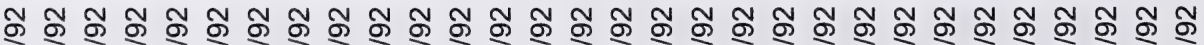

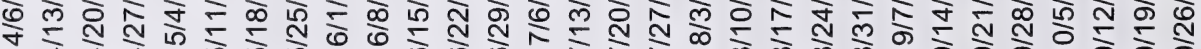

Figure 8. Daily water temperature (Datasonde), dissolved oxygen and flow in the Oldman River near Fort Macleod. April-October 1992. 


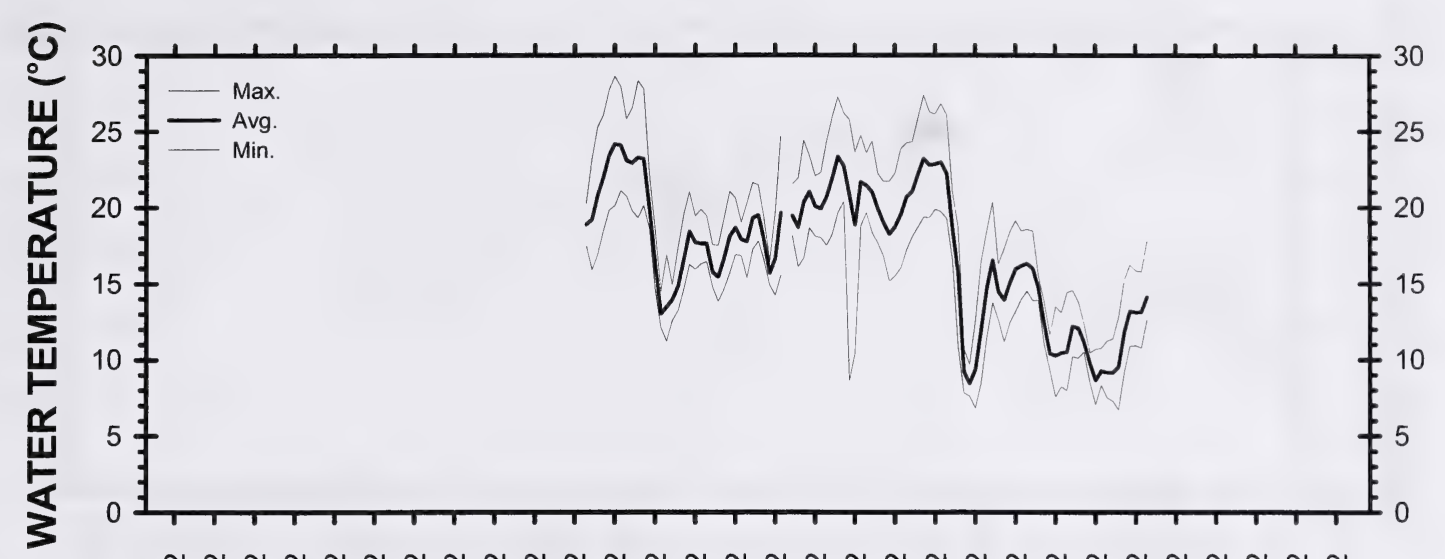

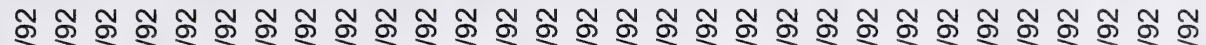
仓

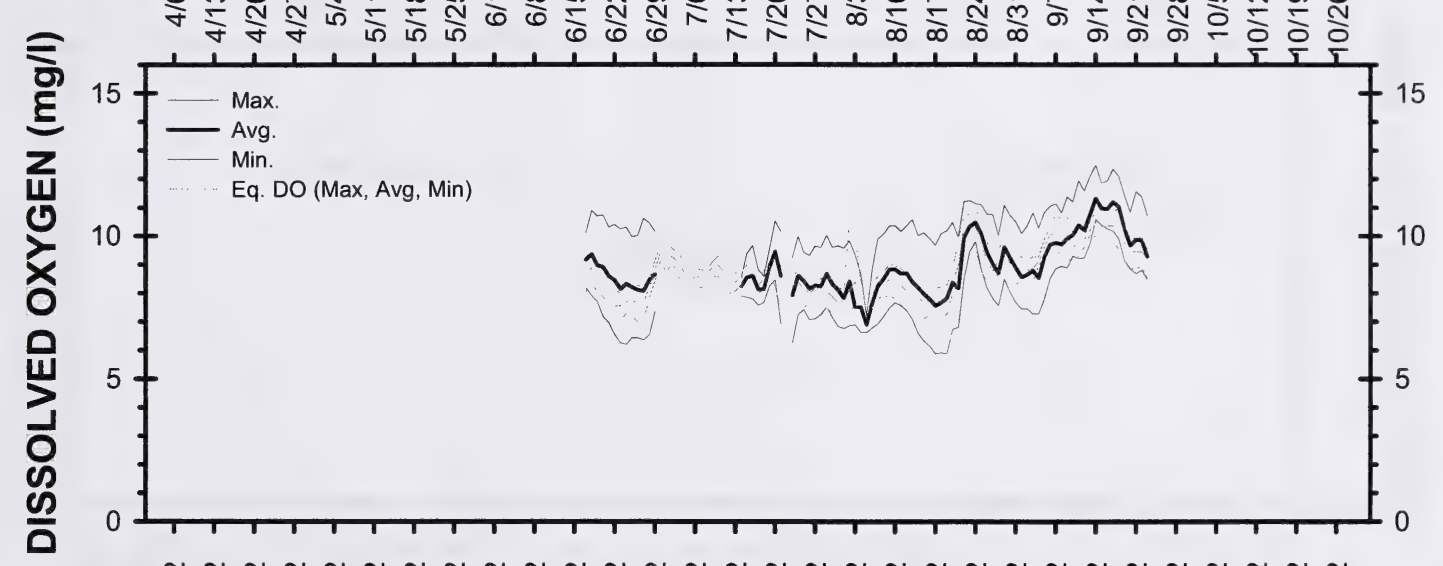

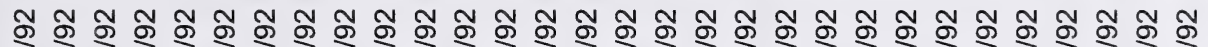

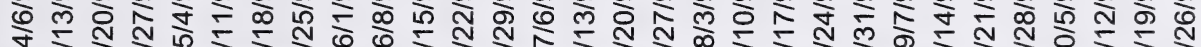

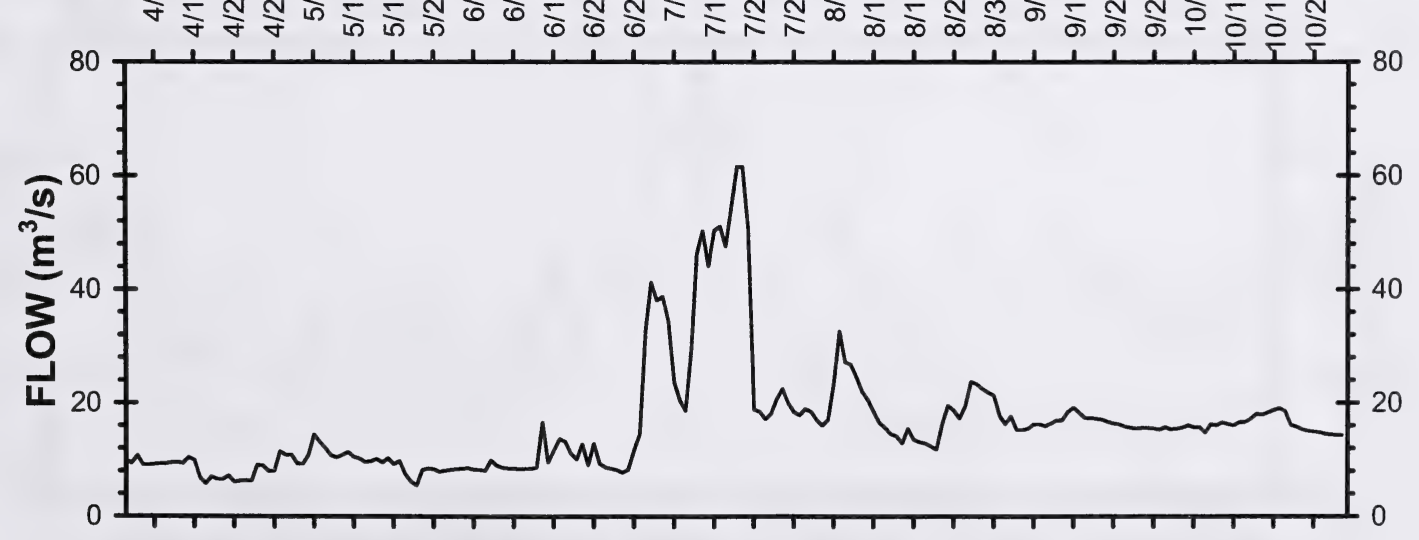

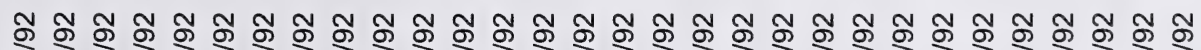

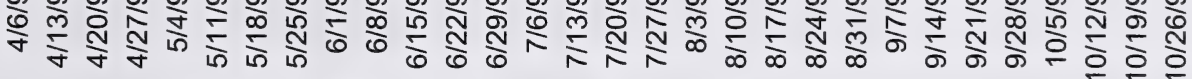

Figure 9. Daily water temperature (Datasonde), dissolved oxygen and flow in the Oldman River near Monarch. April-October 1992. 


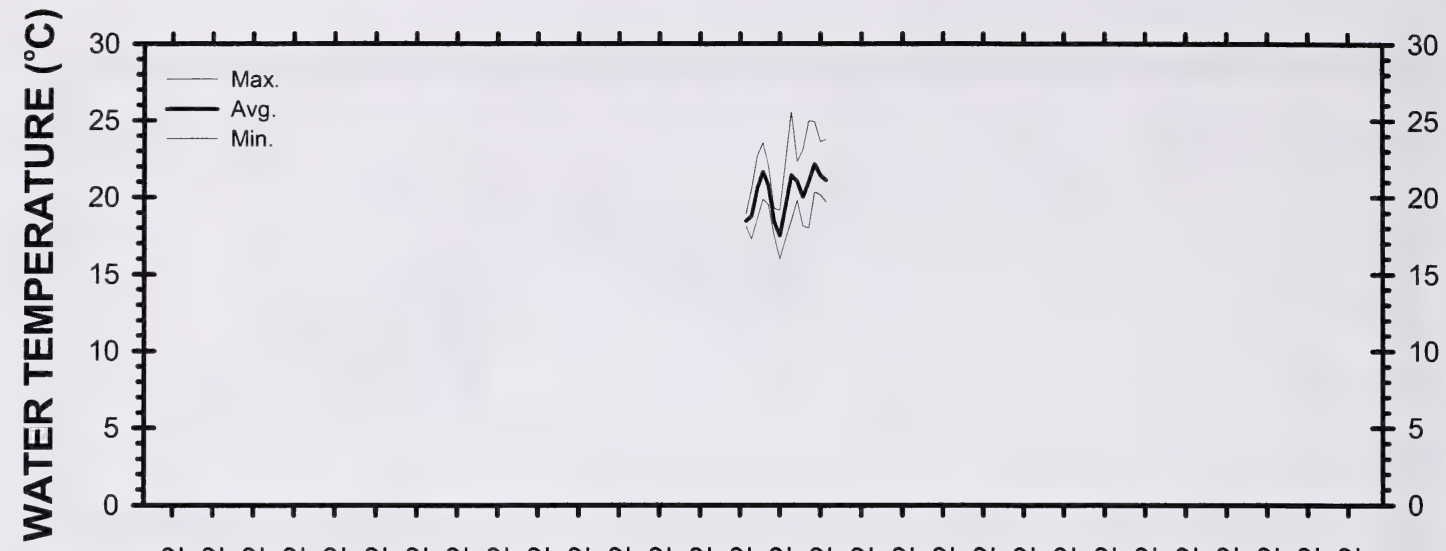

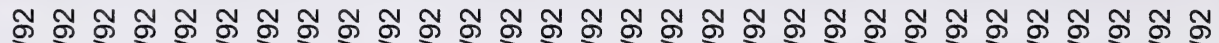
फ

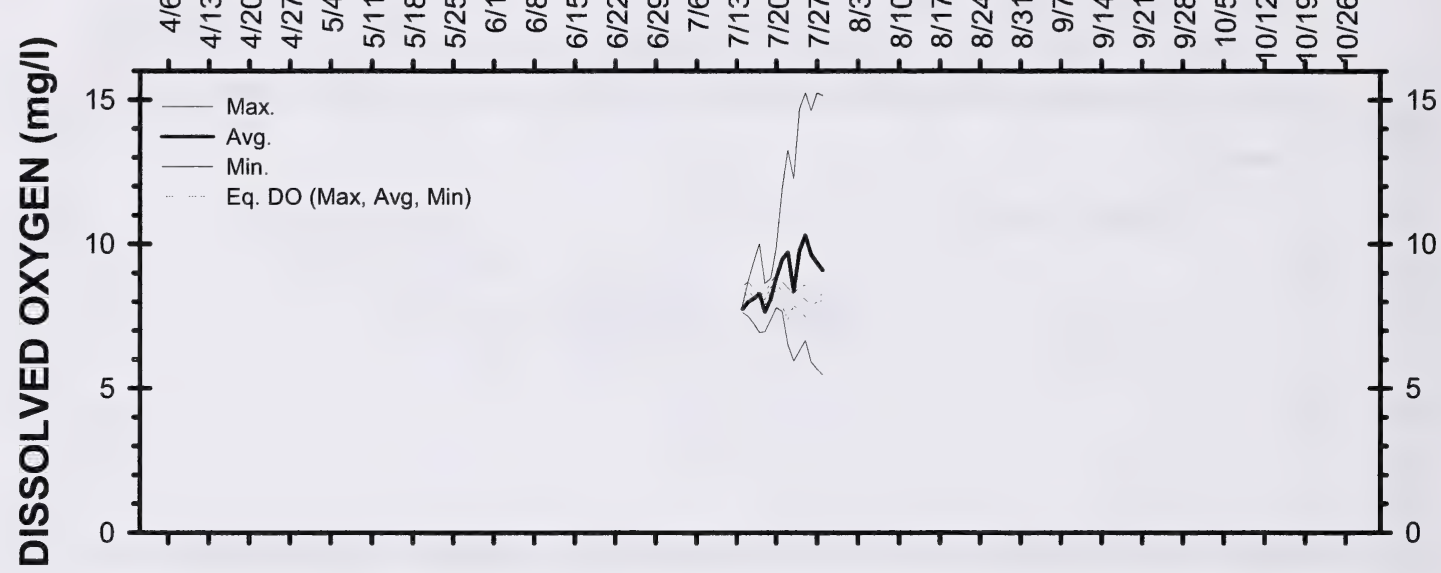

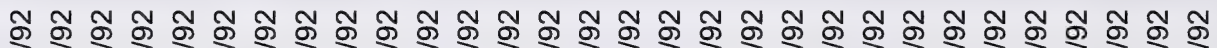

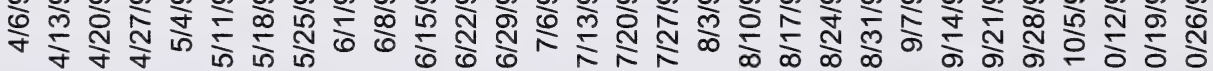

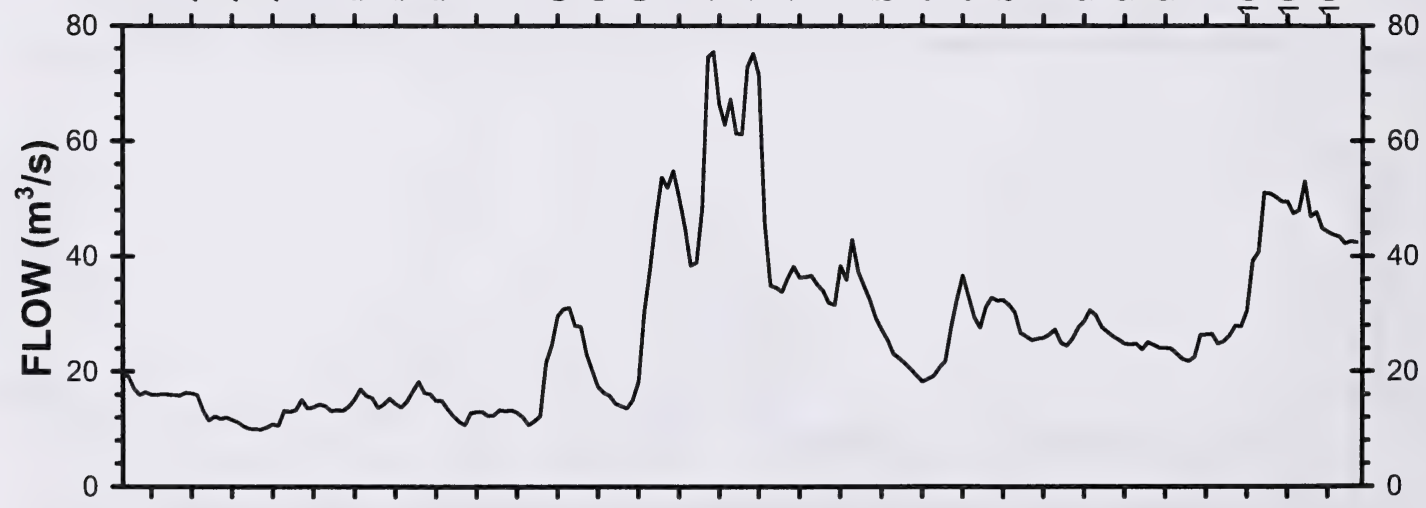

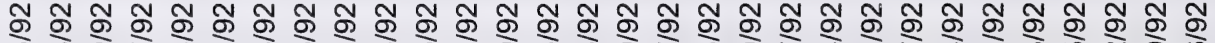
అ

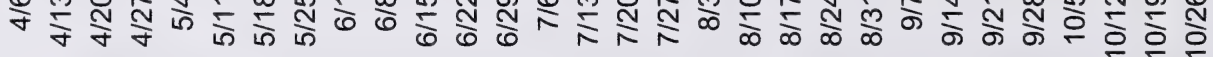

Figure 10. Daily water temperature (Datasonde), dissolved oxygen and flow in the Oldman River downstream of Lethbridge. April-October 1992. 

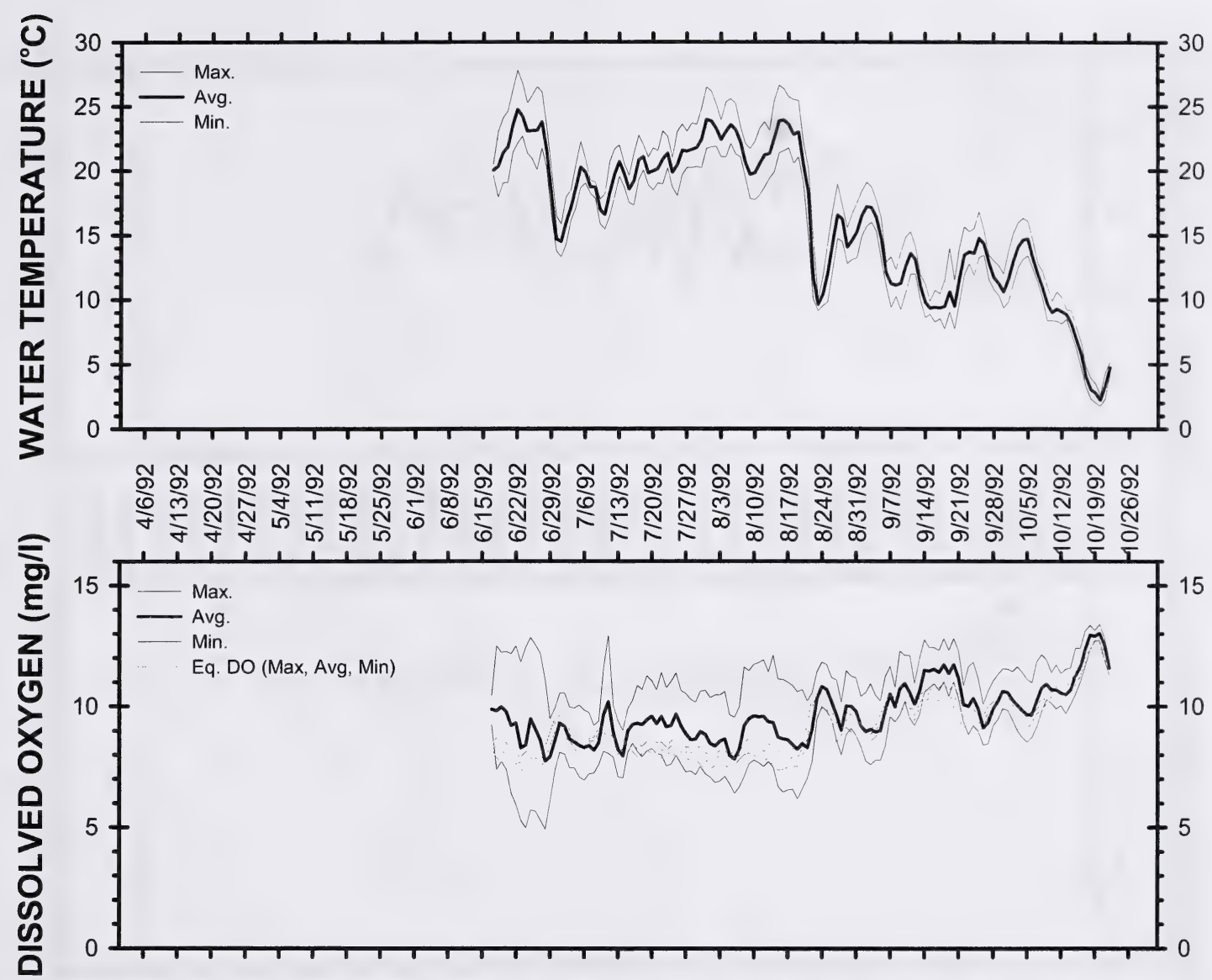

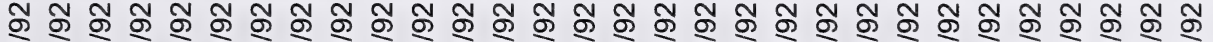

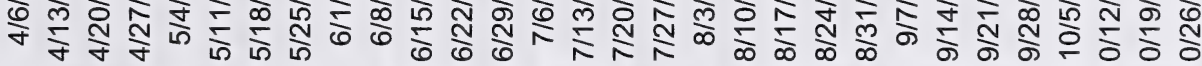

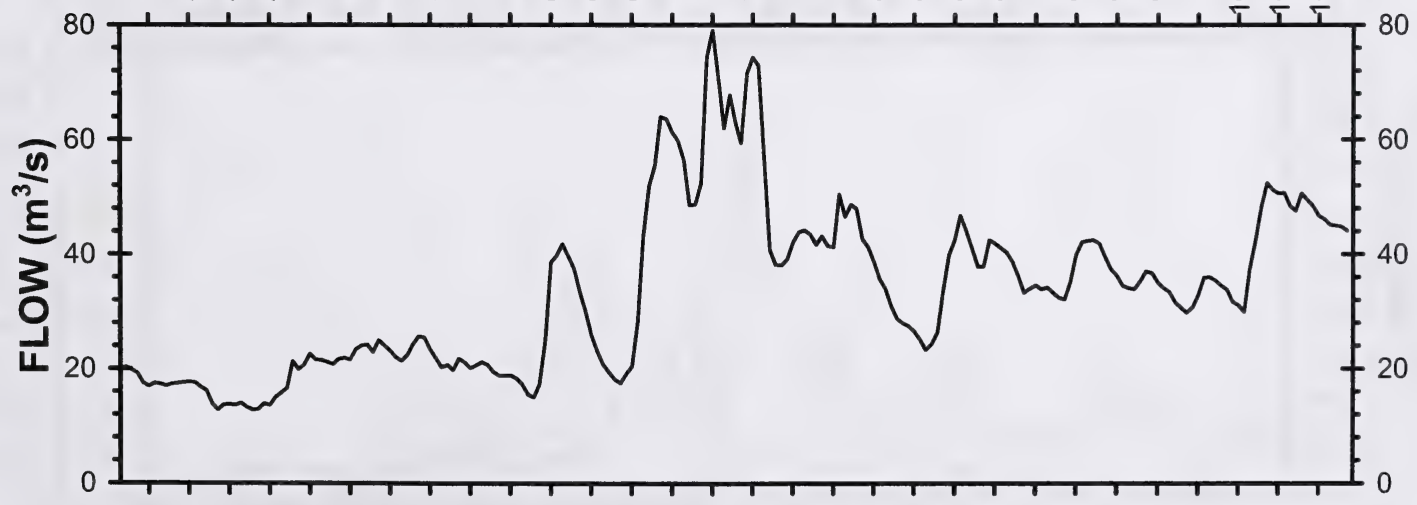

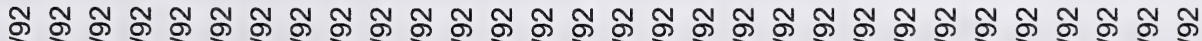

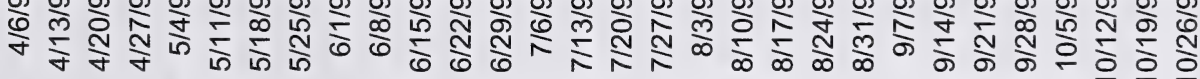

Figure 11. Daily water temperature (Datasonde), dissolved oxygen and flow in the Oldman River at the Bow River confluence. April-October 1992. 


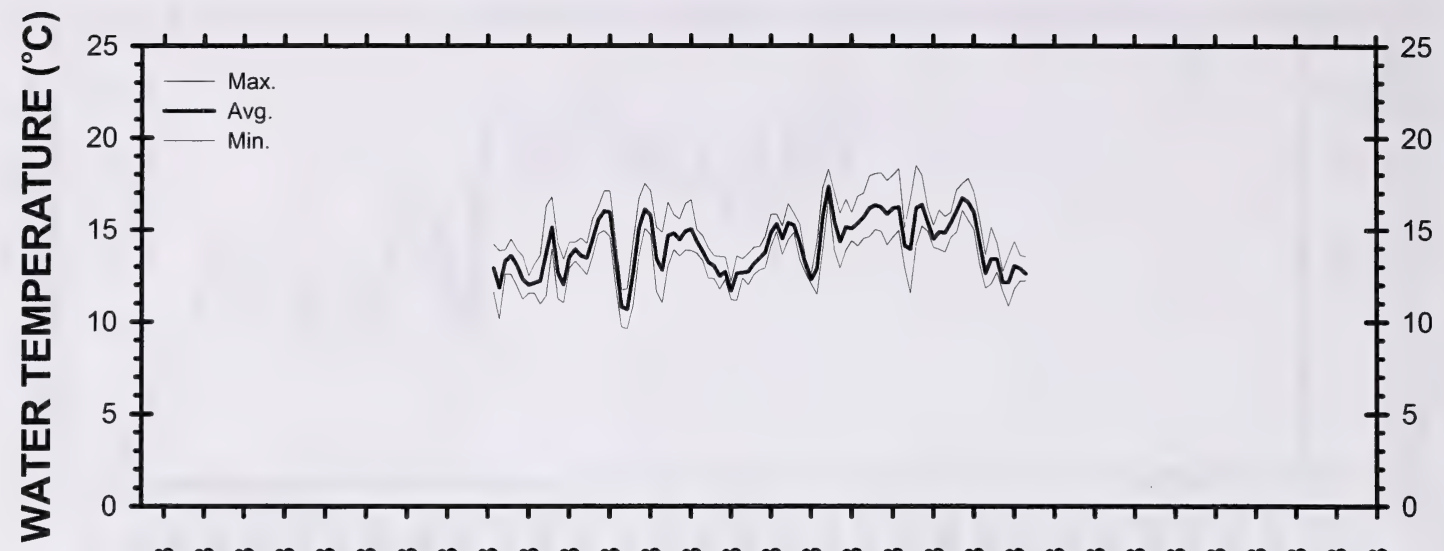

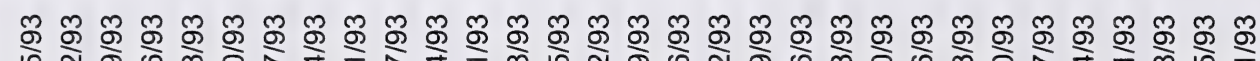

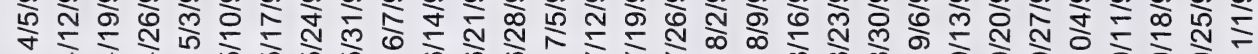

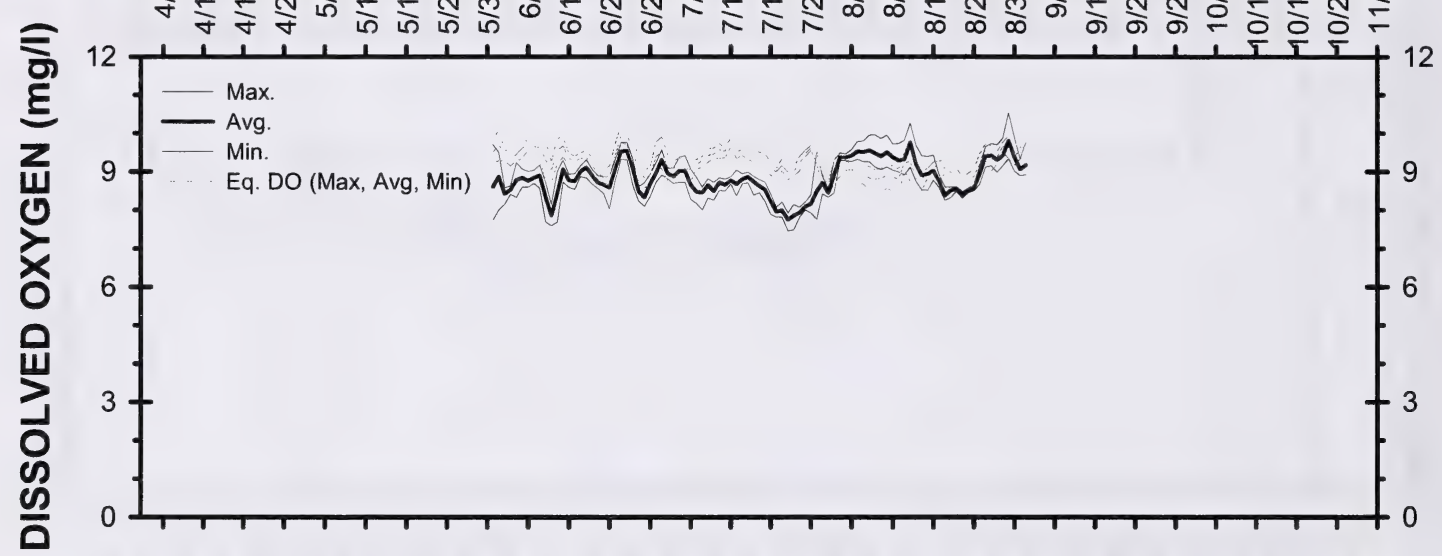

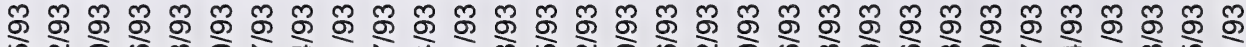

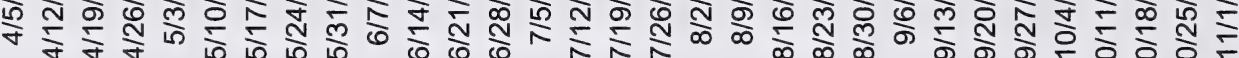

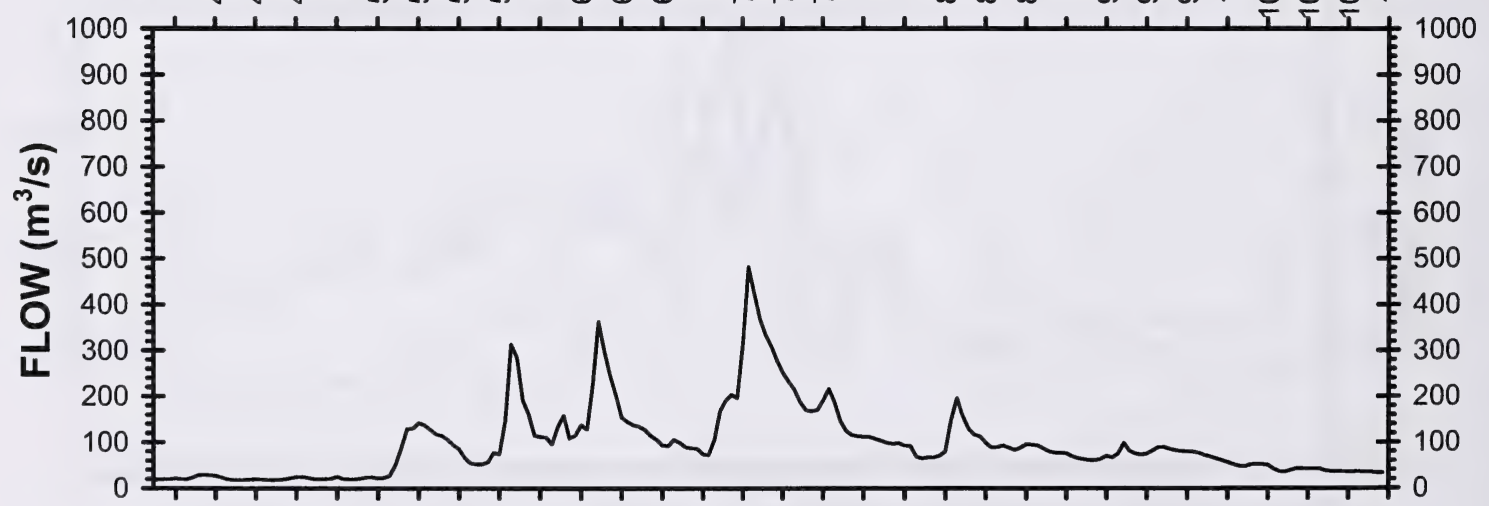

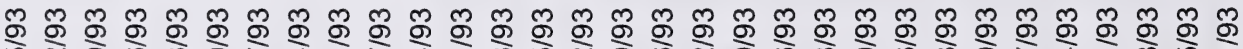

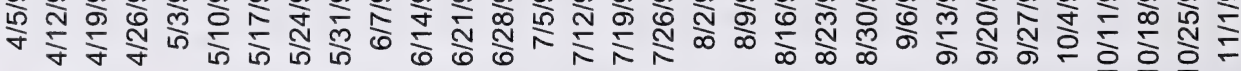

Figure 12. Daily water temperature (Datasonde), dissolved oxygen and flow in the Oldman River near Monarch. April-October 1993. 


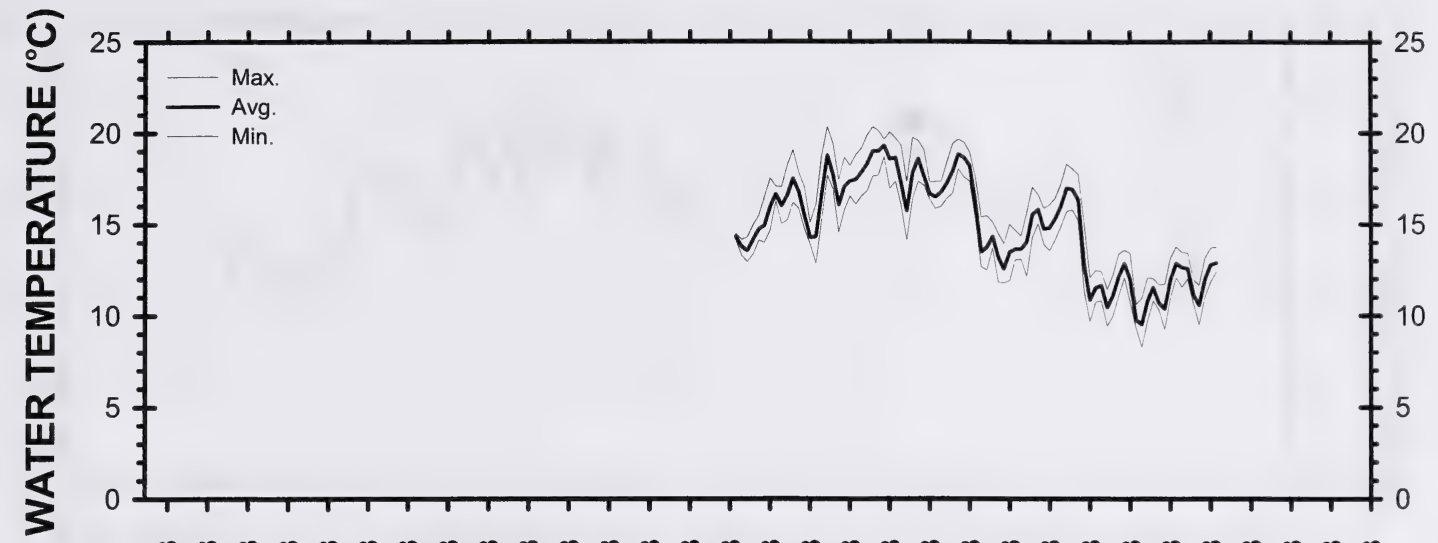

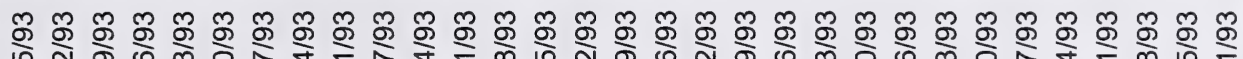

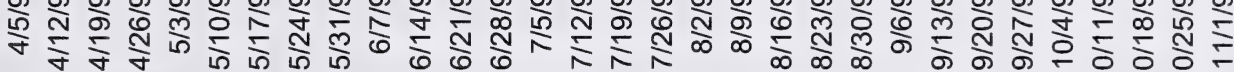

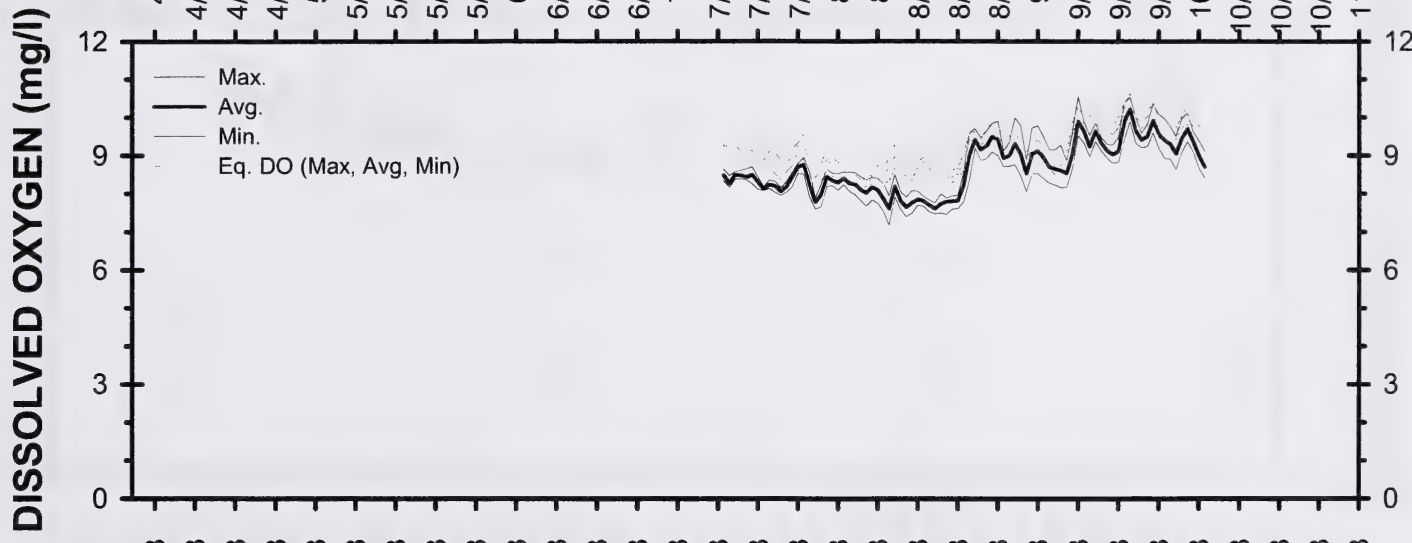

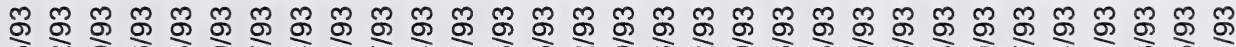

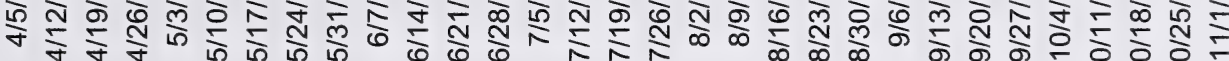

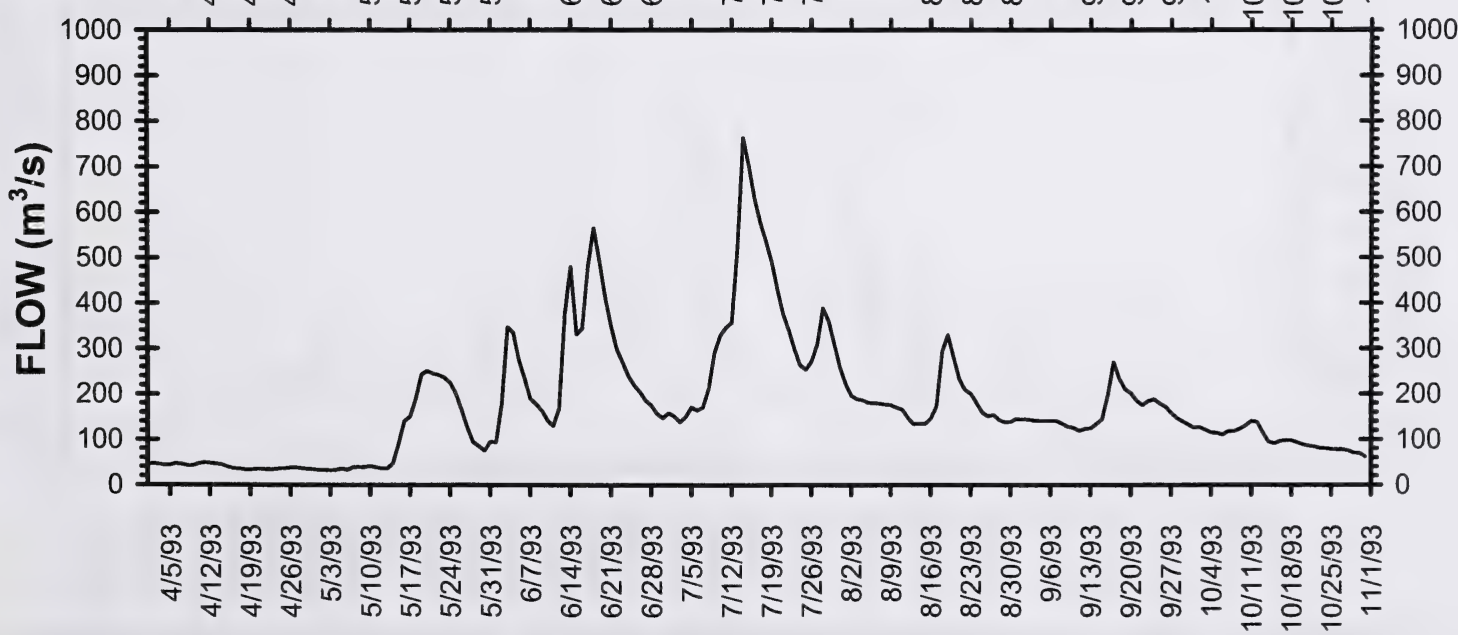

Figure 13. Daily water temperature (Datasonde), dissolved oxygen and flow in the Oldman River upstream of Lethbridge. April-October 1993. 


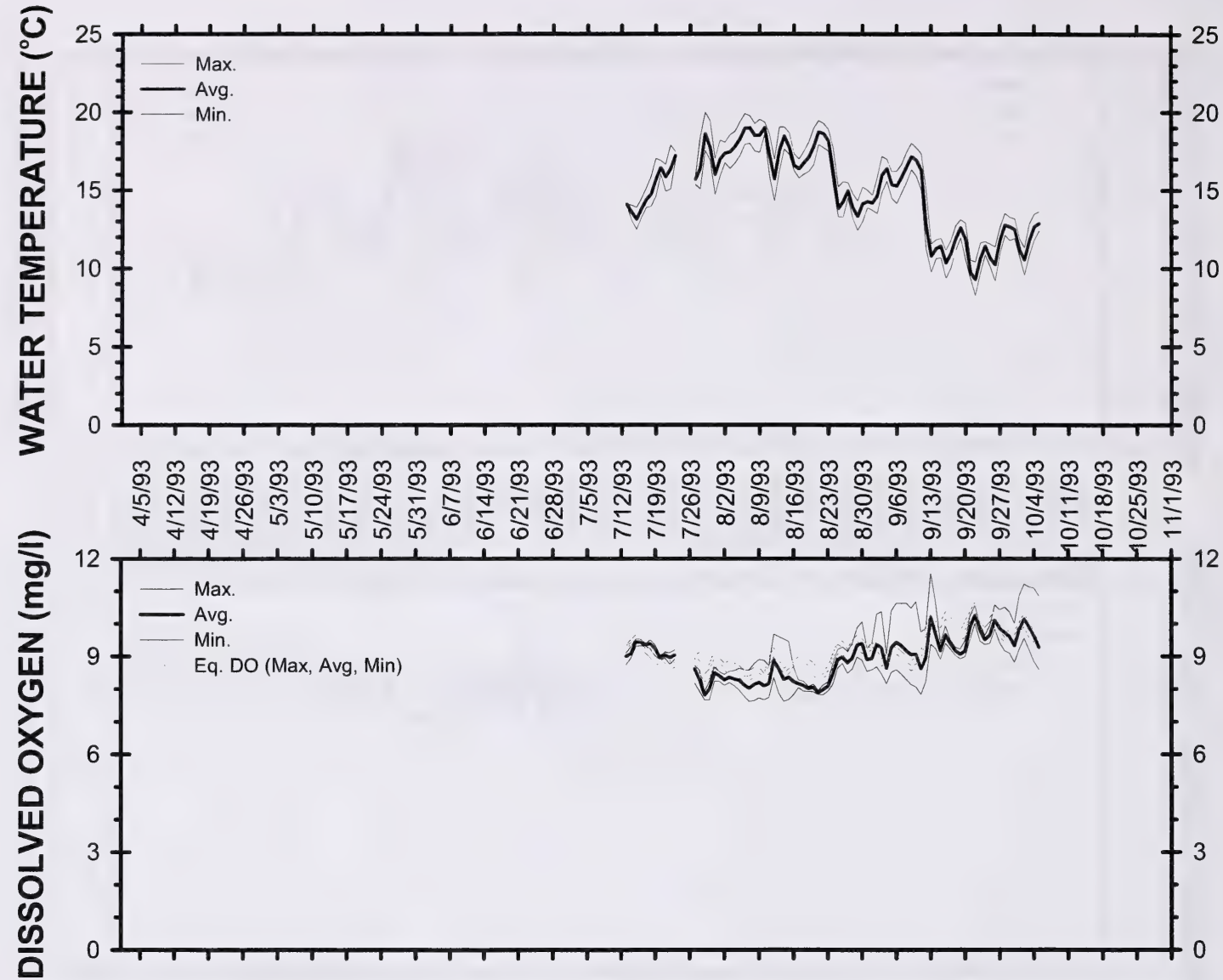

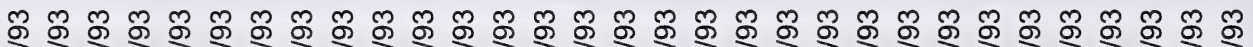

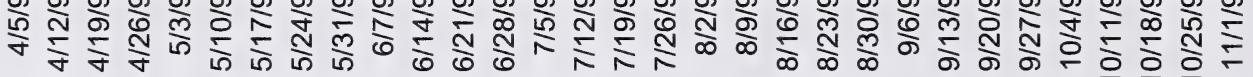

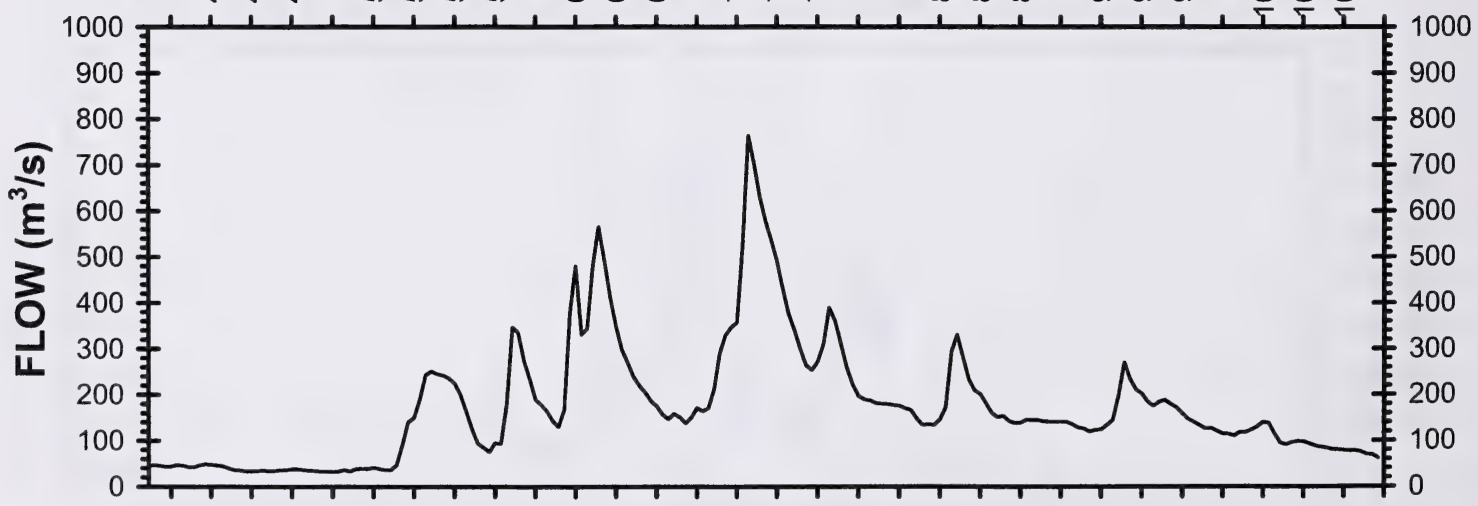

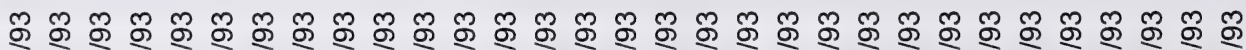

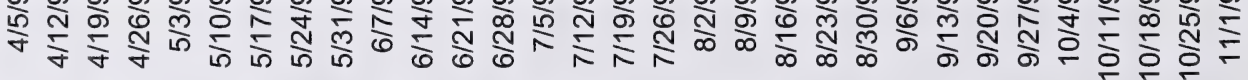

Figure 14. Daily water temperature (Datasonde), dissolved oxygen and flow in the Oldman River downstream of Lethbridge. April-October 1993. 


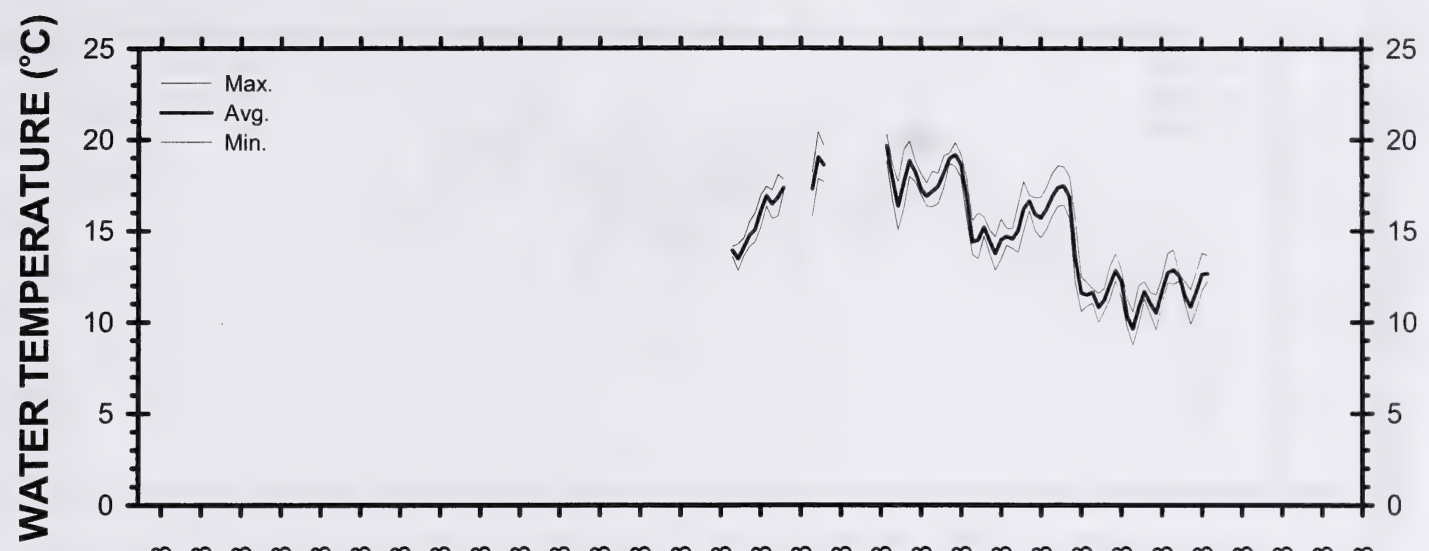

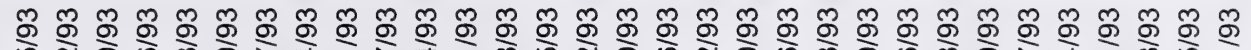

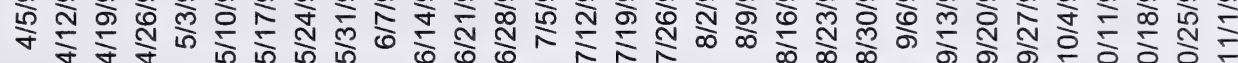

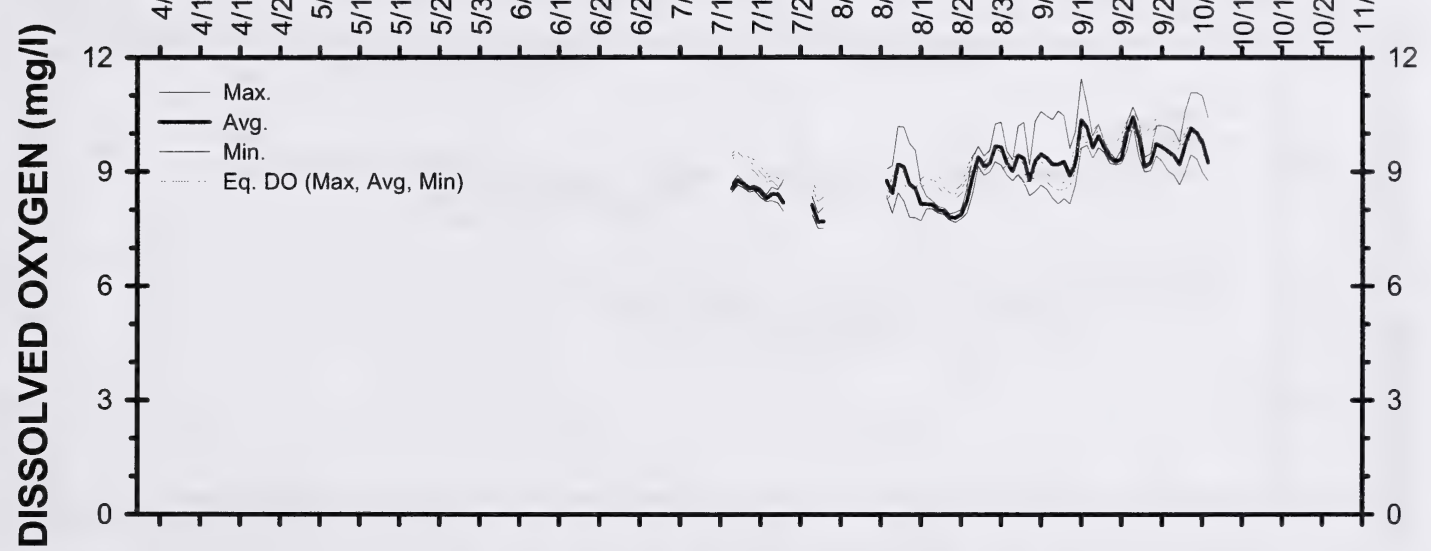

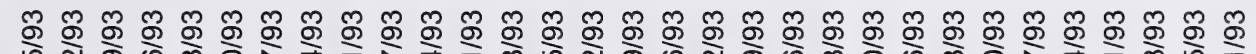

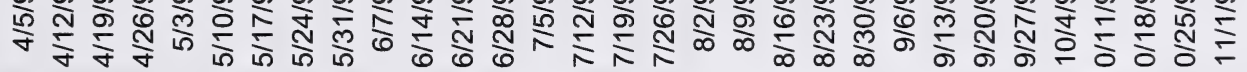

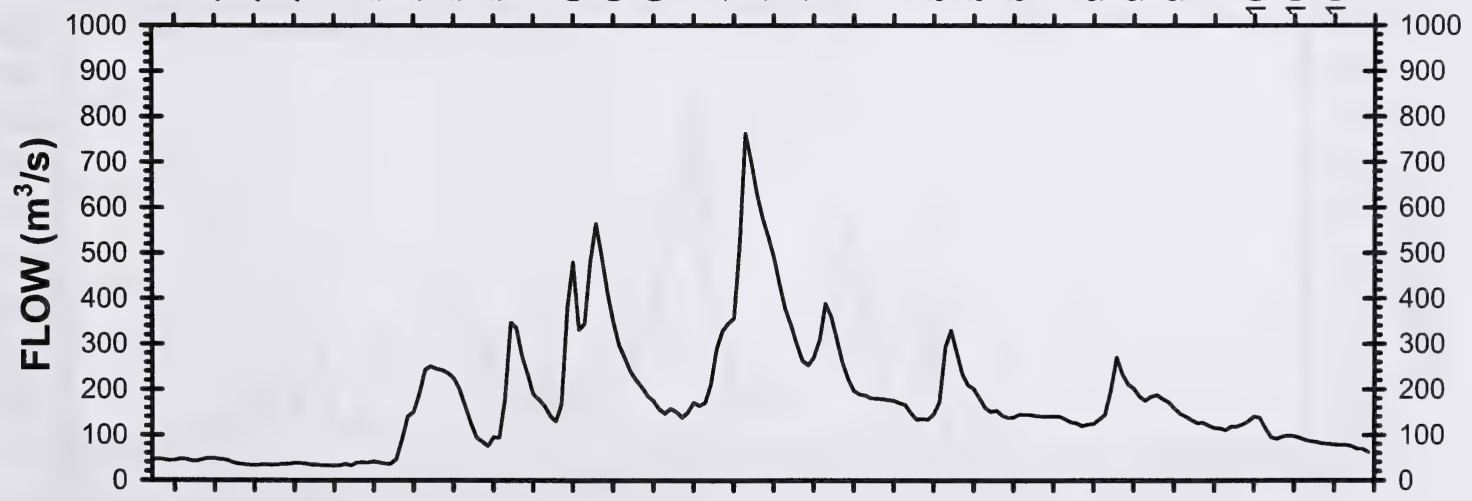

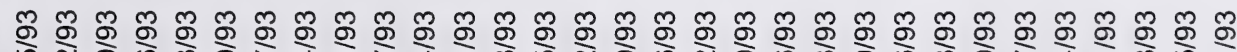

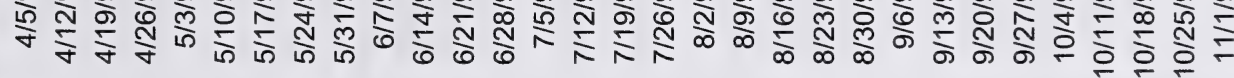

Figure 15. Daily water temperature (Datasonde), dissolved oxygen and flow in the Oldman River near Hwy. 845. April-October 1993. 

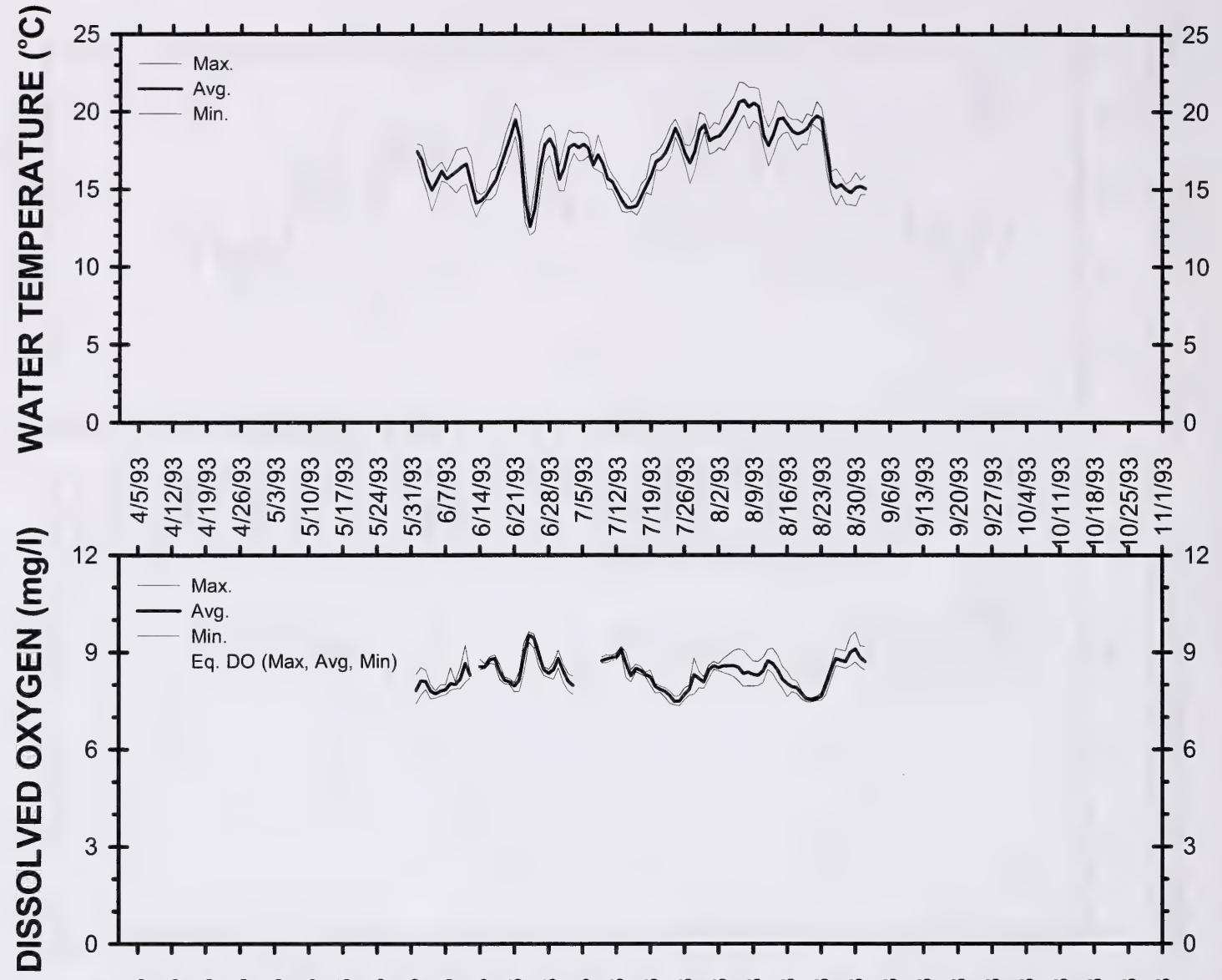

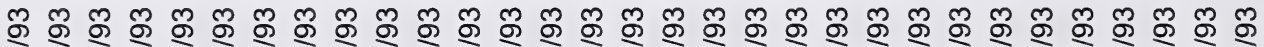

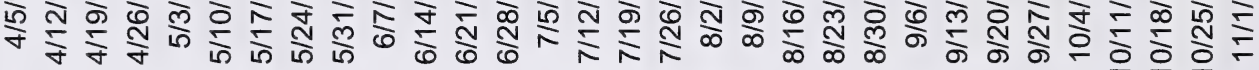

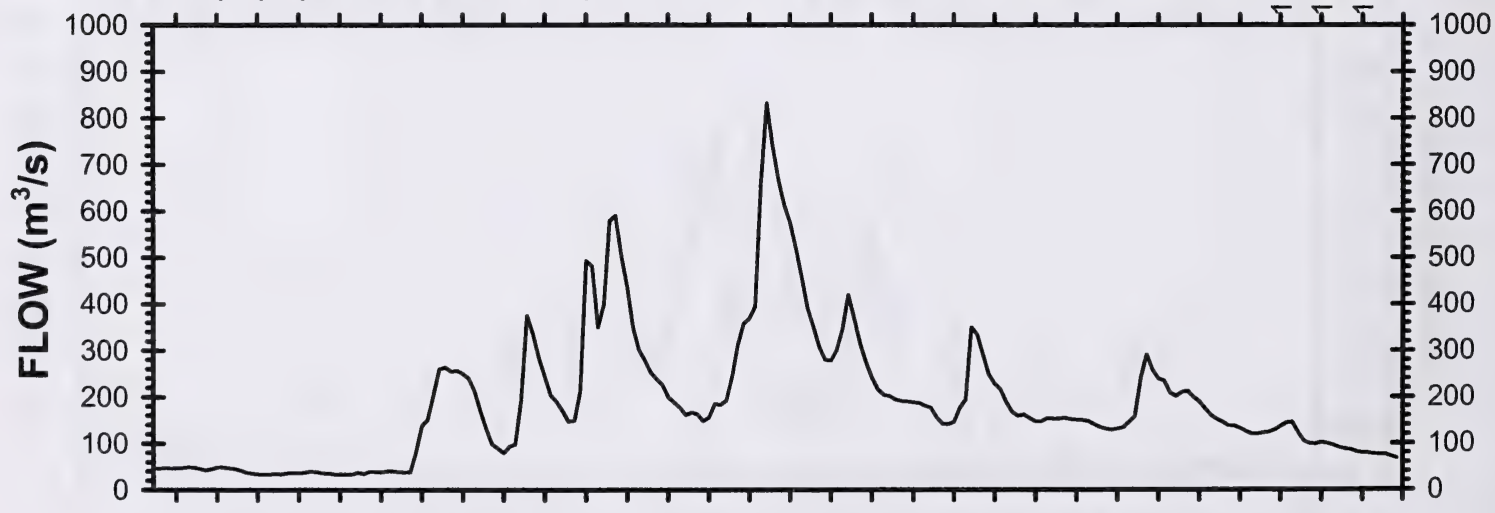

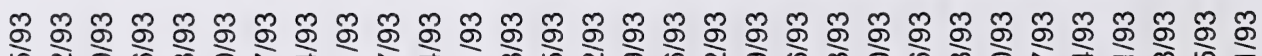

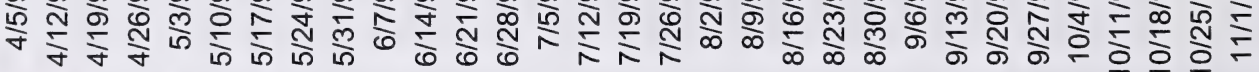

Figure 16. Daily water temperature (Datasonde), dissolved oxygen and flow in the Oldman River at the Bow River confluence. April-October 1993. 

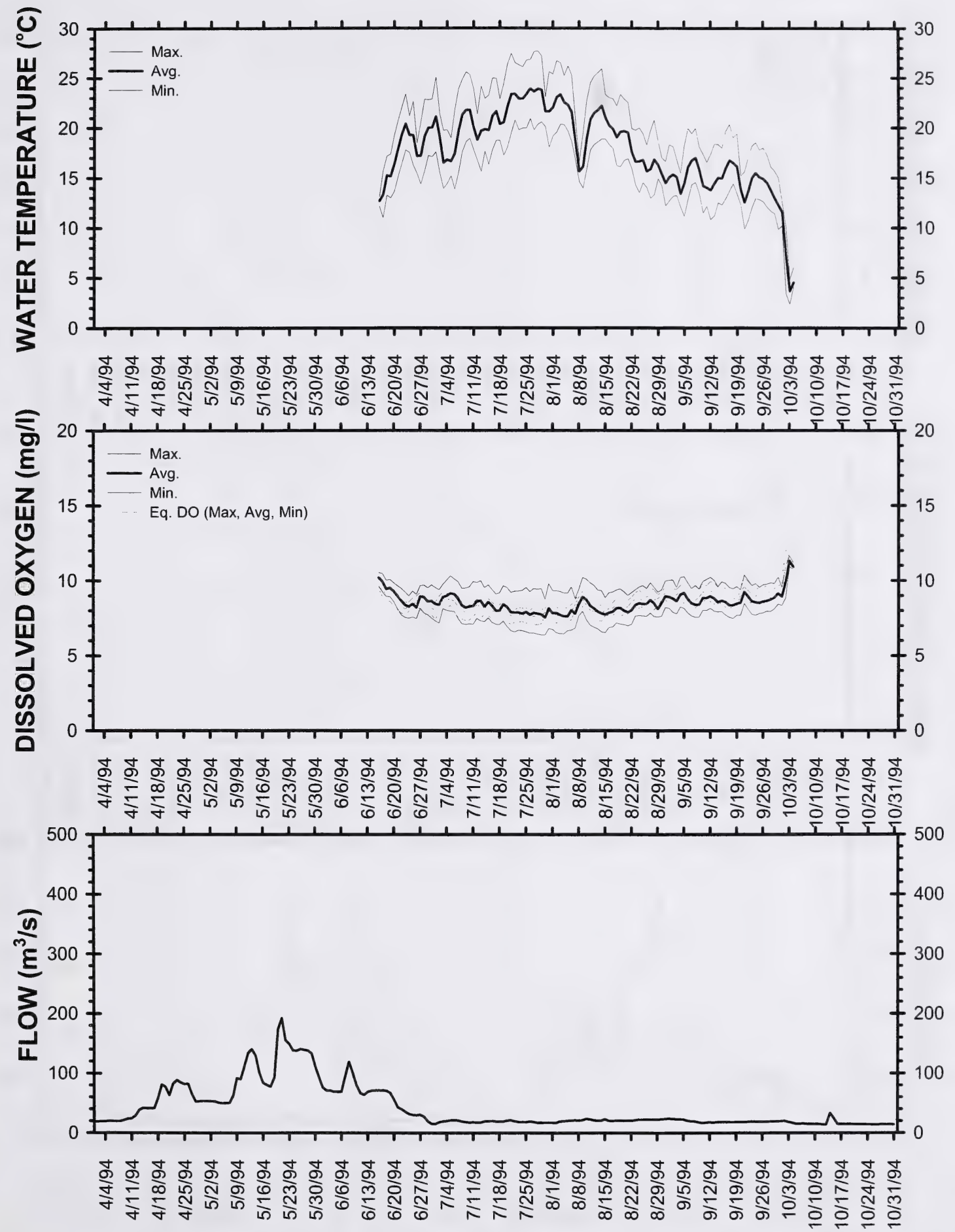

Figure 17. Daily water temperature (Datasonde), dissolved oxygen and flow in the Oldman River near Monarch. April-October 1994. 


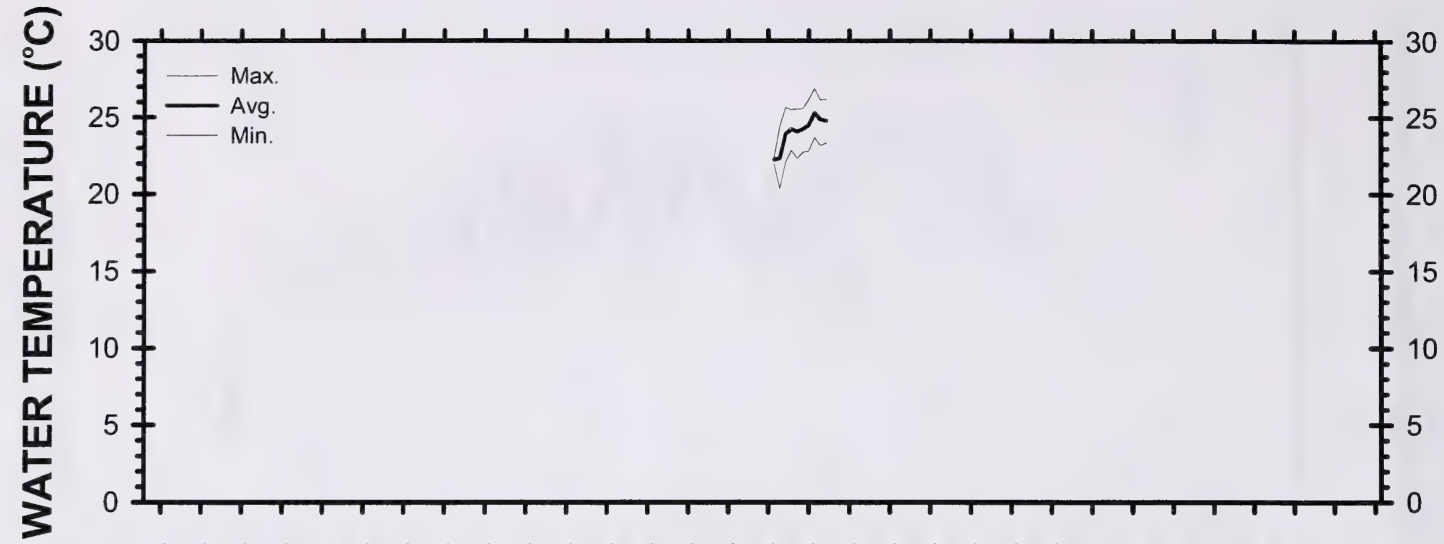

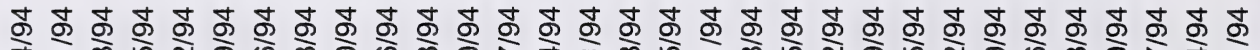

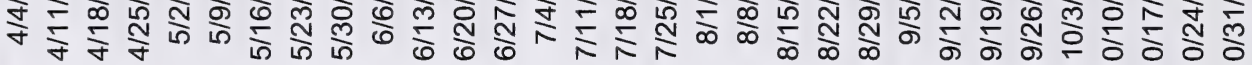
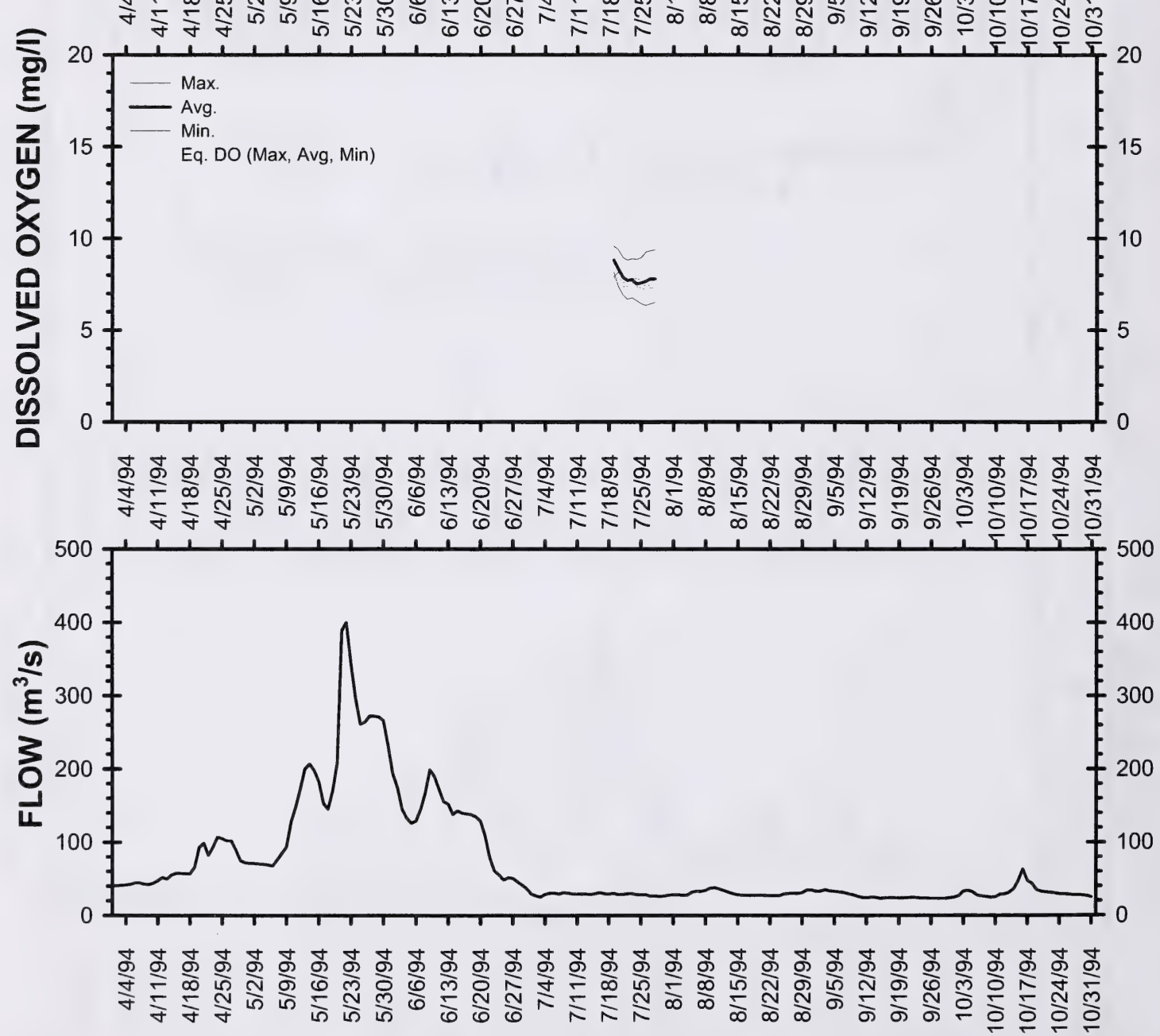

Figure 18. Daily water temperature (Datasonde), dissolved oxygen and flow in the Oldman River upstream of Lethbridge. April-October 1994. 


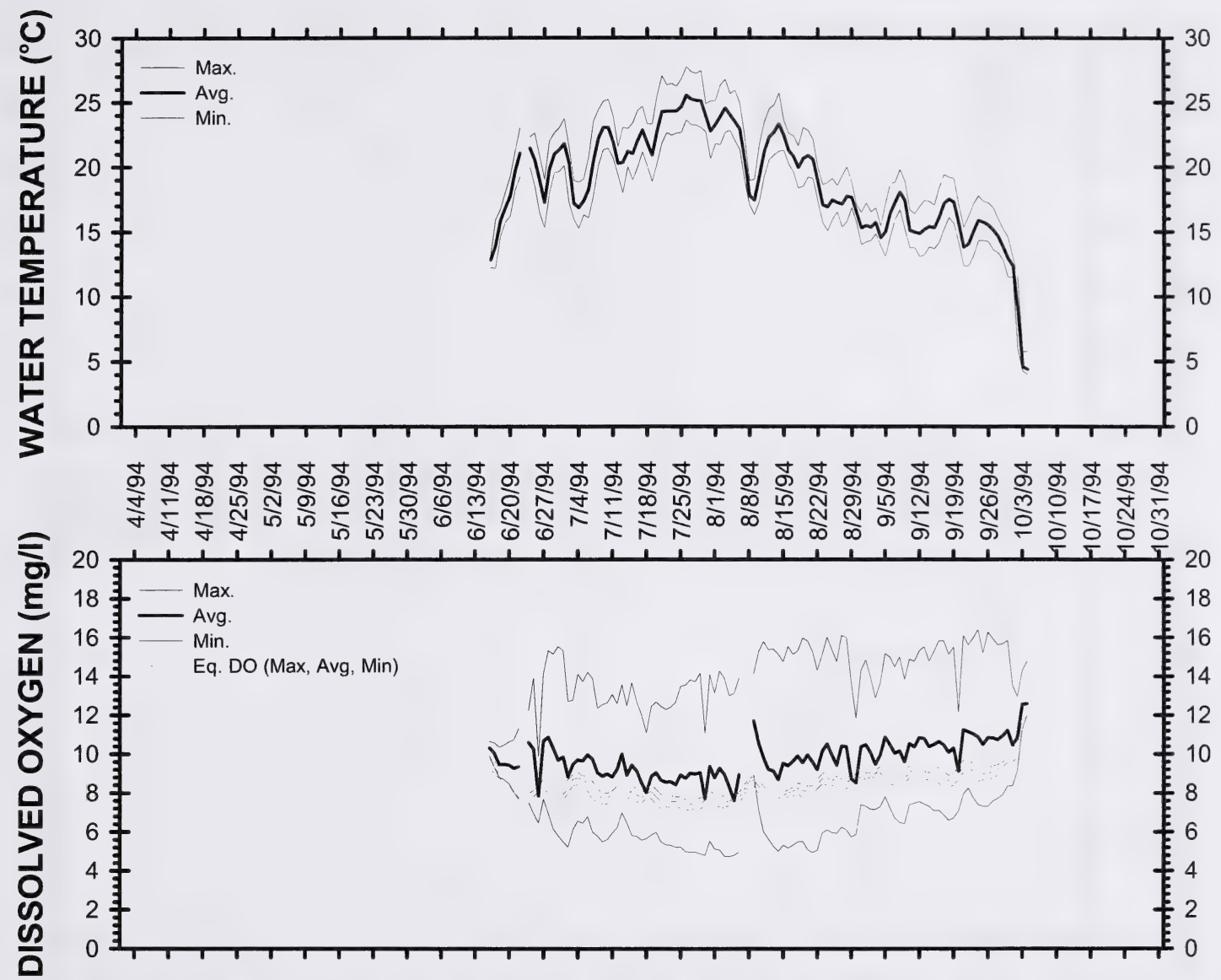

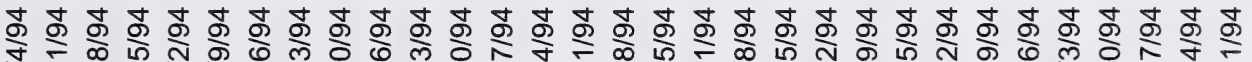

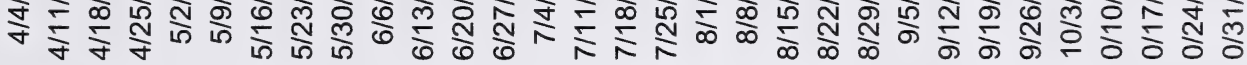

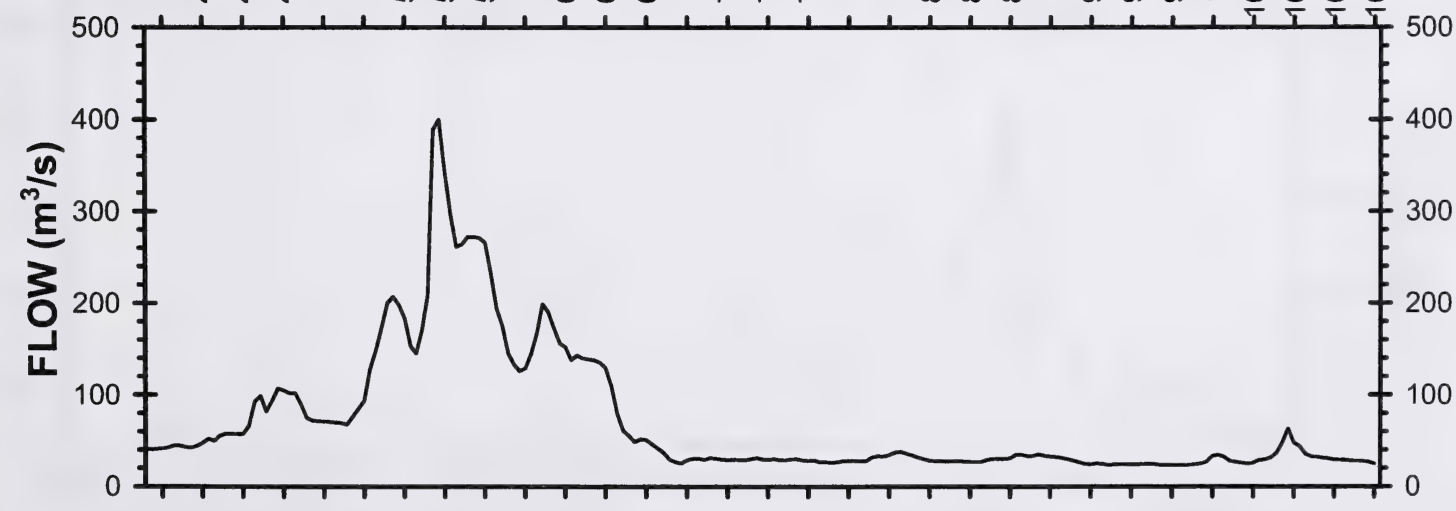

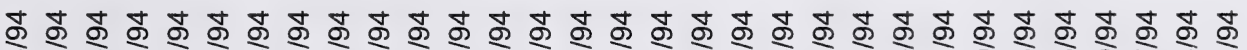

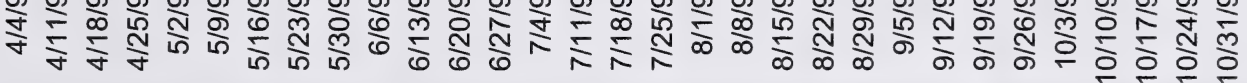

Figure 19. Daily water temperature (Datasonde), dissolved oxygen and flow in the Oldman River downstream of Lethbridge. April-October 1994. 


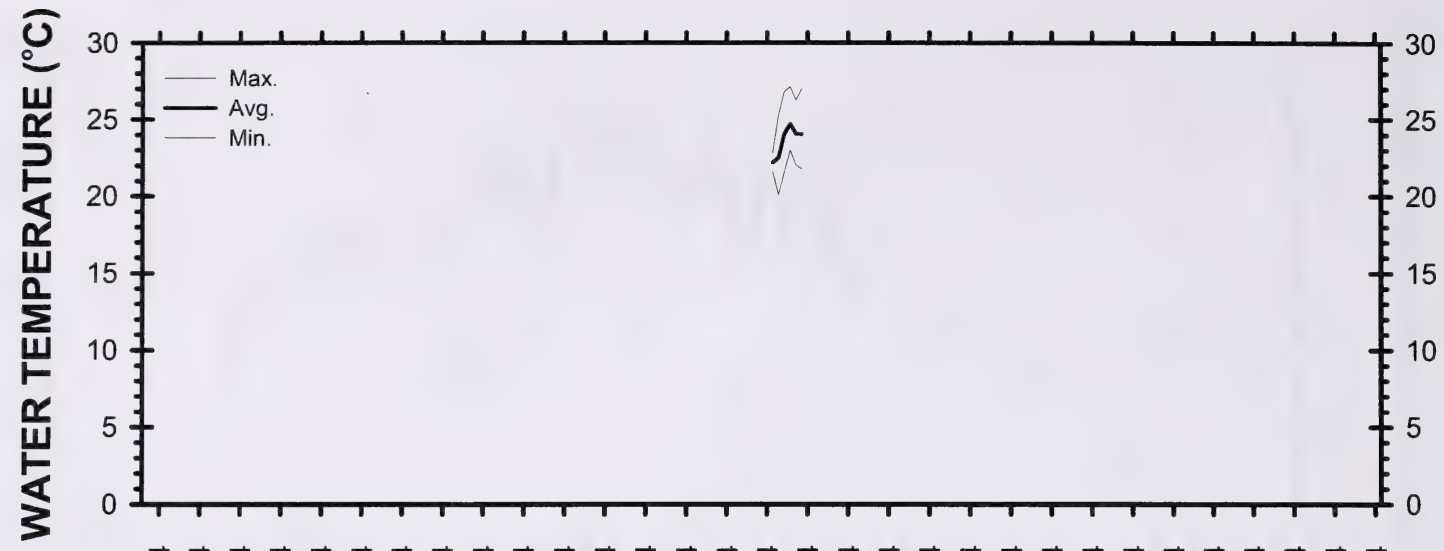

ఫ

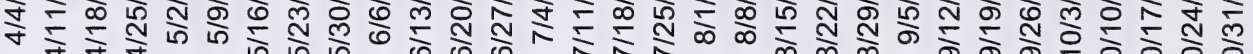

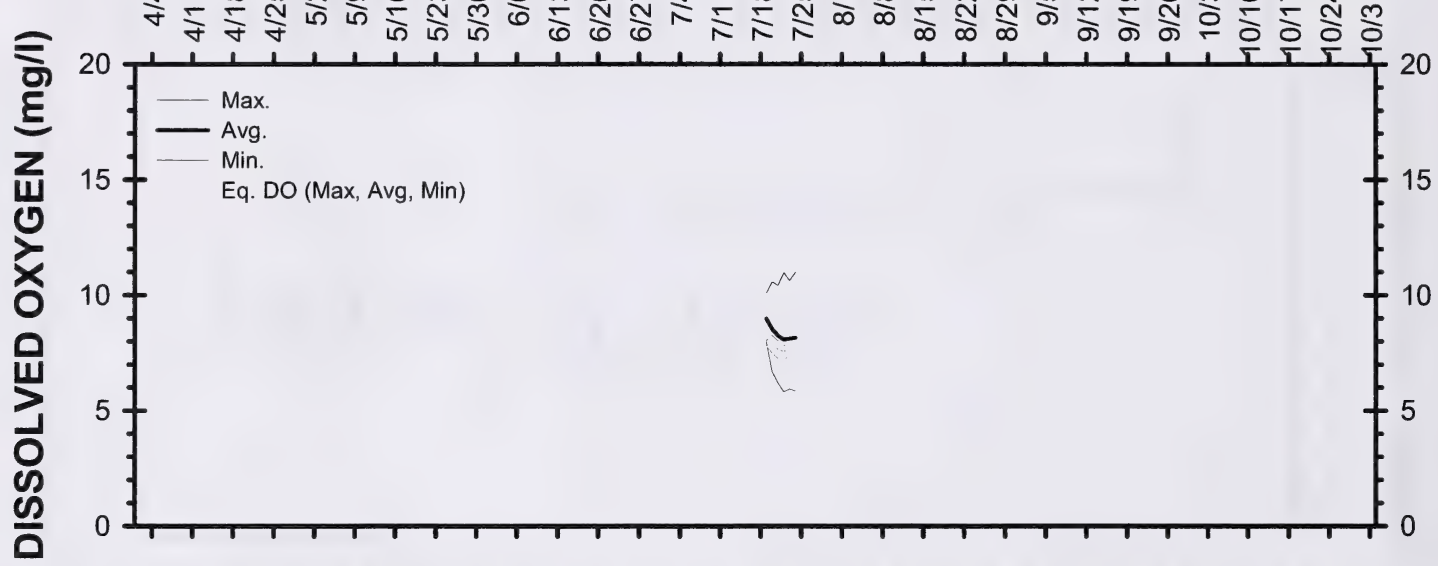

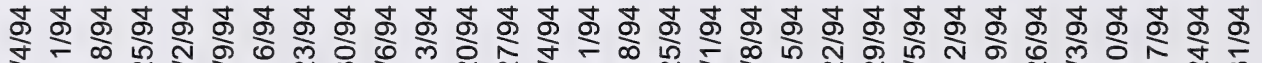

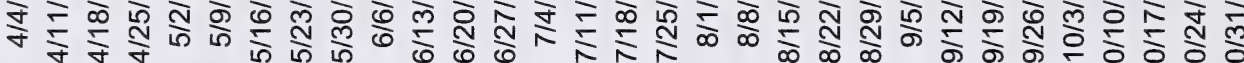

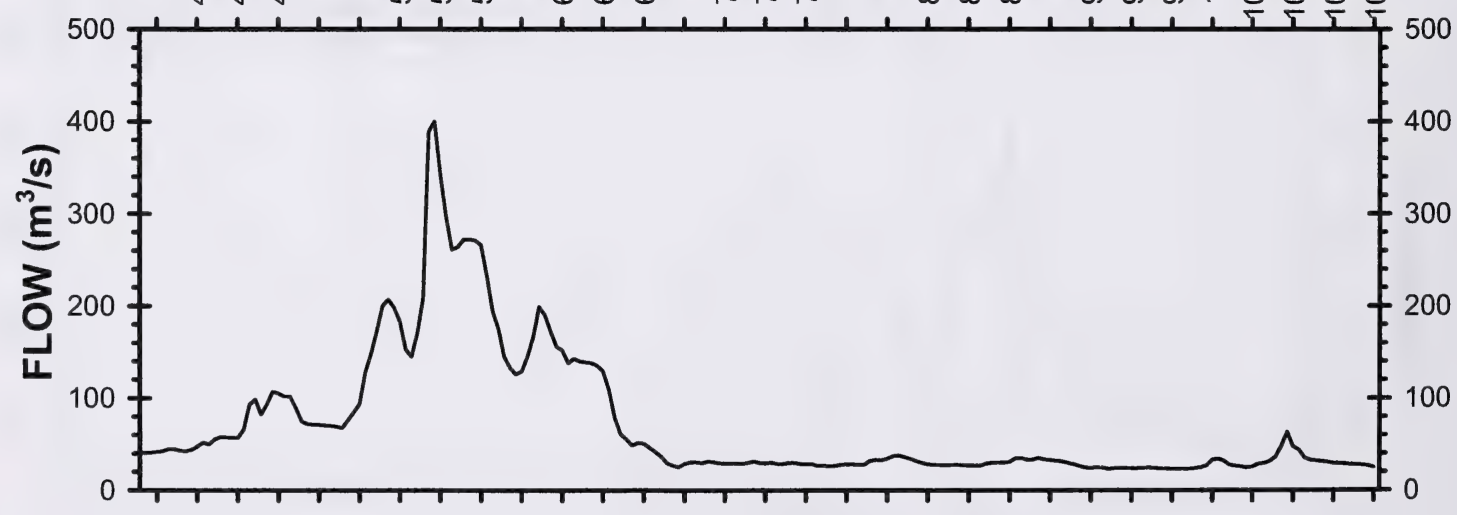

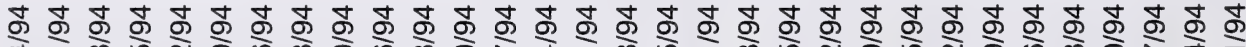

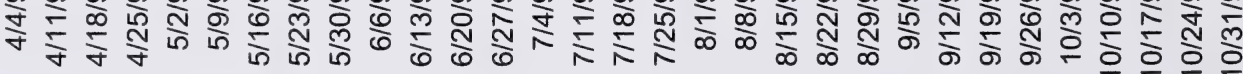

Figure 20. Daily water temperature (Datasonde), dissolved oxygen and flow in the Oldman River near Hwy. 845. April-October 1994. 

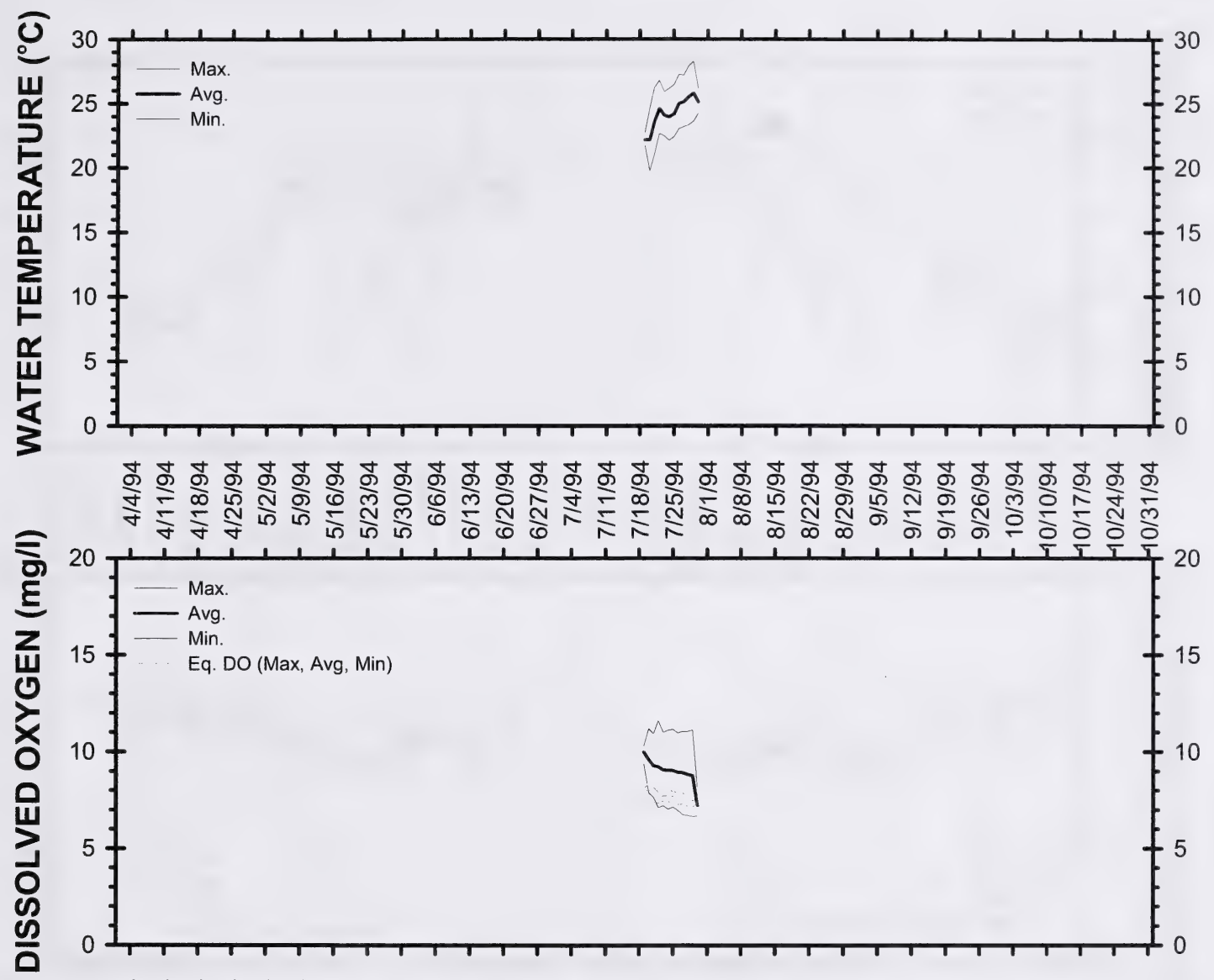

ఫ ఫ

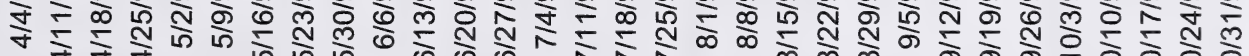

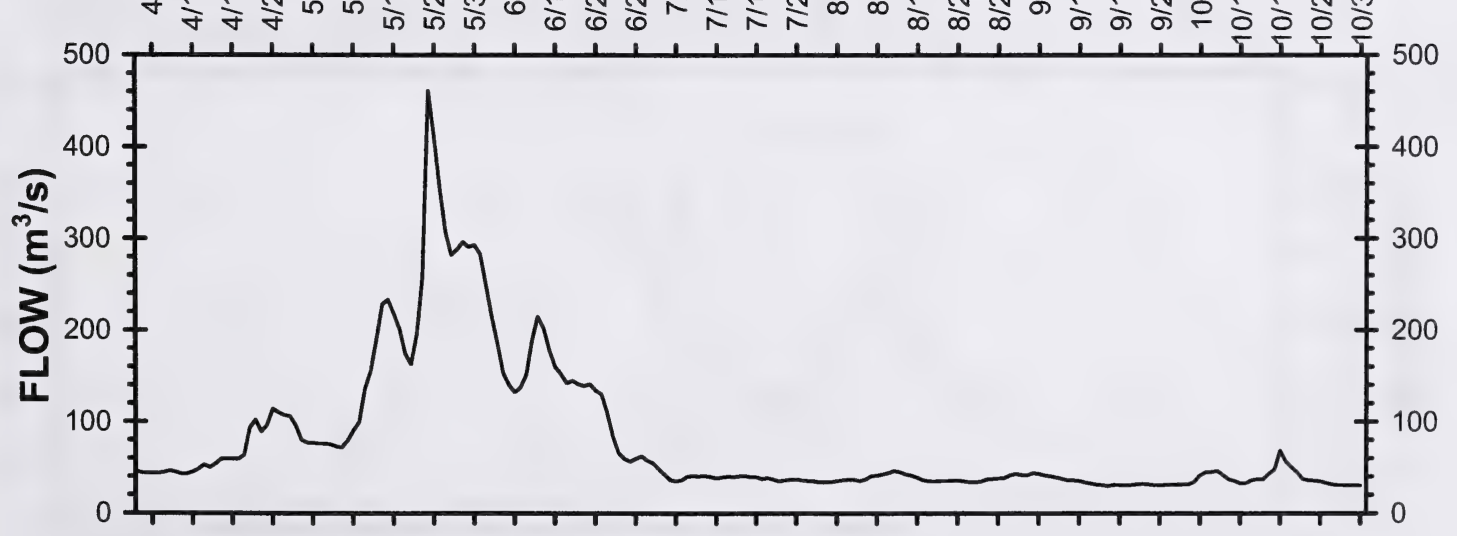

ॠ

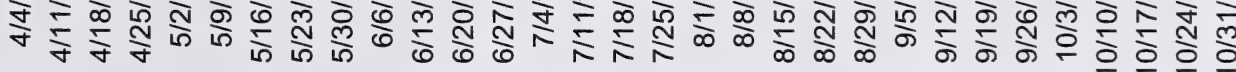

Figure 21. Daily water temperature (Datasonde), dissolved oxygen and flow in the Oldman River at the Bow River confluence. April-October 1994. 


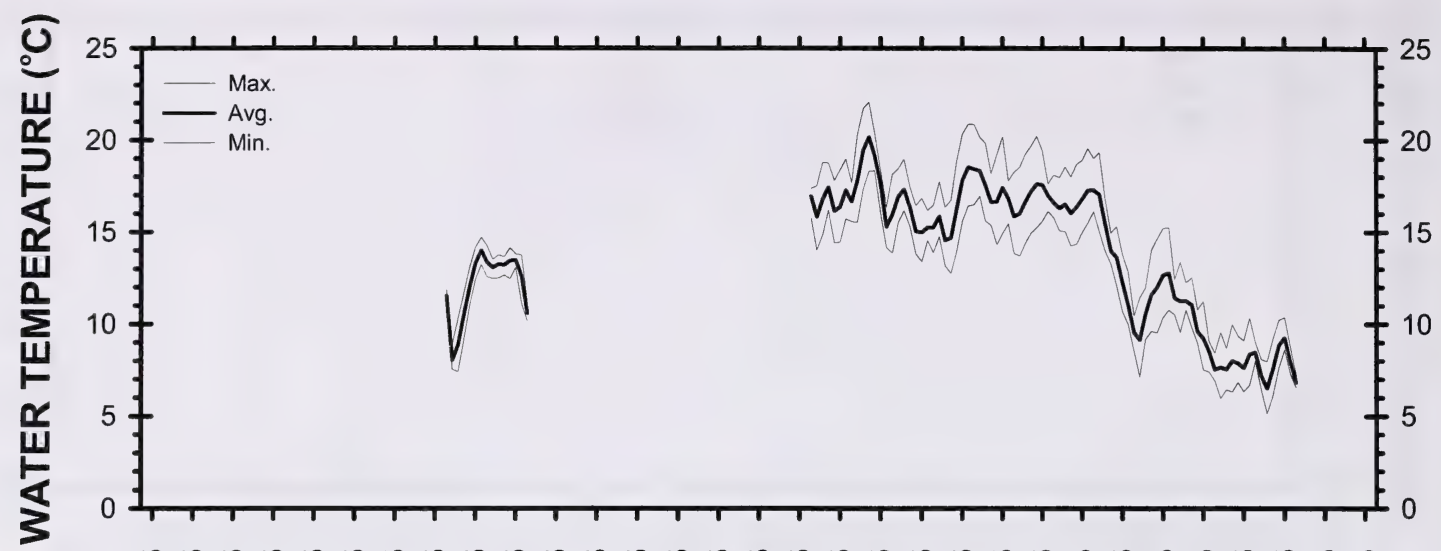

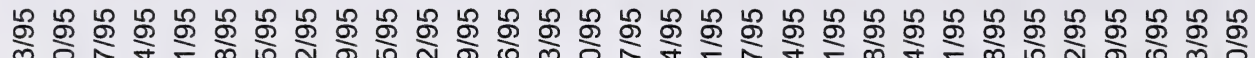

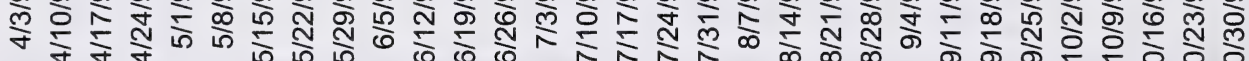
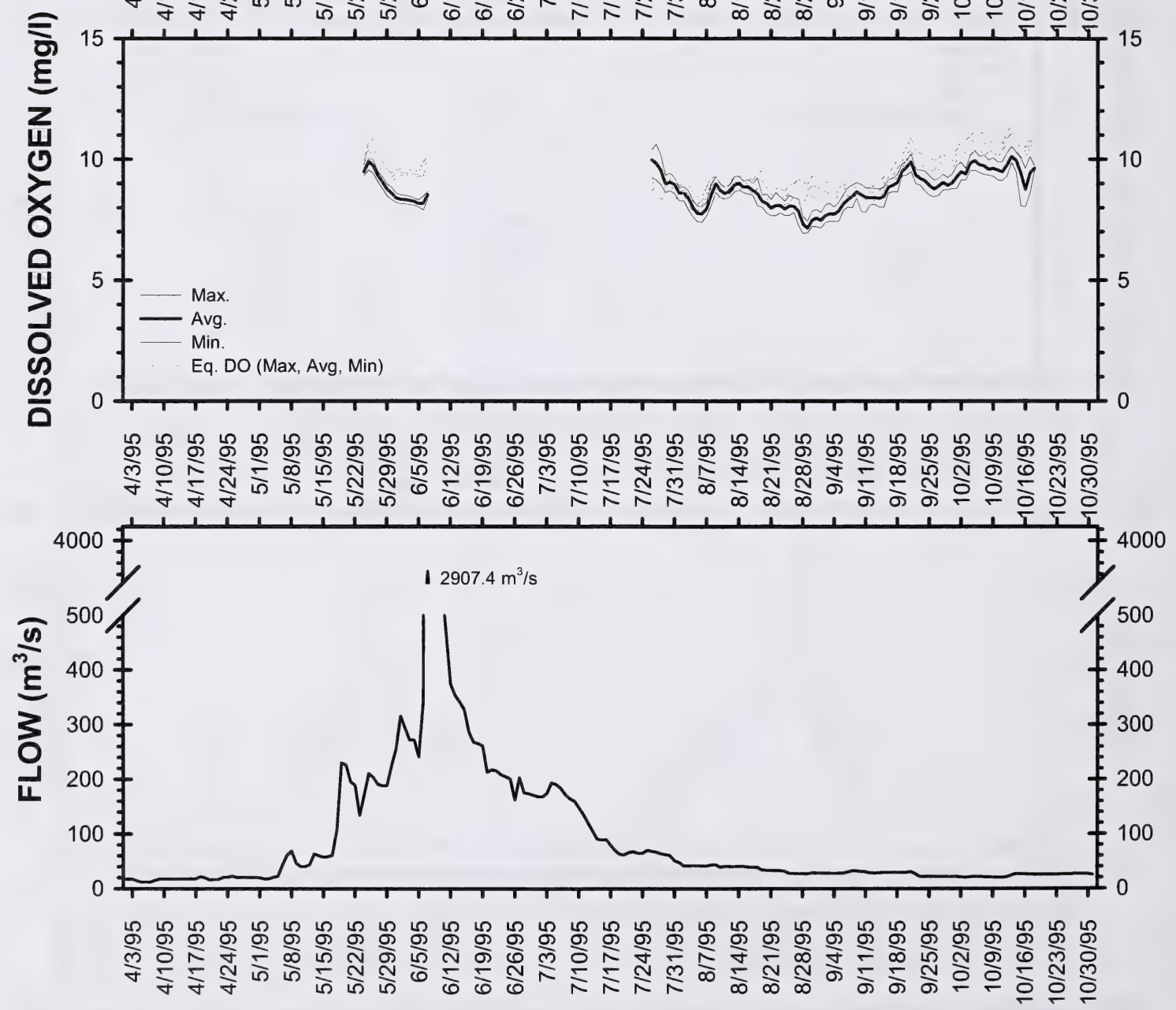

Figure 22. Daily water temperature (Datasonde), dissolved oxygen and flow in the Oldman River near Monarch. April-October 1995. 

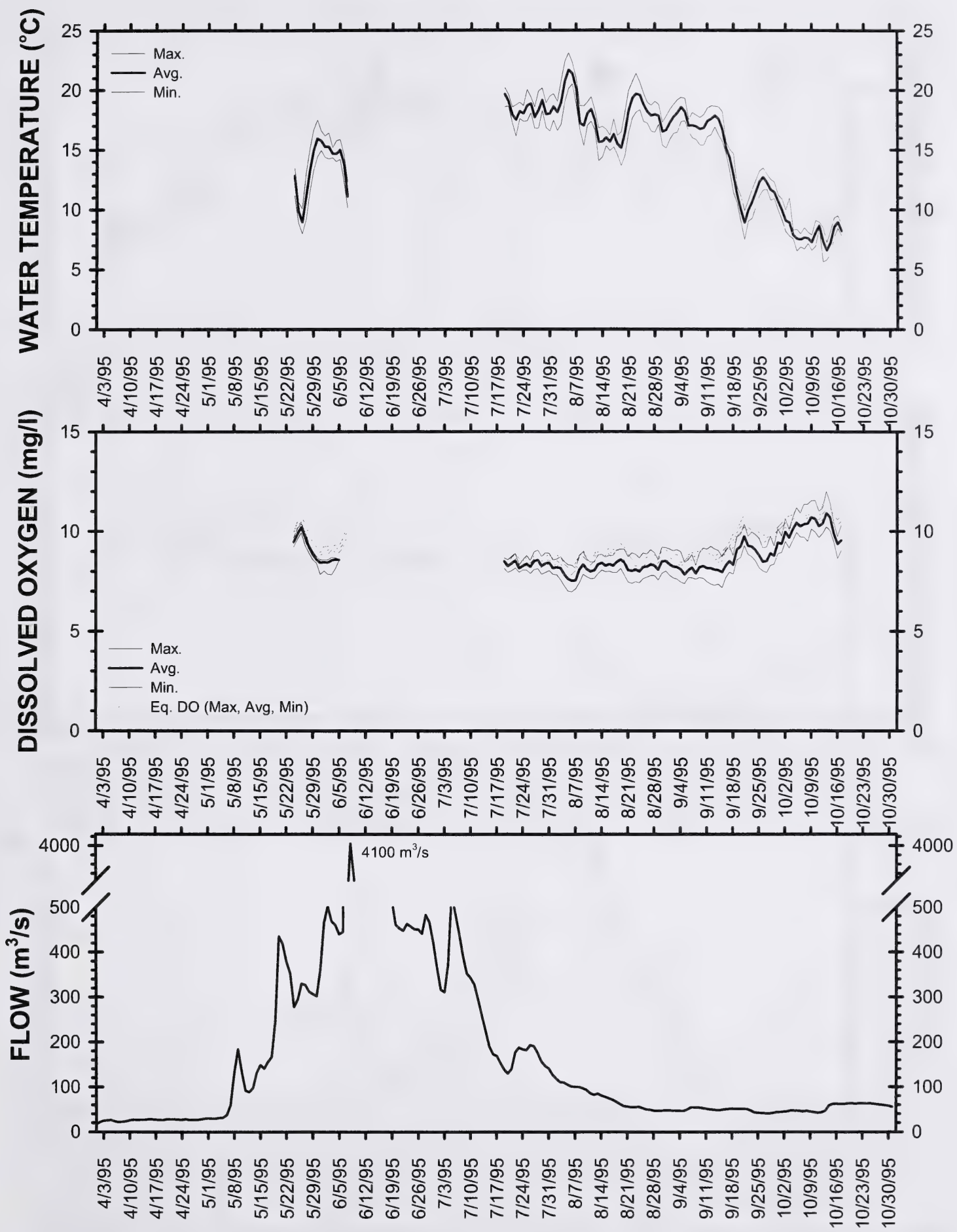

Figure 23. Daily water temperature (Datasonde), dissolved oxygen and flow in the Oldman River upstream of Lethbridge. April-October 1995. 

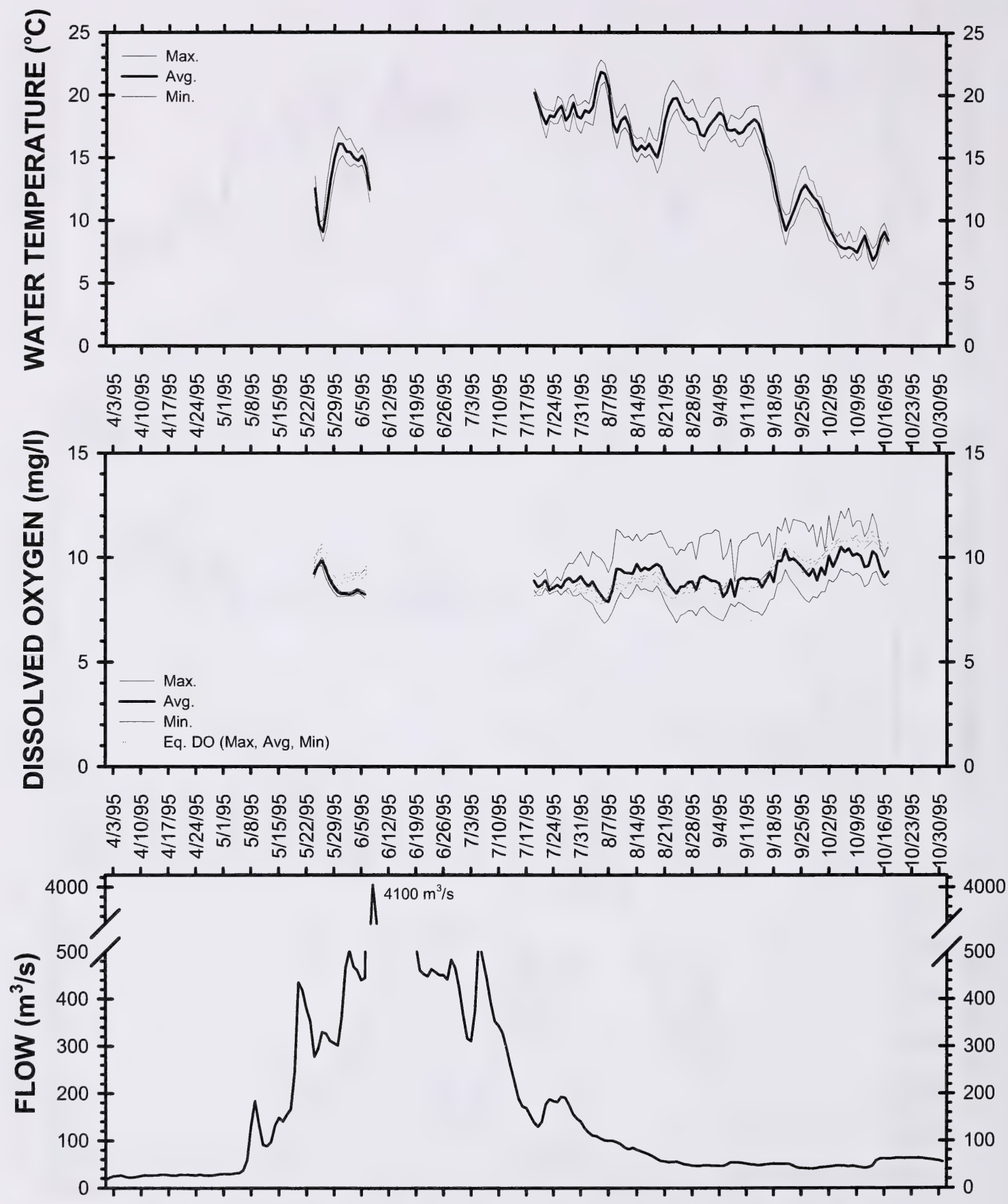

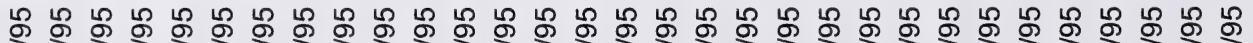

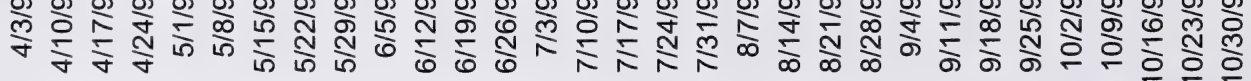

Figure 24. Daily water temperature (Datasonde), dissolved oxygen and flow in the Oldman River downstream of Lethbridge. April-October 1995. 


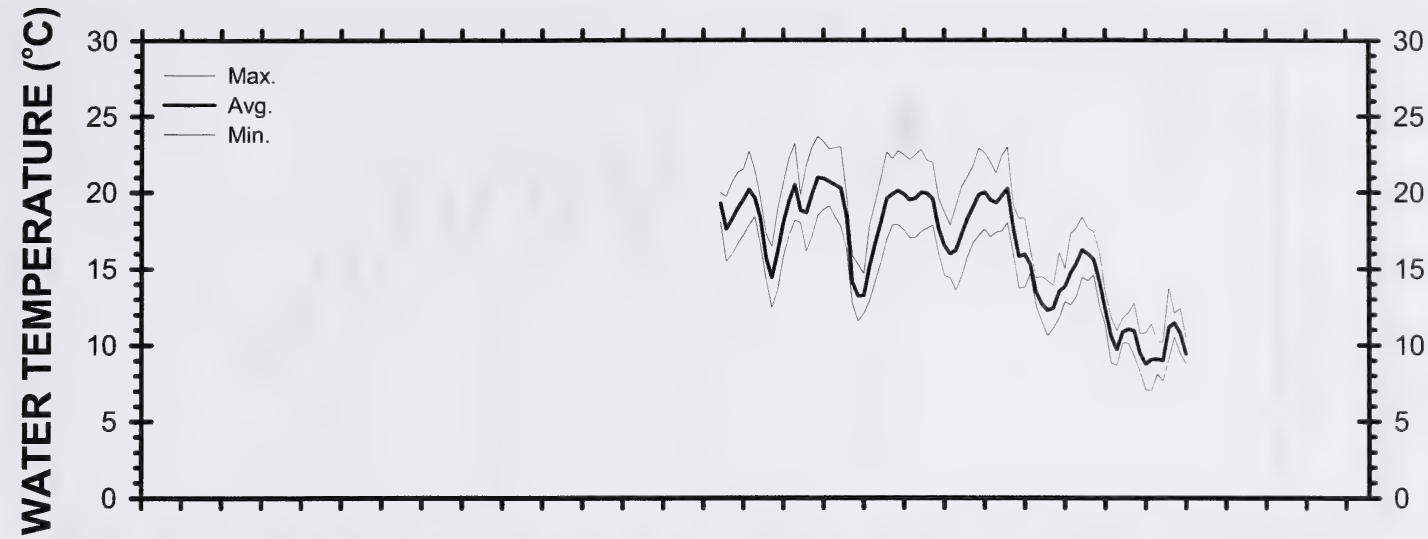

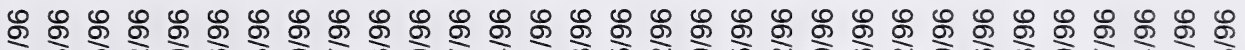

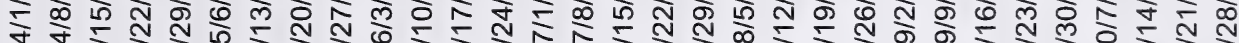

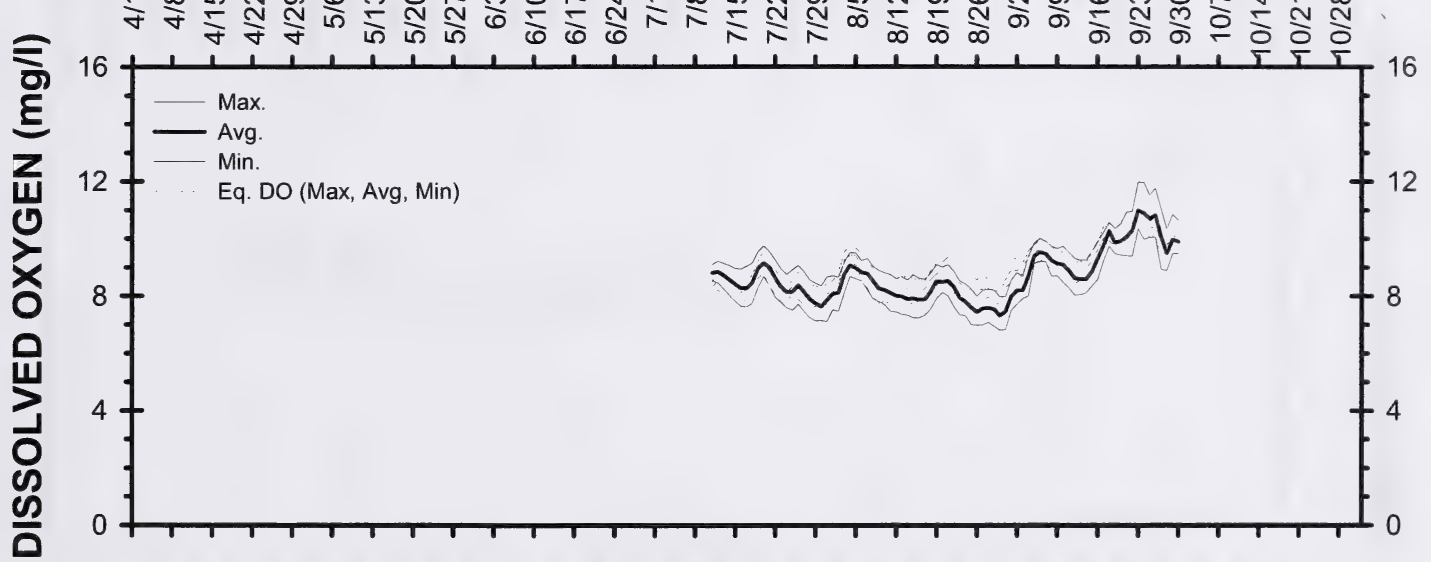

ம 劣

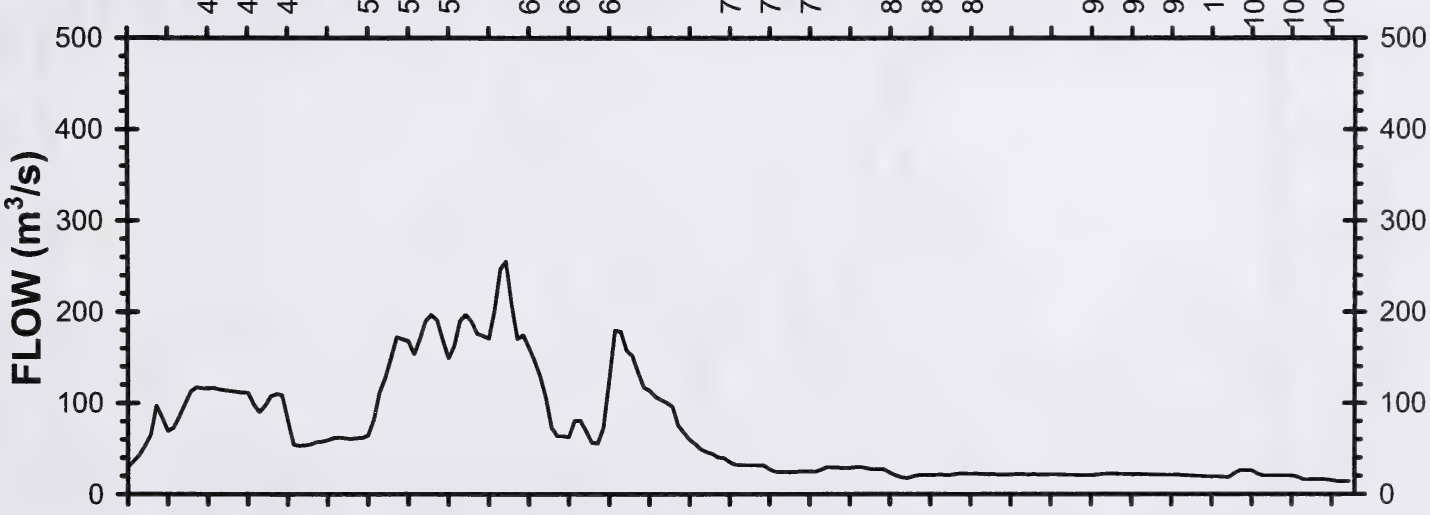

Ю

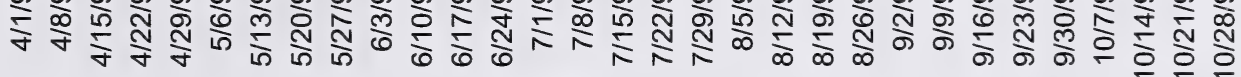

Figure 25. Daily water temperature (Datasonde), dissolved oxygen and flow in the Oldman River near Monarch. April-October 1996. 


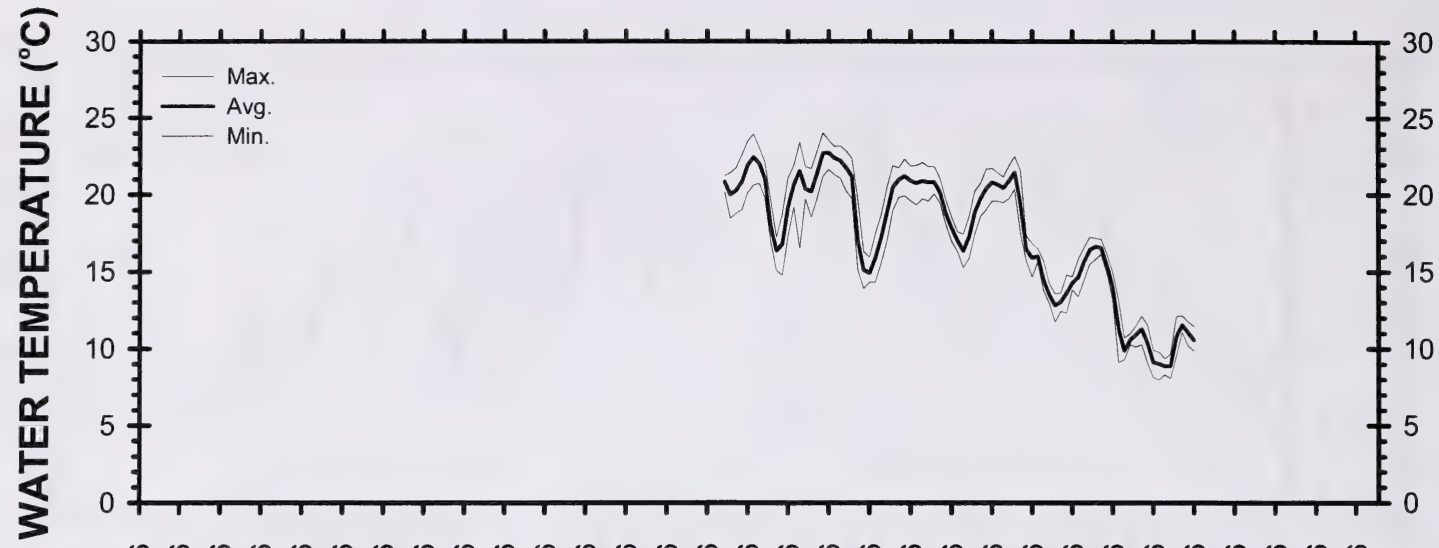

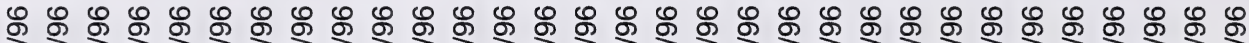

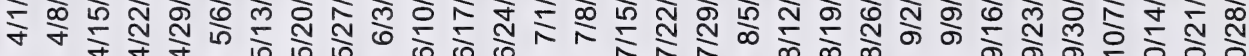

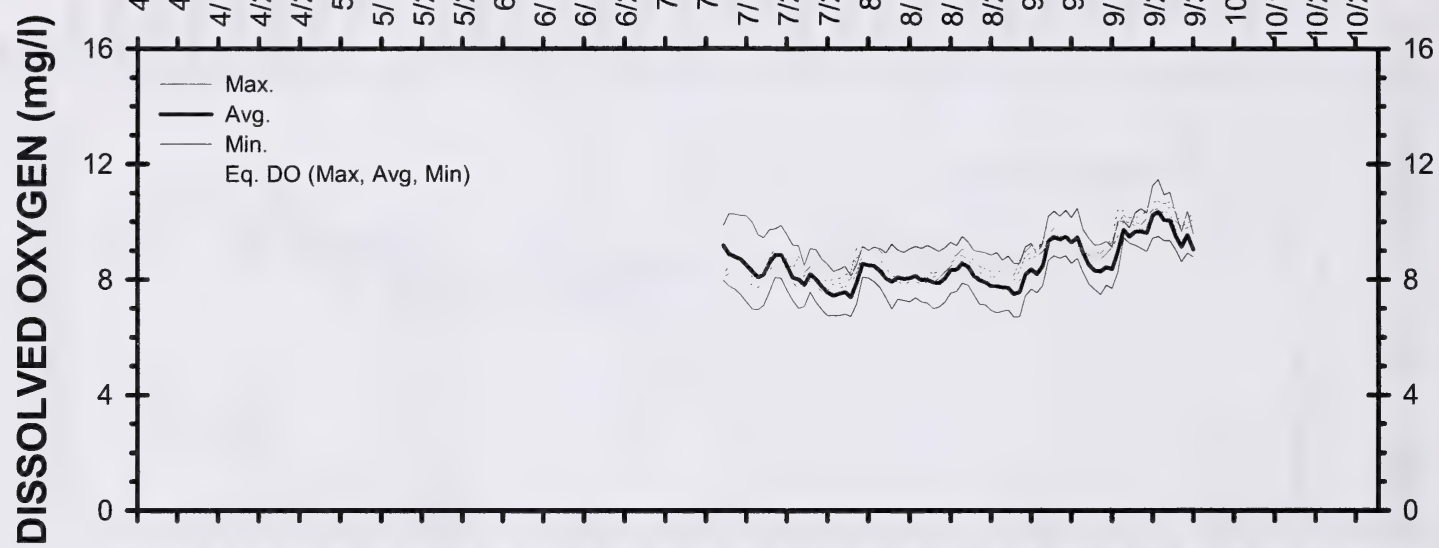

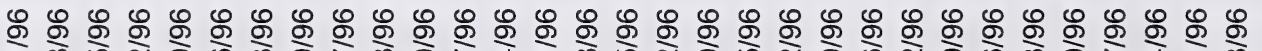

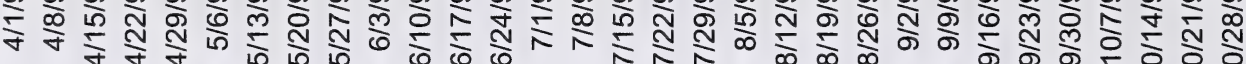

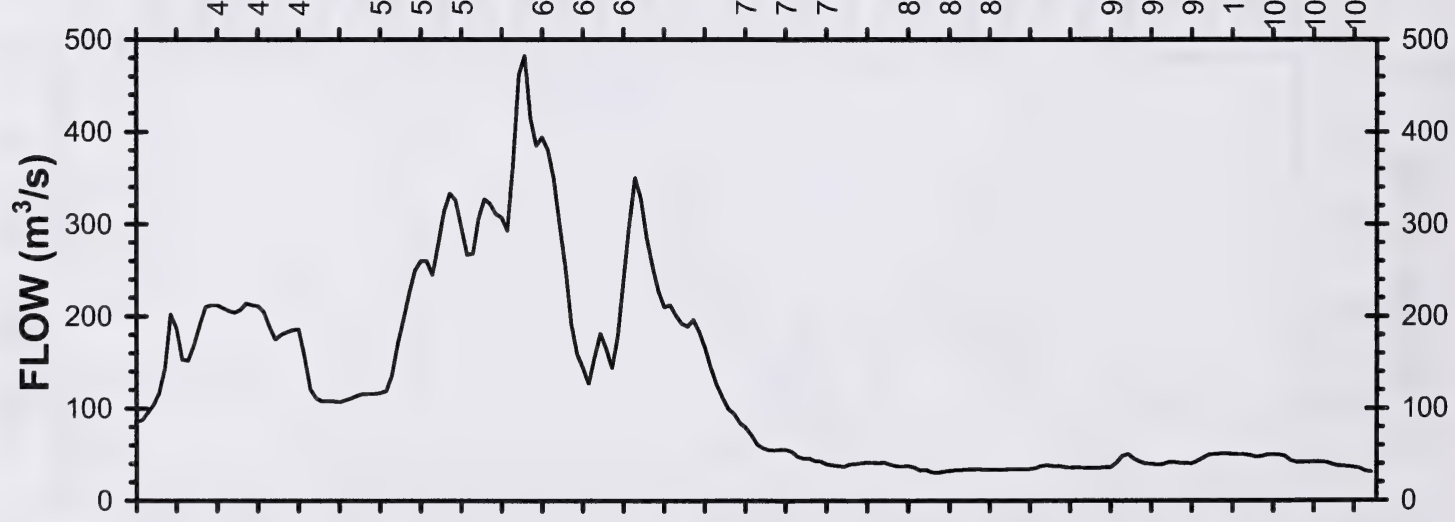

ஆ

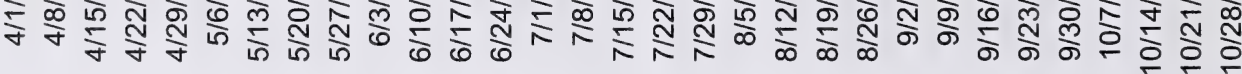

Figure 26. Daily water temperature (Datasonde), dissolved oxygen and flow in the Oldman River upstream of Lethbridge. April-October 1996. 


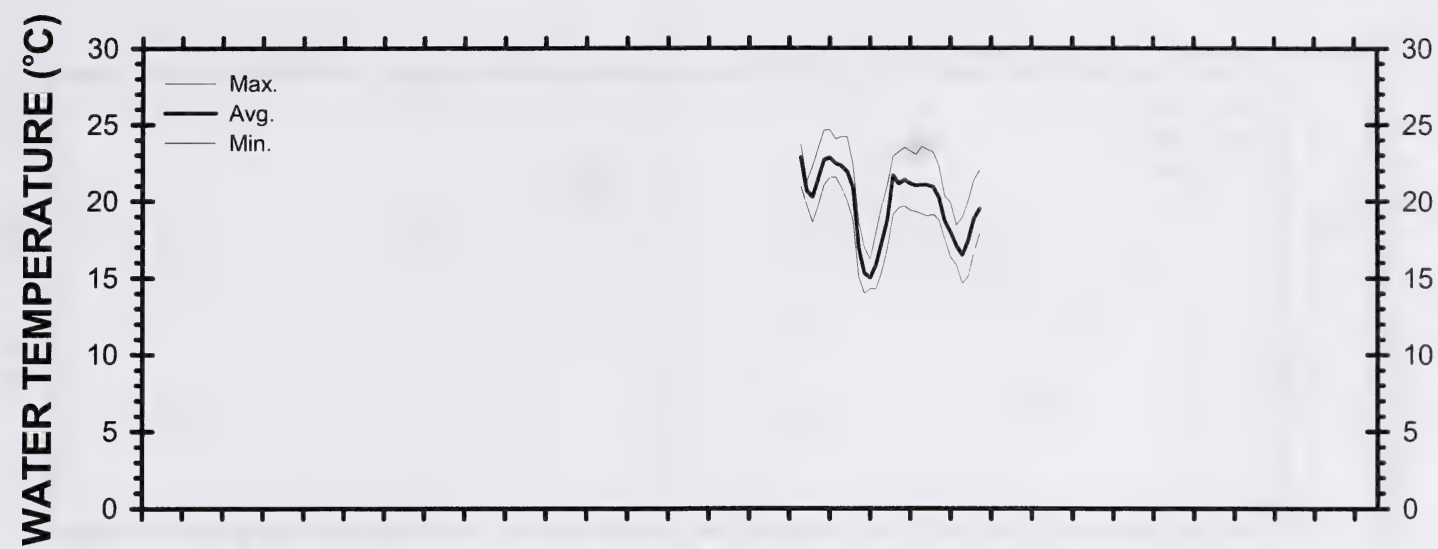

Ю

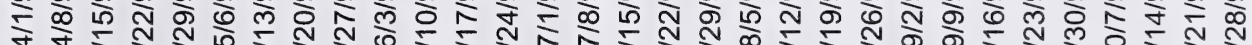

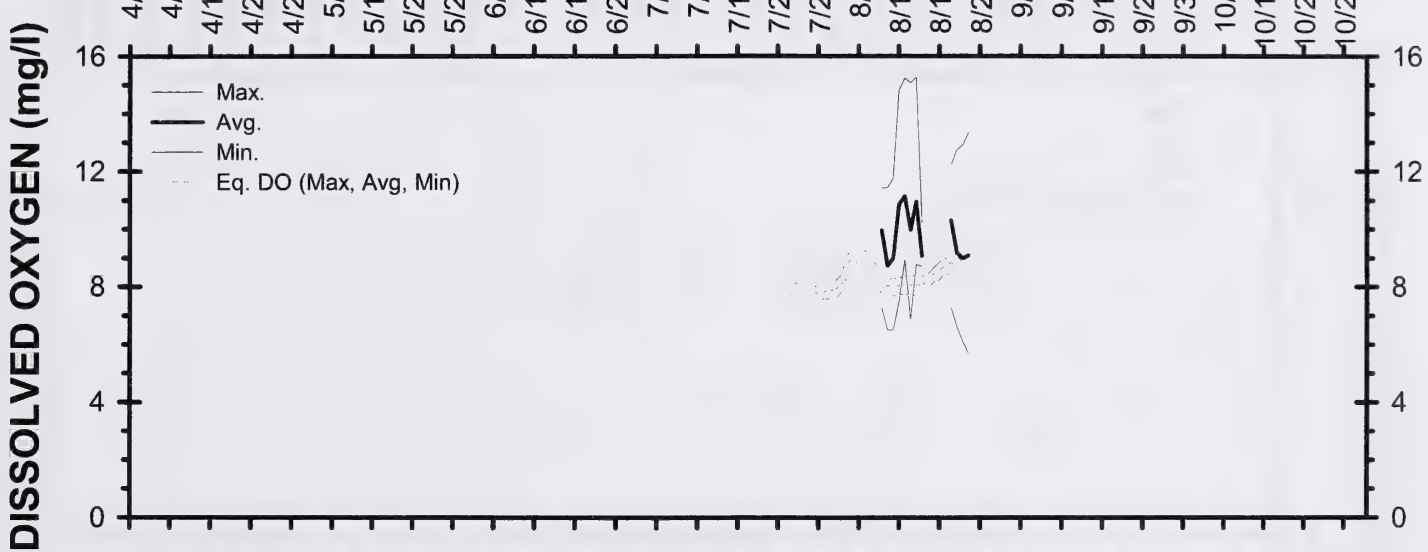

ஸ

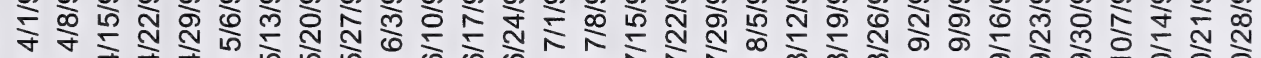

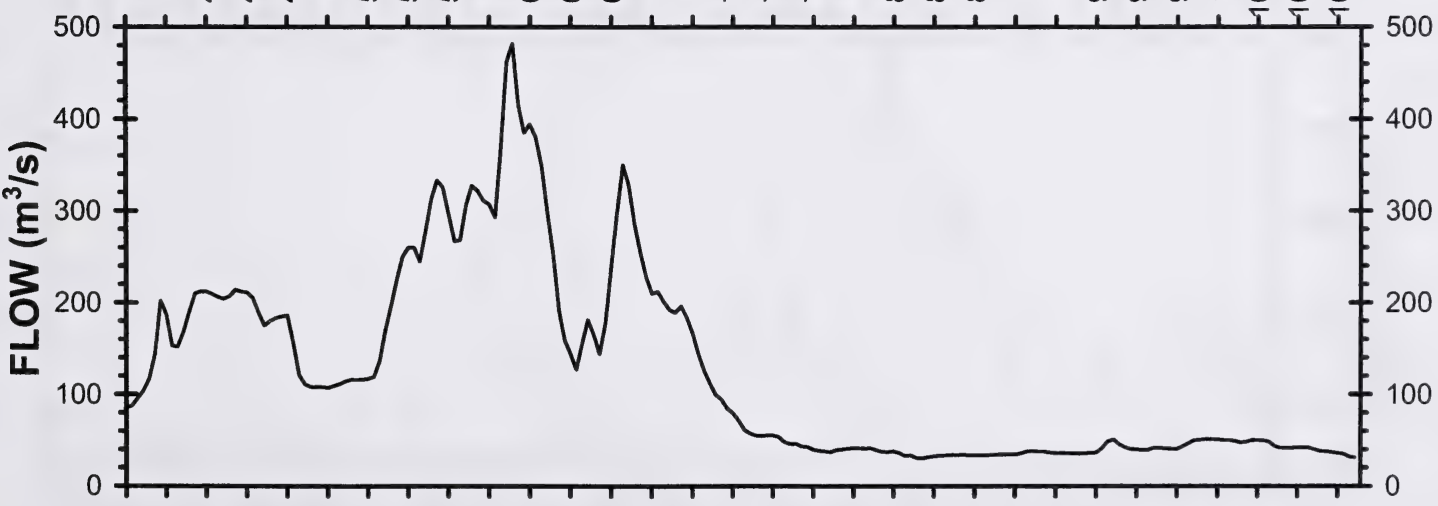

ஜ

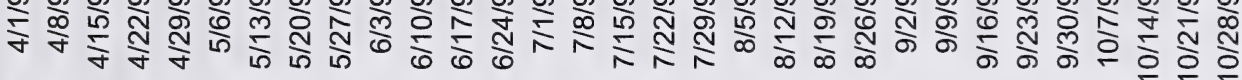

Figure 27. Daily water temperature (Datasonde), dissolved oxygen and flow in the Oldman River downstream of Lethbridge. April-October 1996. 

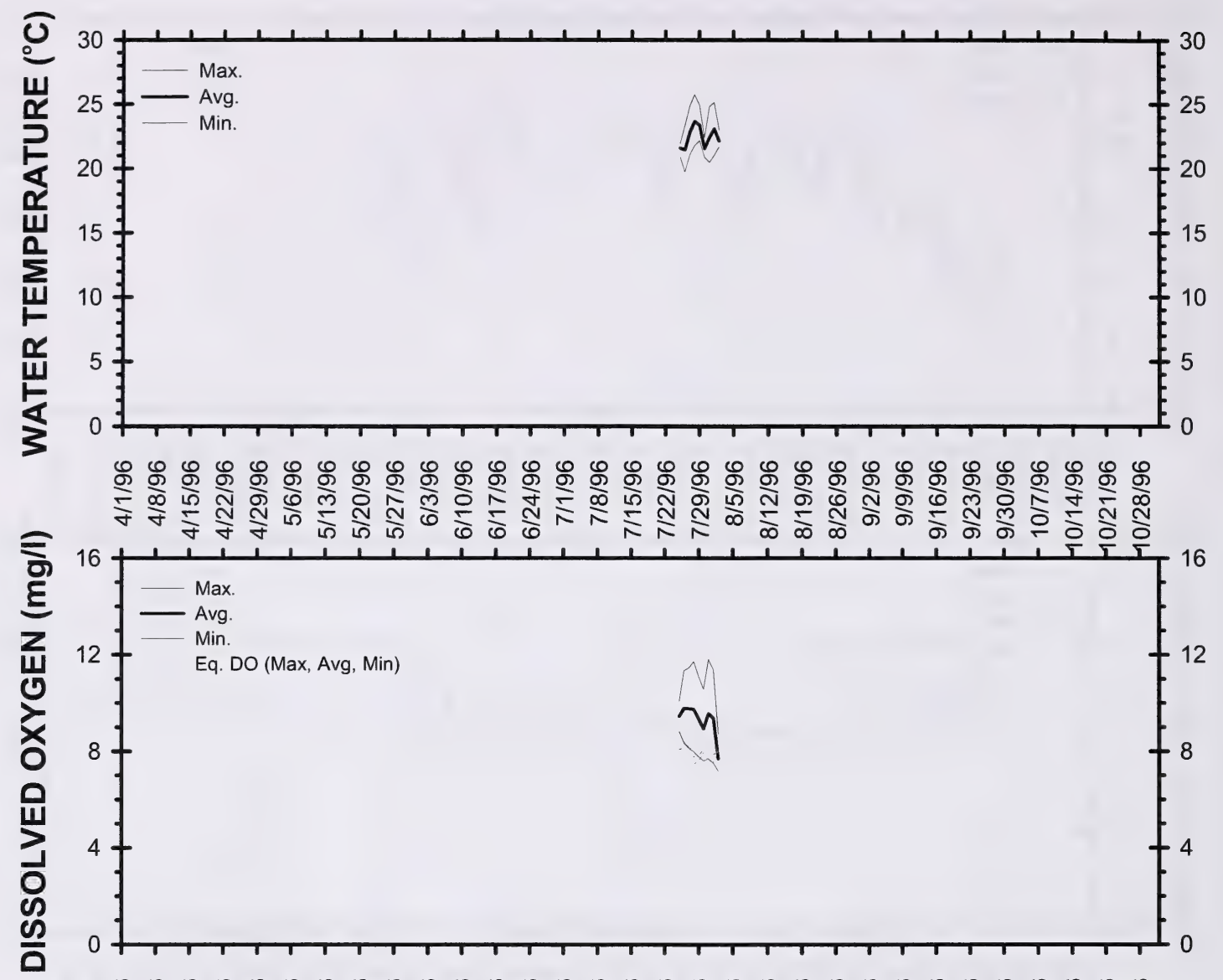

ஜ

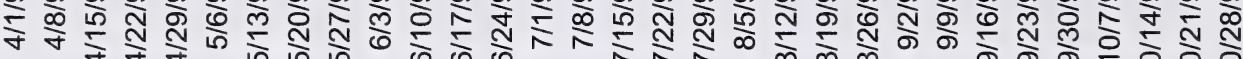

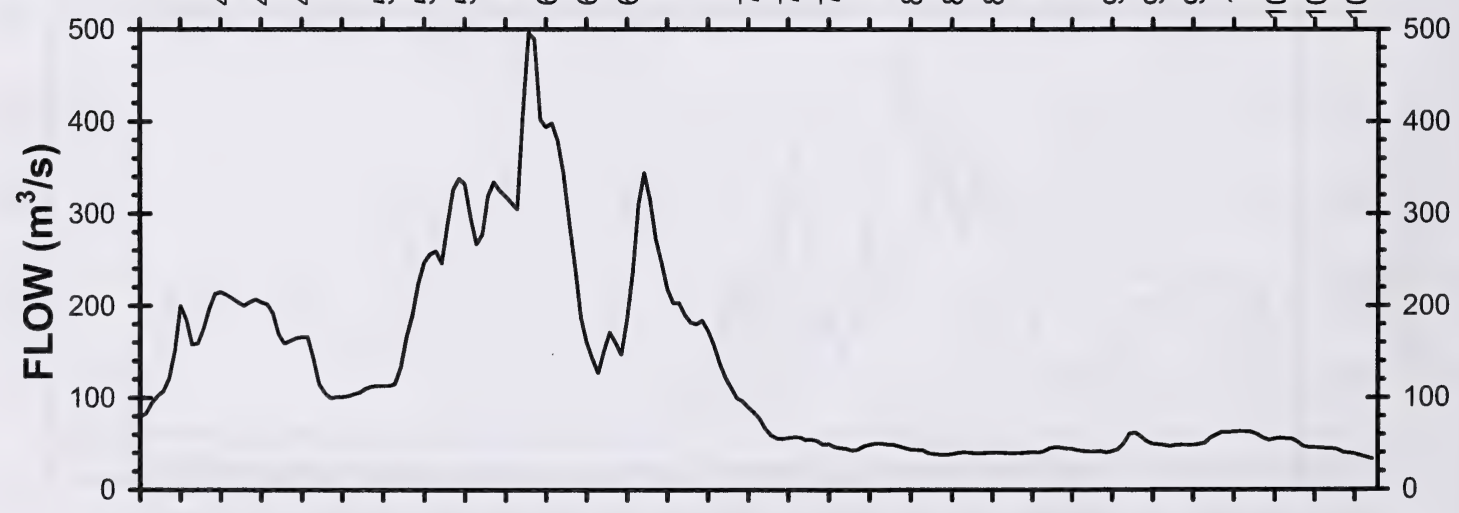

ஆ

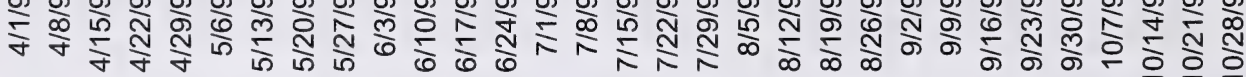

Figure 28. Daily water temperature (Datasonde), dissolved oxygen and flow in the Oldman River at the Bow River confluence. April-October 1996. 

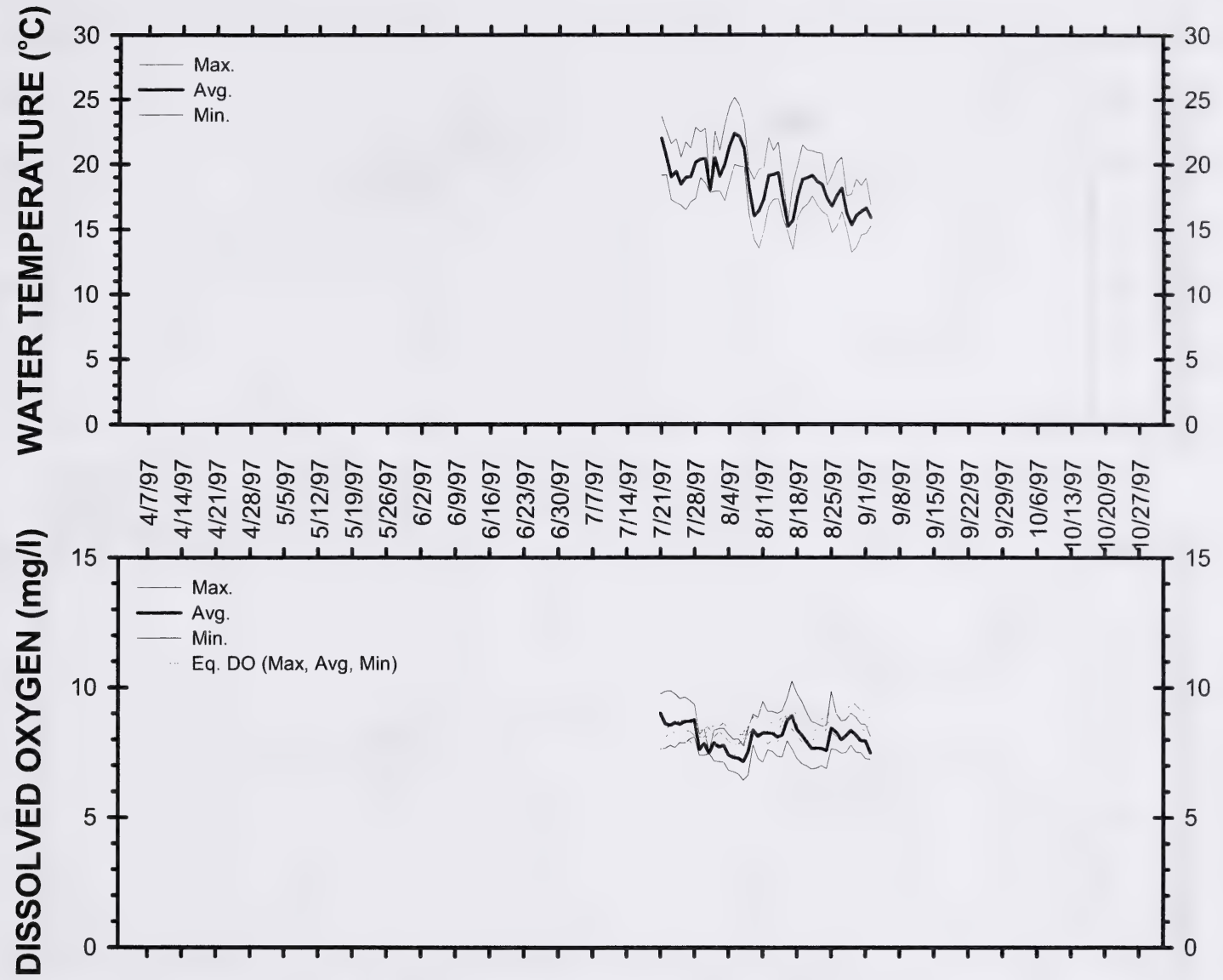

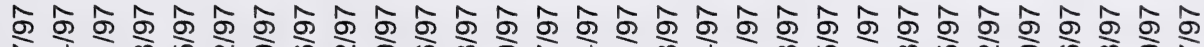

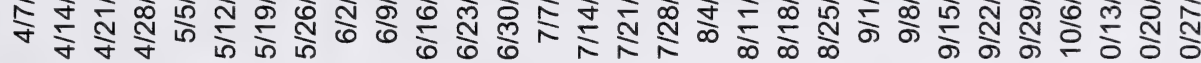

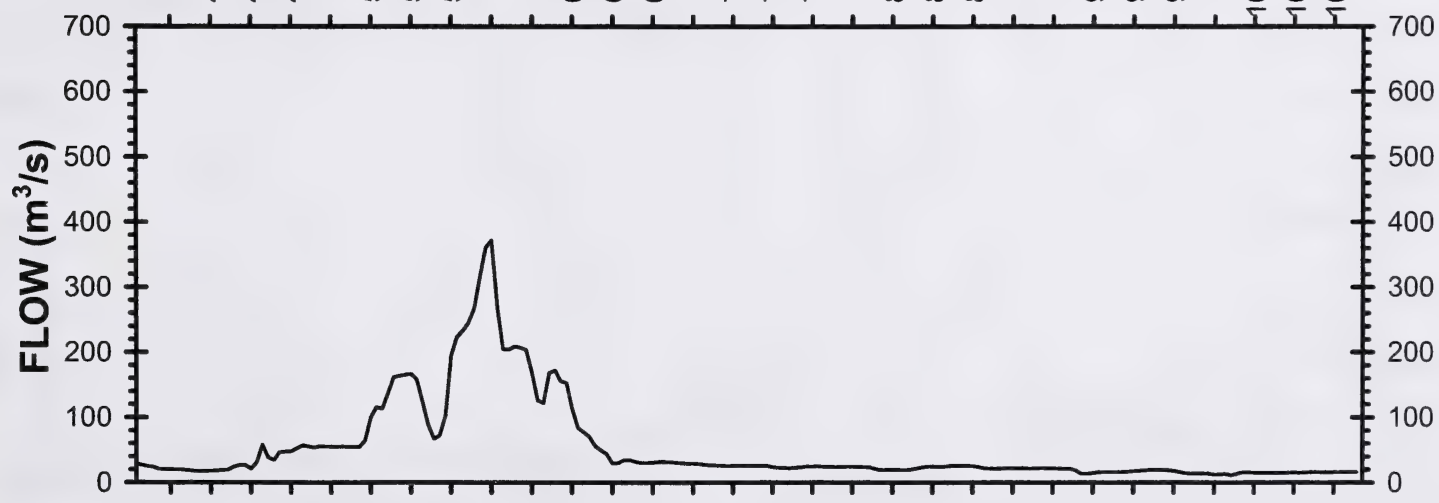

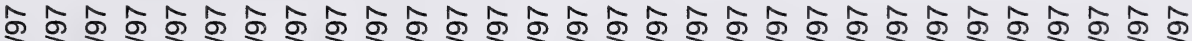

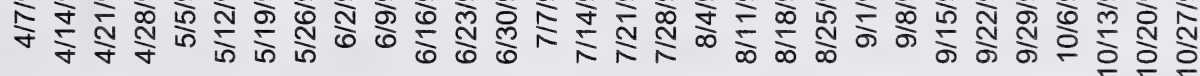

Figure 29. Daily water temperature (Datasonde), dissolved oxygen and flow in the Oldman River near Monarch. April-October 1997. 


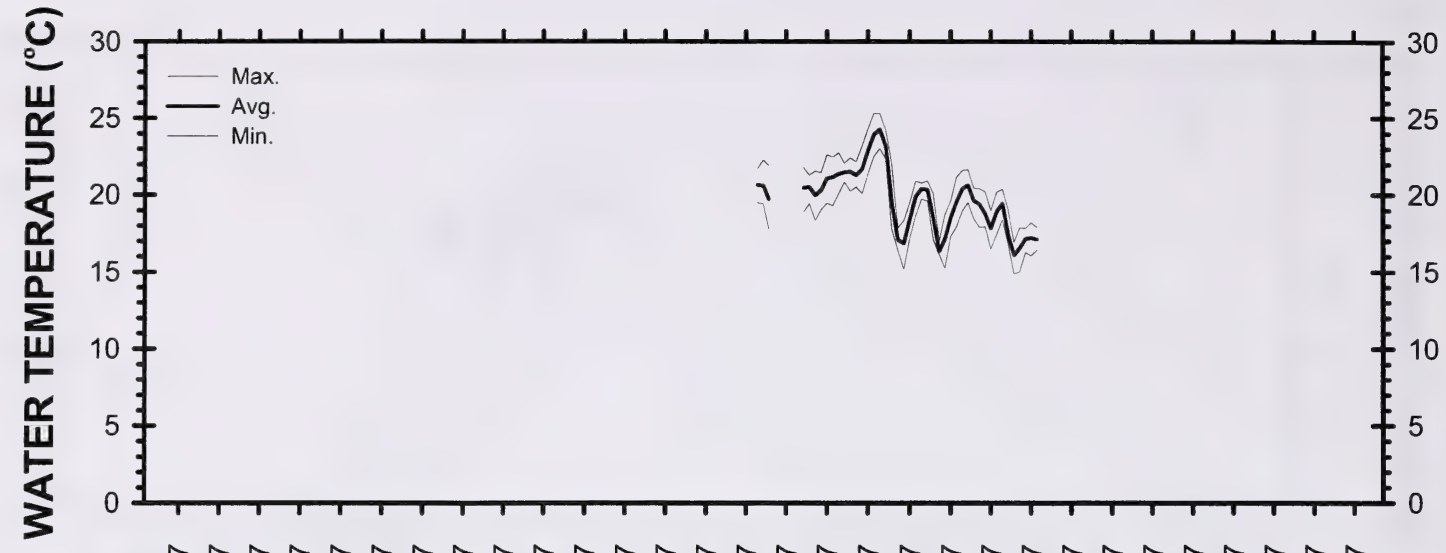

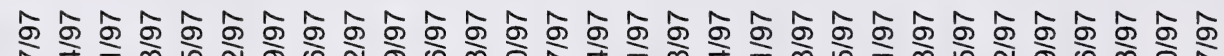

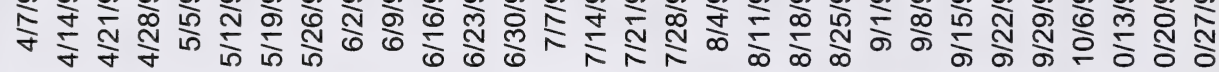

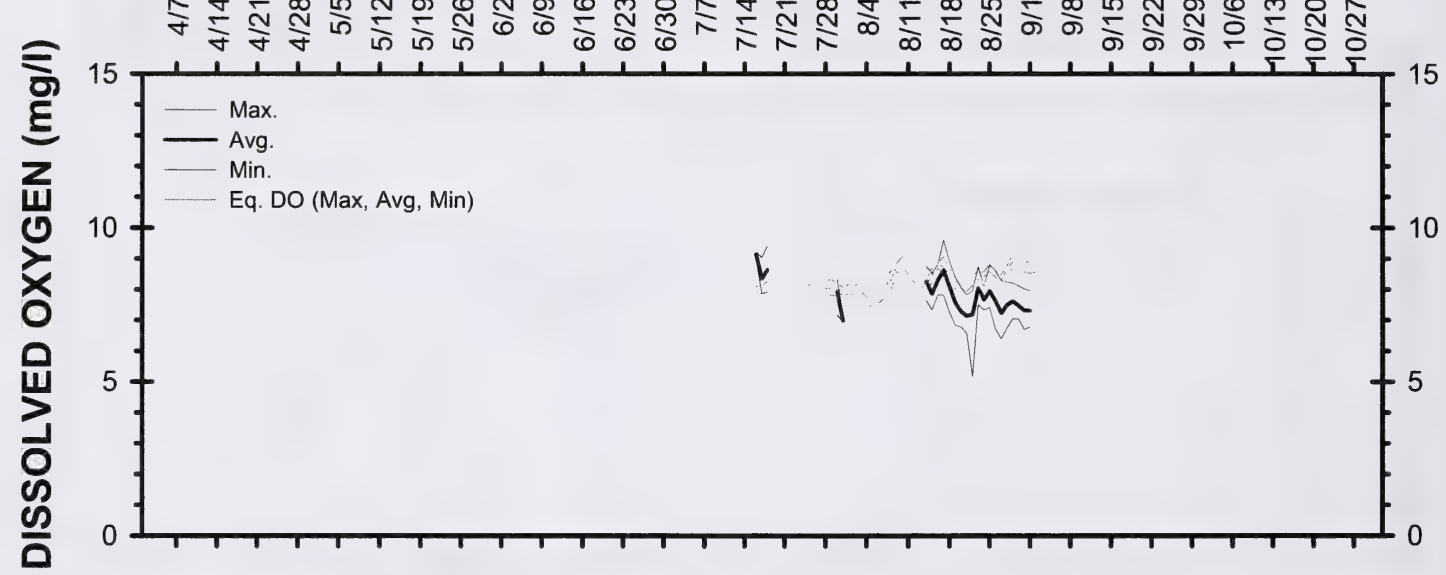

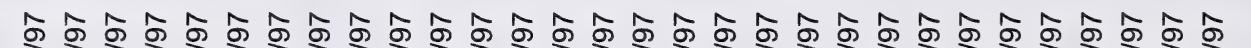

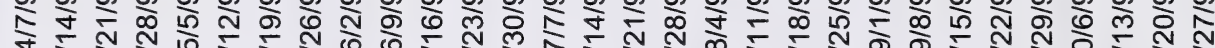

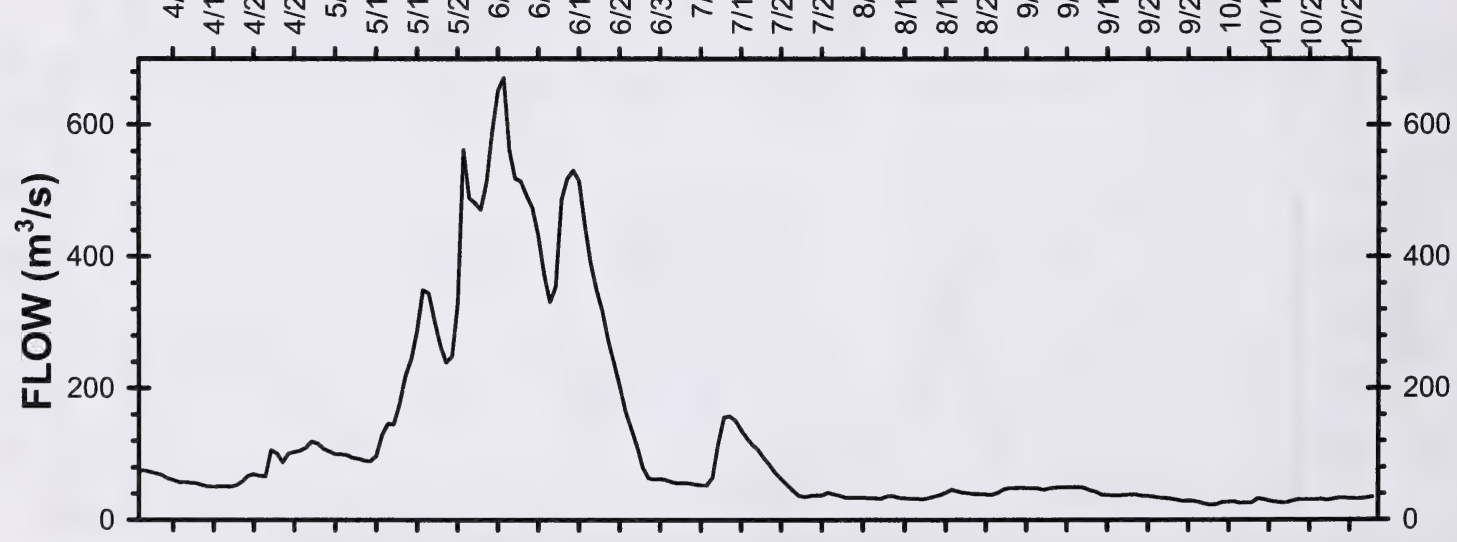

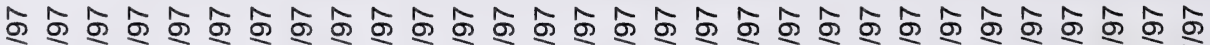

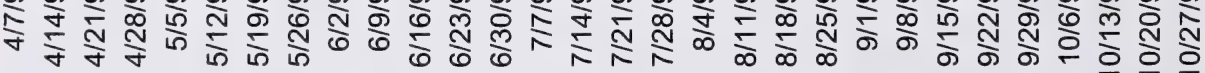

Figure 30. Daily water temperature (Datasonde), dissolved oxygen and flow in the Oldman River upstream of Lethbridge. April-October 1997. 


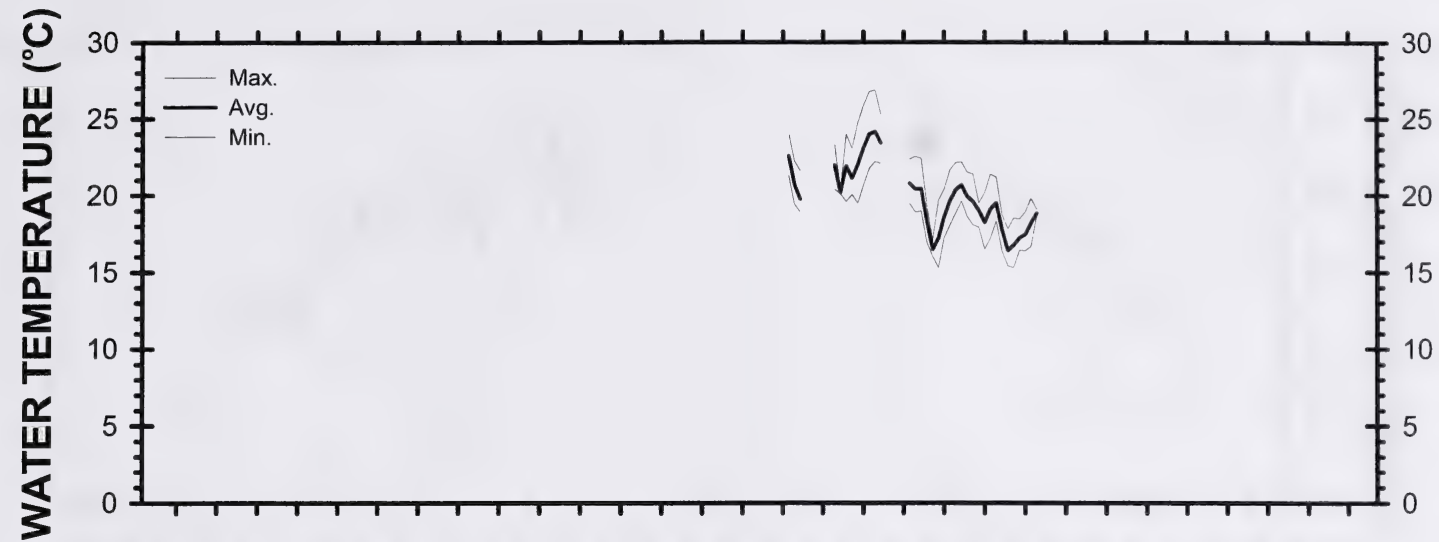

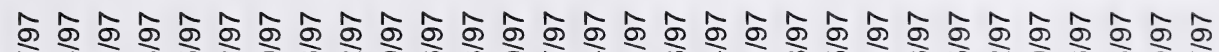

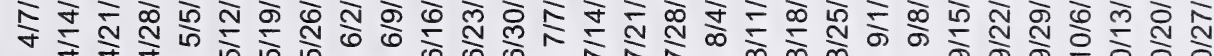

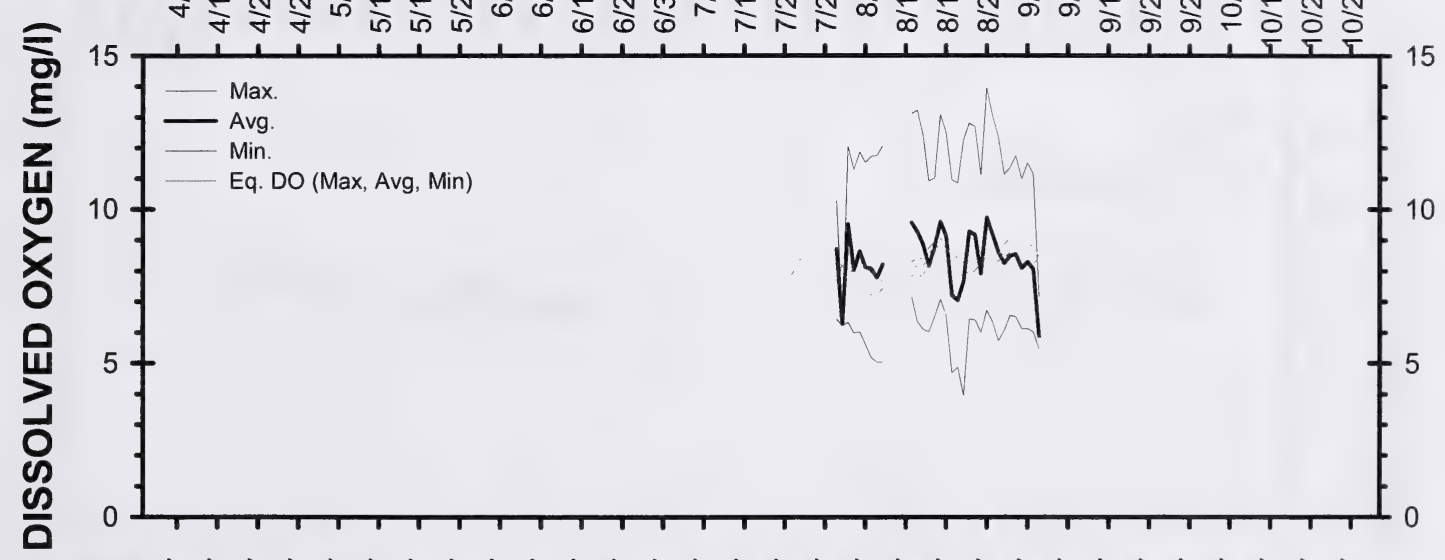

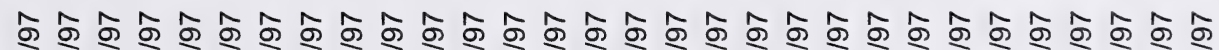

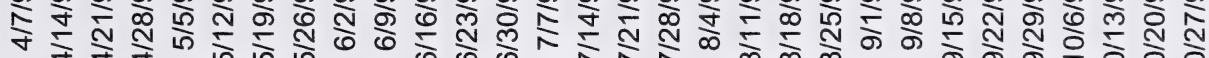

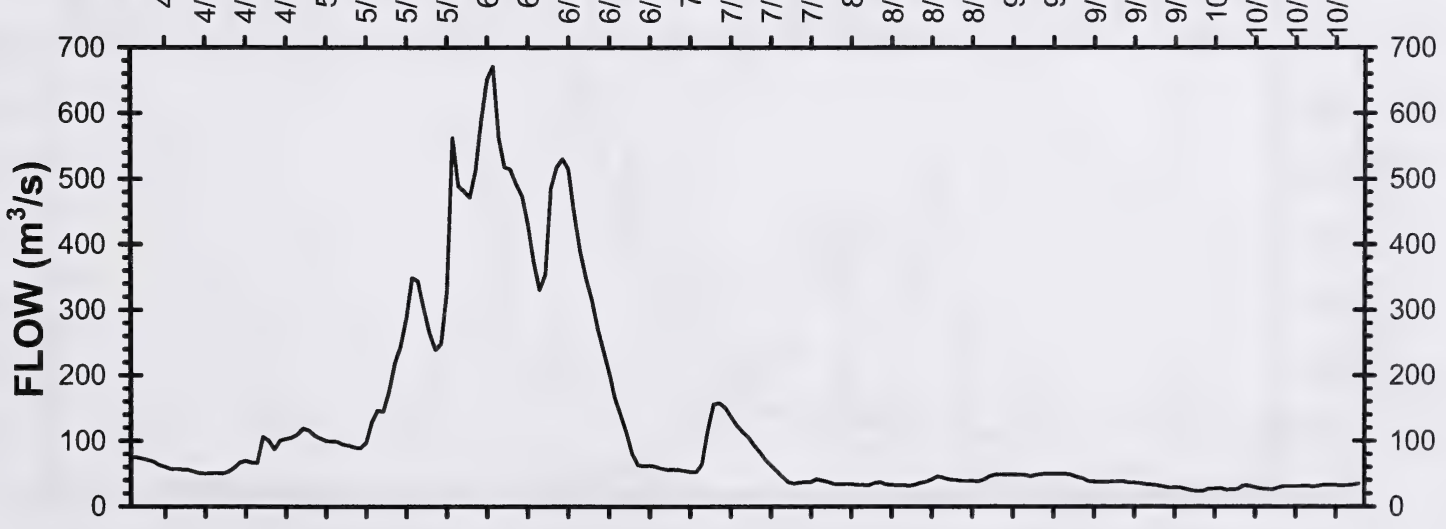

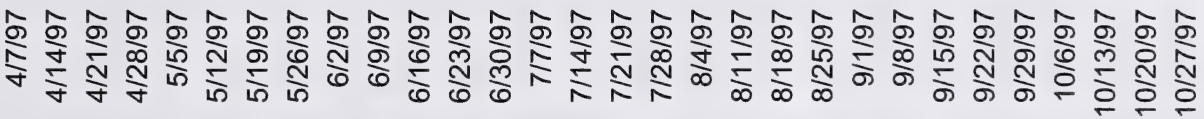

Figure 31. Daily water temperature (Datasonde), dissolved oxygen and flow in the Oldman River downstream of Lethbridge. April-October 1997. 

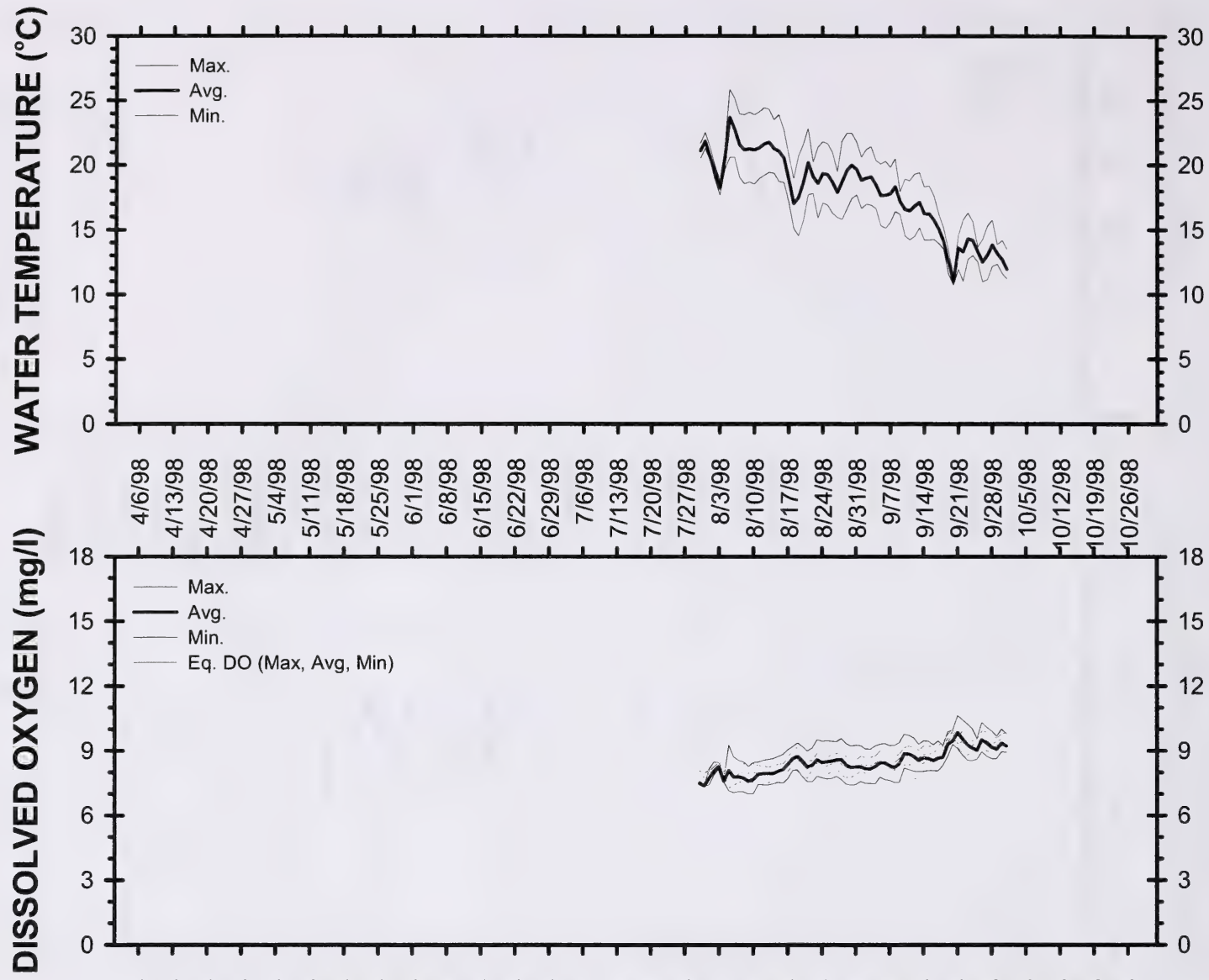

\% \% 乌 m

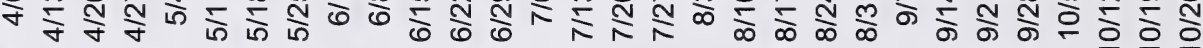

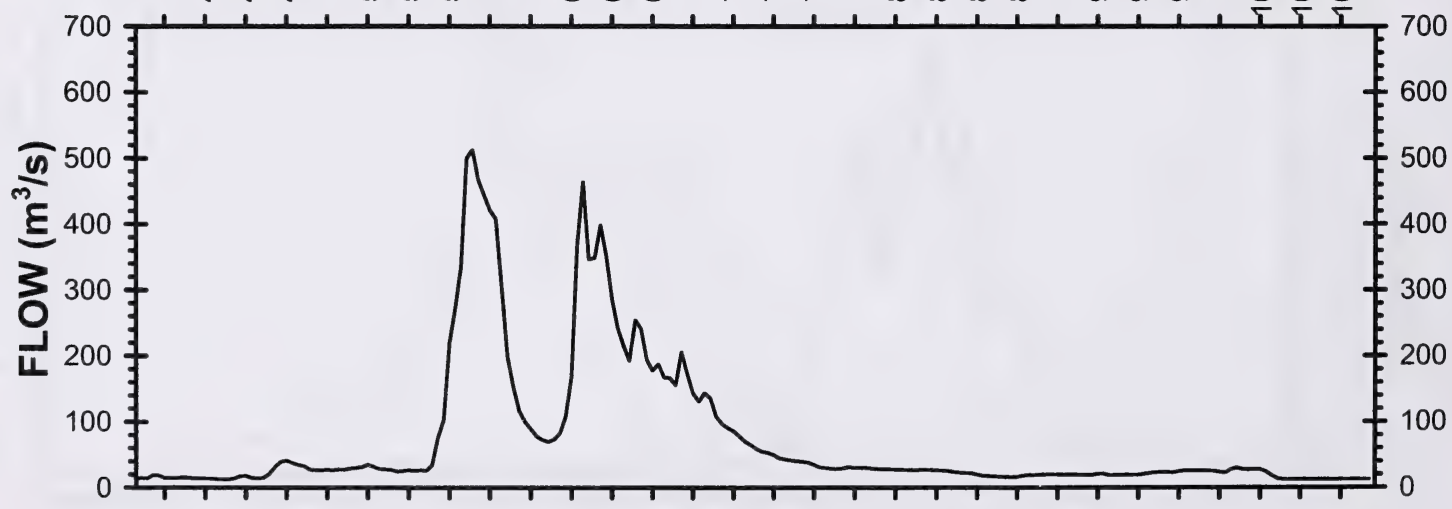

ஜ

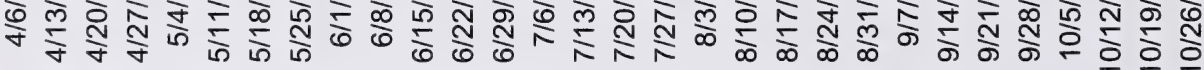

Figure 32. Daily water temperature (Datasonde), dissolved oxygen and flow in the Oldman River near Monarch. April-October 1998. 


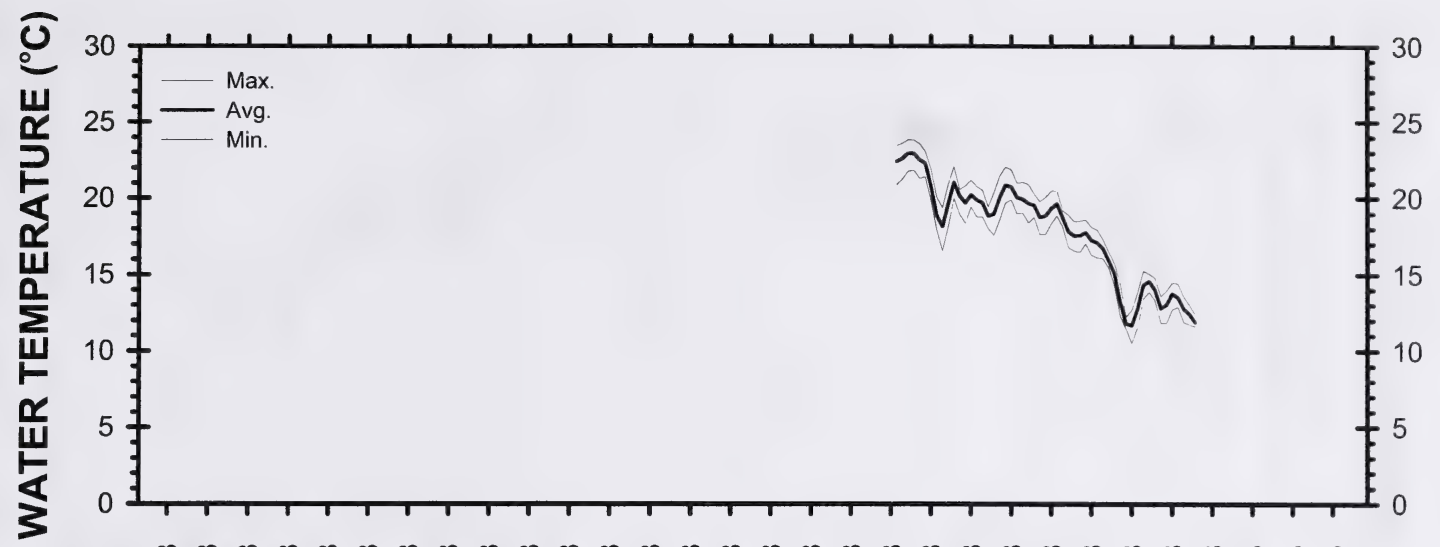

\% \% \%

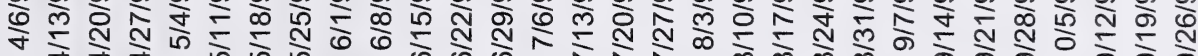

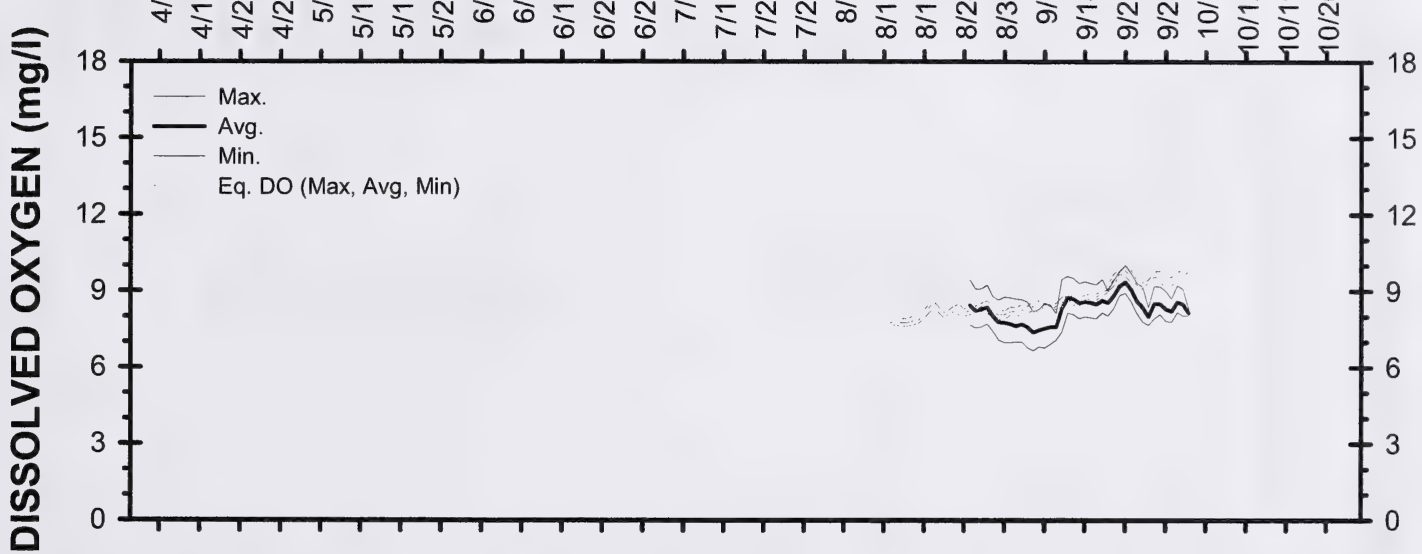

\% ⿹

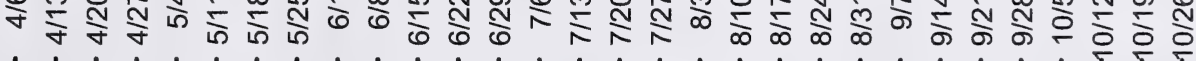

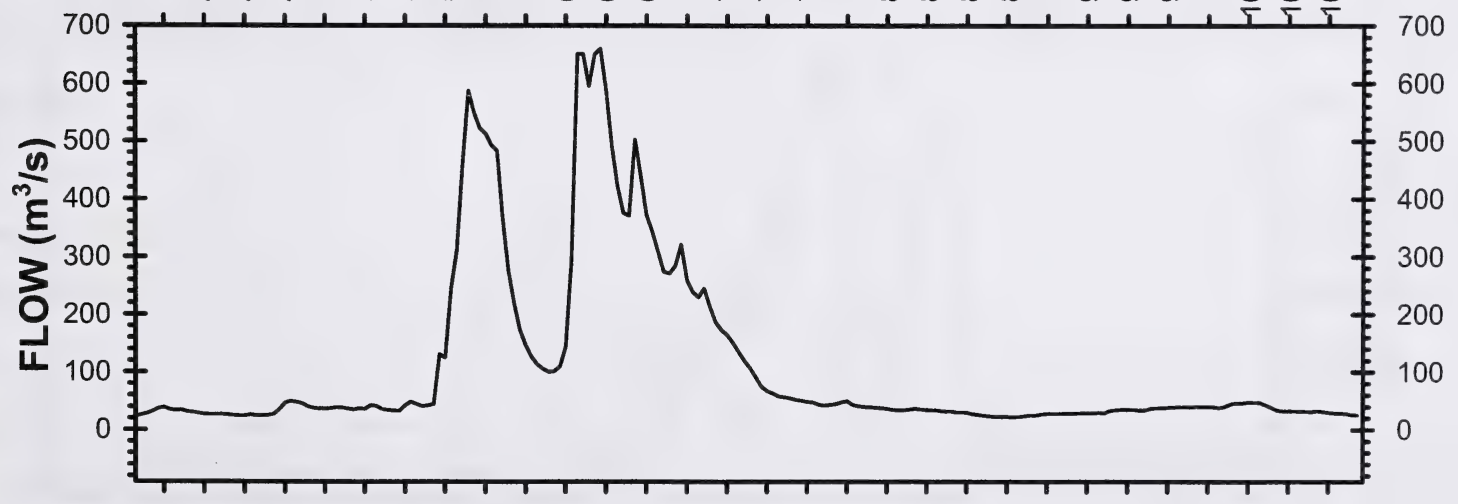

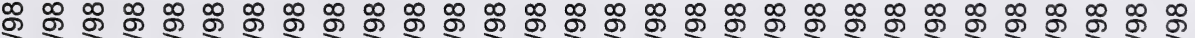

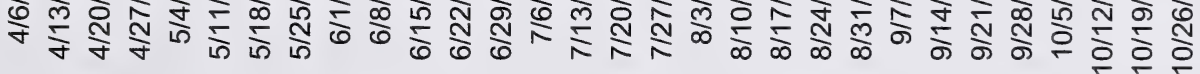

Figure 33. Daily water temperature (Datasonde), dissolved oxygen and flow in the Oldman River upstream of Lethbridge. April-October 1998. 


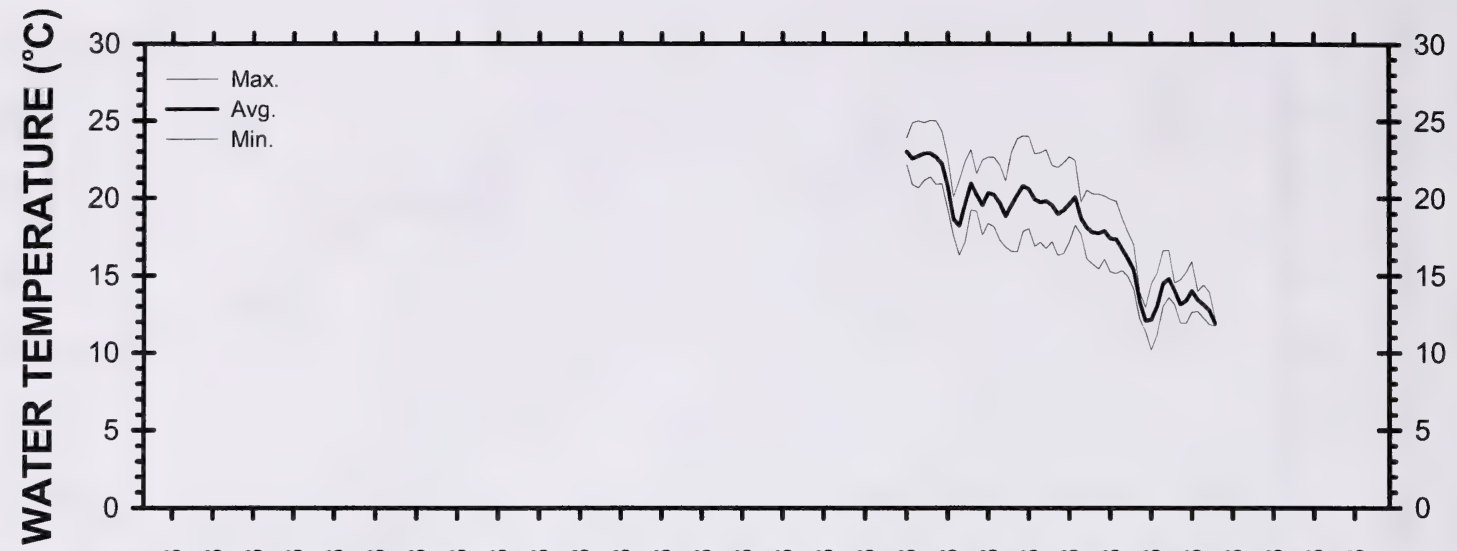

œ ט.

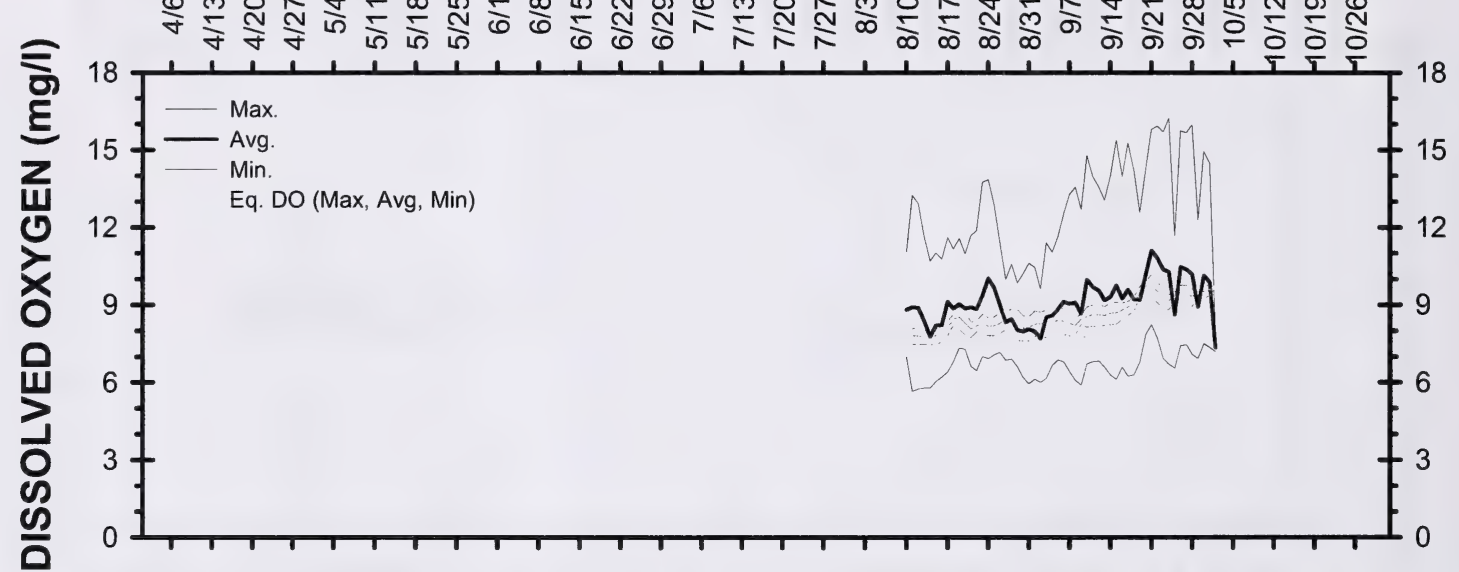

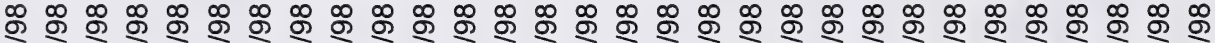

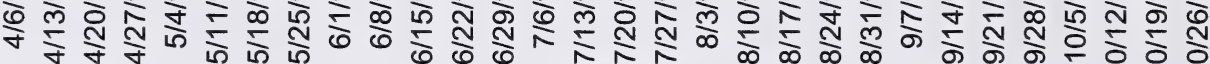

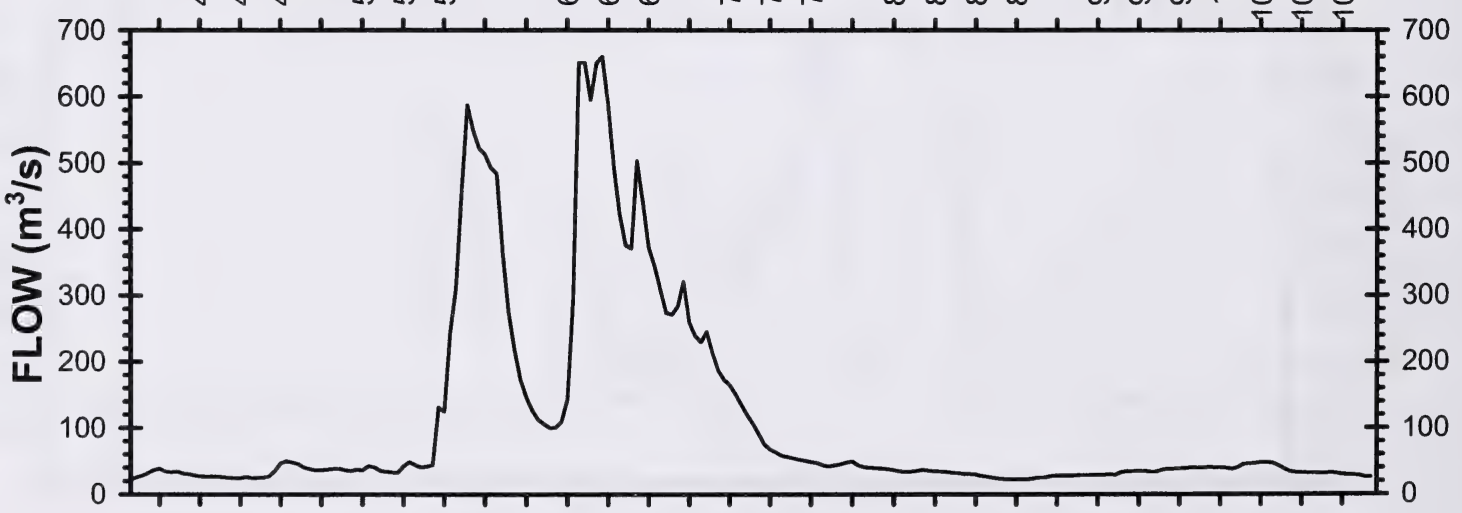

\% \%

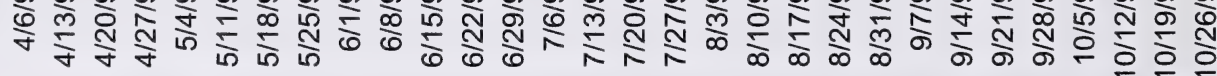

Figure 34. Daily water temperature (Datasonde), dissolved oxygen and flow in the Oldman River downstream of Lethbridge. April-October 1998. 


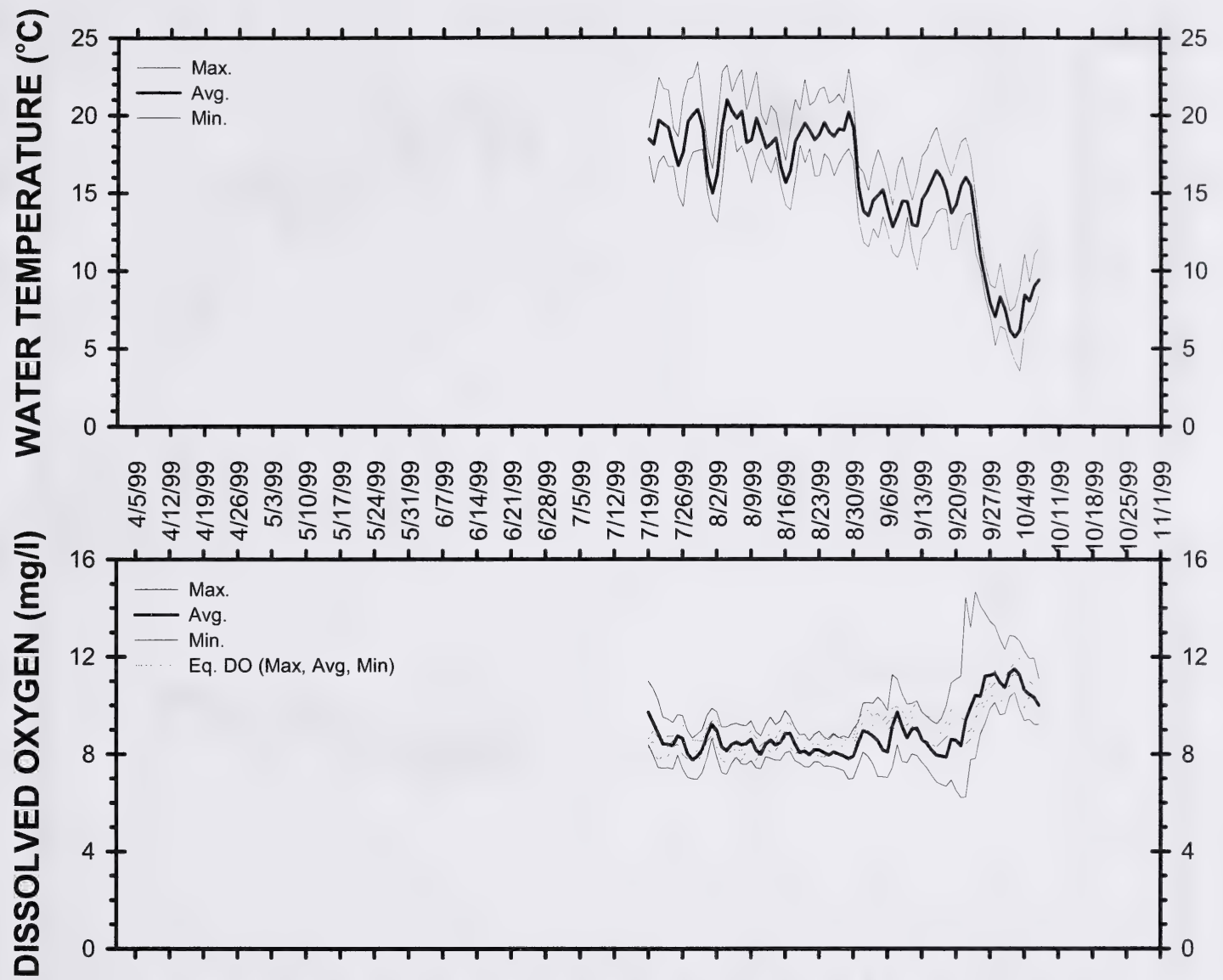

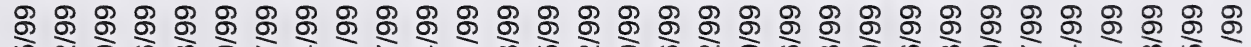

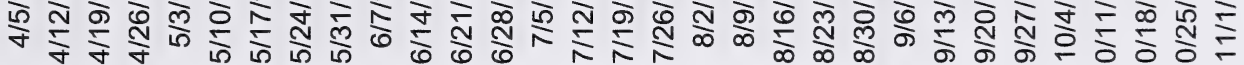

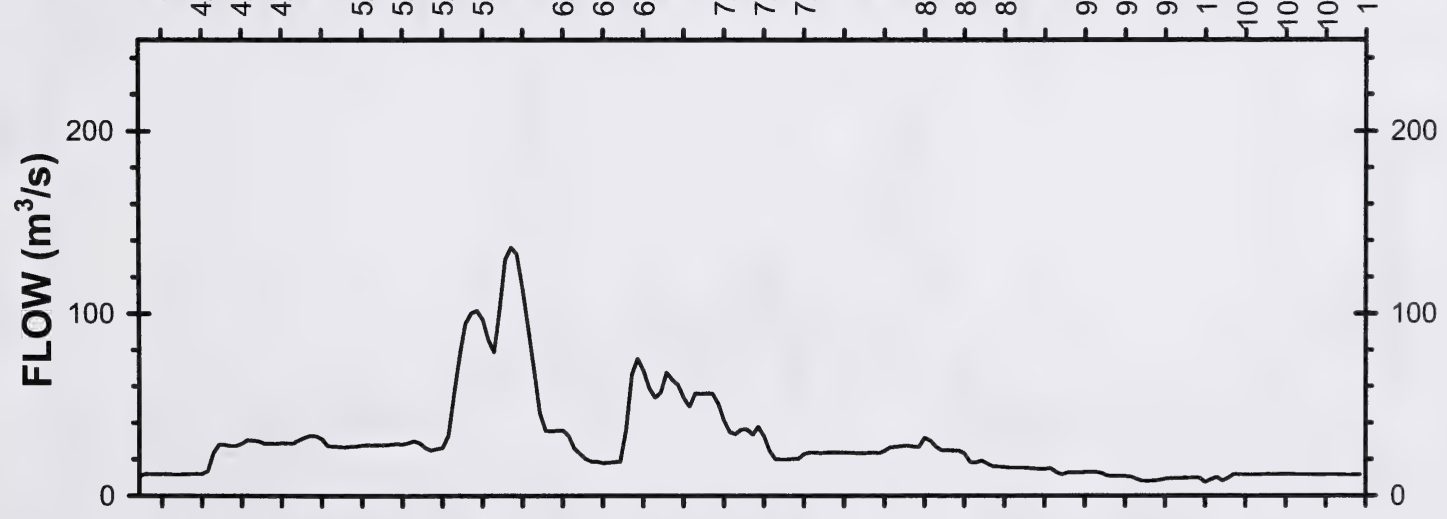

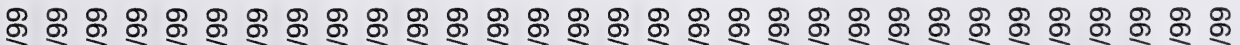

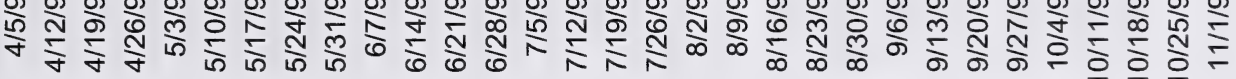

Figure 35. Daily water temperature (Datasonde), dissolved oxygen and flow in the Oldman River near Monarch. April-October 1999. 


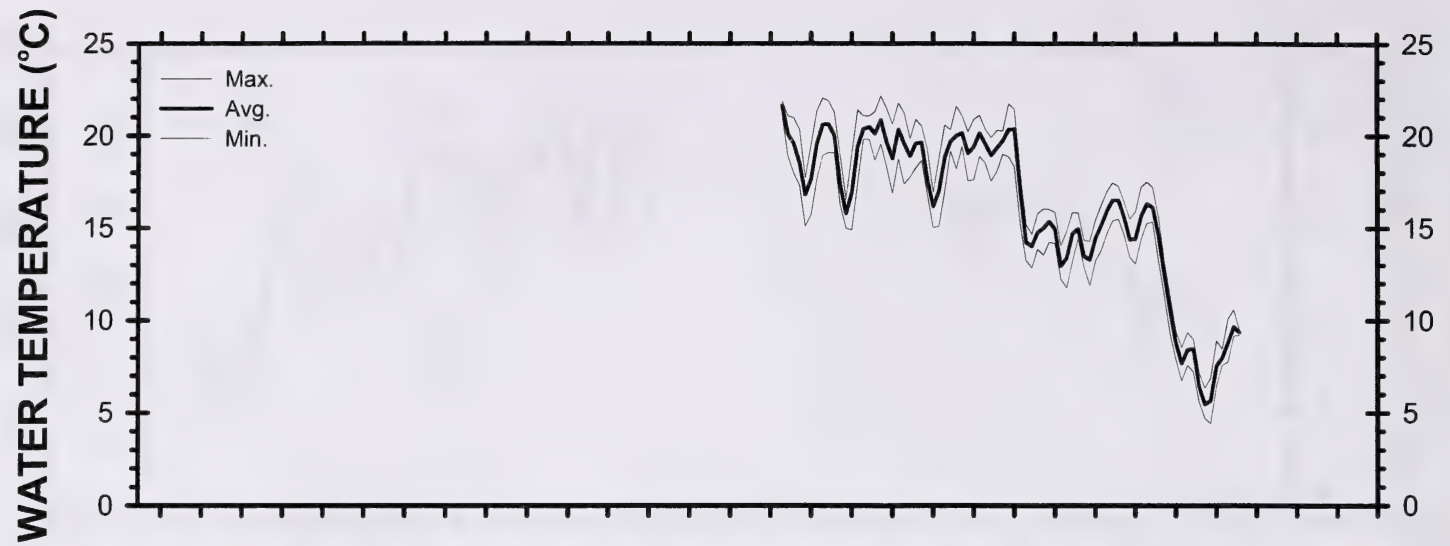

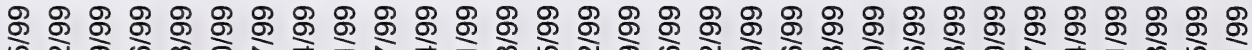

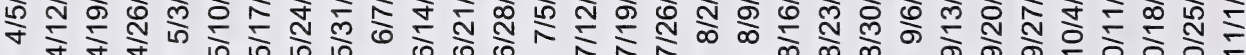

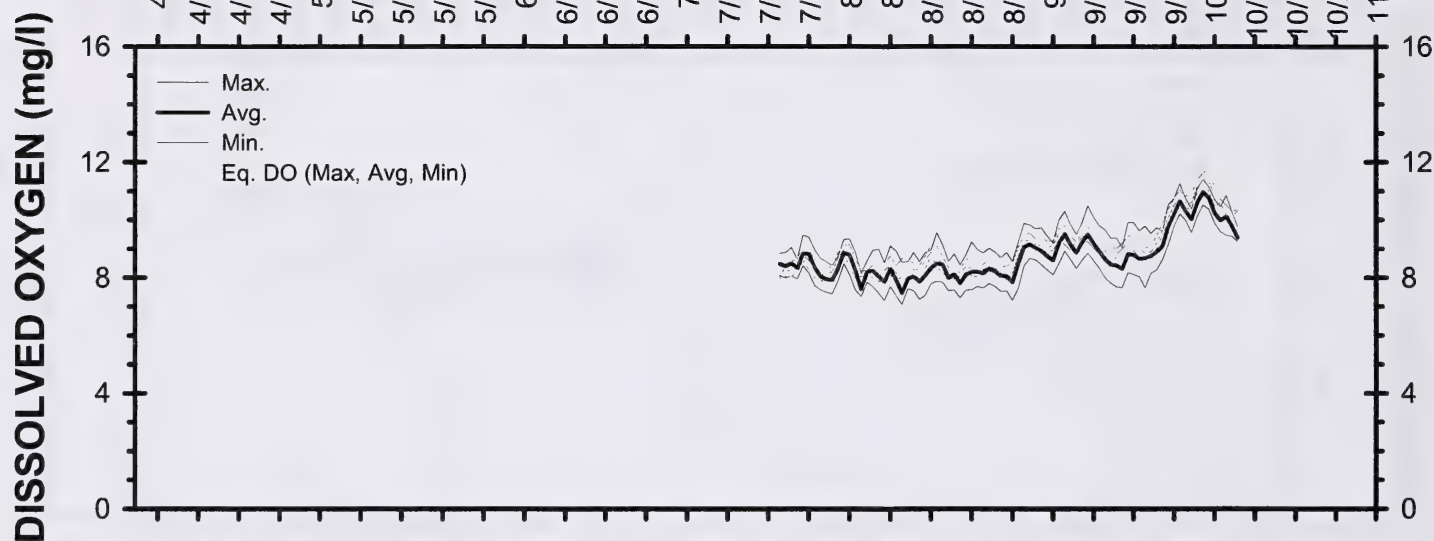

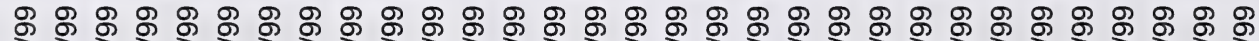

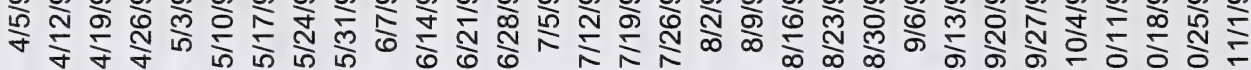

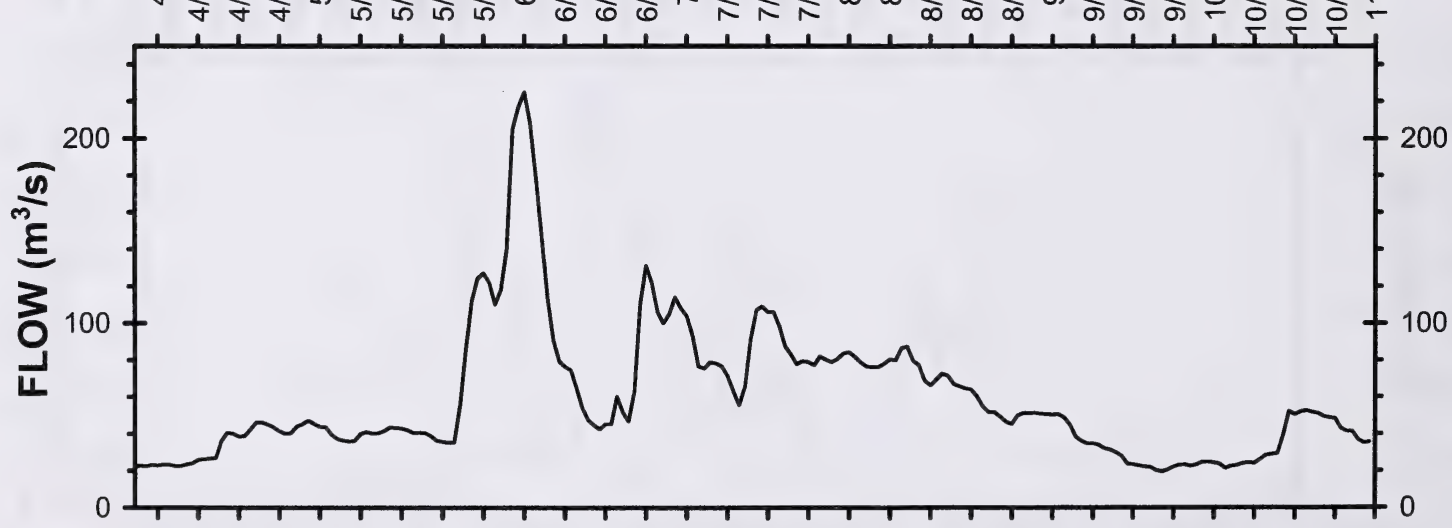

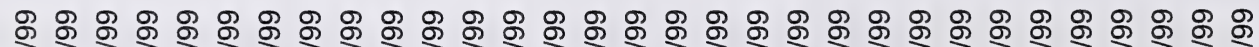

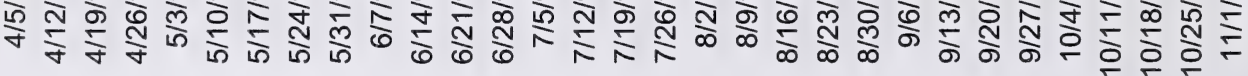

Figure 36. Daily water temperature (Datasonde), dissolved oxygen and flow in the Oldman River upstream of Lethbridge. April-October 1999. 


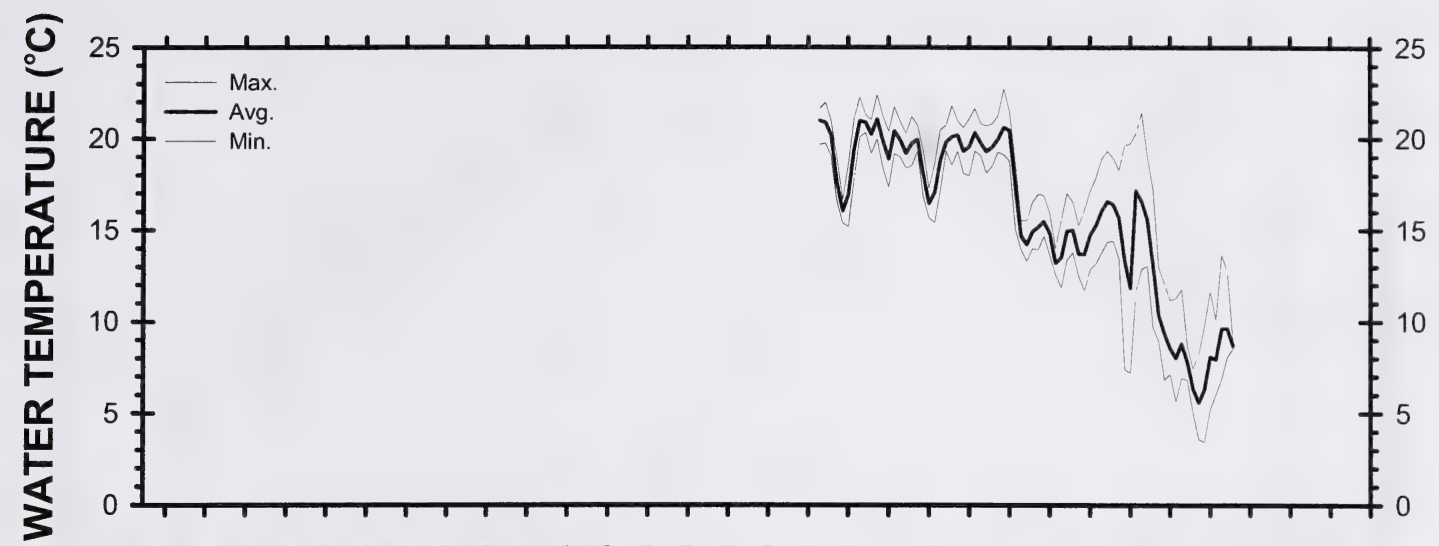

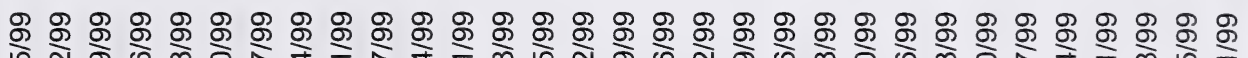

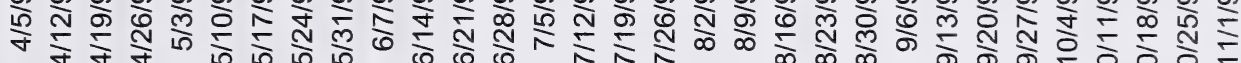

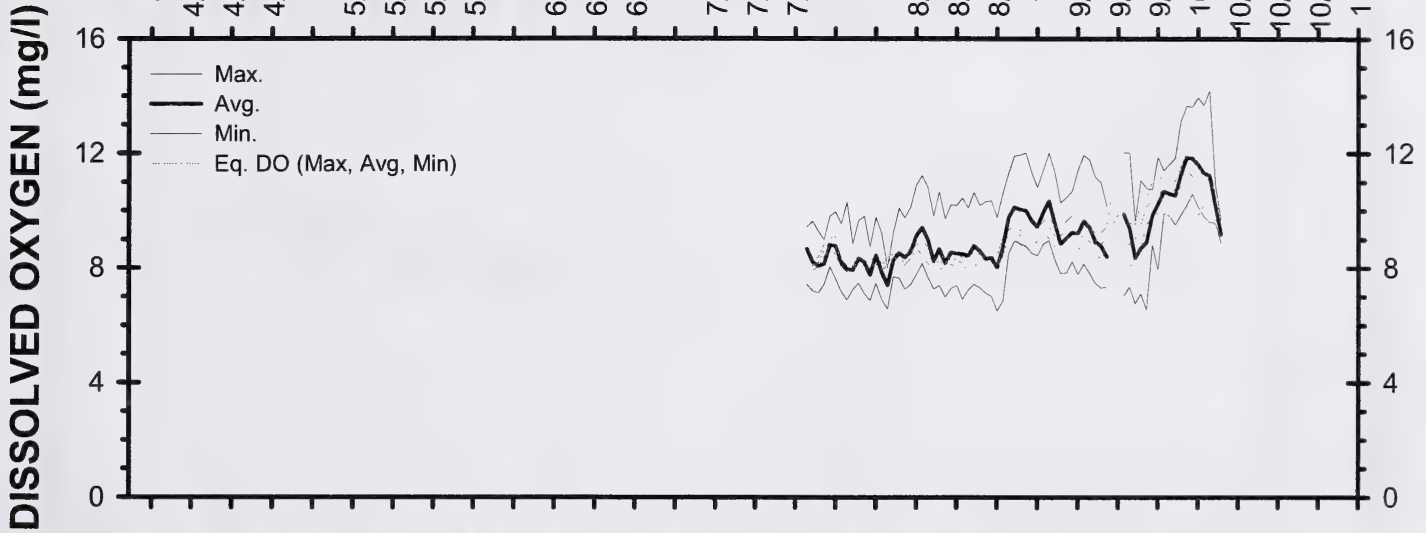

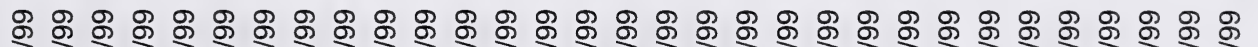

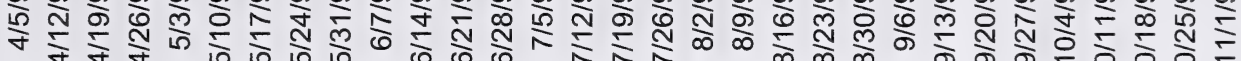

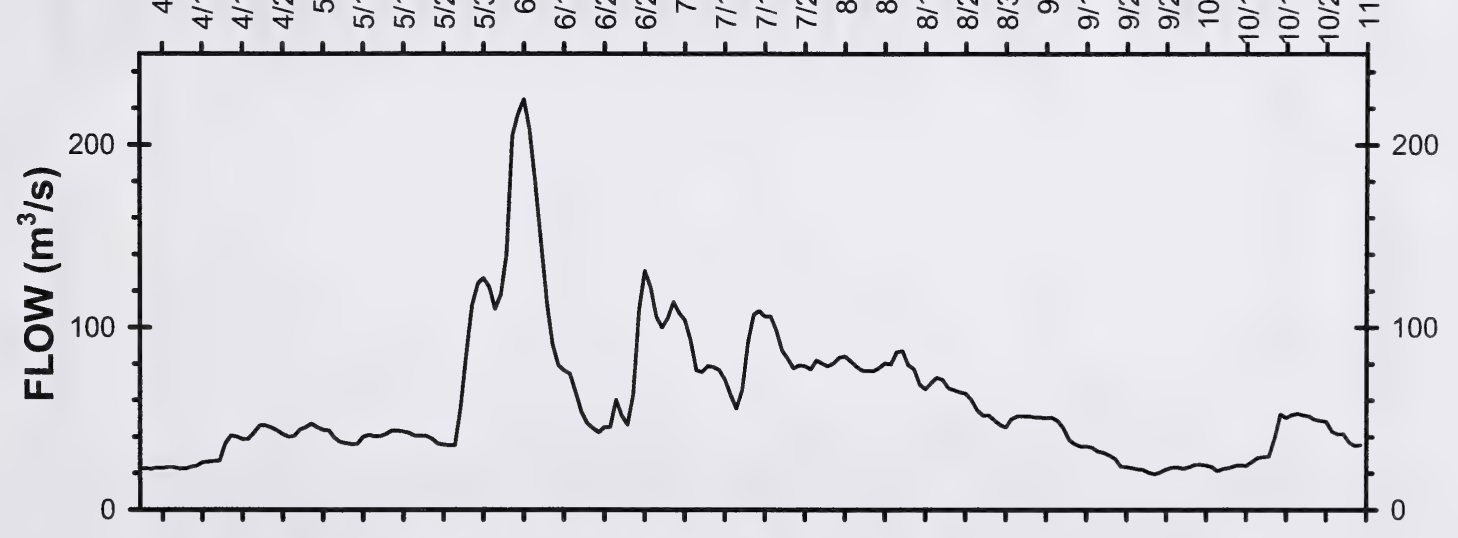

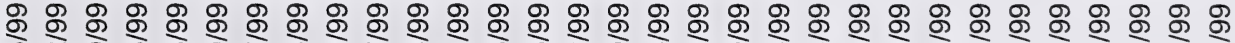

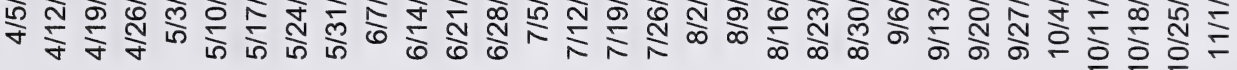

Figure 37. Daily water temperature (Datasonde), dissolved oxygen and flow in the Oldman River downstream of Lethbridge. April-October 1999. 


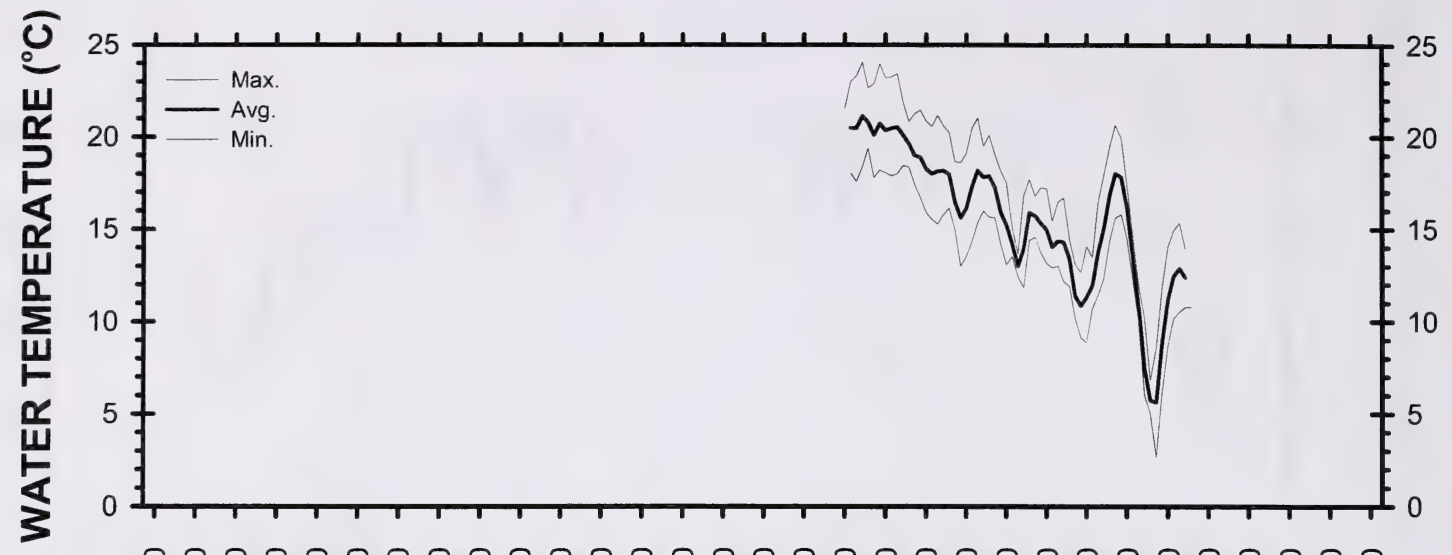

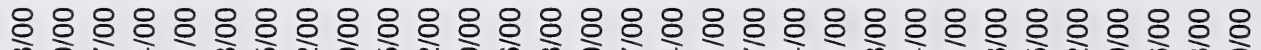
m은 근

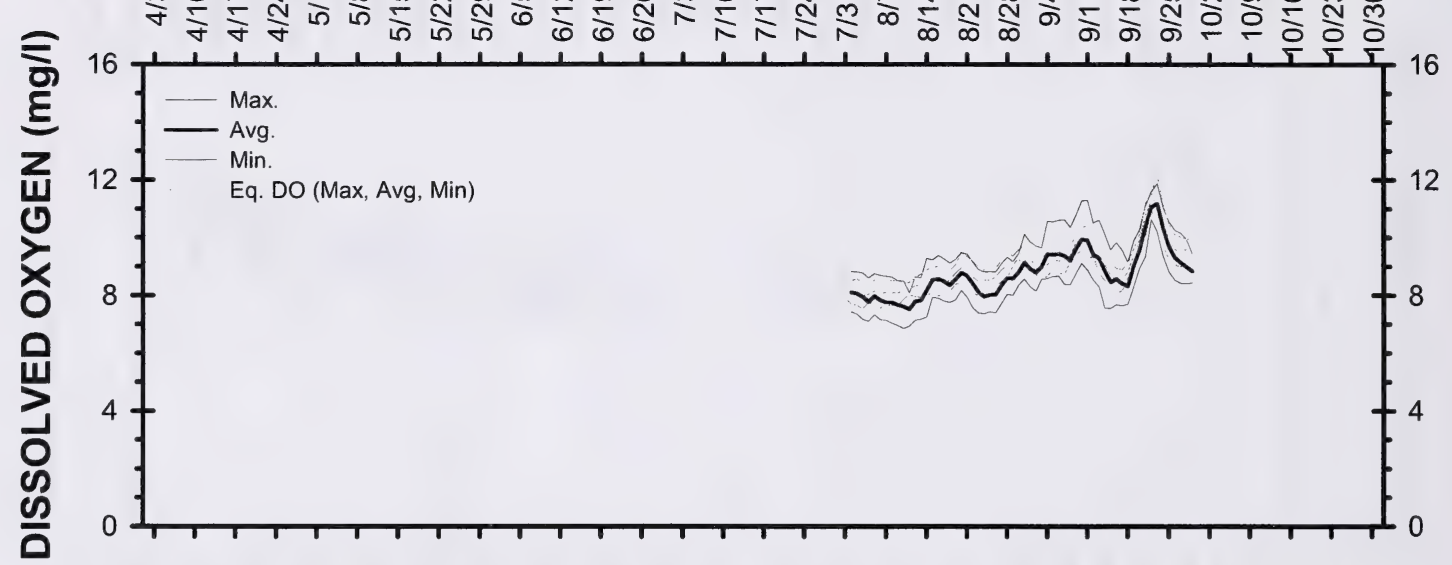

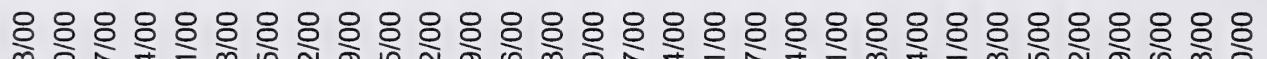

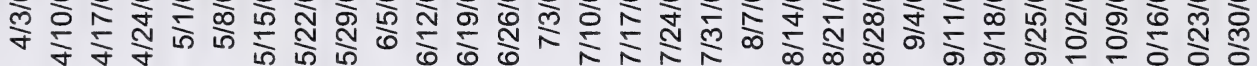

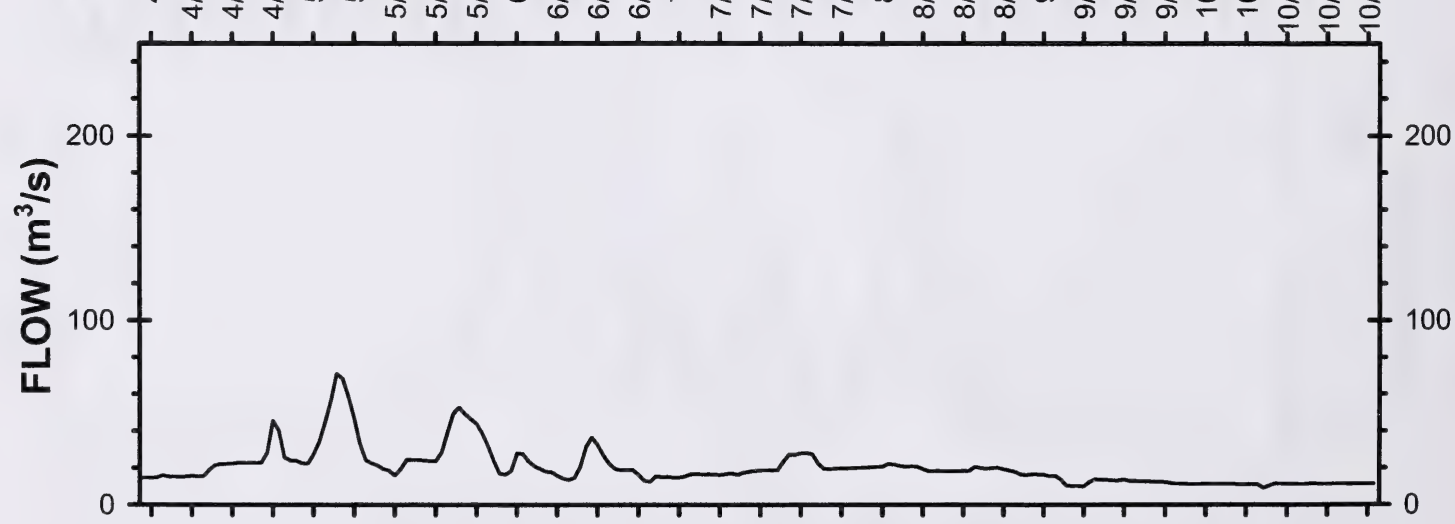

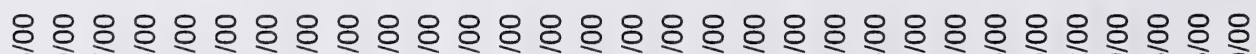

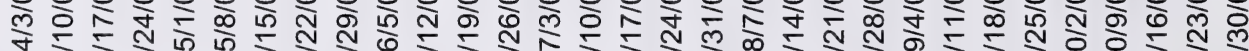

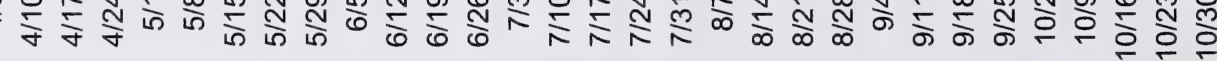

Figure 38. Daily water temperature (Datasonde), dissolved oxygen and flow in the Oldman River near Monarch. April-October 2000. 


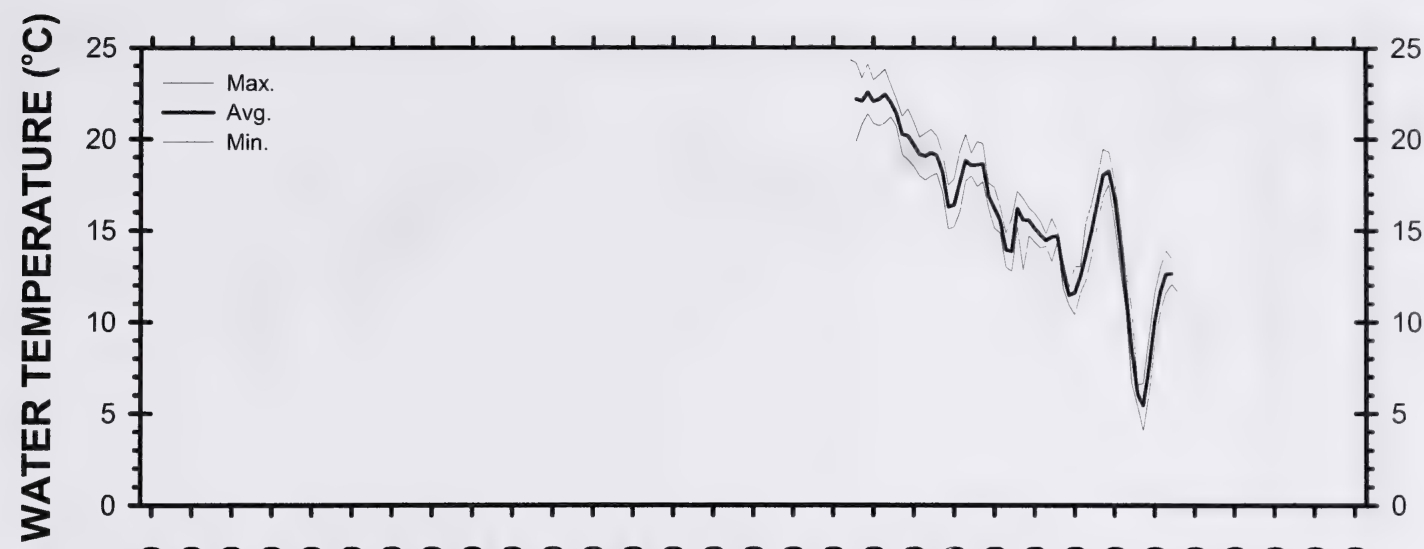

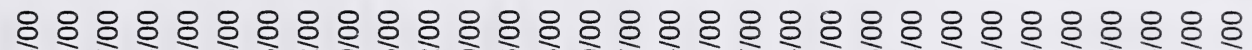

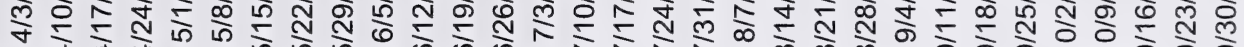

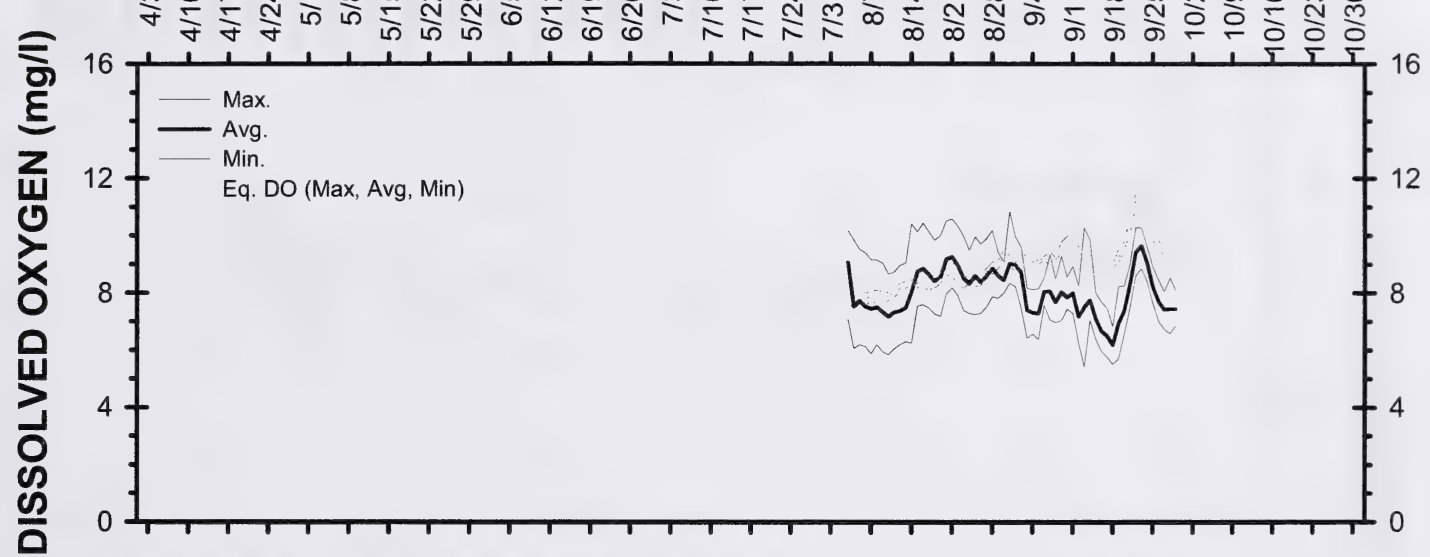

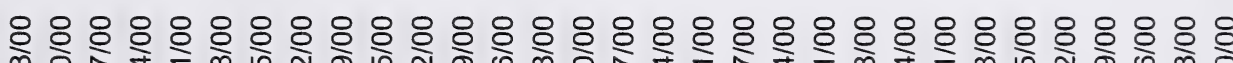

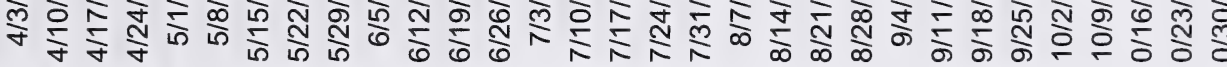

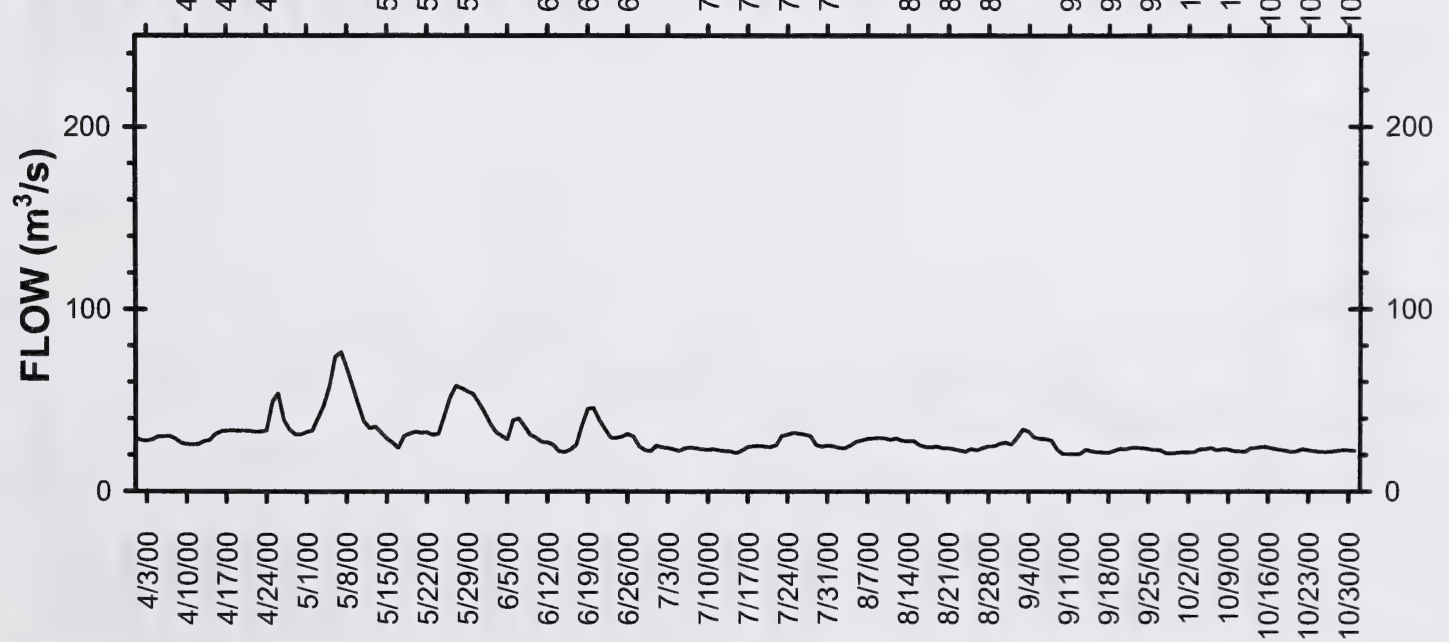

Figure 39. Daily water temperature (Datasonde), dissolved oxygen and flow in the Oldman River upstream of Lethbridge. April-October 2000. 


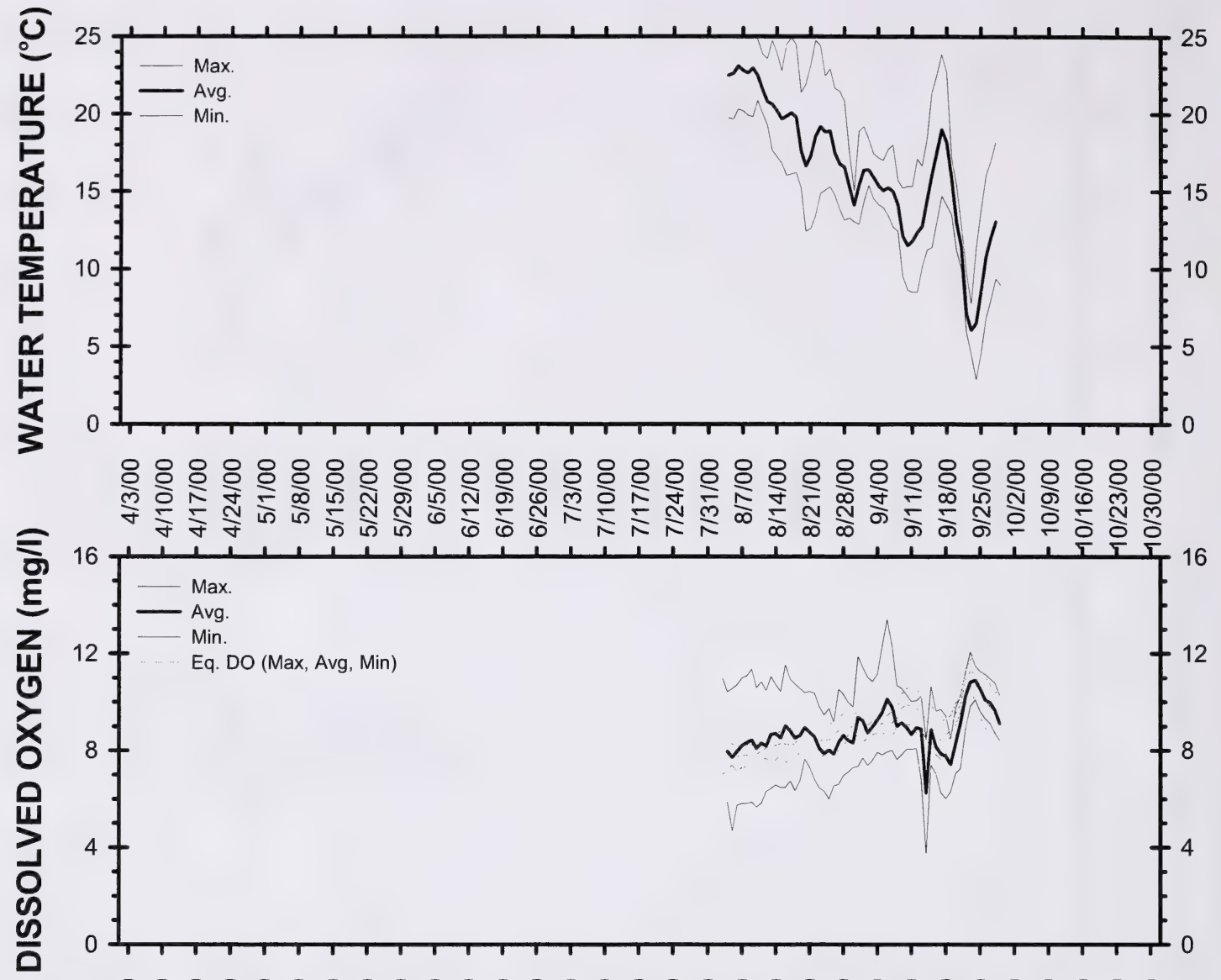

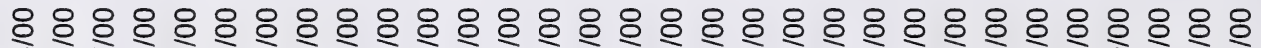

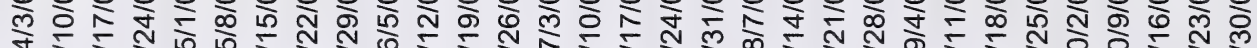

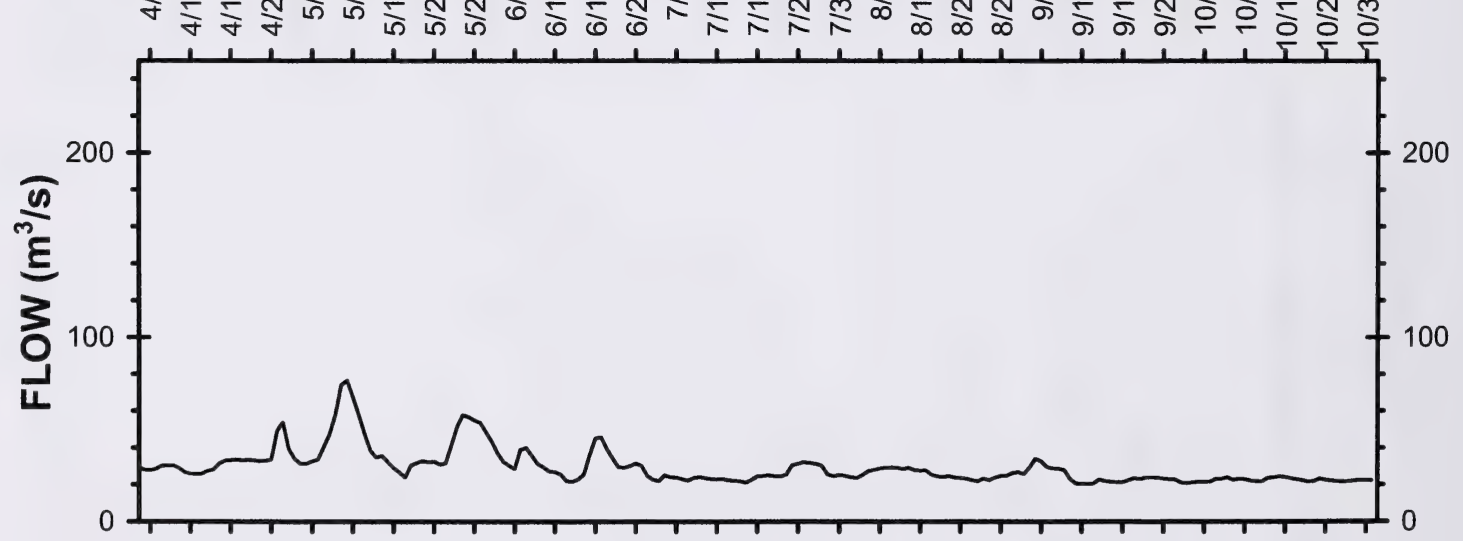

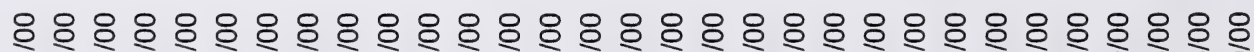

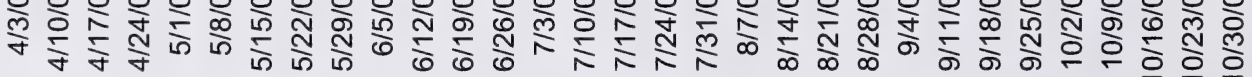

Figure 40. Daily water temperature (Datasonde), dissolved oxygen and flow in the Oldman River downstream of Lethbridge. April-October 2000. 


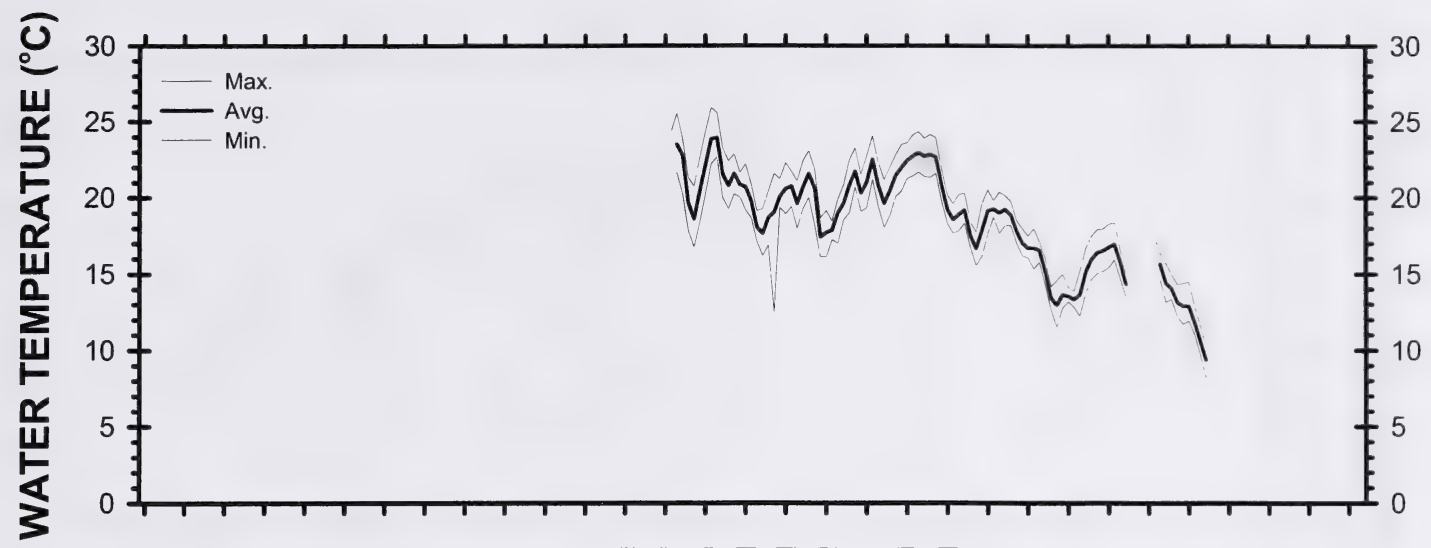

市

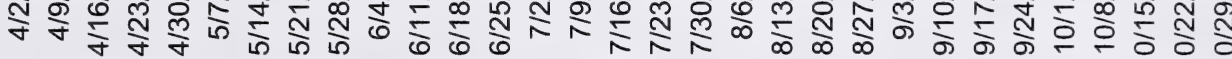

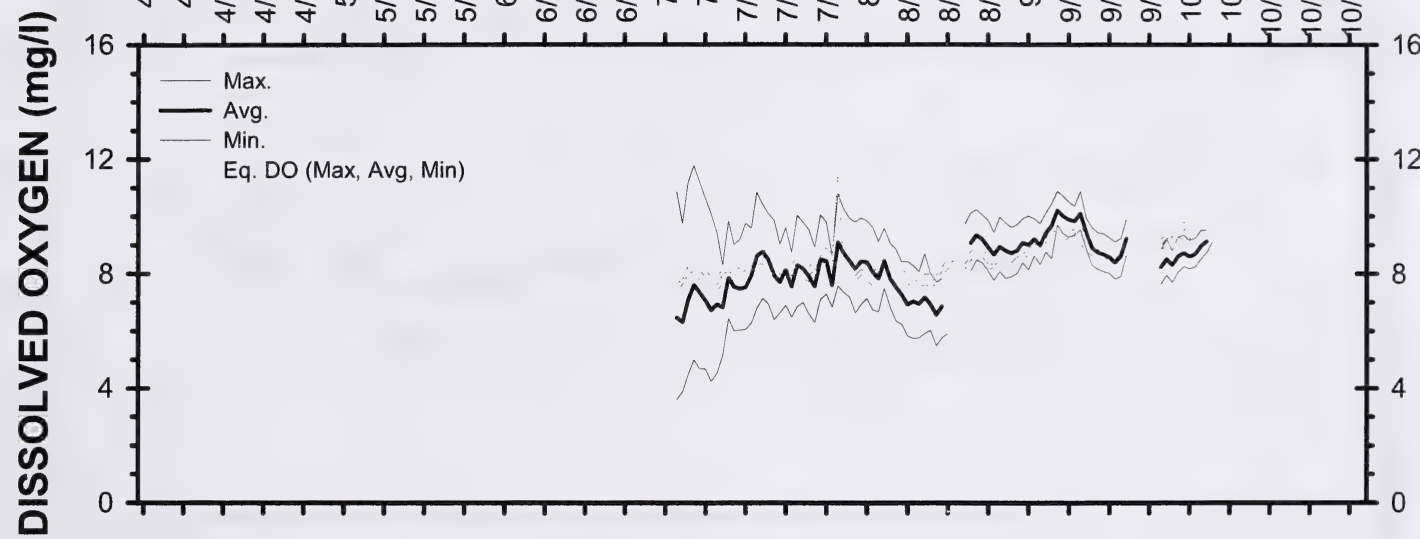

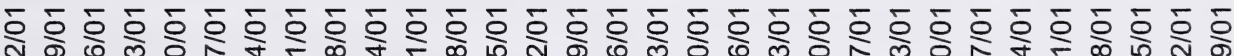

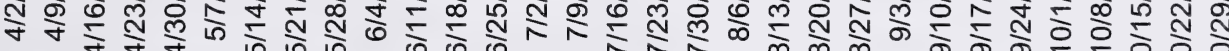

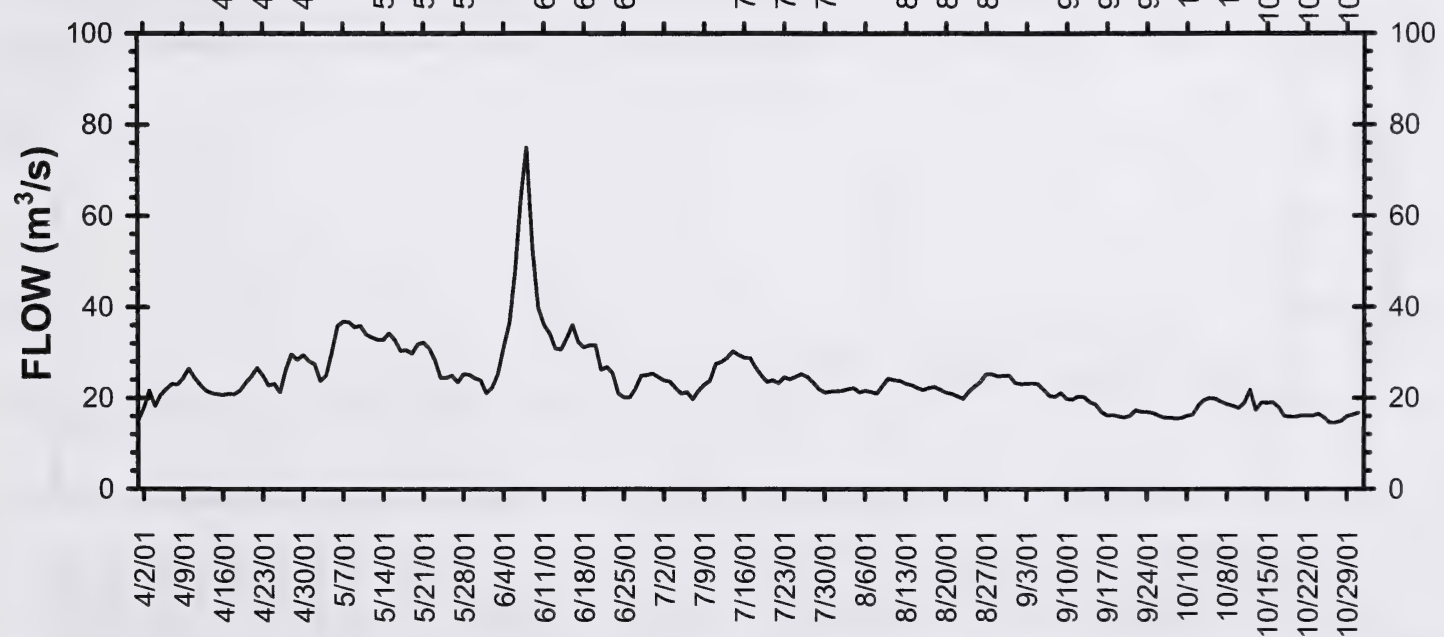

Figure 41. Daily water temperature (Datasonde), dissolved oxygen and flow in the Oldman River upstream of Lethbridge. April-October 2001. 


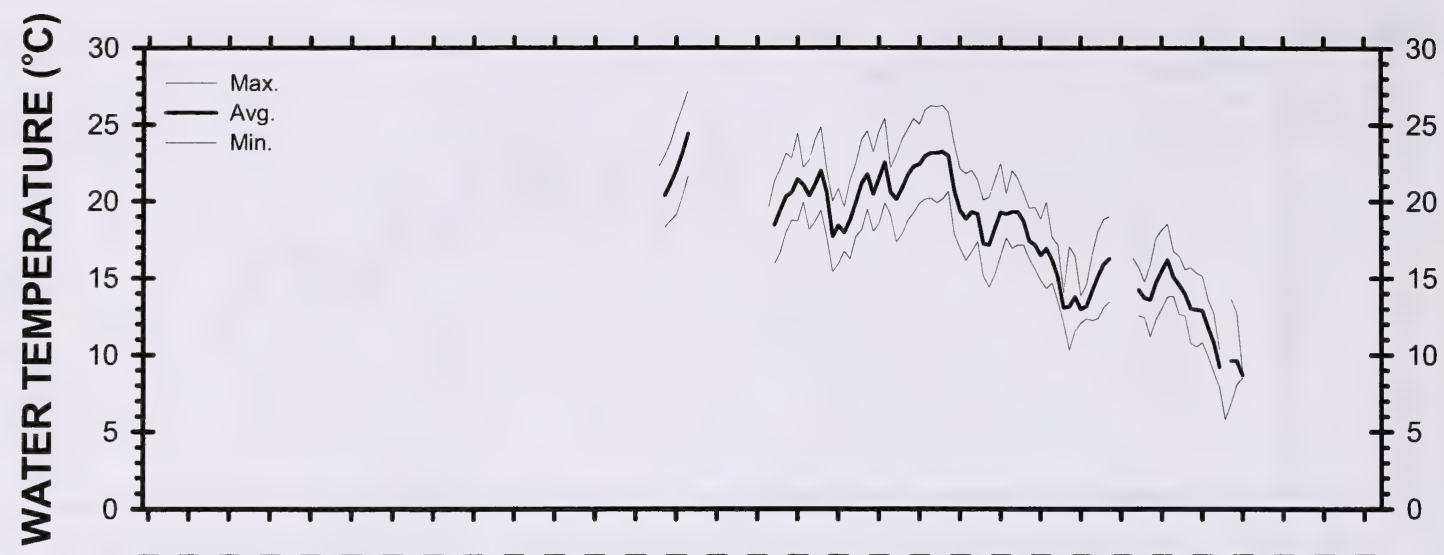

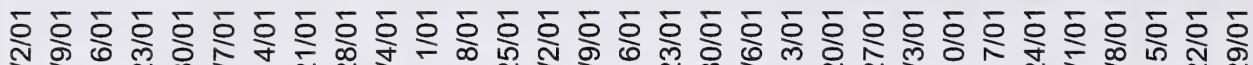

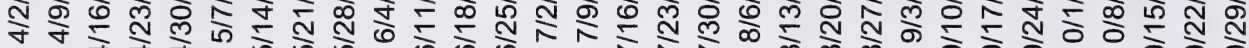

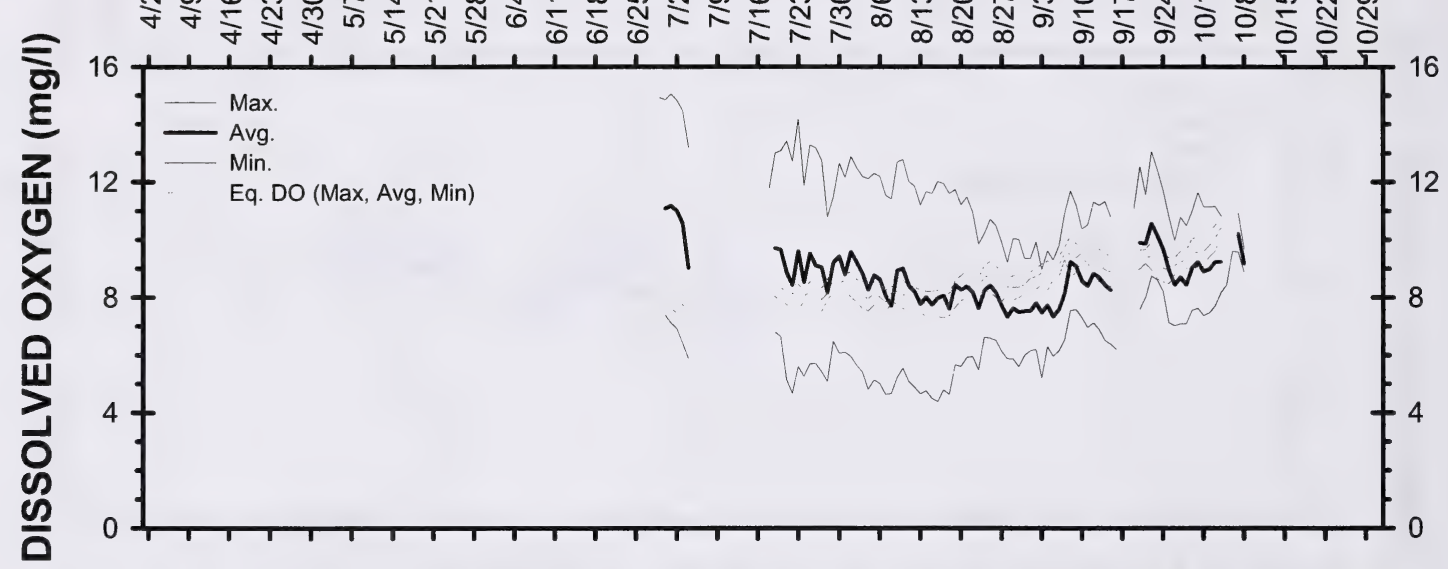
б

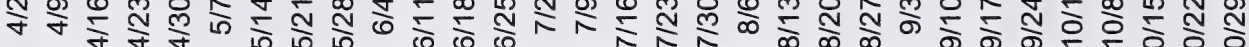

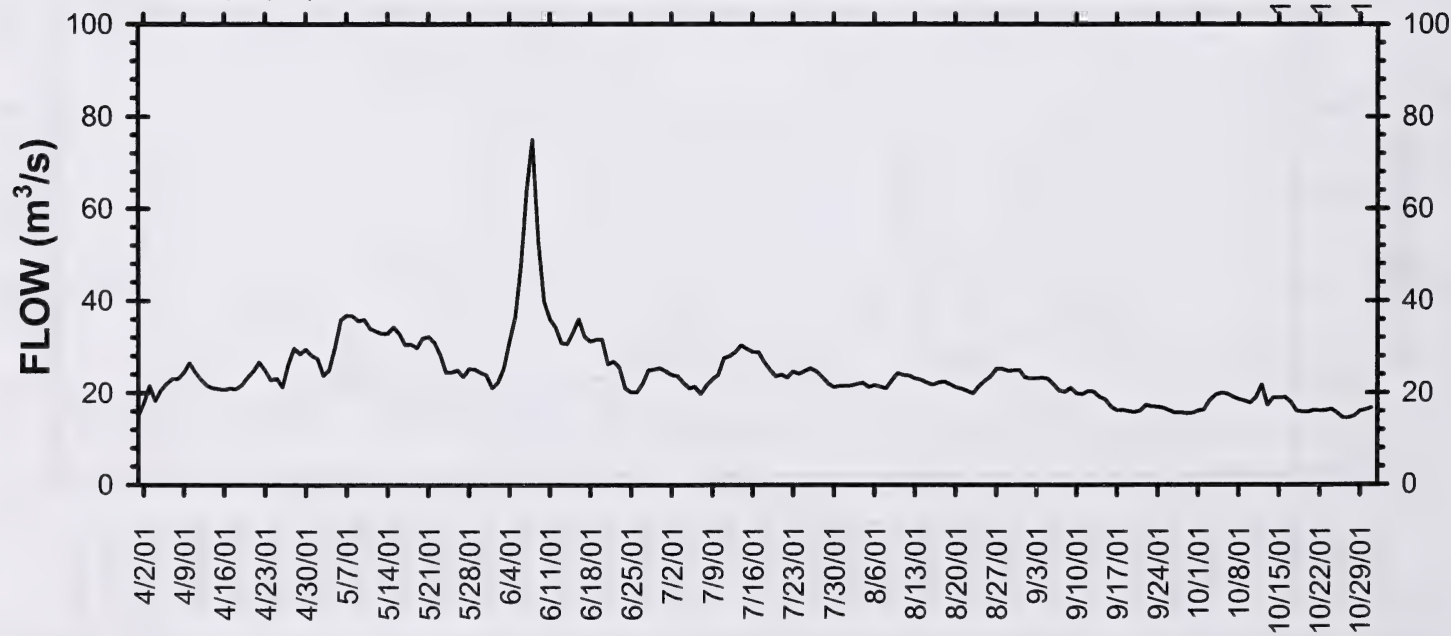

Figure 42. Daily water temperature (Datasonde), dissolved oxygen and flow in the Oldman River downstream of Lethbridge. April-October 2001. 


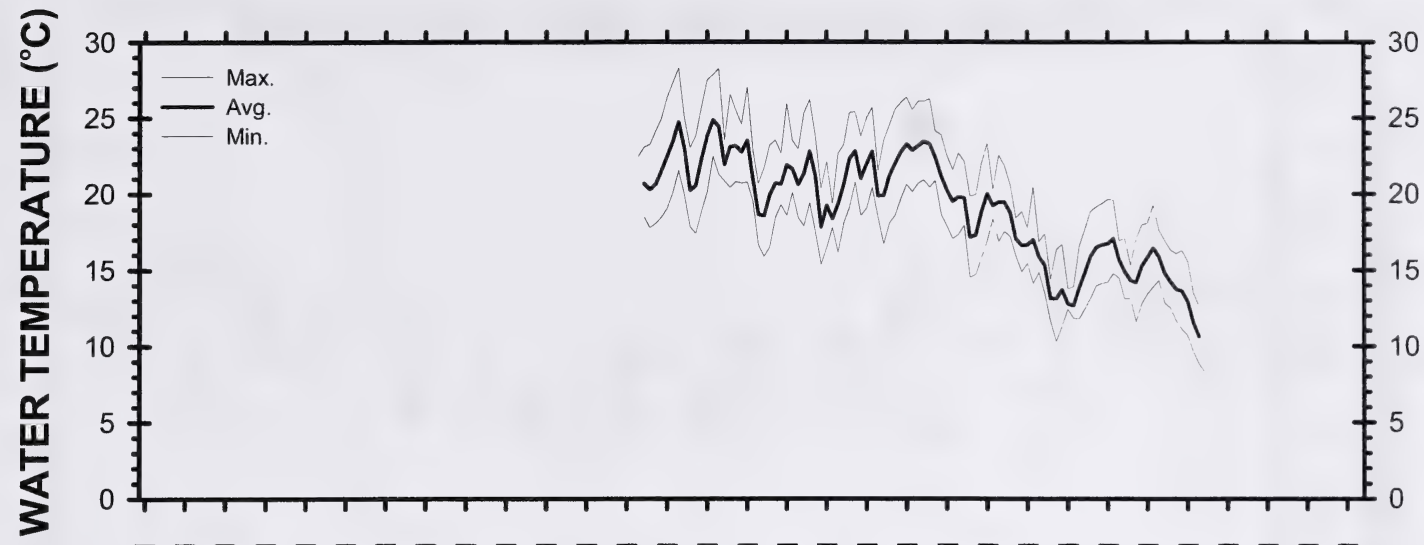

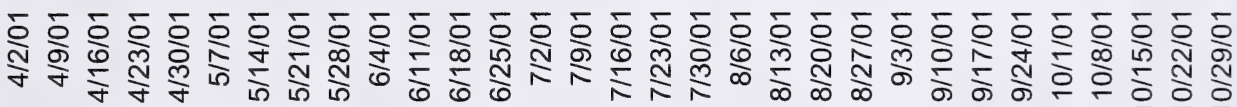

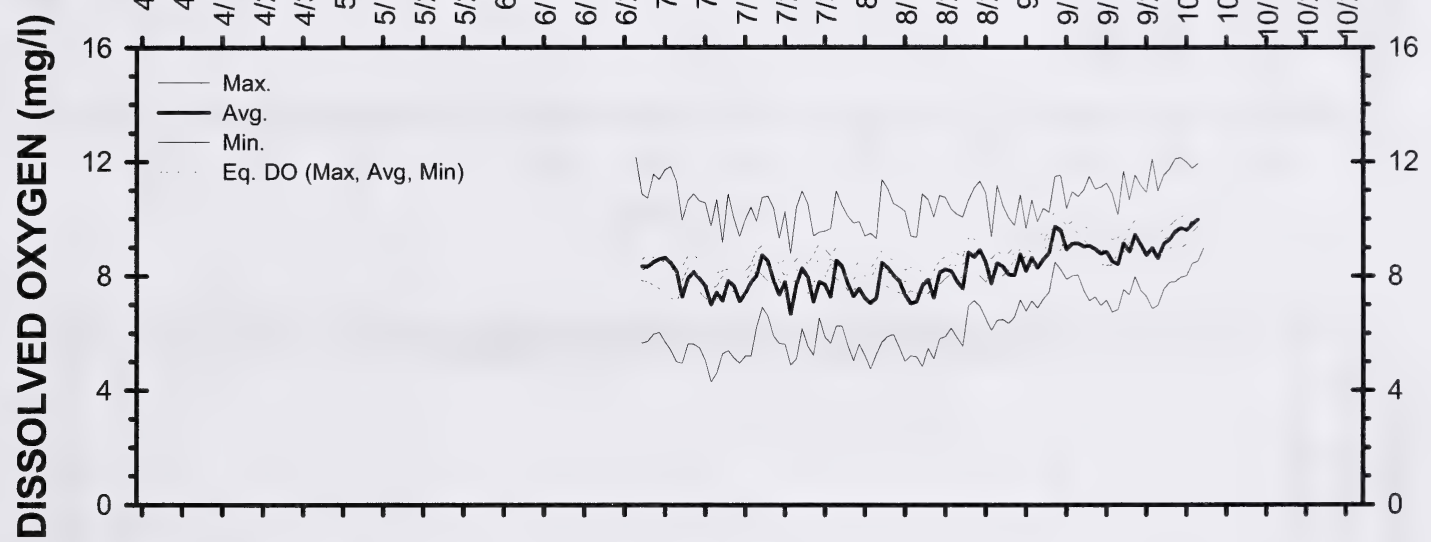

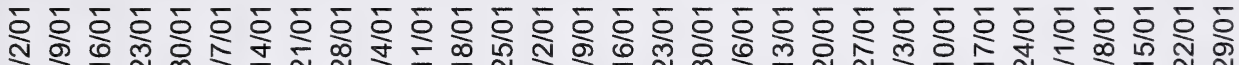

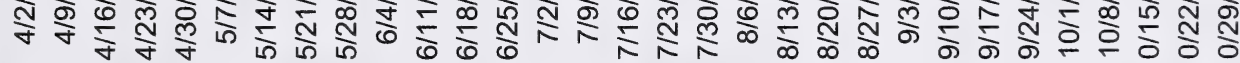

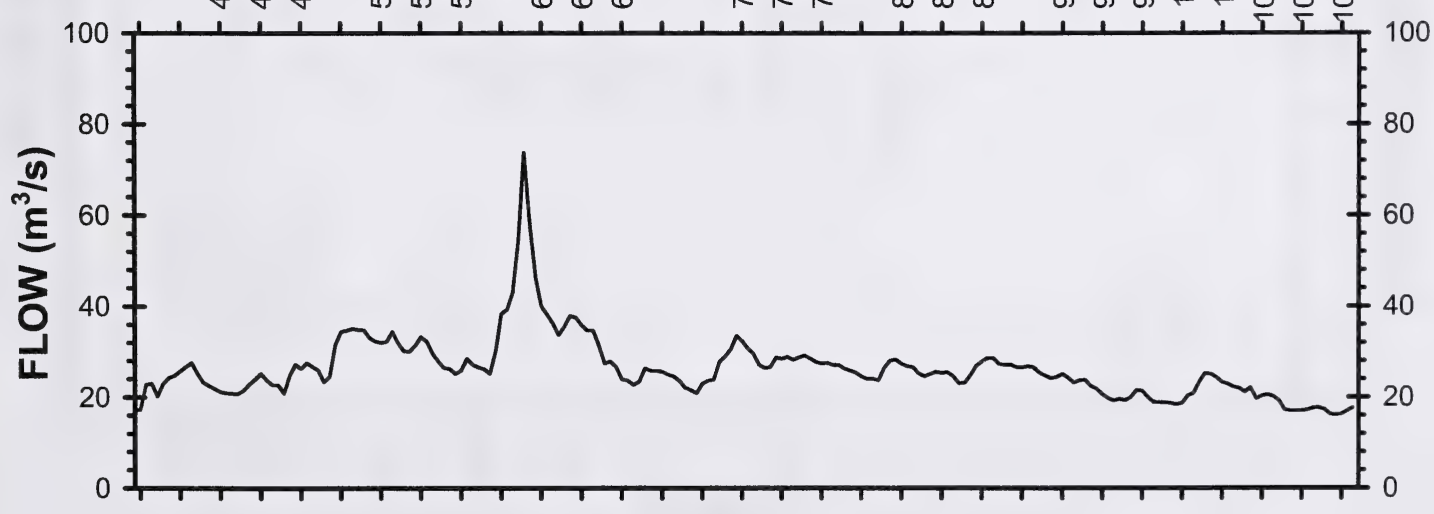

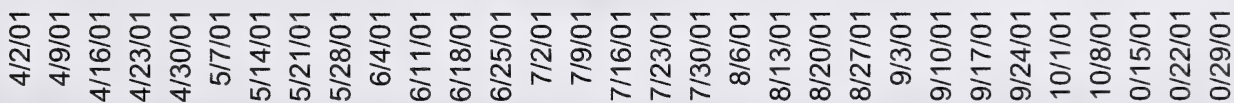

Figure 43. Daily water temperature (Datasonde), dissolved oxygen and flow in the Oldman River downstream of Highway 36. April-October 2001. 

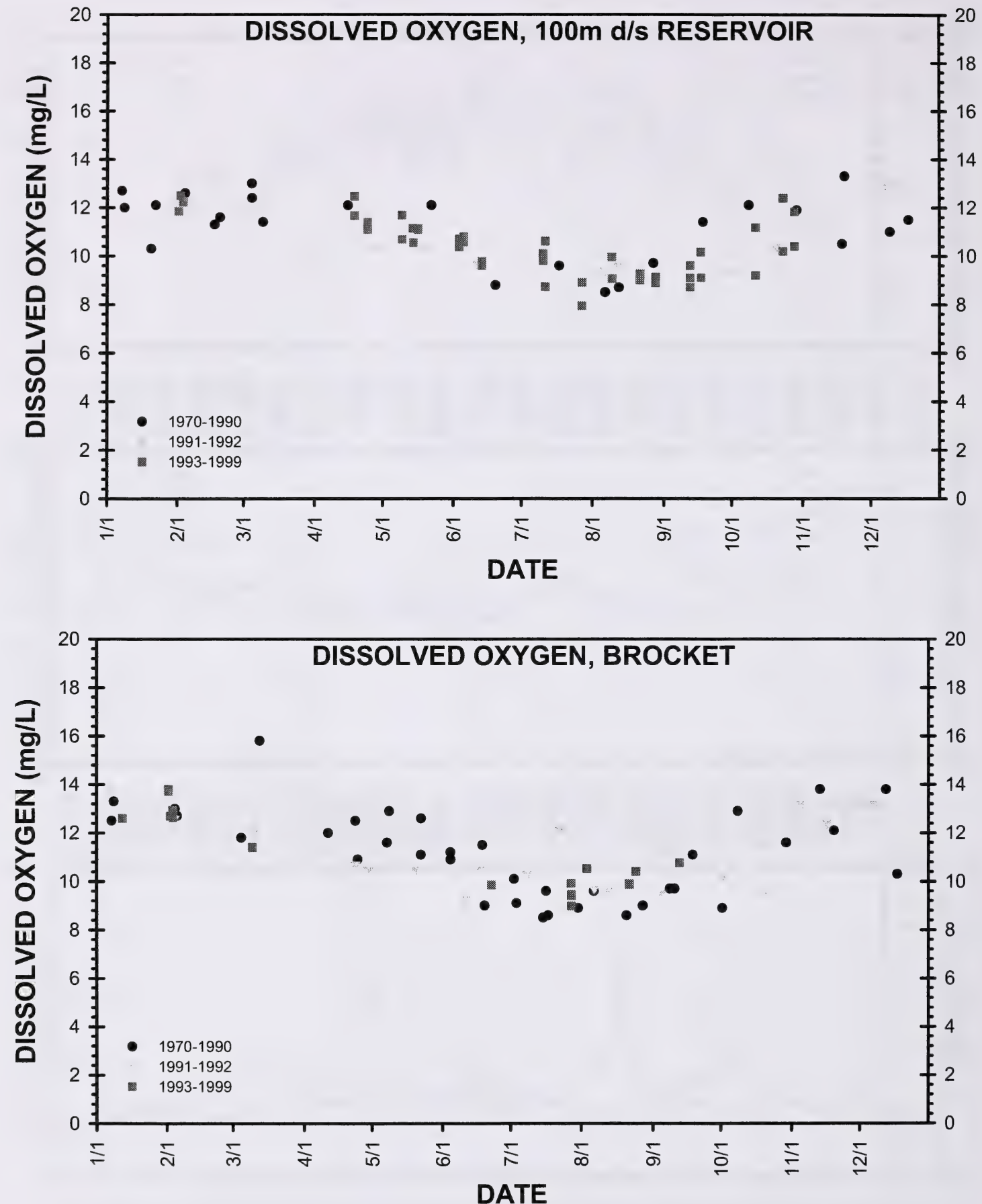

Figure 44. Dissolved oxygen (spot measurements) in the Oldman River $100 \mathrm{~m}$ downstream of the reservoir and near Brocket for pre-impoundment, transition, and post-impoundment years. 

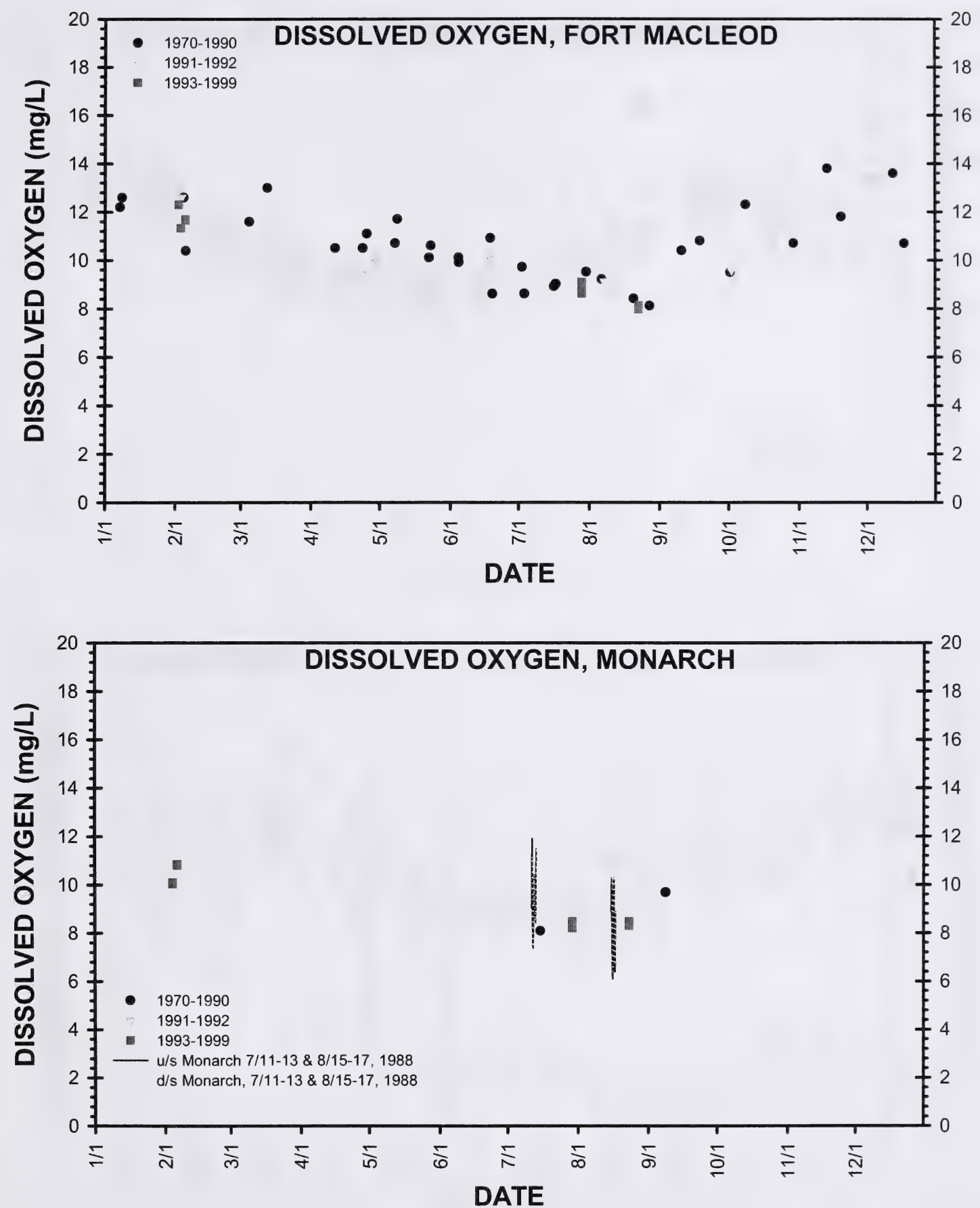

Figure 45. Dissolved oxygen (spot measurements) in the Oldman River near Fort Macleod and Monarch for pre-impoundment, transition, and post-impoundment years. 

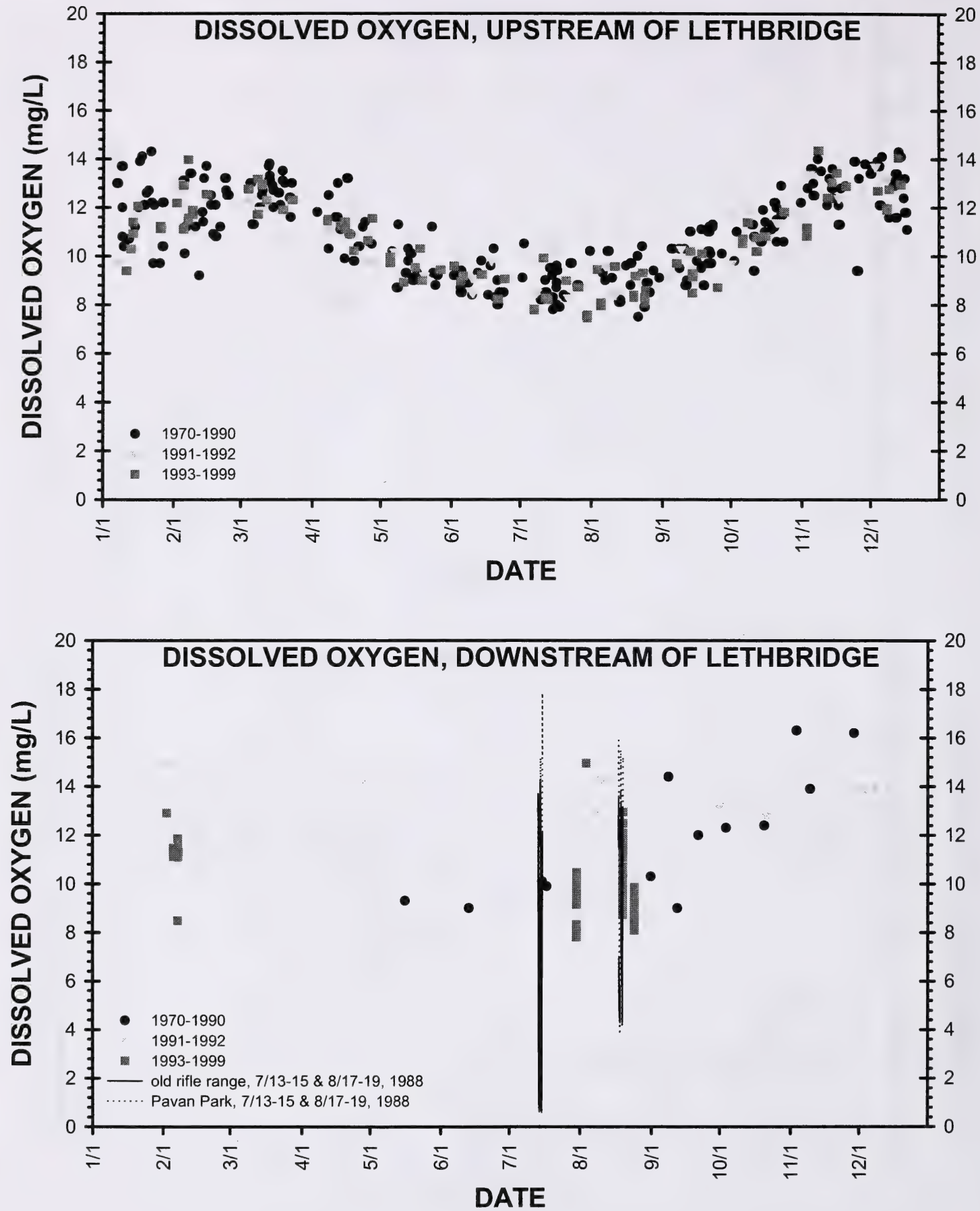

Figure 46. Dissolved oxygen (spot measurements) in the Oldman River upstream and downstream of Lethbridge for pre-impoundment, transition, and post-impoundment years. 

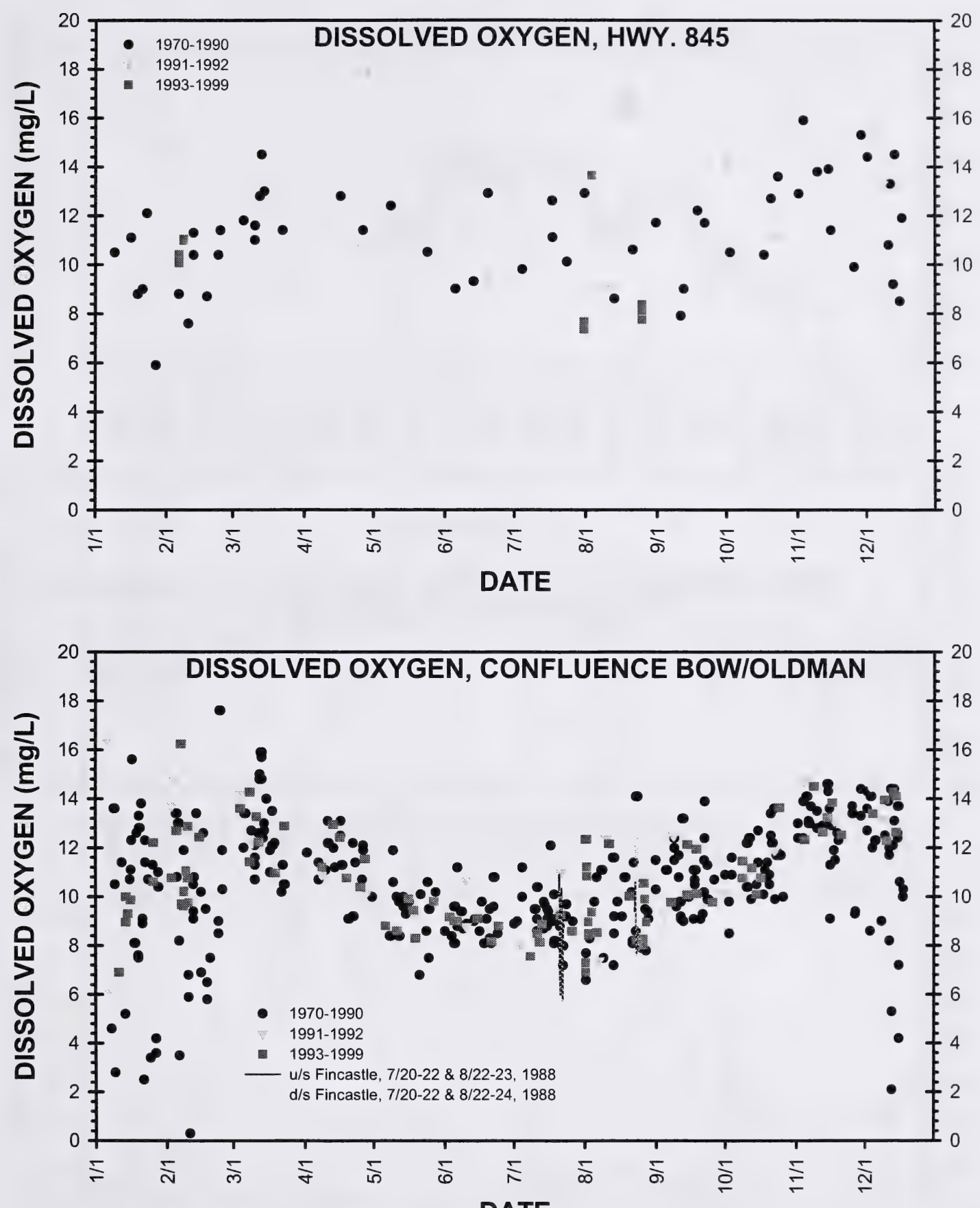

DATE

Figure 47. Dissolved oxygen (spot measurements) in the Oldman River near Hwy. 845 and the confluence of the Bow and Oldman rivers for pre-impoundment, transition, and post-impoundment years. 


\section{APPENDIX B}

WATER TEMPERATURE, AIR TEMPERATURE, AND FLOW FIGURES AND WATER TEMPERATURE TABLES 


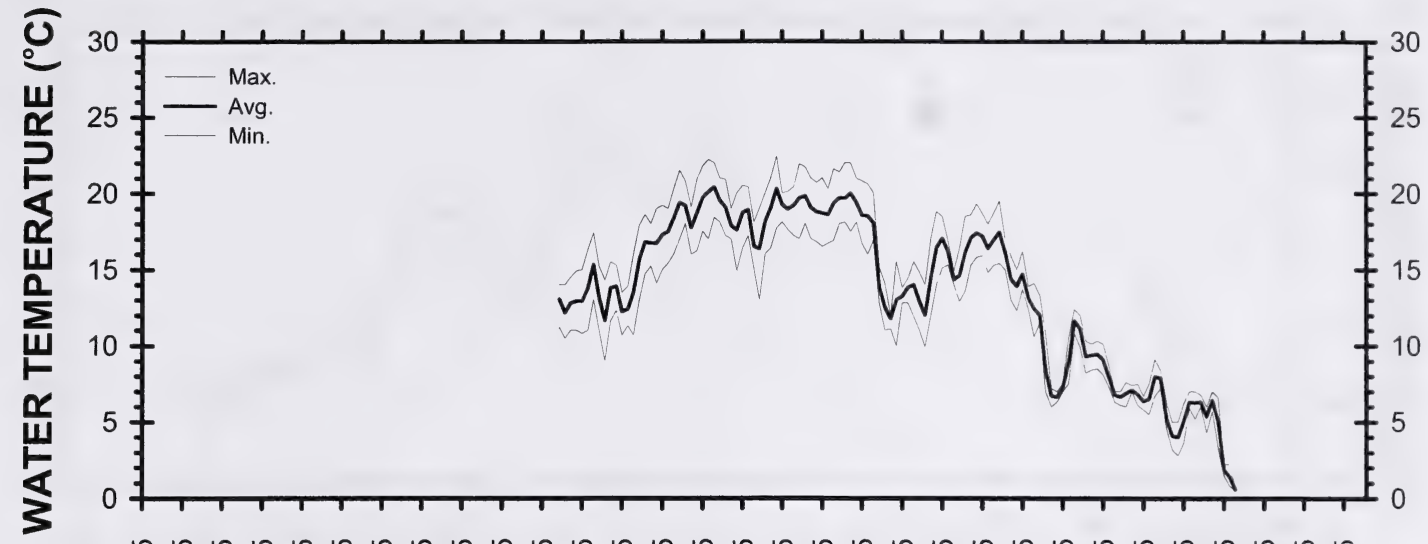

œ

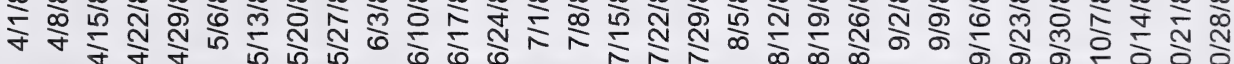

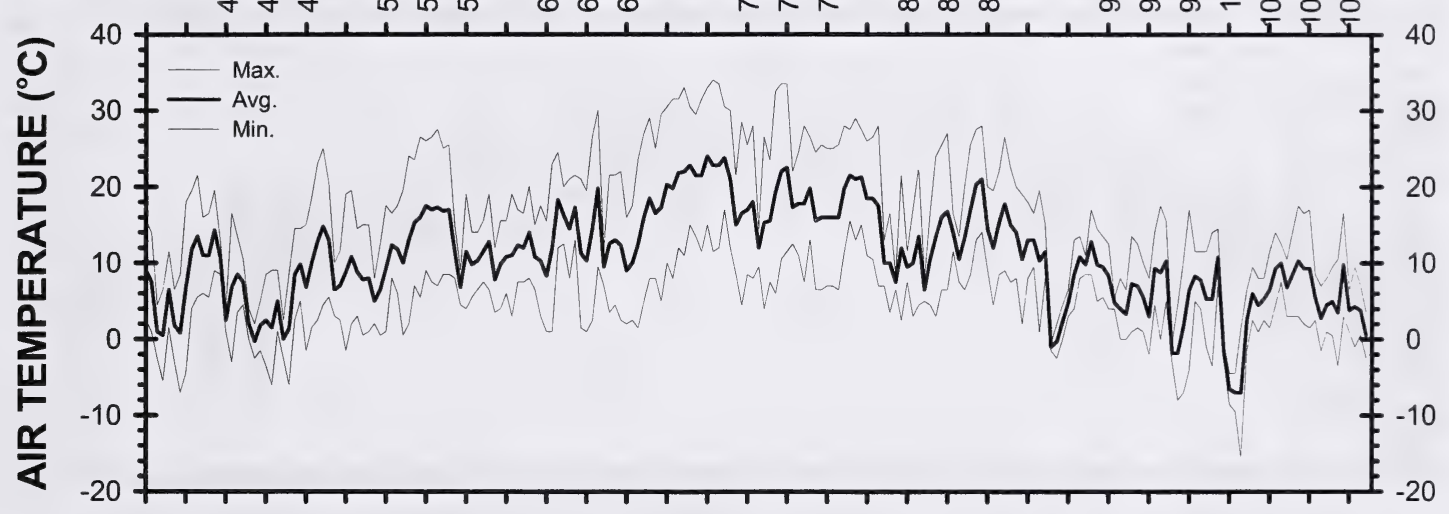

œ

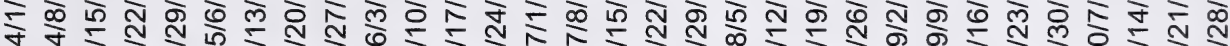

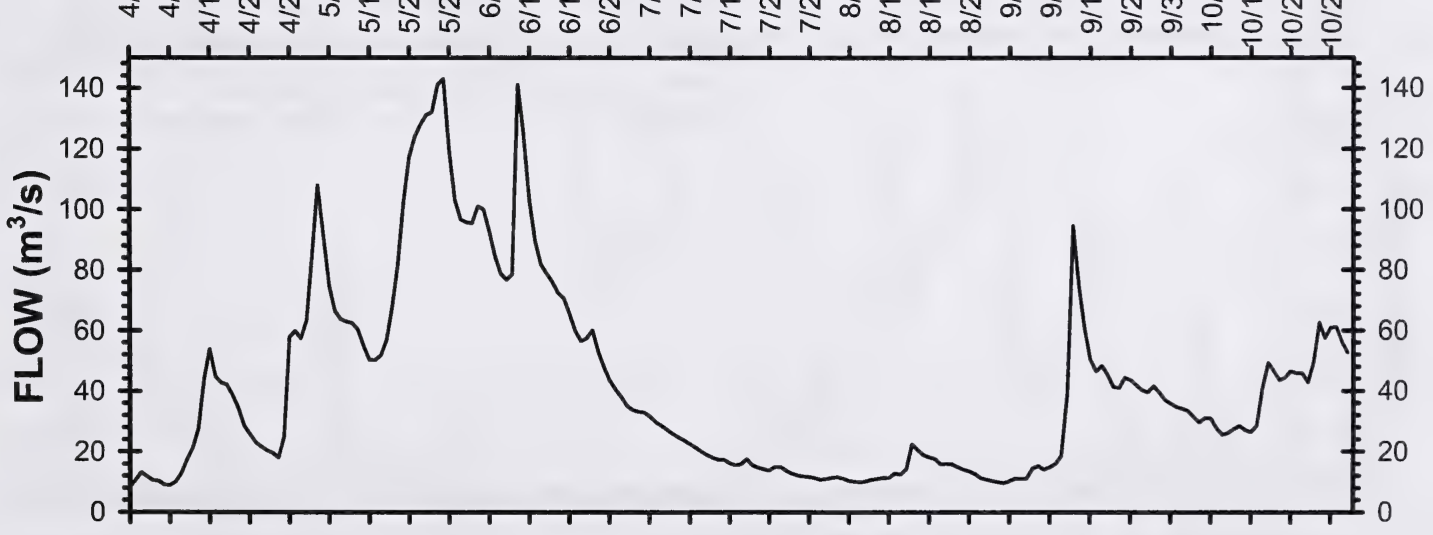

œ

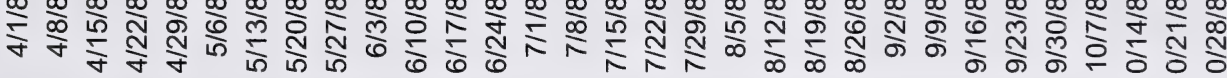

Figure 1. Daily water temperature (Thermograph), air temperature and flow in the Oldman River near Brocket. April-October 1985. 


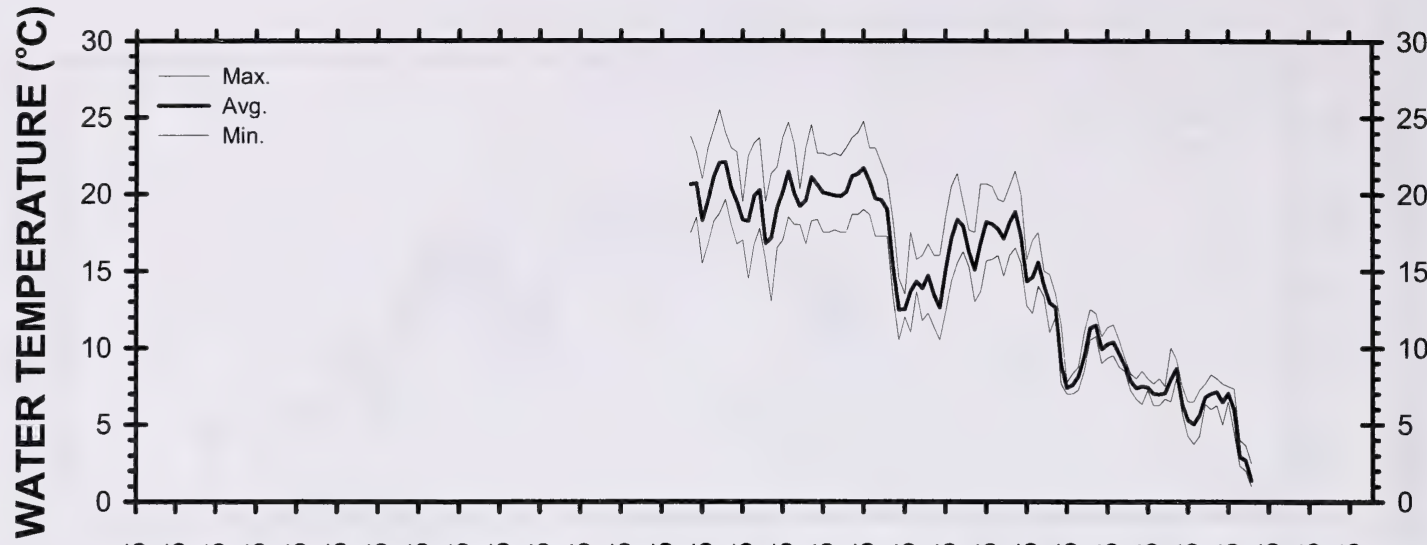

œ

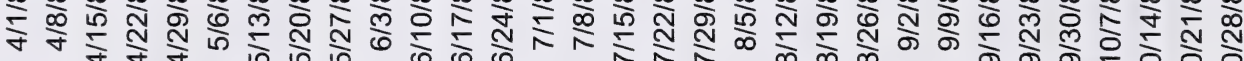

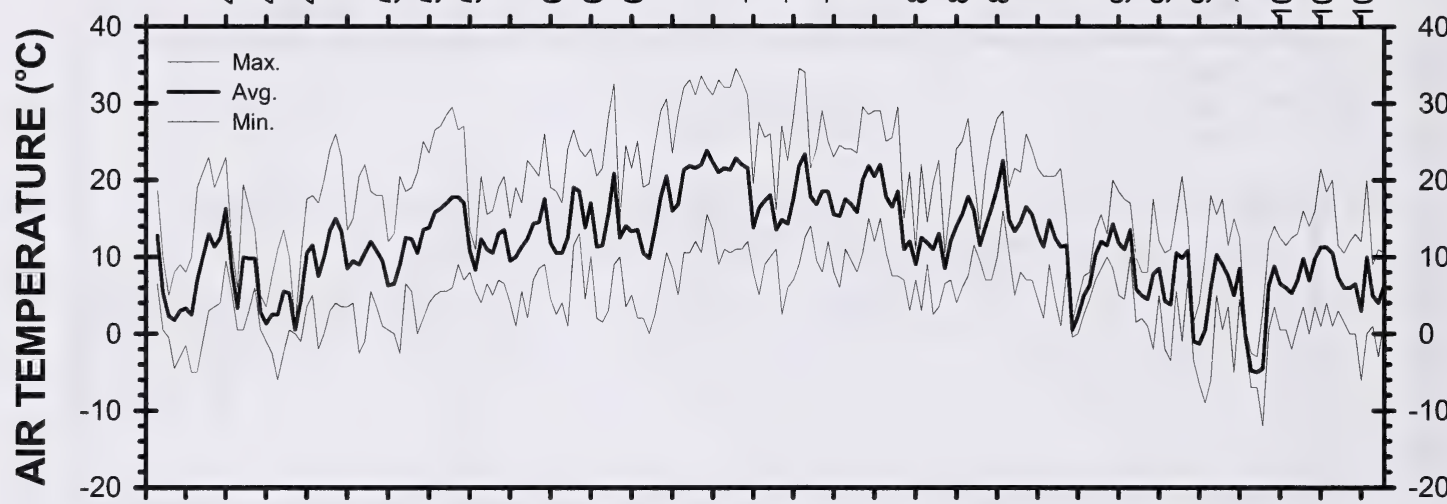

œ

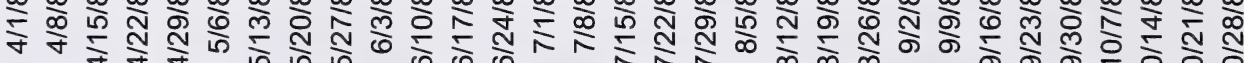

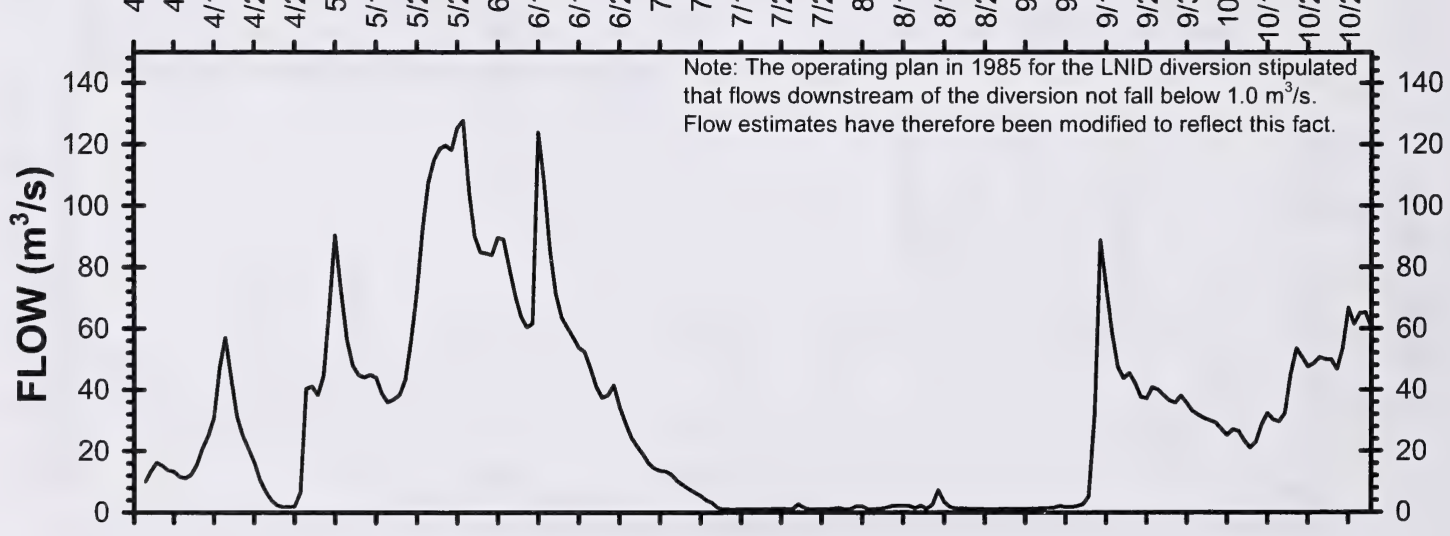

œ

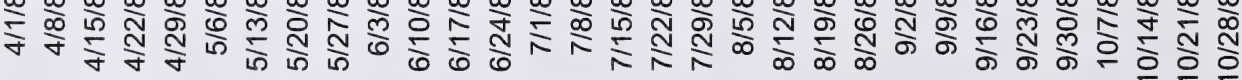

Figure 2. Daily water temperature (Thermograph), air temperature and flow in the Oldman River near Fort Macleod. April-October 1985. 

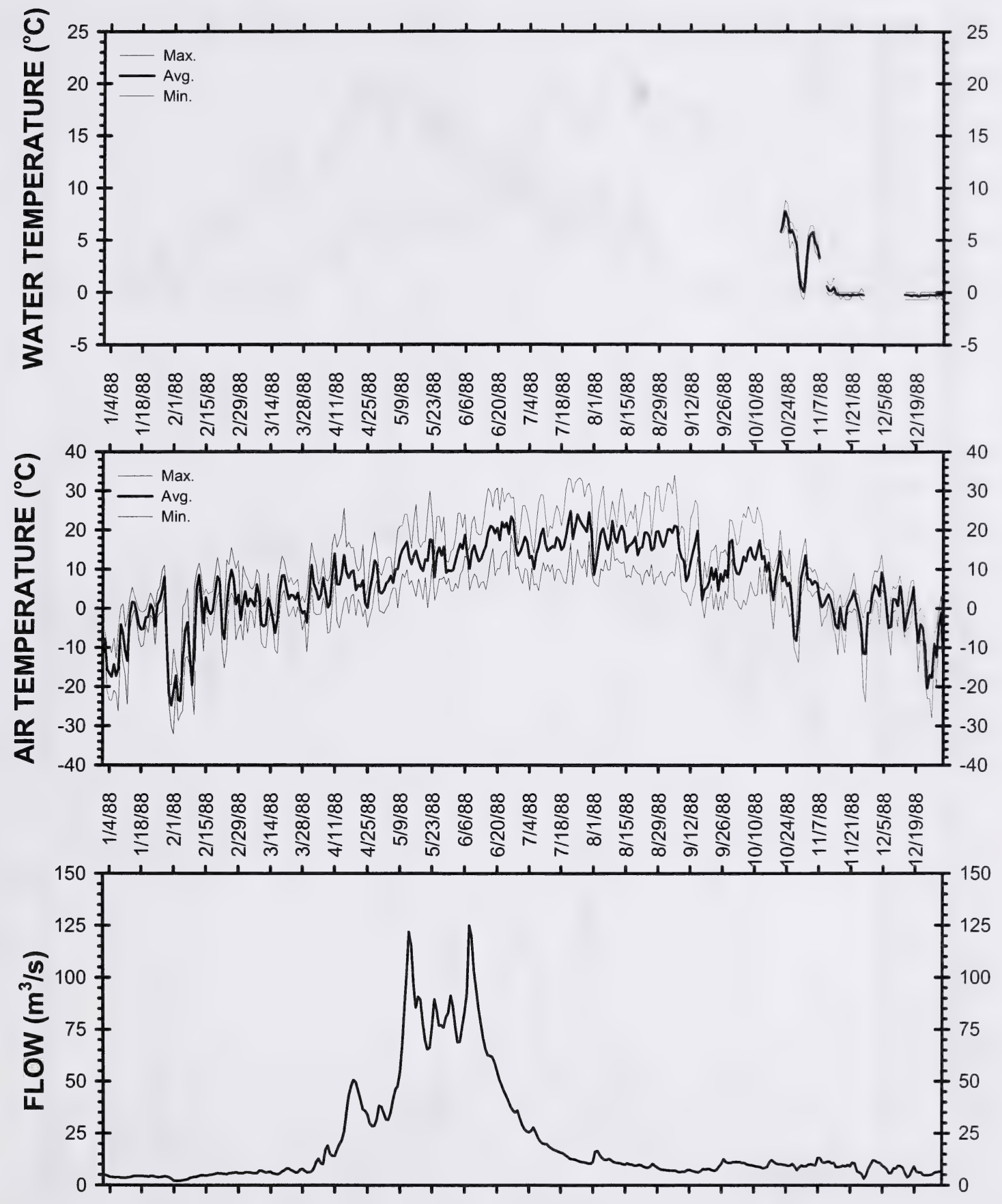

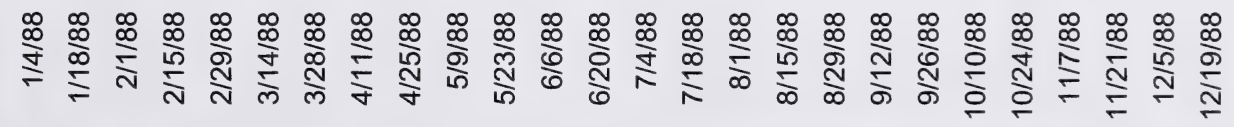

Figure 3. Daily water temperature (HANDAR 560), air temperature and flow in the Oldman River near Brocket. January-December, 1988. 


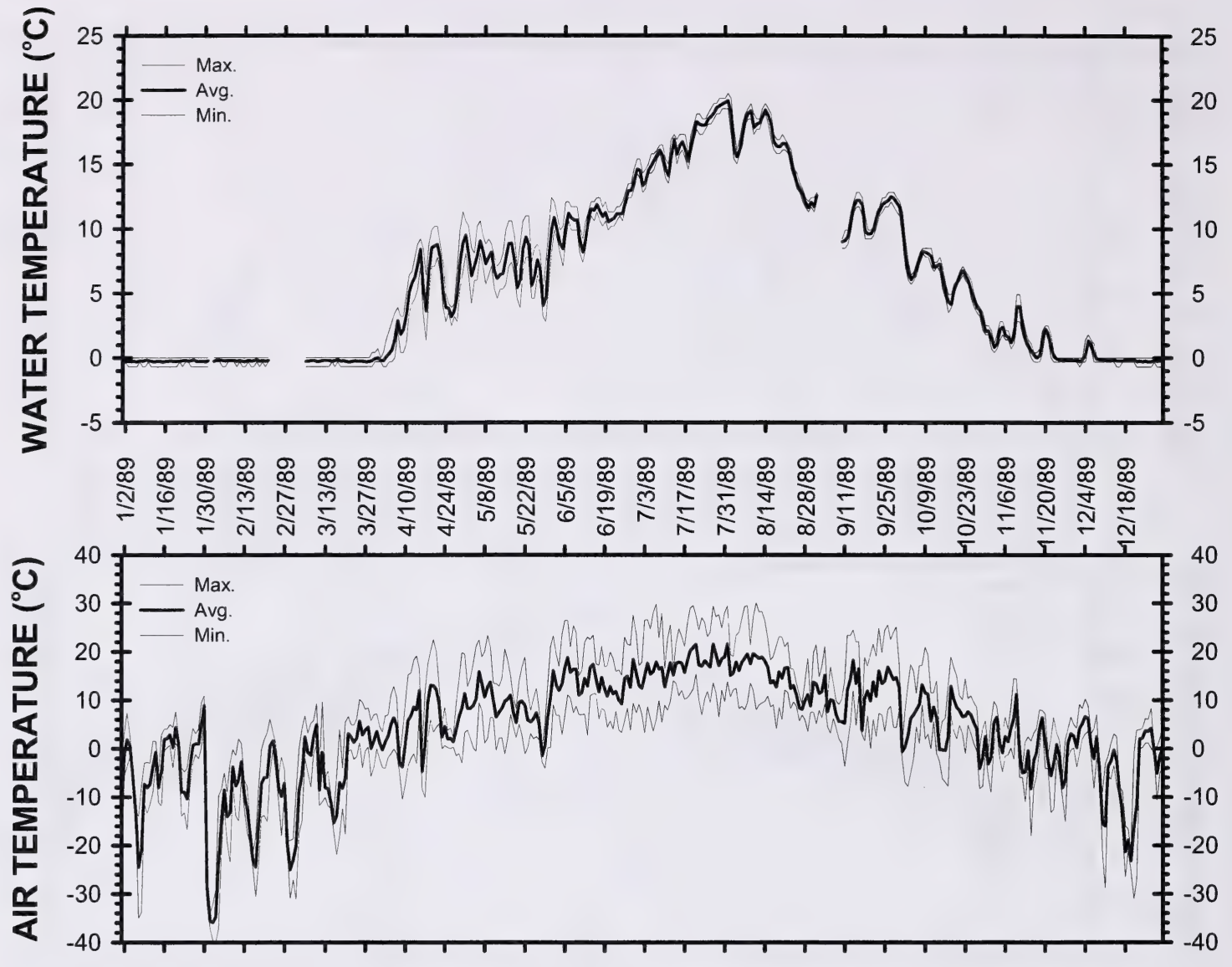

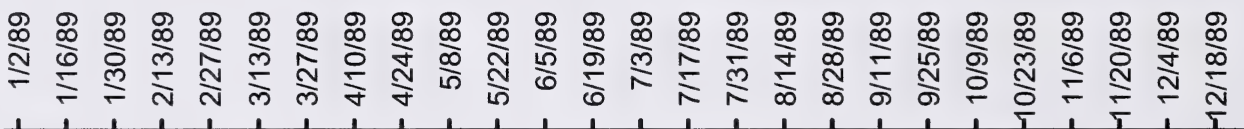

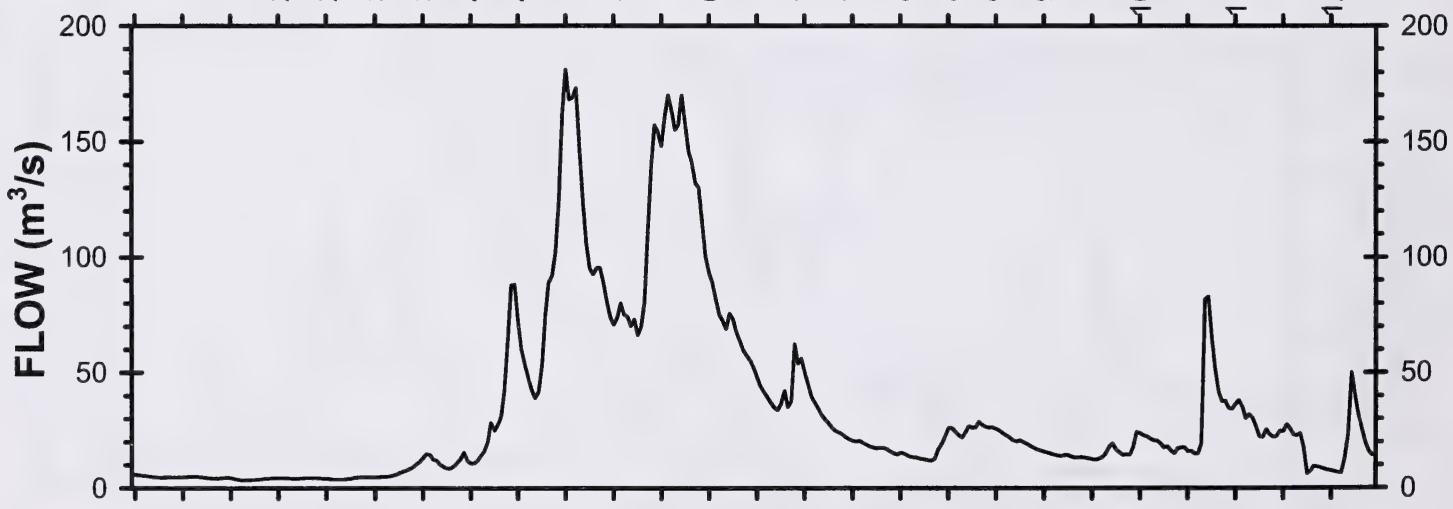

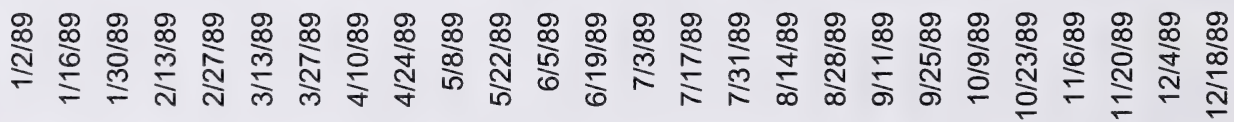

Figure 4. Daily water temperature (HANDAR 560), air temperature and flow in the Oldman River near Brocket. January-December, 1989. 


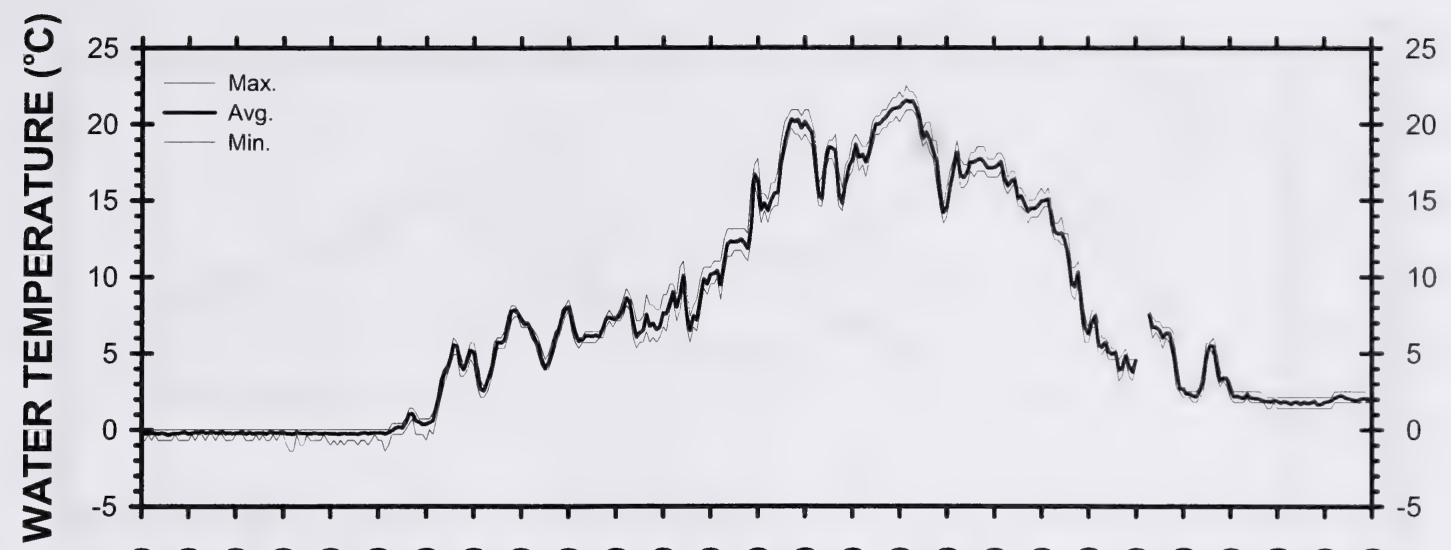

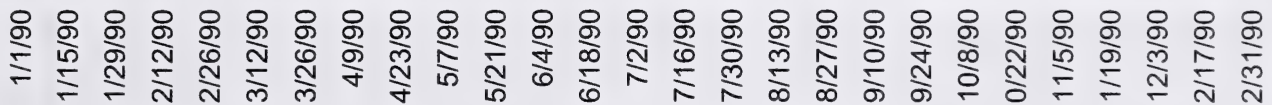

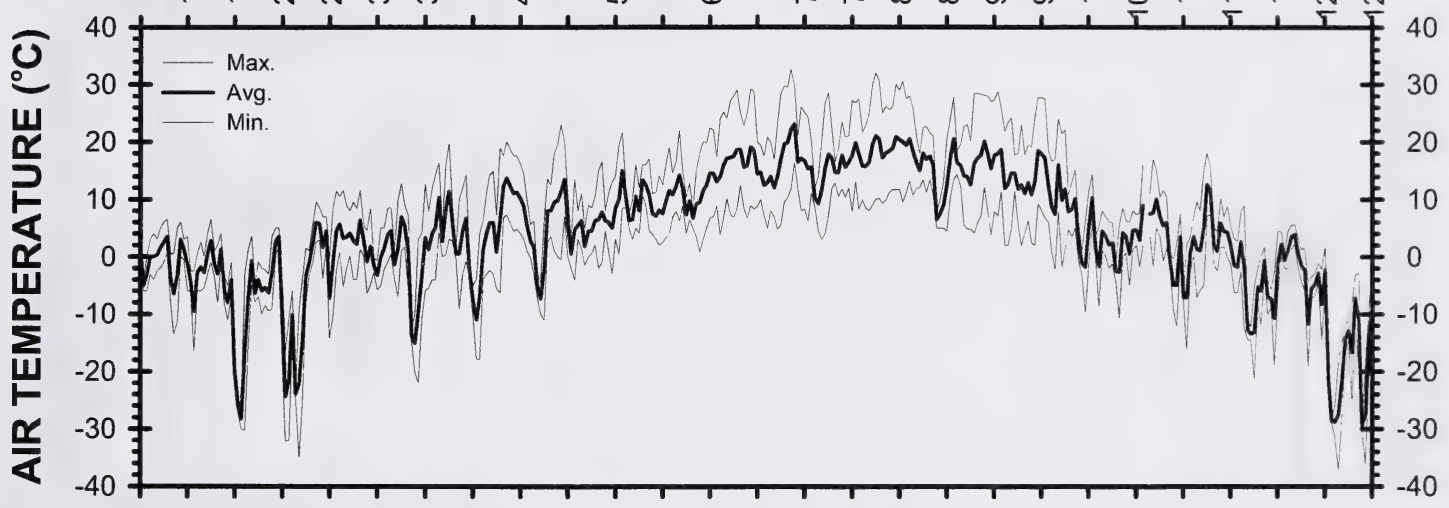

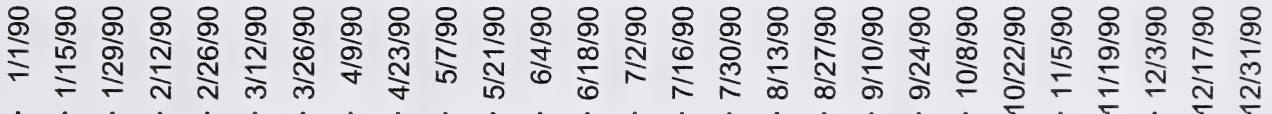

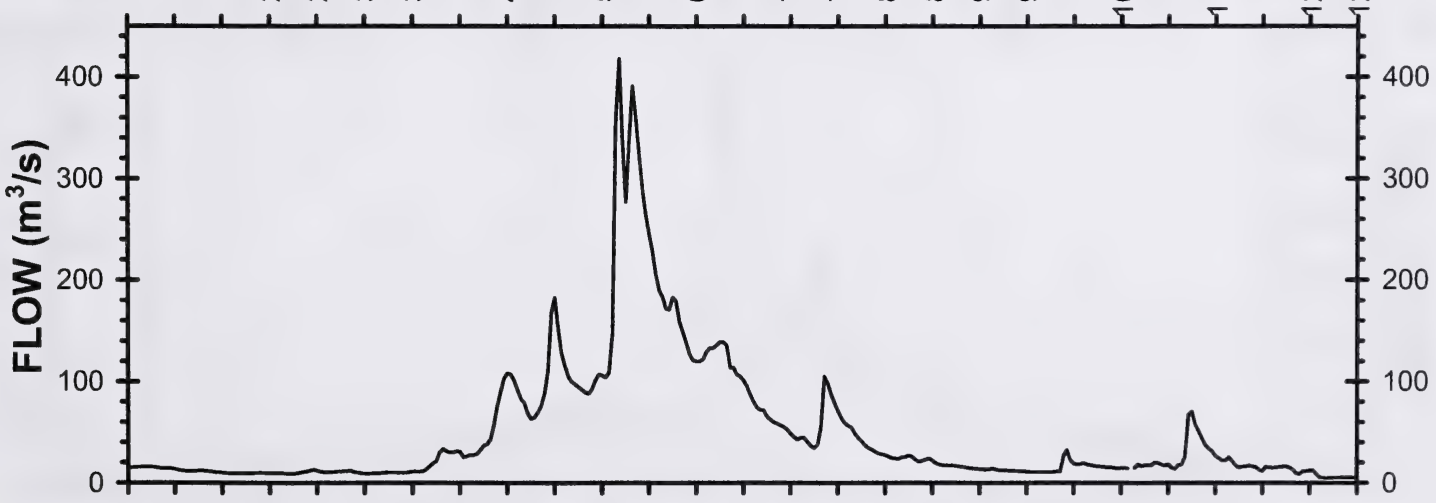

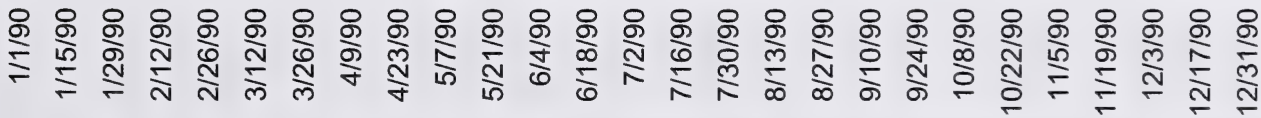

Figure 5. Daily water temperature (HANDAR 560), air temperature and flow in the Oldman River near Brocket. January-December, 1990. 


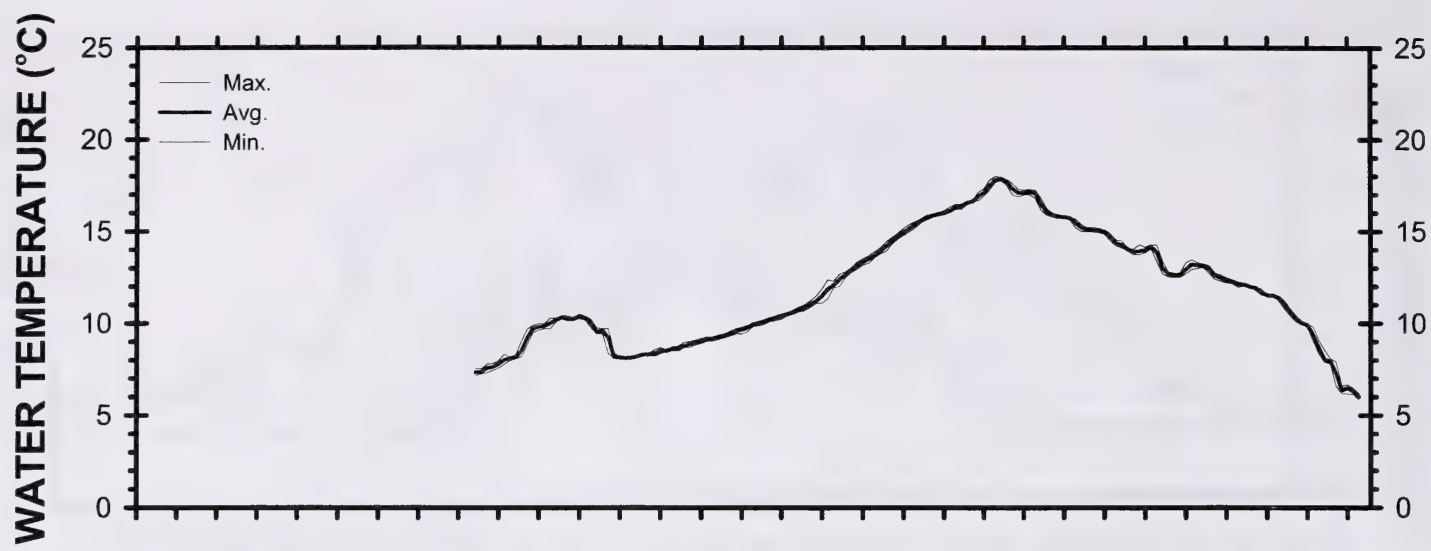

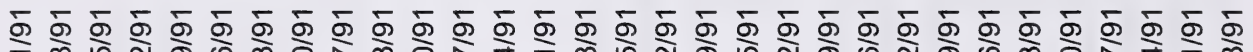

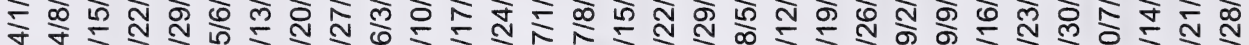

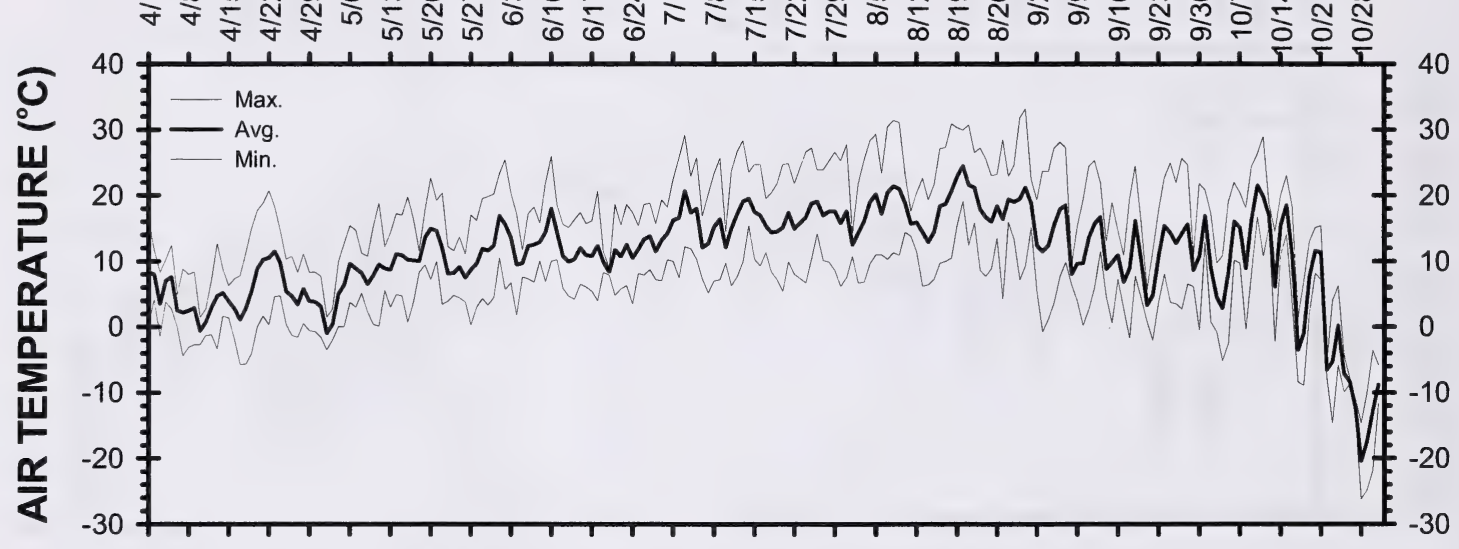

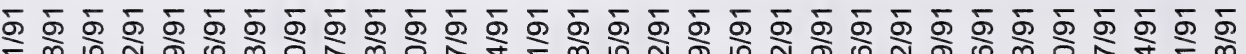

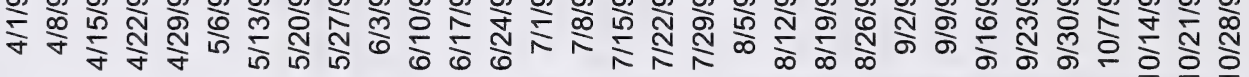

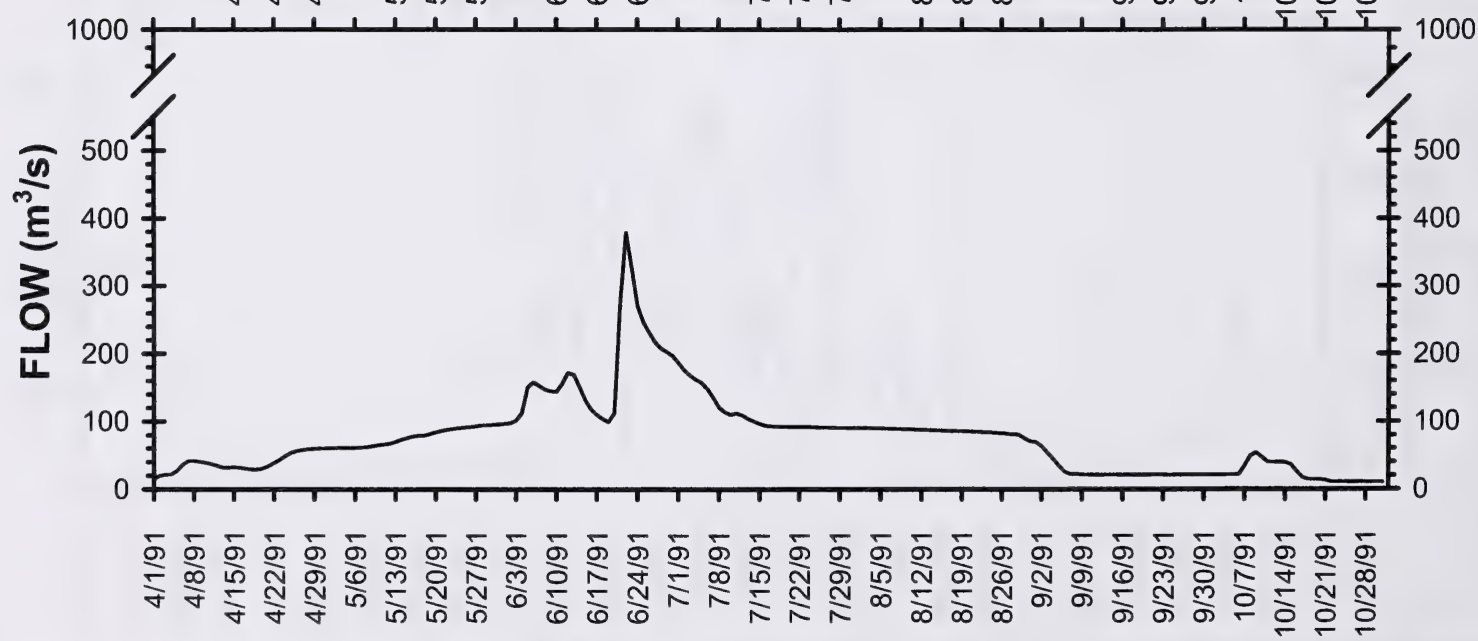

Figure 6. Daily water temperature (Datasonde), air temperature and flow in the Oldman River near Brocket. April-October 1991. 

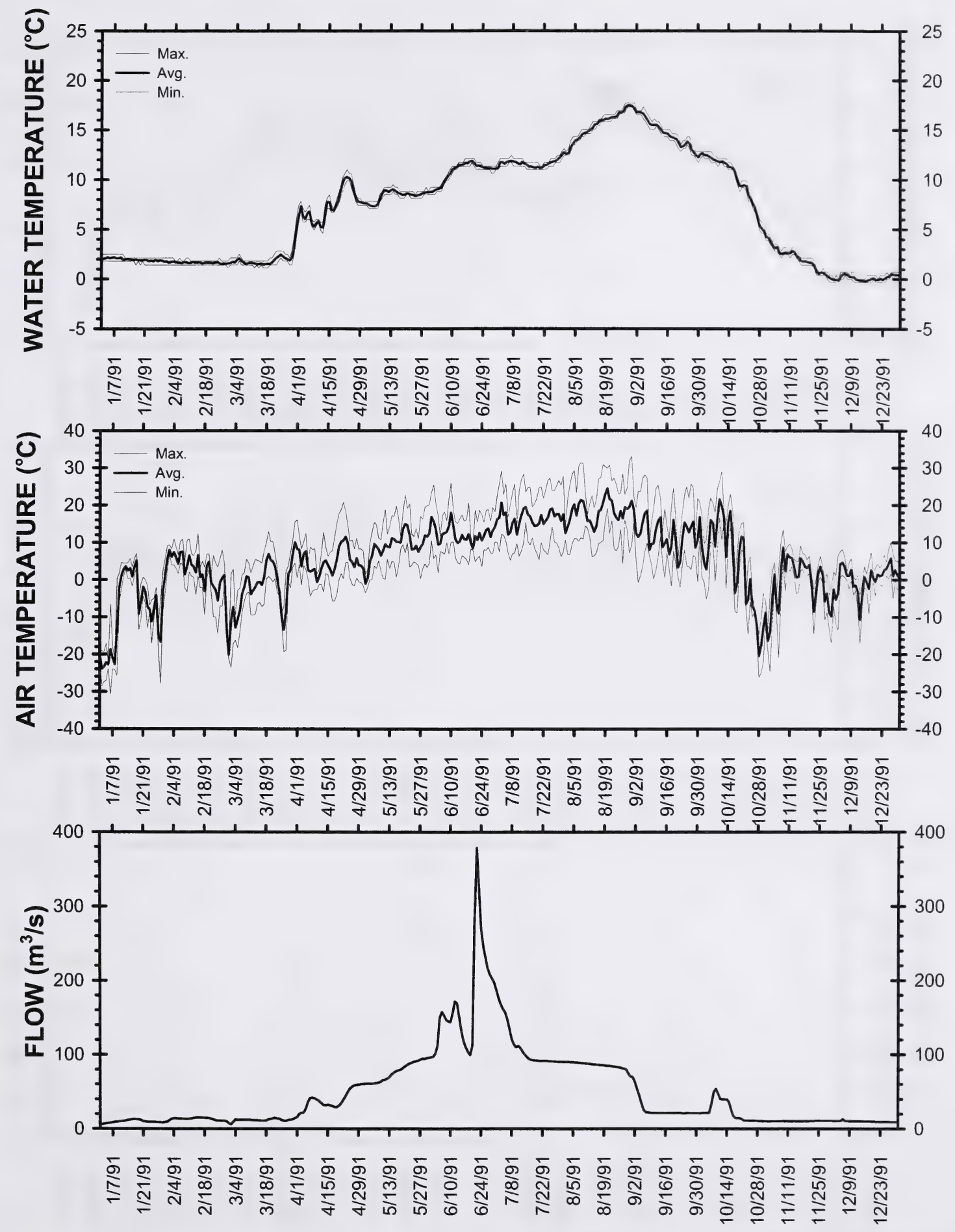

Figure 7. Daily water temperature (HANDAR 560), air temperature and flow in the Oldman River near Brocket. January-December, 1991. 


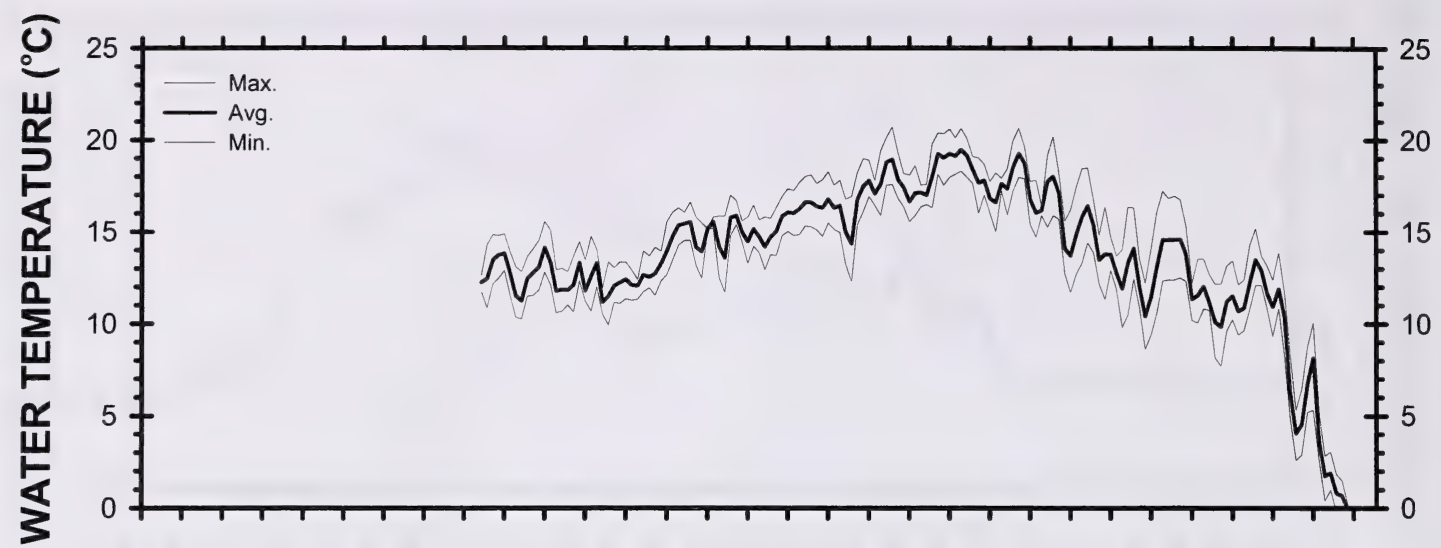

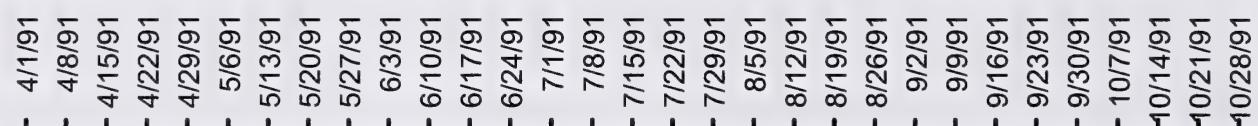
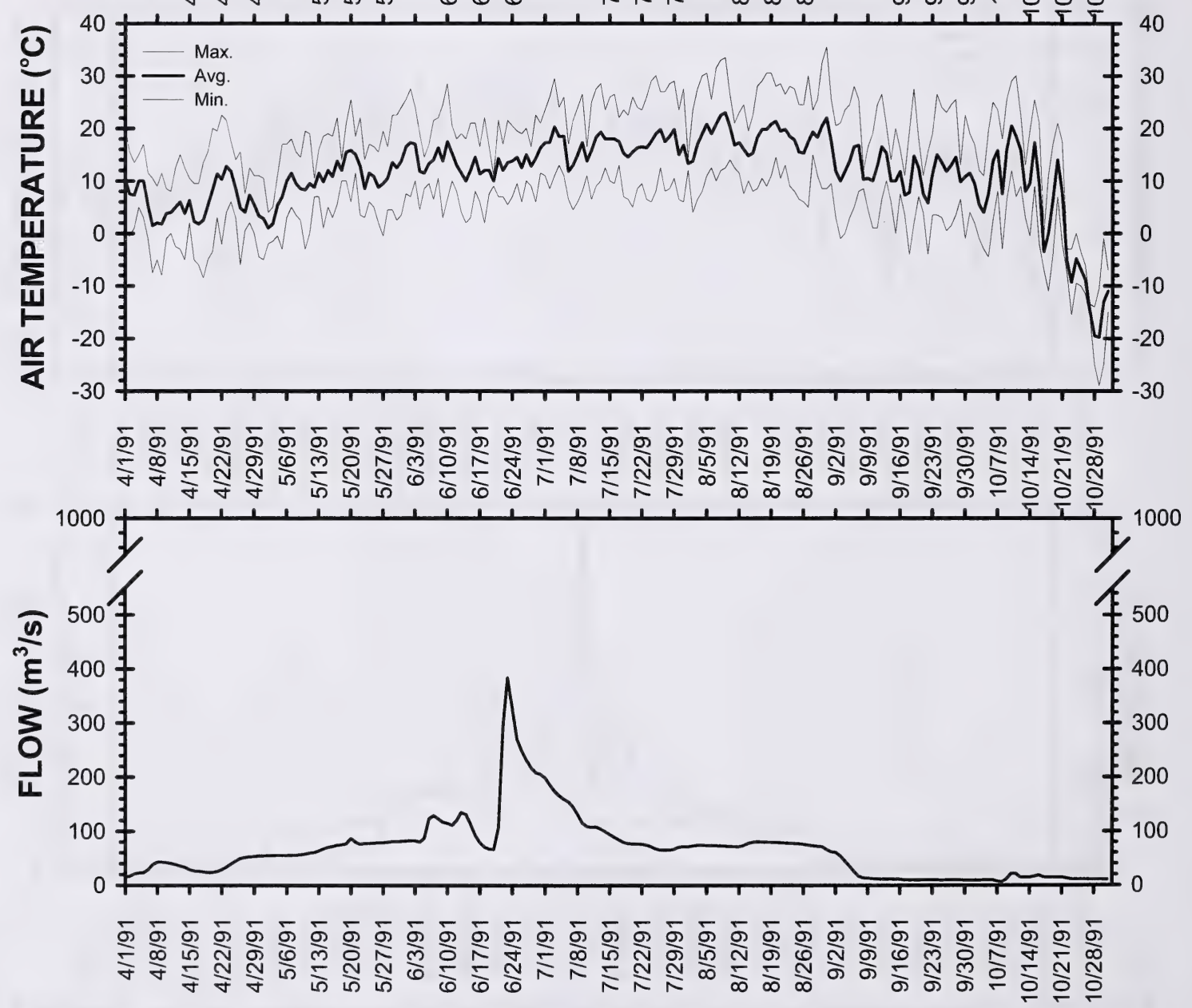

Figure 8. Daily water temperature (Datasonde), air temperature and flow in the Oldman River near Fort Macleod. April-October 1991. 


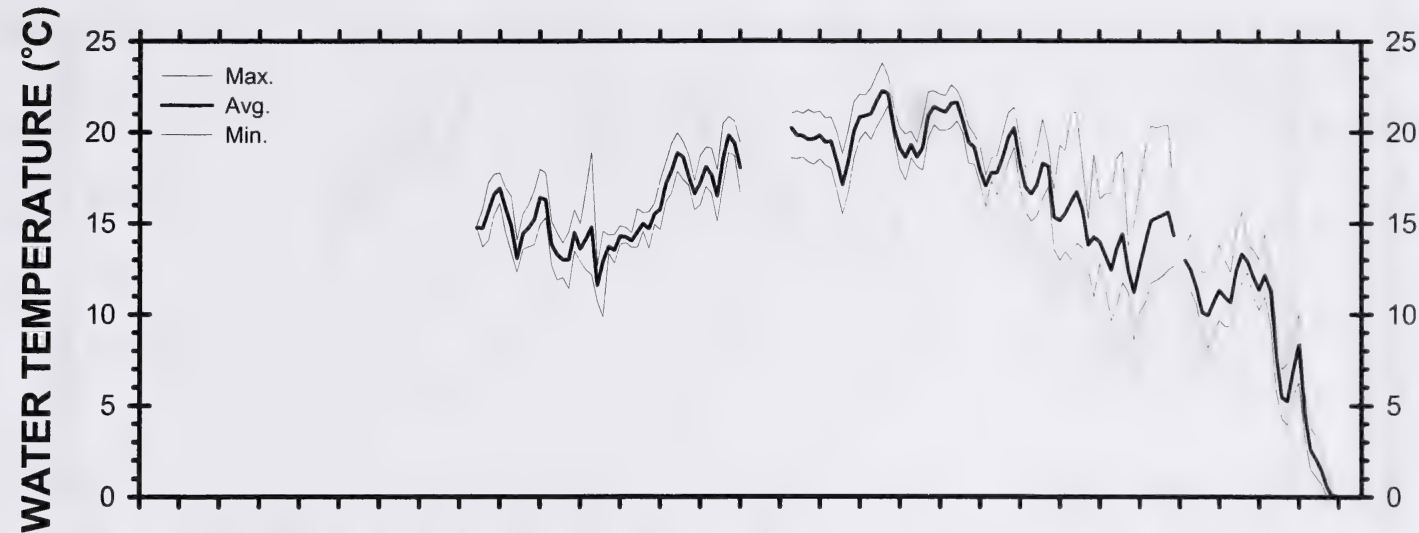

б চু

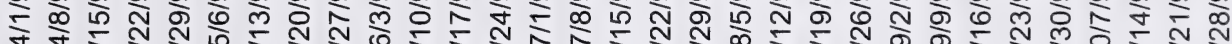

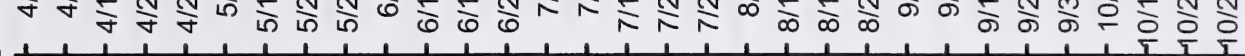

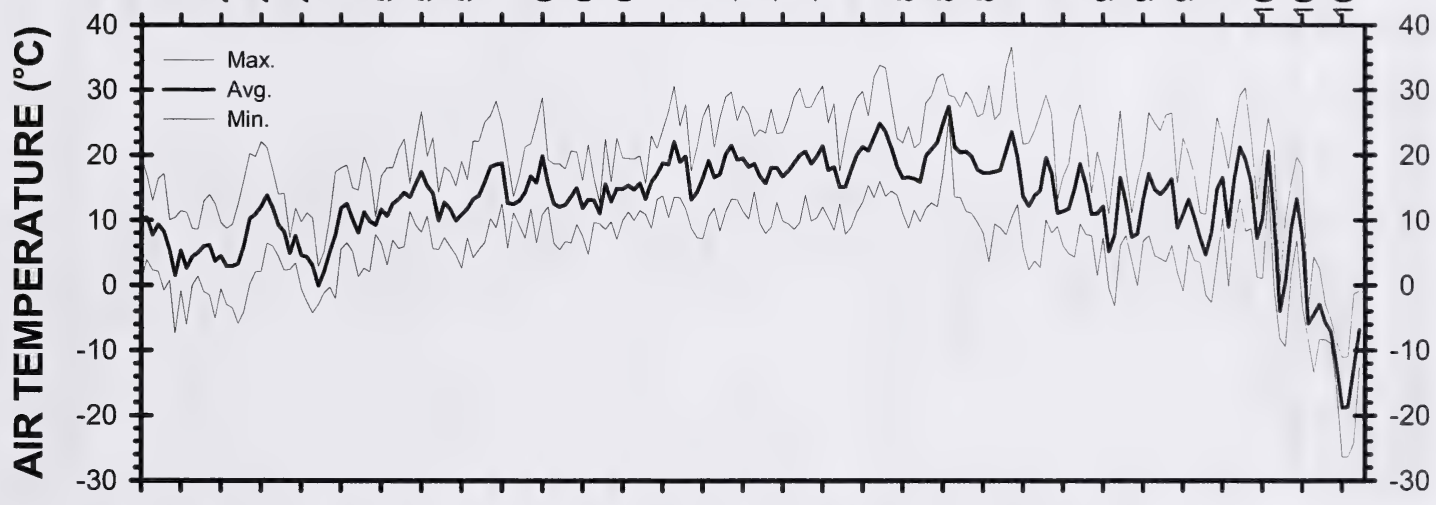

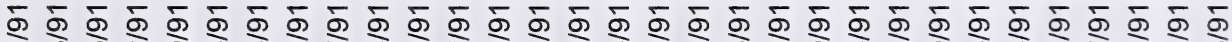

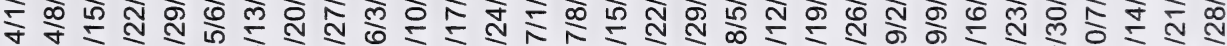

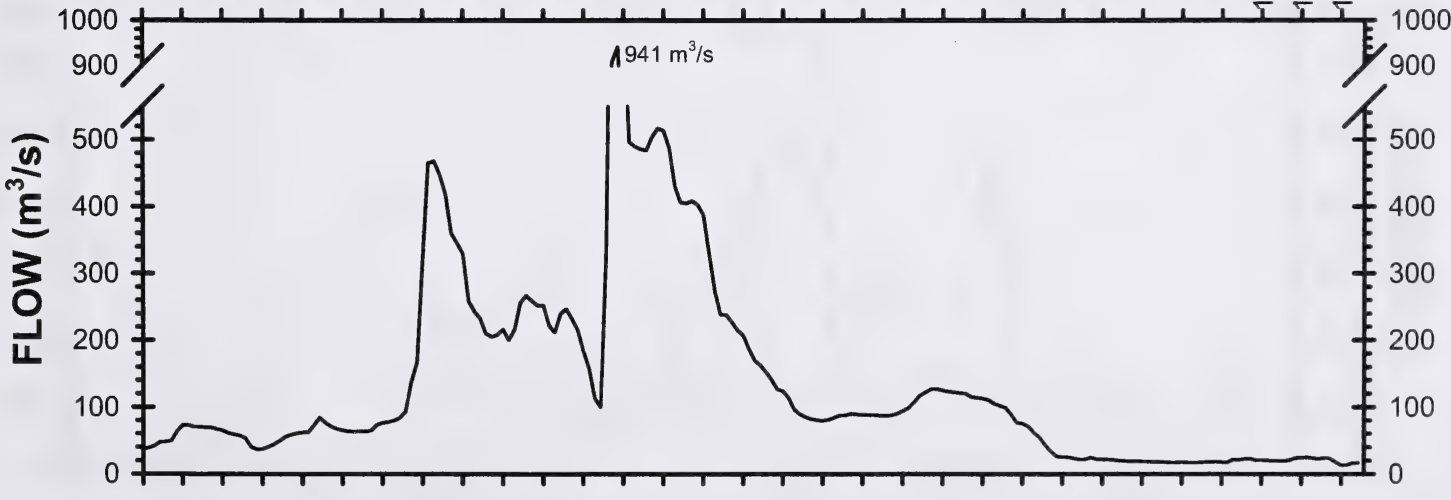

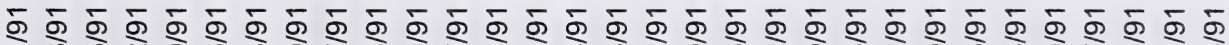

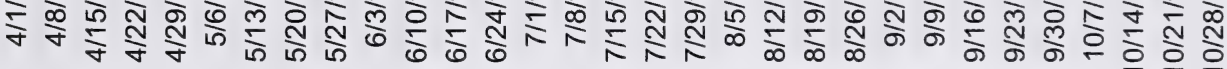

Figure 9. Daily water temperature (Datasonde), air temperature and flow in the Oldman River downstream of Lethbridge. April-October 1991. 


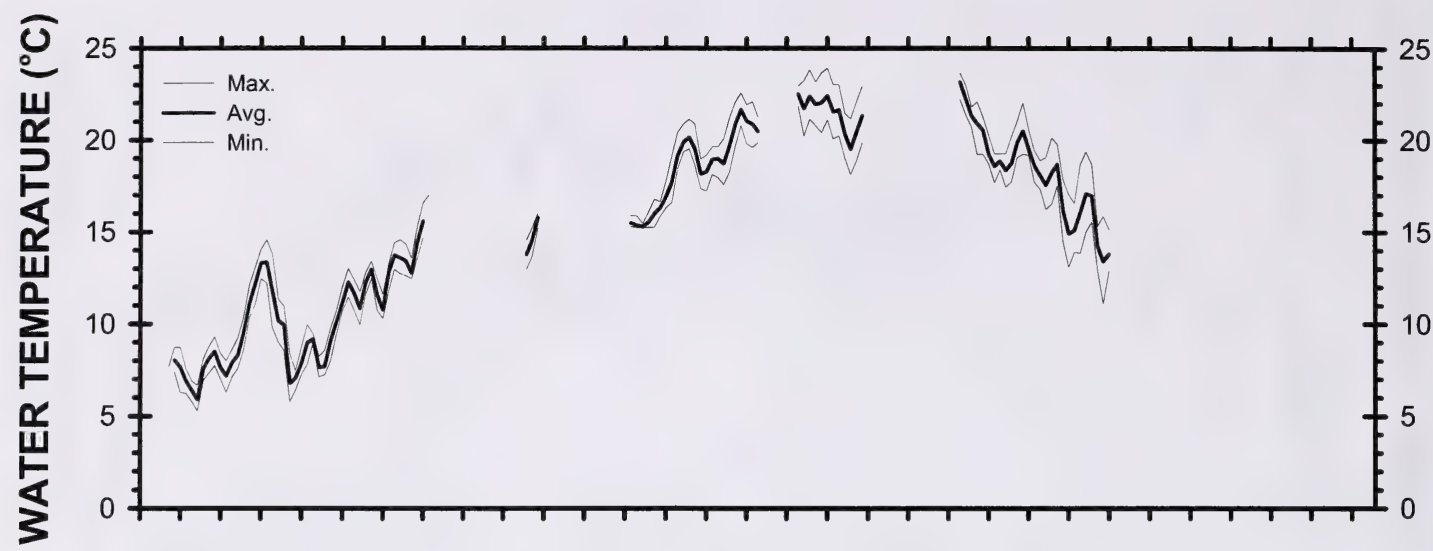

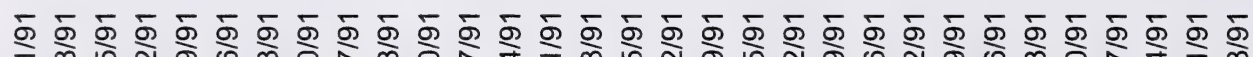
ᄀ $\frac{\gamma}{\sim}$ 令

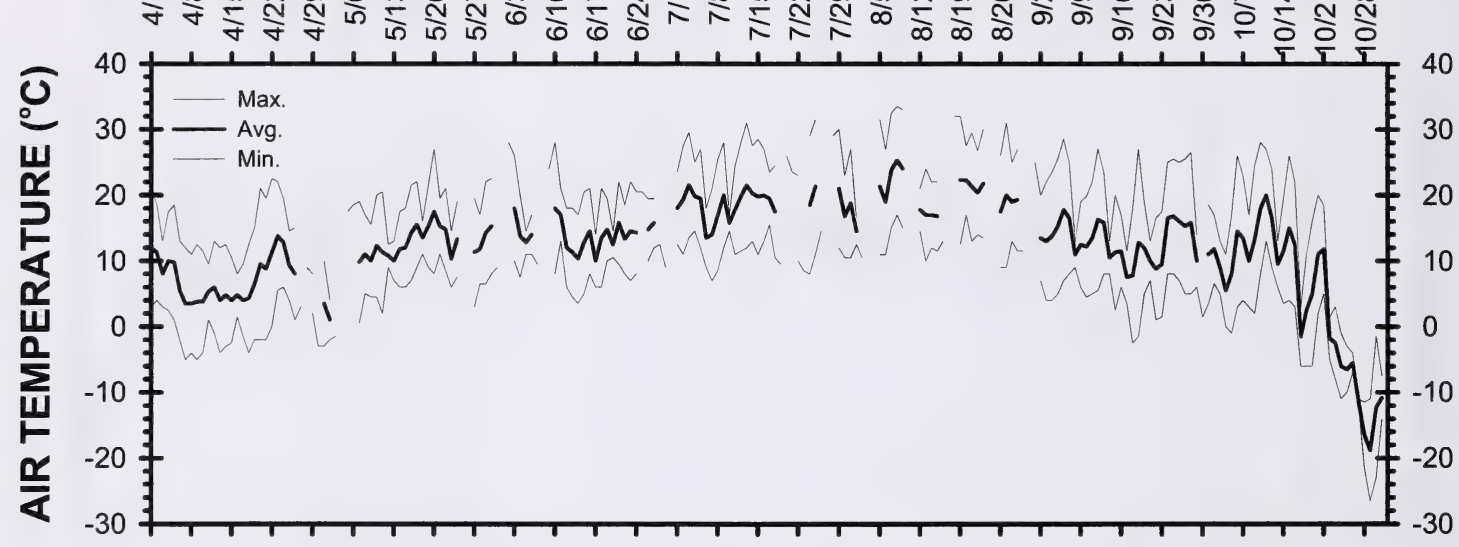

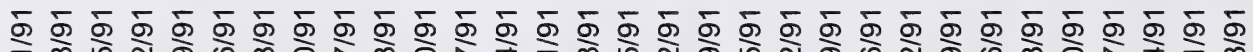

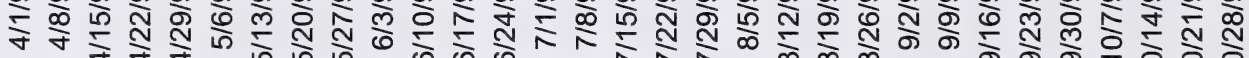

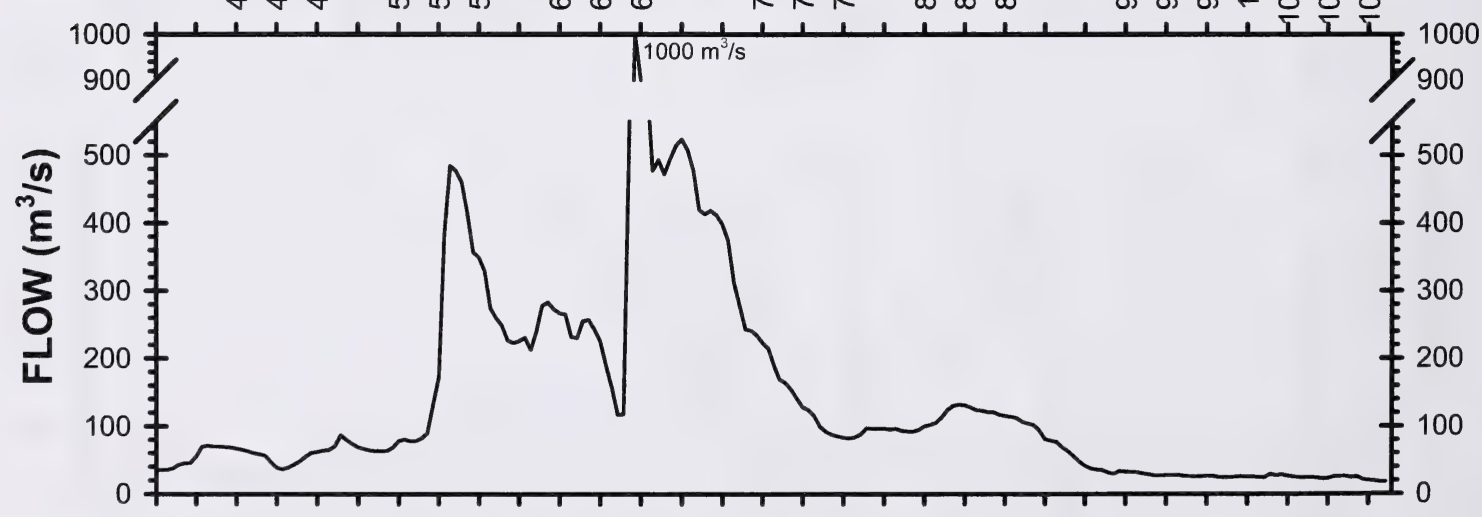

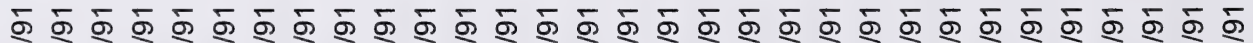

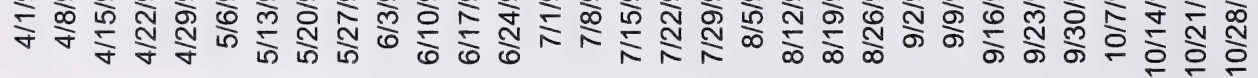

Figure 10. Daily water temperature (Datasonde), air temperature and flow in the Oldman River at the Bow River confluence. April-October 1991. 


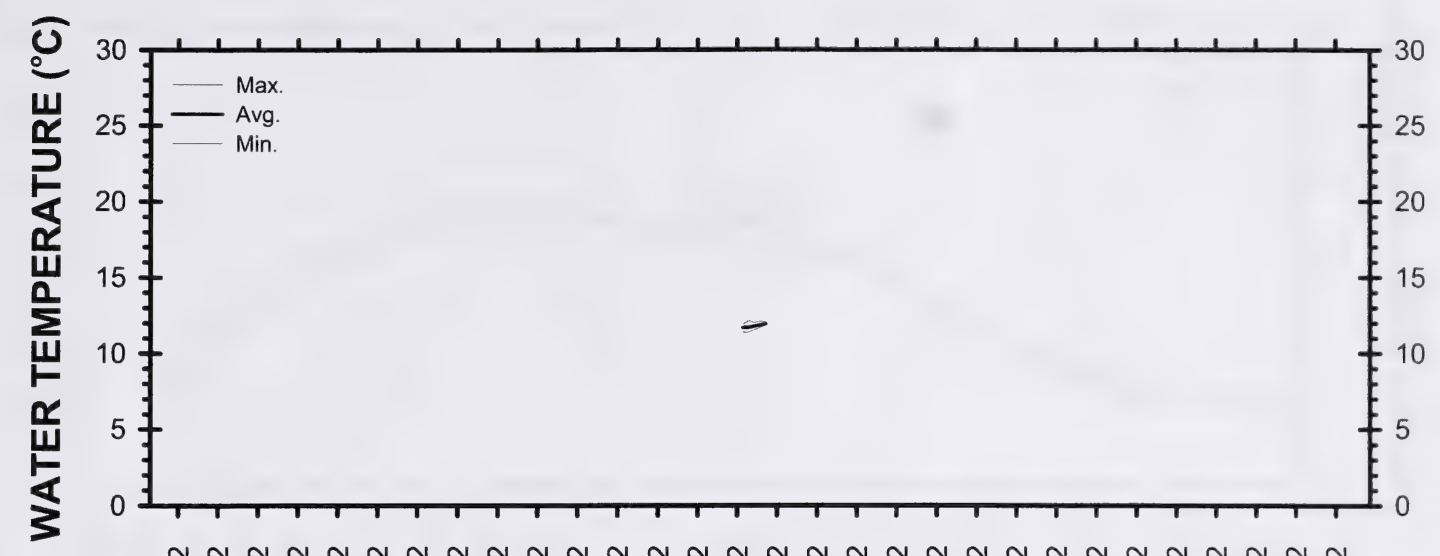

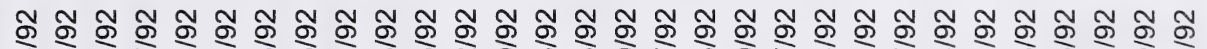

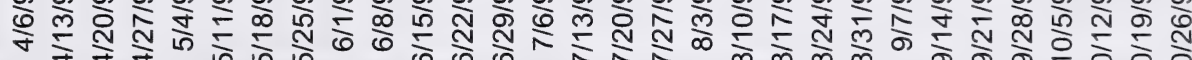

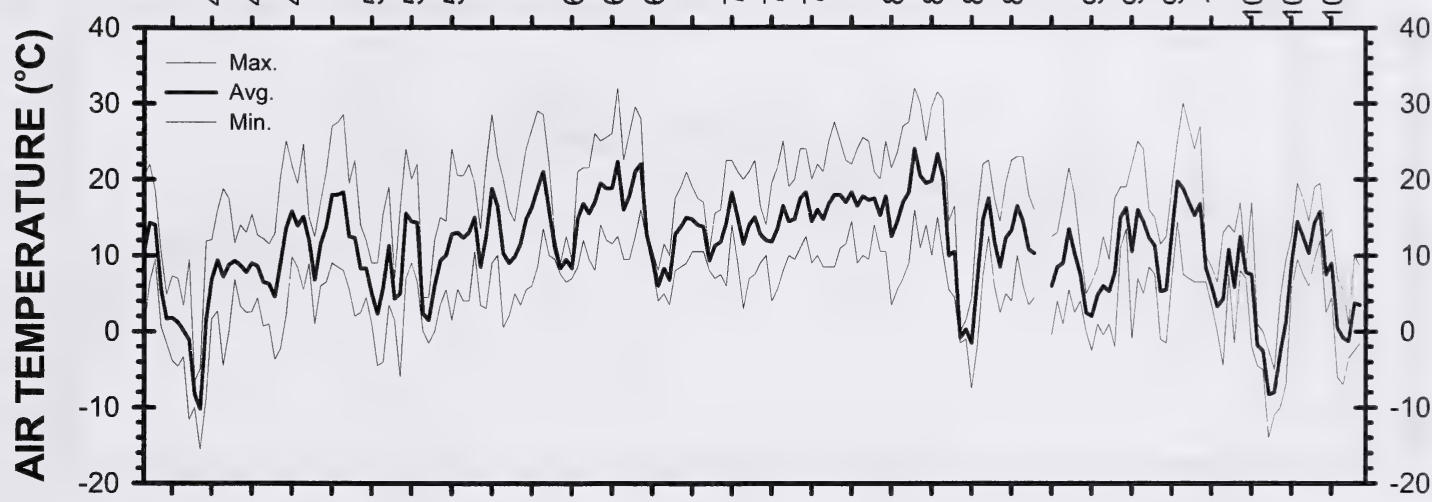

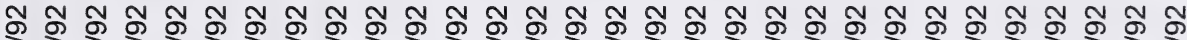

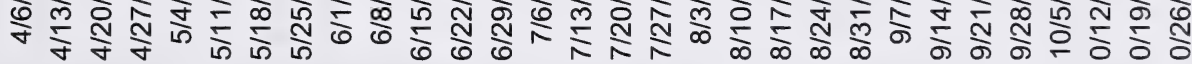

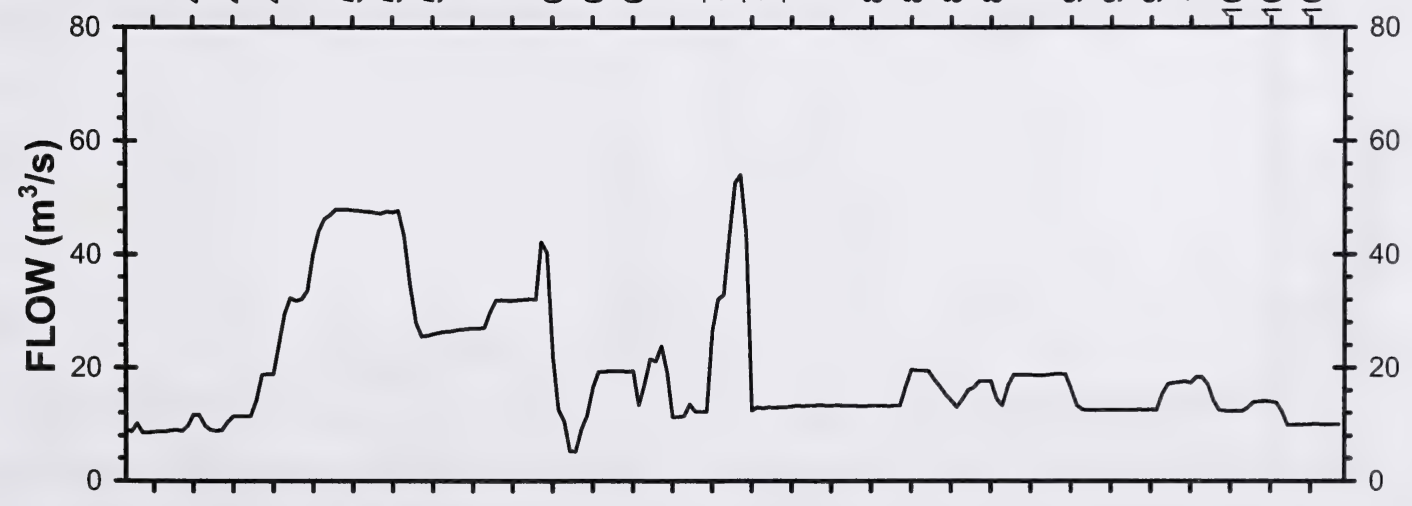

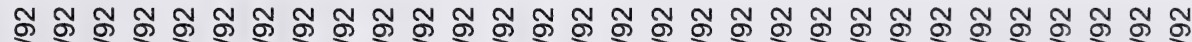

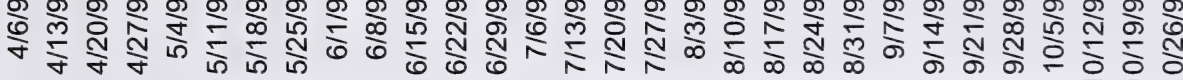

Figure 11. Daily water temperature (Datasonde), air temperature and flow in the Oldman River near Brocket. April-October 1992. 

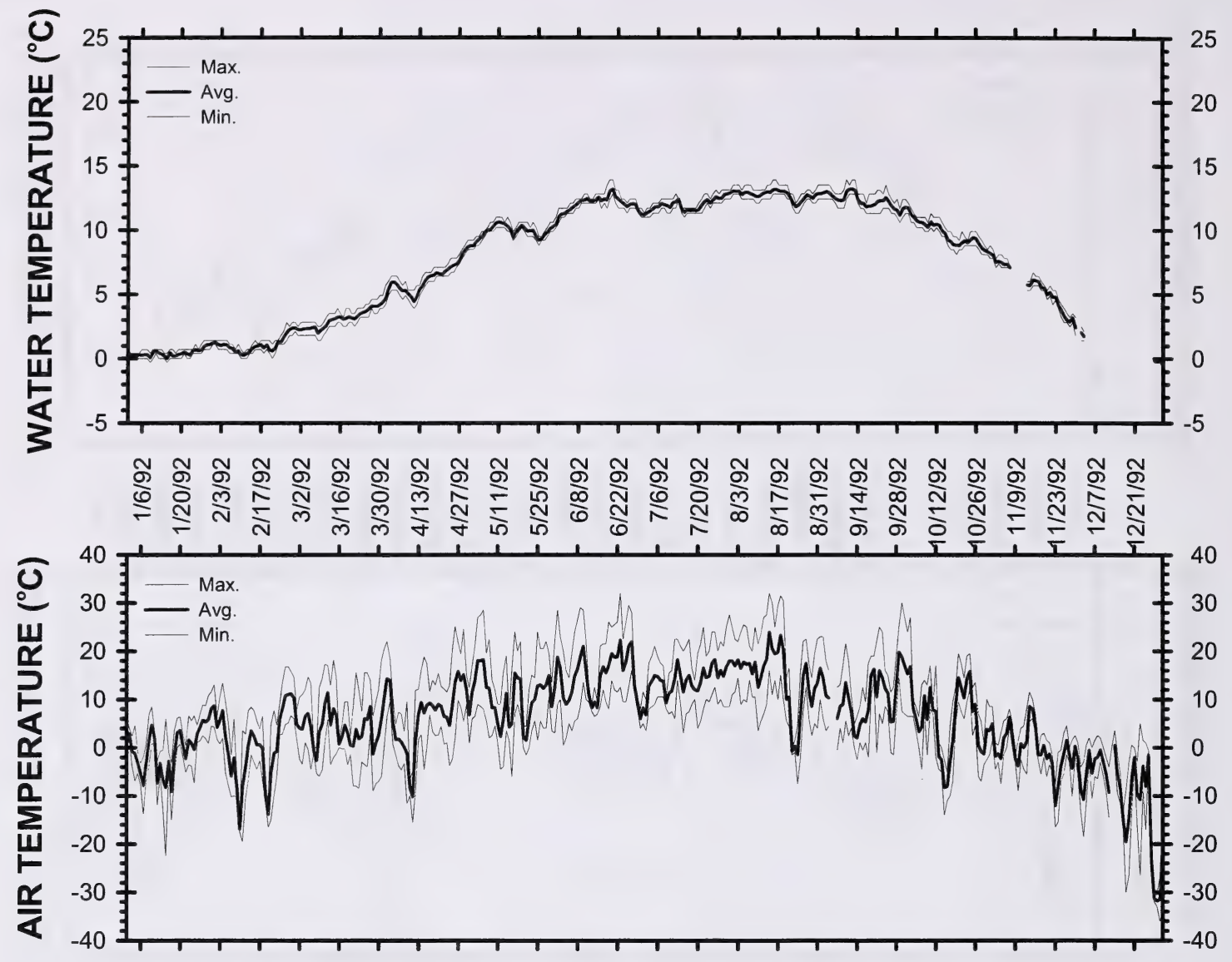

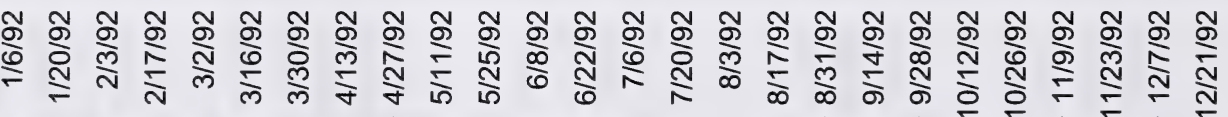

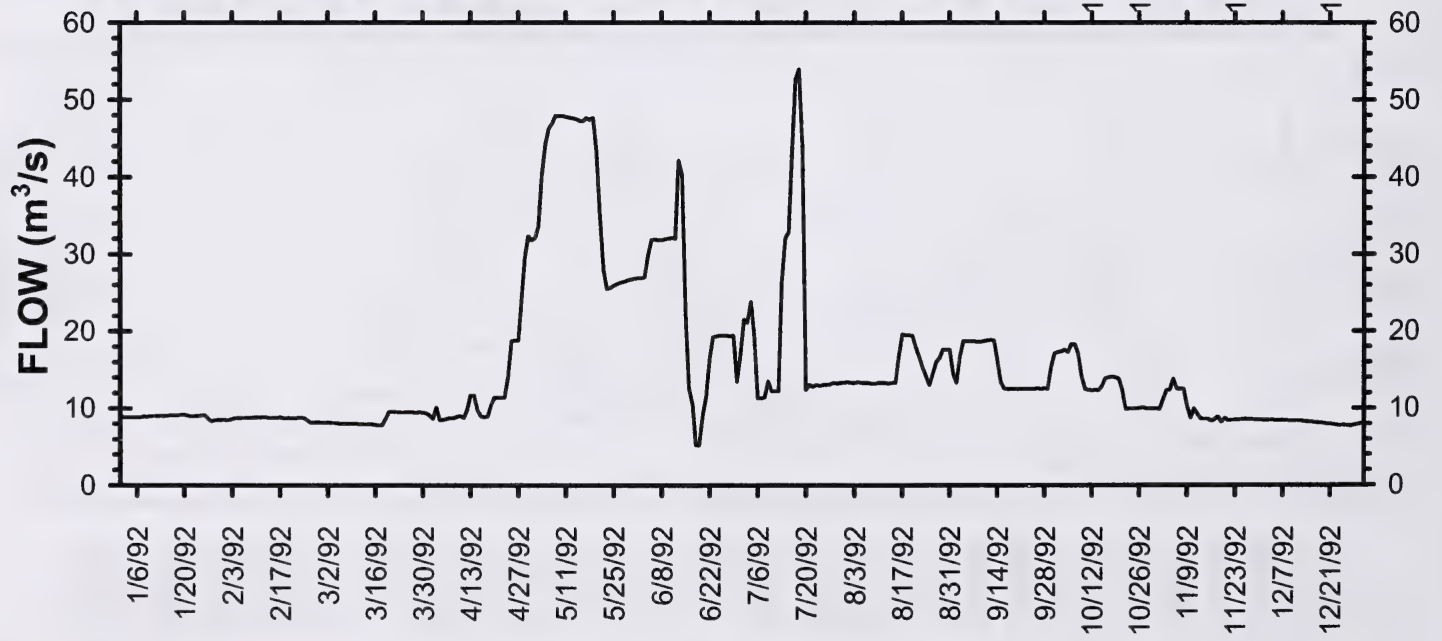

Figure 12. Daily water temperature (HANDAR 560), air temperature and flow in the Oldman River near Brocket. January-December, 1992. 


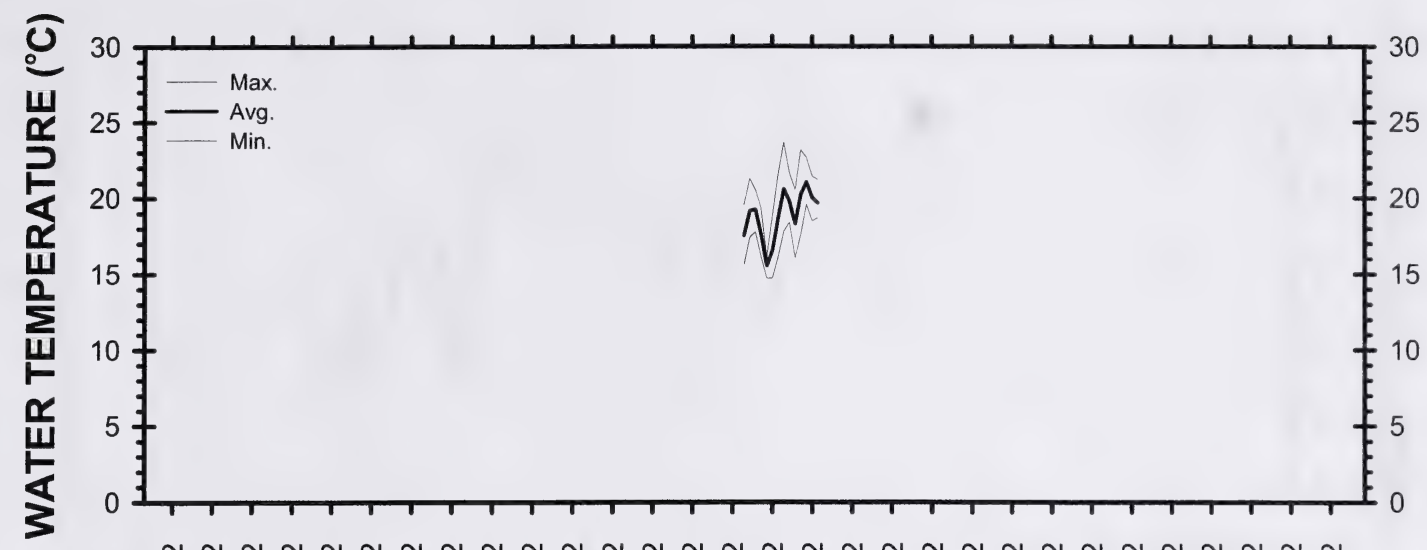

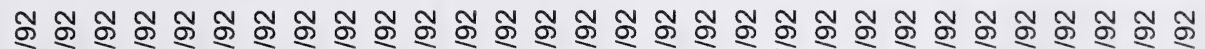

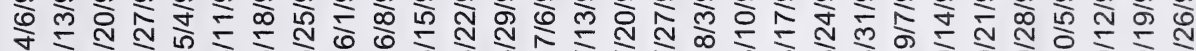

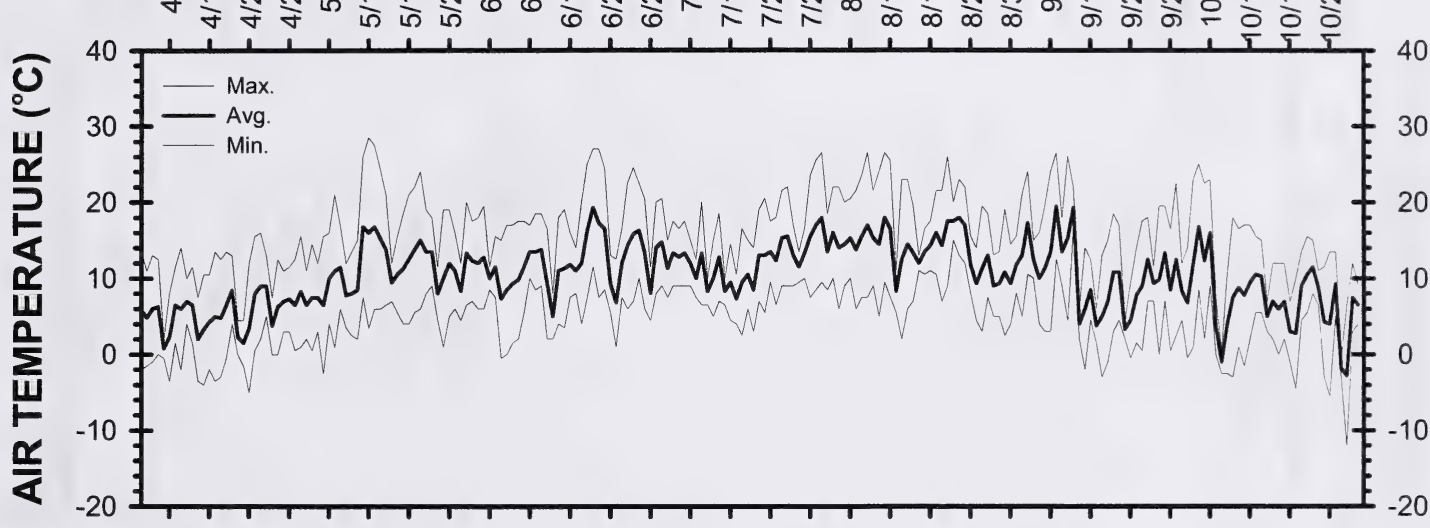

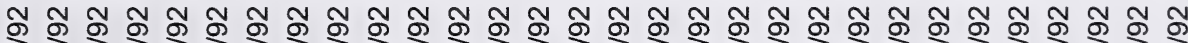

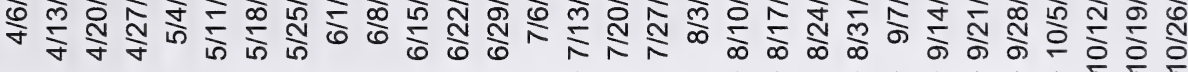

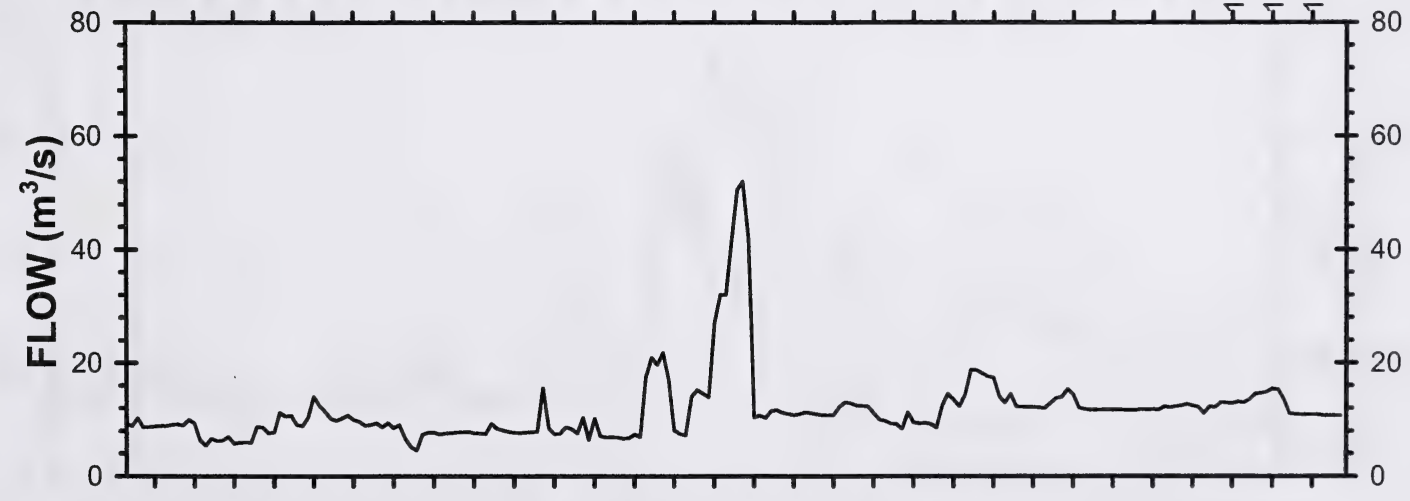

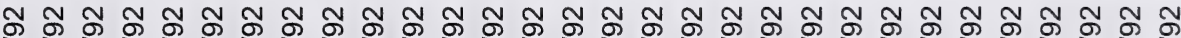

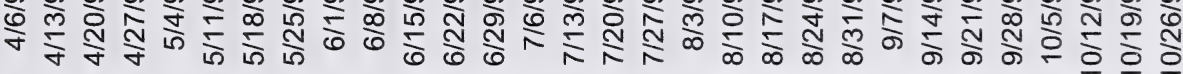

Figure 13. Daily water temperature (Datasonde), air temperature and flow in the Oldman River near Fort Macleod. April-October 1992. 


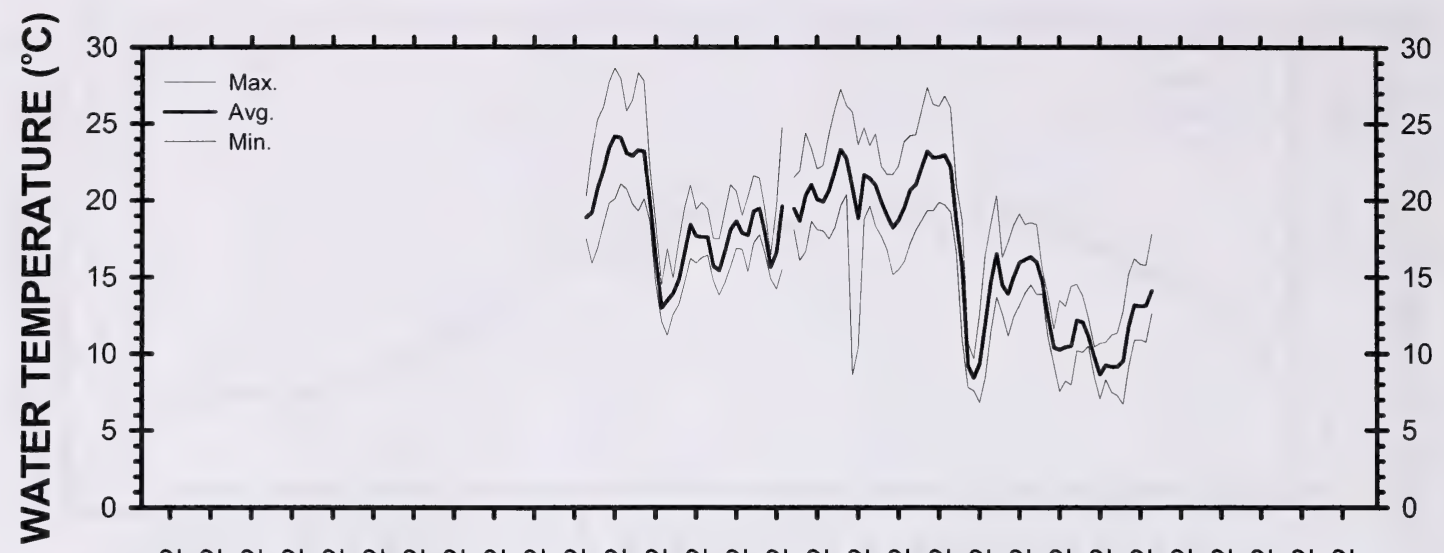

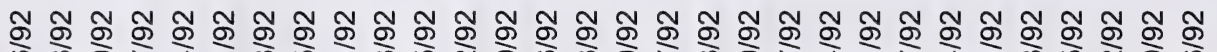

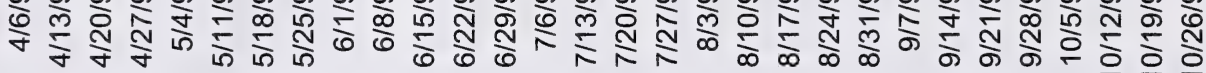

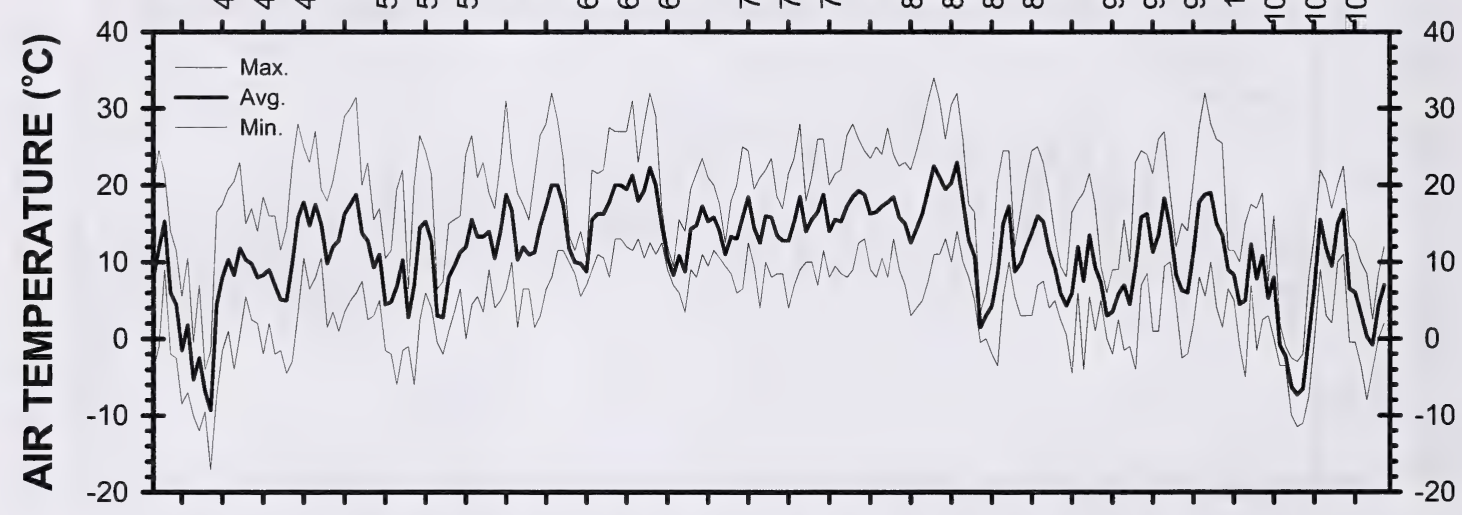

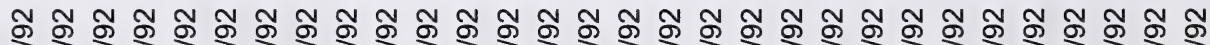

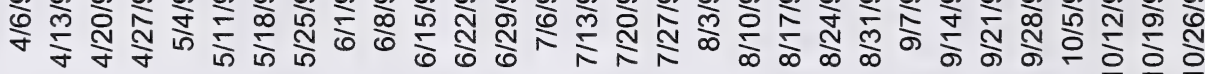

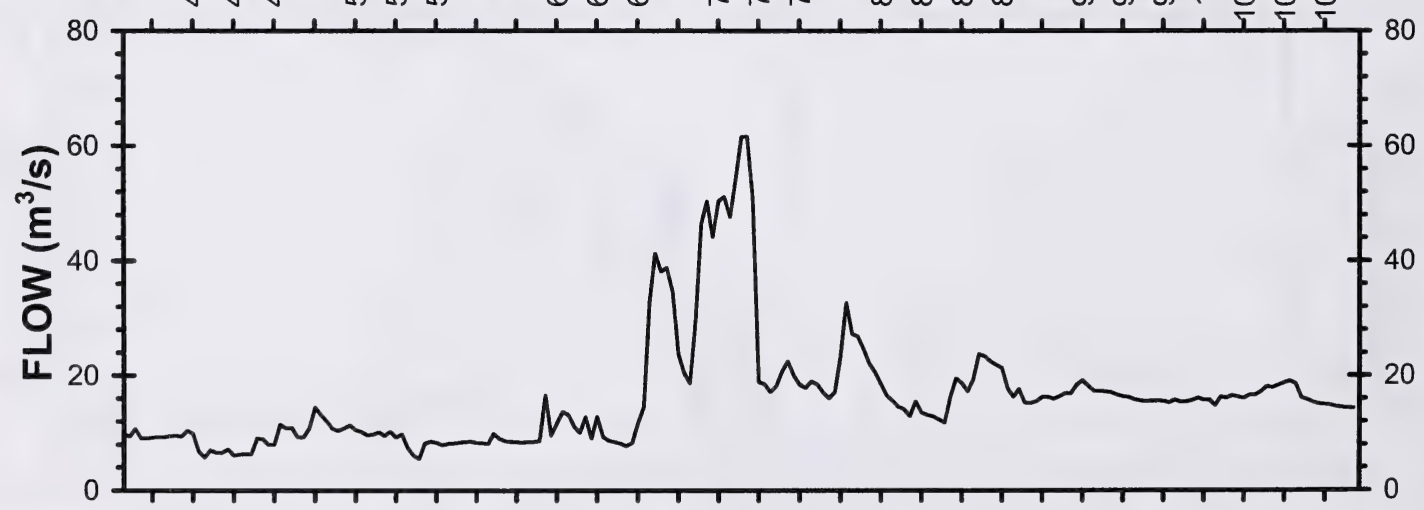

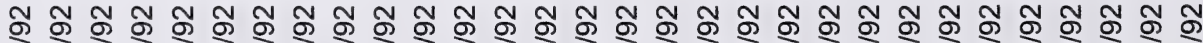

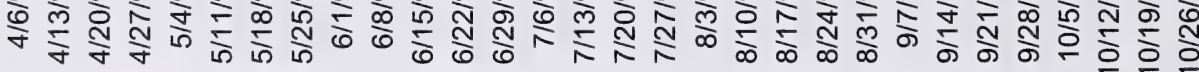

Figure 14. Daily water temperature (Datasonde), air temperature and flow in the Oldman River near Monarch. April-October 1992. 


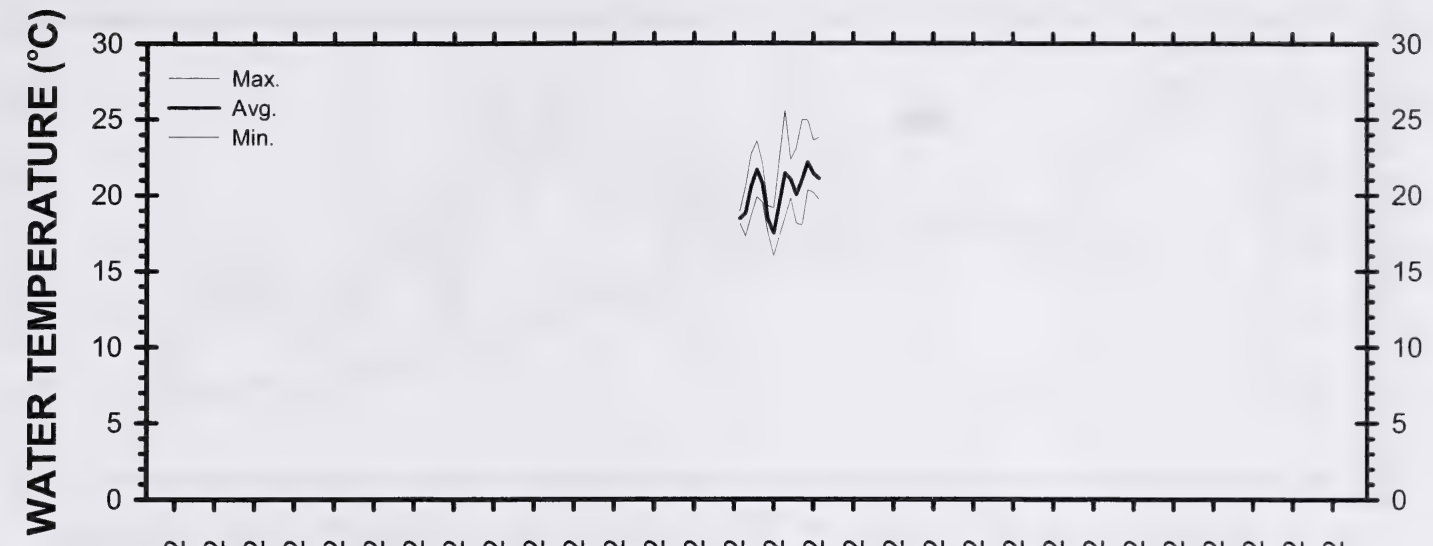

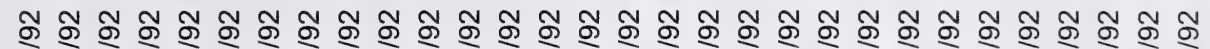
尚

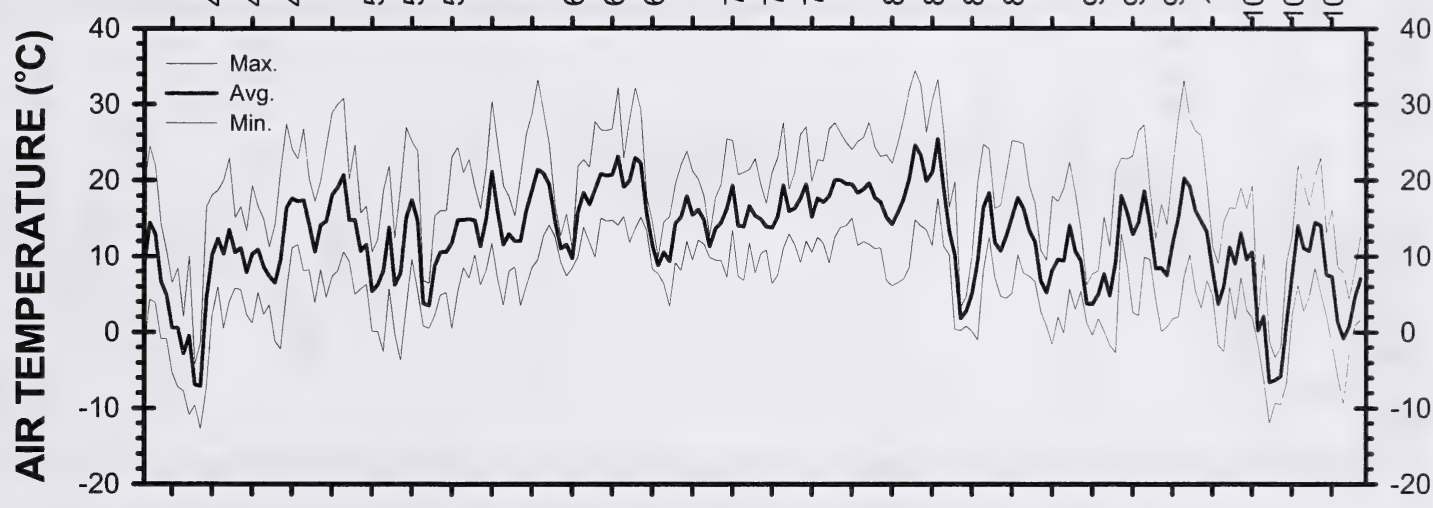

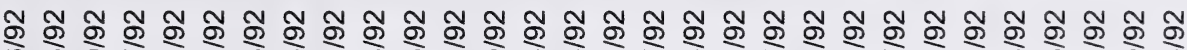
v

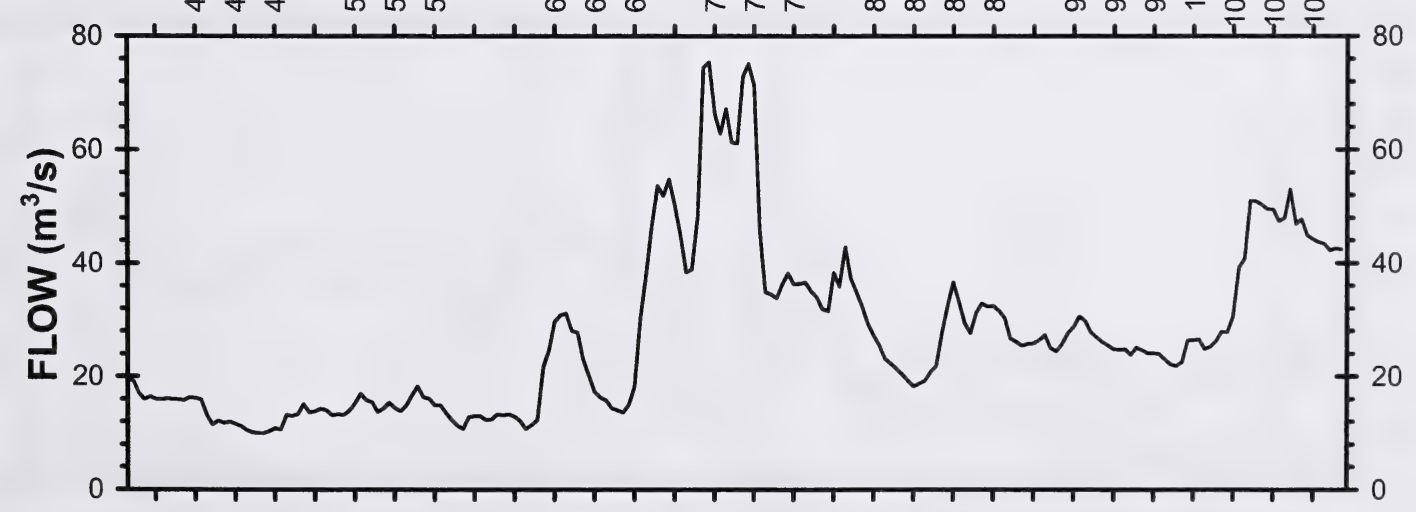

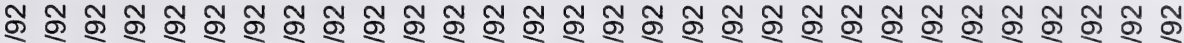

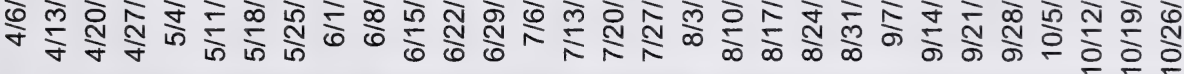

Figure 15. Daily water temperature (Datasonde), air temperature and flow in the Oldman River downstream of Lethbridge. April-October 1992. 


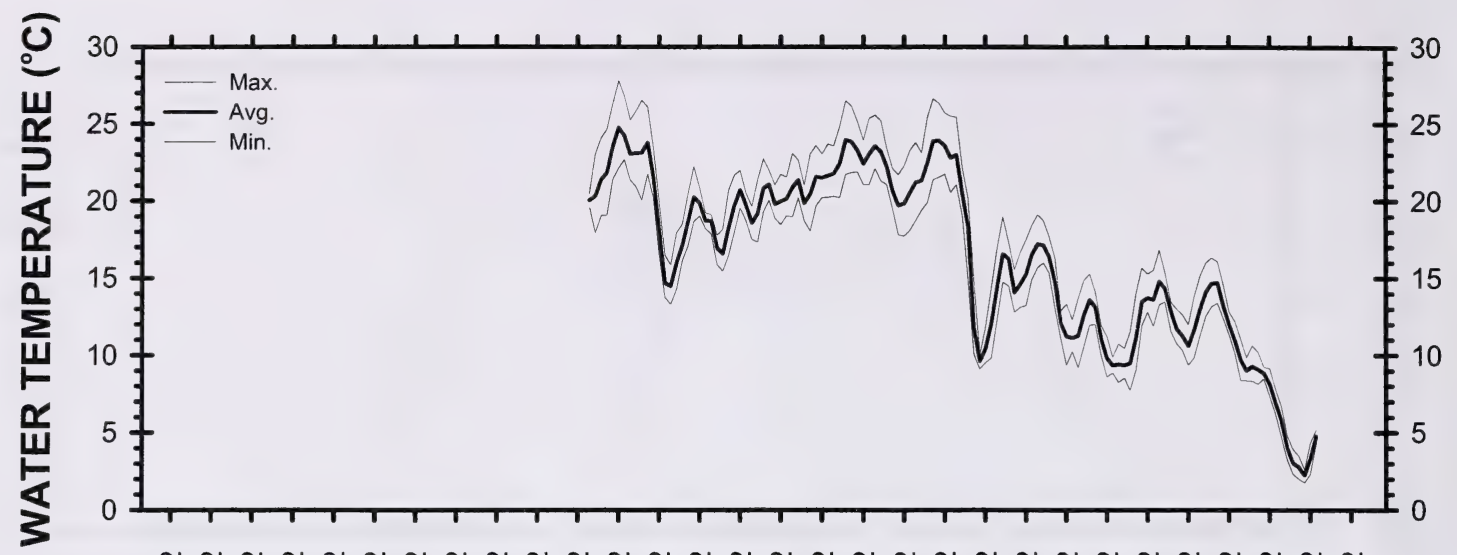

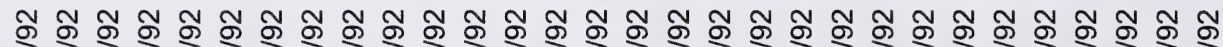

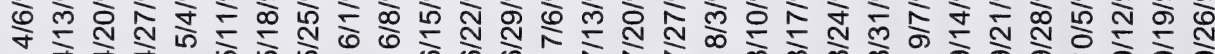

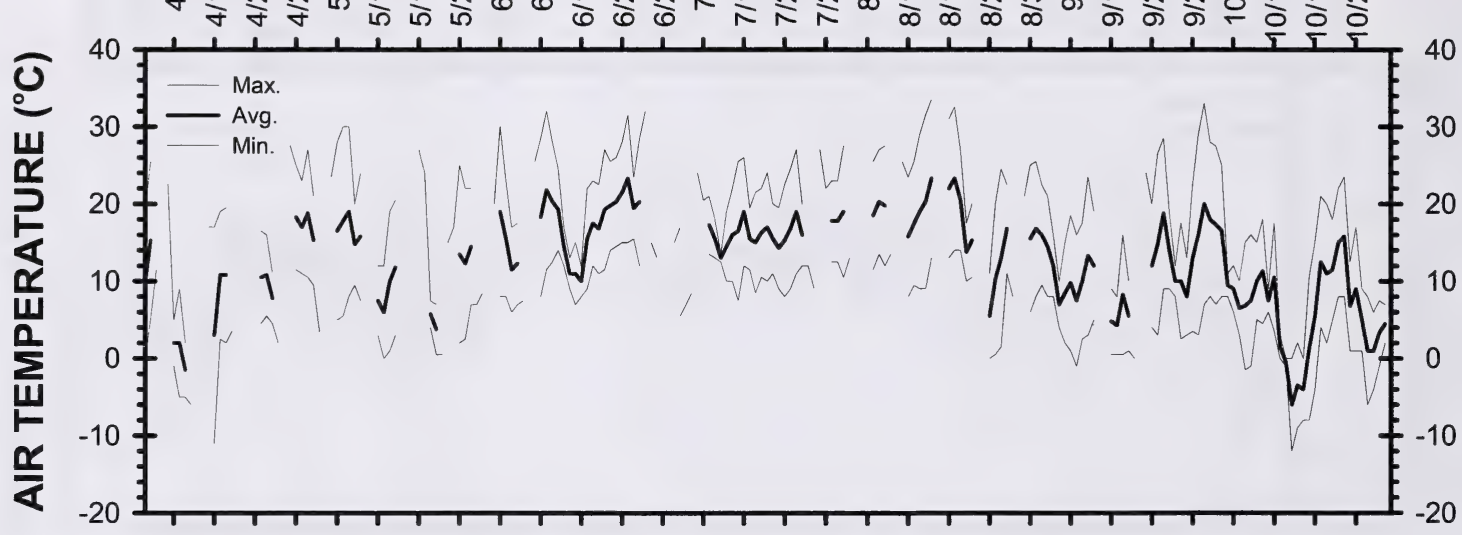

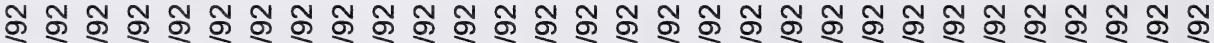

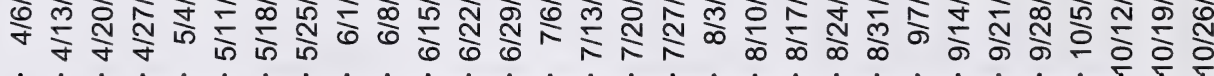

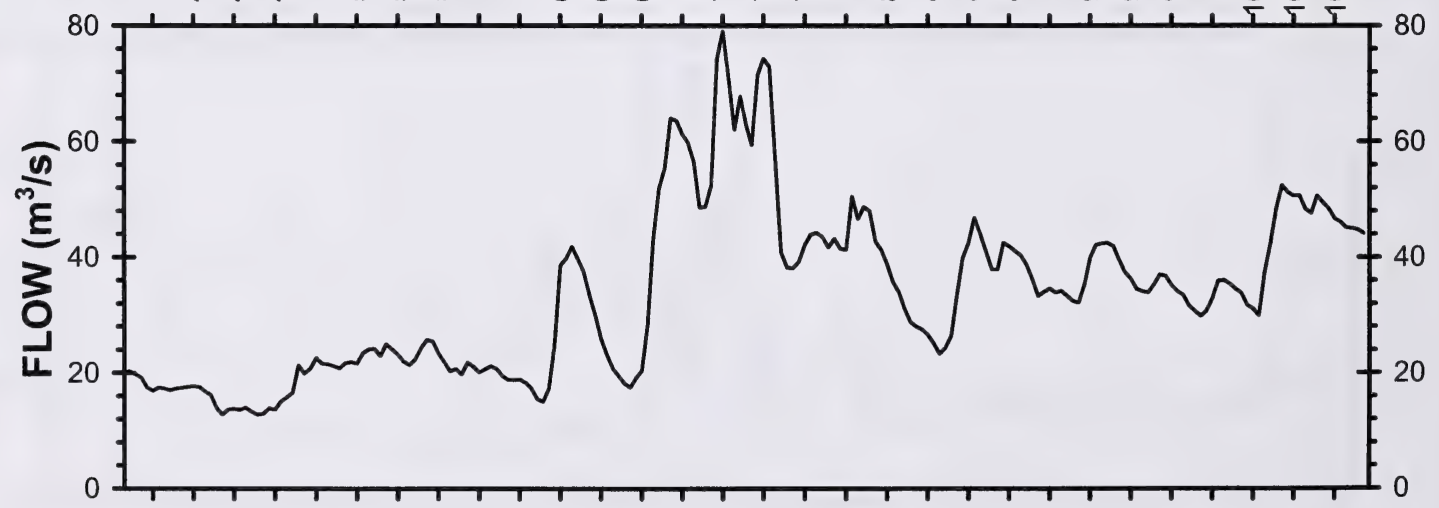

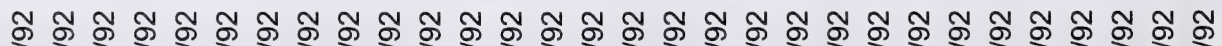

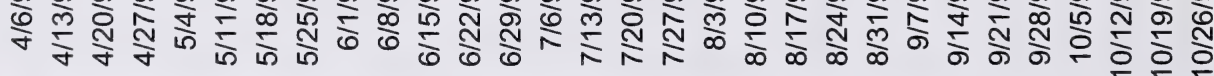

Figure 16. Daily water temperature (Datasonde), air temperature and flow in the Oldman River at the Bow River confluence. April-October 1992. 

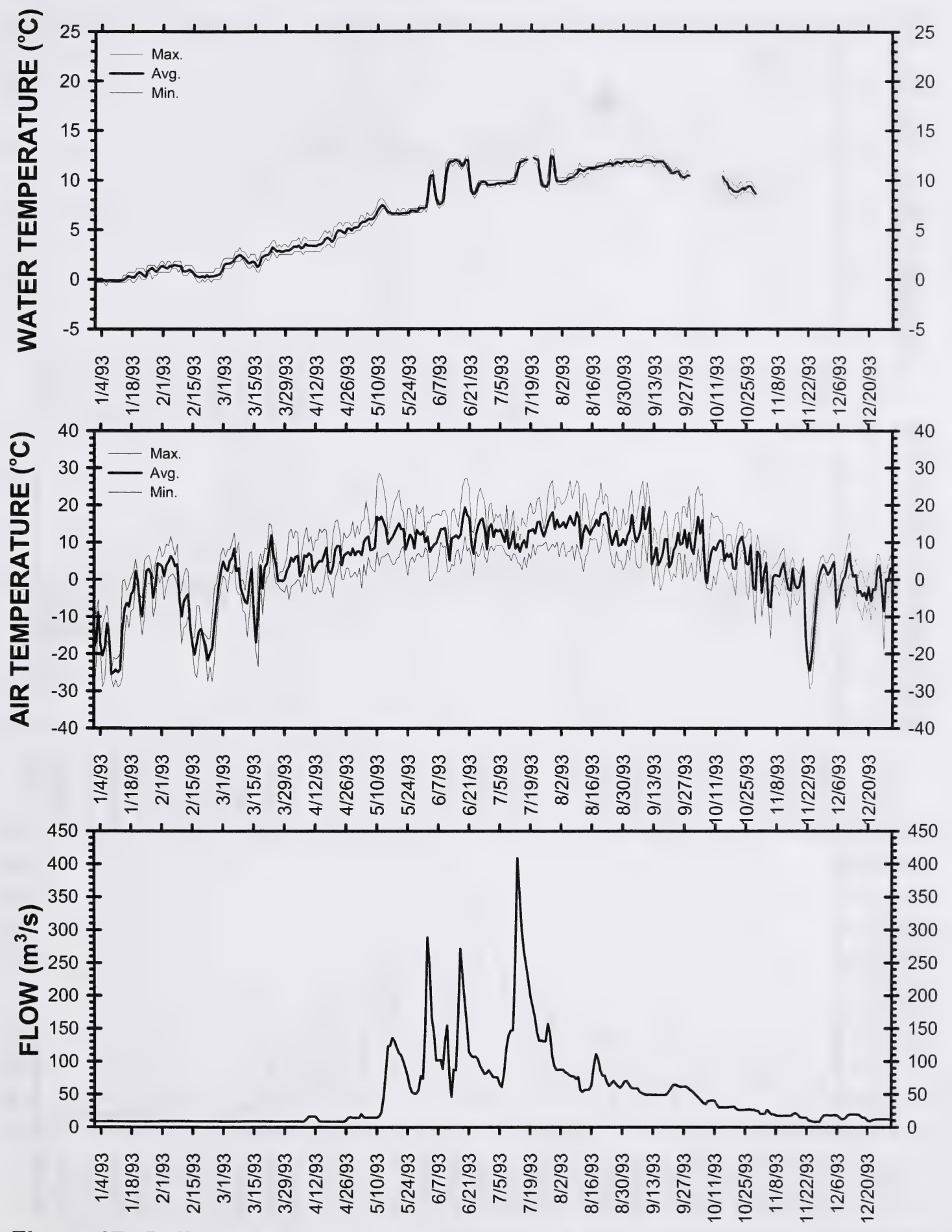

Figure 17. Daily water temperature (HANDAR 560), air temperature and flow in the Oldman River near Brocket. January-December, 1993. 


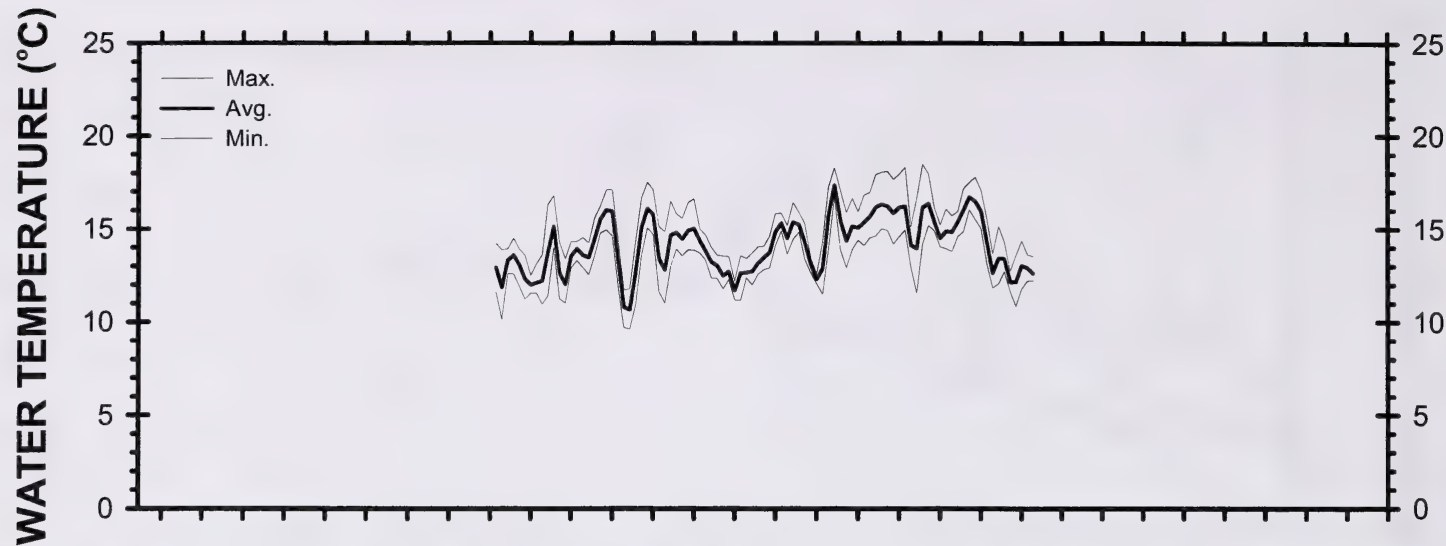

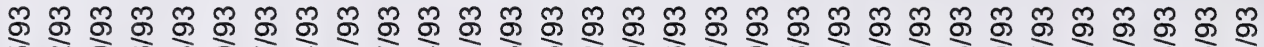

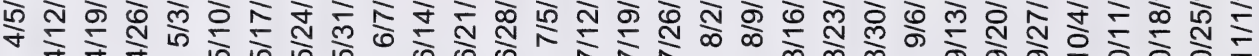

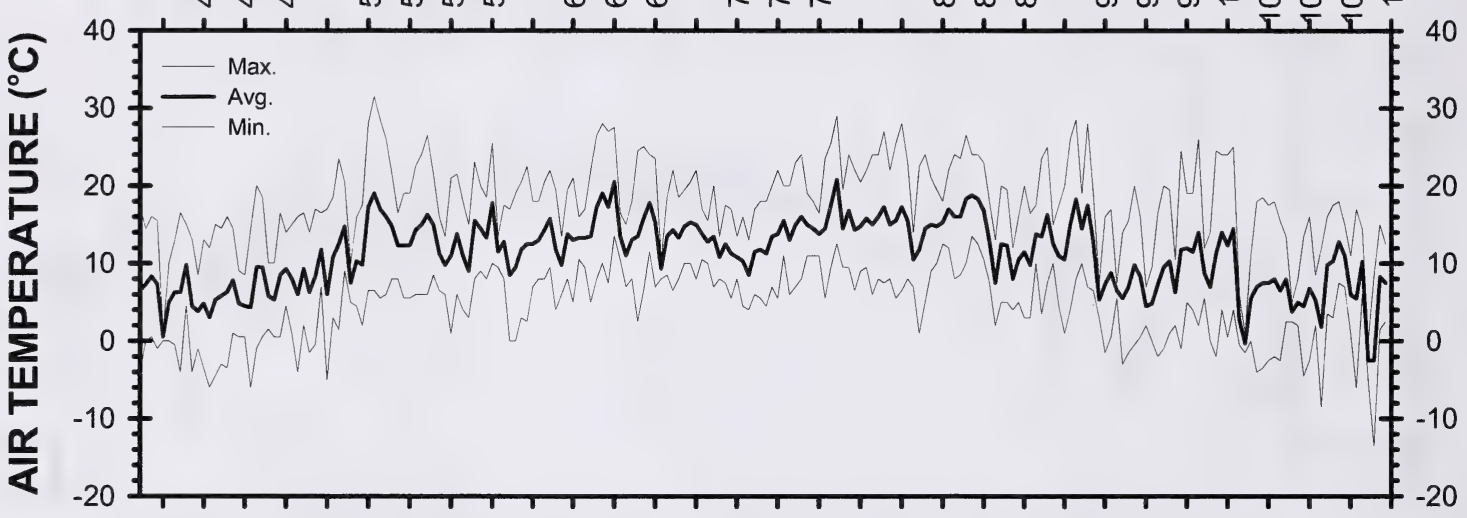

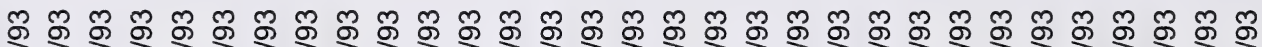

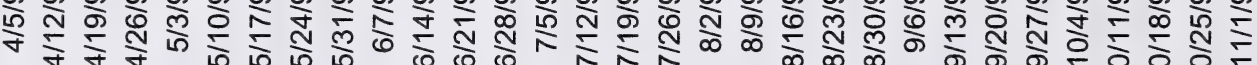

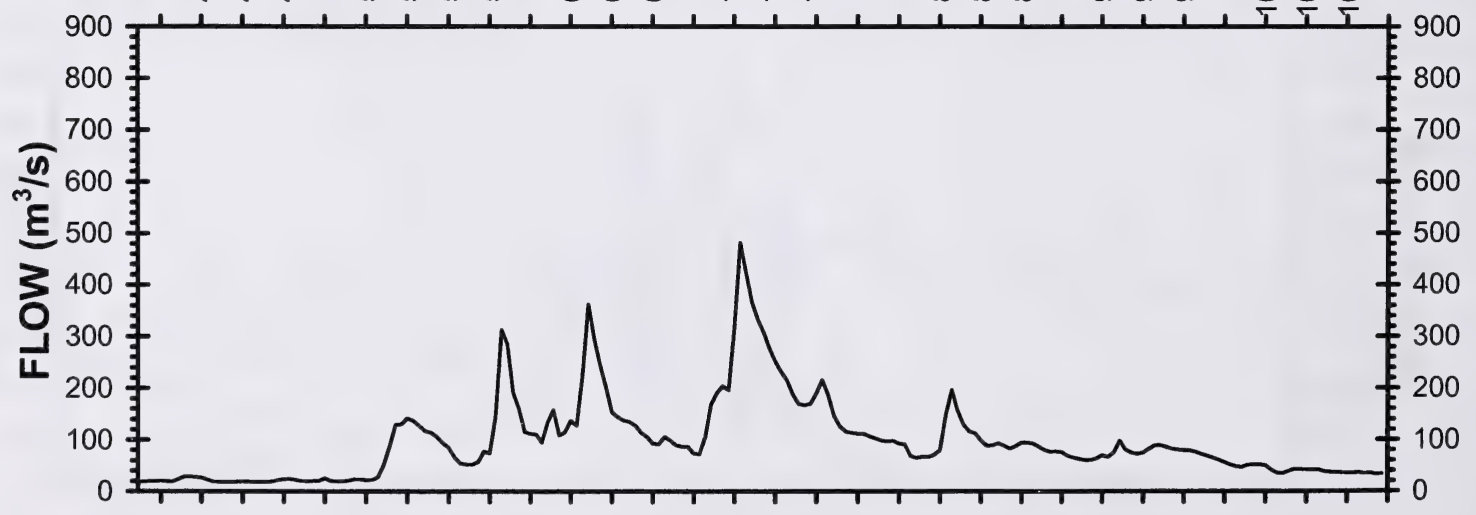

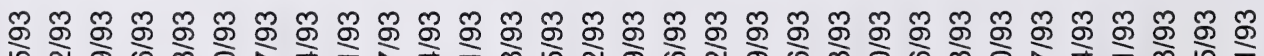

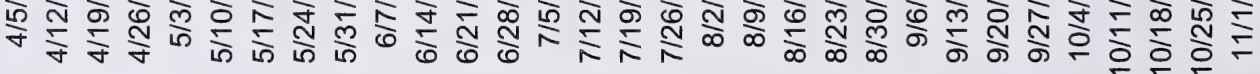

Figure 18. Daily water temperature (Datasonde), air temperature and flow in the Oldman River near Monarch. April-October 1993. 


\section{(0)}

需 25

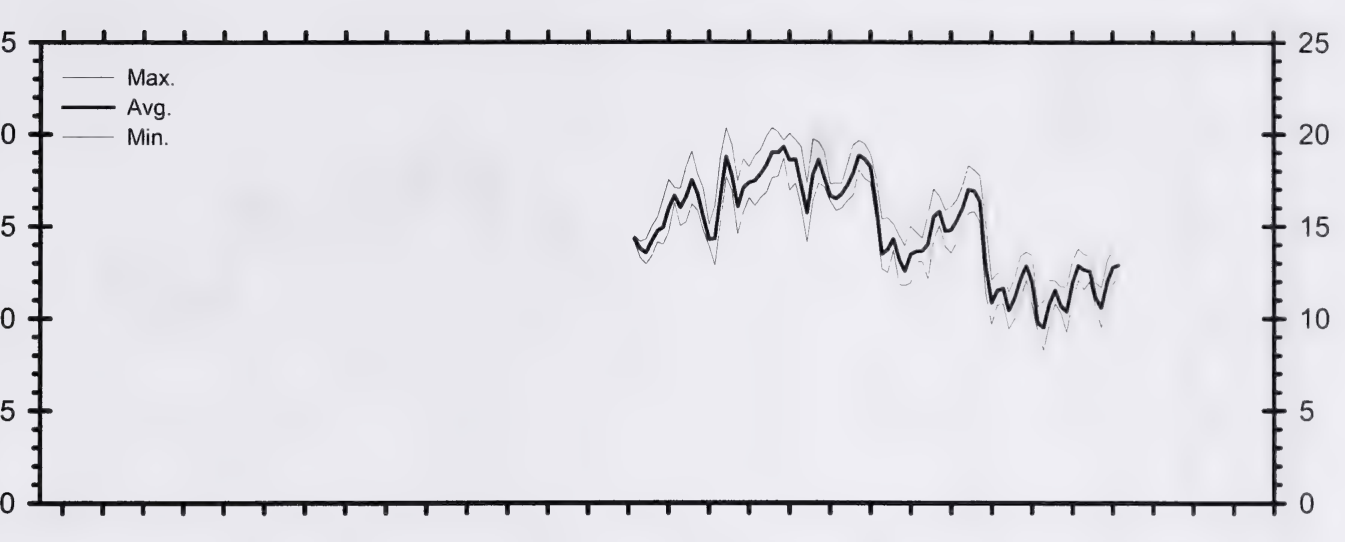

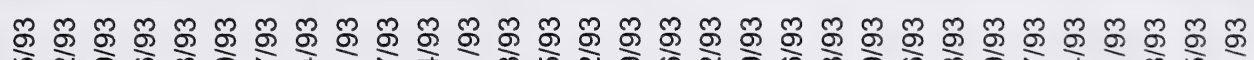

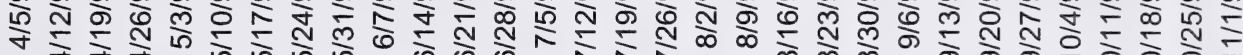

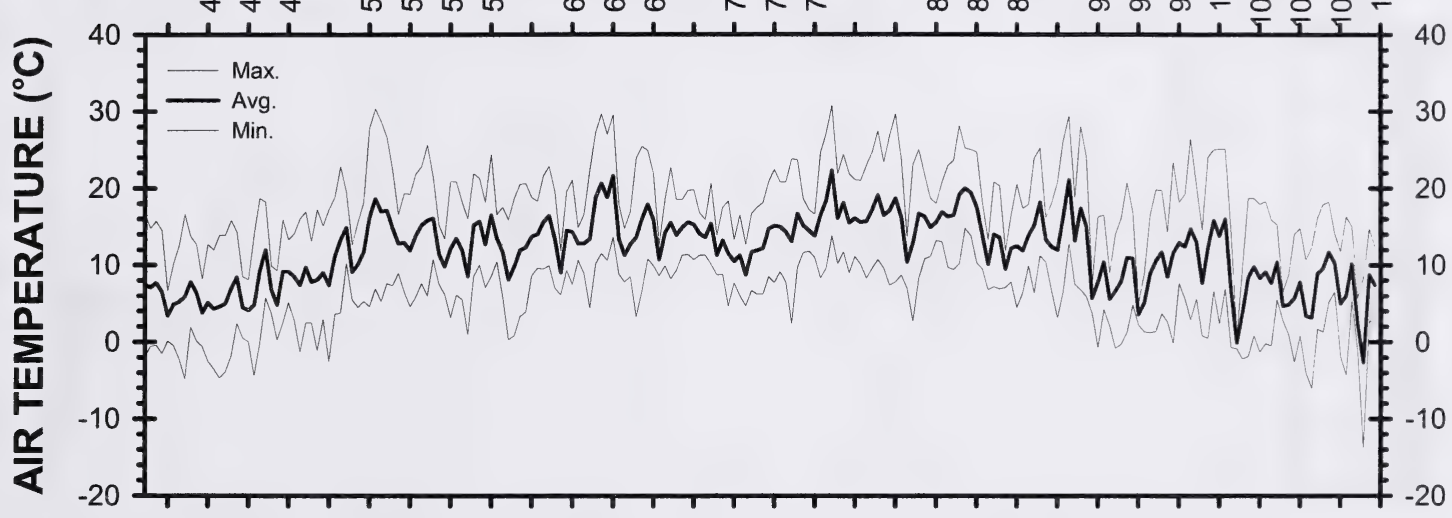

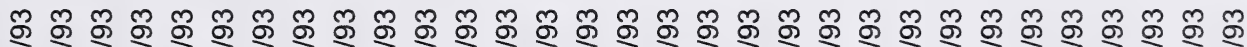

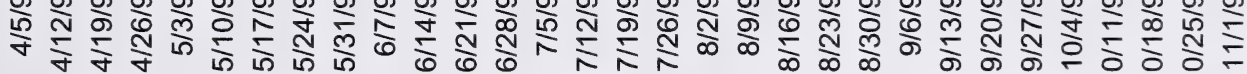

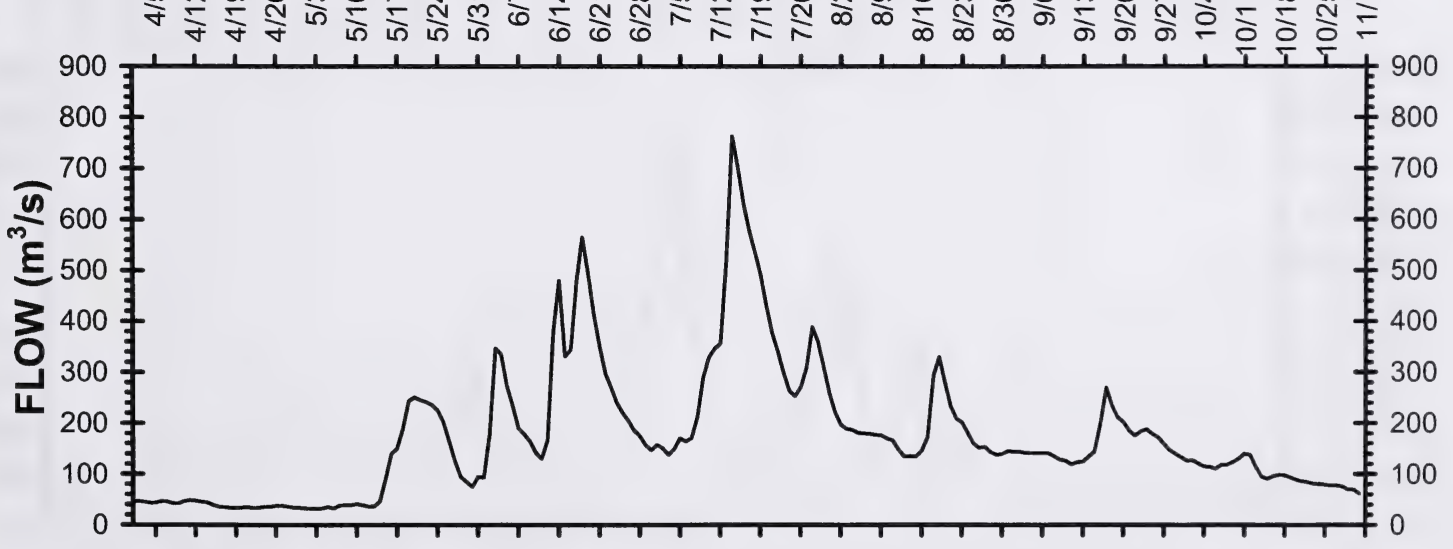

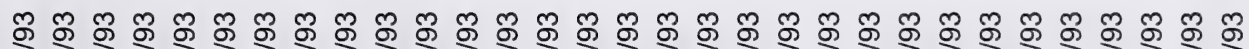

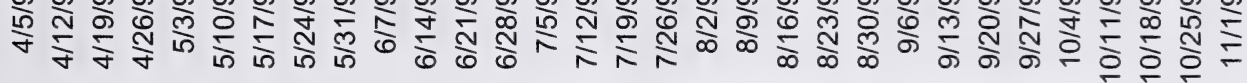

Figure 19. Daily water temperature (Datasonde), air temperature and flow in the Oldman River upstream of Lethbridge. April-October 1993. 


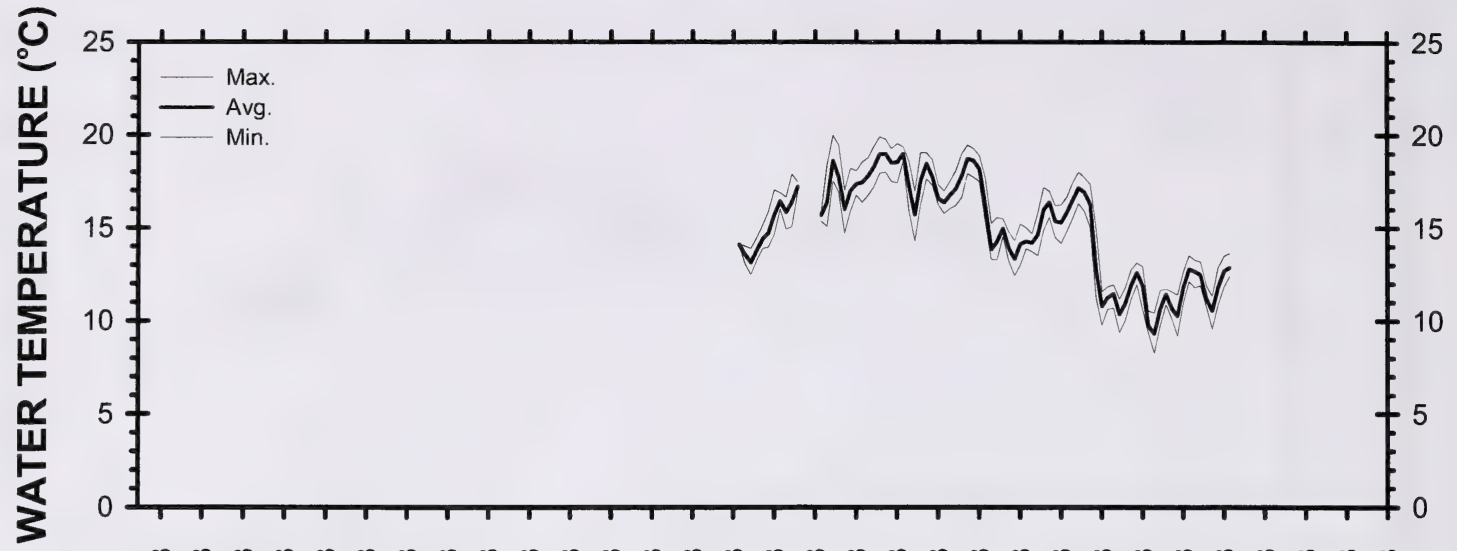

\%

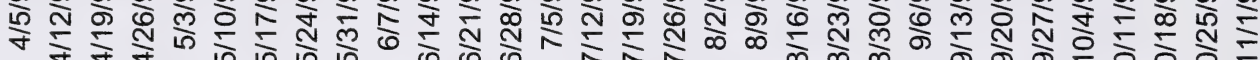

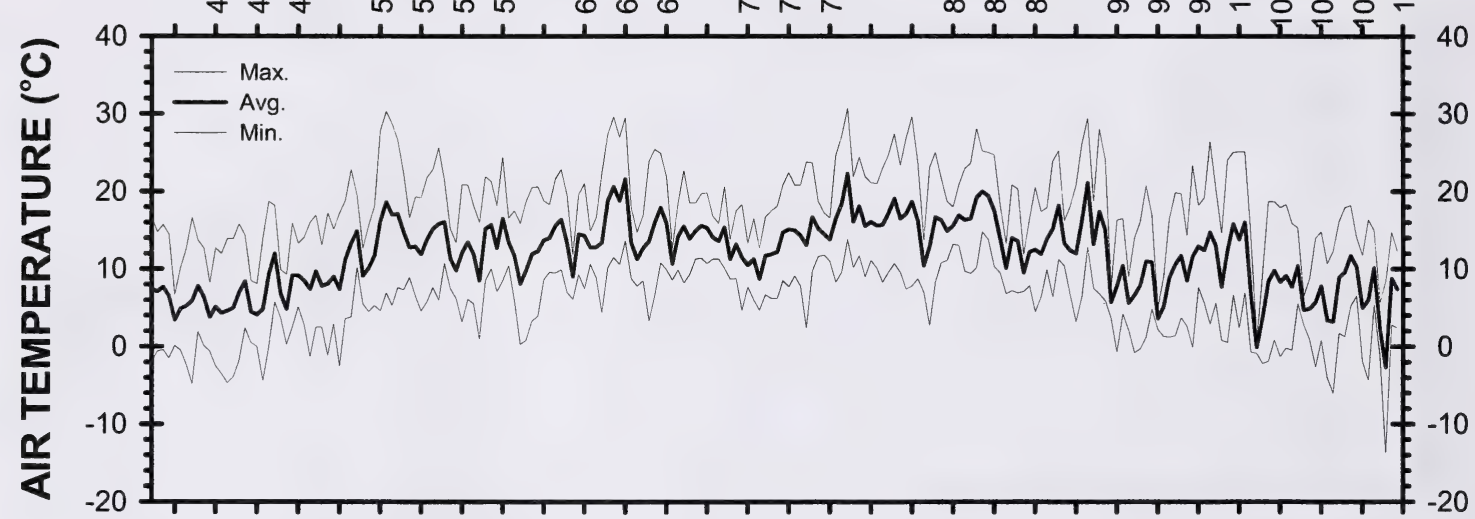

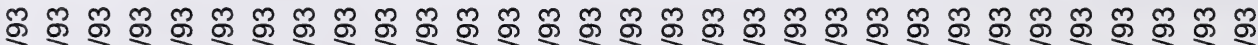

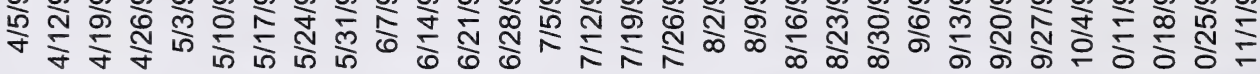

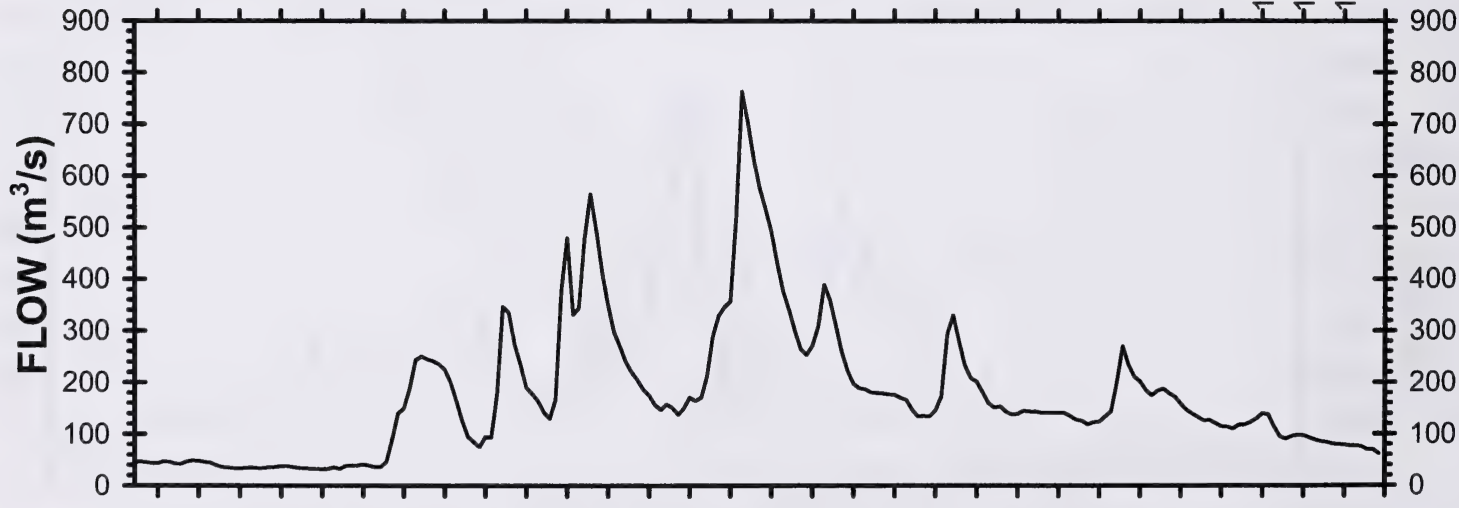

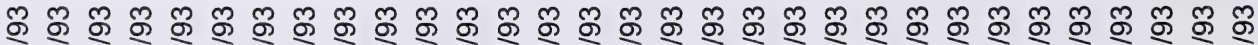

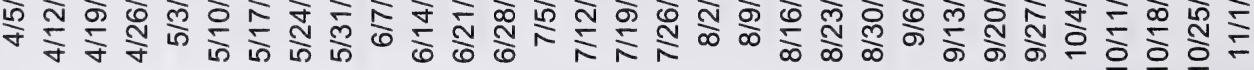

Figure 20. Daily water temperature (Datasonde), air temperature and flow in the Oldman River downstream of Lethbridge. April-October 1993. 


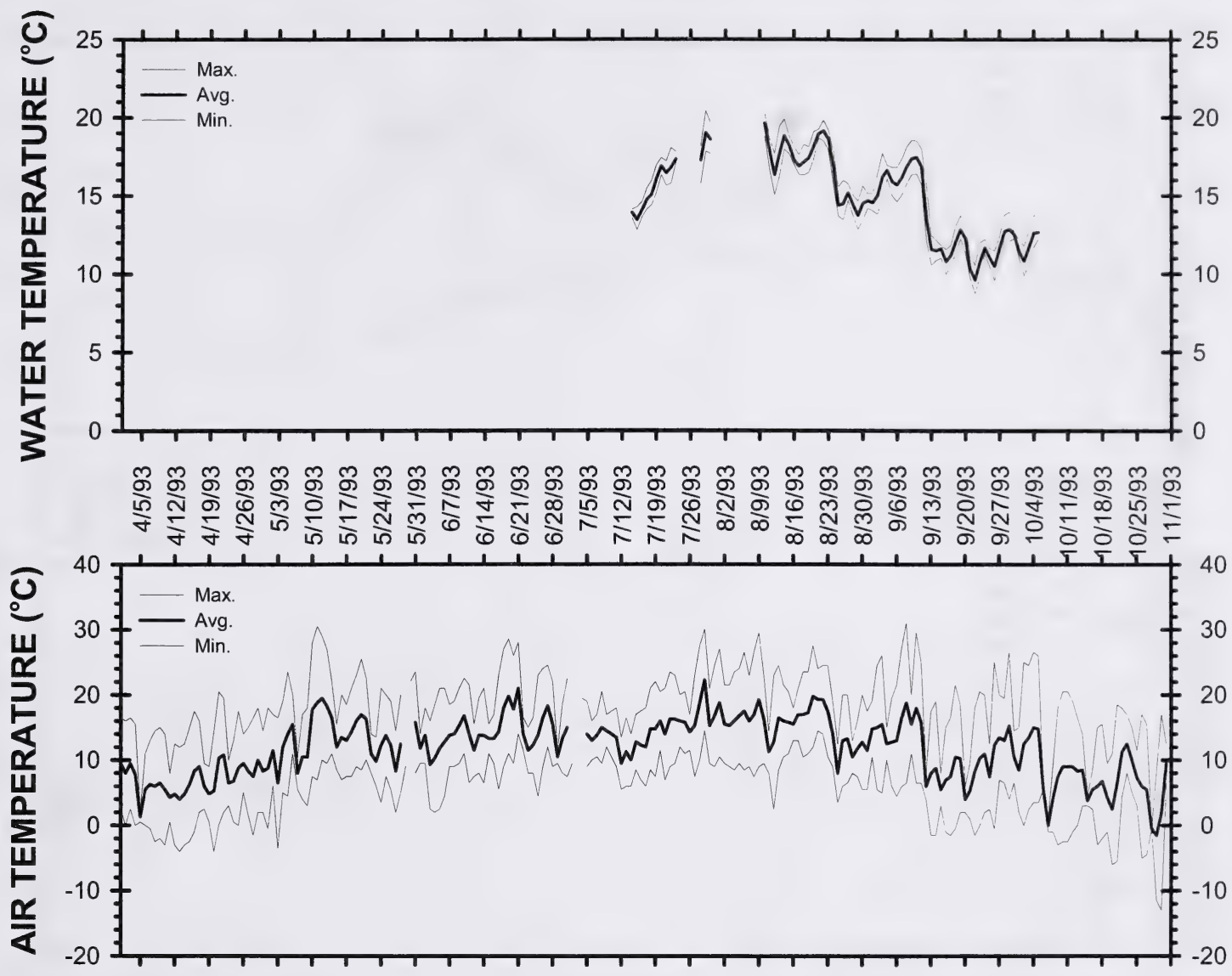

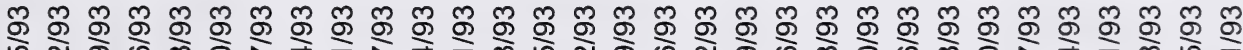

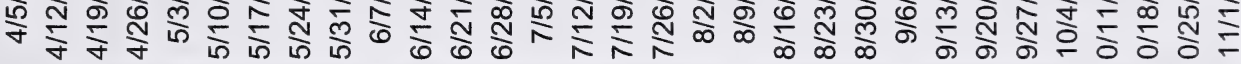

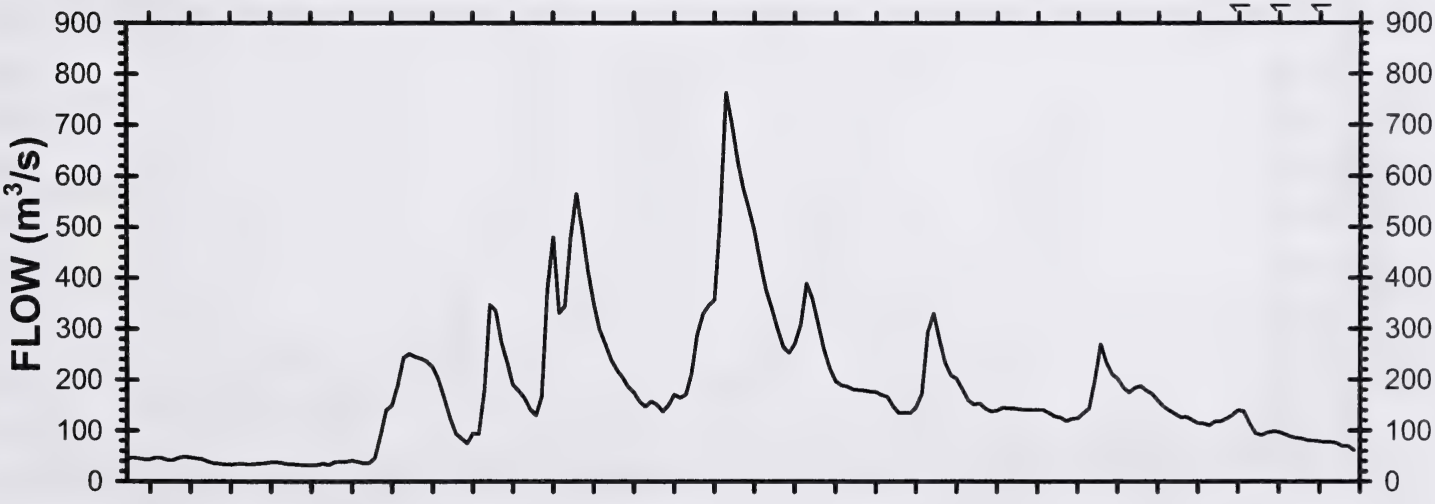

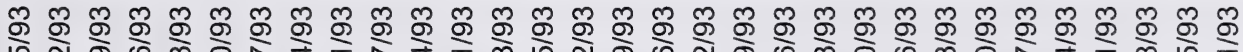

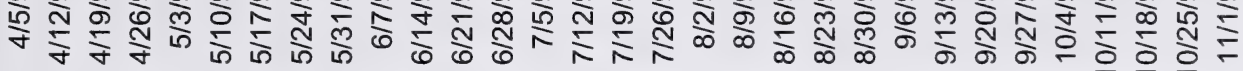

Figure 21. Daily water temperature (Datasonde), air temperature and flow in the Oldman River near Hwy. 845. April-October 1993. 


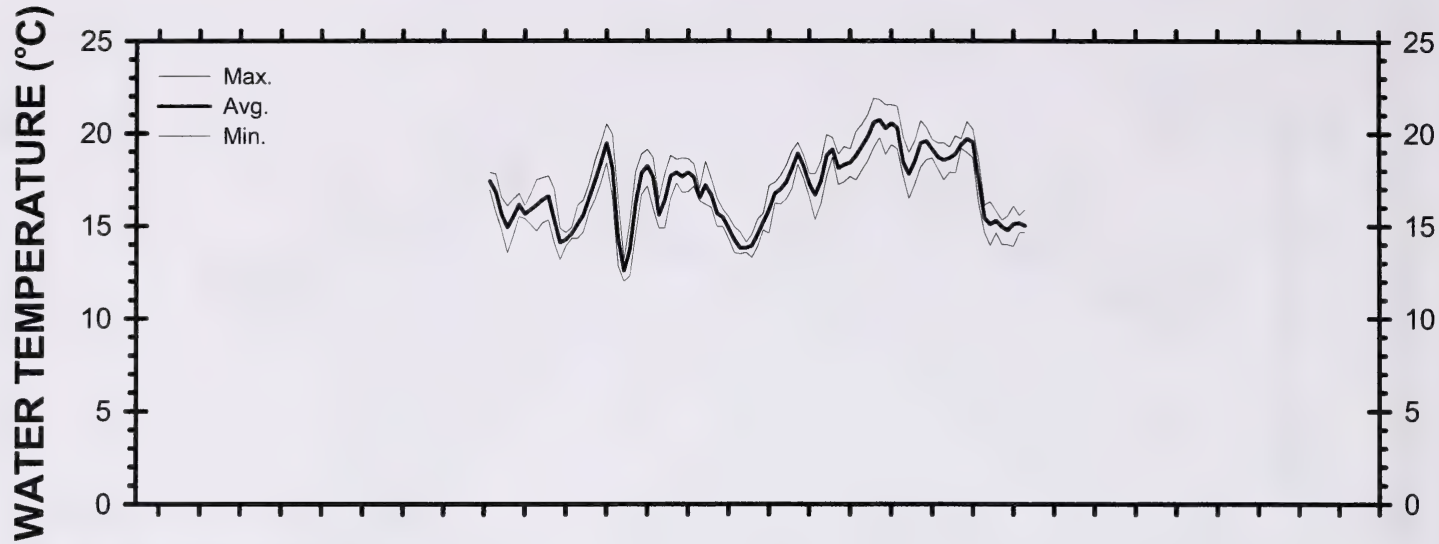

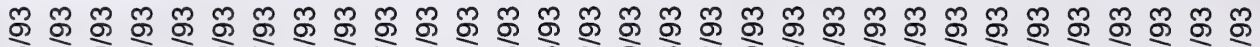

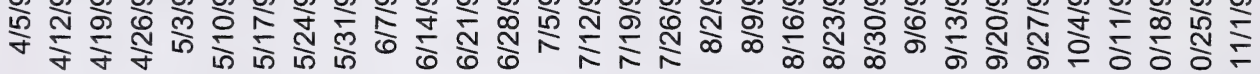

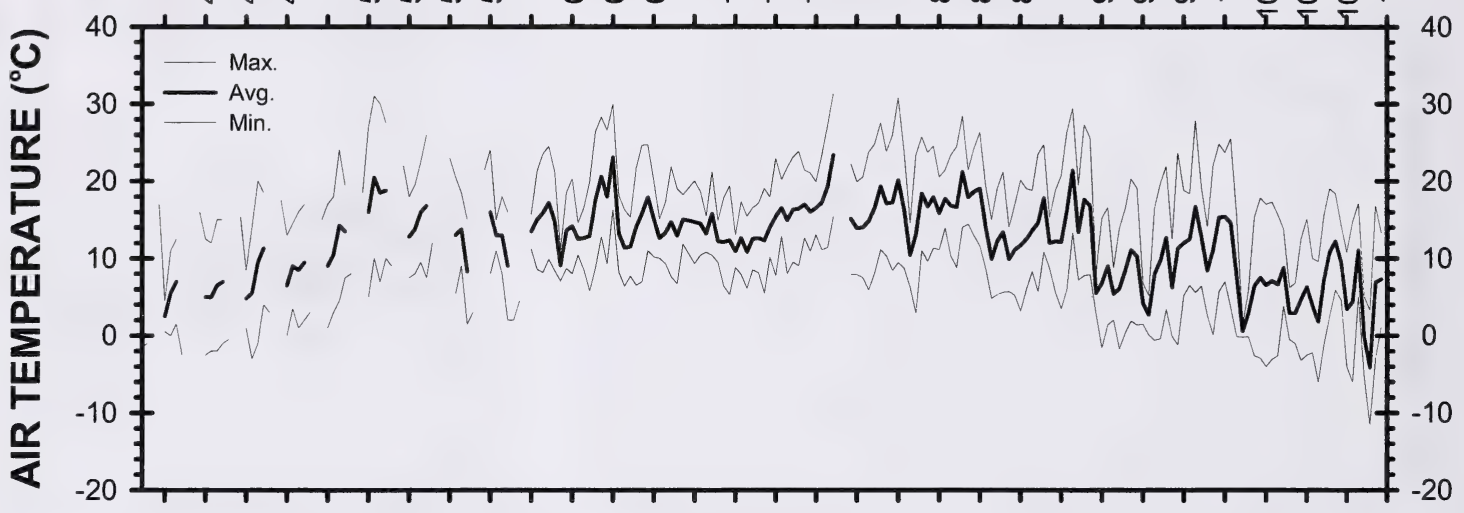

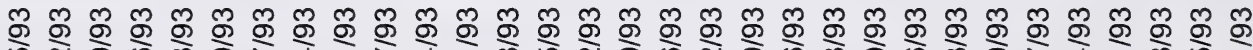

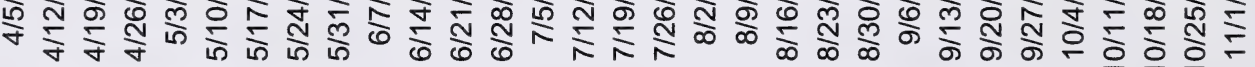

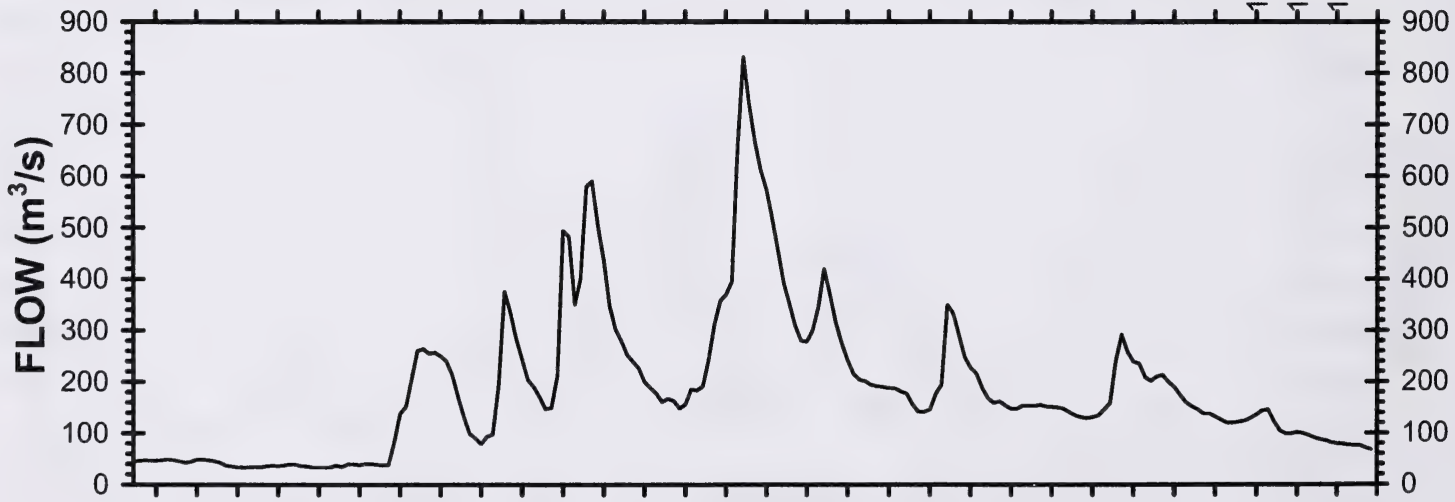

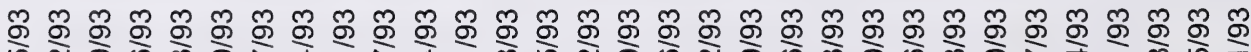
w

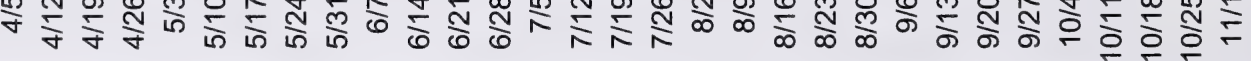

Figure 22. Daily water temperature (Datasonde), air temperature and flow in the Oldman River at the Bow River confluence. April-October 1993. 


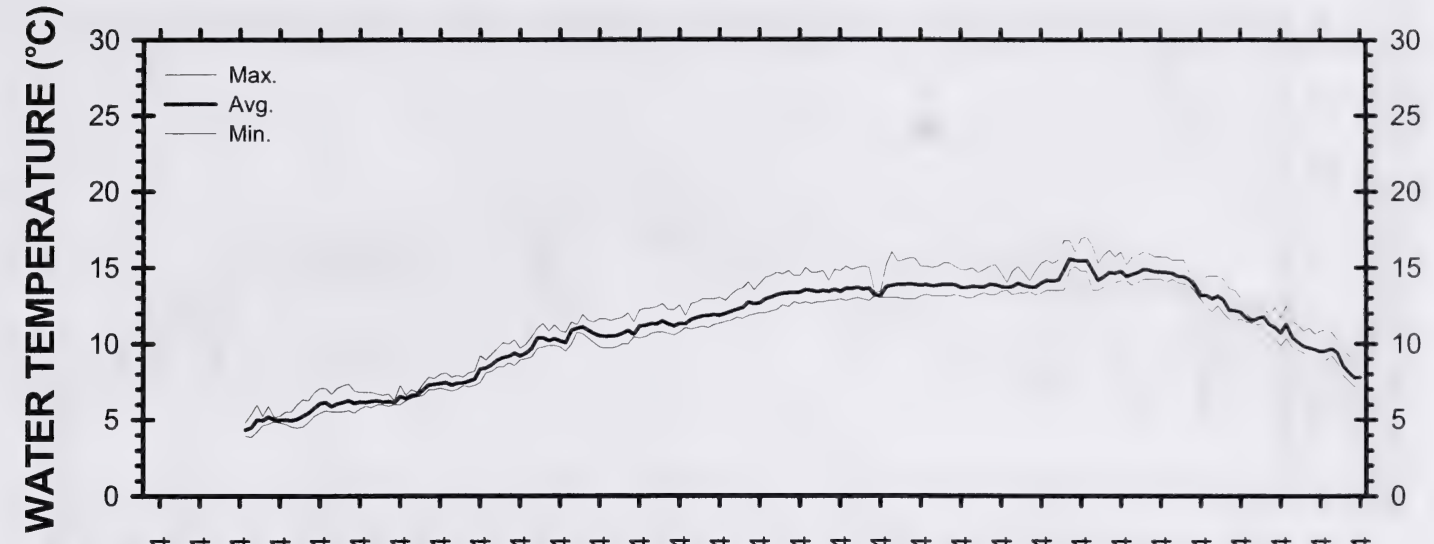

ఫ

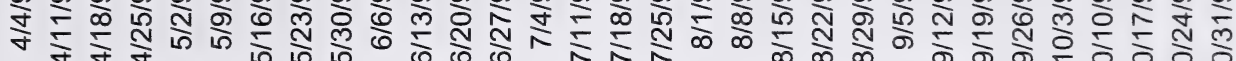

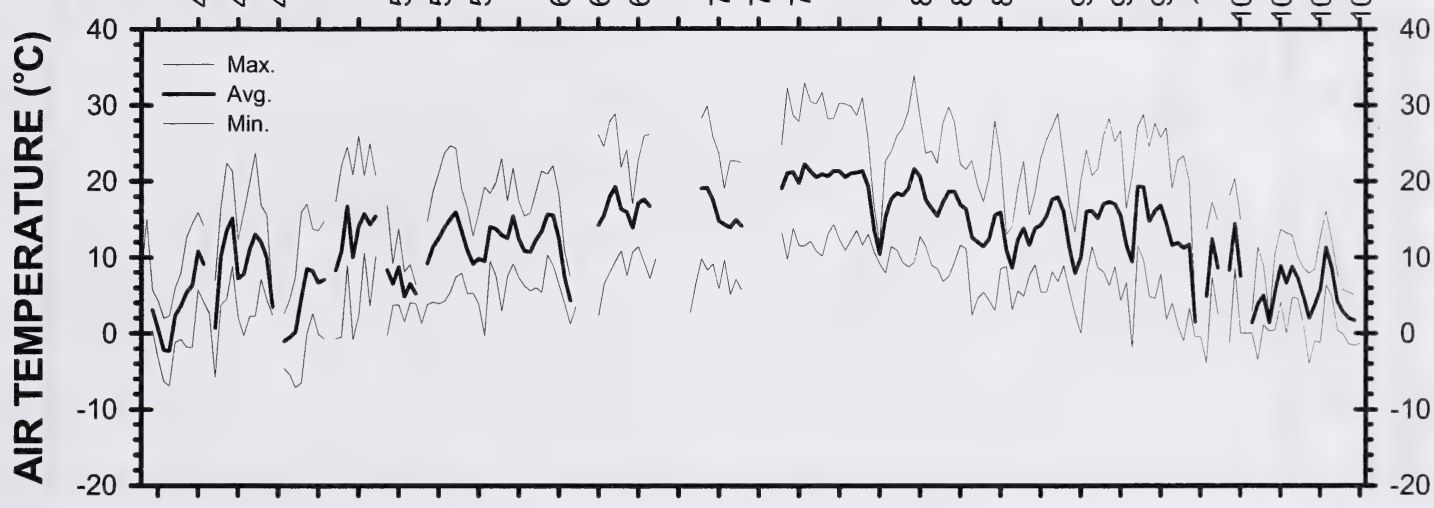

ఫ 子

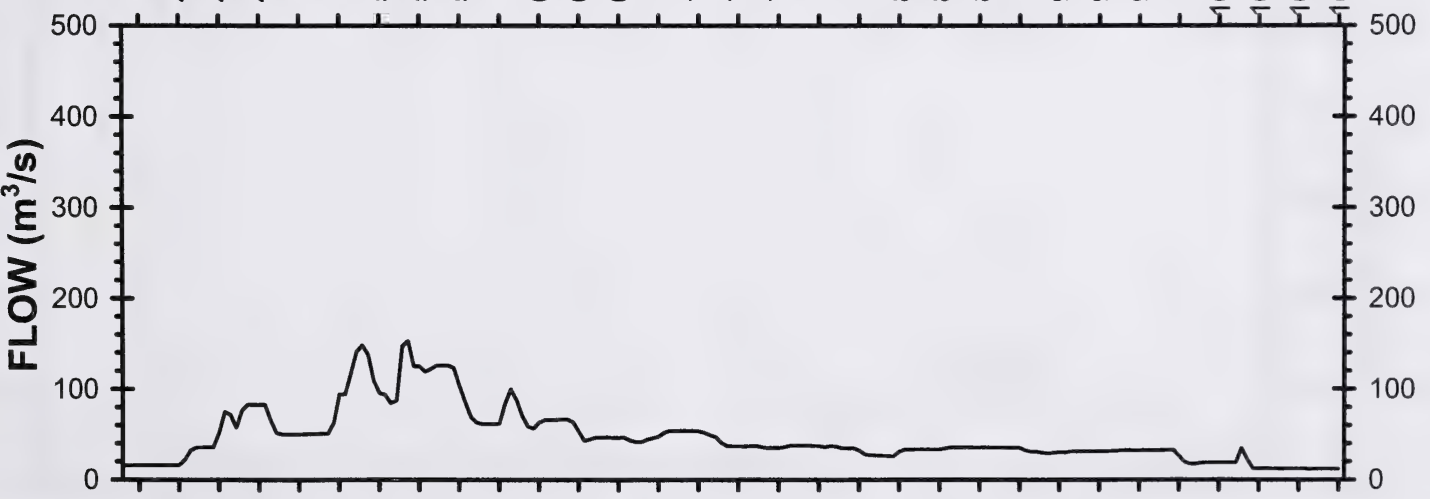

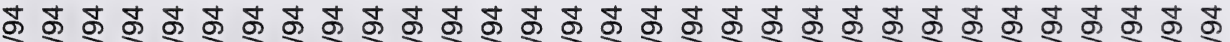

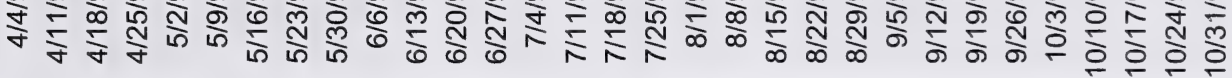

Figure 23. Daily water temperature (Thermograph), air temperature and flow in the Oldman River near Brocket. April-October 1994. 


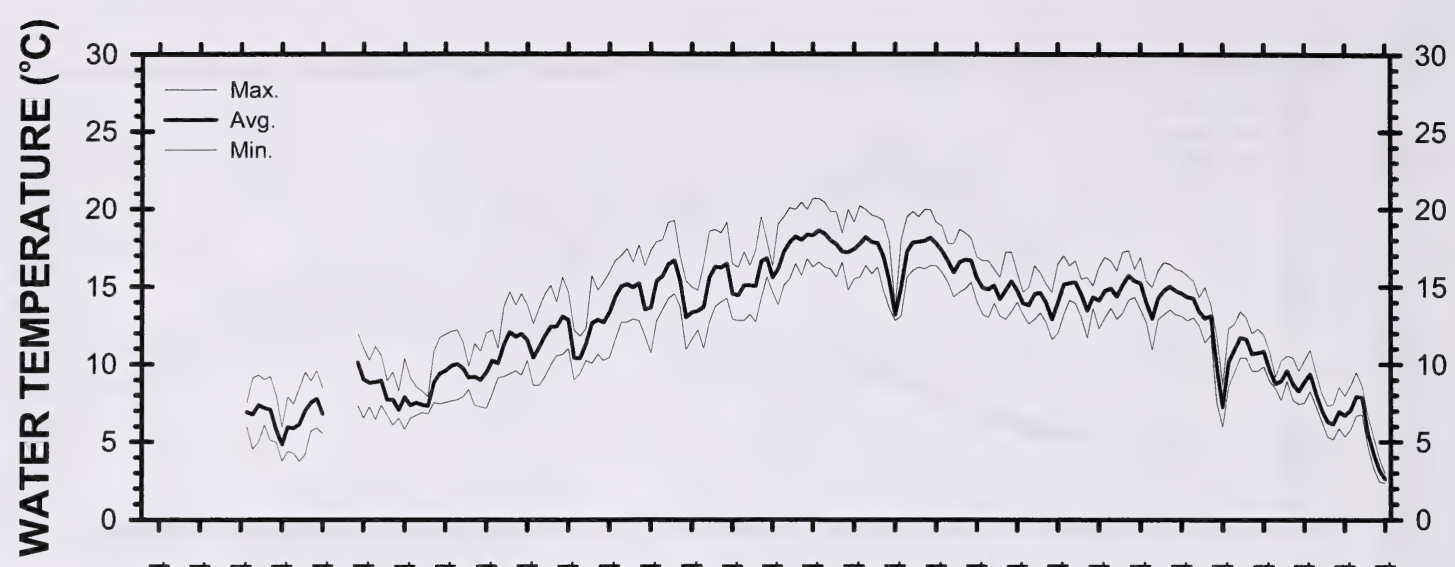

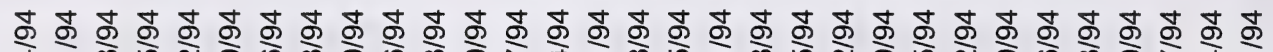

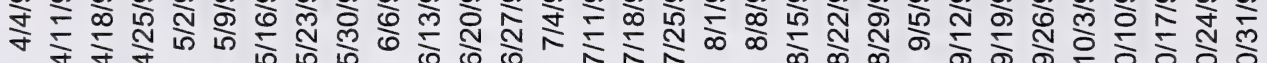

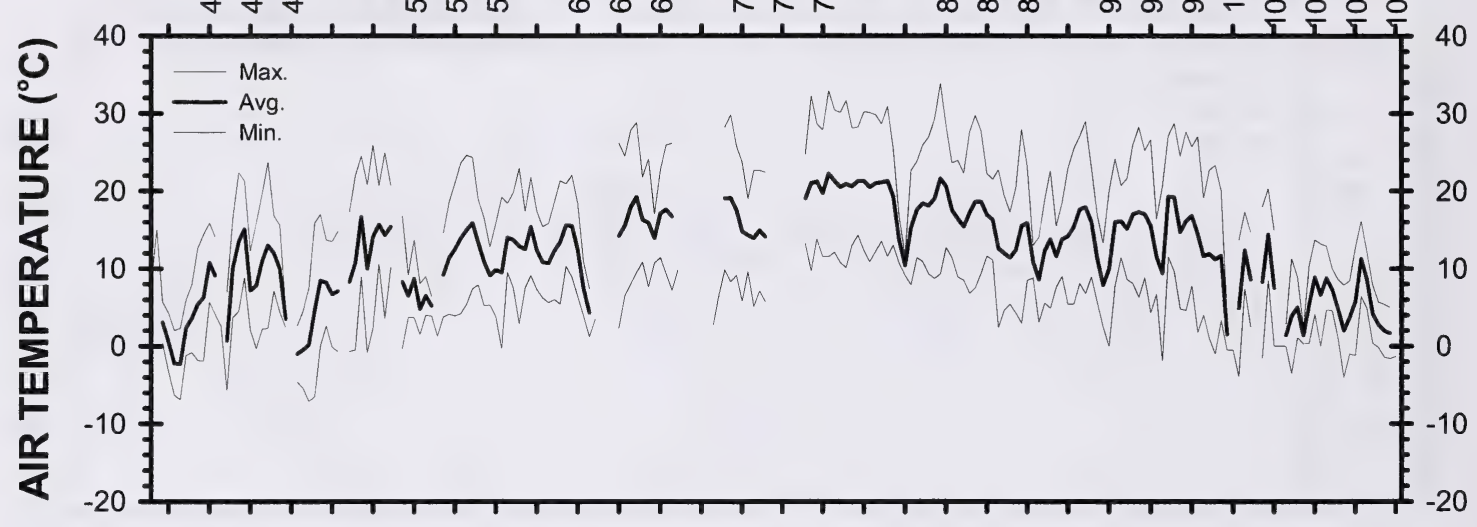

ఫ ఫ

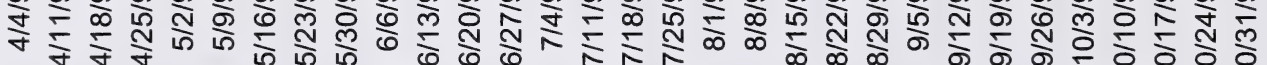

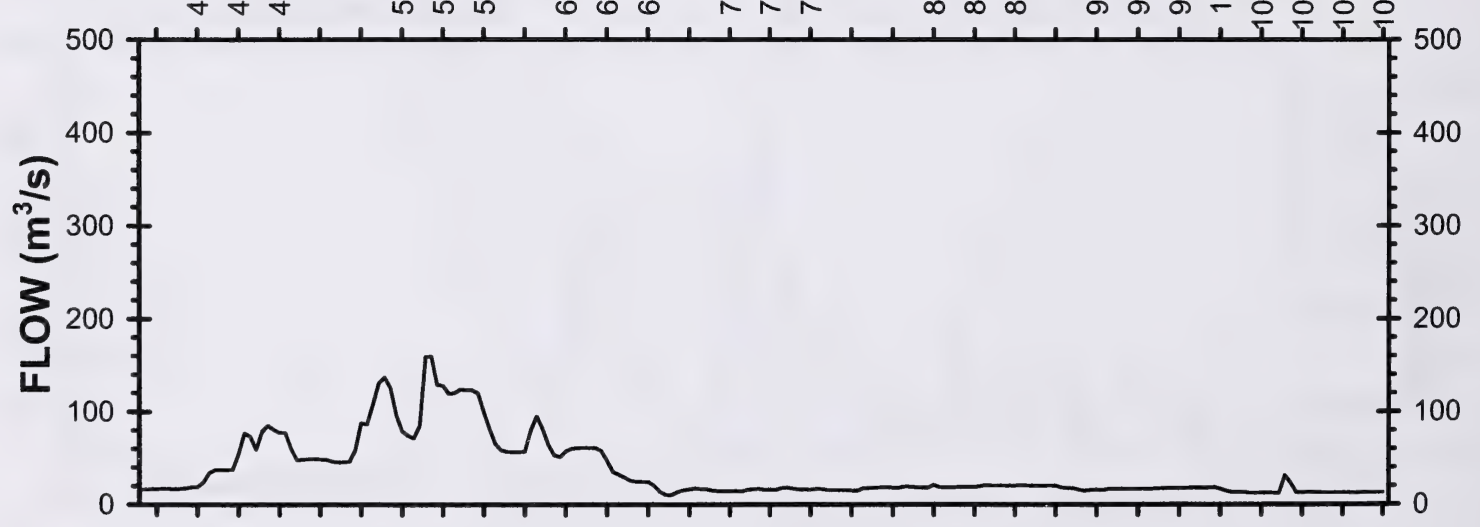

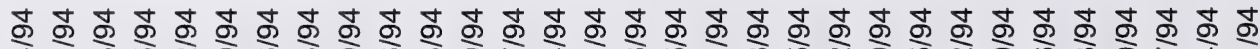

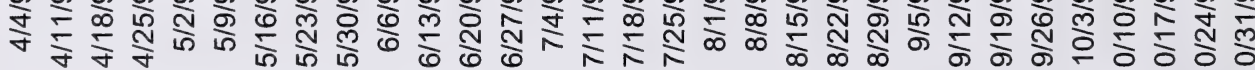

Figure 24. Daily water temperature (Thermograph), air temperature and flow in the Oldman River downstream of the LNHD. April-October 1994. 


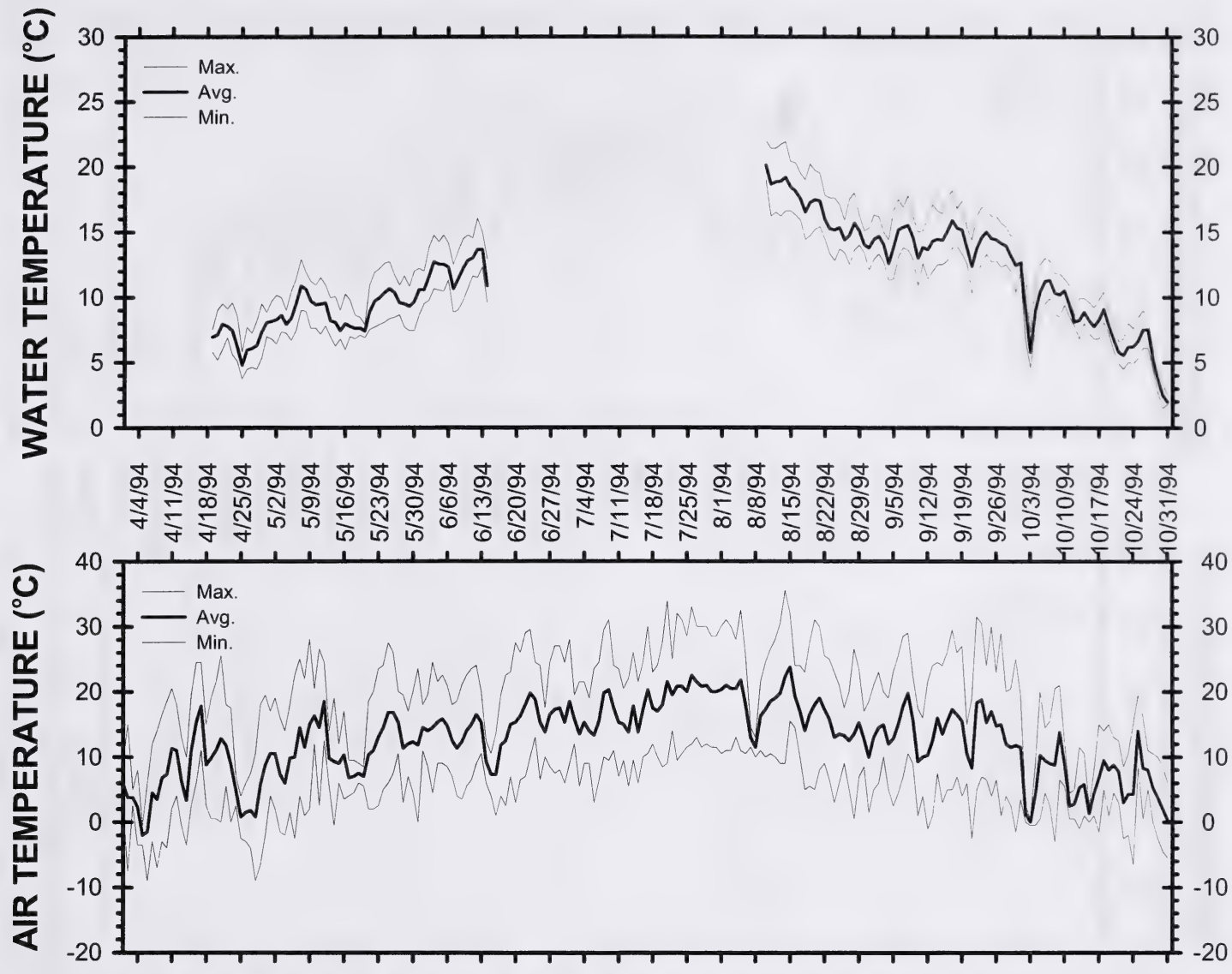

ఫั

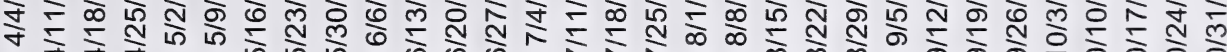

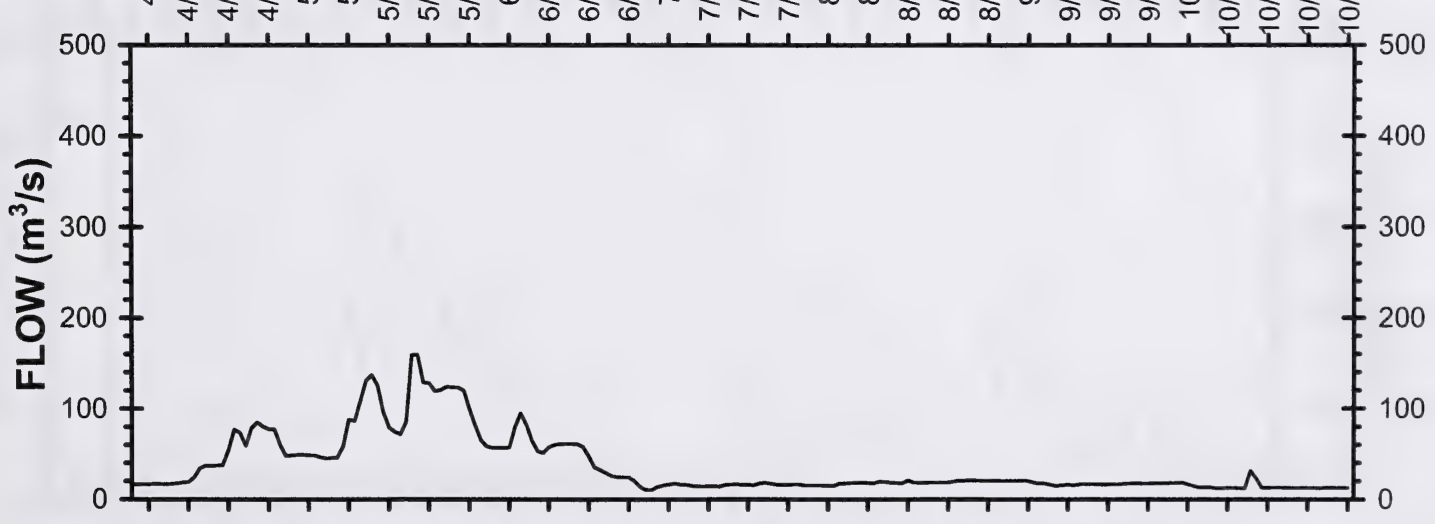

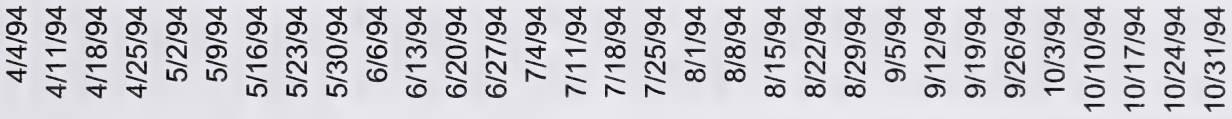

Figure 25. Daily water temperature (Thermograph), air temperature and flow in the Oldman River near Fort Macleod. April-October 1994. 


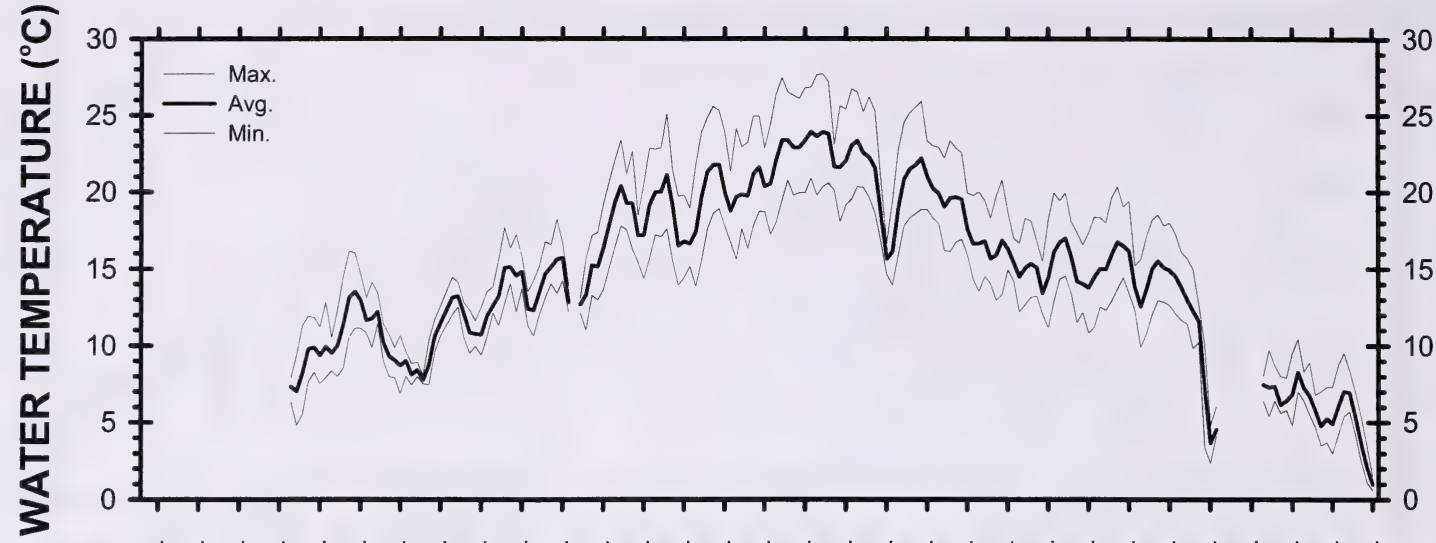

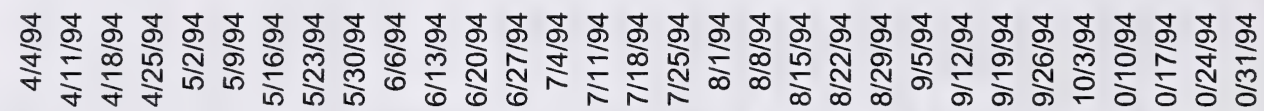
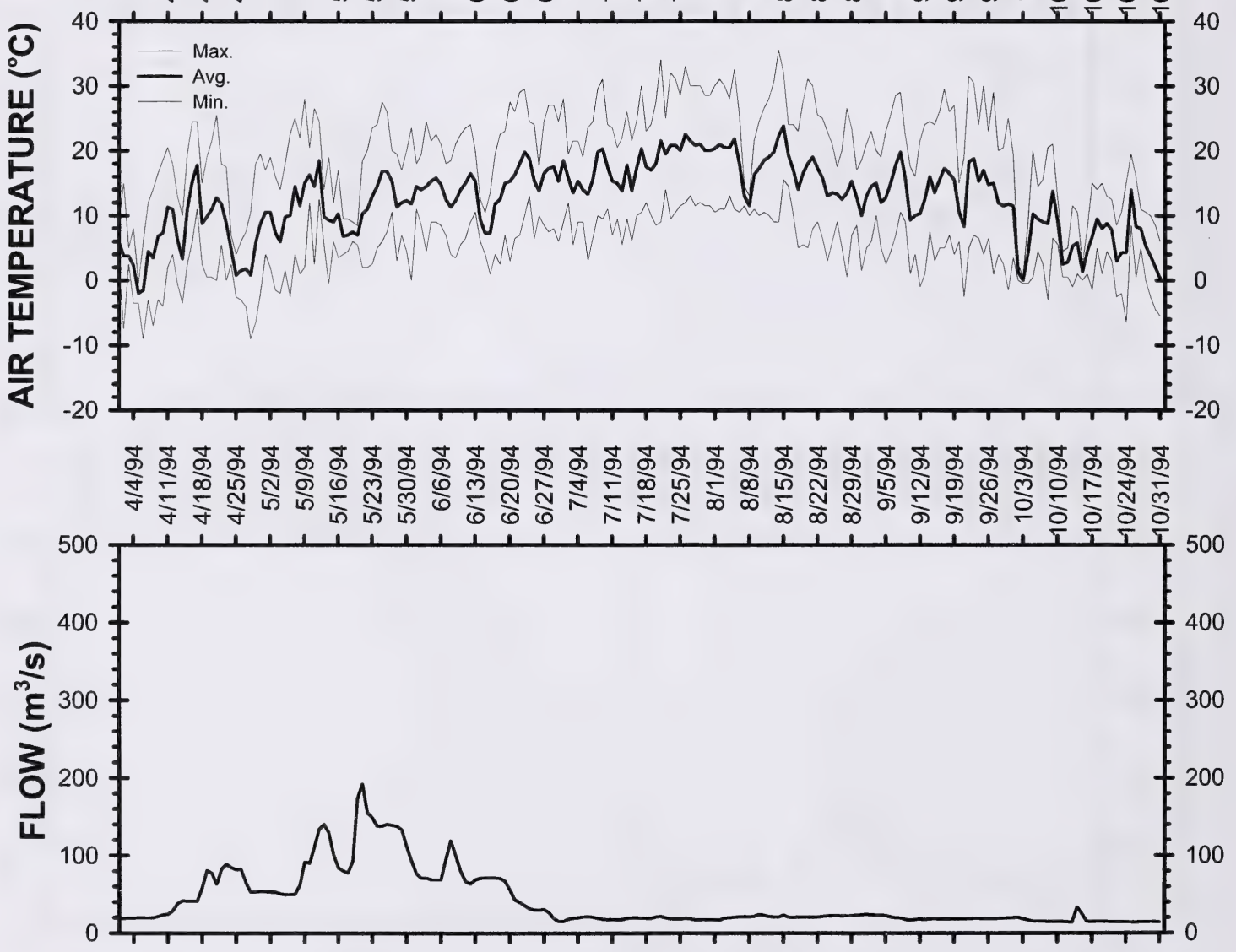

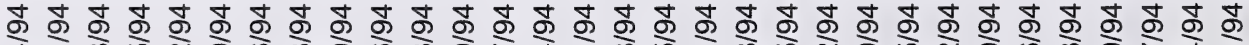

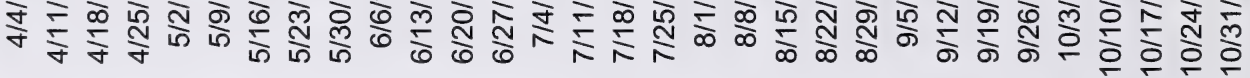

Figure 26. Daily water temperature (Thermograph), air temperature and flow in the Oldman River near Monarch. April-October 1994. 


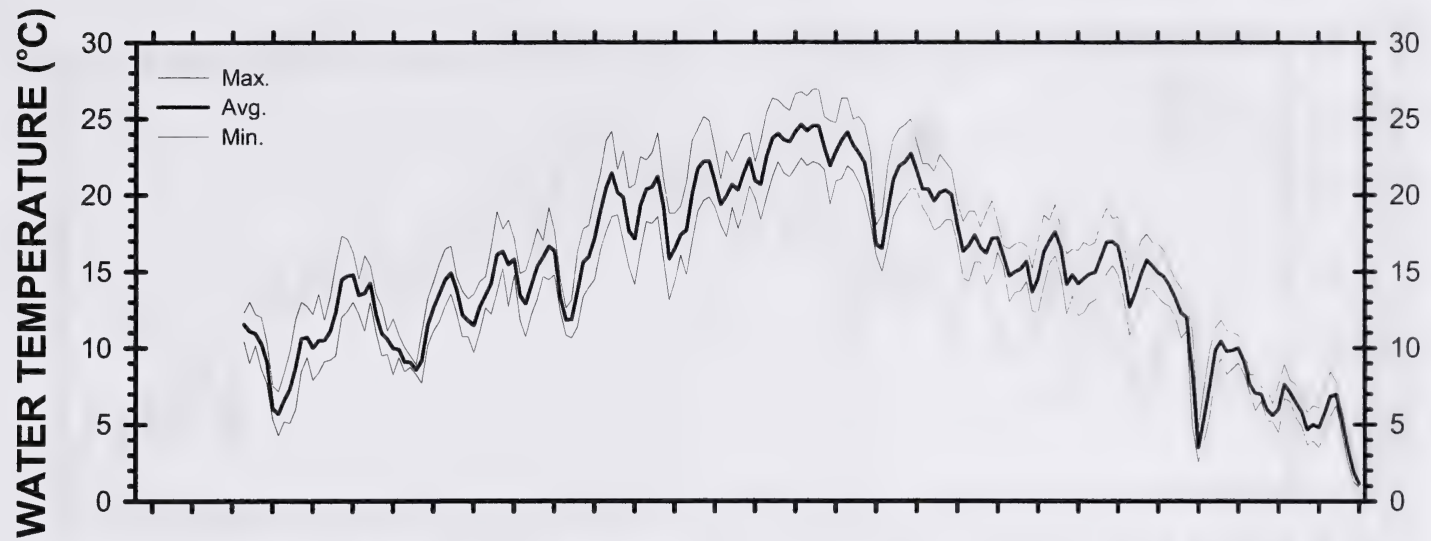

ఫ ఫ

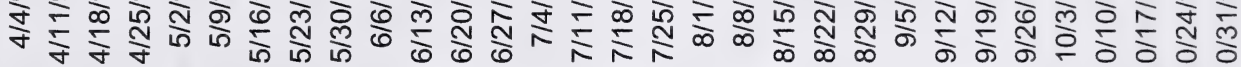
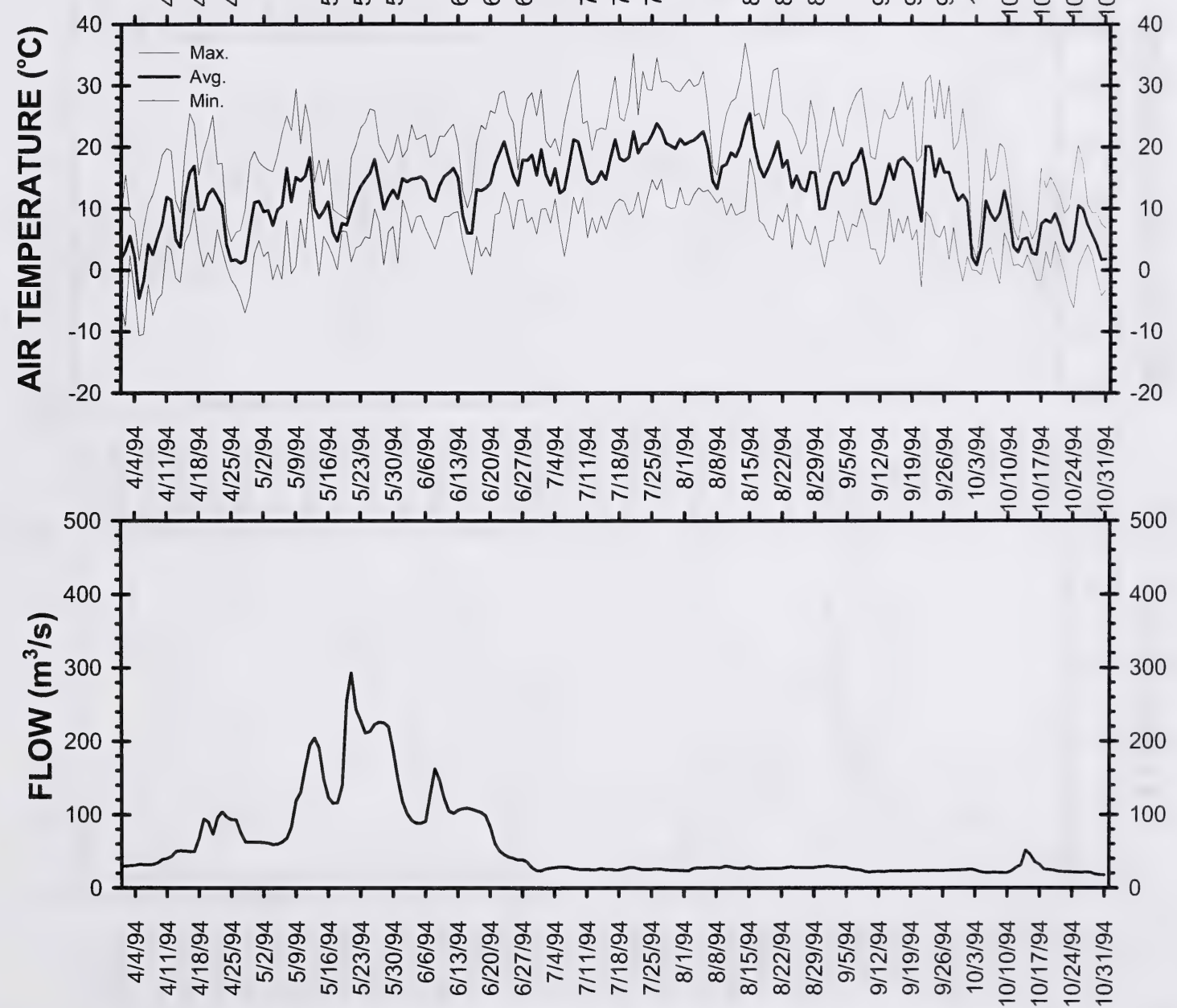

Figure 27. Daily water temperature (Thermograph), air temperature and flow in the Oldman River downstream of the Belly River. April-October 1994. 


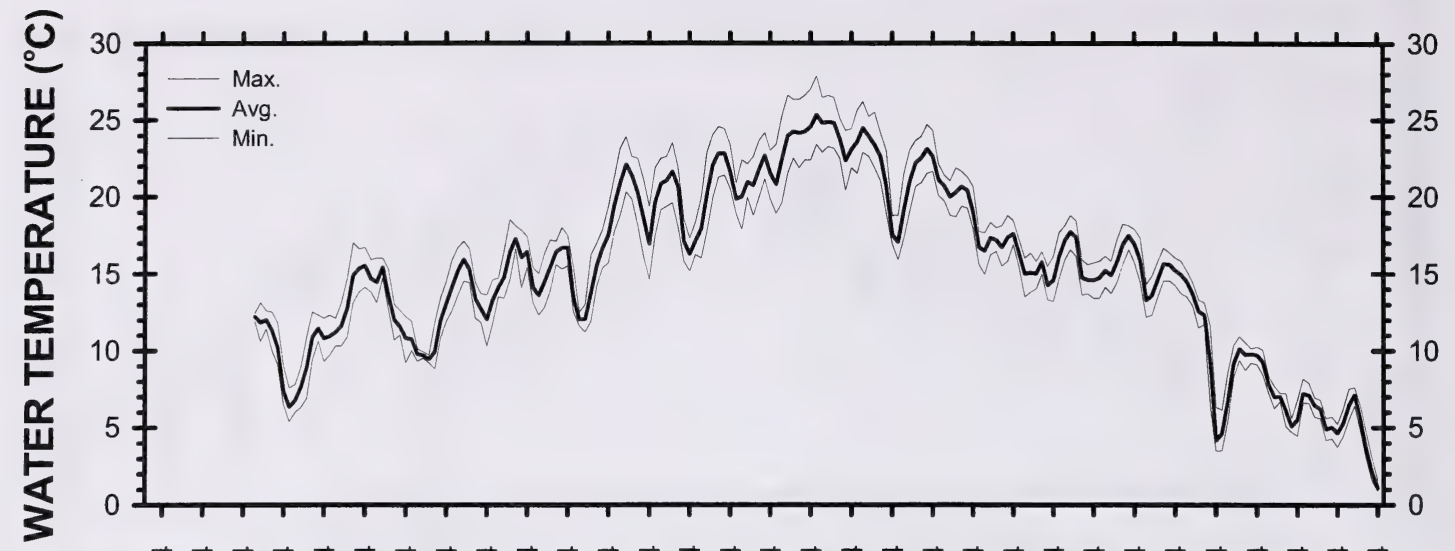

ষ্ণ

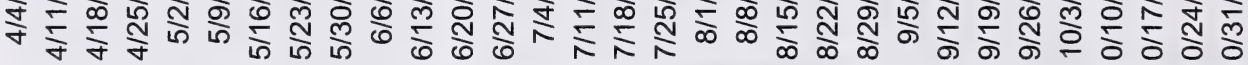

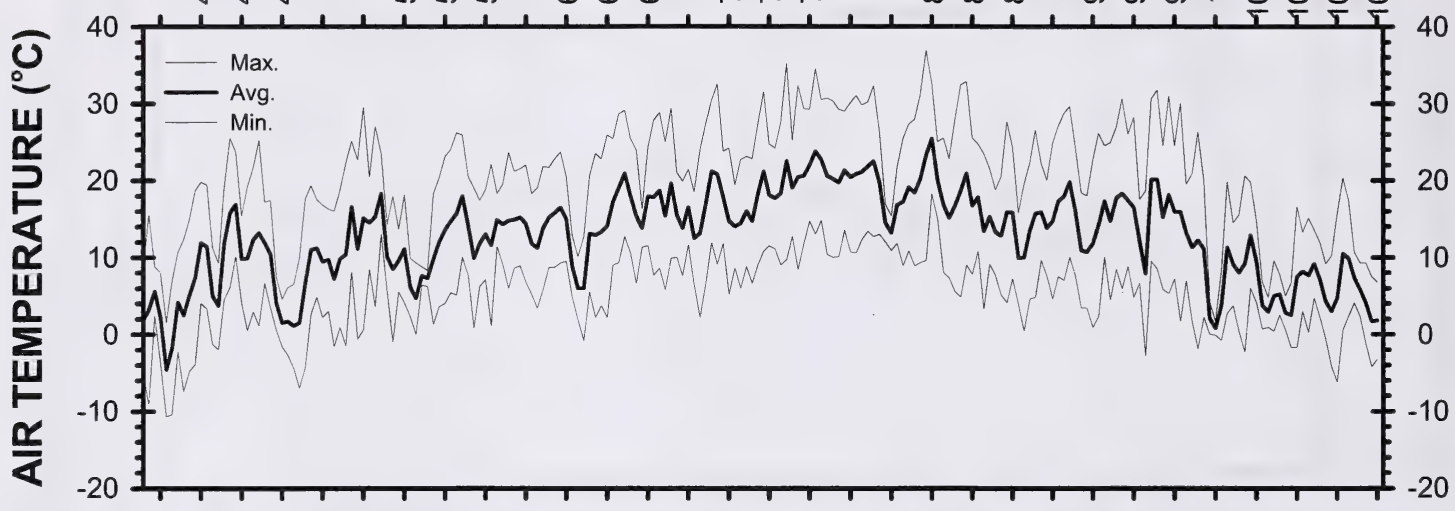

す

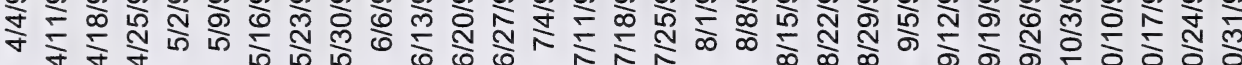

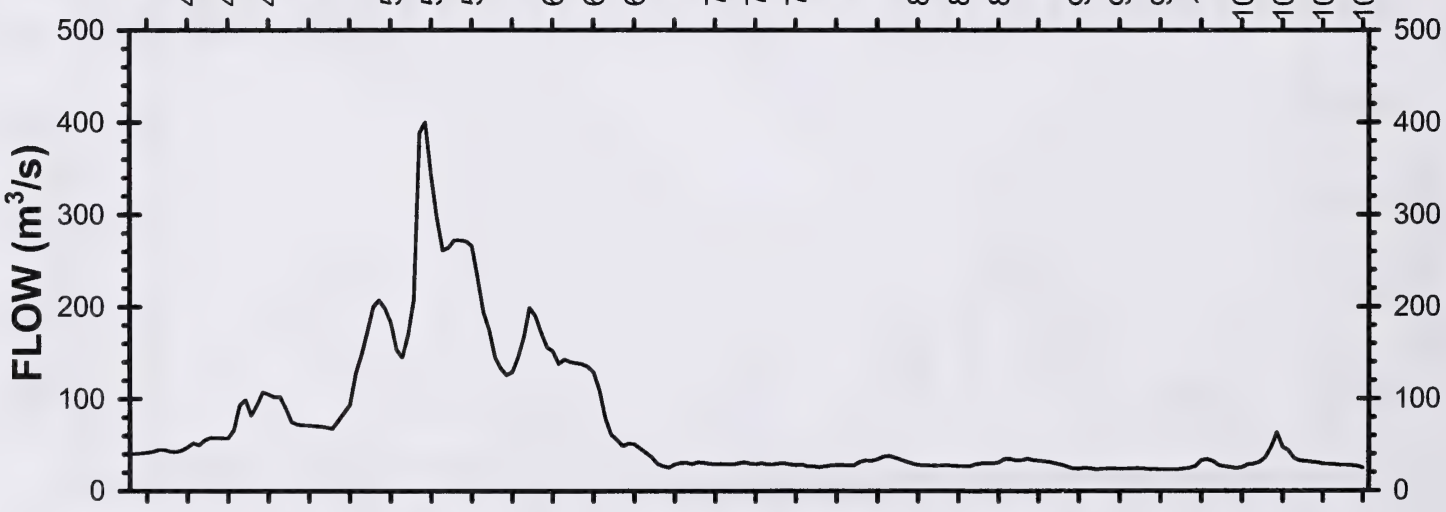

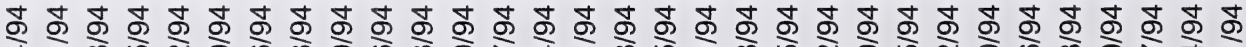

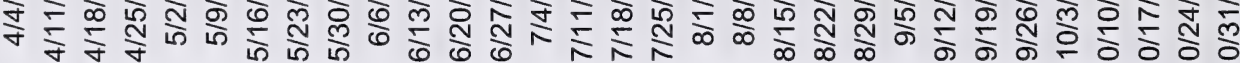

Figure 28. Daily water temperature (Thermograph), air temperature and flow in the Oldman River upstream of Lethbridge. April-October 1994. 


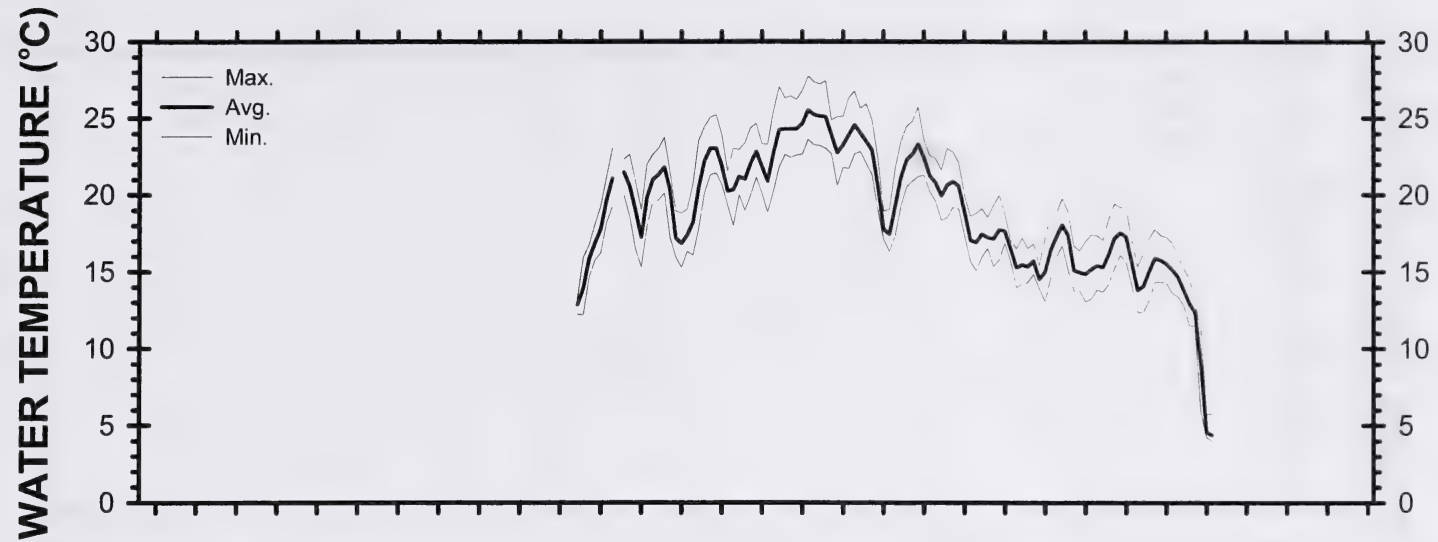

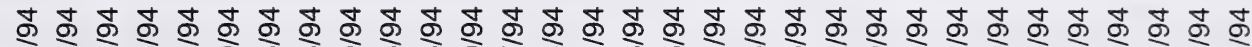

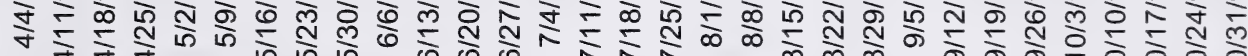
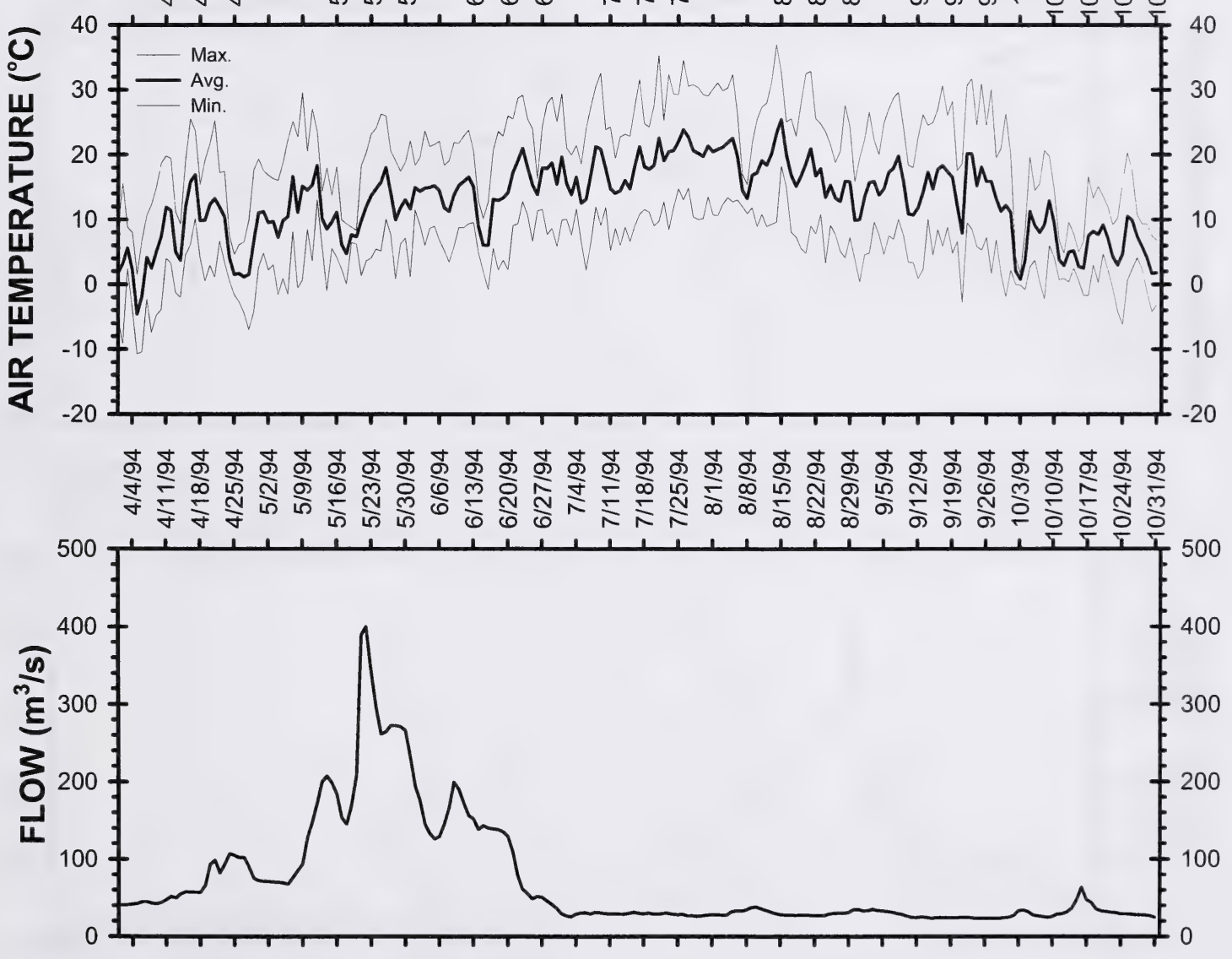

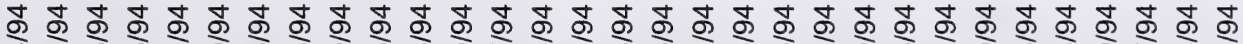

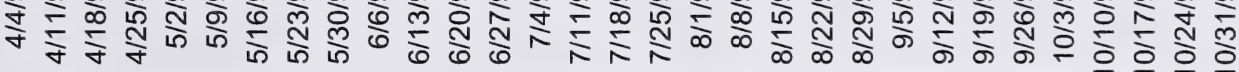

Figure 29. Daily water temperature (Datasonde), air temperature and flow in the Oldman River downstream of Lethbridge. April-October 1994. 


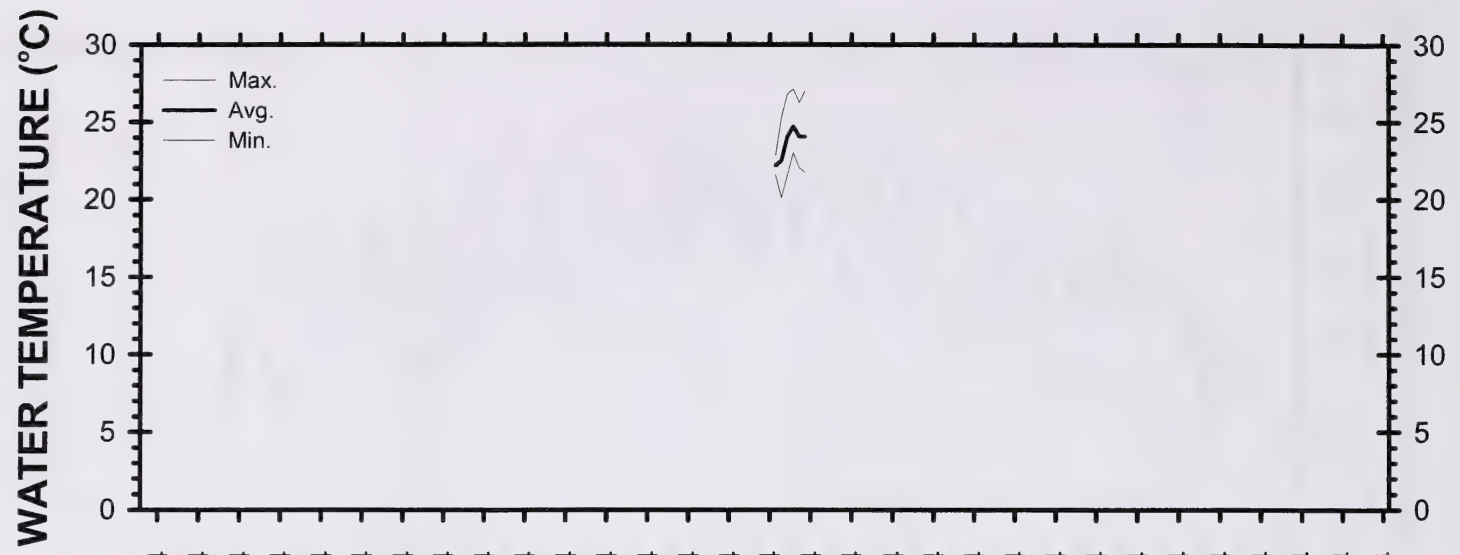

ఫ

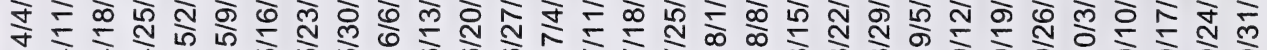

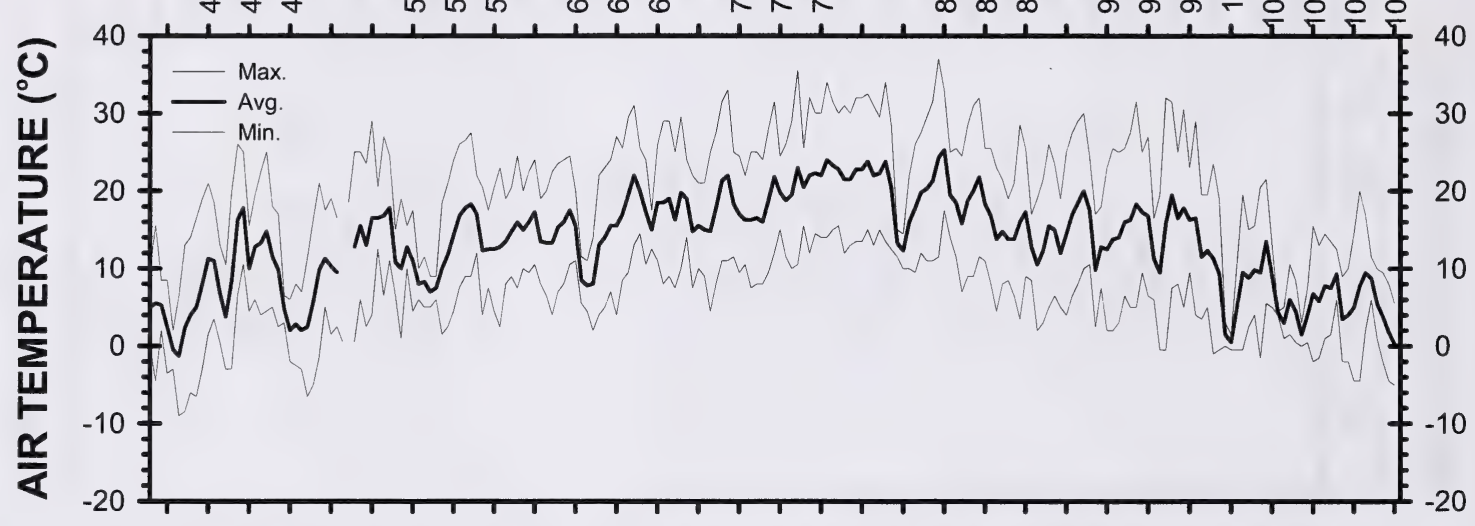

ॠ ఫ

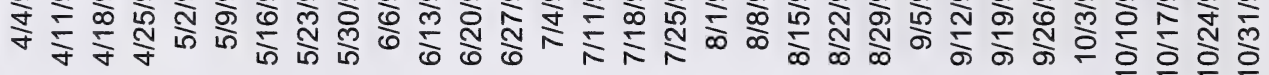

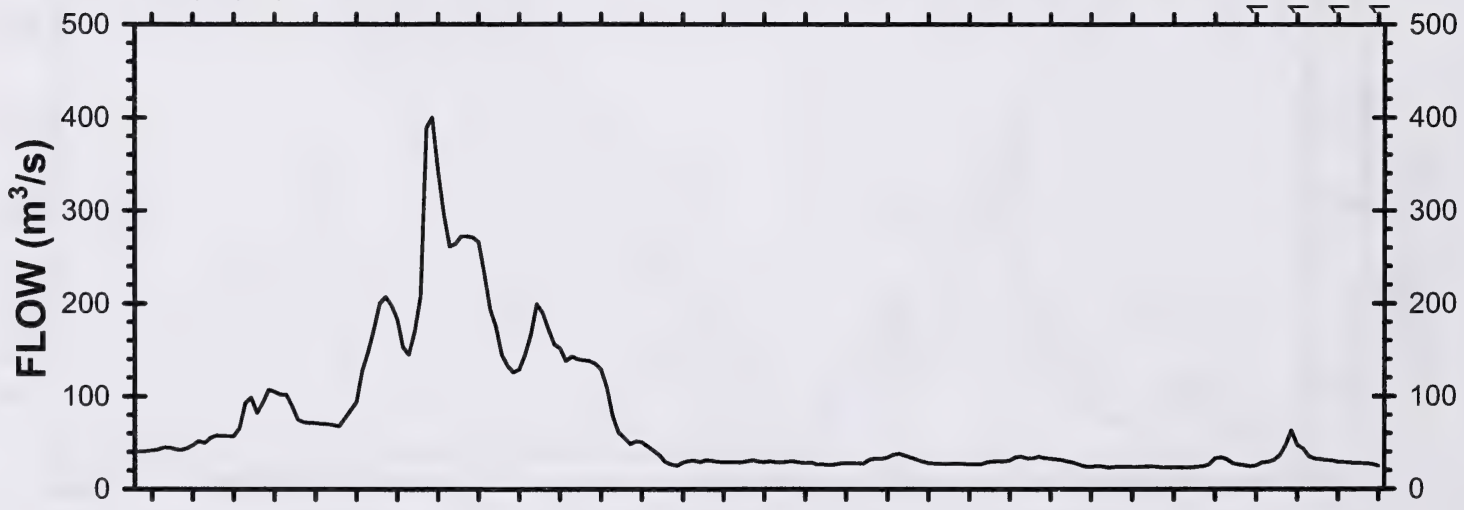

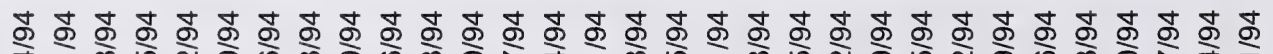

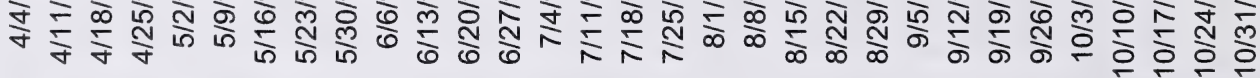

Figure 30. Daily water temperature (Datasonde), air temperature and flow in the Oldman River near Hwy. 845. April-October 1994. 


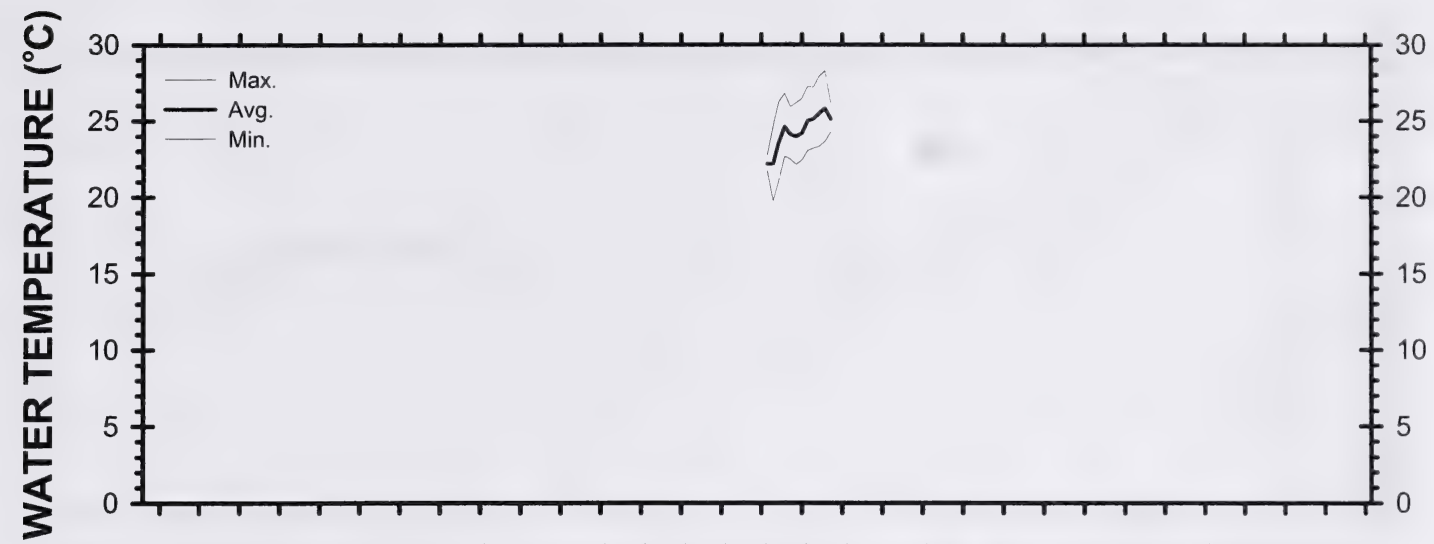

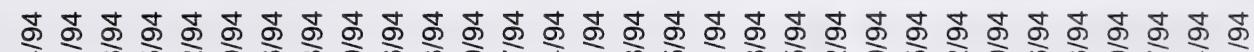

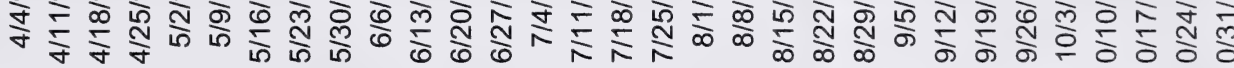

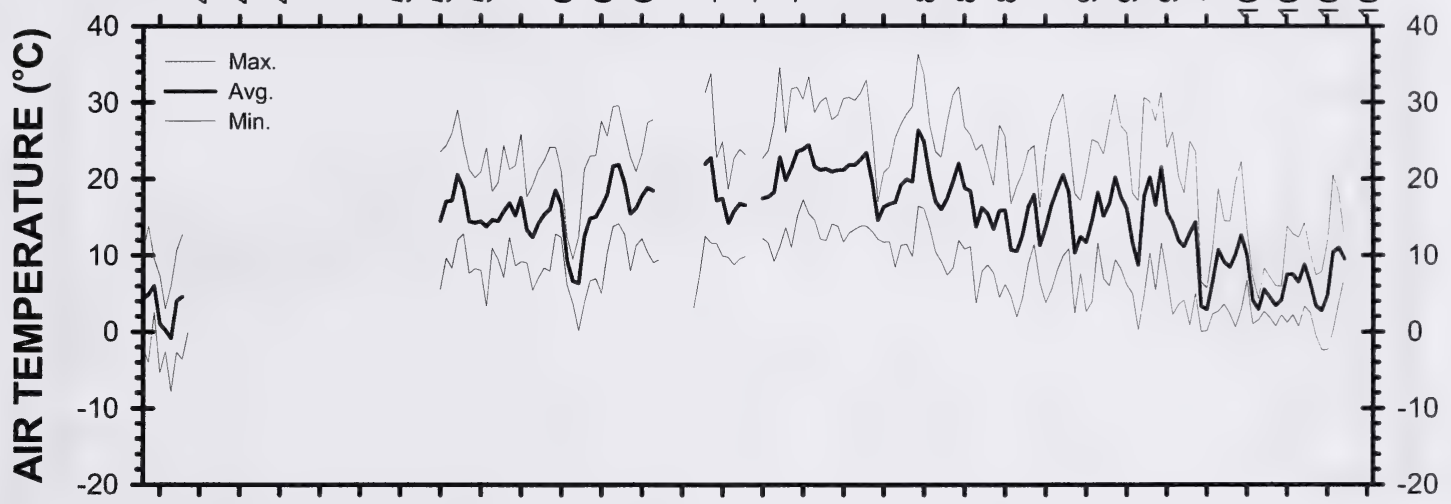

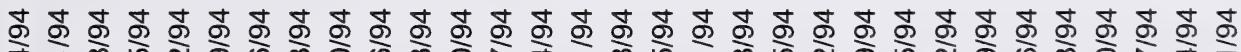

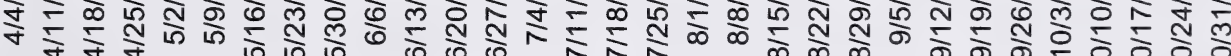

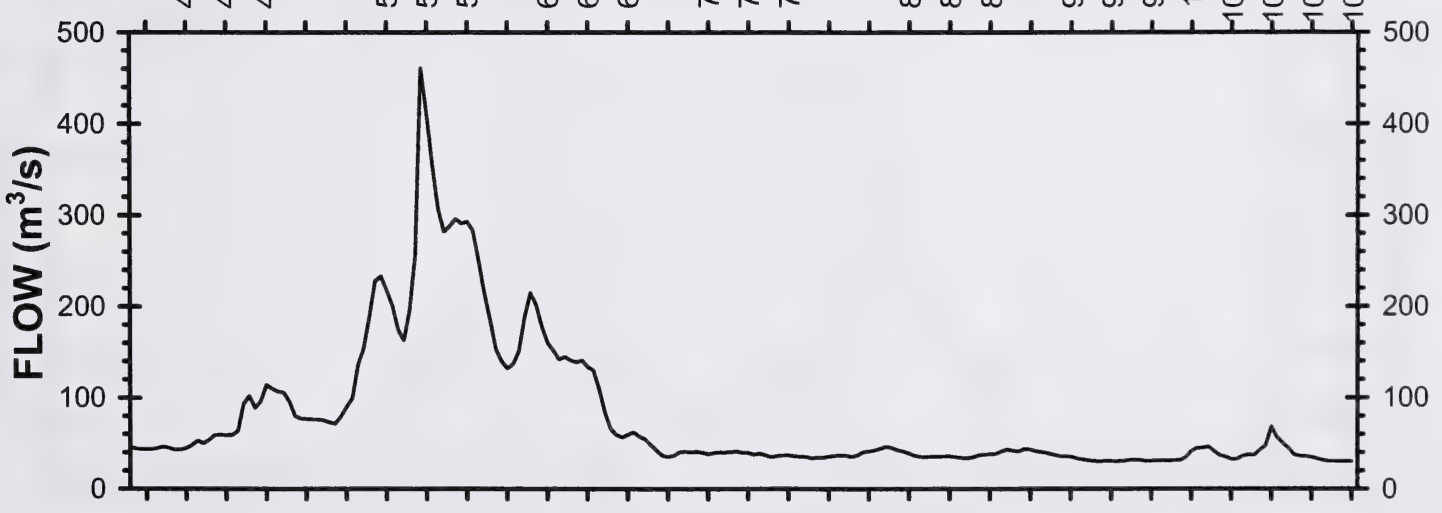

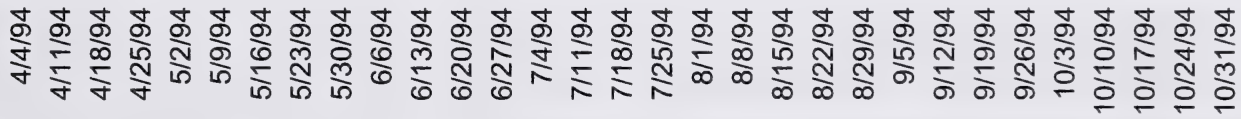

Figure 31. Daily water temperature (Datasonde), air temperature and flow in the Oldman River at the Bow River confluence. April-October 1994. 


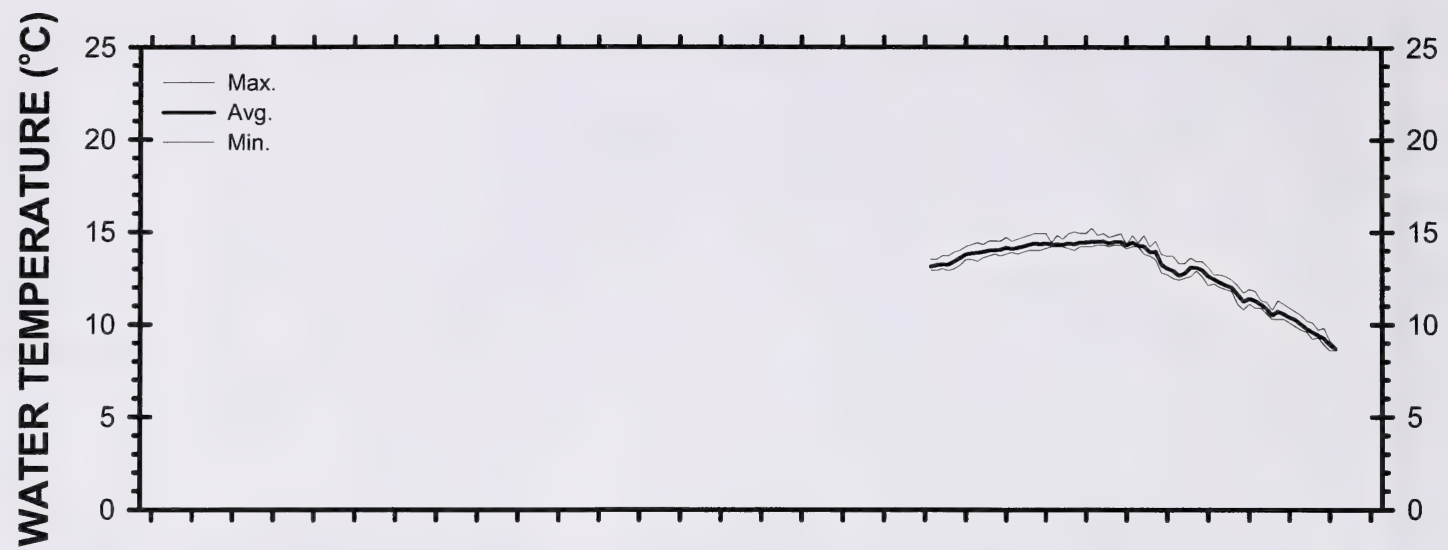

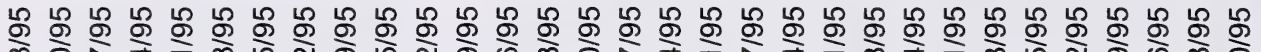

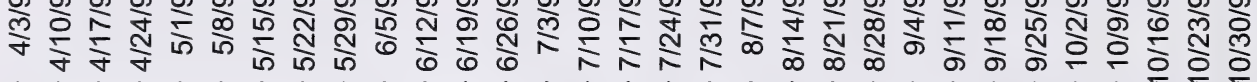

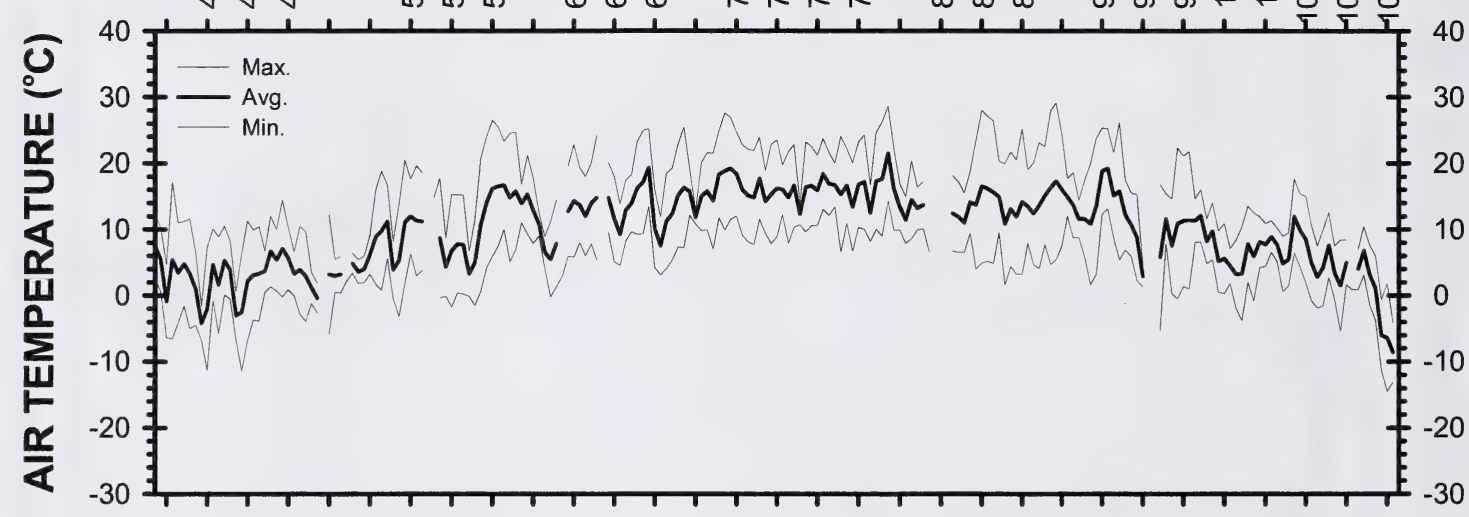

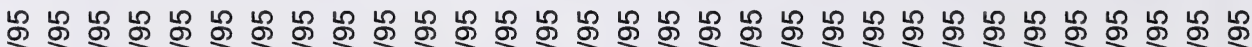

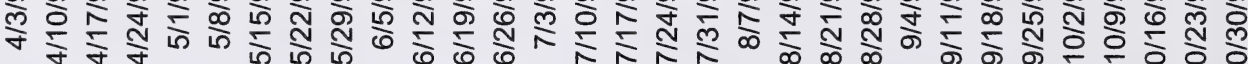

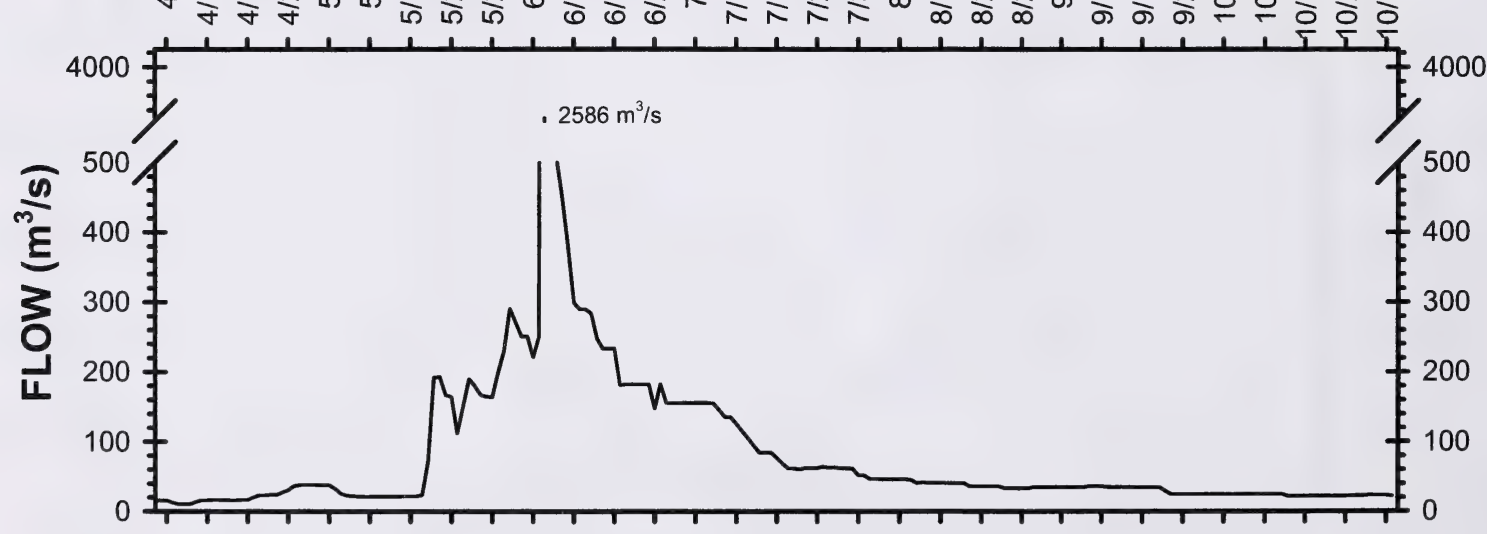

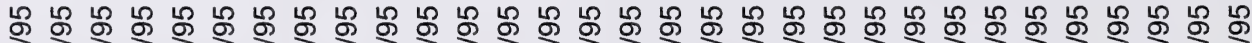

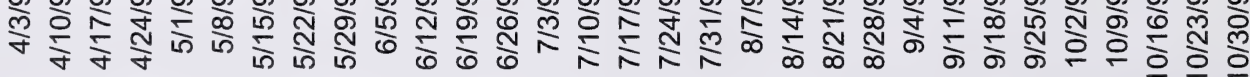

Figure 32. Daily water temperature (Thermograph), air temperature and flow in th Oldman River near the reservoir bottom release. April-October 1995. 


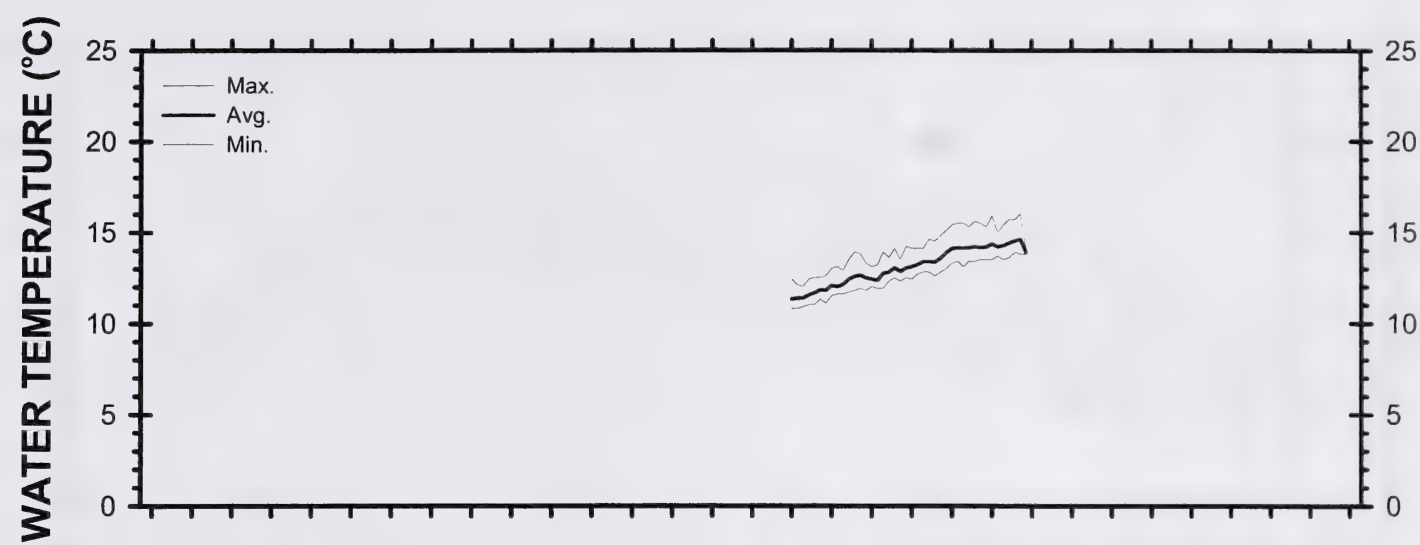

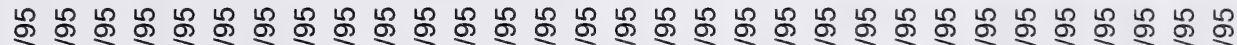

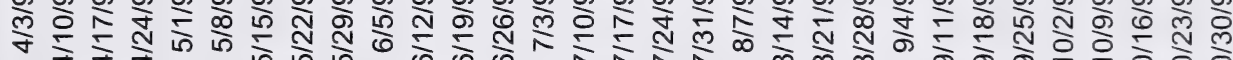

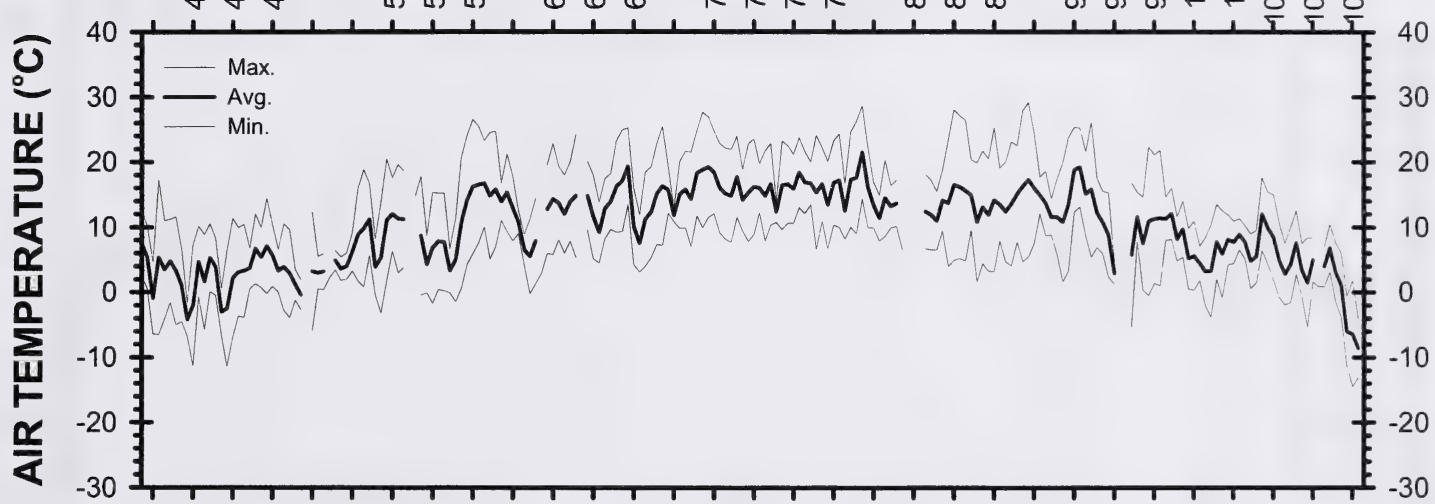

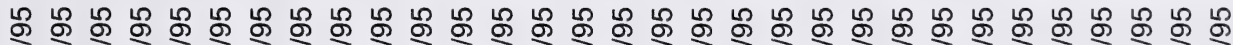

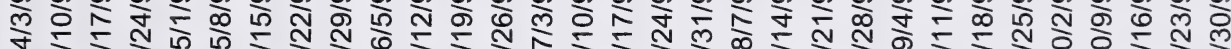

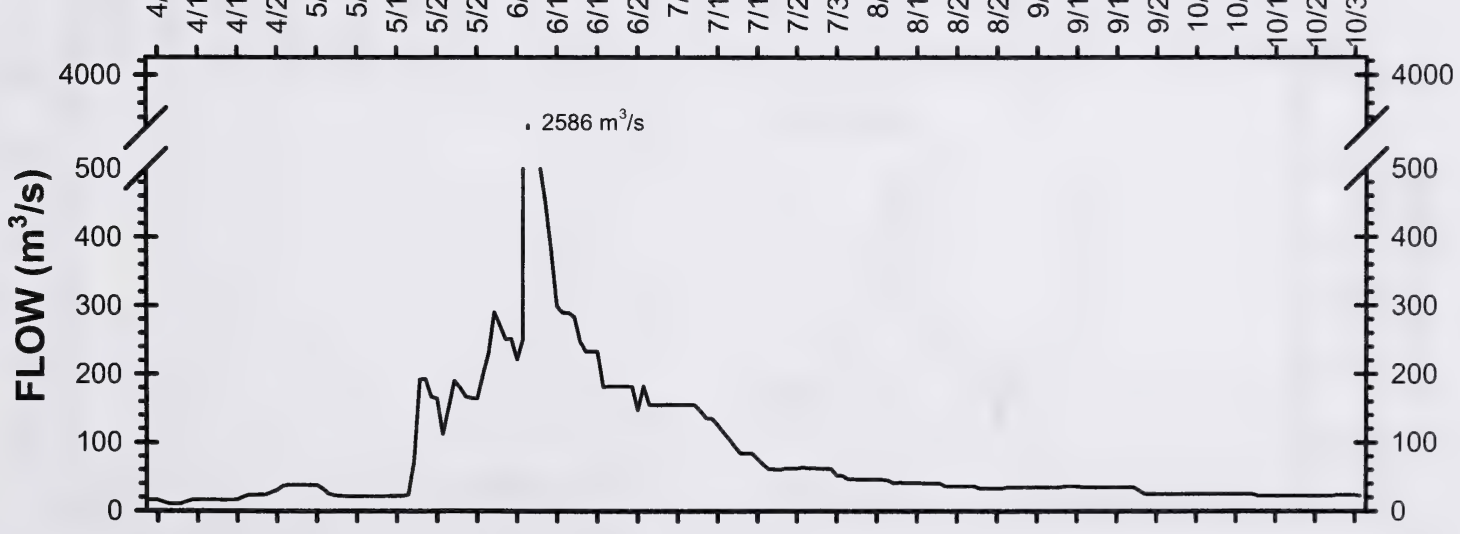

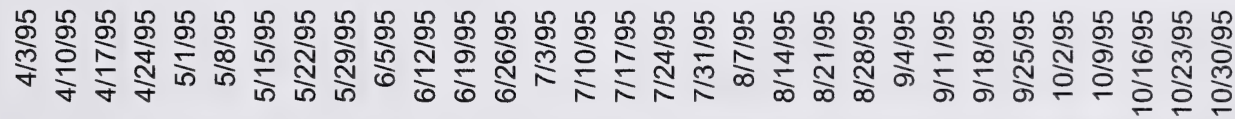

Figure 33. Daily water temperature (Thermograph), air temperature and flow in the Oldman River near Brocket. April-October 1995. 


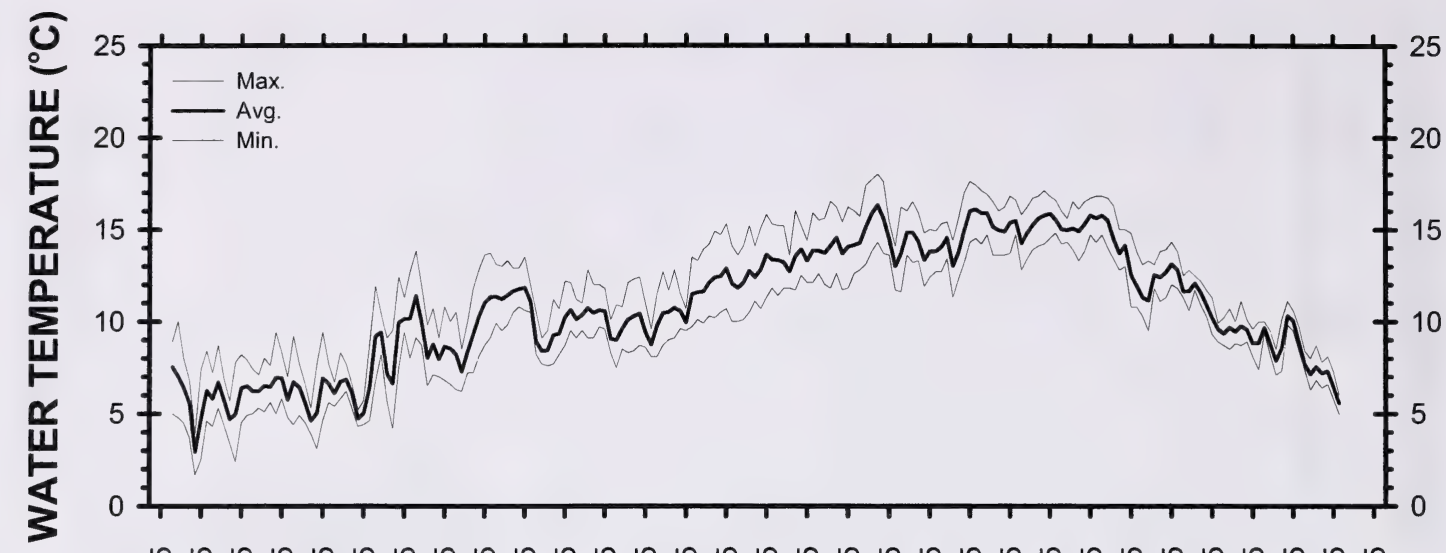

டீ โ

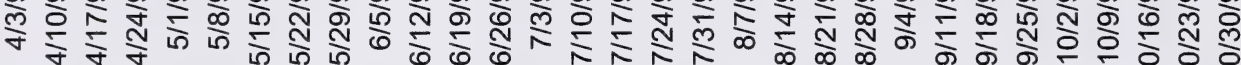

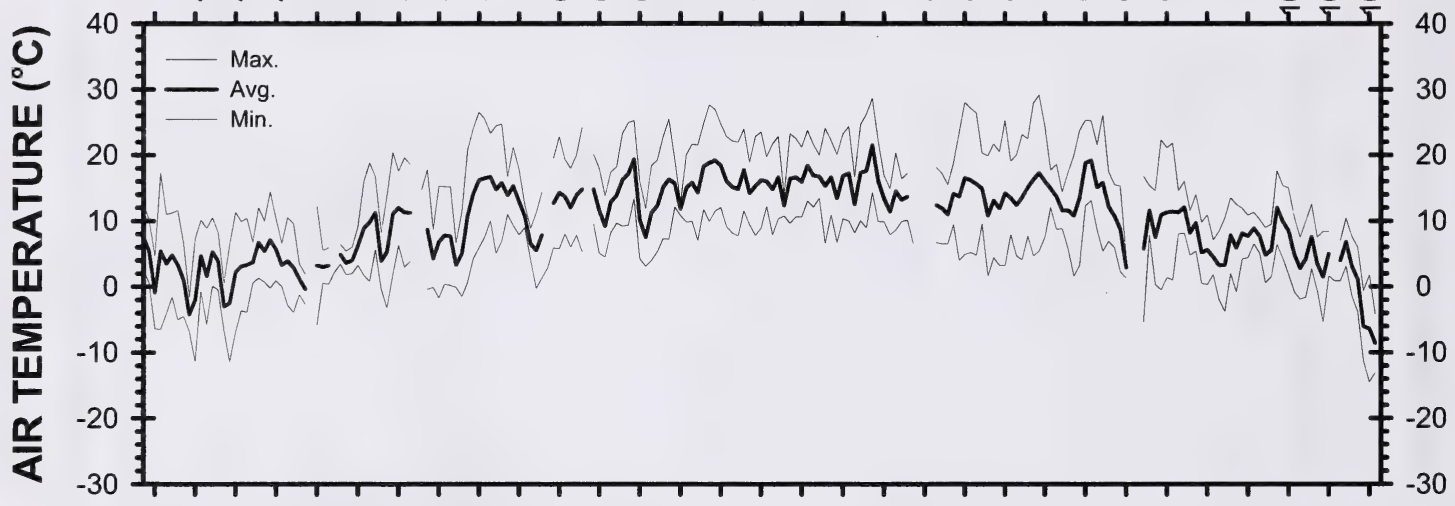

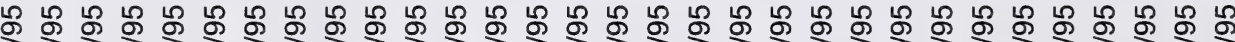
m

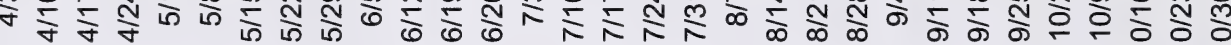

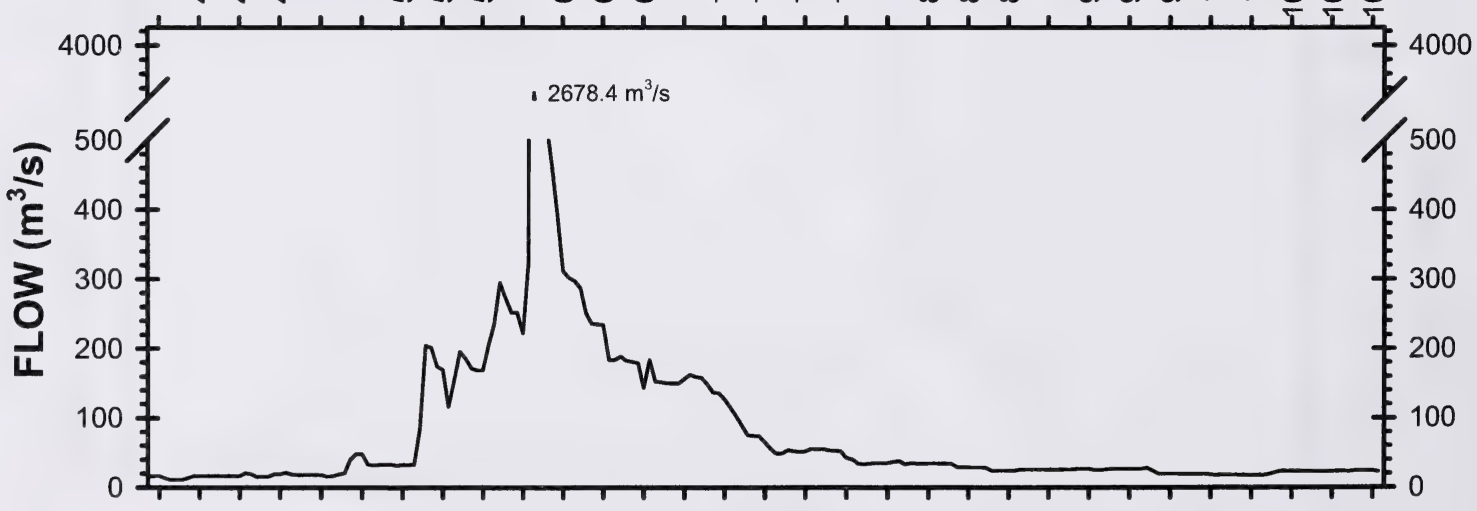

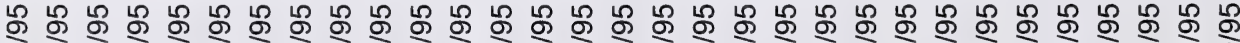

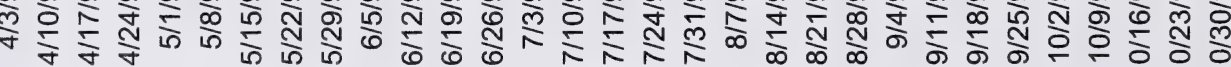

Figure 34. Daily water temperature (Thermograph), air temperature and flow in the Oldman River below the LNHD. April-October 1995. 


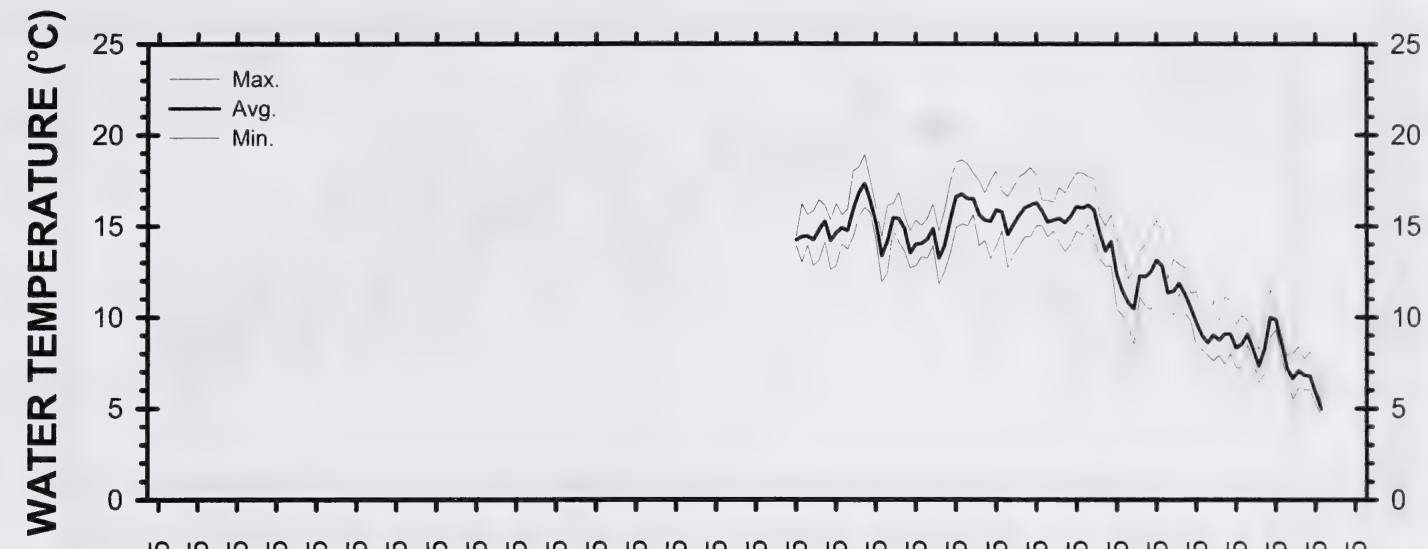

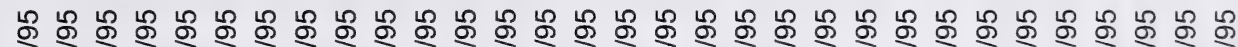

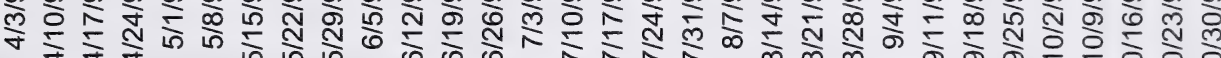

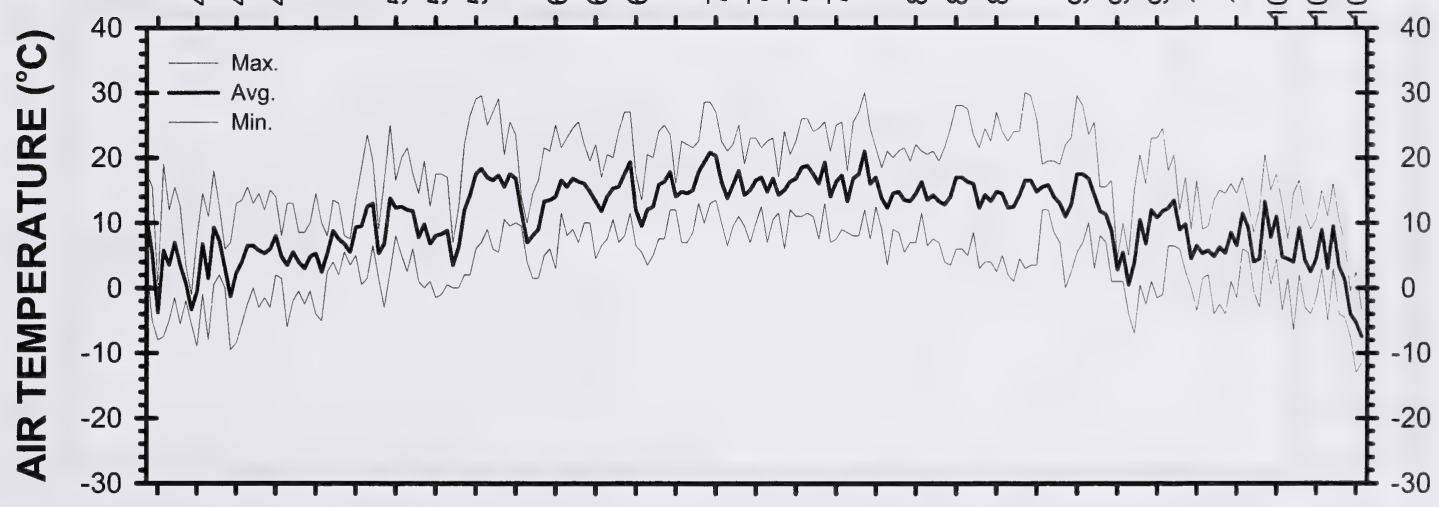

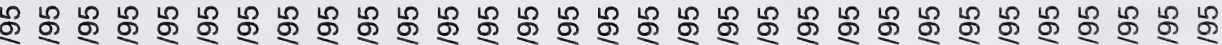

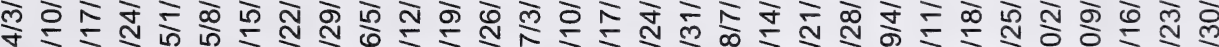

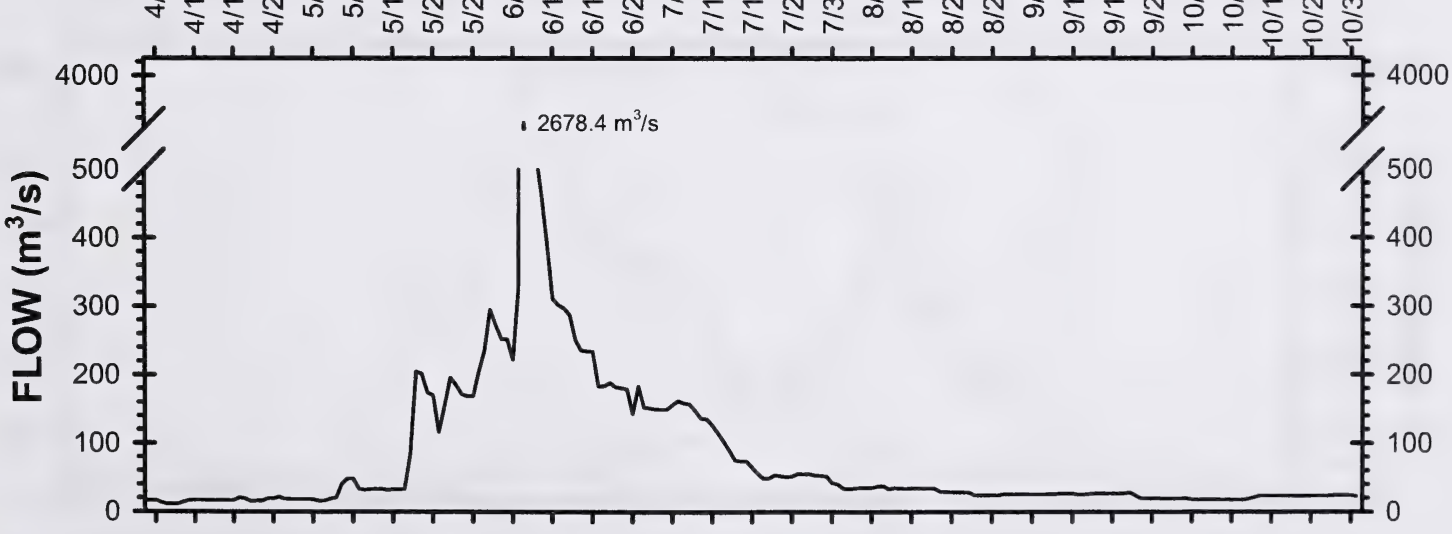

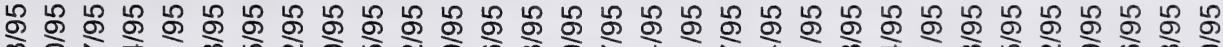

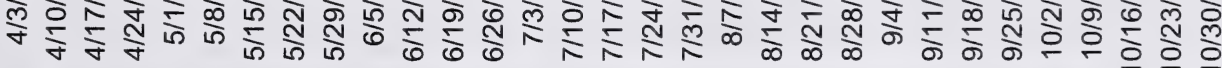

Figure 35. Daily water temperature (Thremograph), air temperature and flow in the Oldman River near Fort Macleod. April-October 1995. 


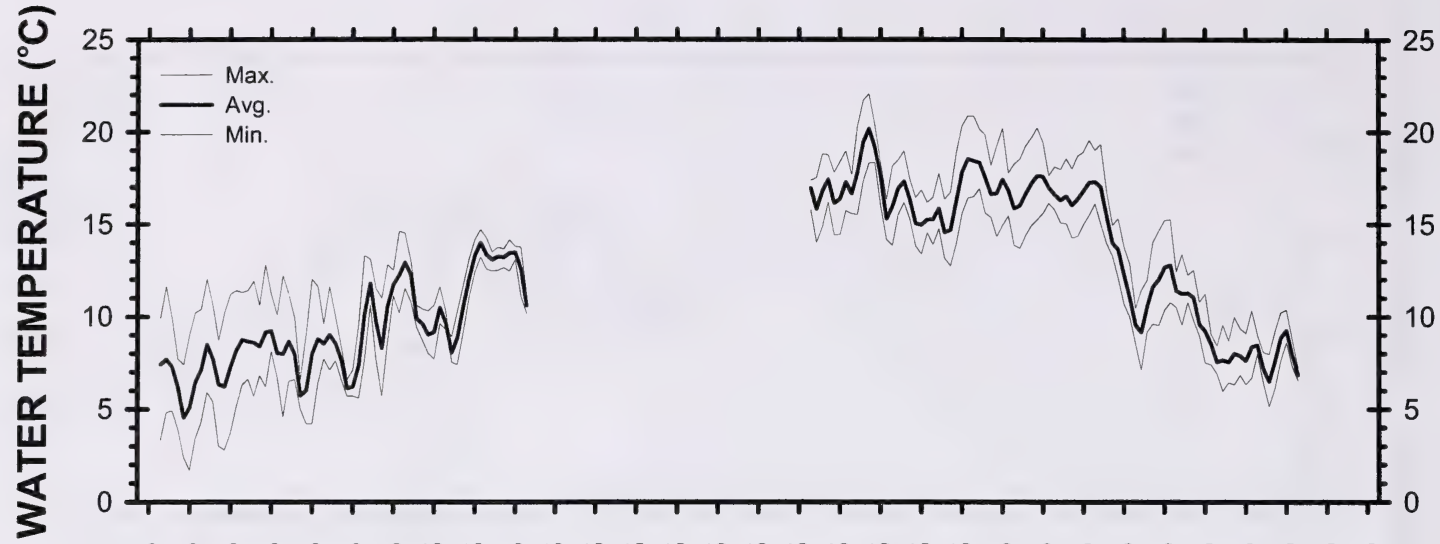

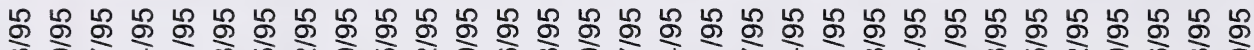

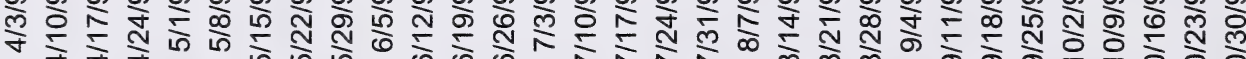

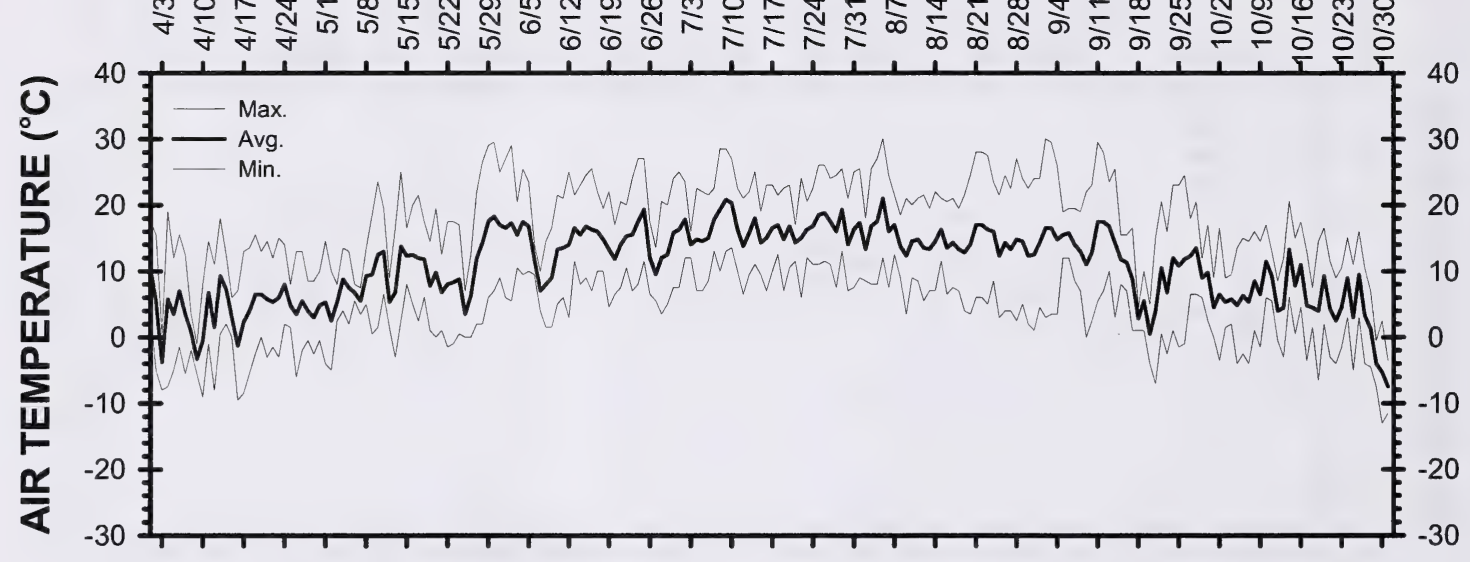

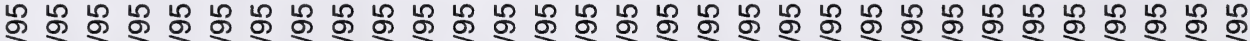

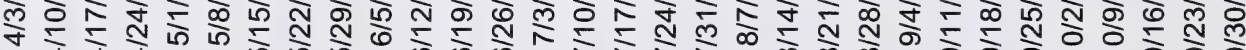

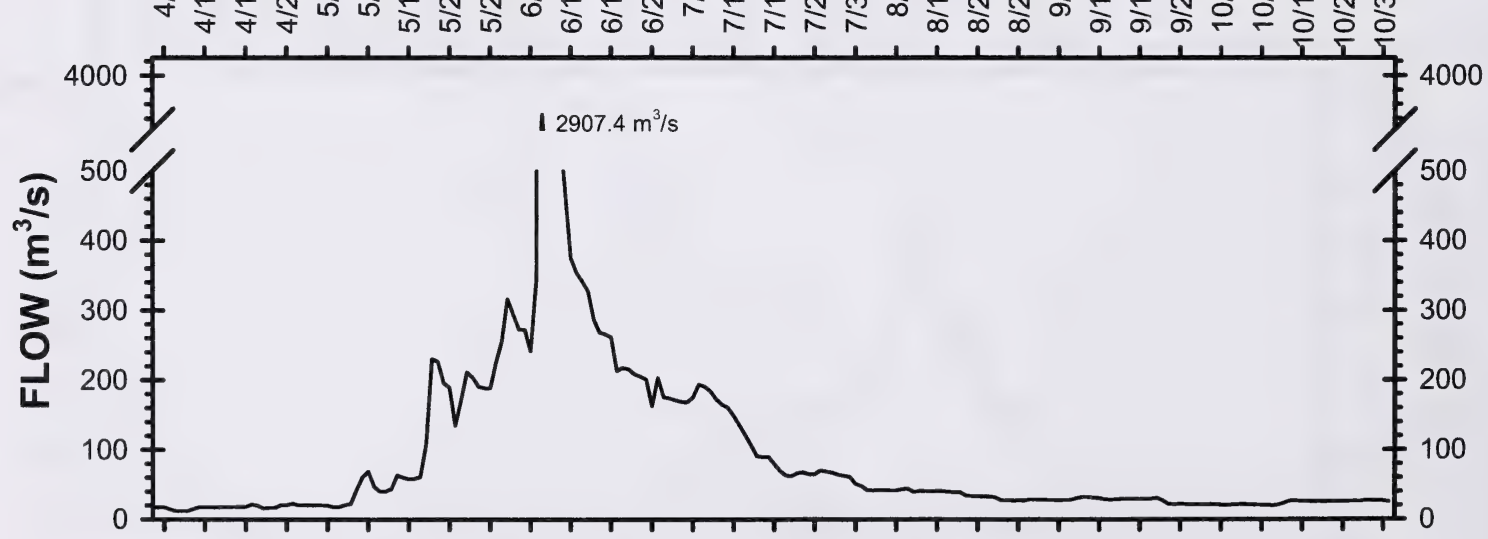

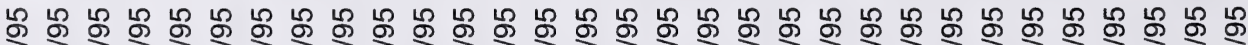

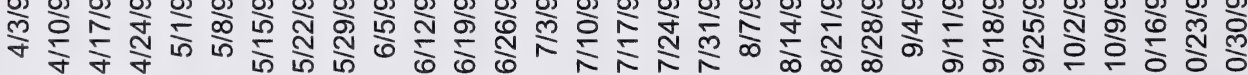

Figure 36. Daily water temperature (Thermograph/Datasonde), air temperature and flow in the Oldman River near Monarch. April-October 1995. 


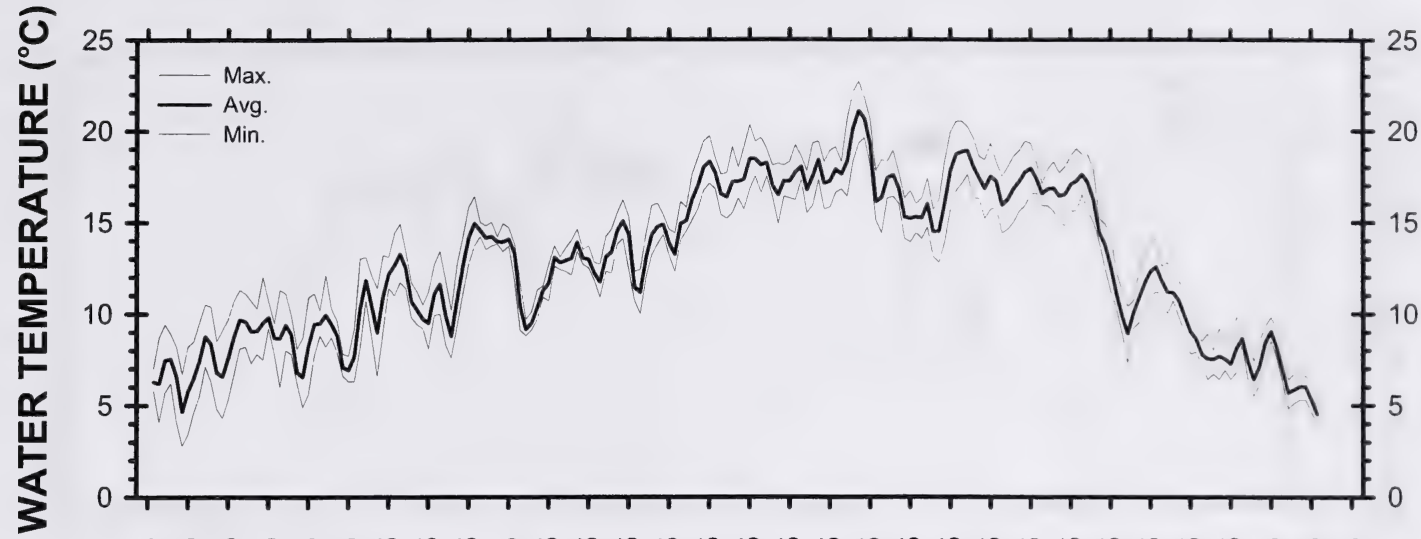

セ

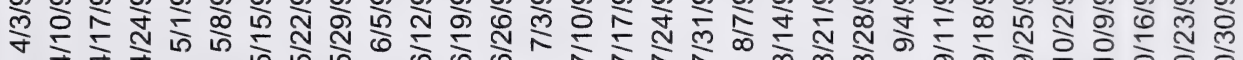

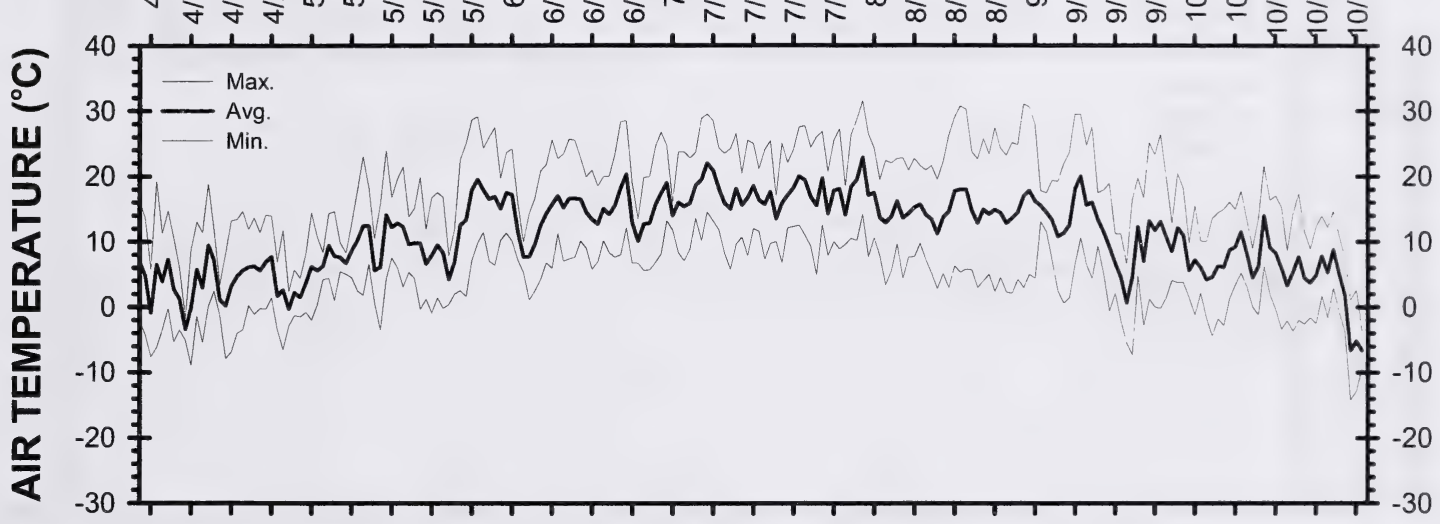

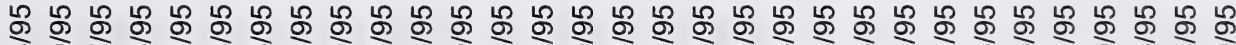

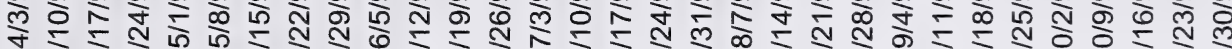

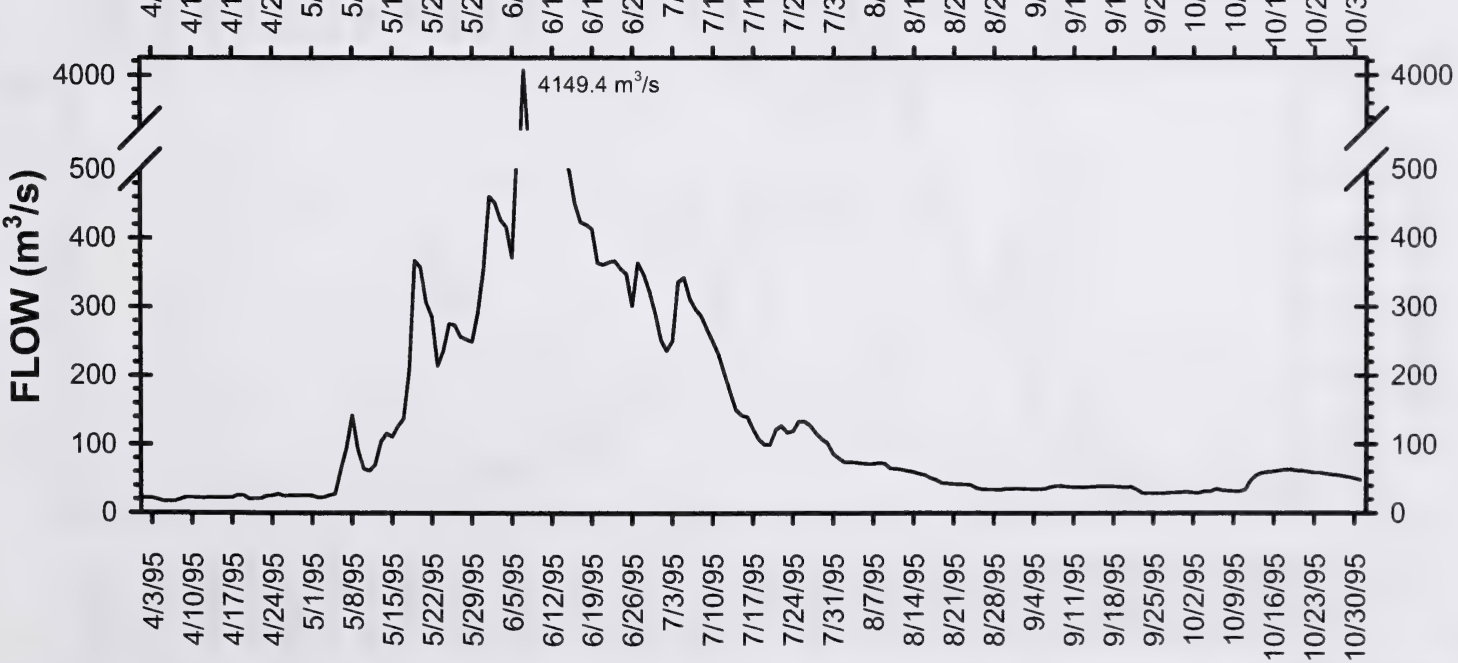

Figure 37. Daily water temperature (Thermograph), air temperature and flow in the Oldman River downstream of the Belly River. April-October 1995. 


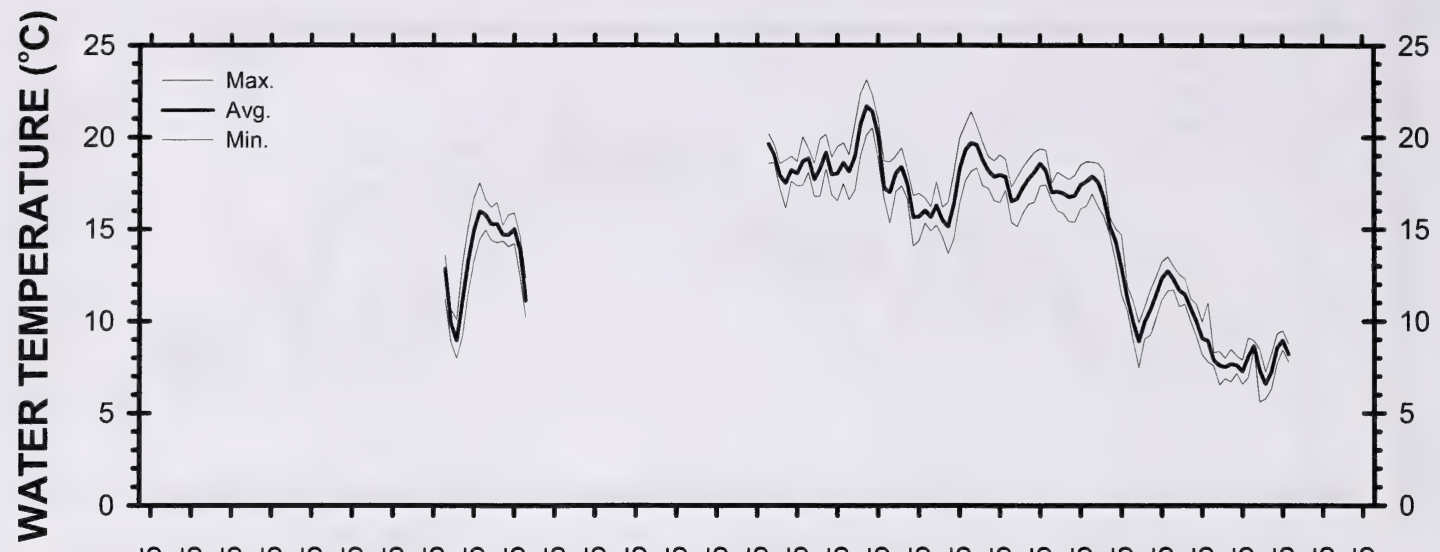

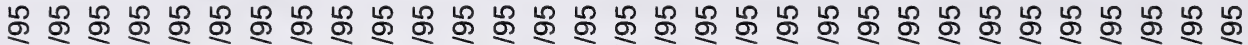

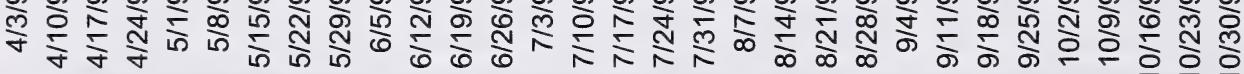
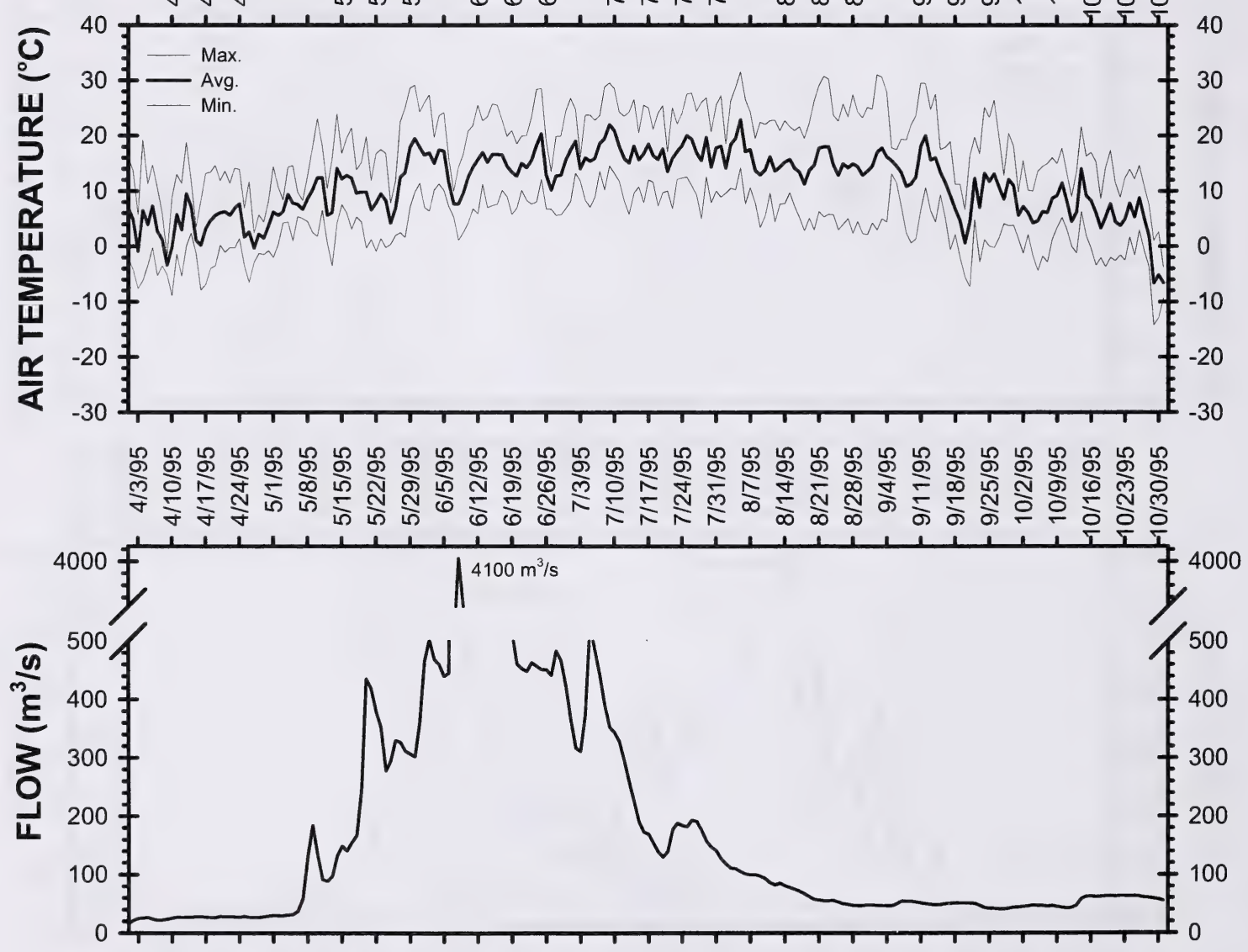

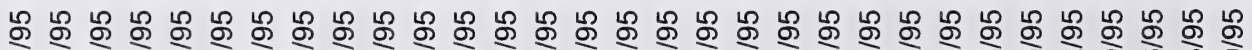

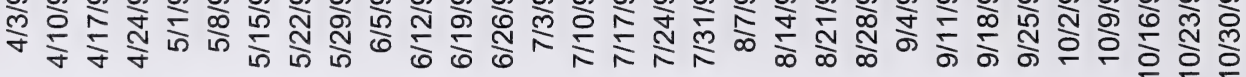

Figure 38. Daily water temperature (Thermograph), air temperature and flow in the Oldman River upstream of Lethbridge. April-October 1995. 


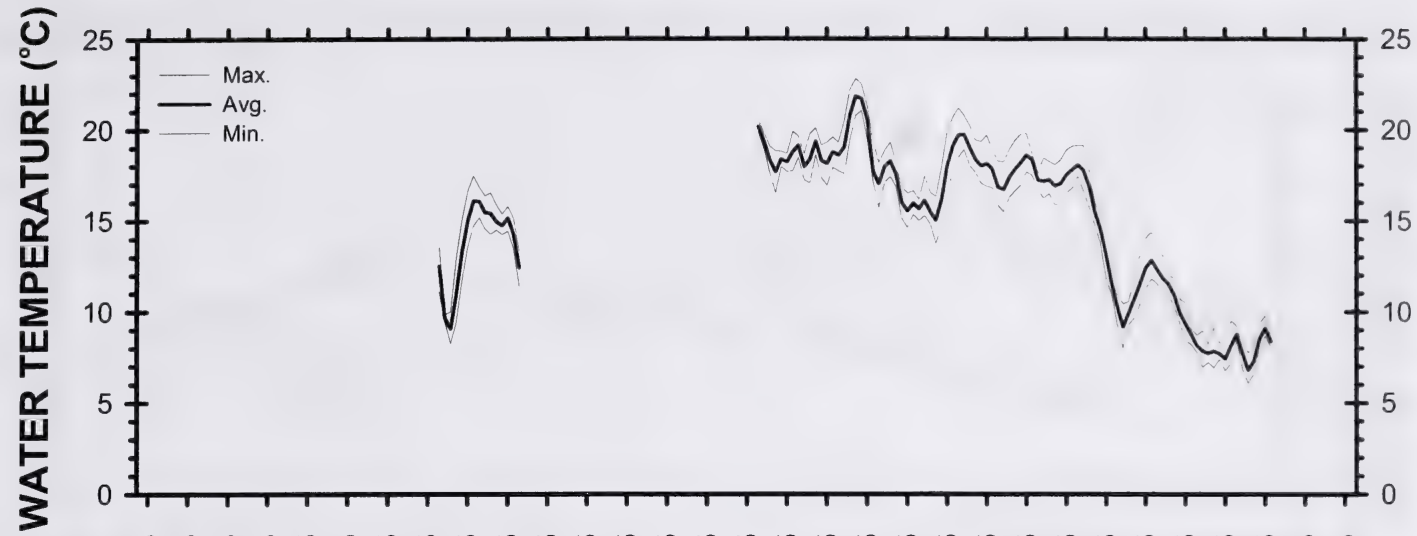

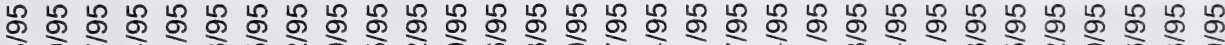

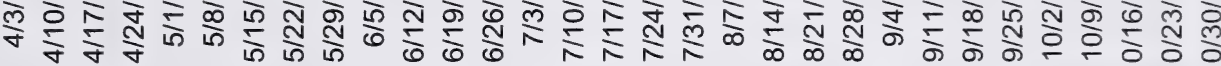

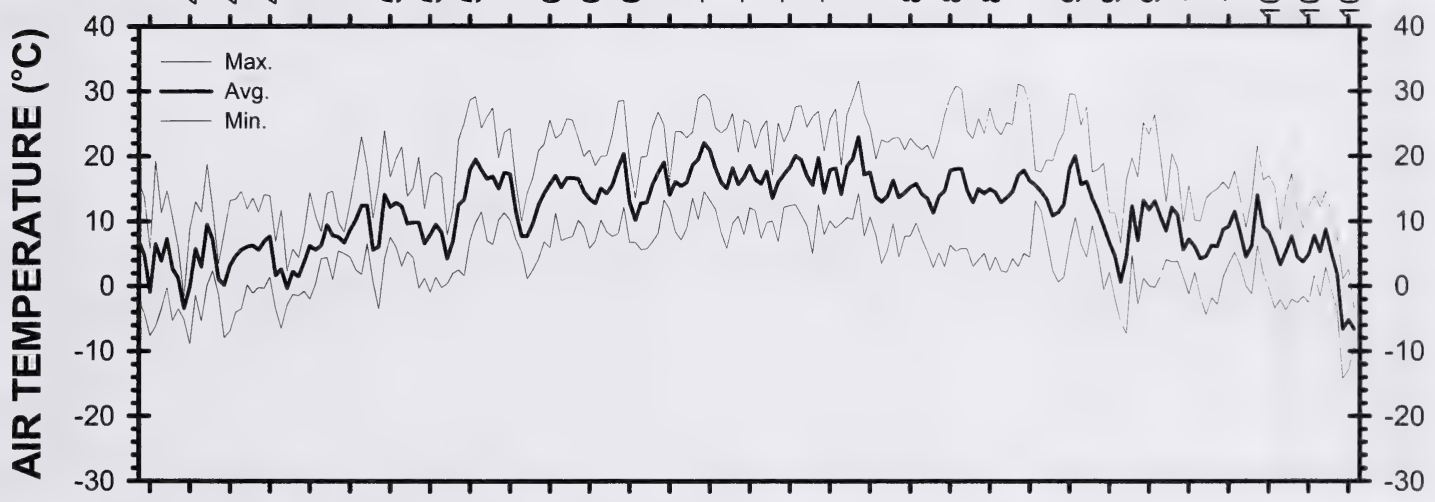

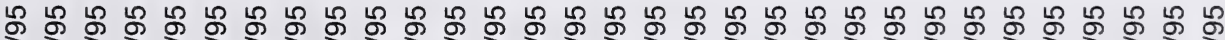

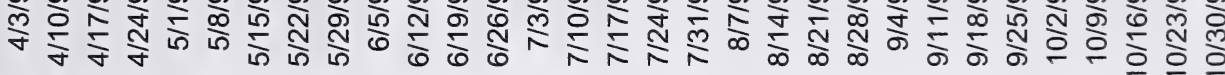

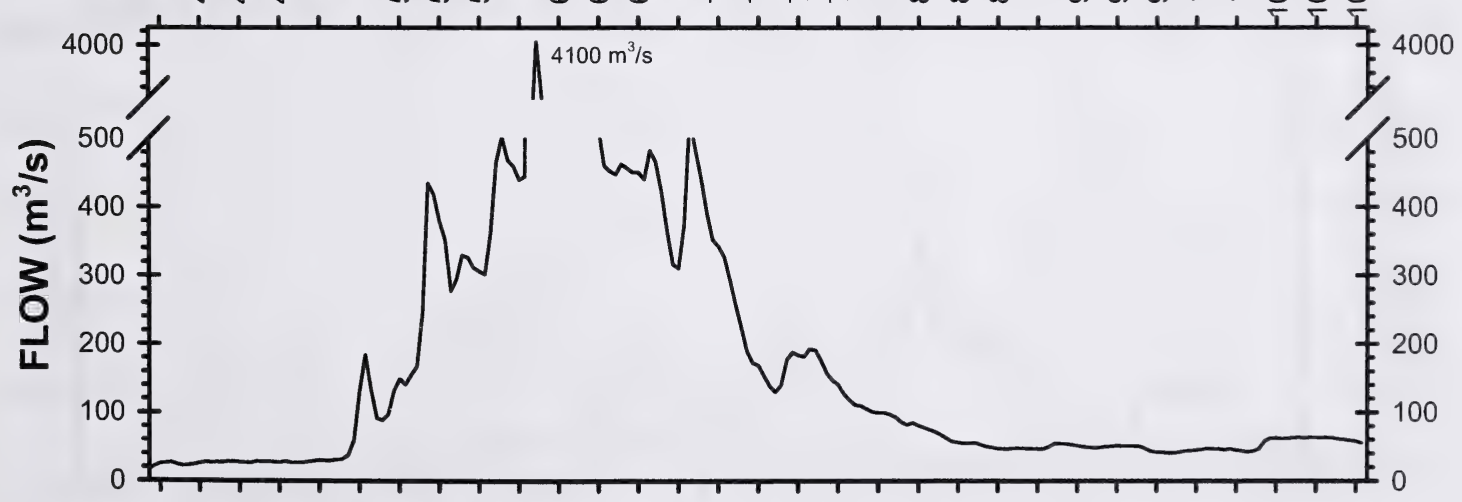

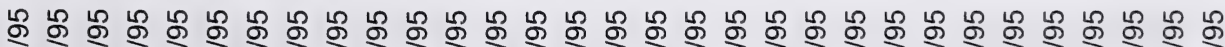

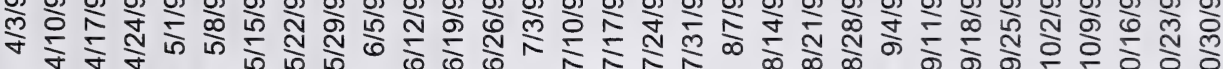

Figure 39. Daily water temperature (Datasonde), air temperature and flow in the Oldman River downstream of Lethbridge. April-October 1995. 


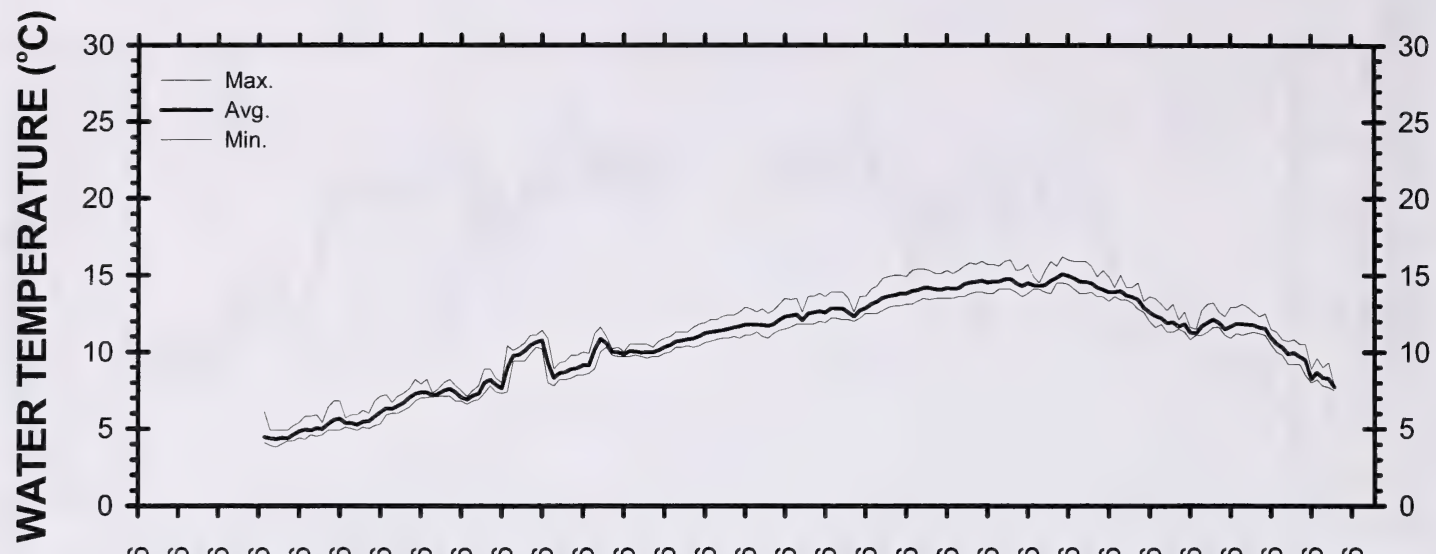

ஜ

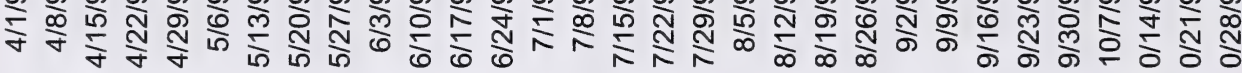

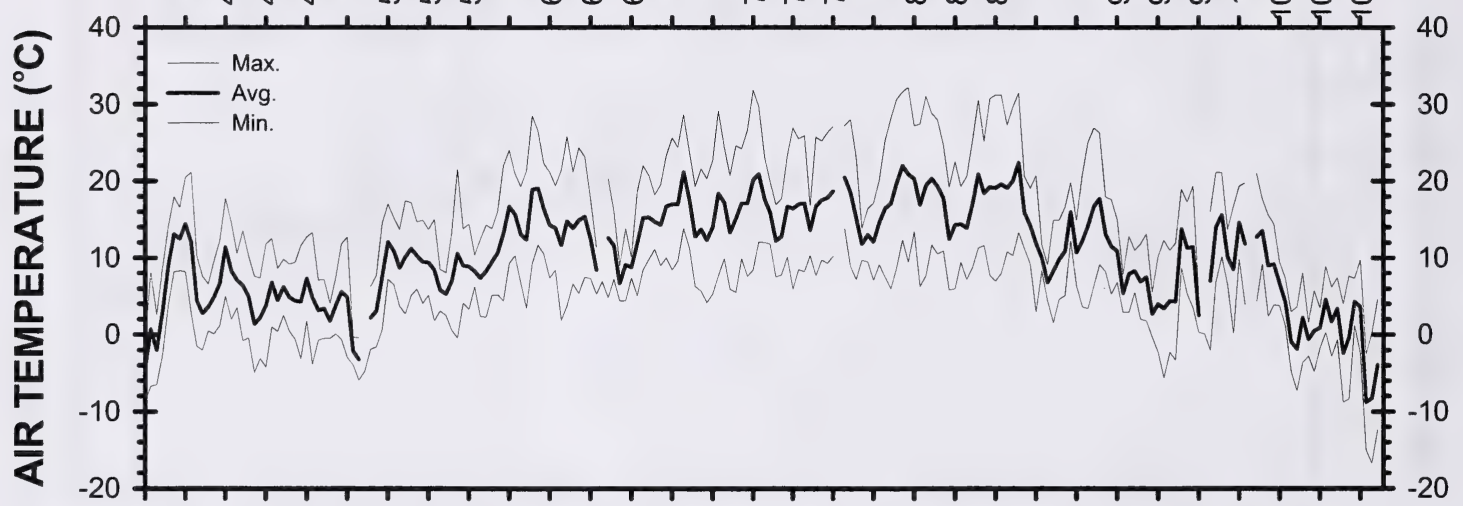

Ю

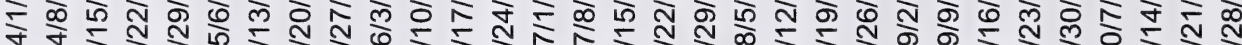

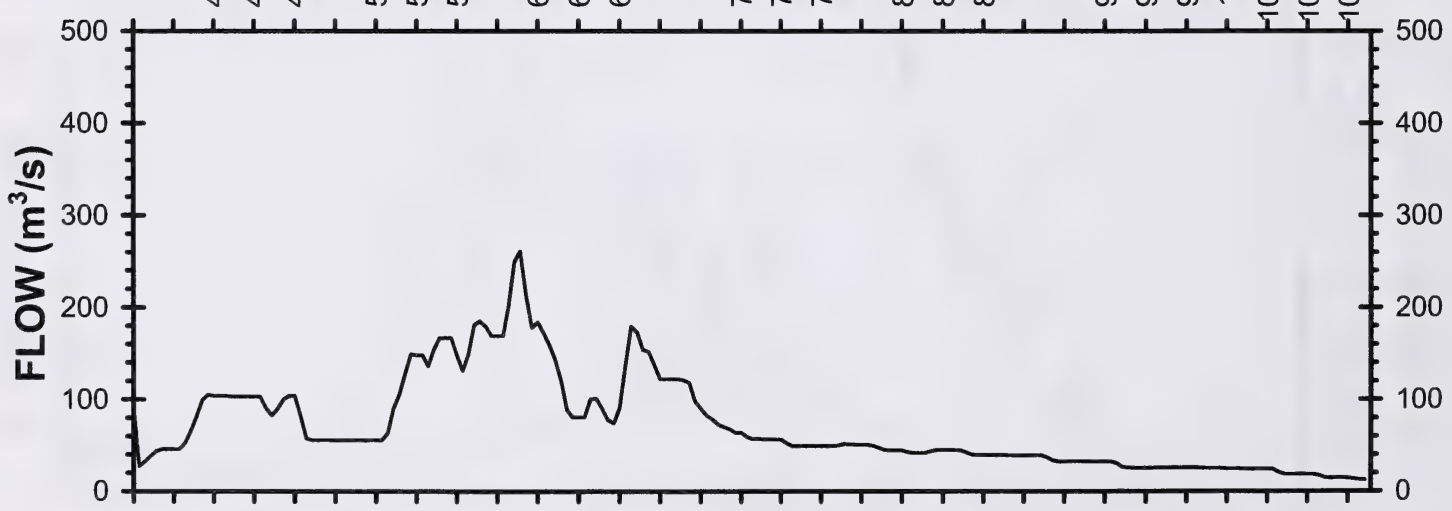

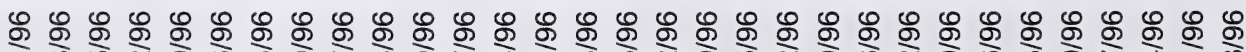

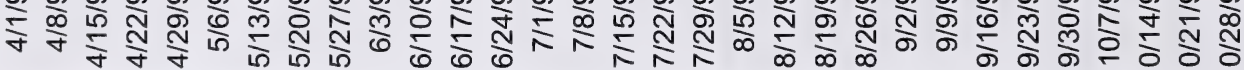

Figure 40. Daily water temperature (Thermograph), air temperature and flow in the Oldman River near Brocket. April-October 1996. 


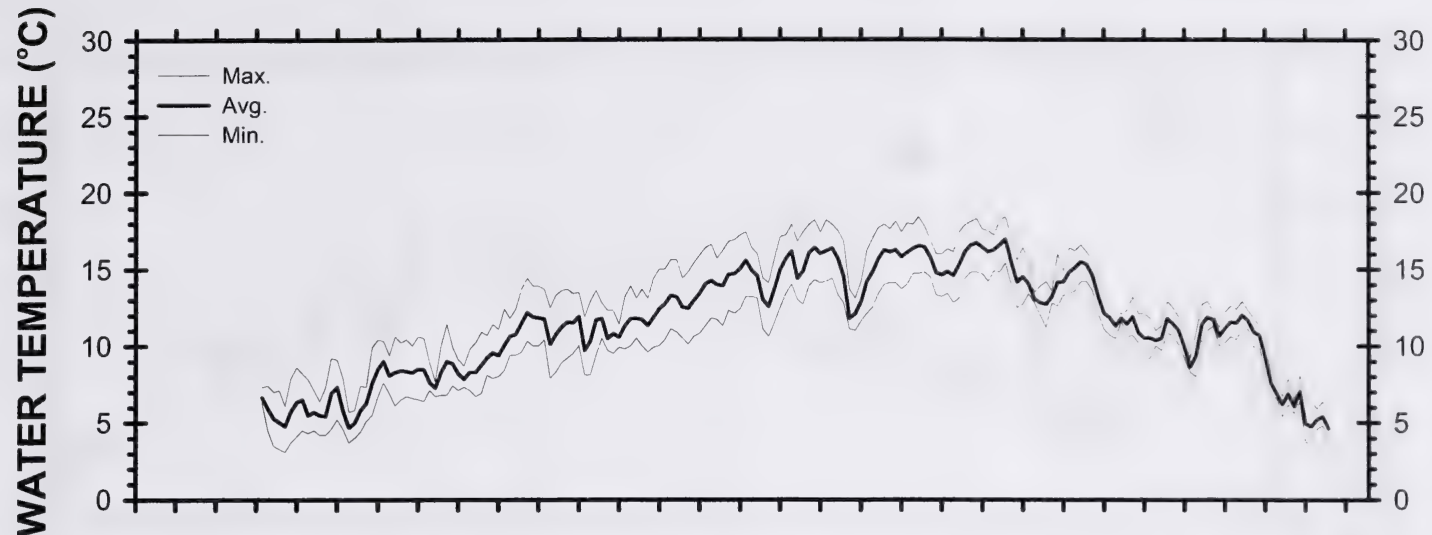

ஜ

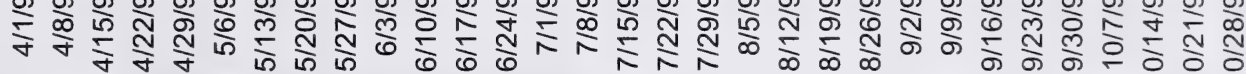

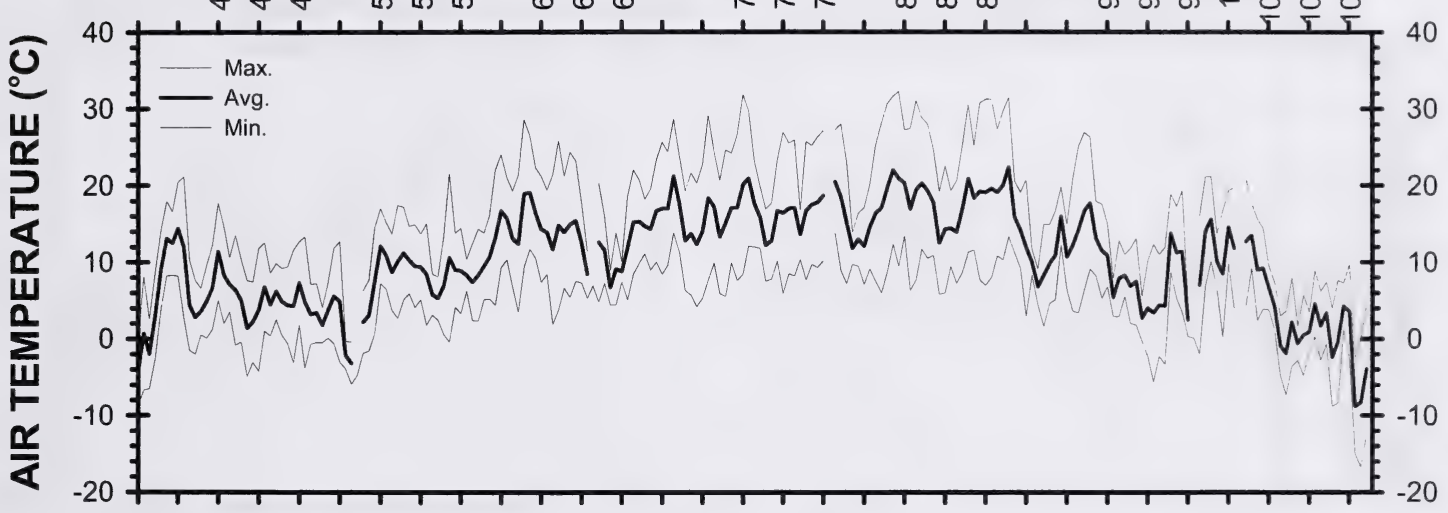

ஜ

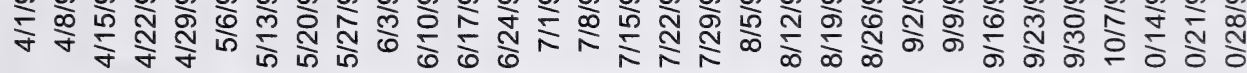

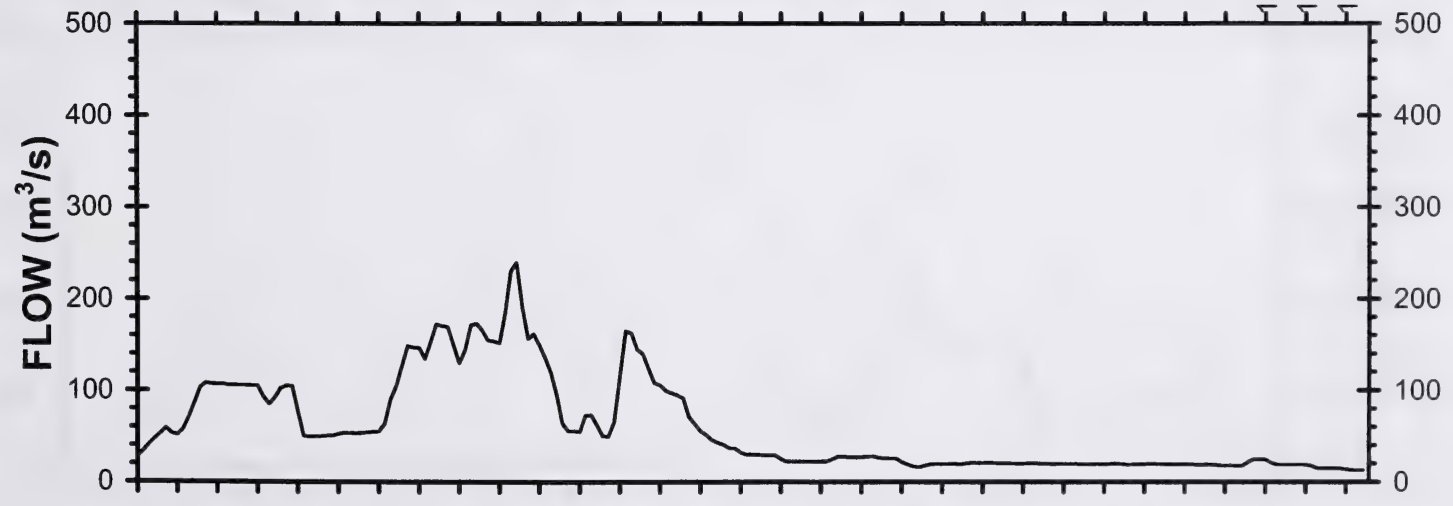

ஜ

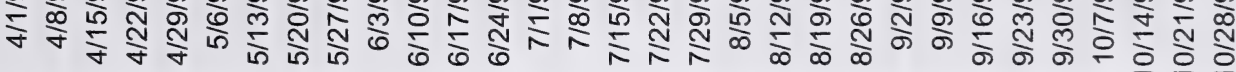

Figure 41. Daily water temperature (Thermograph), air temperature and flow in the Oldman River downstream of the LNHD. April-October 1996. 


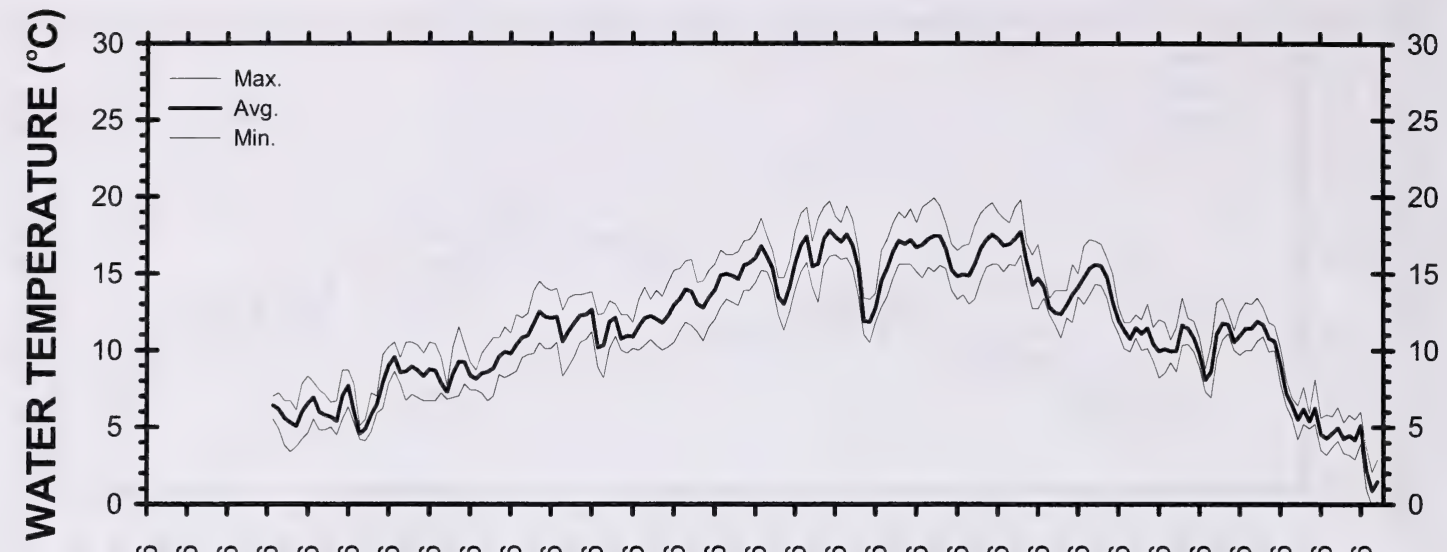

Ю

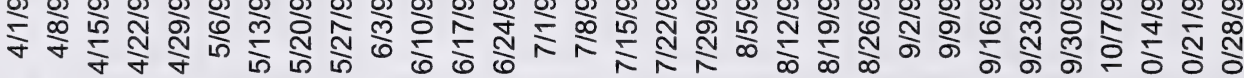

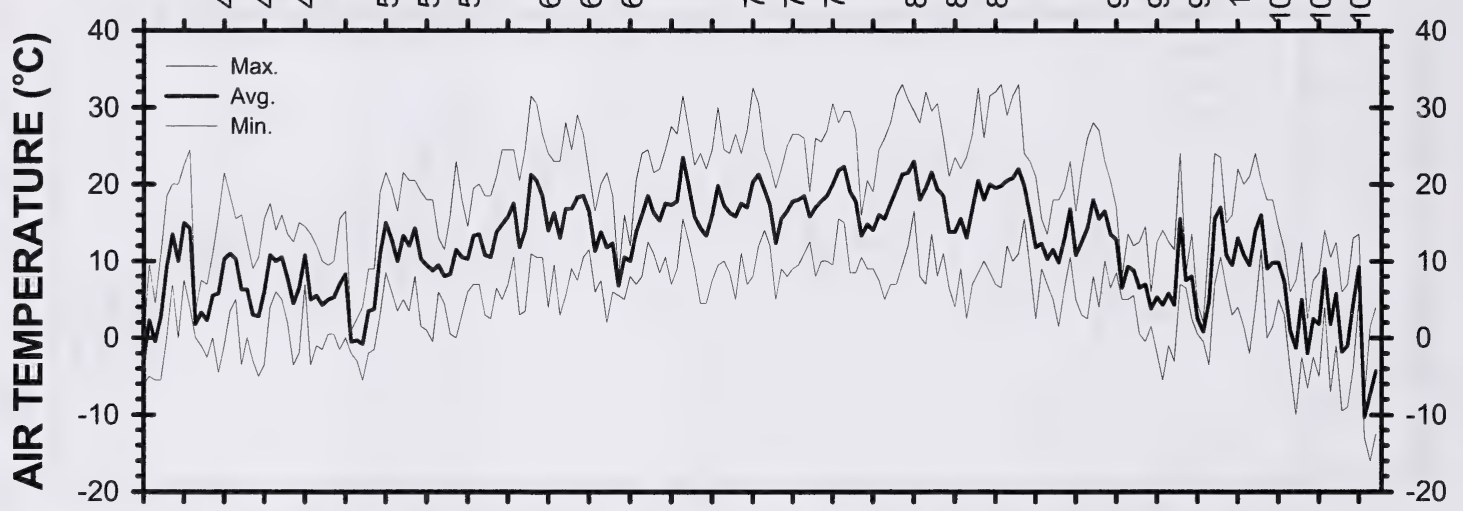

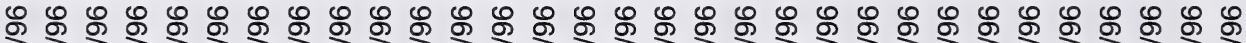
子

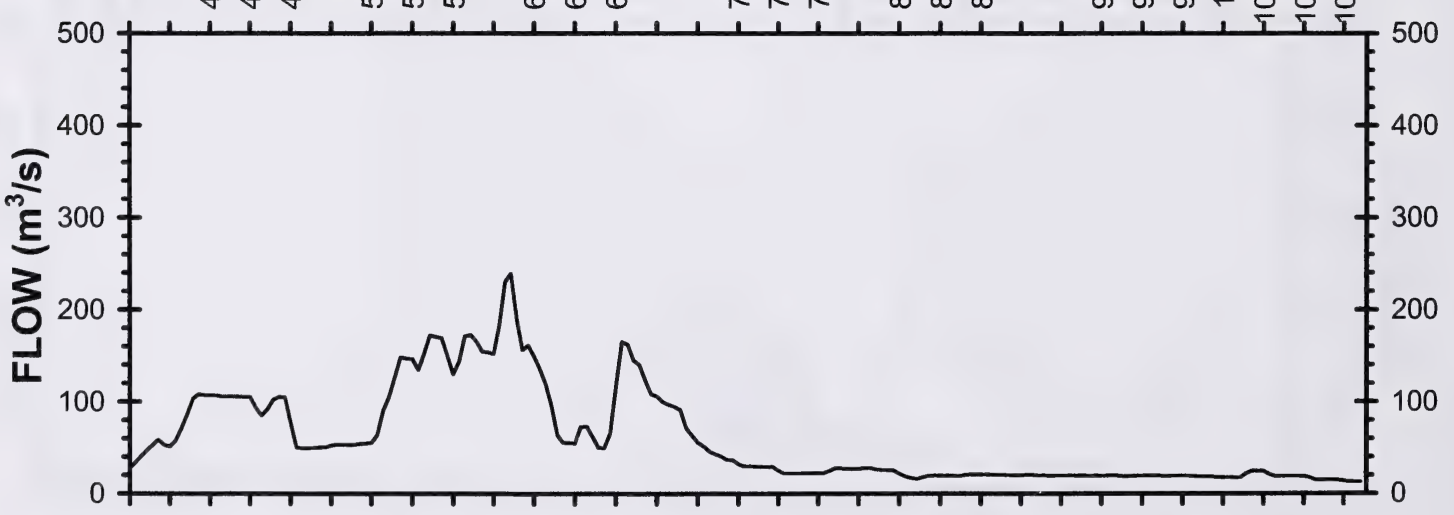

\%

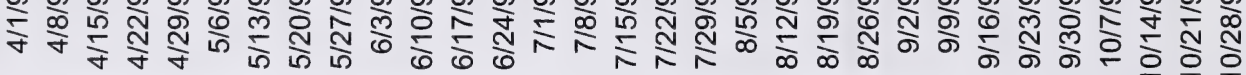

Figure 42. Daily water temperature (Thermograph), air temperature and flow in the Oldman River near Fort Macleod. April-October 1996. 


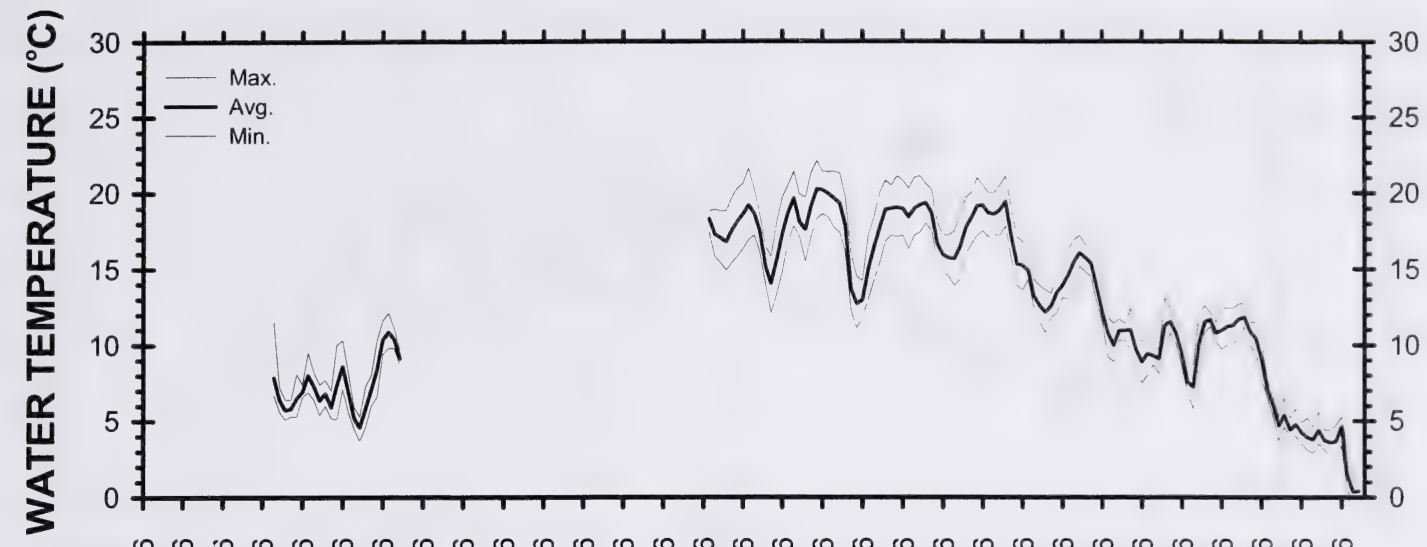

ஃ \% \% \%

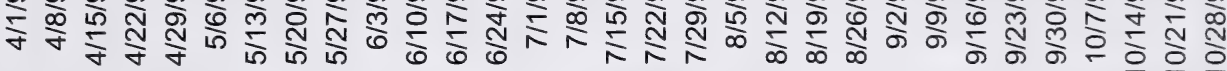

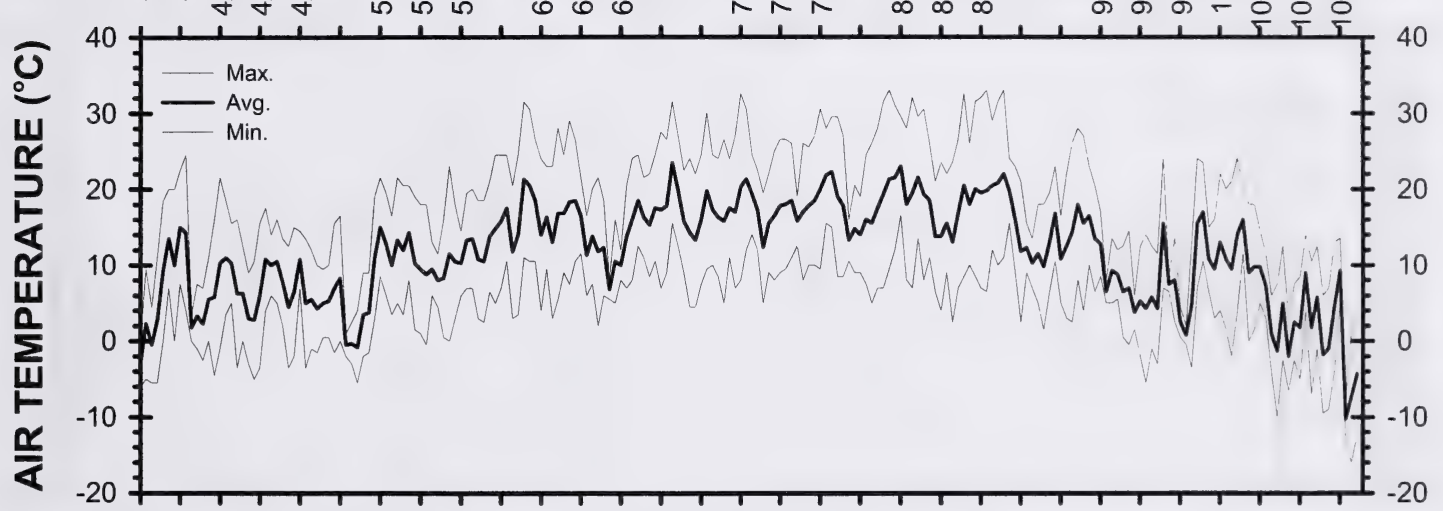

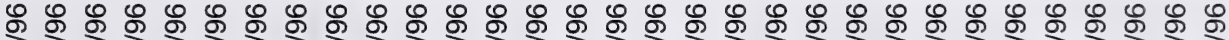

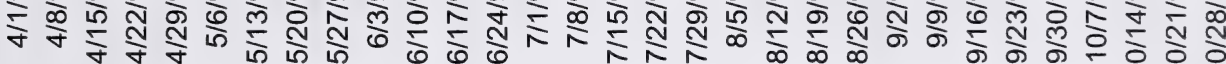

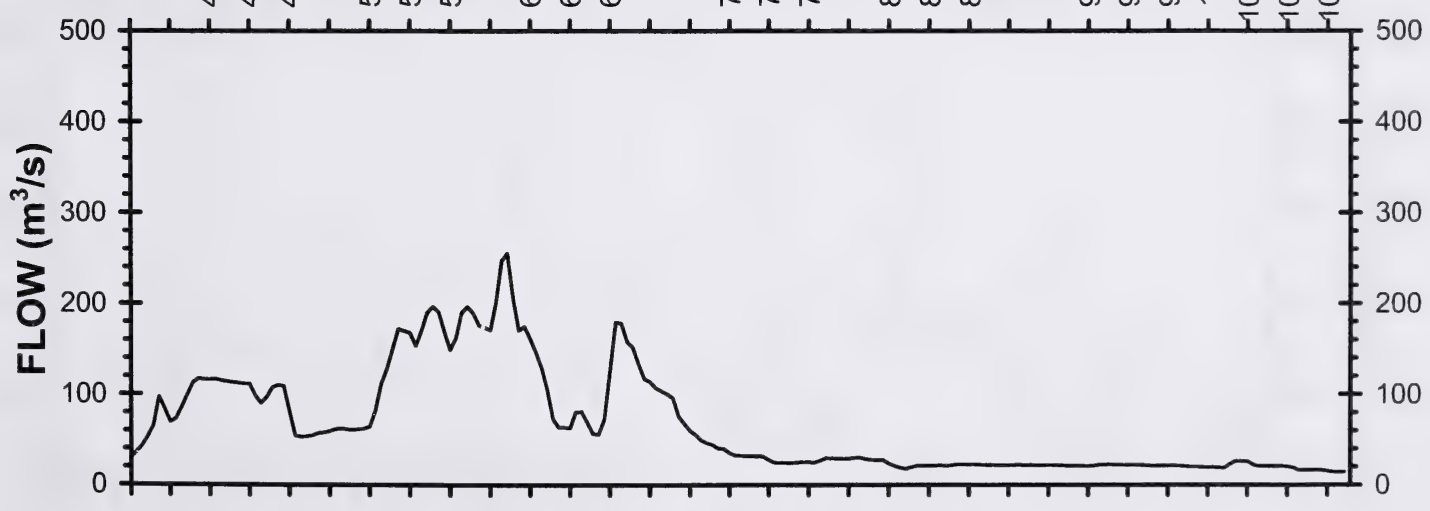

ஜ

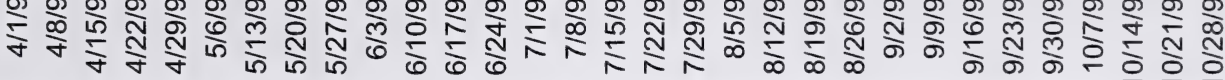

Figure 43. Daily water temperature (Thermograph), air temperature and flow in the Oldman River near Rocky Coulee. April-October 1996. 


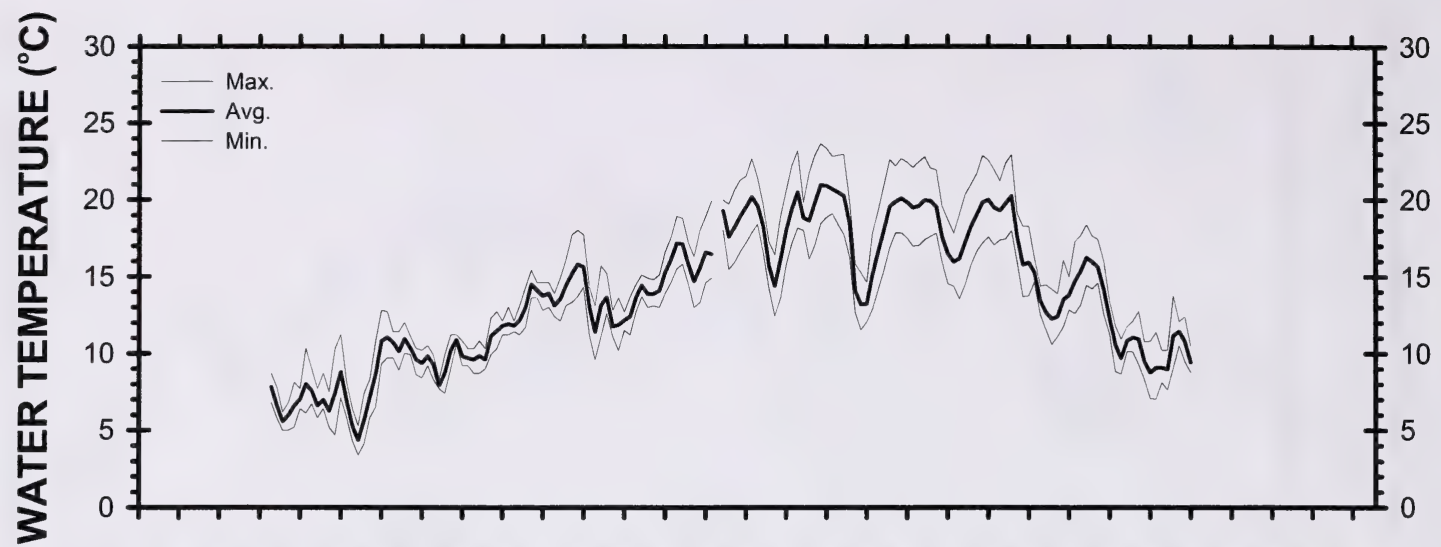

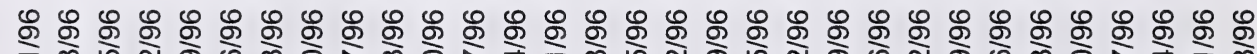
亦

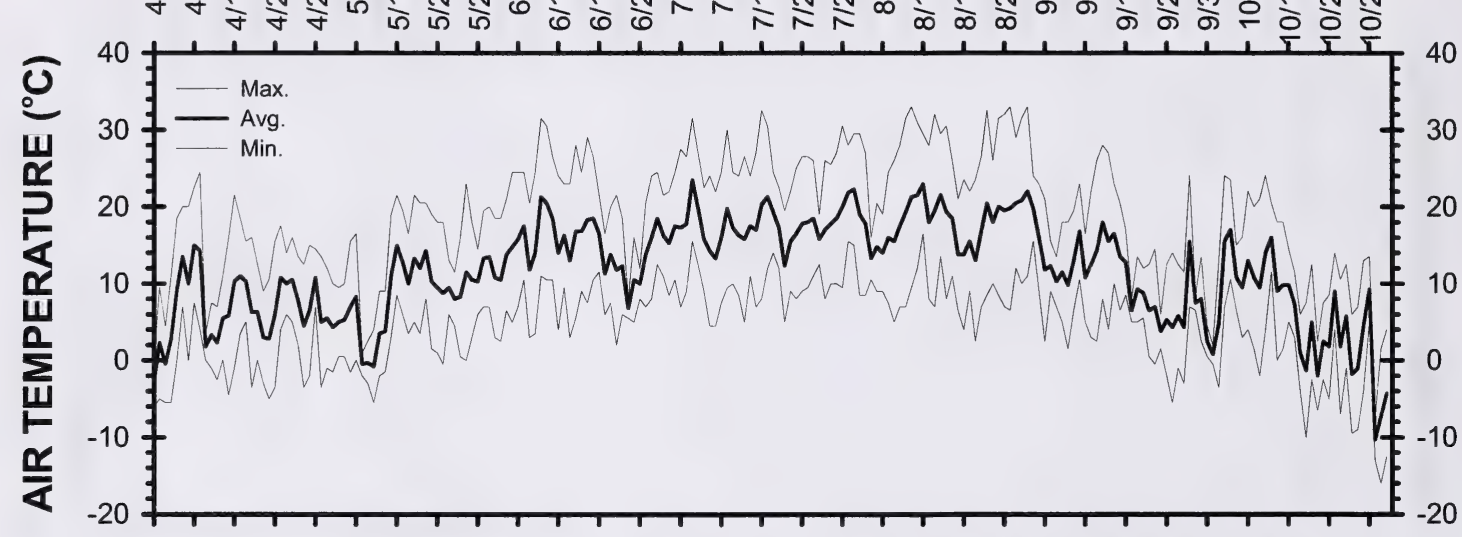

\%

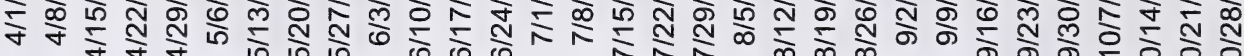

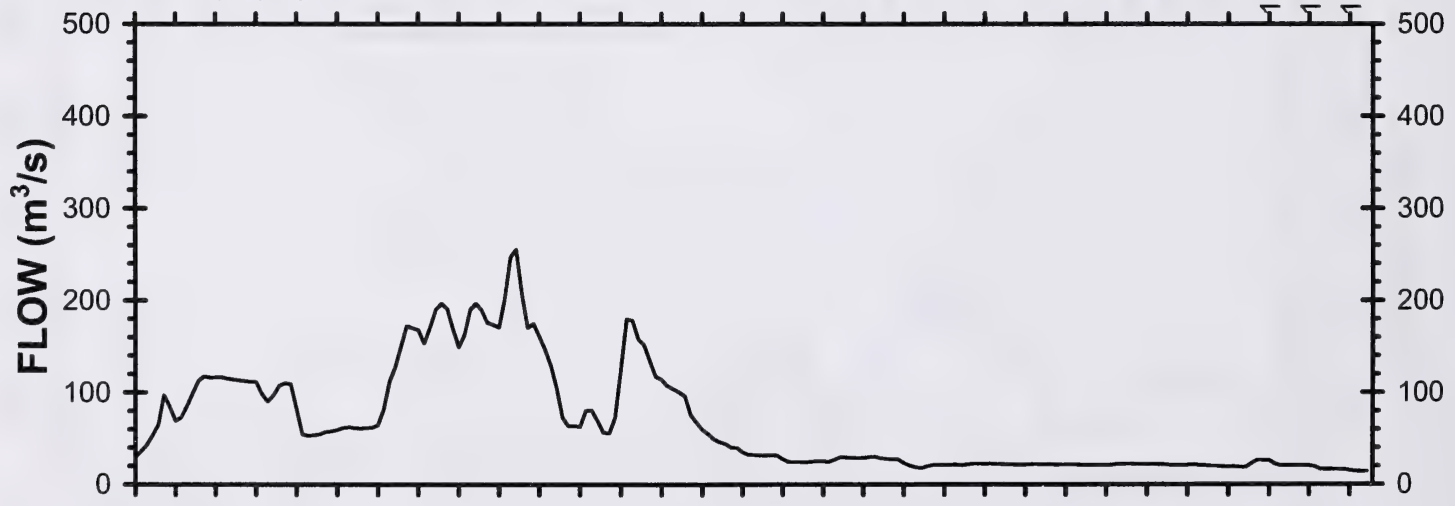

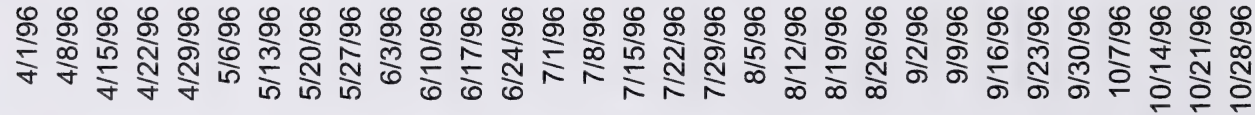

Figure 44. Daily water temperature (Thermograph), air temperature and flow in the Oldman River near Monarch. April-October 1996. 


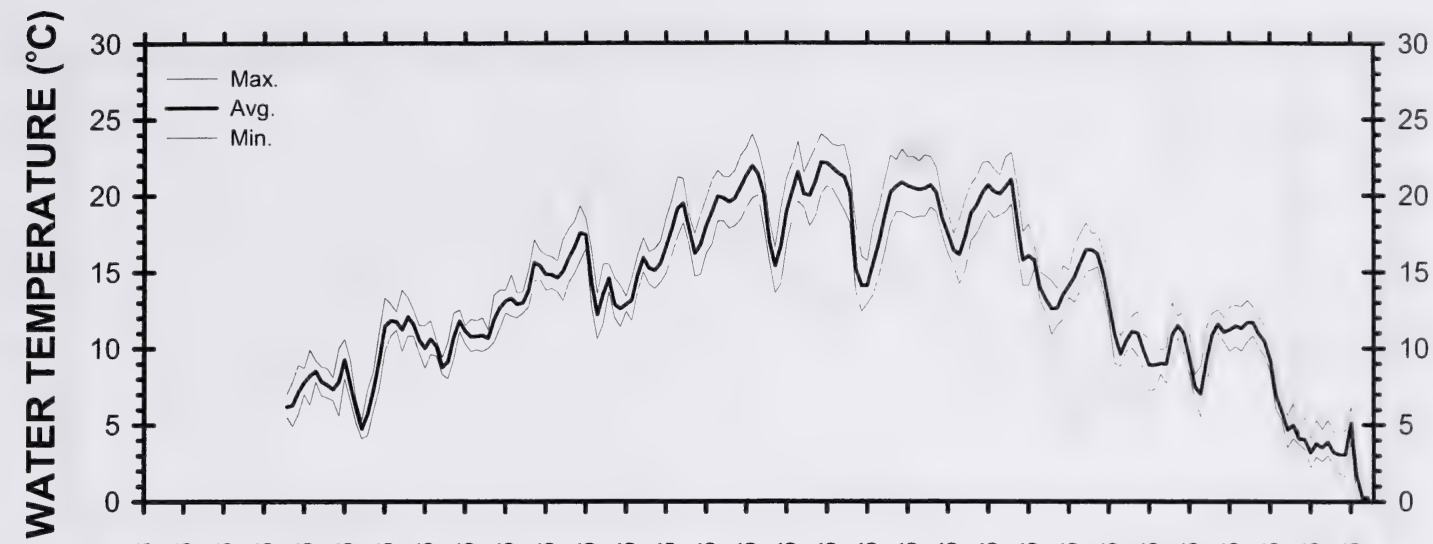

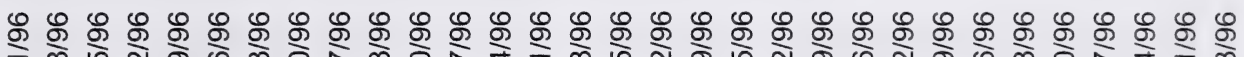

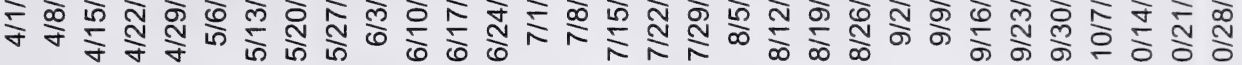

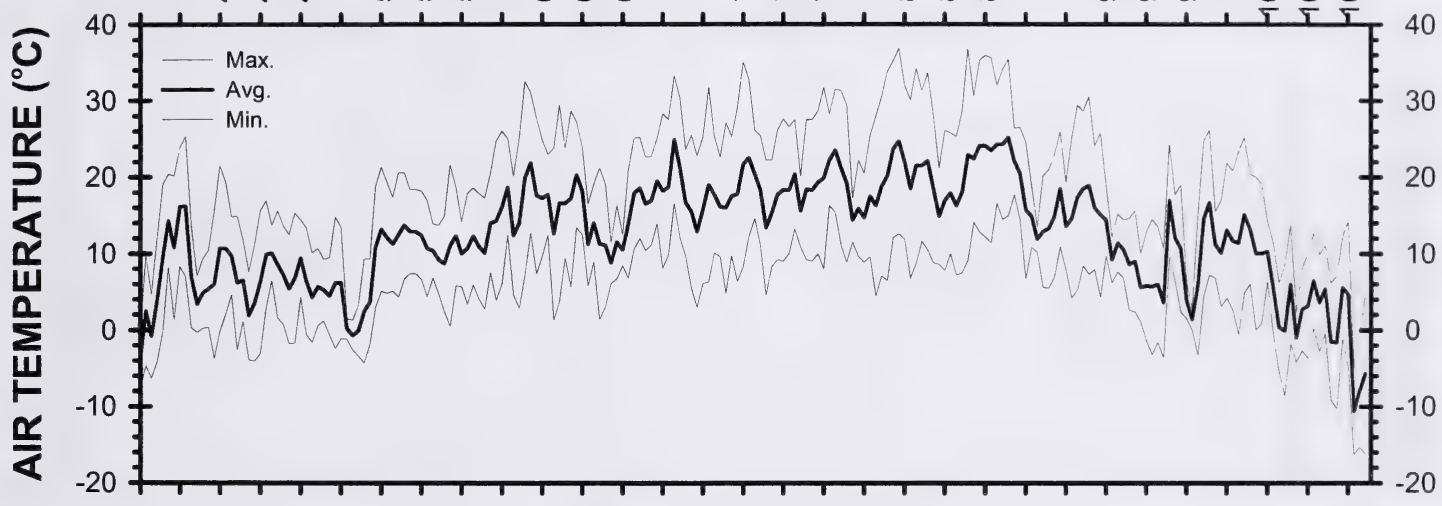

\%

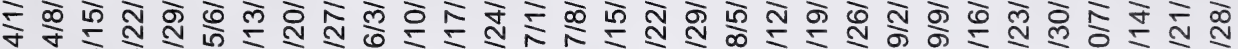

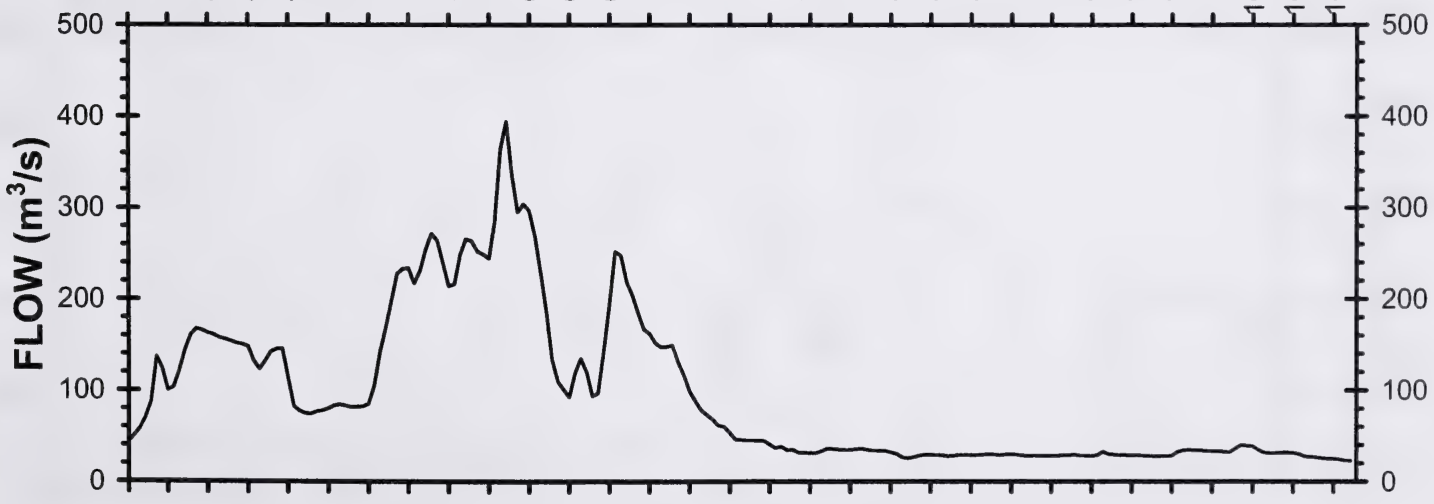

๑

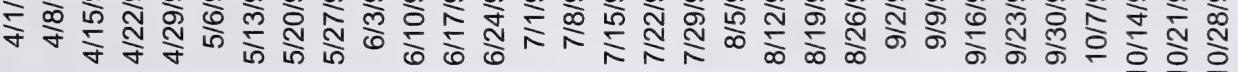

Figure 45. Daily water temperature (Thermograph), air temperature and flow in the Oldman River downstream of the Belly River. April-October 1996. 


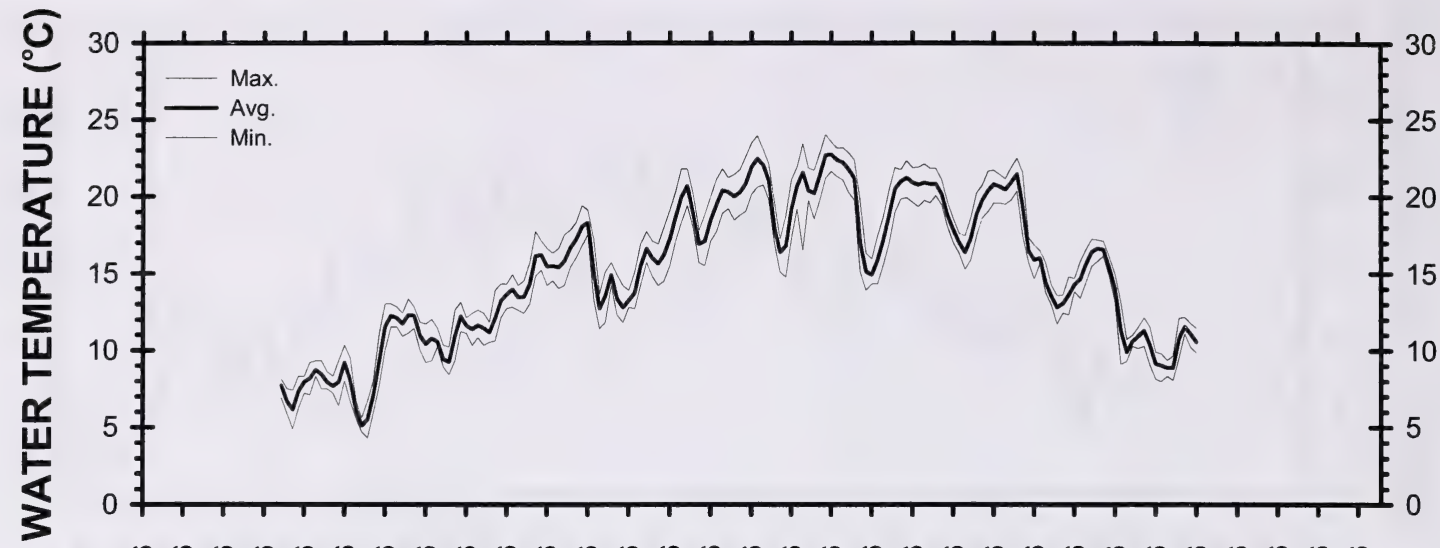

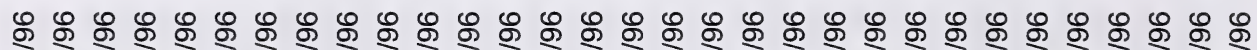

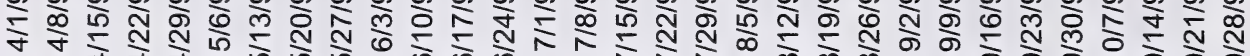

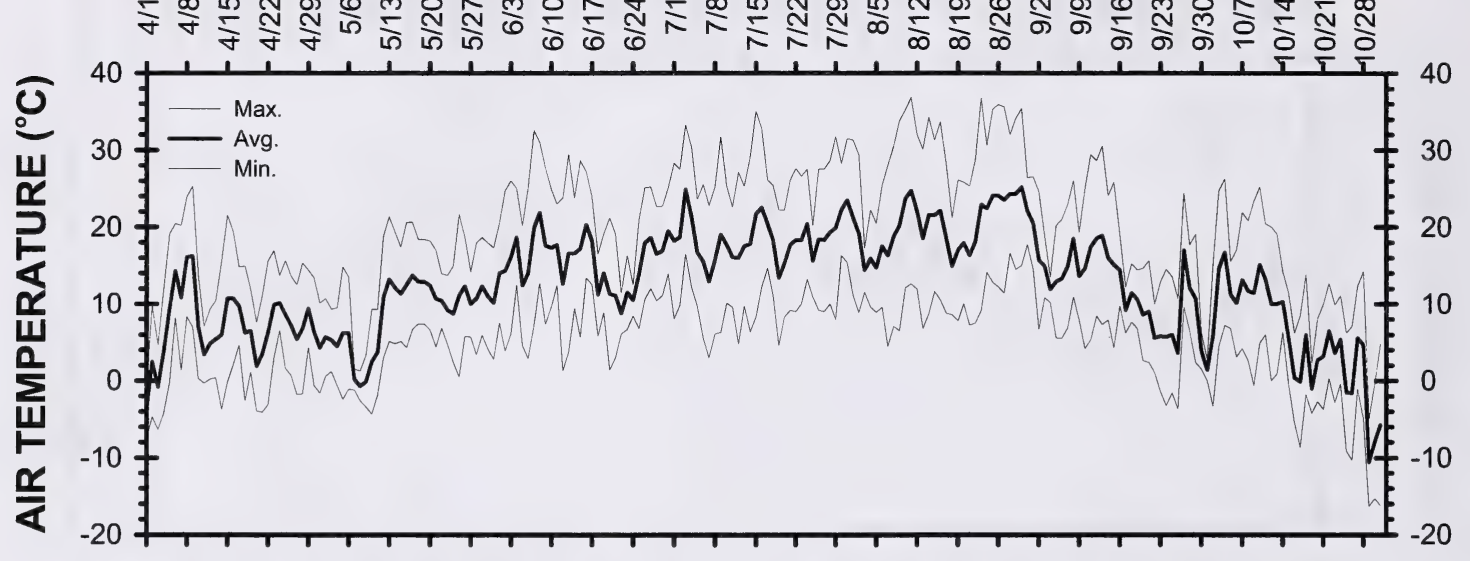

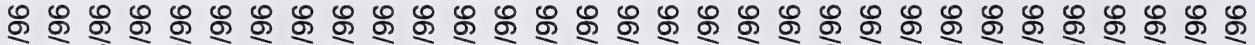
事点 N

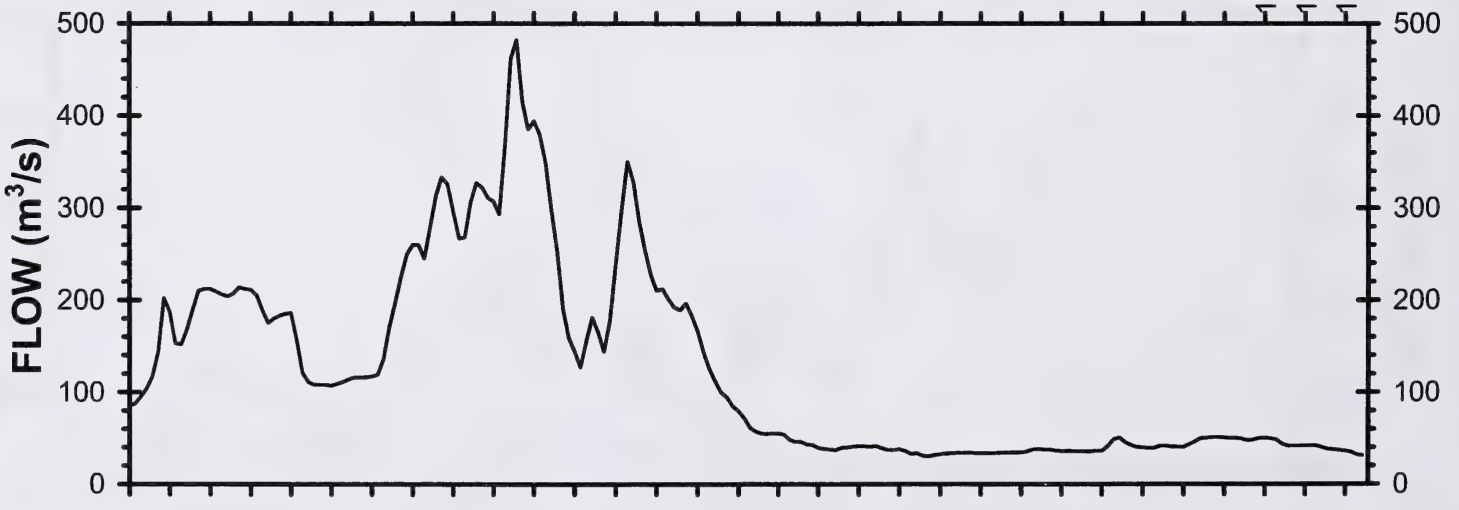

ஜ

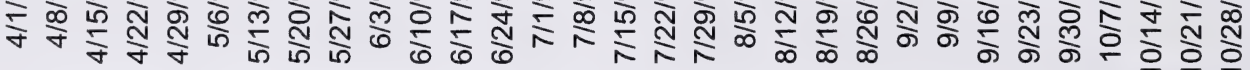

Figure 46. Daily water temperature (Thermograph), air temperature and flow in the Oldman River upstream of Lethbridge. April-October 1996. 


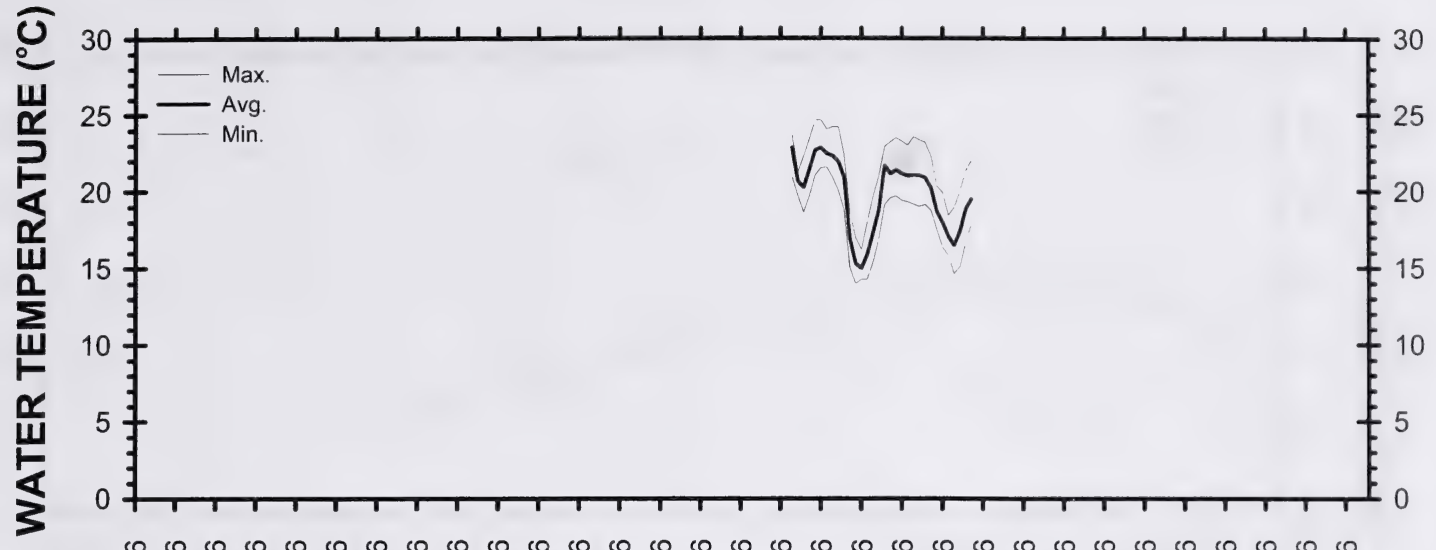

Ю

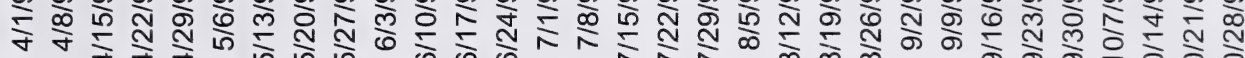

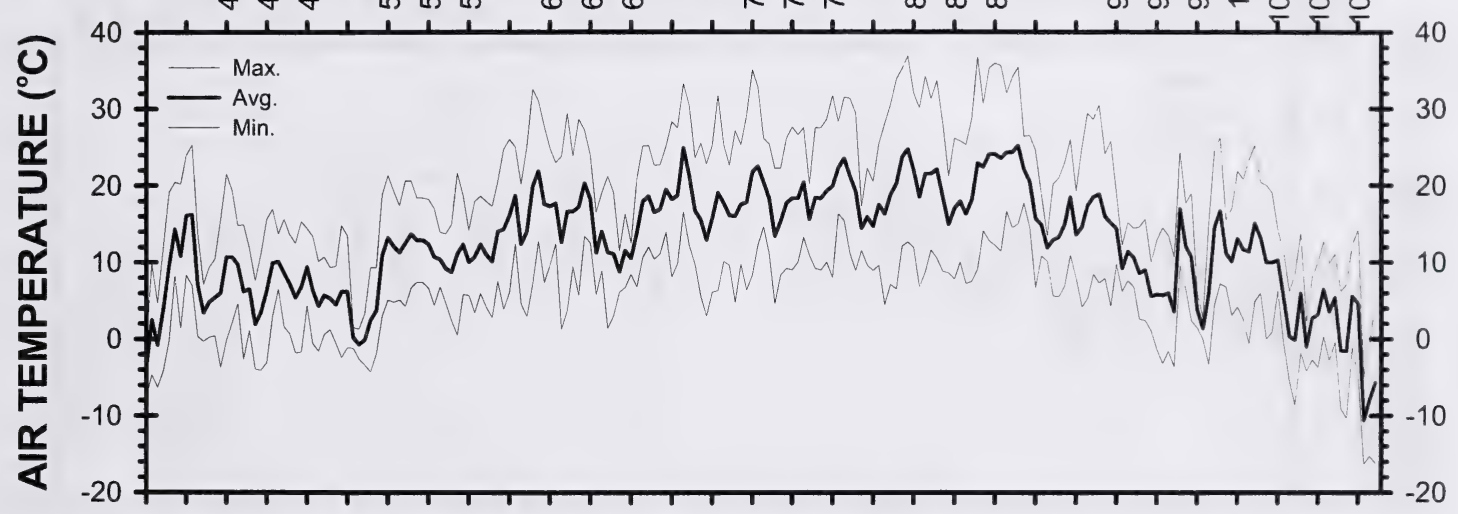

ஜ 인

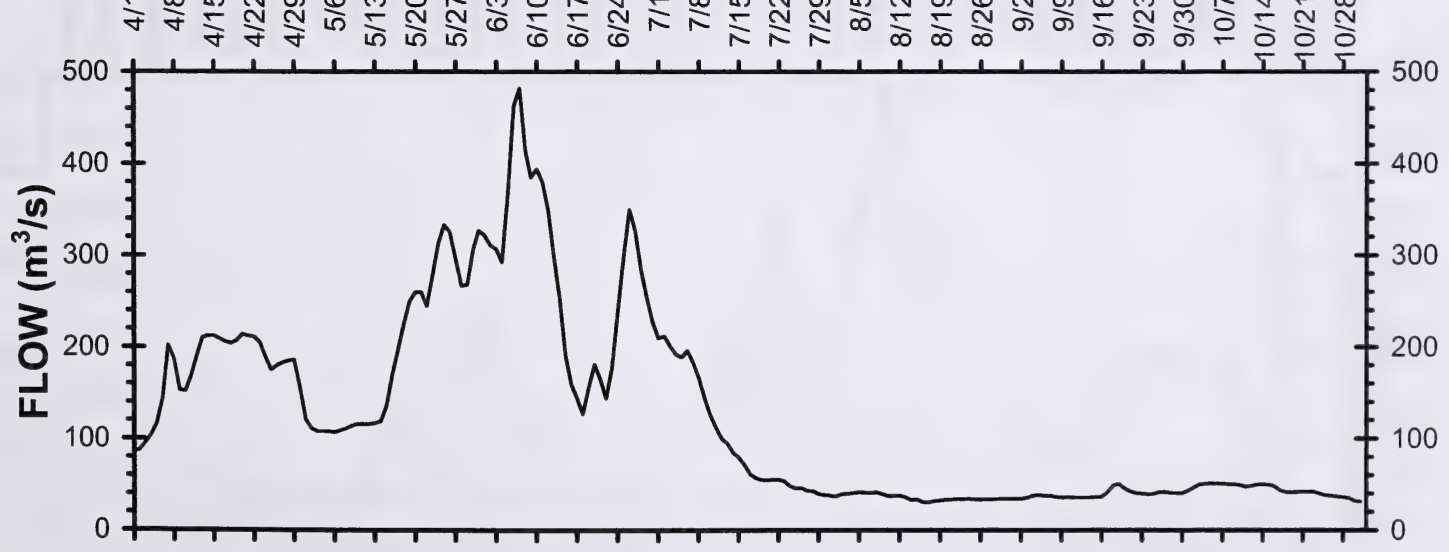

ஜ

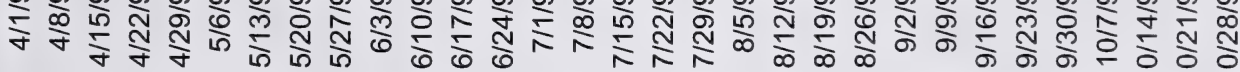

Figure 47. Daily water temperature (Datasonde), air temperature and flow in the Oldman River downstream of Lethbridge. April-October 1996. 


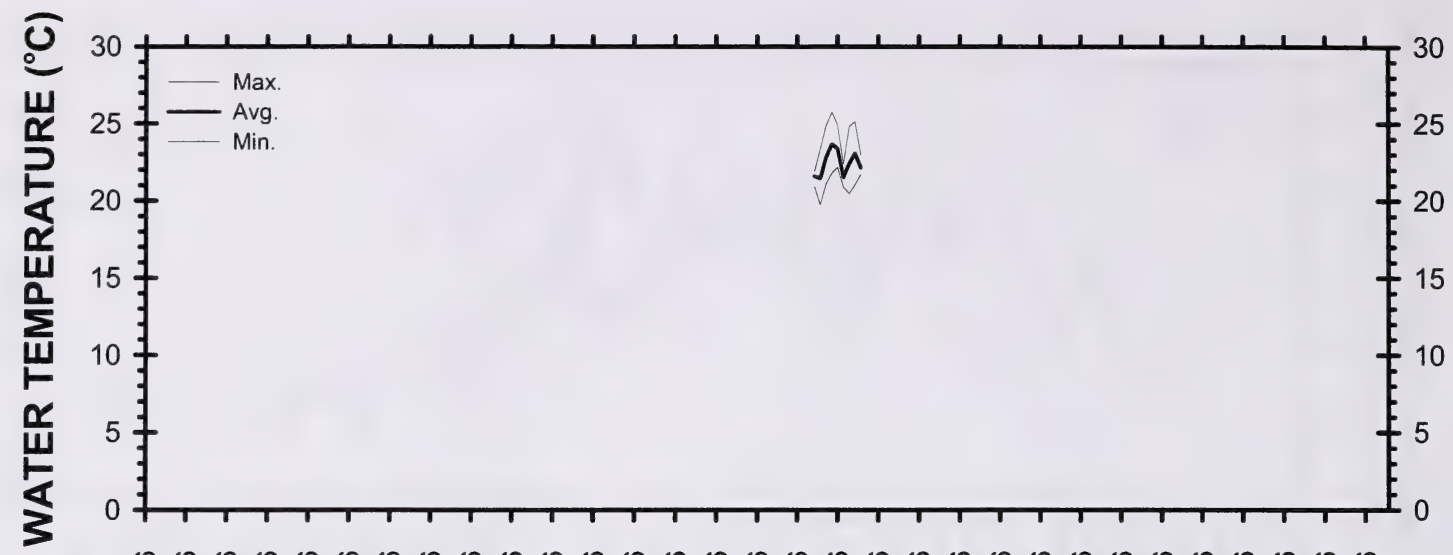

ஜ

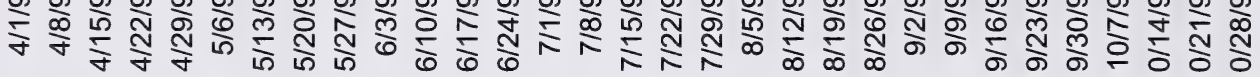

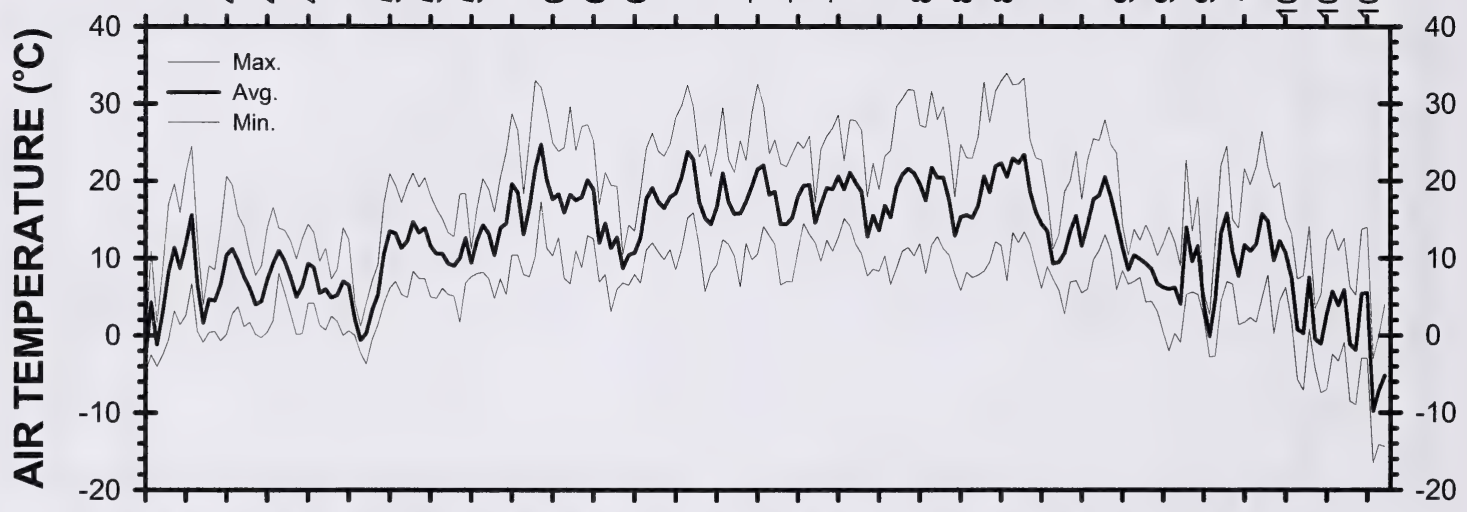

ஜ

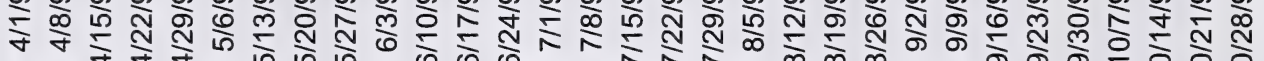

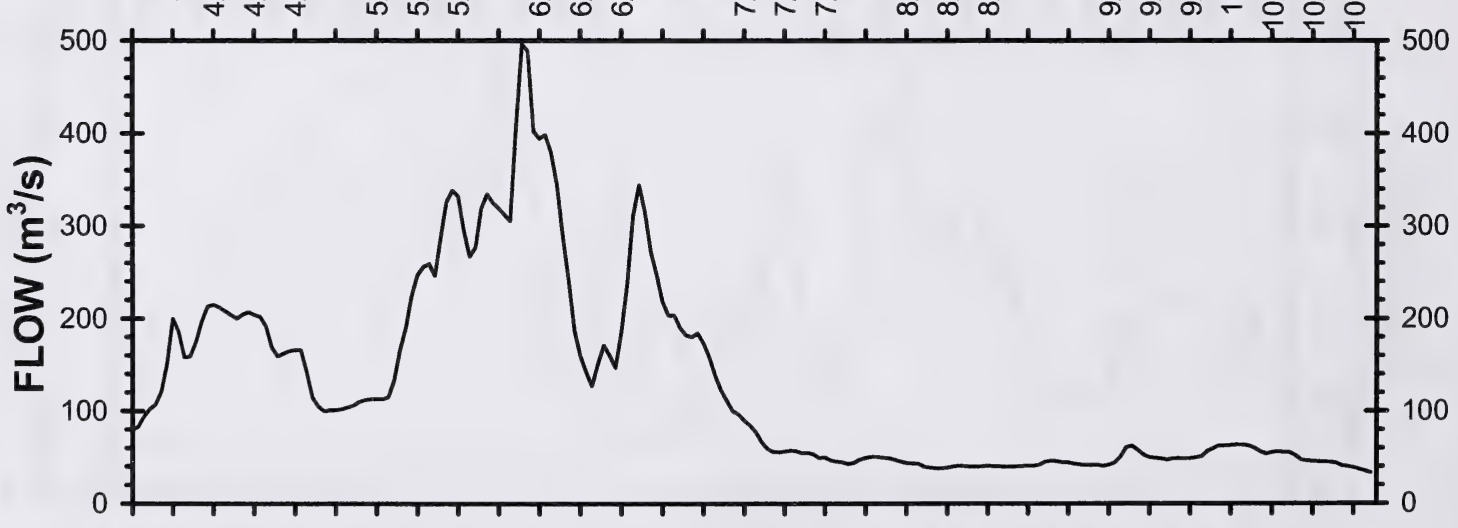

ஜ

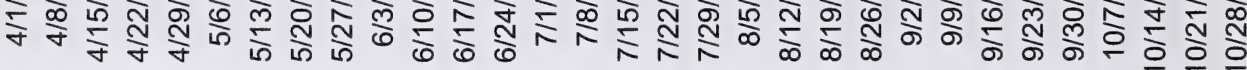

Figure 48. Daily water temperature (Datasonde), air temperature and flow in the Oldman River at the Bow River confluence. April-October 1996. 


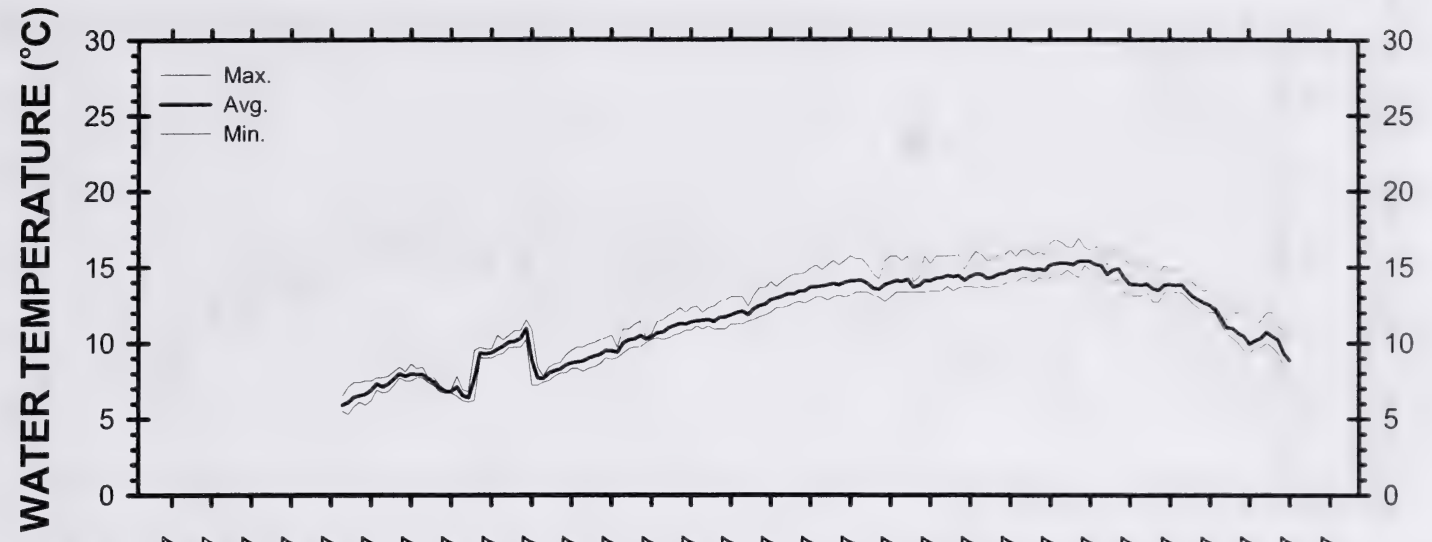

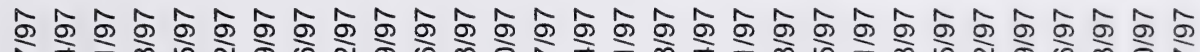

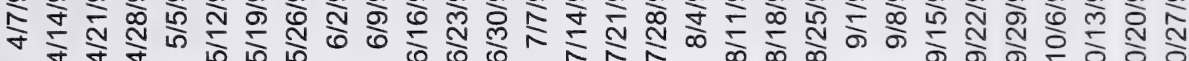

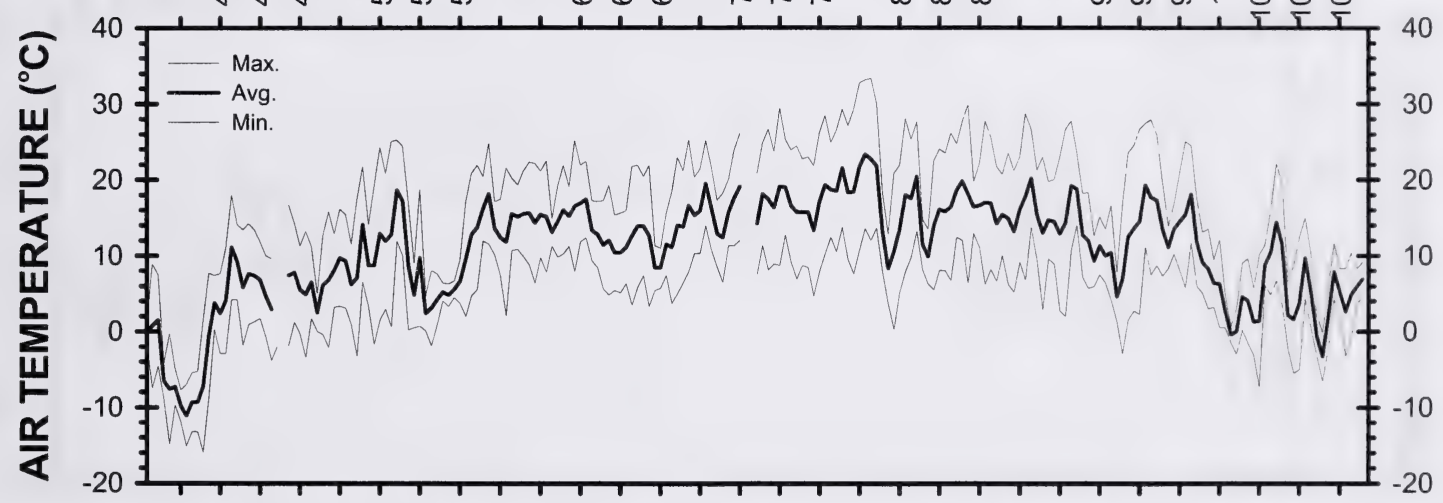

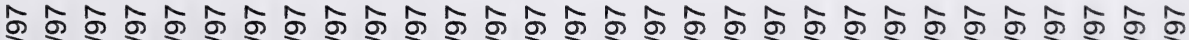

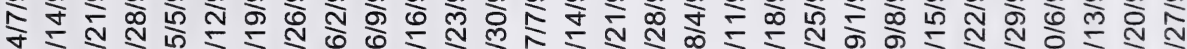

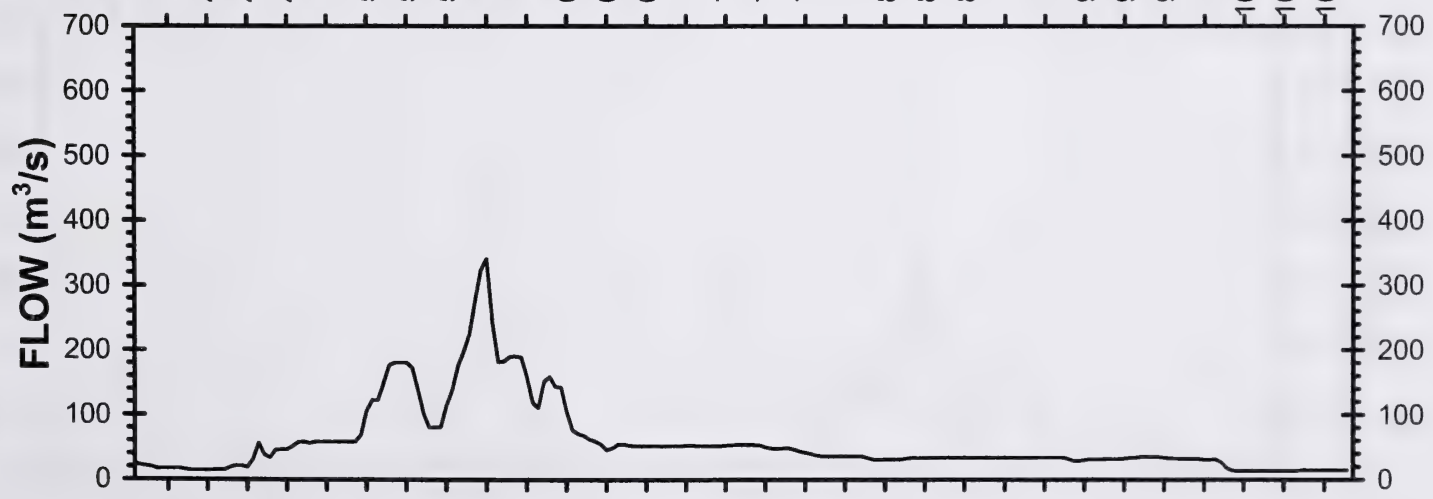

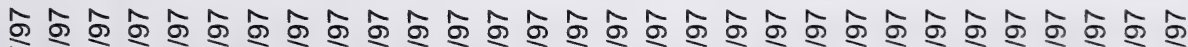

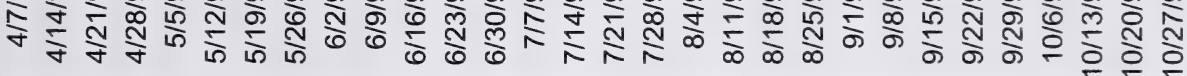

Figure 49. Daily water temperature (Thermograph), air temperature and flow in the Oldman River near Brocket. April-October 1997. 


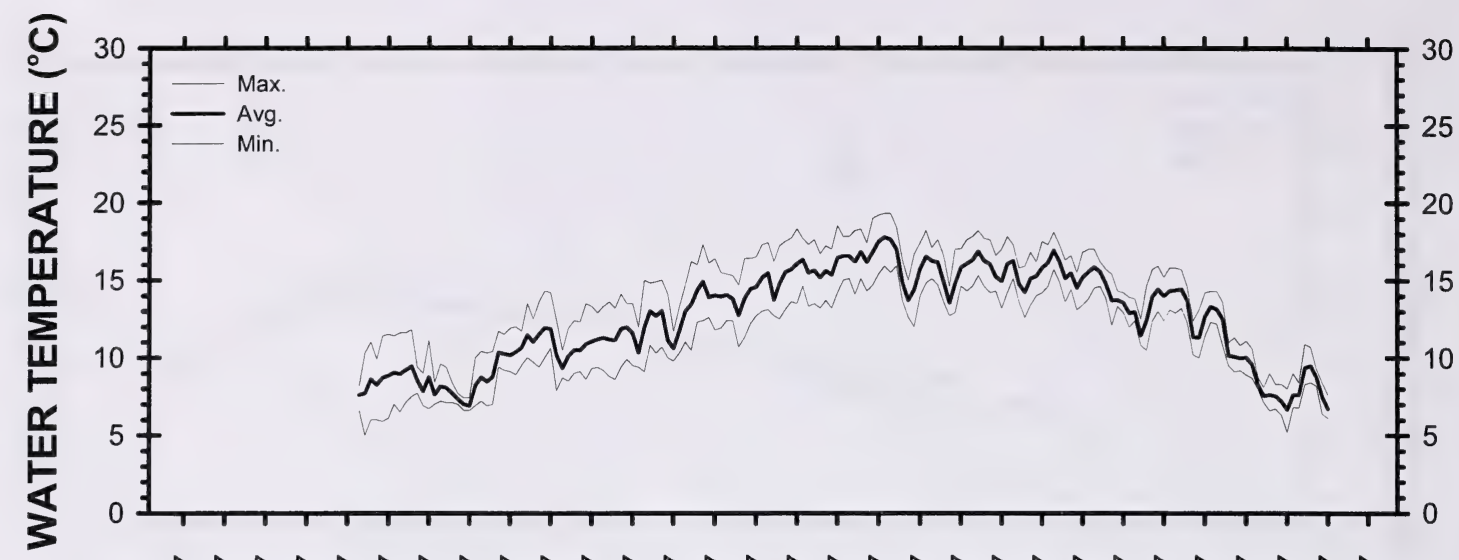

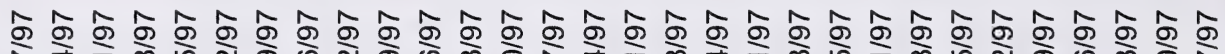

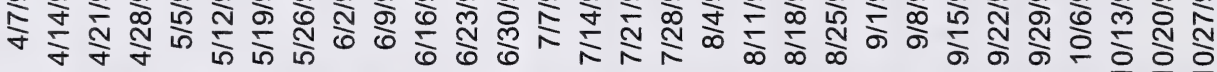
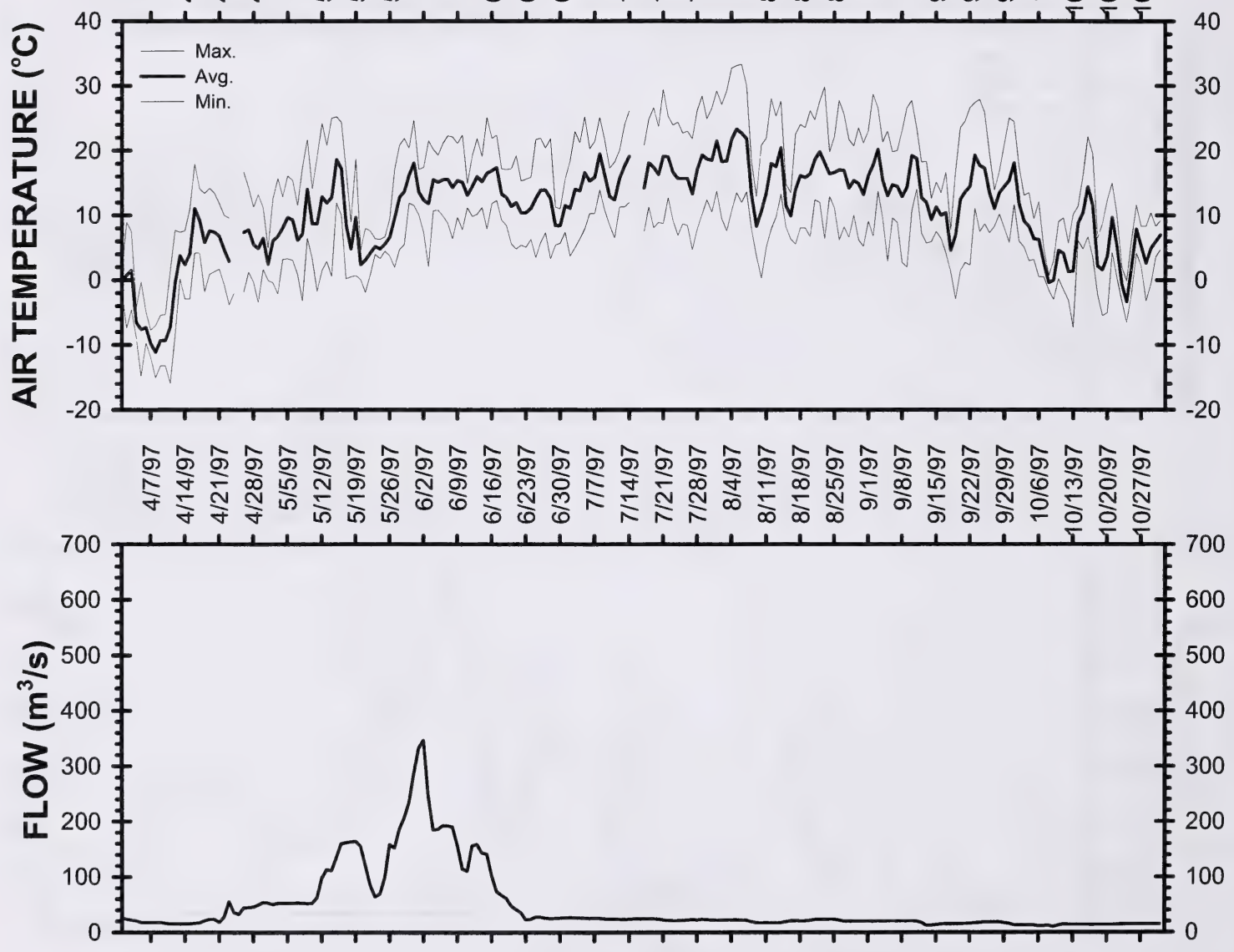

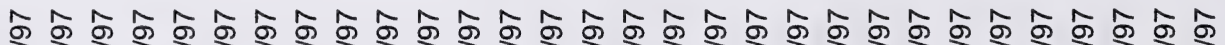

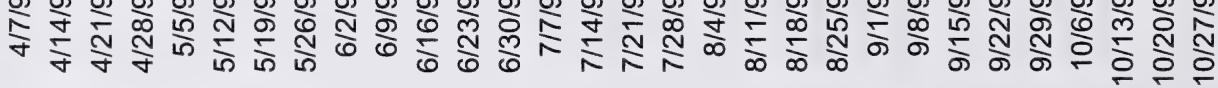

Figure 50. Daily water temperature (Thermograph), air temperature and flow in the Oldman River downstream of the LNHD. April-October 1997. 


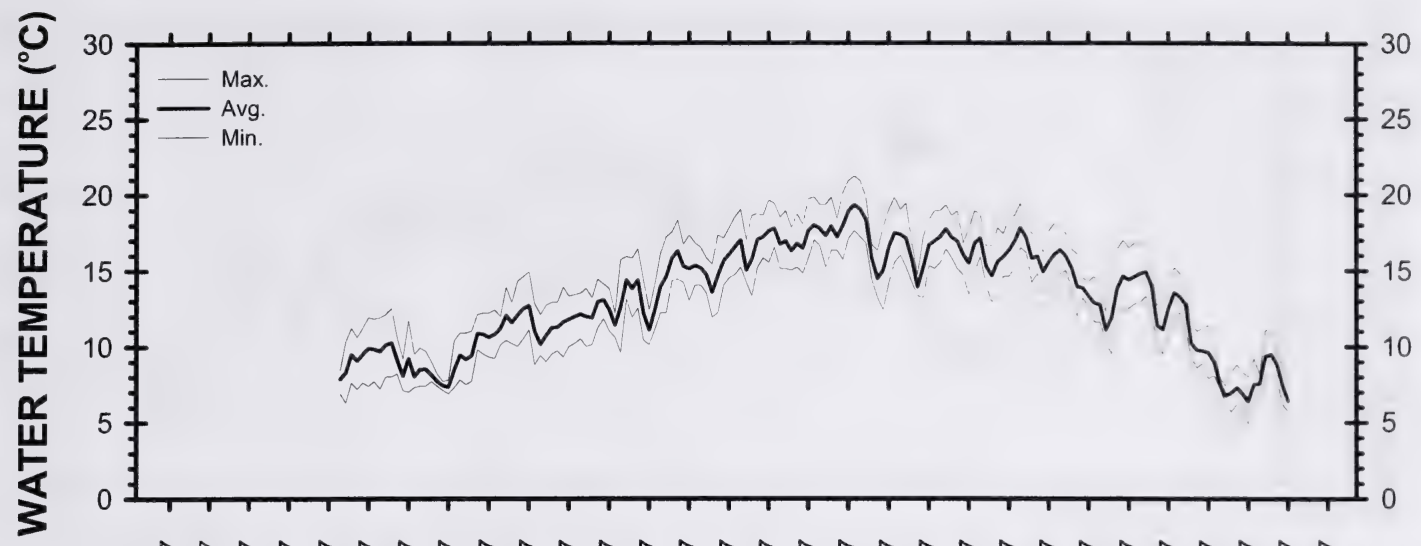

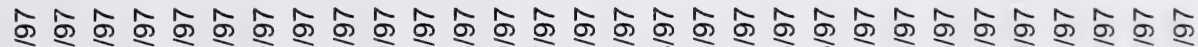

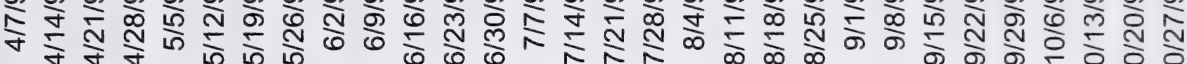

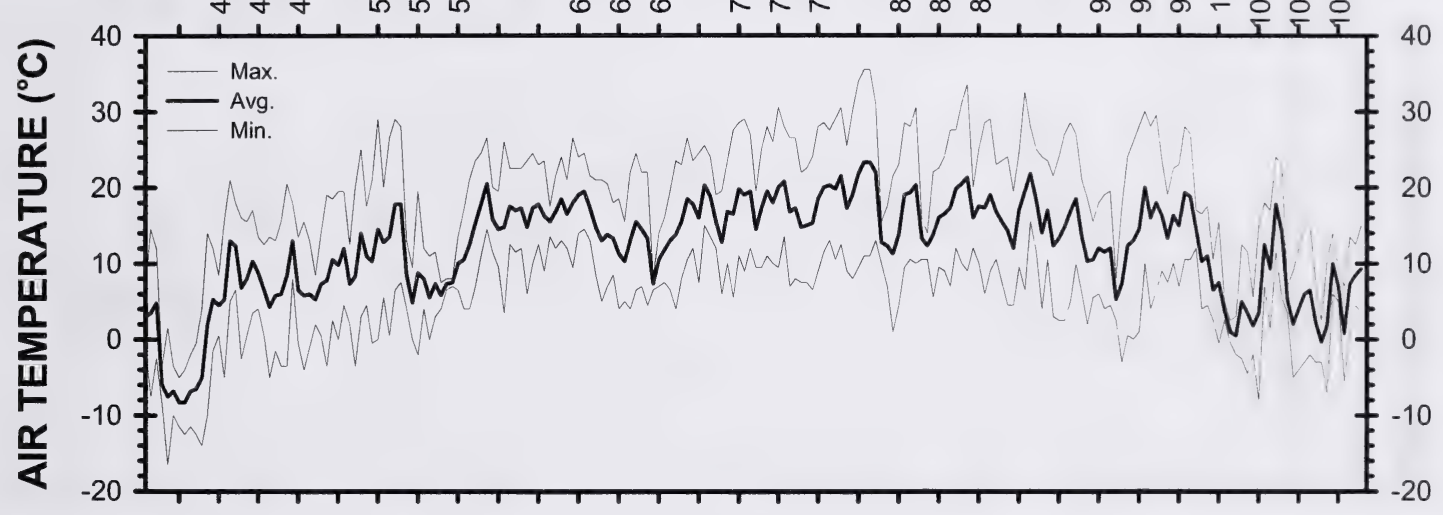

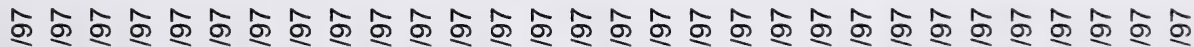

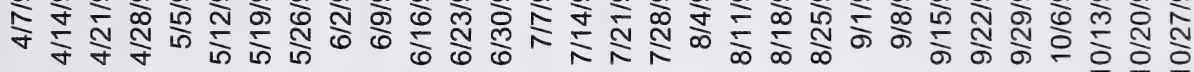

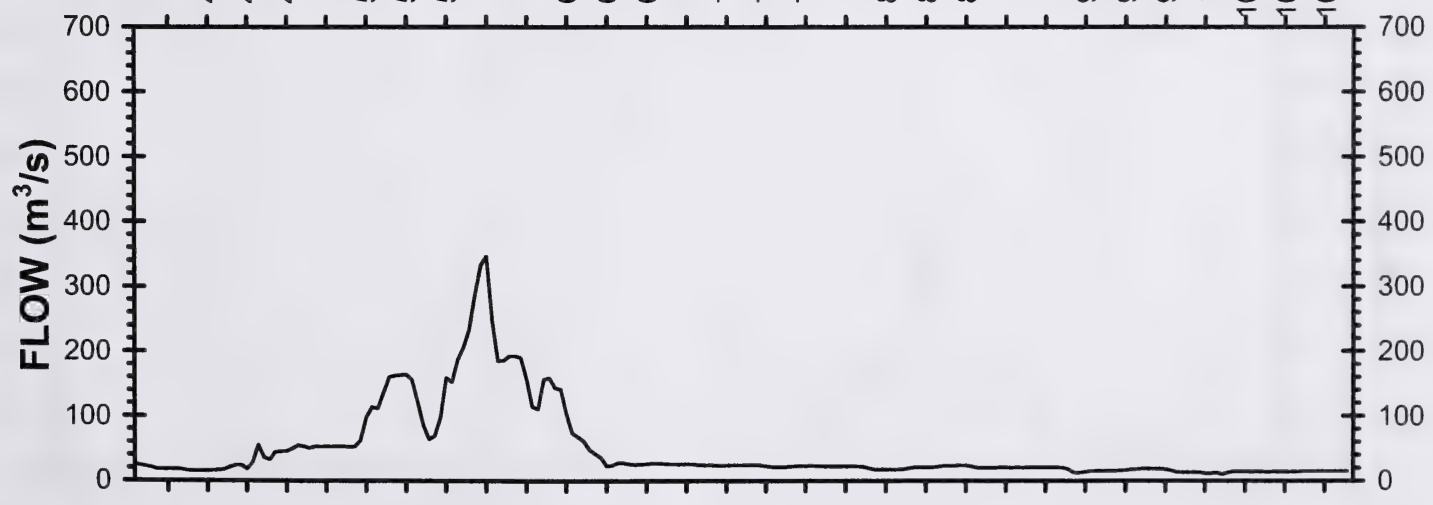

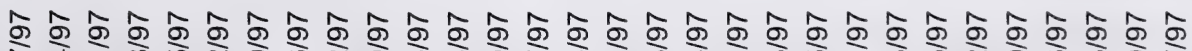

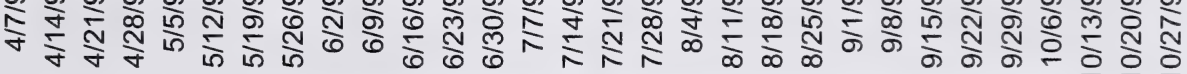

Figure 51. Daily water temperature (Thermograph), air temperature and flow in the Oldman River near Fort Macleod. April-October 1997. 


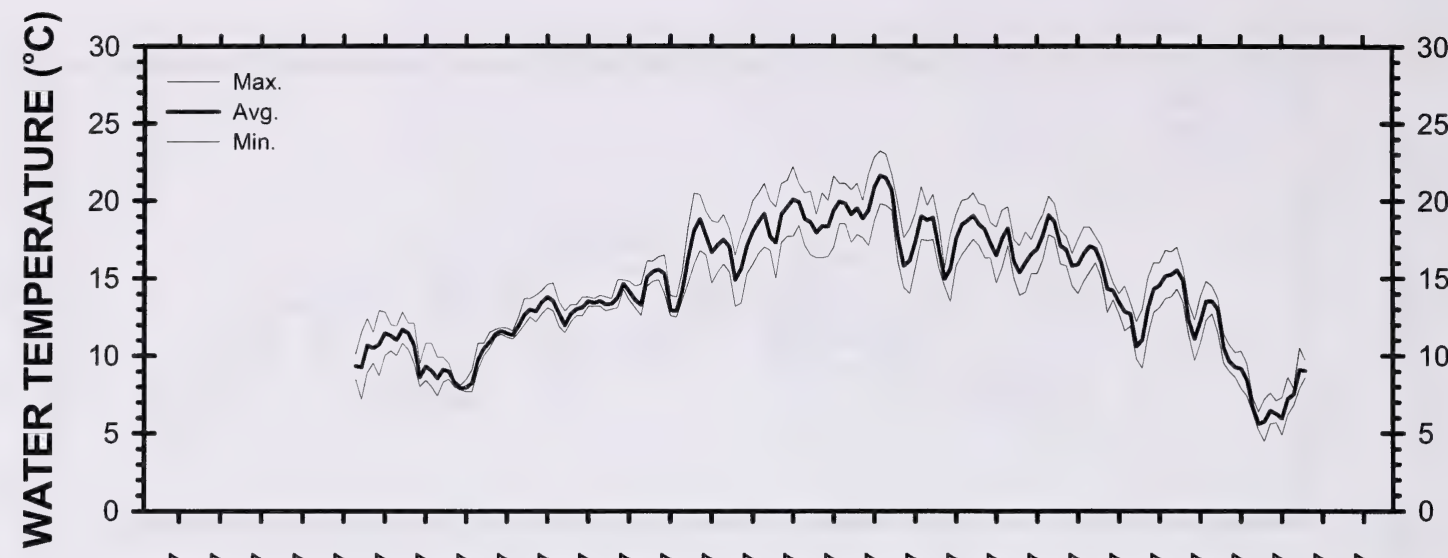

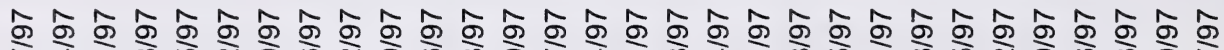

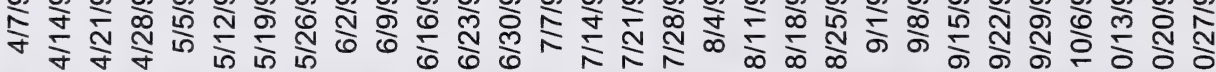

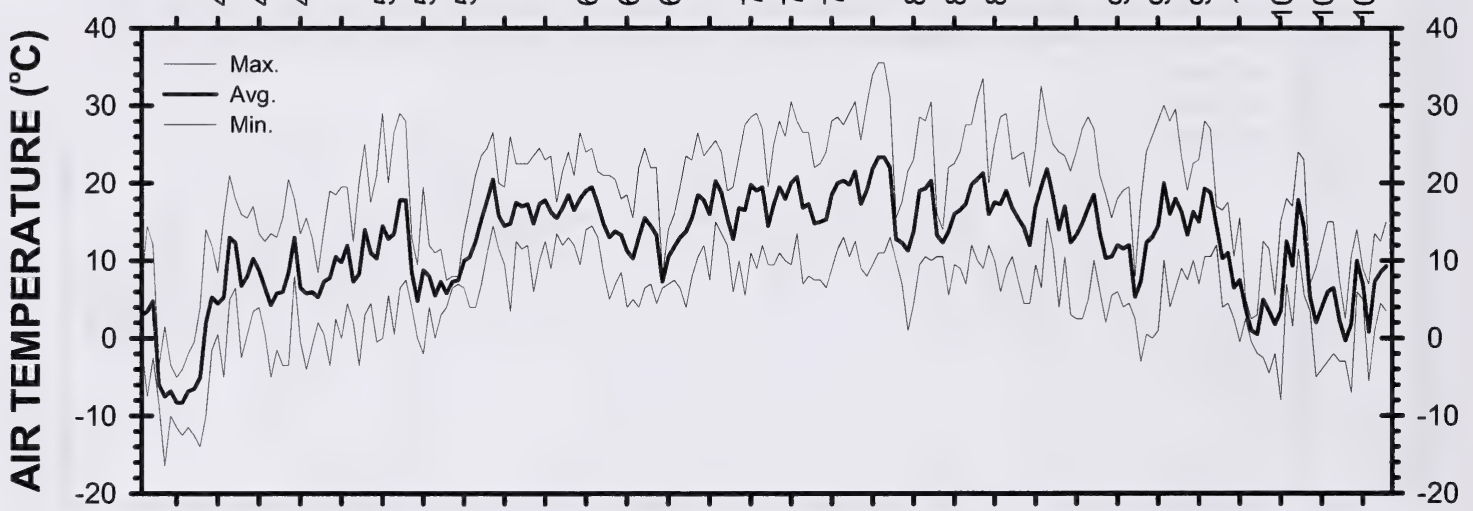

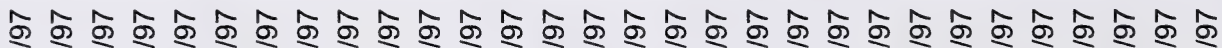

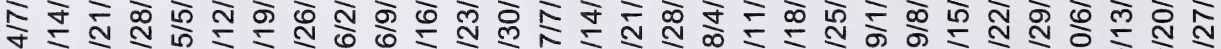

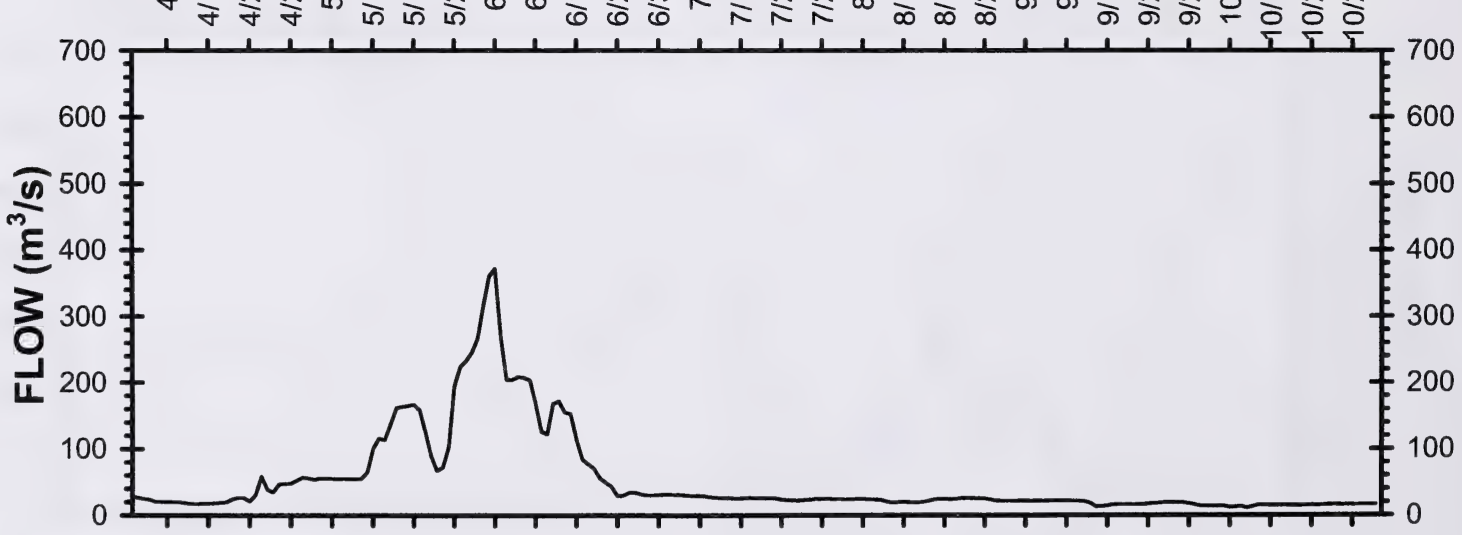

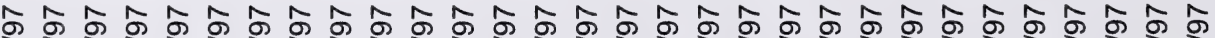

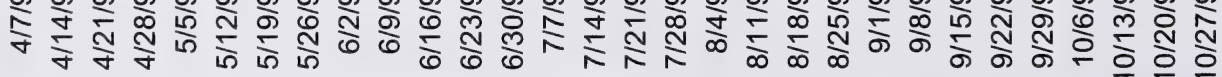

Figure 52. Daily water temperature (Thermograph), air temperature and flow in the Oldman River near Rocky Coulee. April-October 1997. 


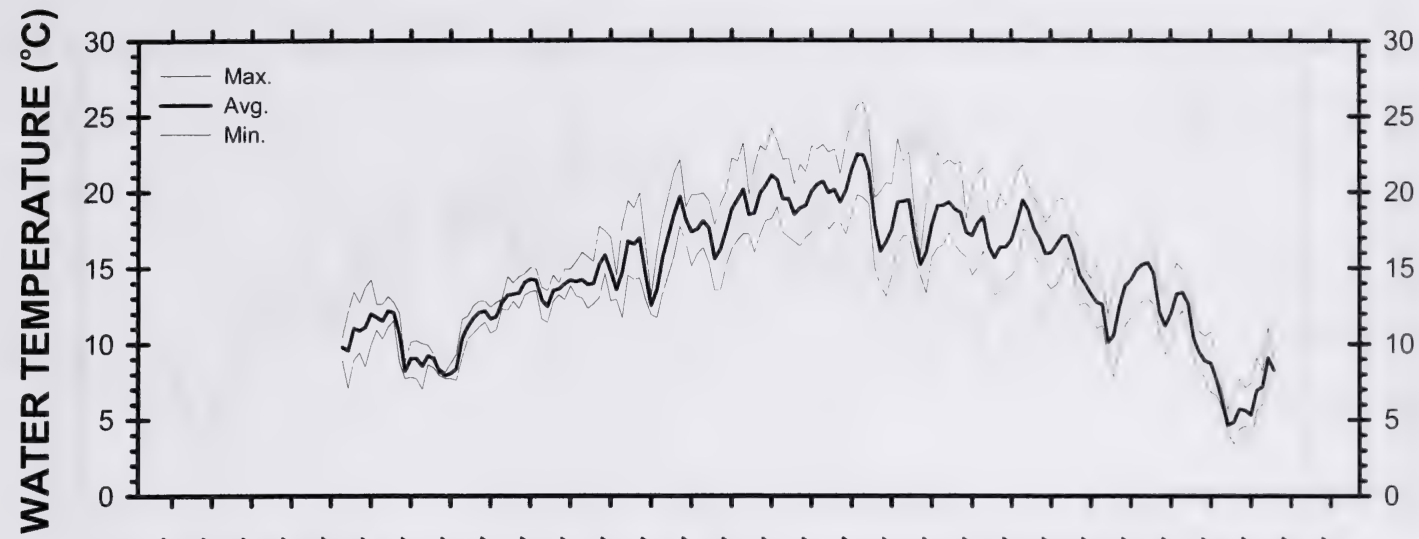

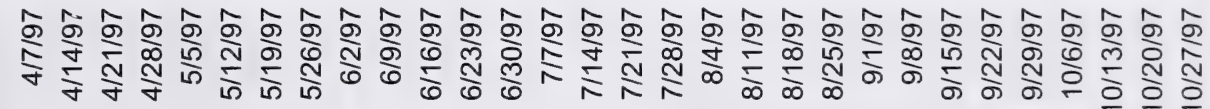

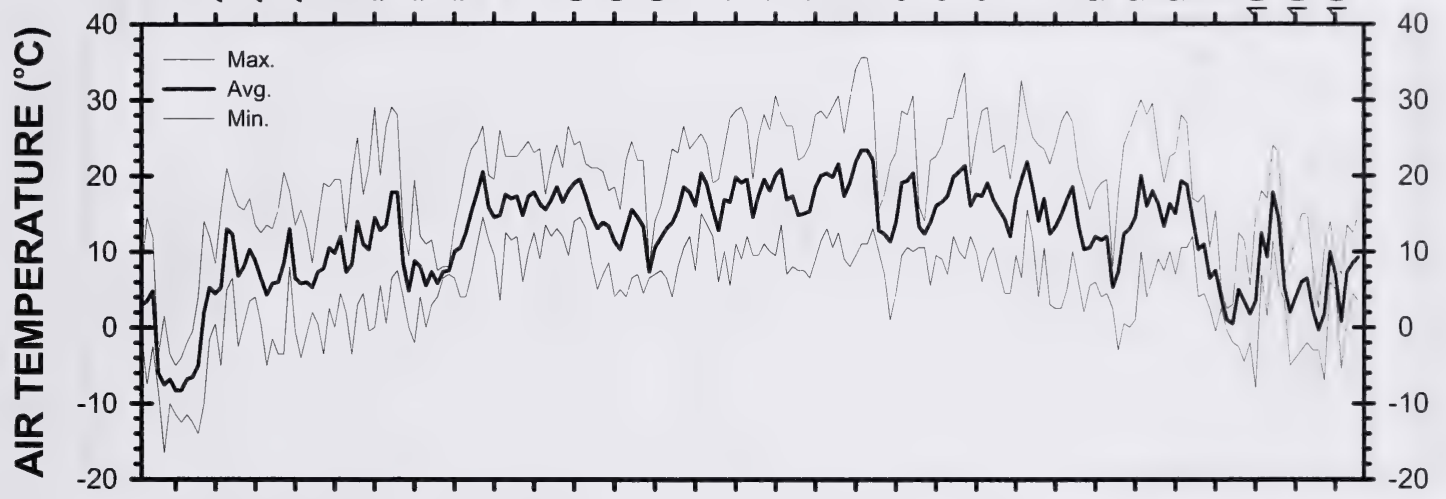

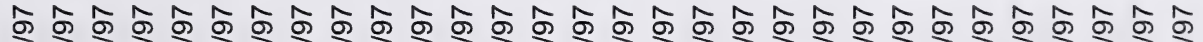

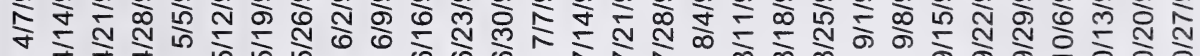

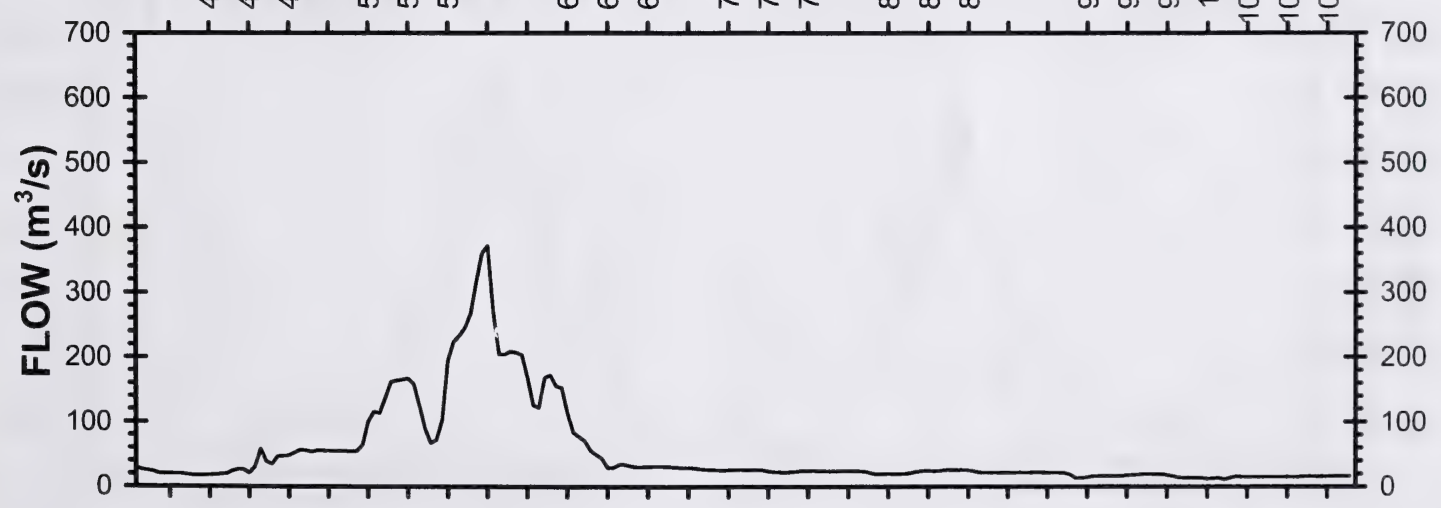

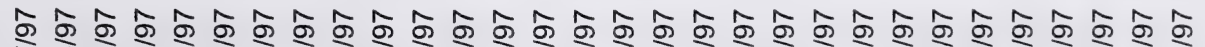

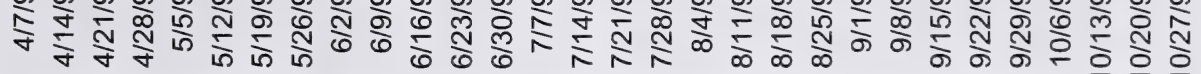

Figure 53. Daily water temperature (Thermograph), air temperature and flow in the Oldman River near Monarch. April-October 1997. 


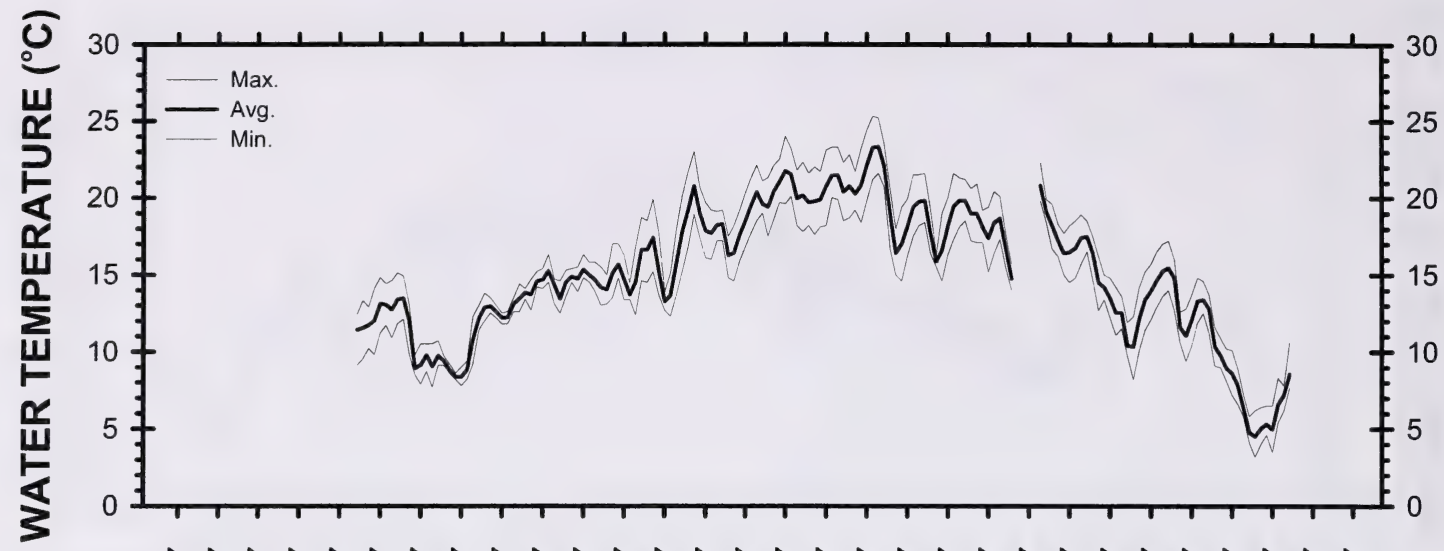

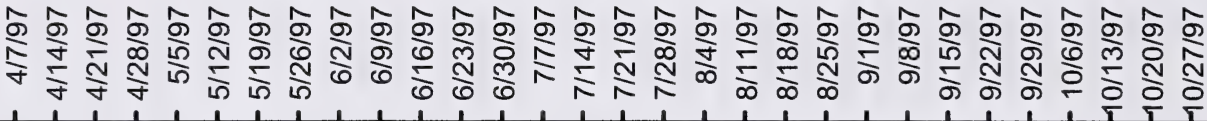

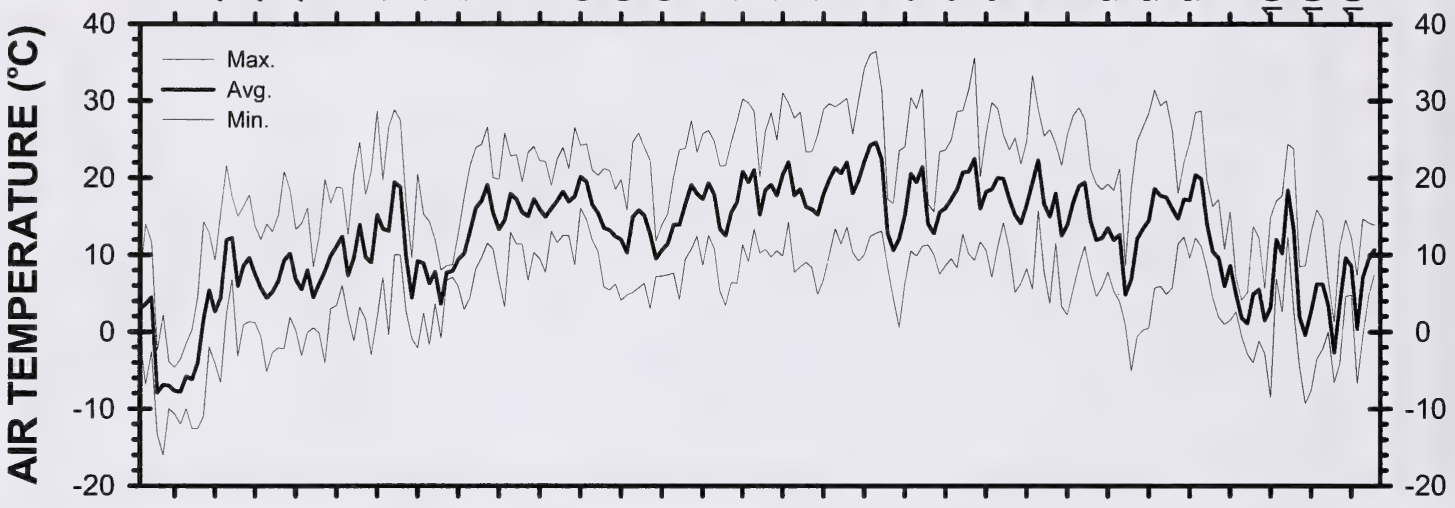

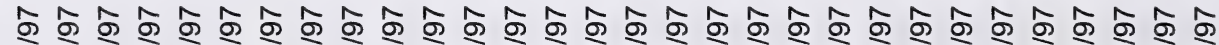

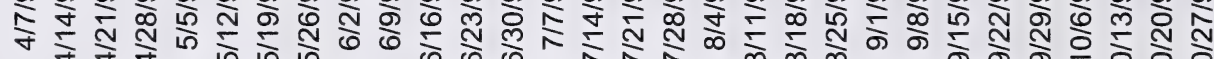

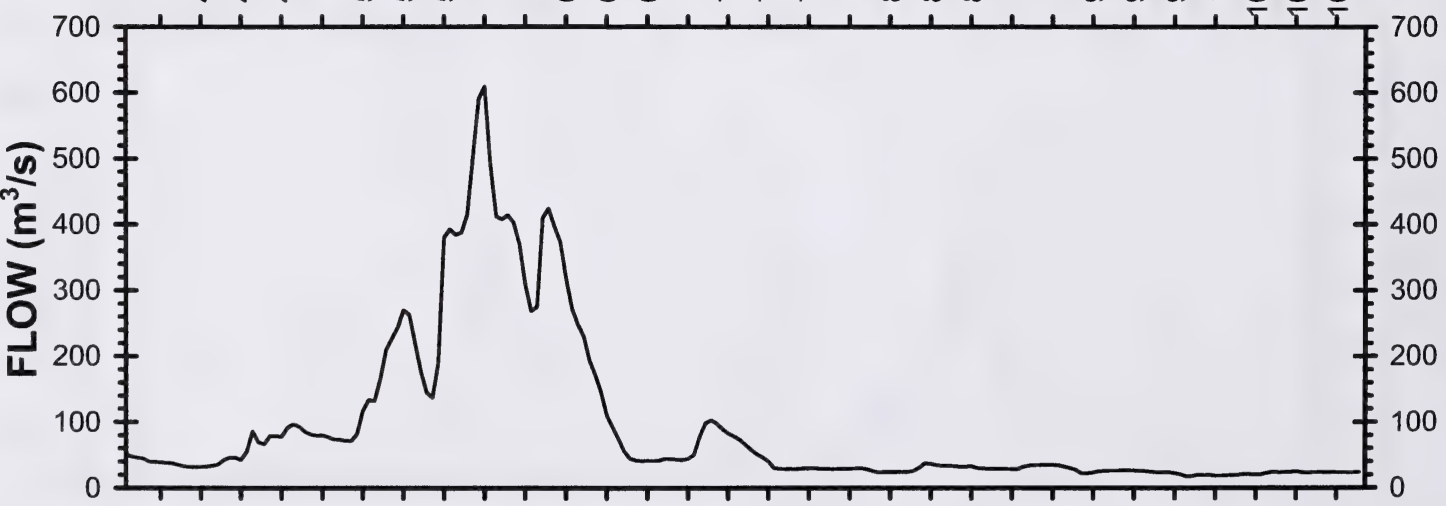

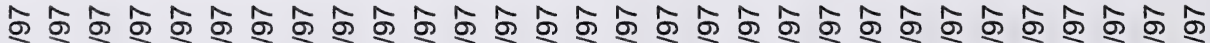

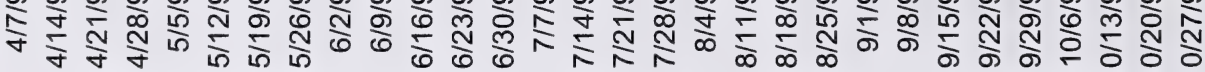

Figure 54. Daily water temperature (Thermograph), air temperature and flow in th Oldman River downstream of the Belly River. April-October 1997. 


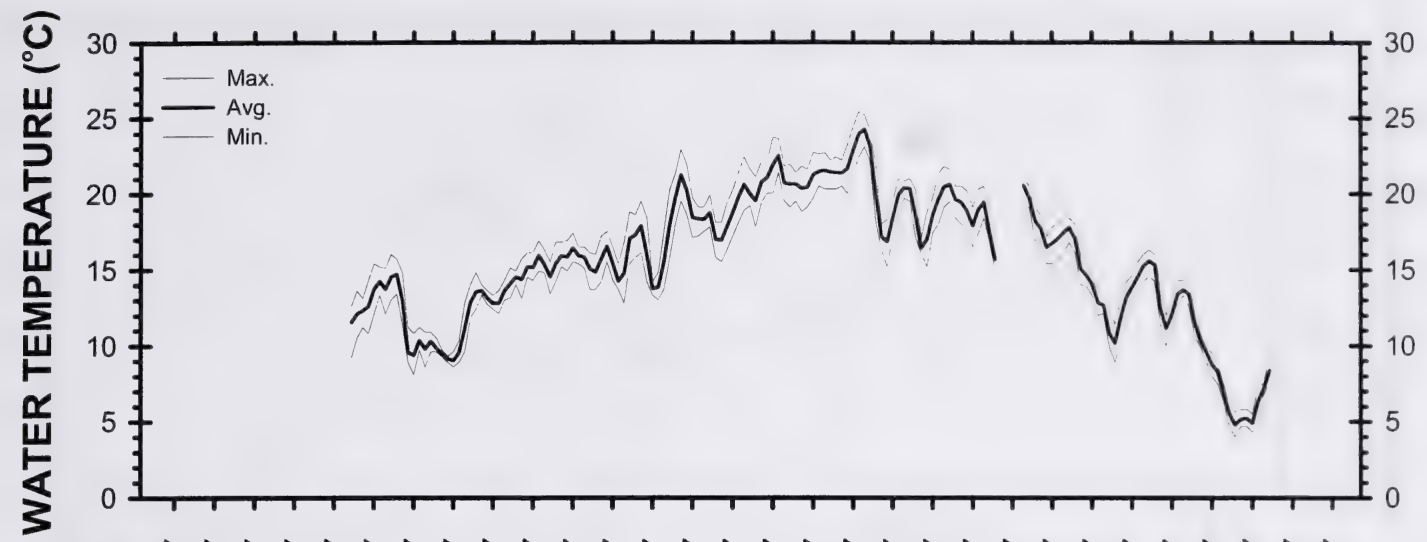

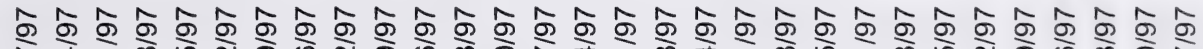

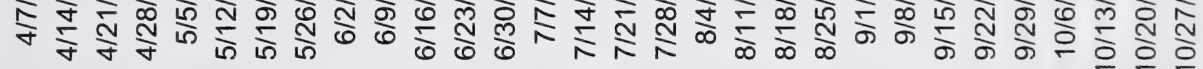

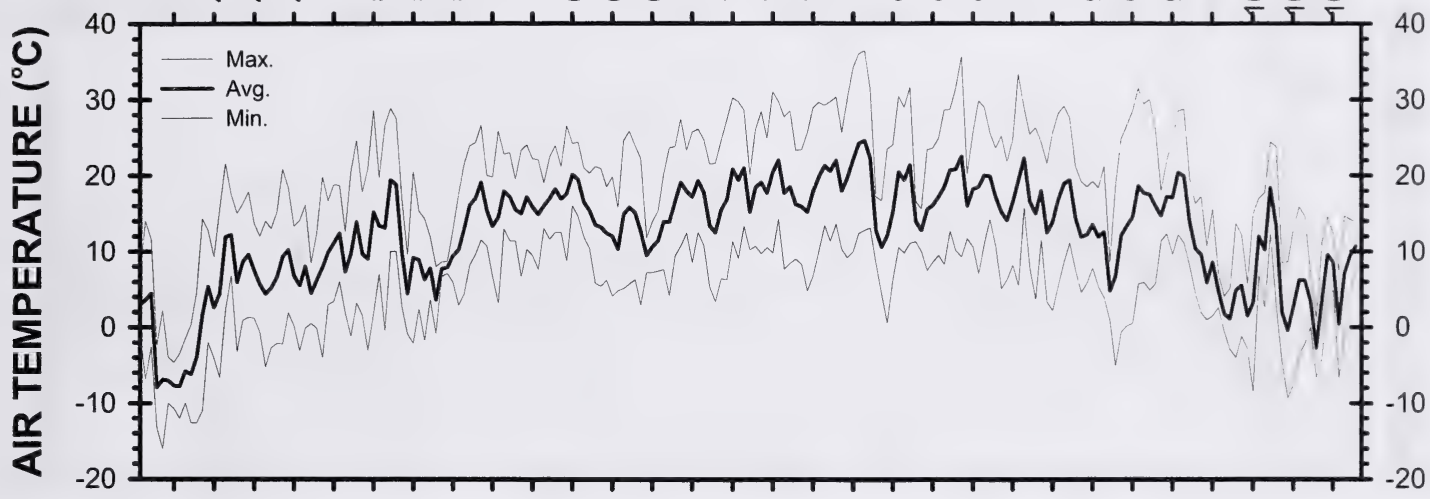

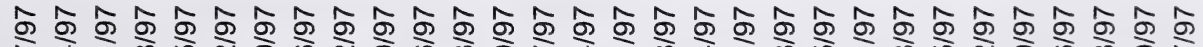

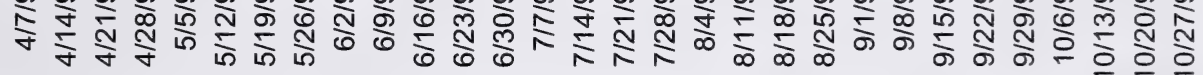

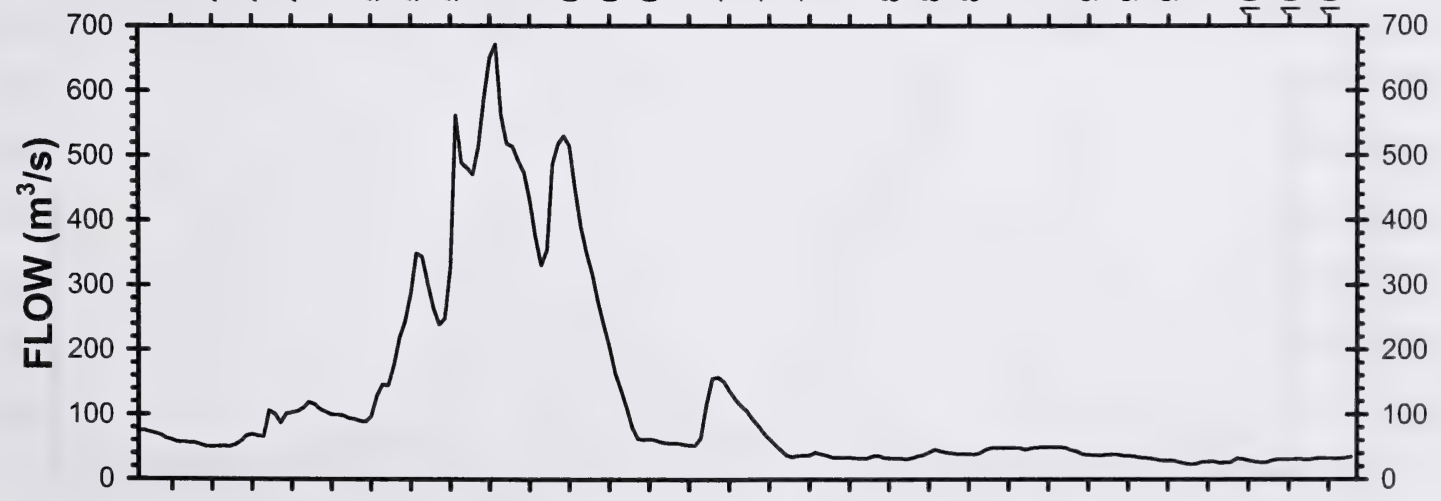

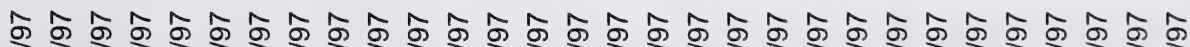

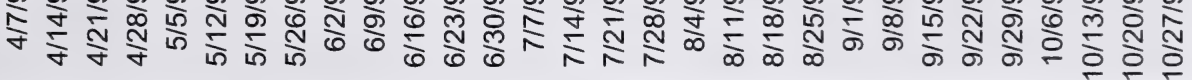

Figure 55. Daily water temperature (Thermograph), air temperature and flow in the Oldman River upstream of Lethbridge. April-October 1997. 


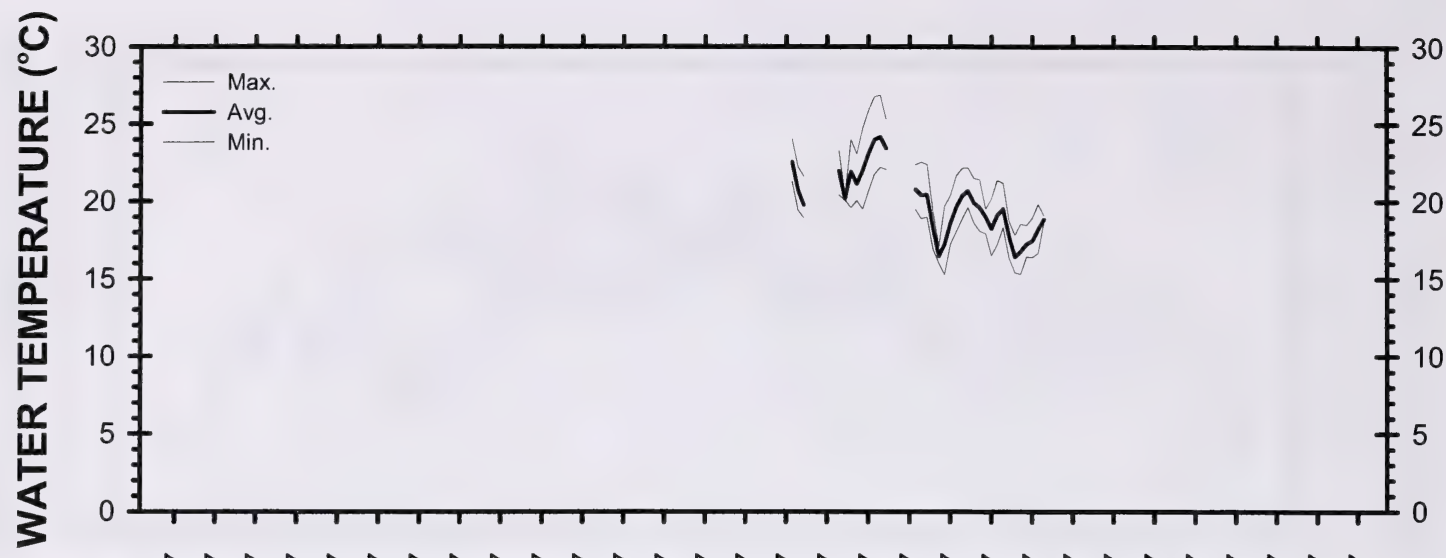

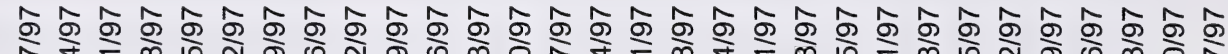

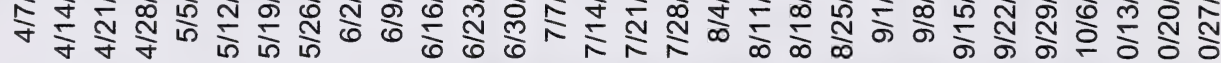

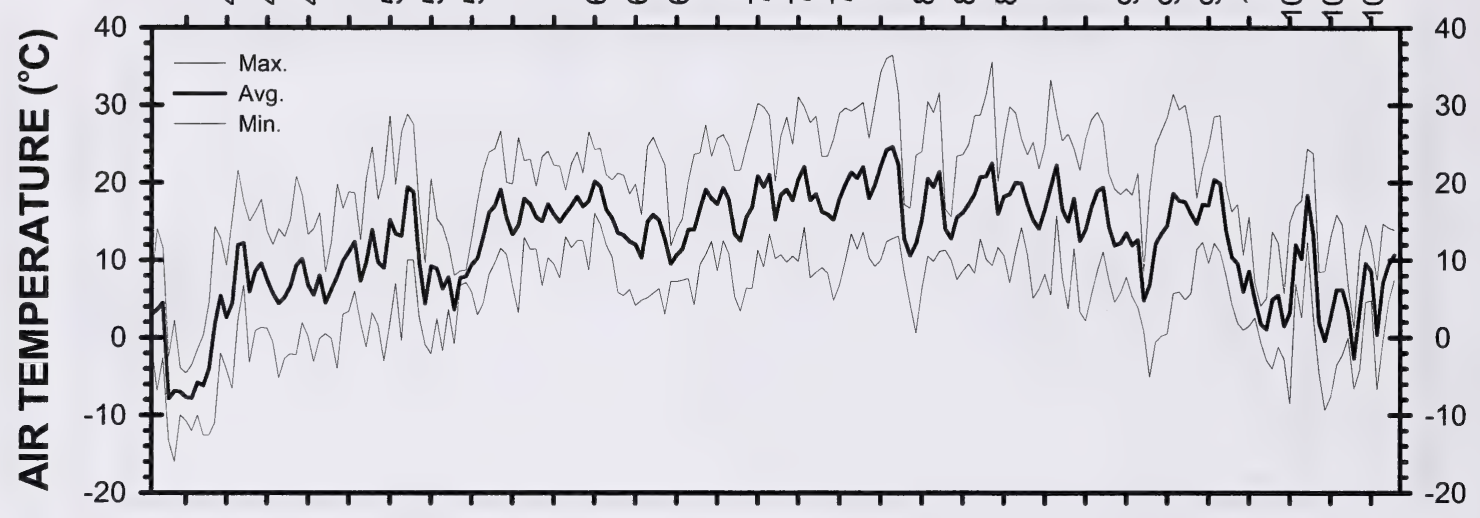

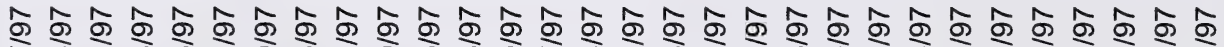

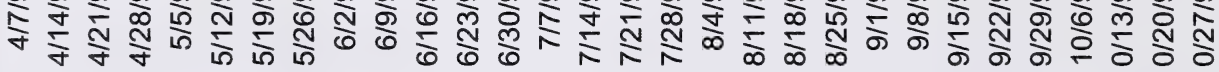

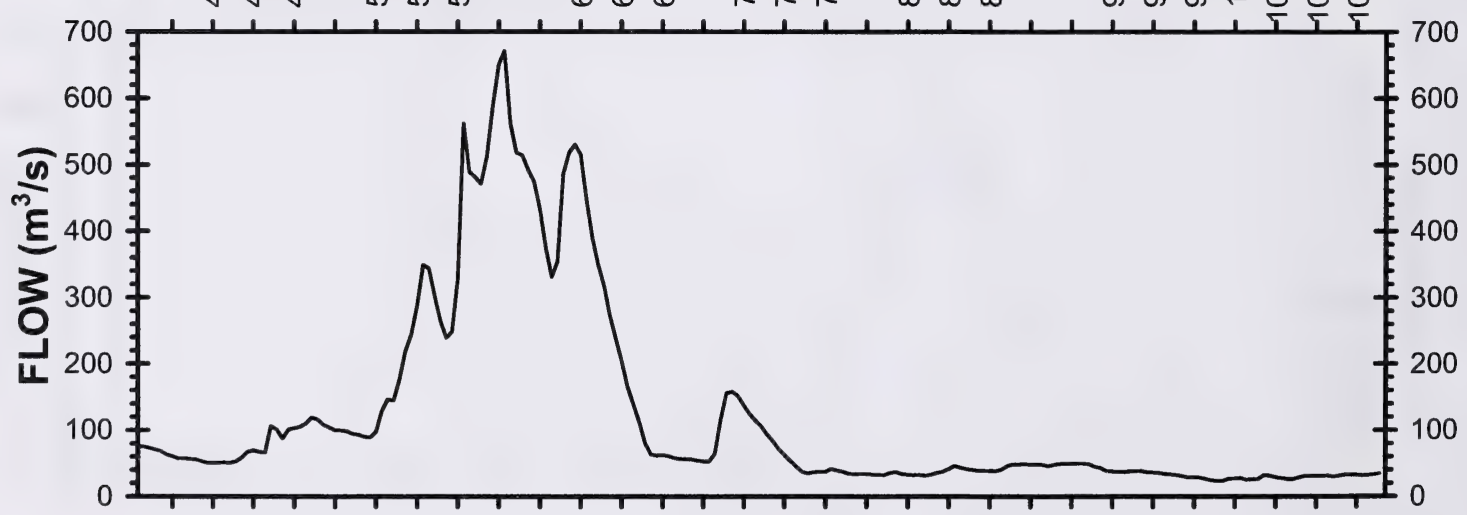

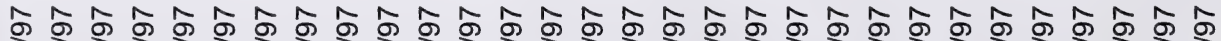

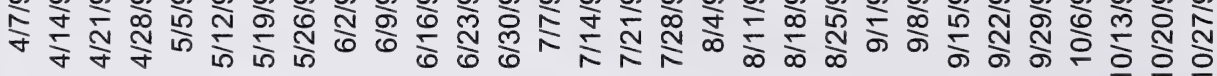

Figure 56. Daily water temperature (Datasonde), air temperature and flow in the Oldman River downstream of Lethbridge. April-October 1997. 


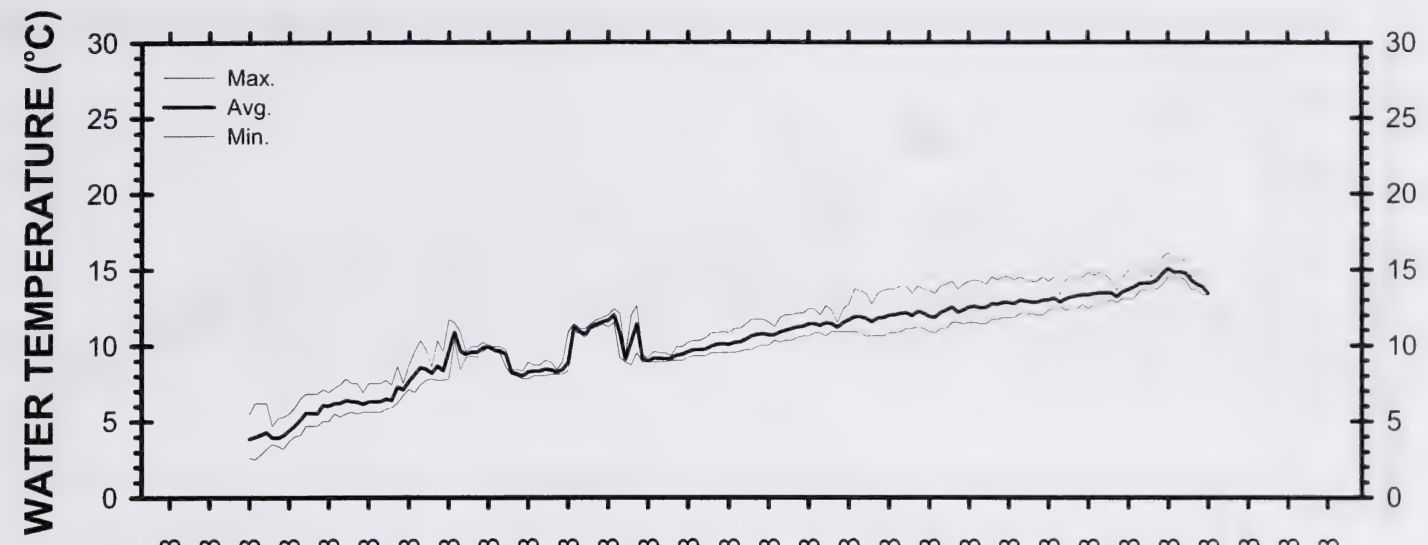

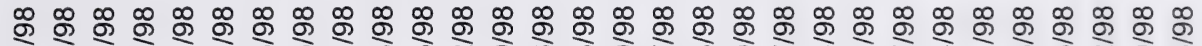
के

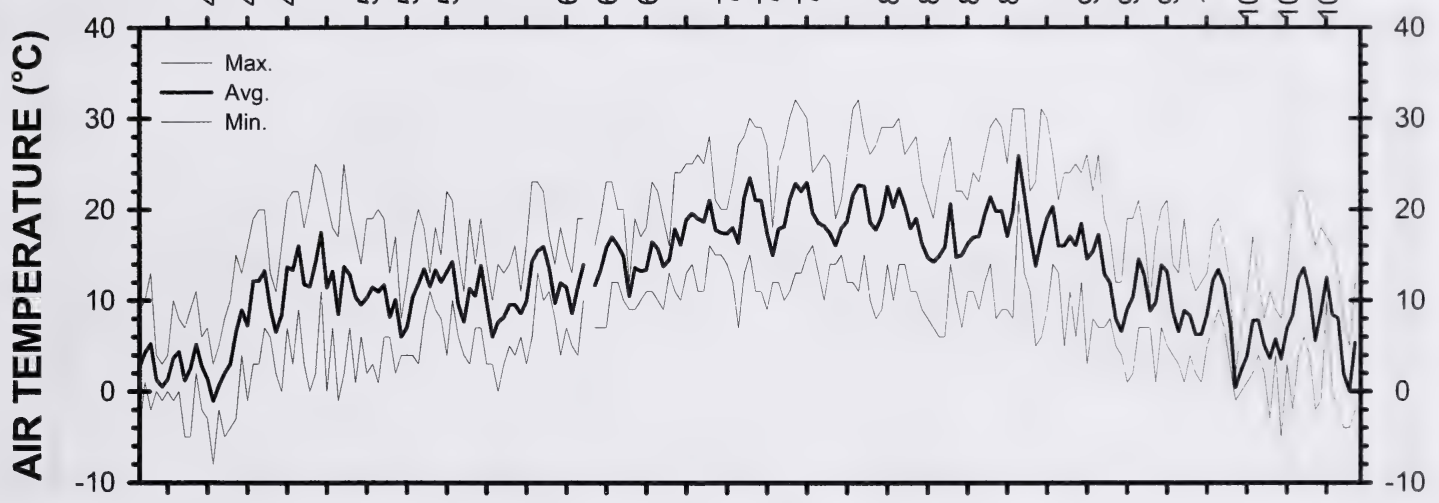

\% \% \%

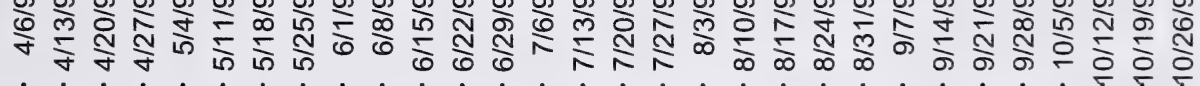

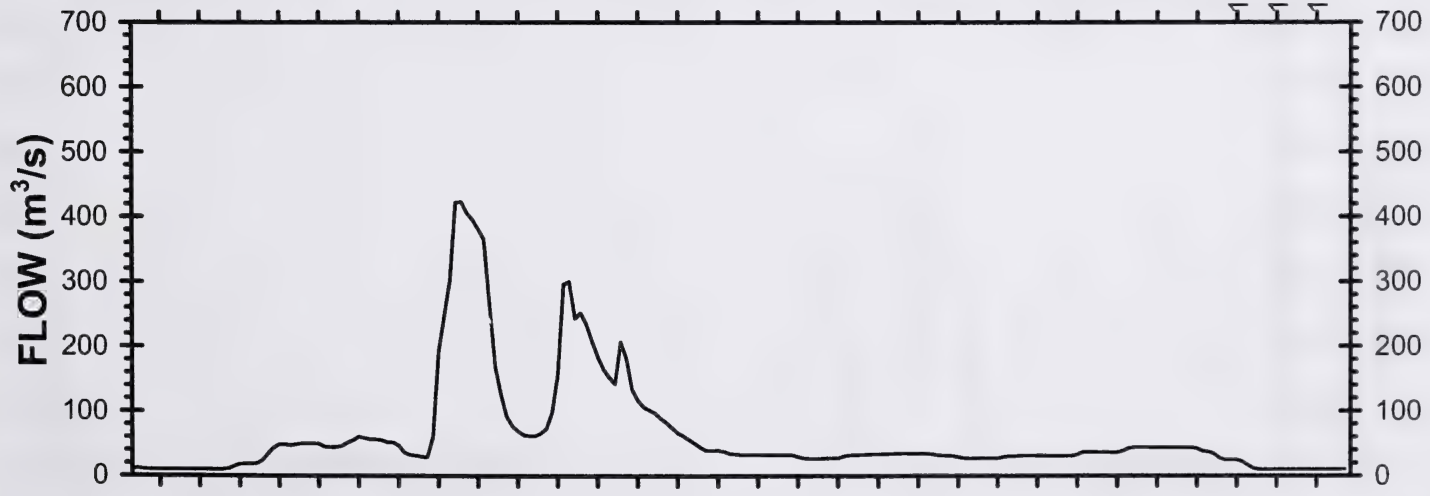

\% \% \% \%

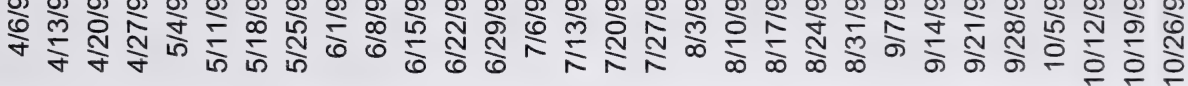

Figure 57. Daily water temperature (Thermograph), air temperature and flow in the Oldman River near Brocket. April-October 1998. 


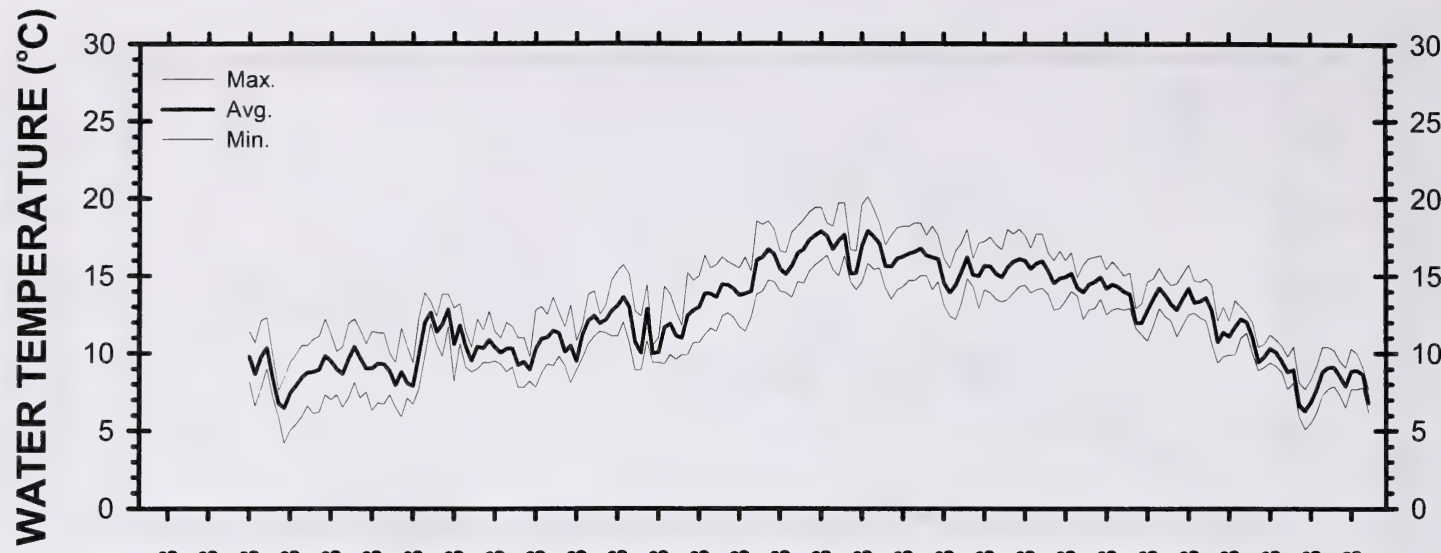

\% ః

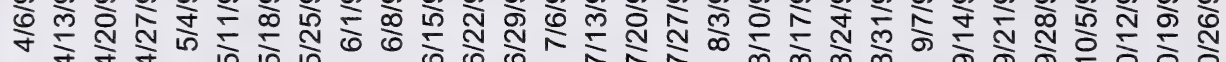

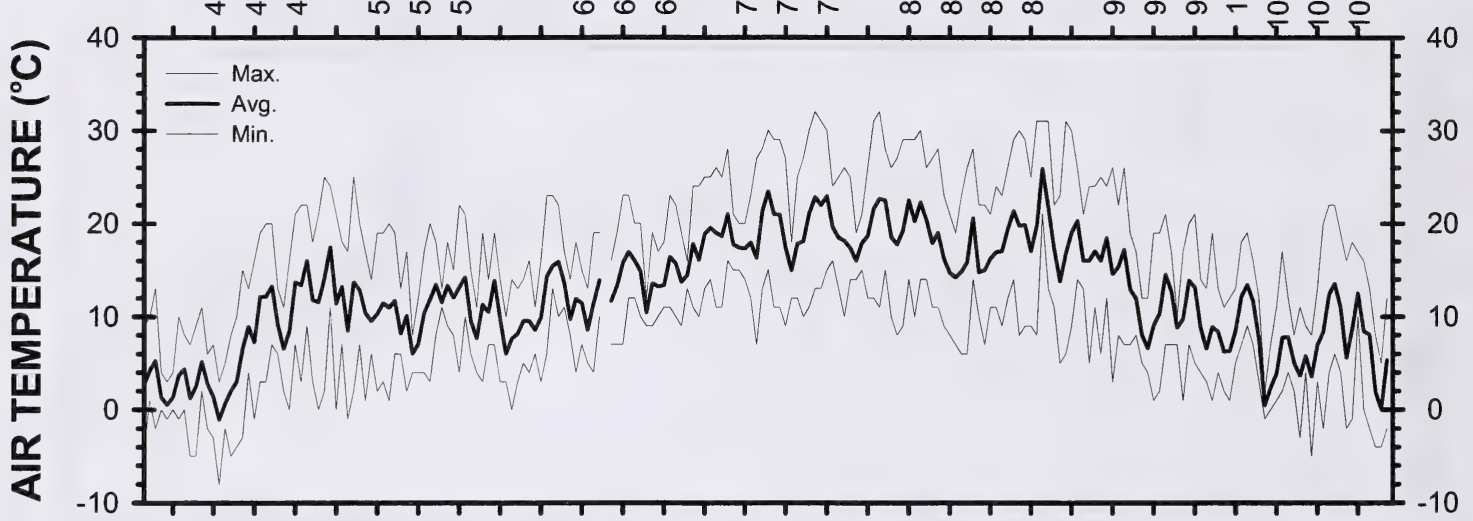

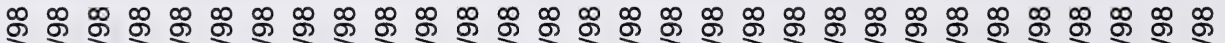

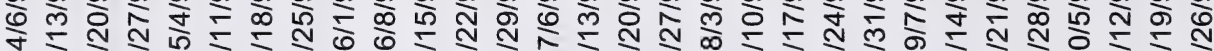

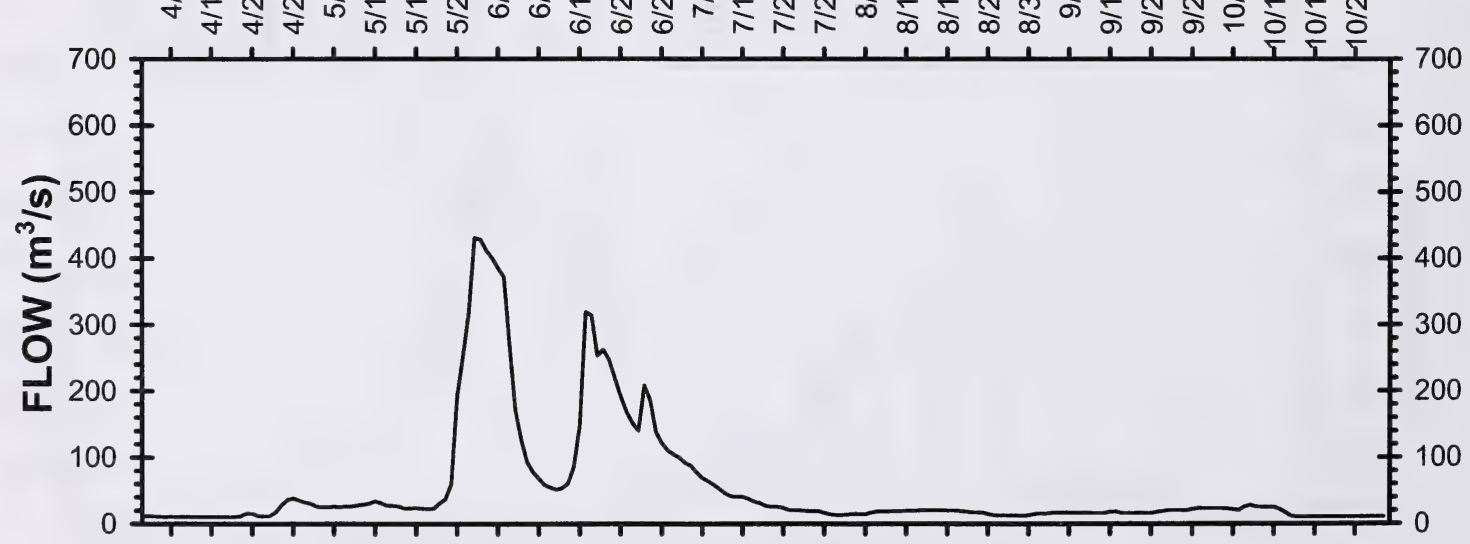

\%

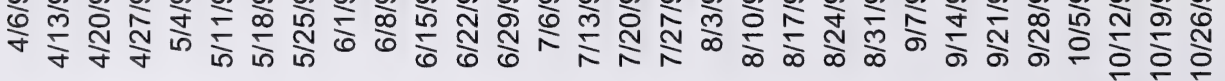

Figure 58. Daily water temperature (Thermograph), air temperature and flow in the Oldman River downstream of the LNHD. April-October 1998. 


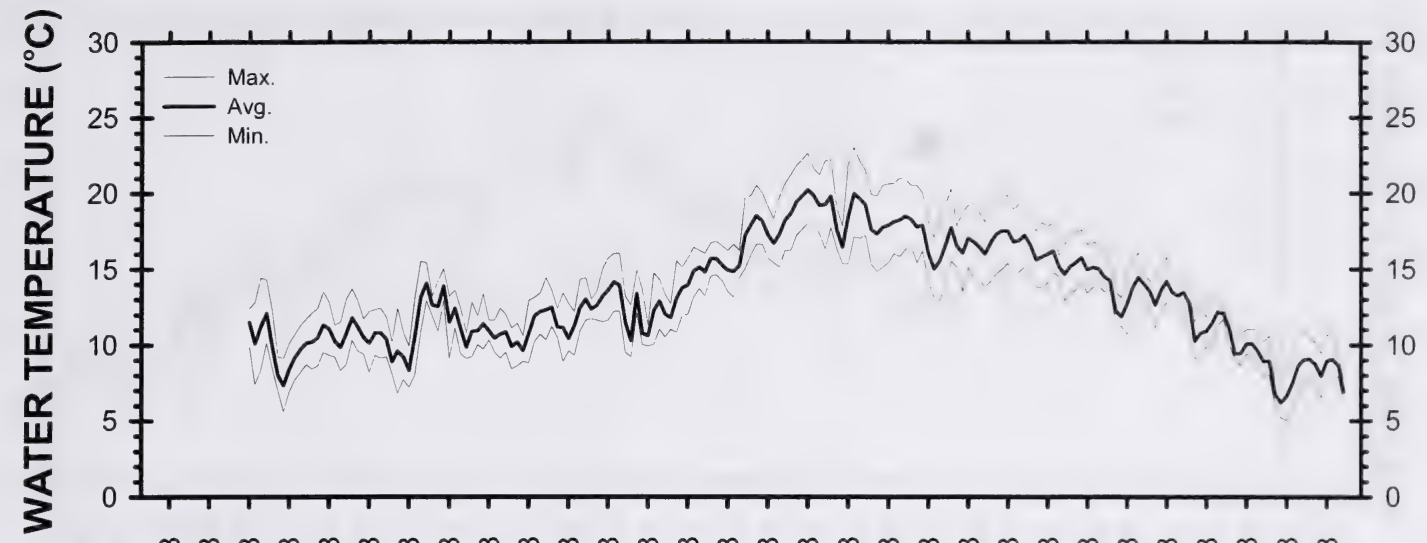

œ \%

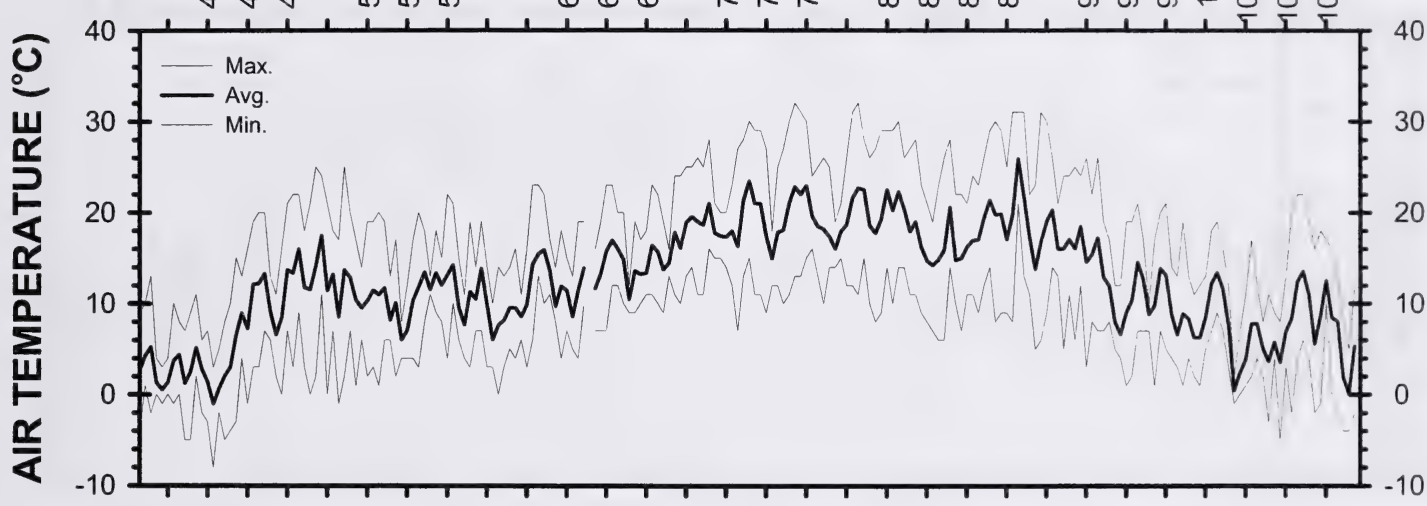

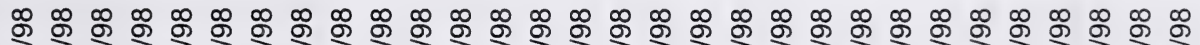

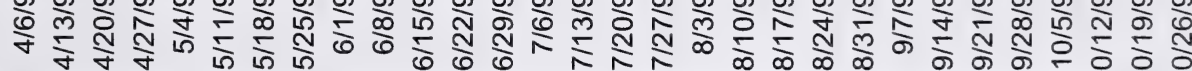

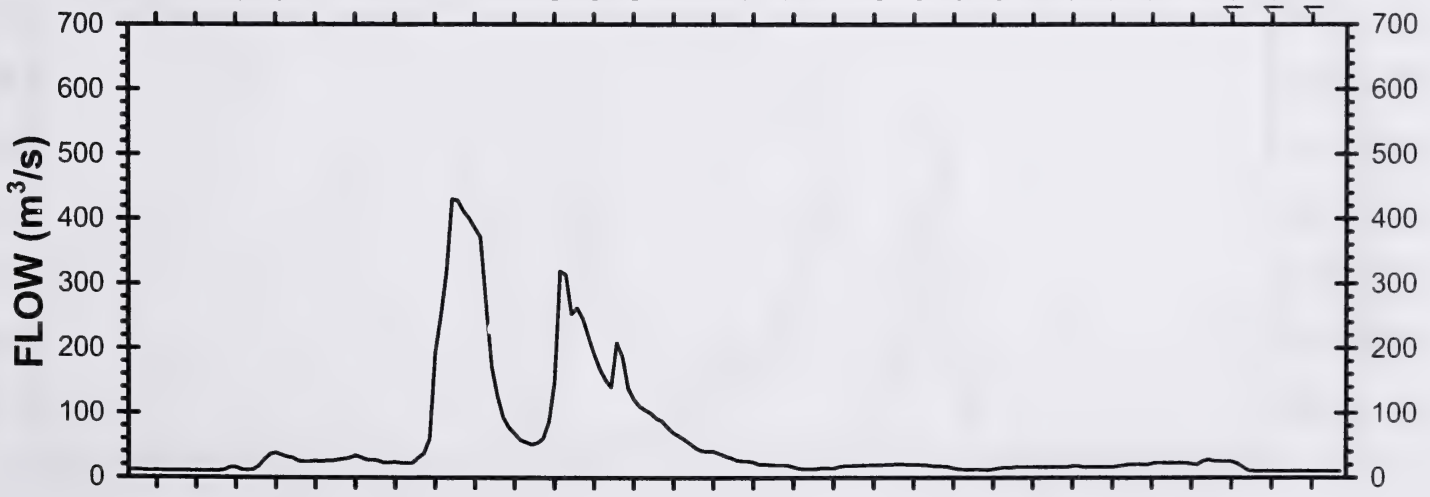

\% \% \%

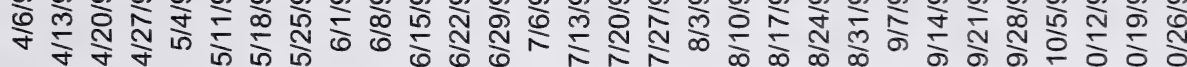

Figure 59. Daily water temperature (Thermograph), air temperature and flow in the Oldman River near Fort Macleod. April-October 1998. 


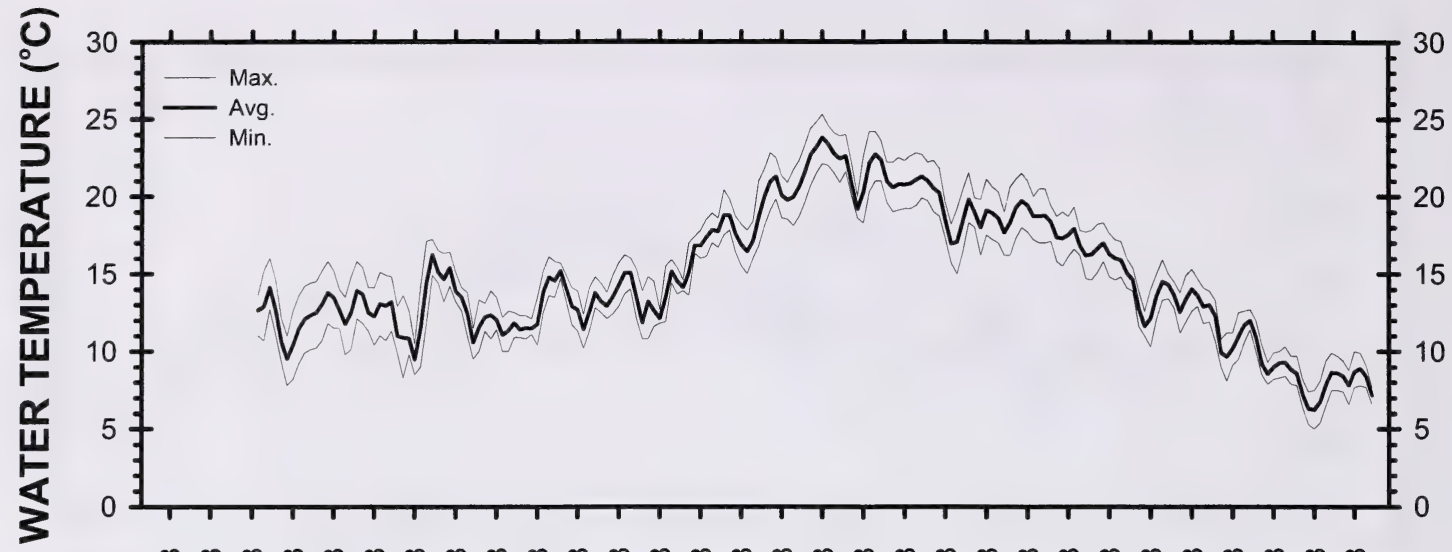

œ 仓

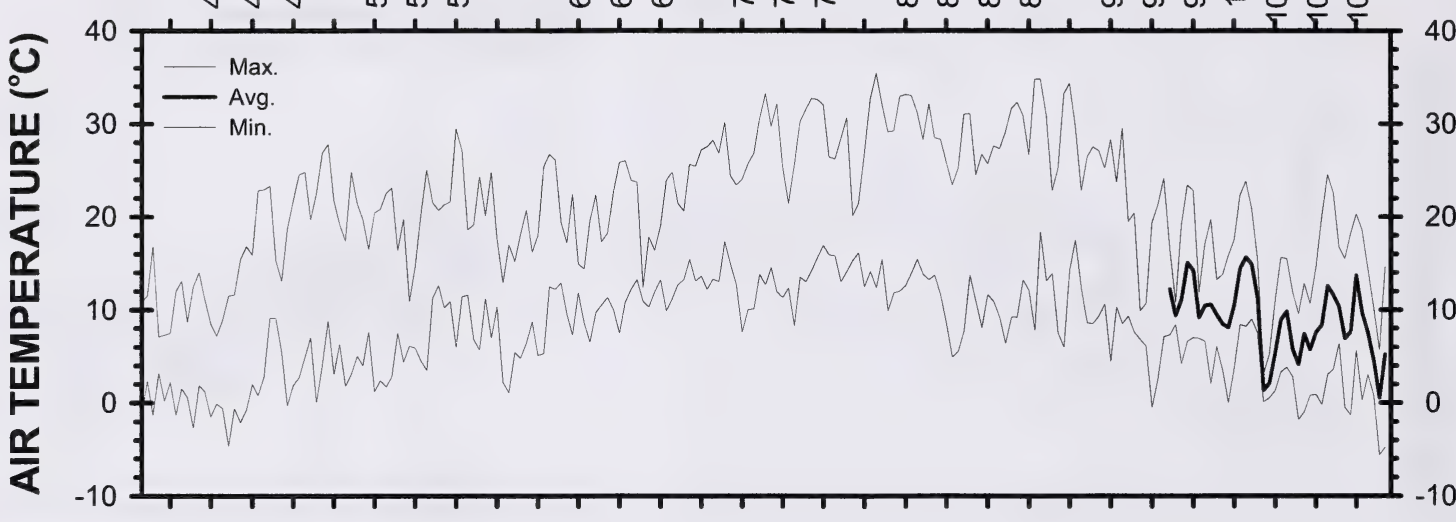

\% ⿹勹巳

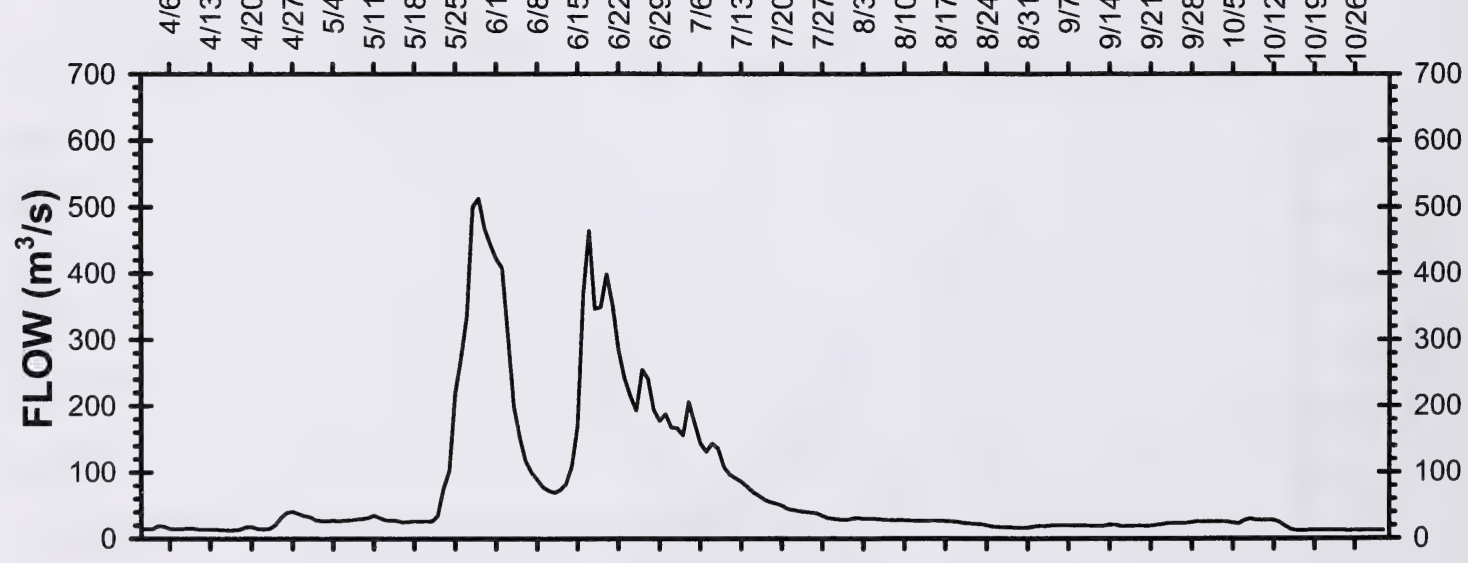

œ

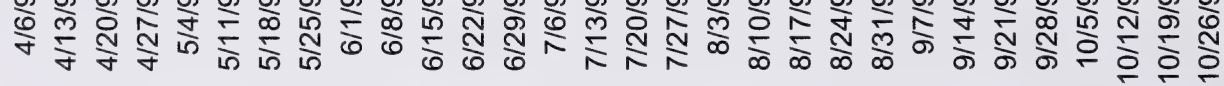

Figure 60. Daily water temperature (Thermograph), air temperature and flow in the Oldman River near Rocky Coulee. April-October 1998. 


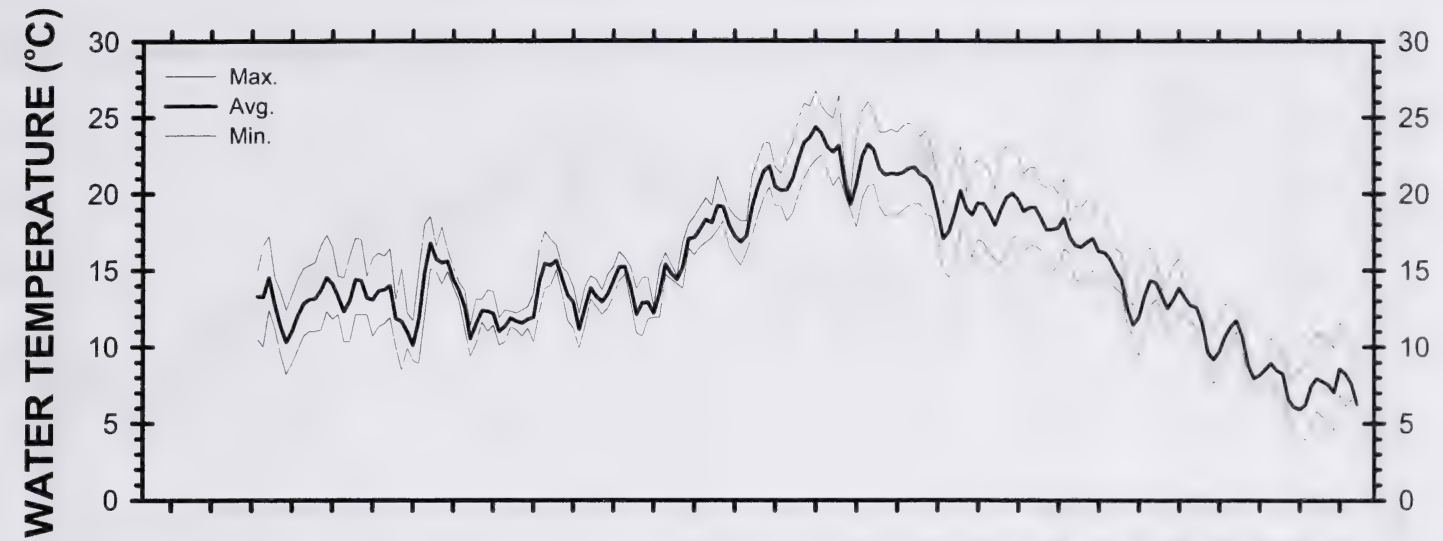

œ

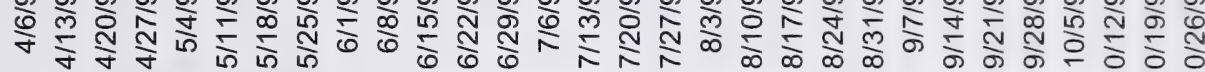

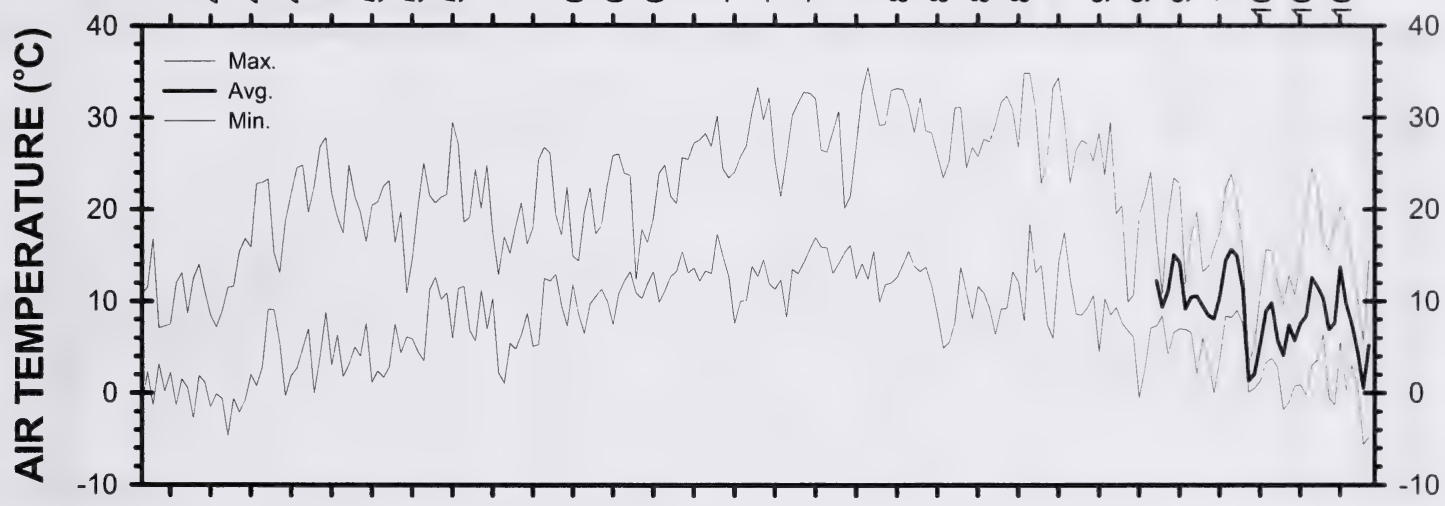

\% \% \% \% \% 仓े

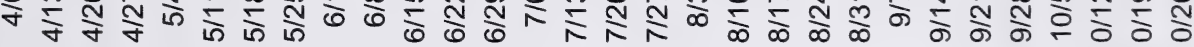

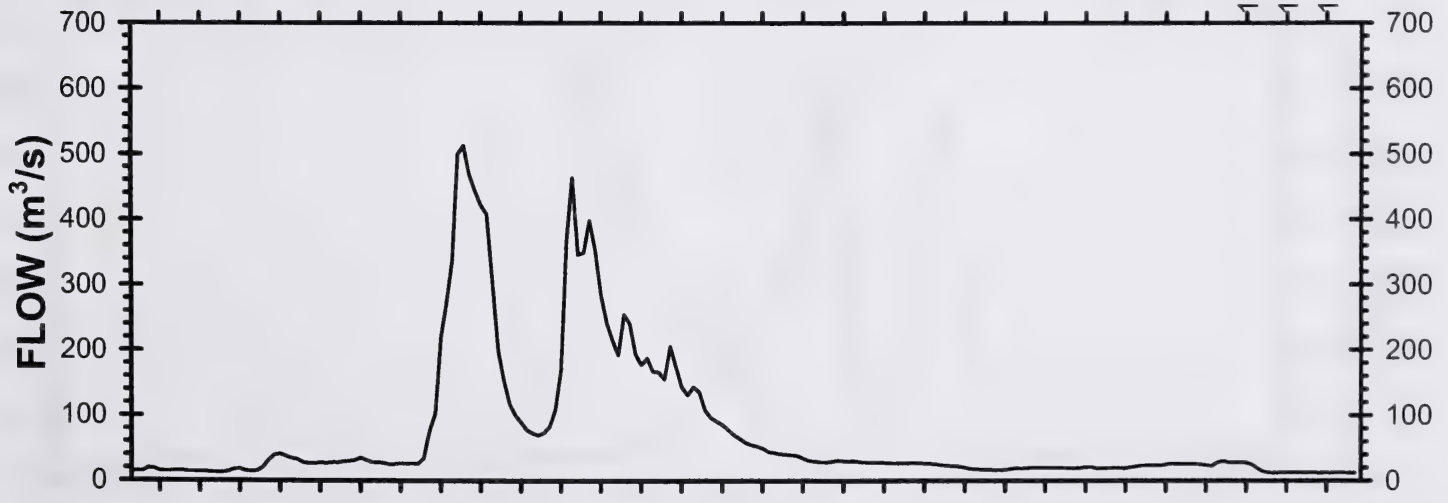

\% \% \% \% \% \%

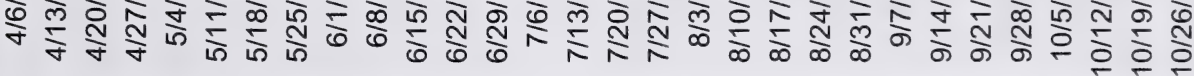

Figure 61. Daily water temperature (Thermograph), air temperature and flow in the Oldman River near Monarch. April-October 1998. 


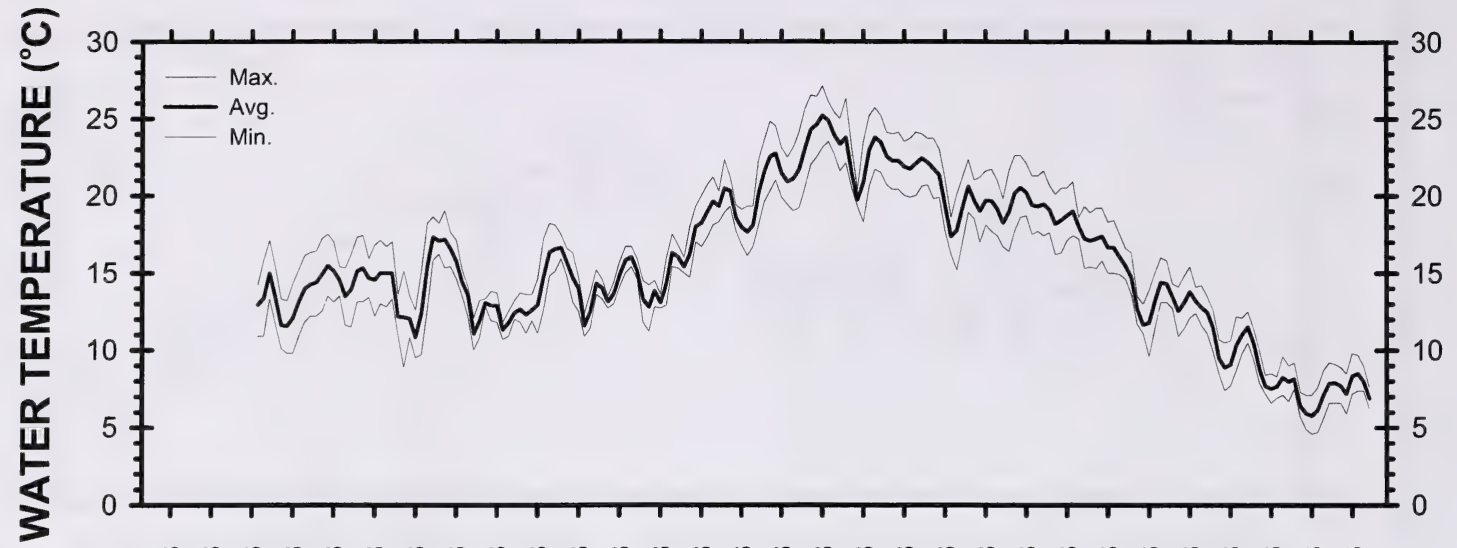

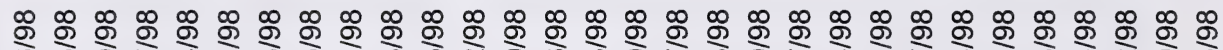

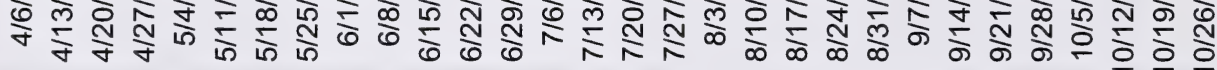

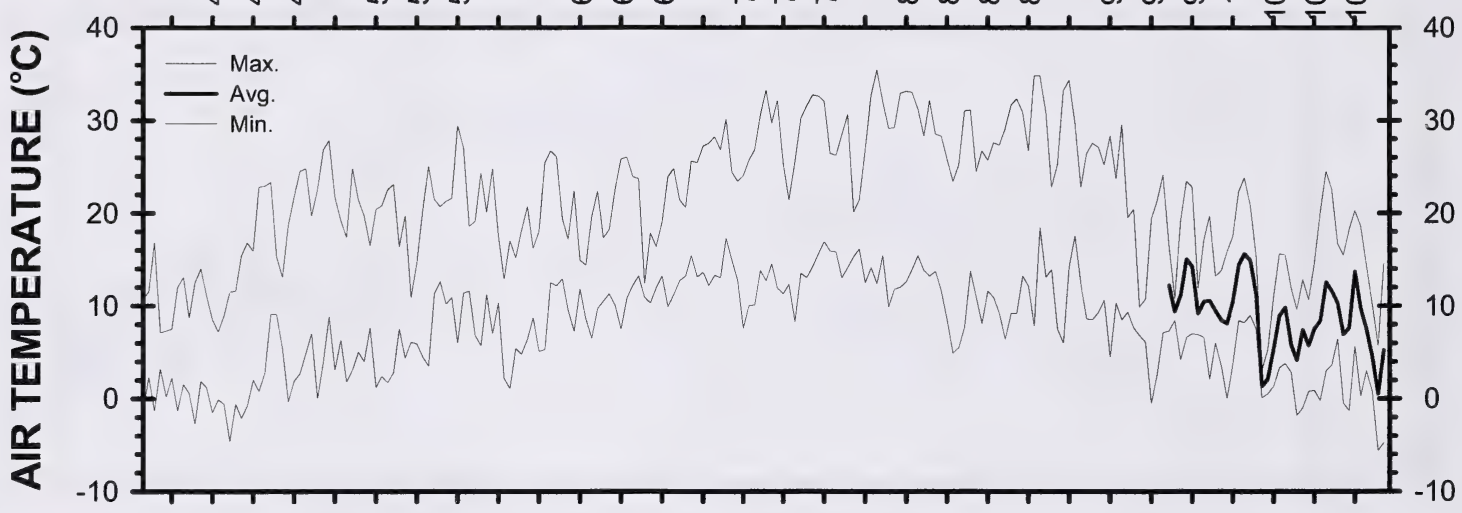

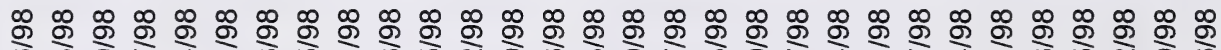
అ

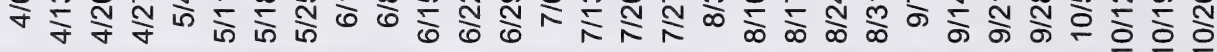

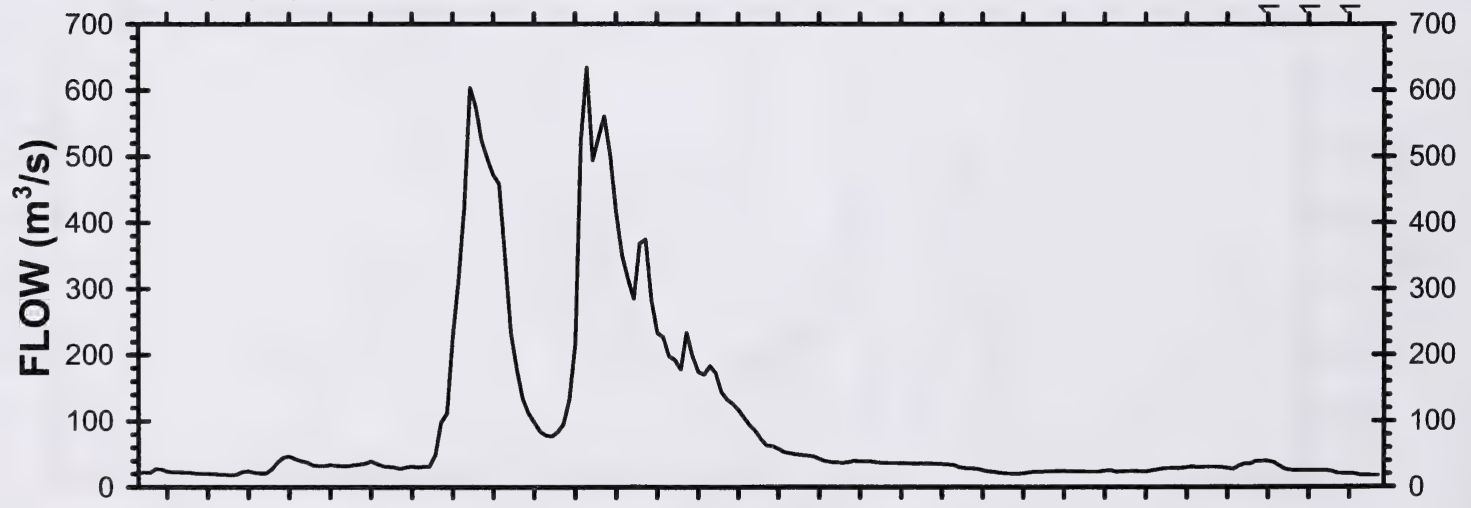

ఝ

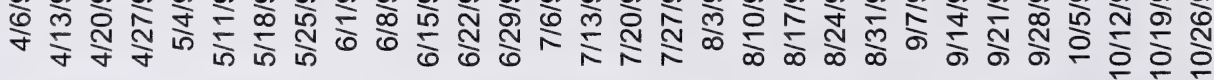

Figure 62. Daily water temperature (Thermograph), air temperature and flow in the Oldman River downstream of the Belly River. April-October 1998. 


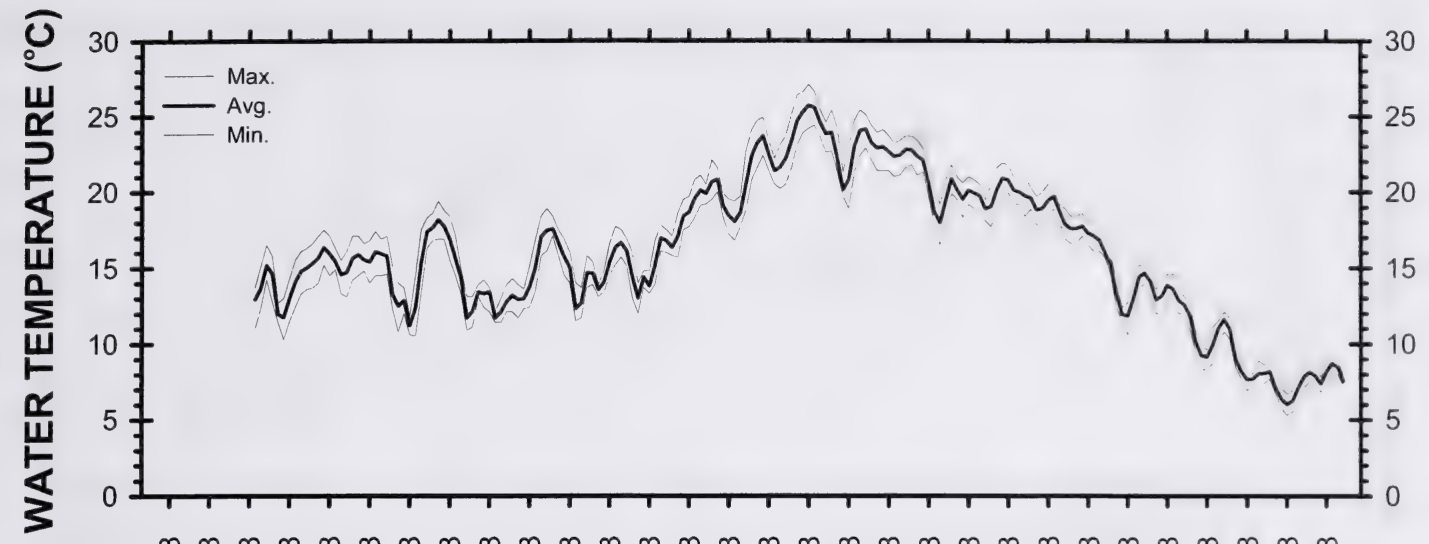

\% \%

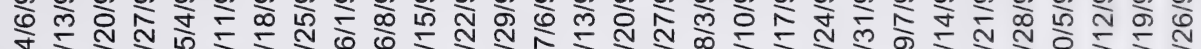

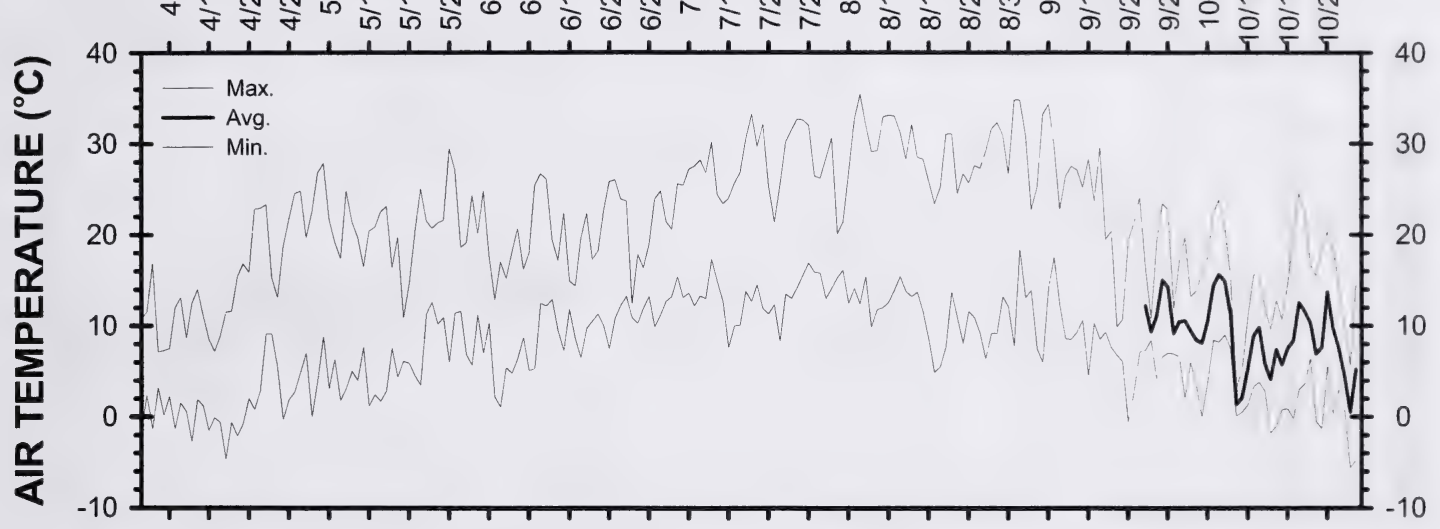

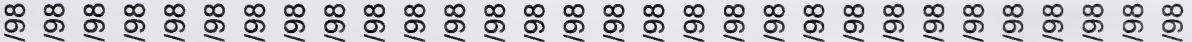
\%

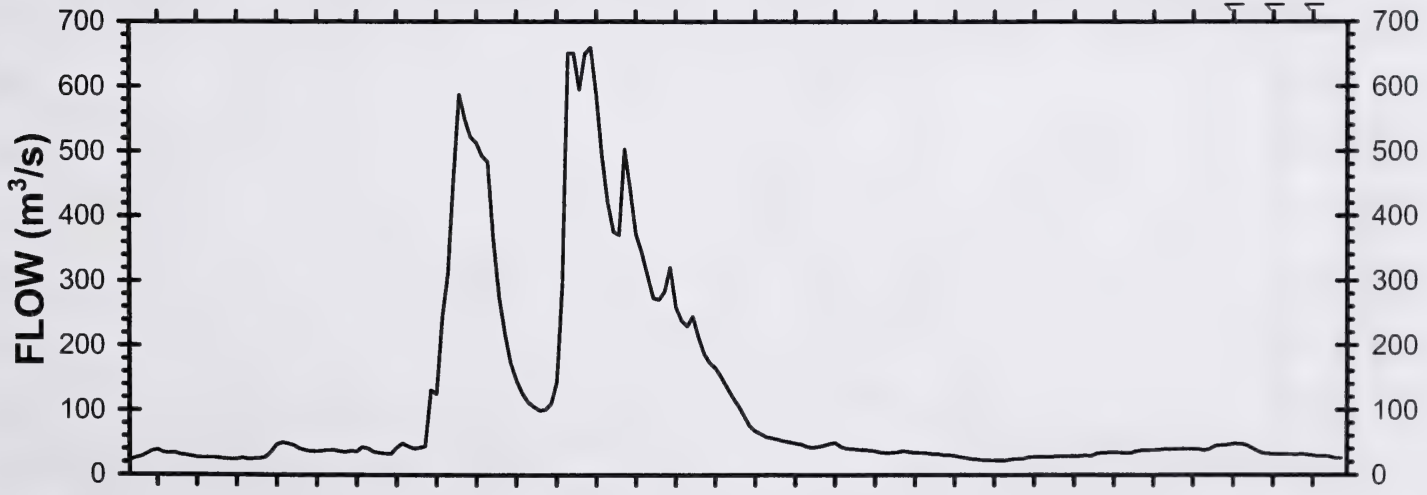

ஜ

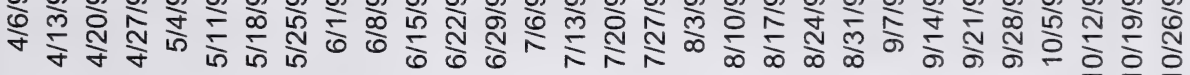

Figure 63. Daily water temperature (Thermograph), air temperature and flow in the Oldman River upstream of Lethbridge. April-October 1998. 


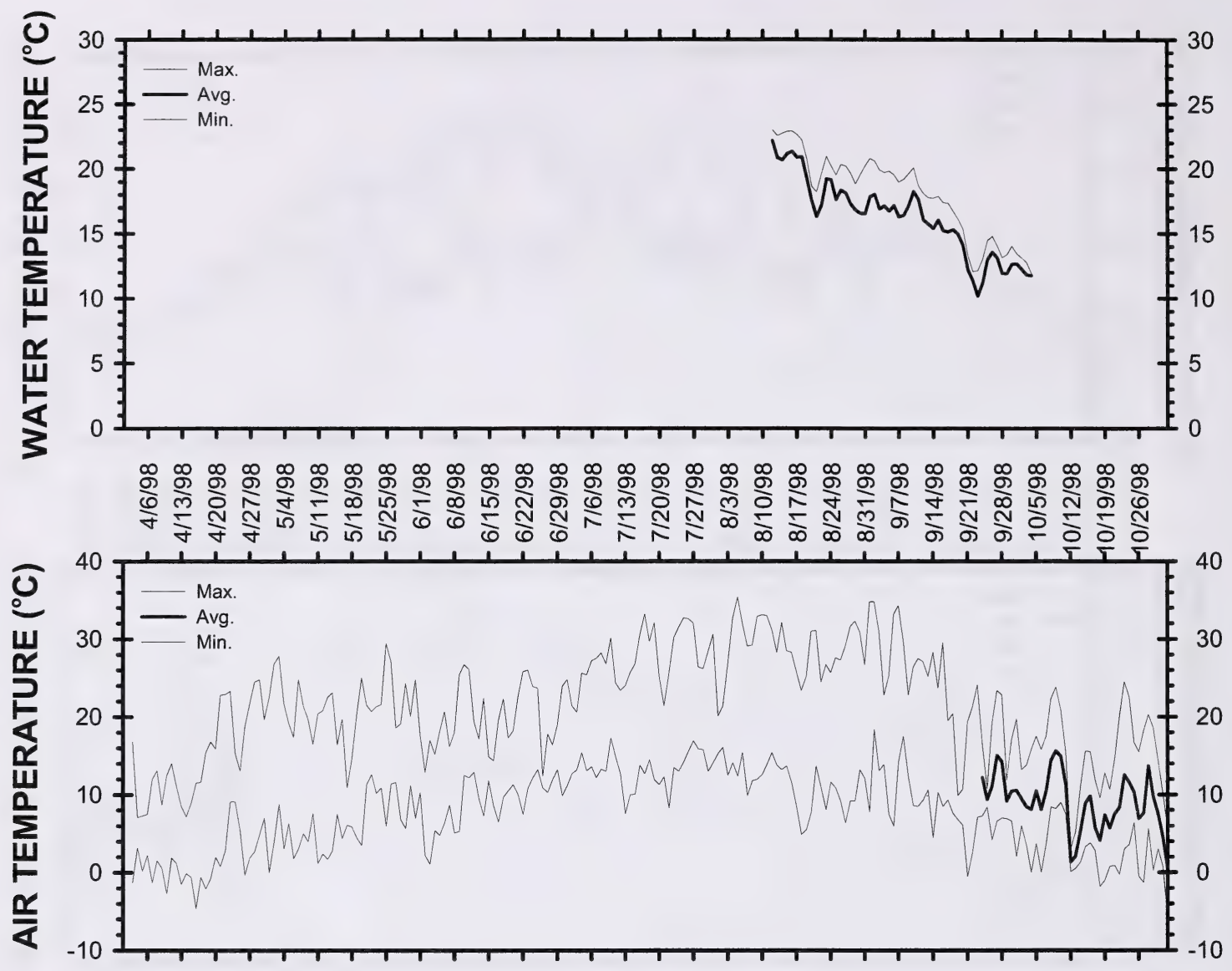

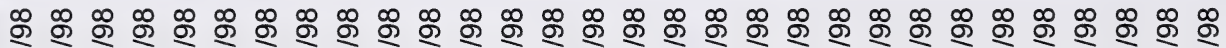
फ

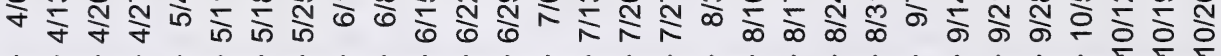

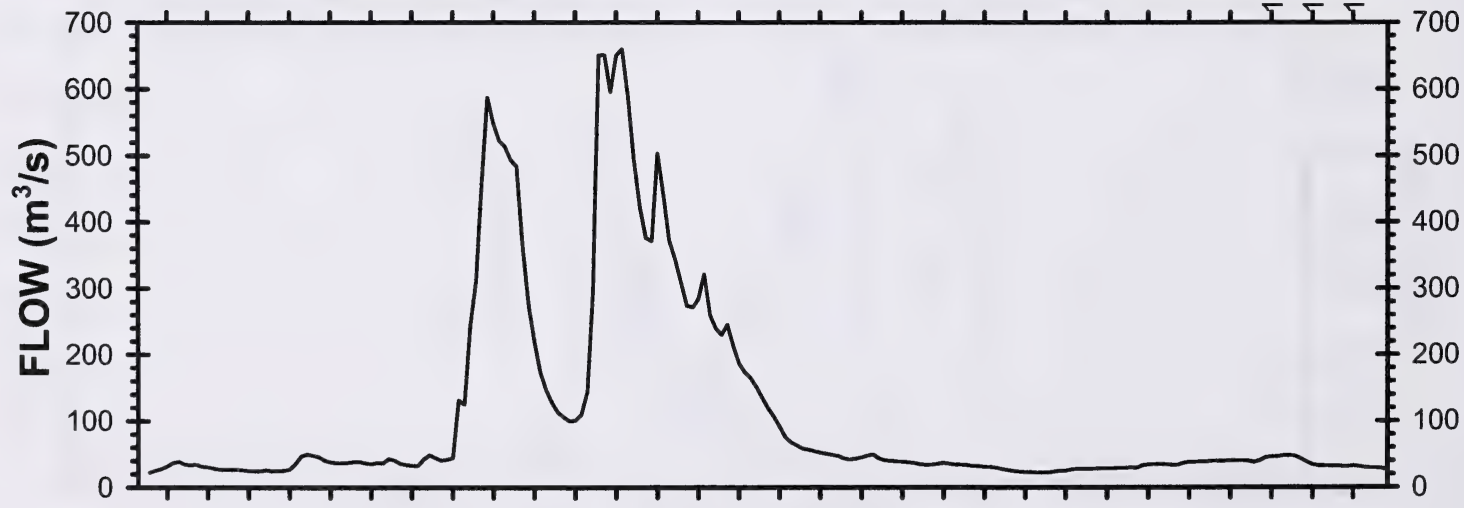

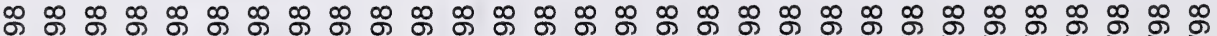

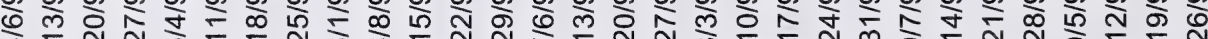

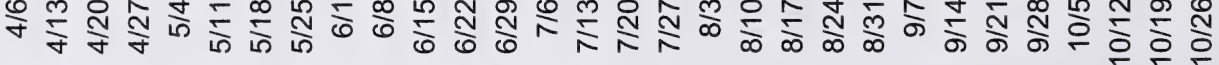

Figure 64. Daily water temperature (Datasonde), air temperature and flow in the Oldman River downstream of Lethbridge. April-October 1998. 


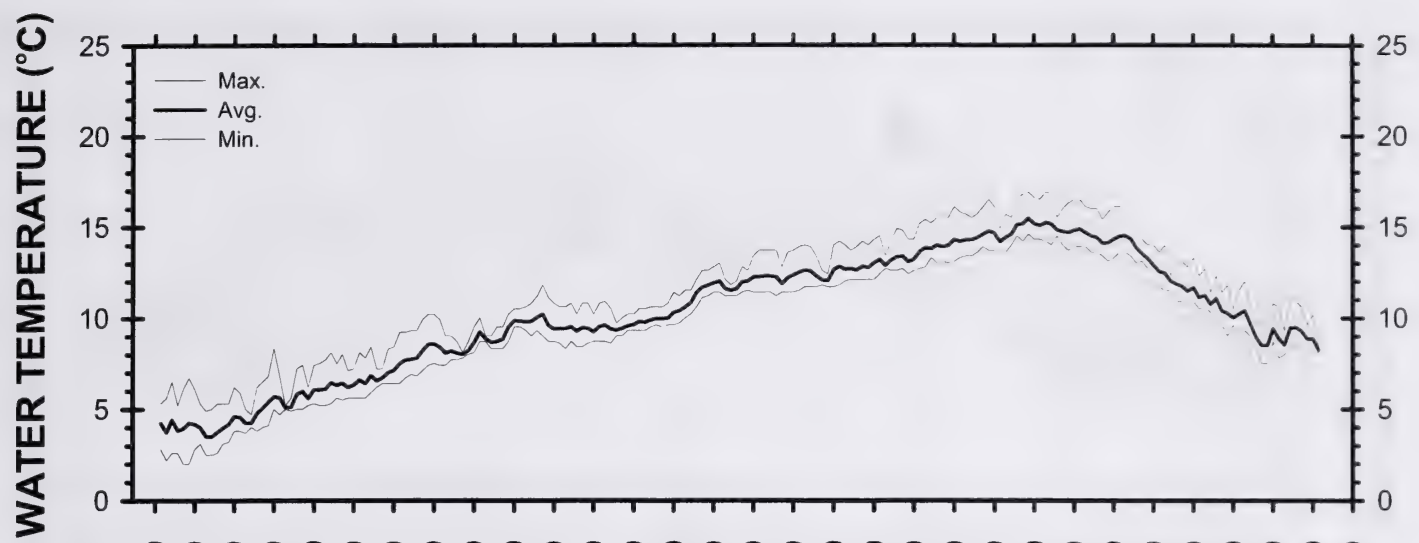

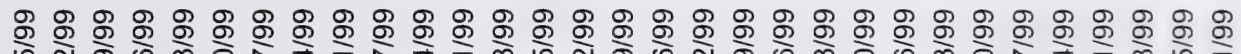

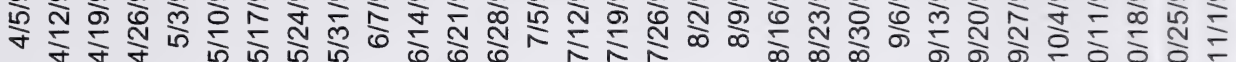

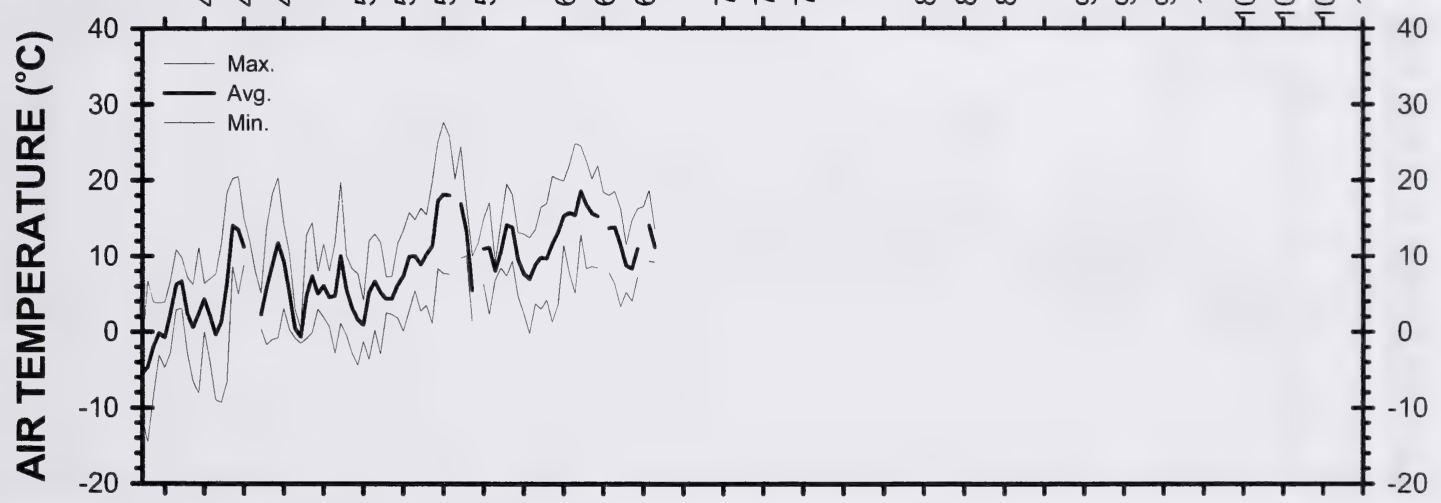

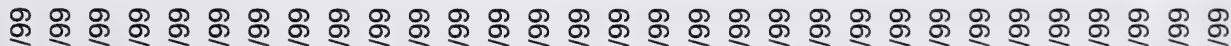

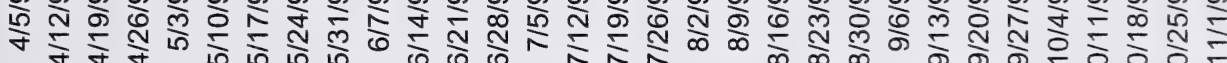

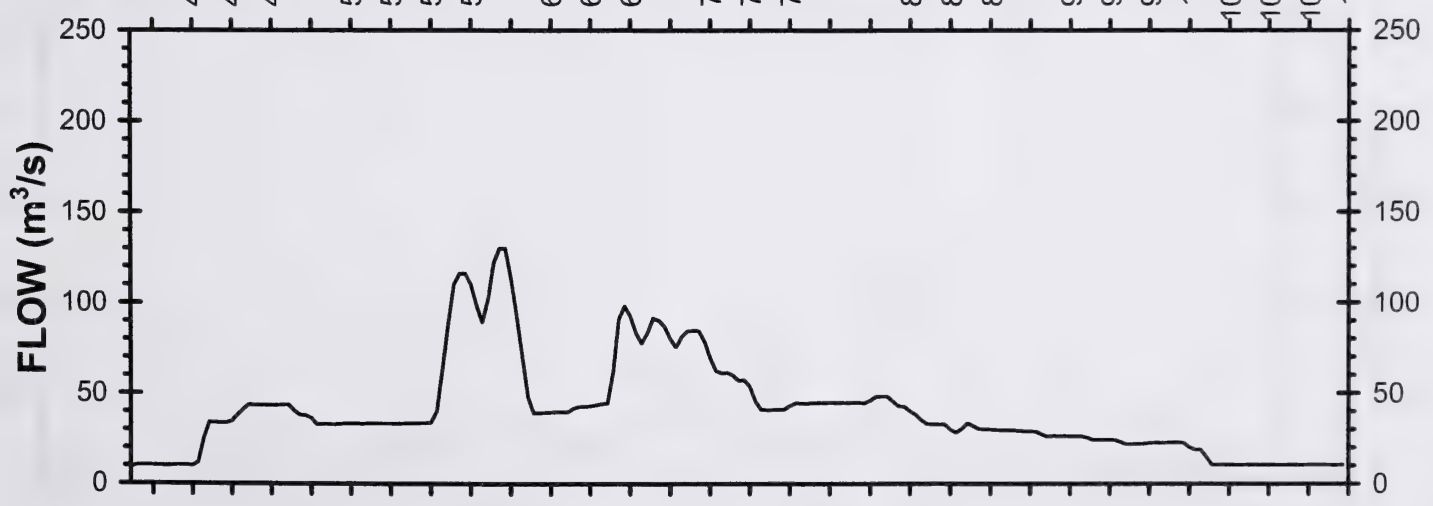

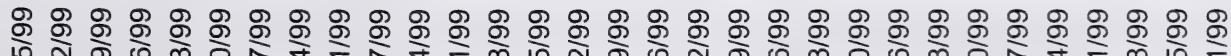

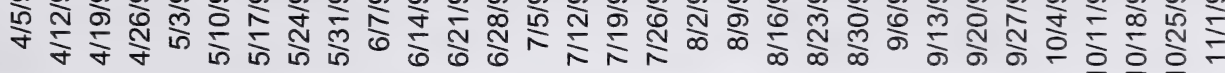

Figure 65. Daily water temperature (Thermograph), air temperature and flow in the Oldman River near Brocket. April-October 1999. 


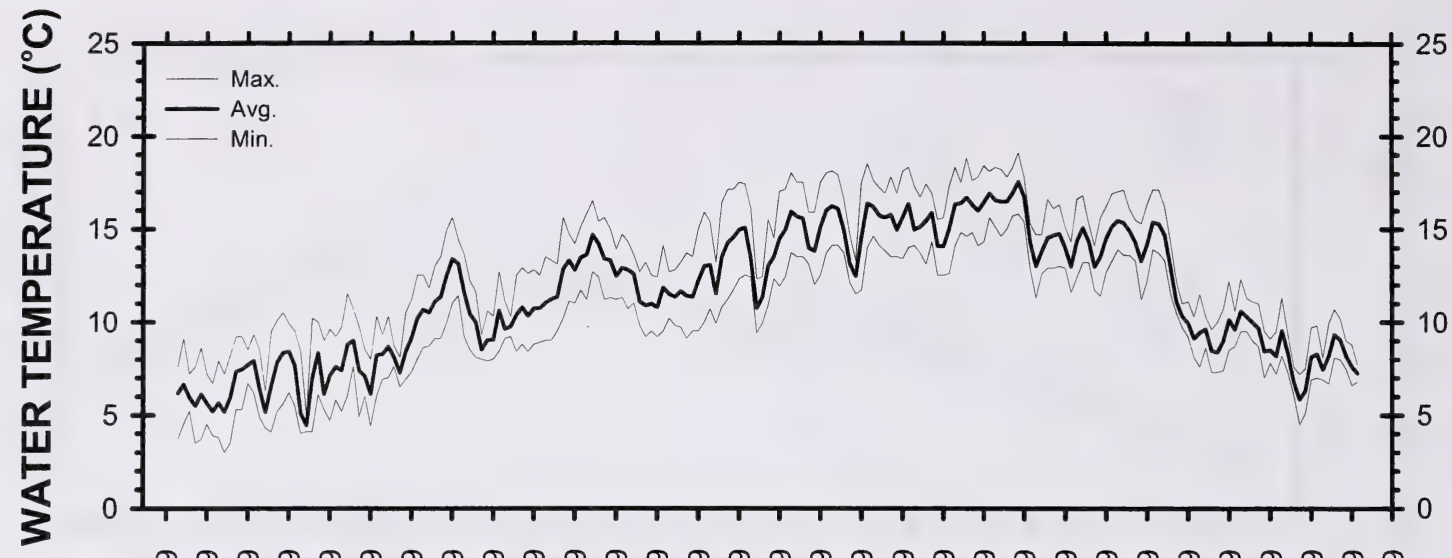

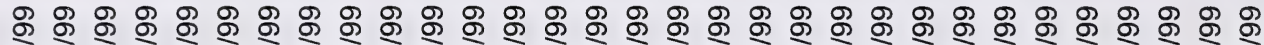

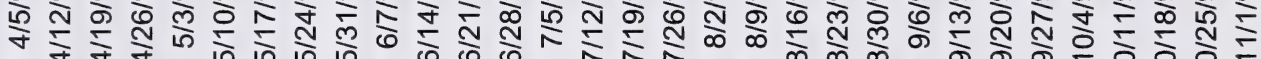

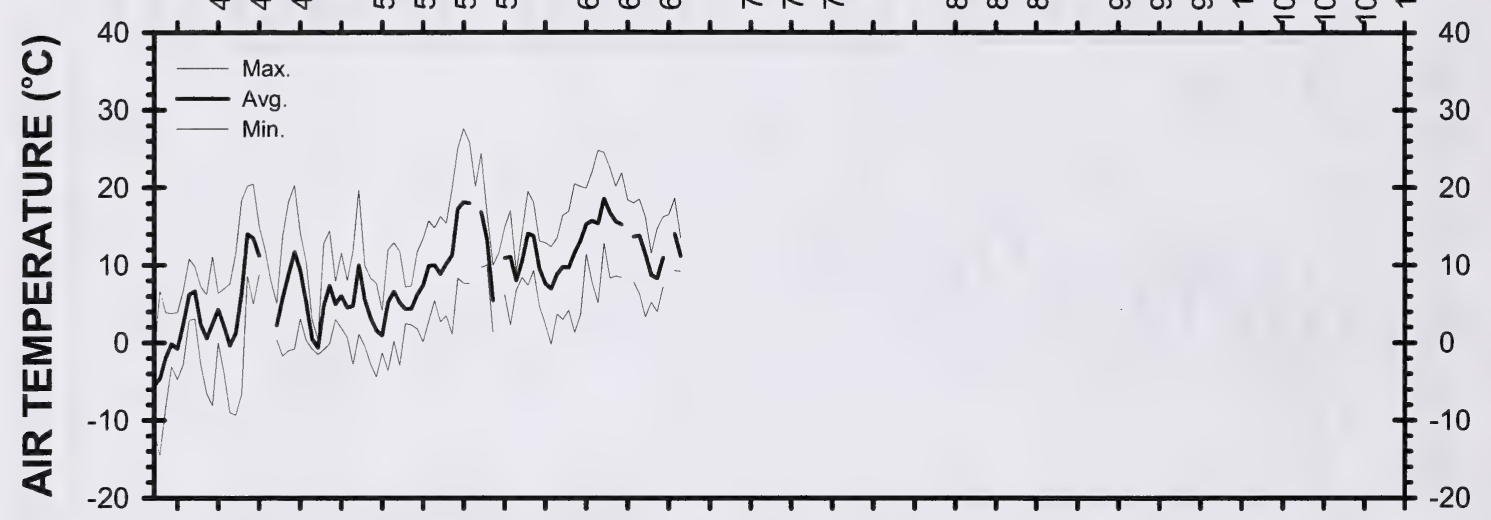

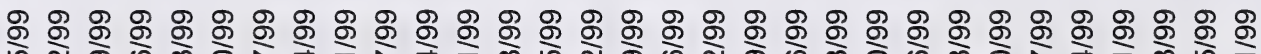

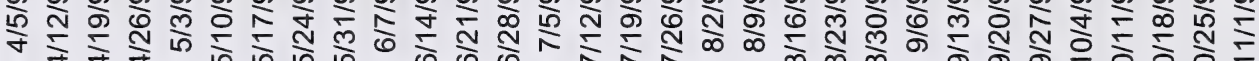

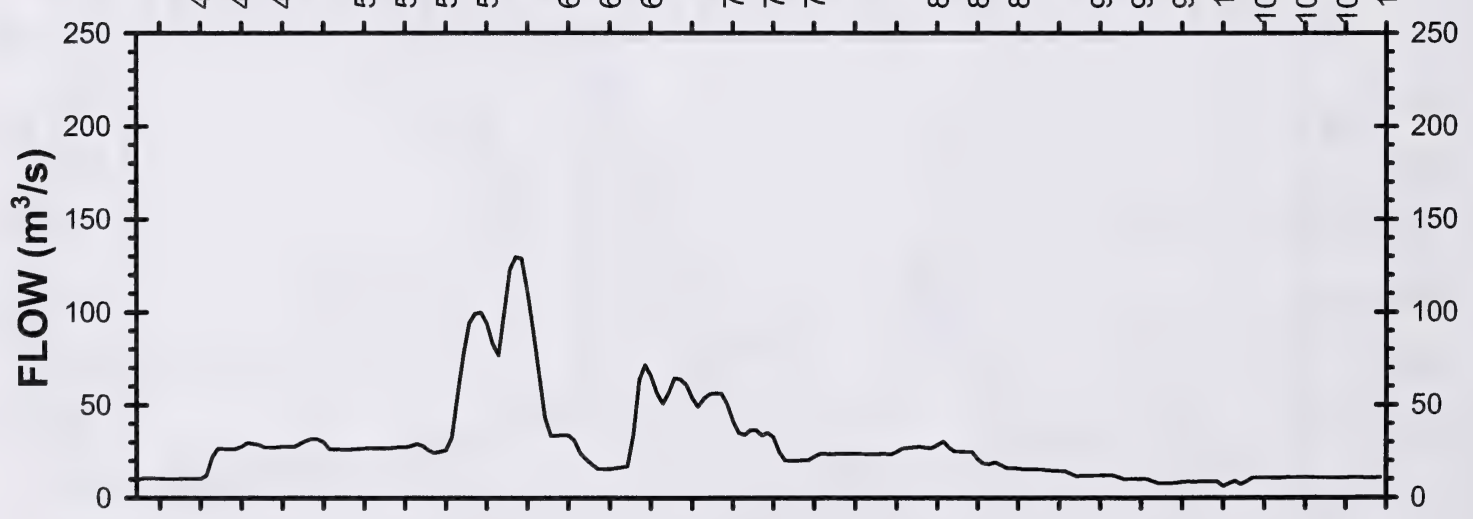

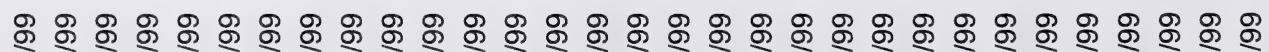

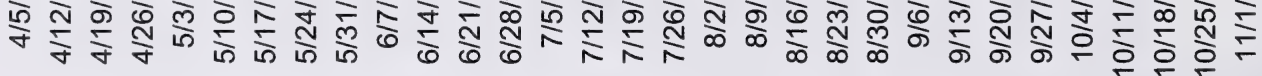

Figure 66. Daily water temperature (Thermograph), air temperature and flow in the Oldman River downstream of the LNHD. April-October 1999. 


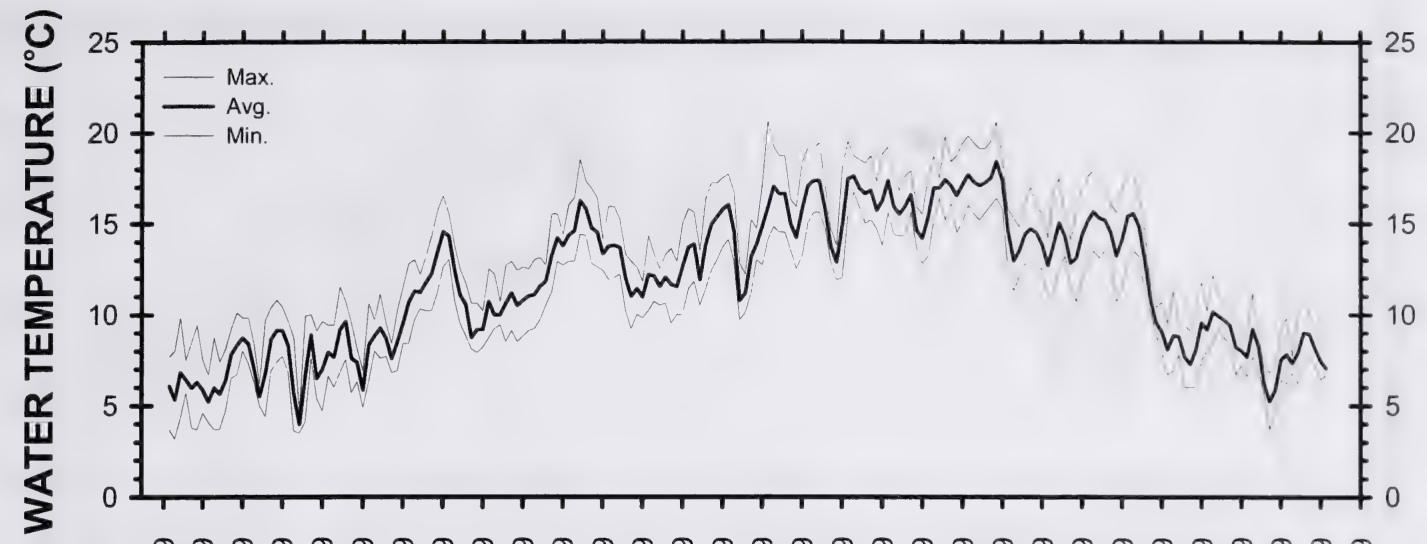

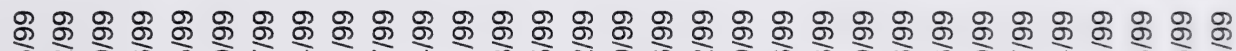

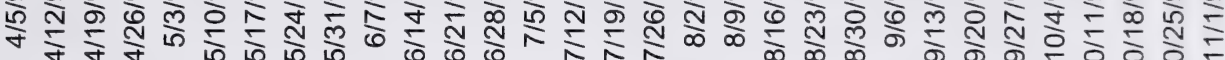

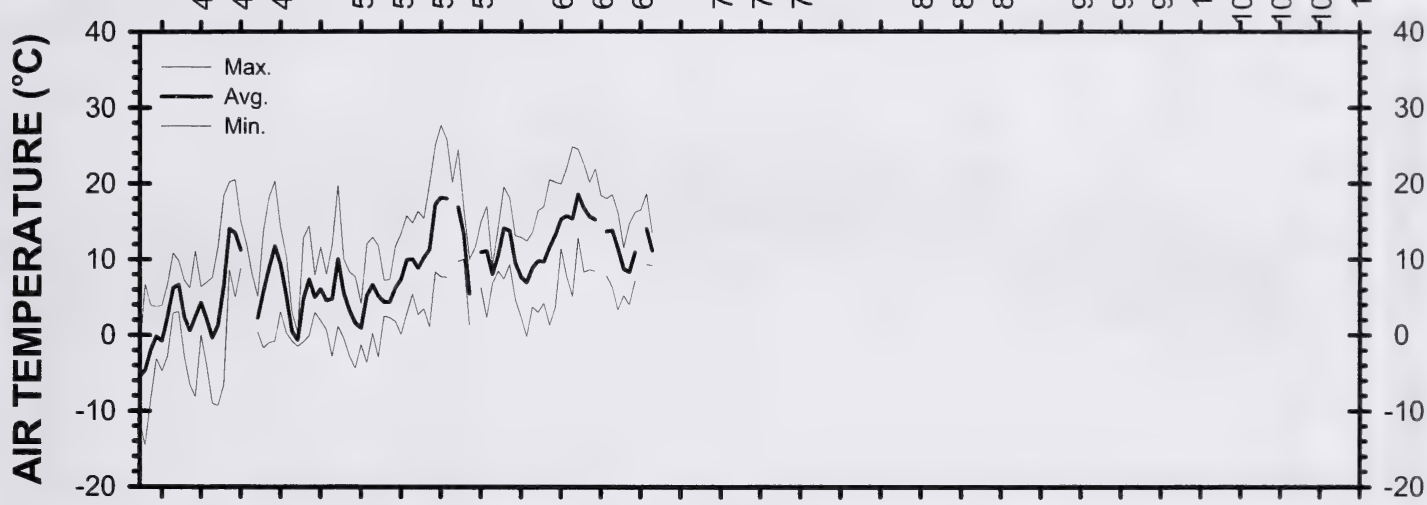

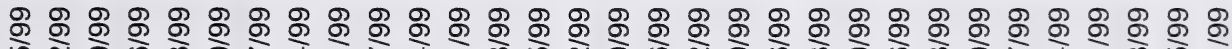

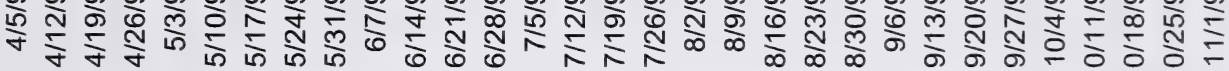

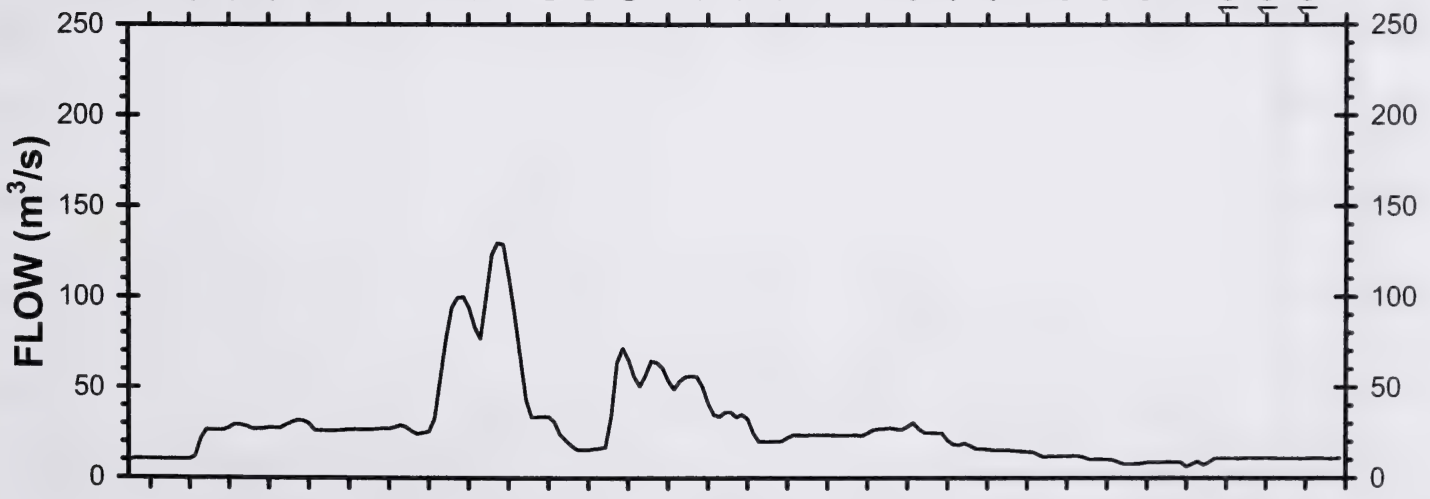

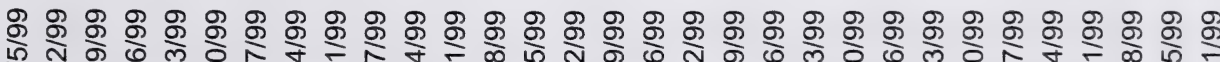

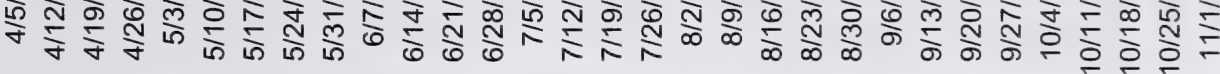

Figure 67. Daily water temperature (Thermograph), air temperature and flow in the Oldman River near Fort Macleod. April-October 1999. 


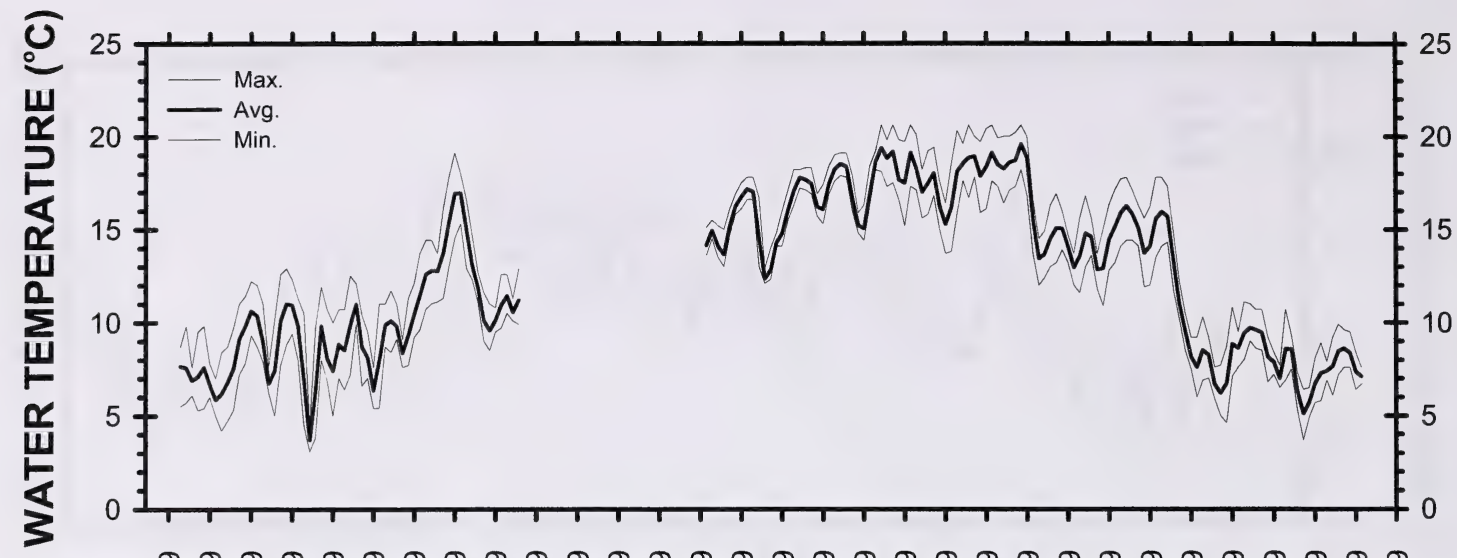

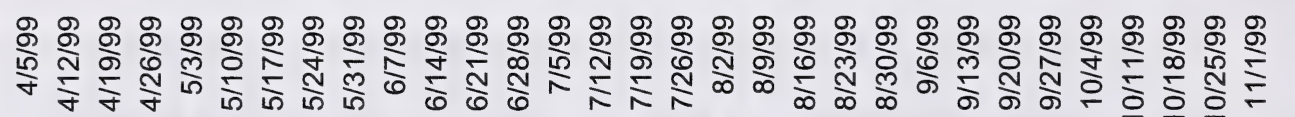

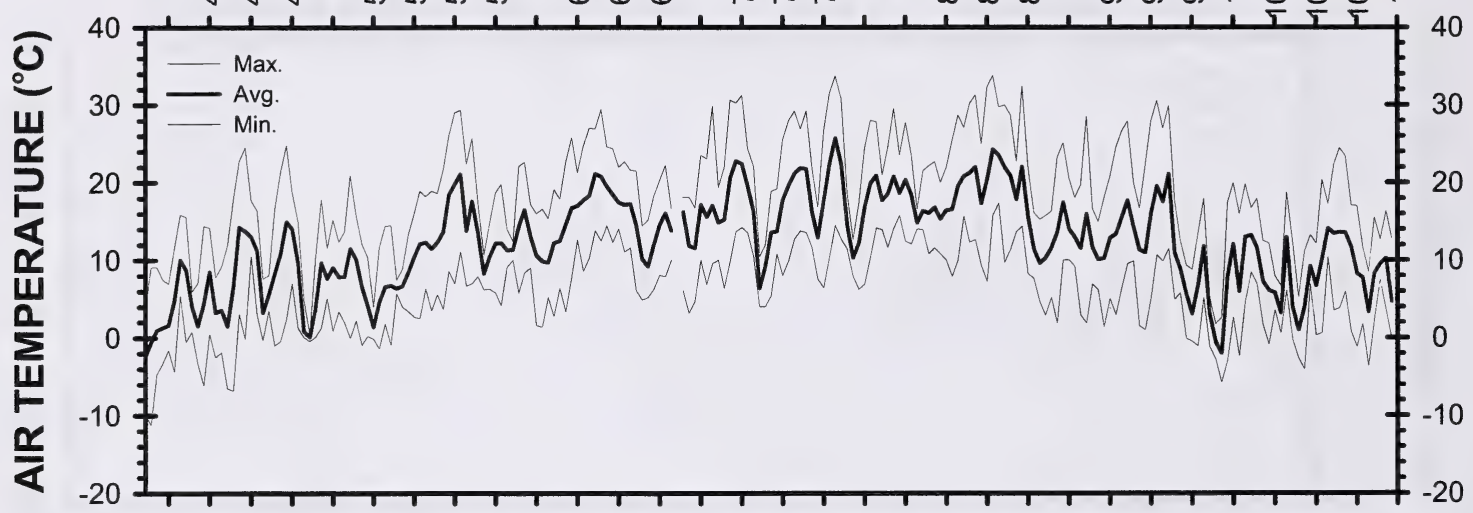

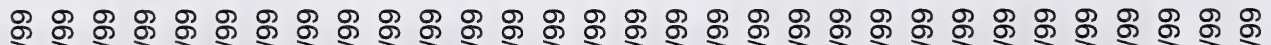

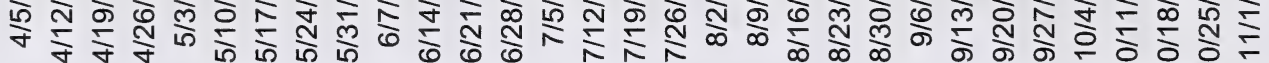

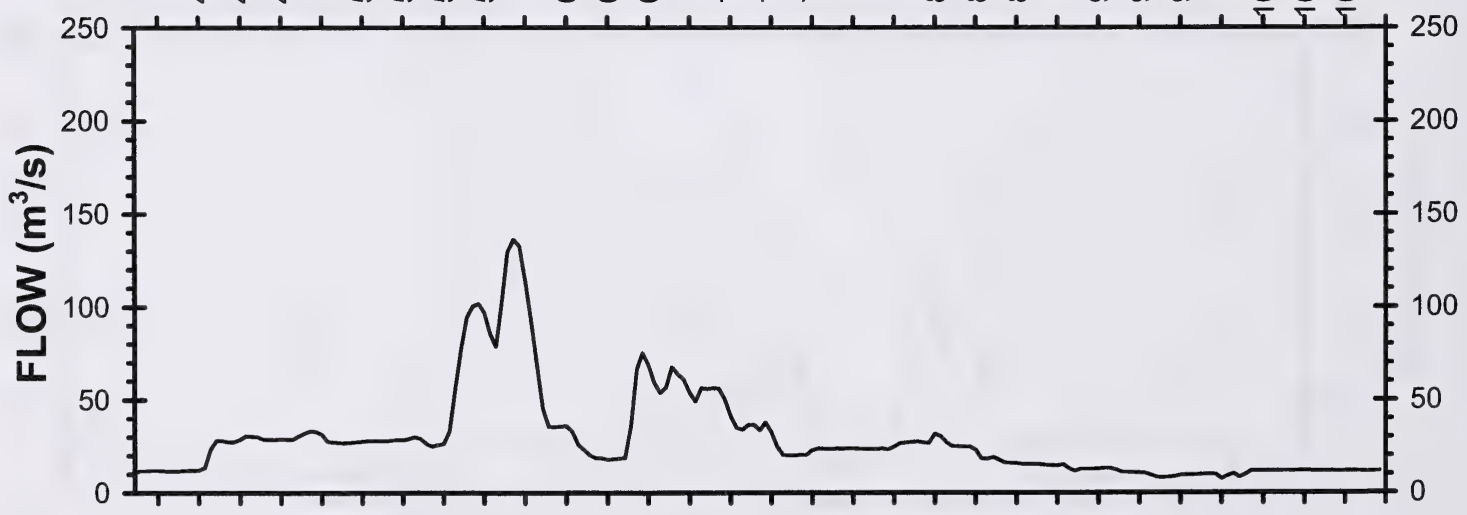

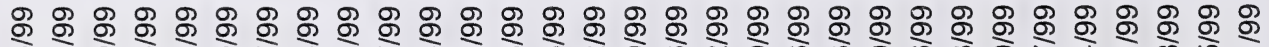

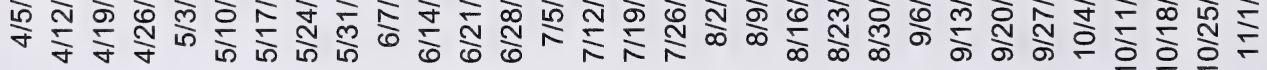

Figure 68. Daily water temperature (Thermograph), air temperature and flow in the Oldman River near Rocky Coulee. April-October 1999. 


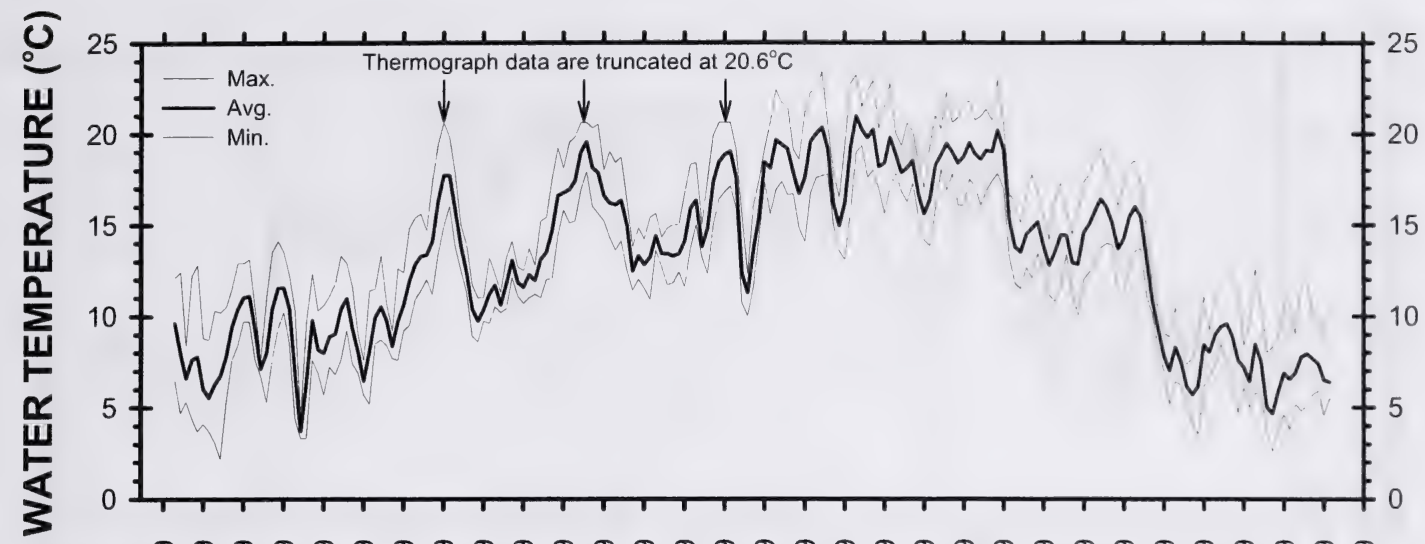

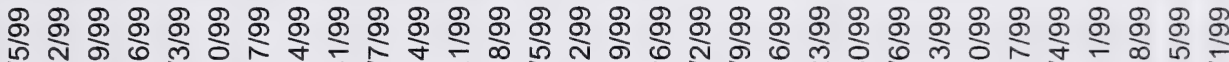

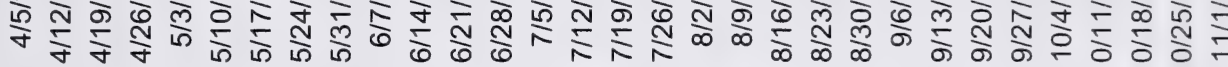

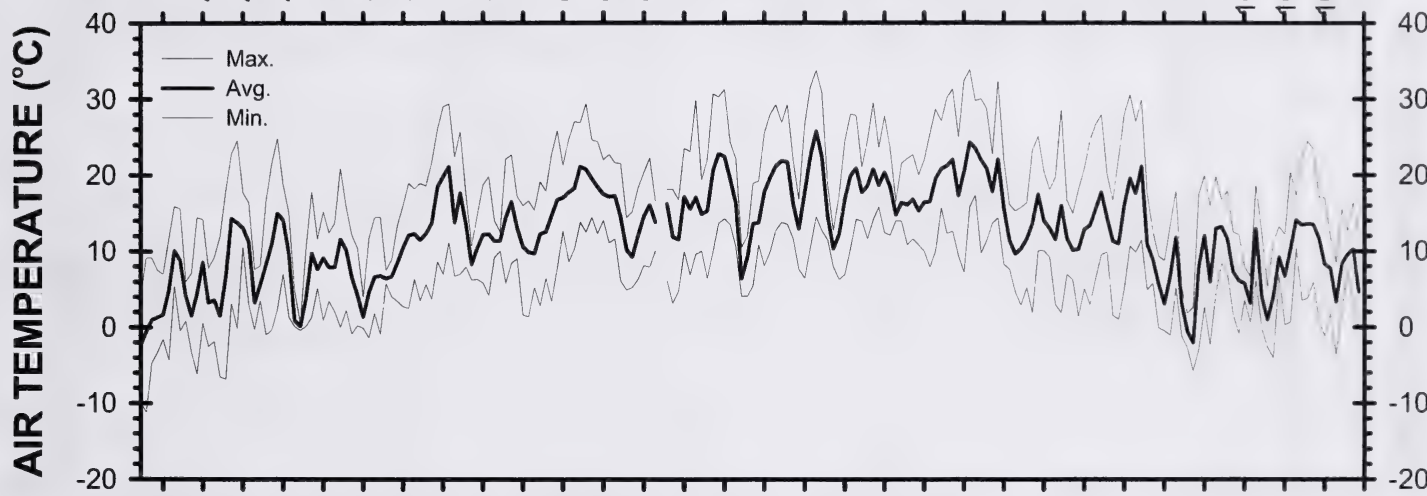

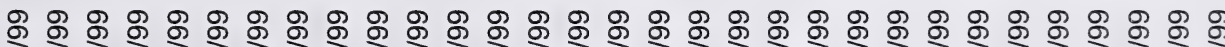

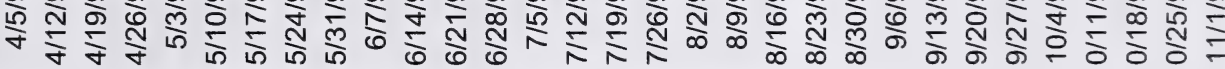

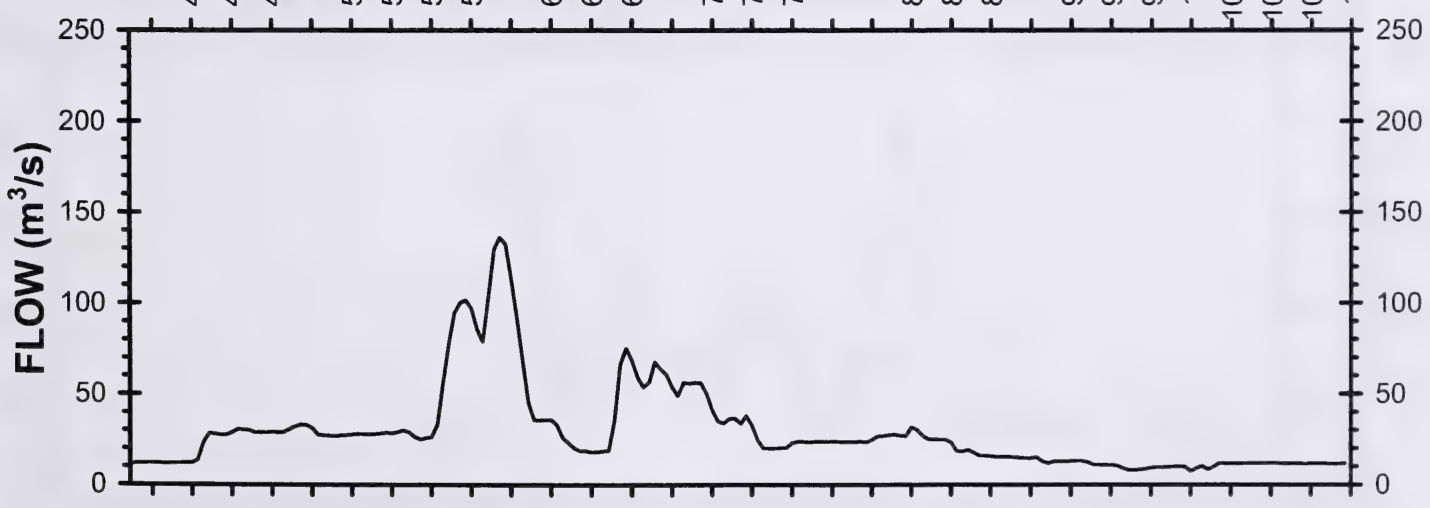

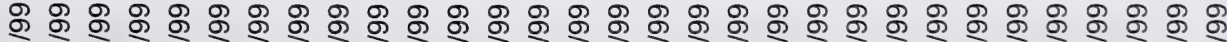

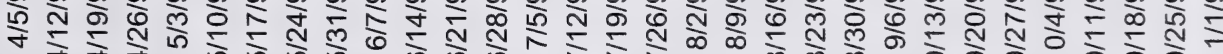

Figure 69. Daily water temperature (Thermograph/Datasonde), air temperature and flow in the Oldman River near Monarch. April-October 1999. 


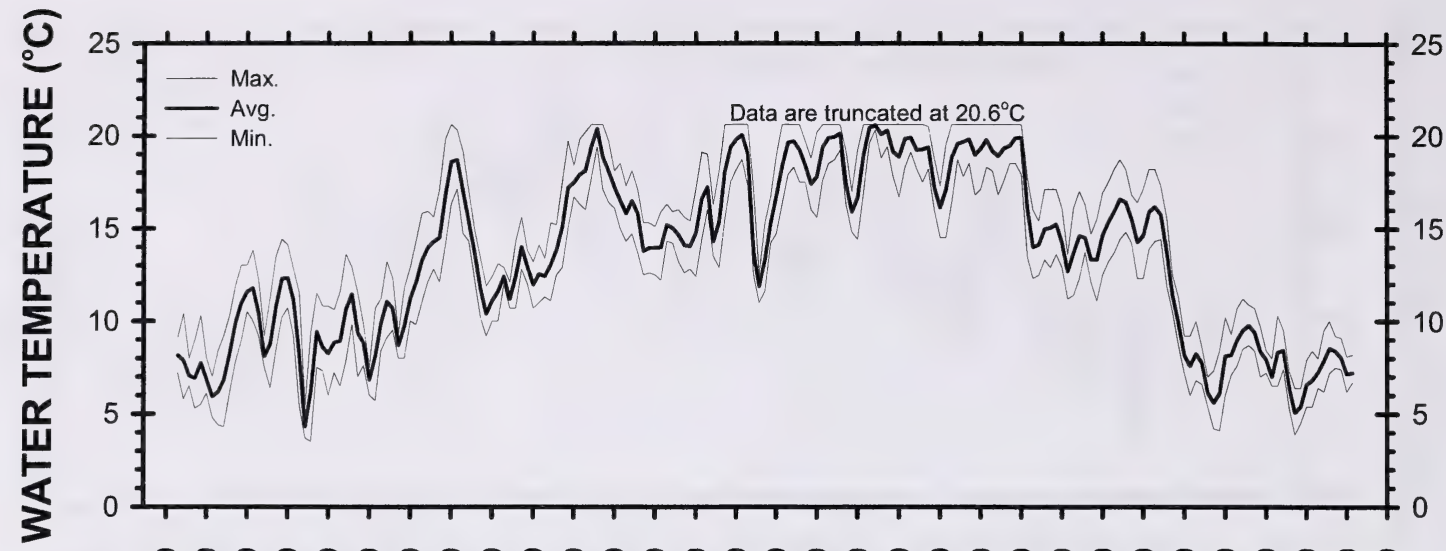

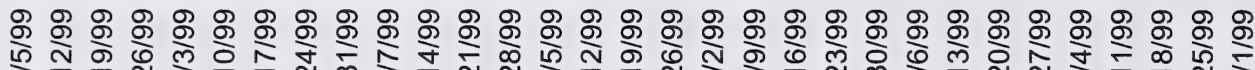

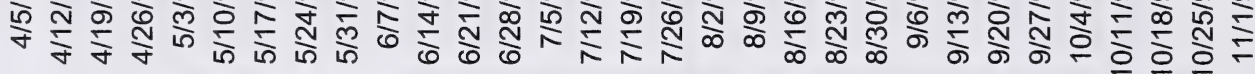

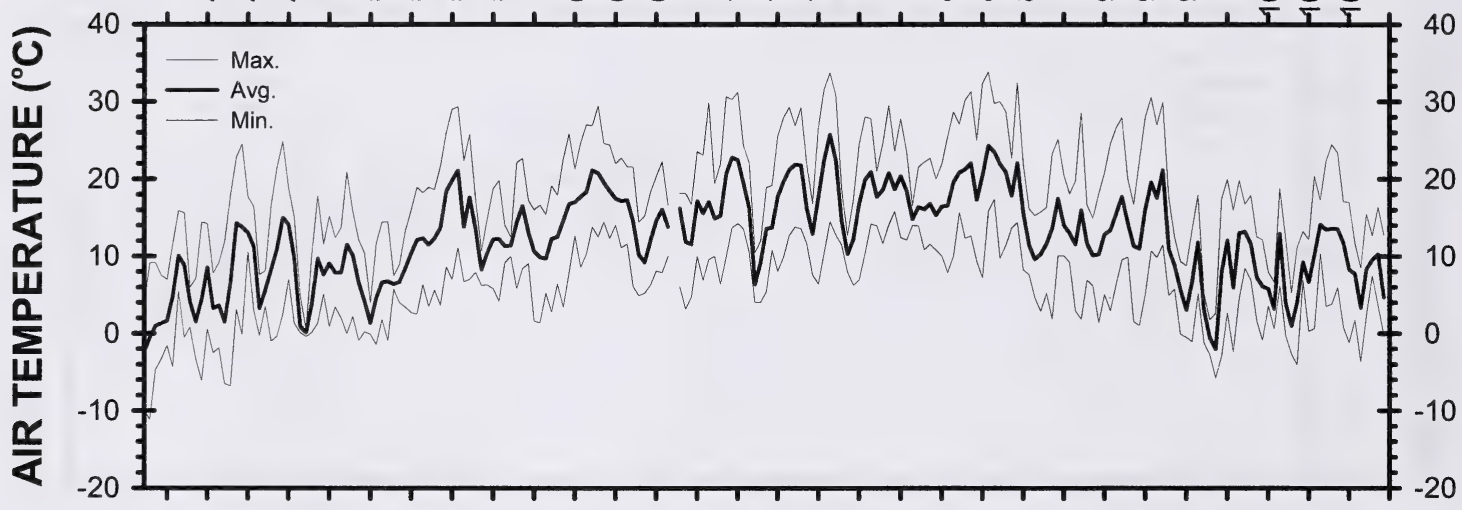

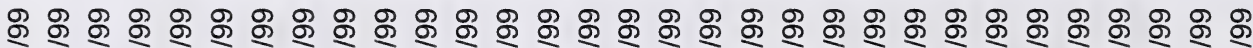

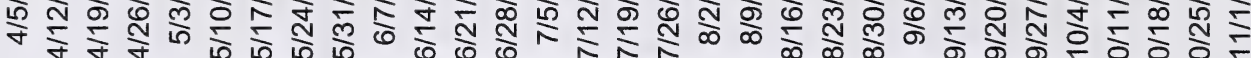

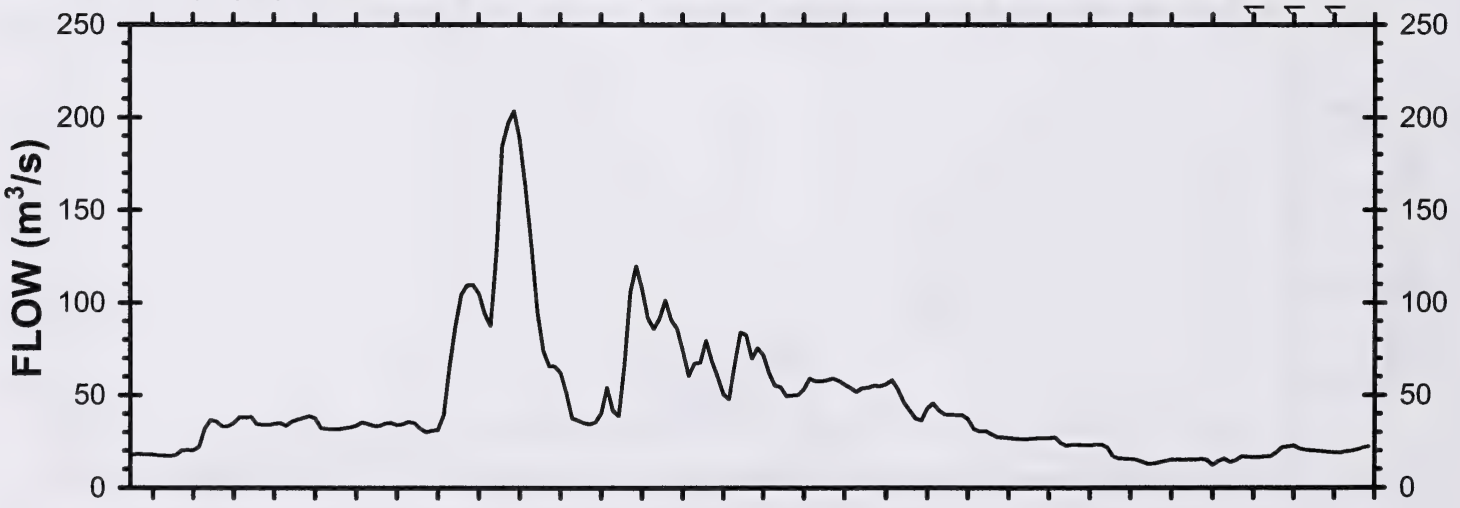

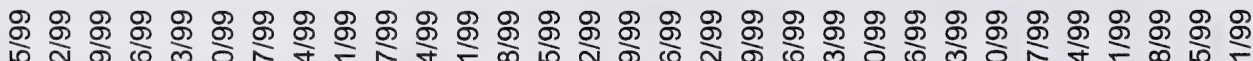

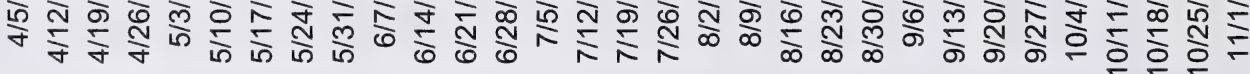

Figure 70. Daily water temperature (Thermograph), air temperature and flow in the Oldman River downstream of the Belly River. April-October 1999. 


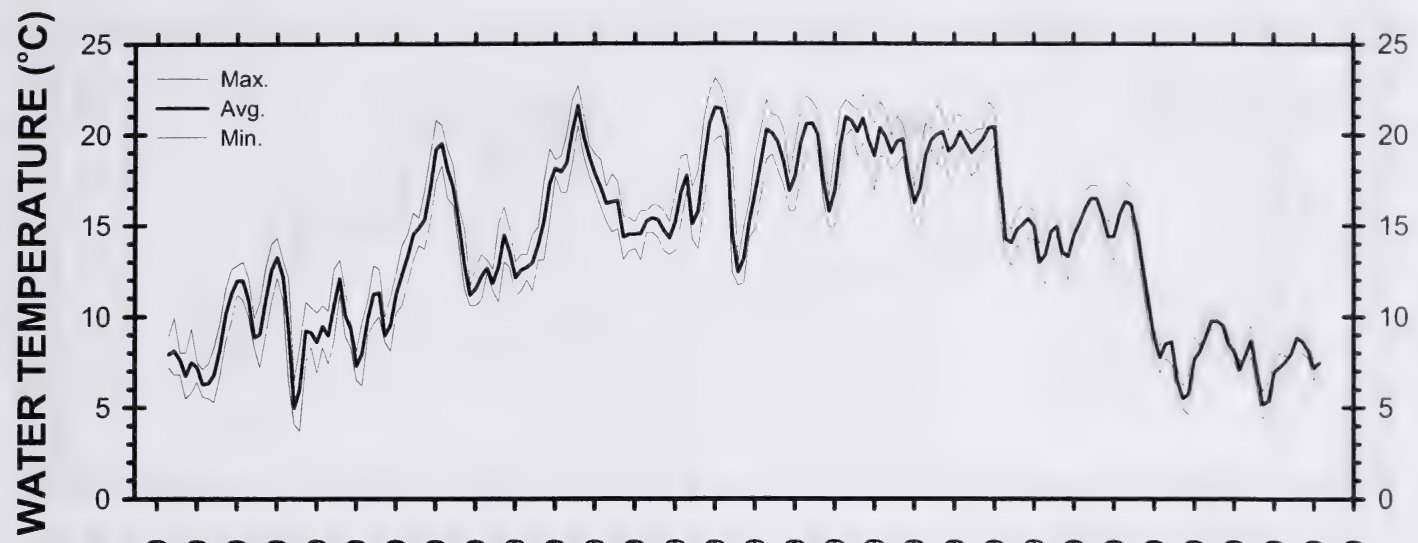

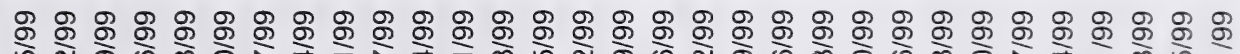

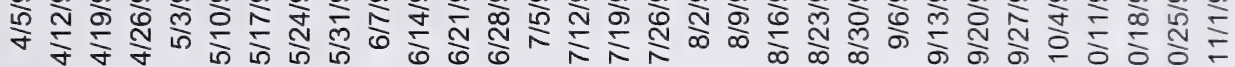

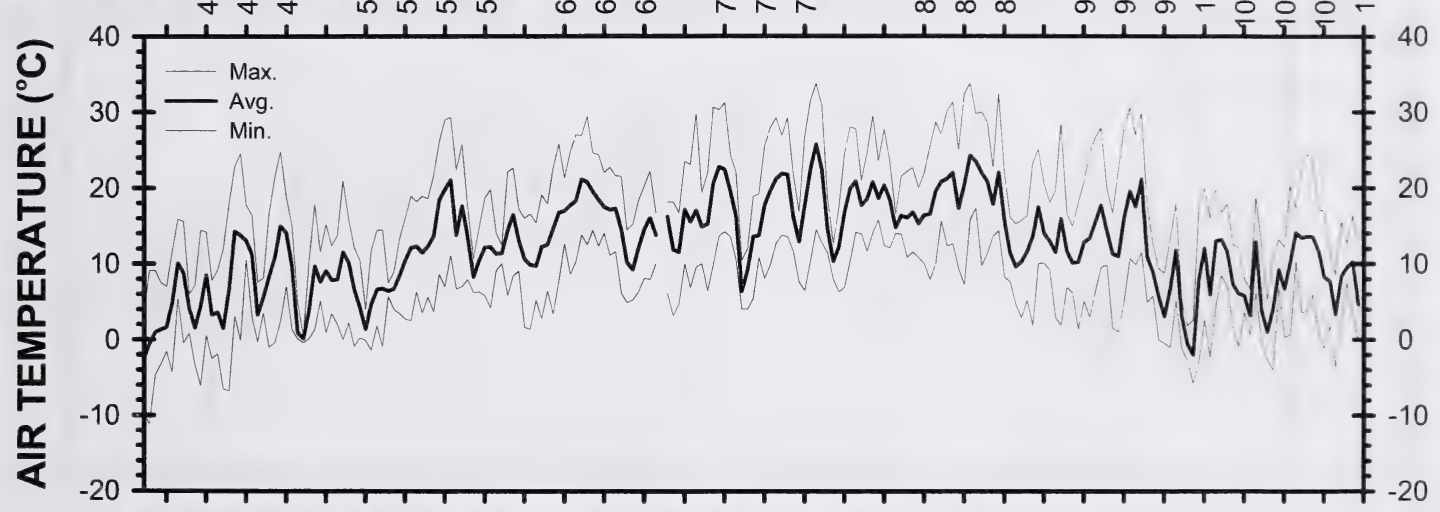

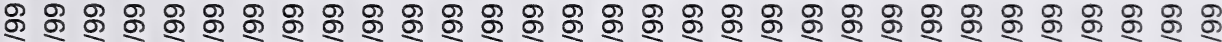

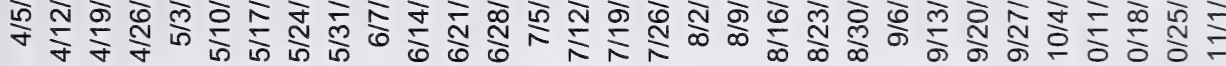

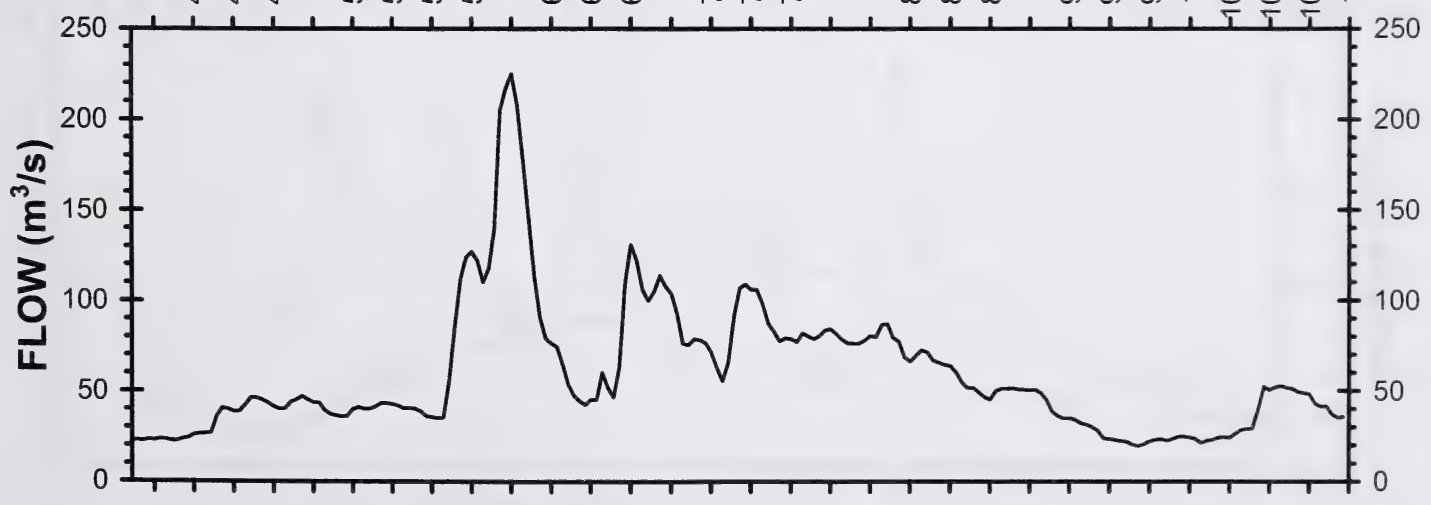

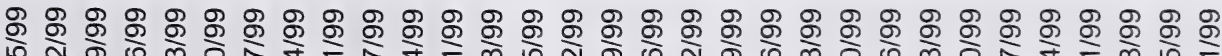

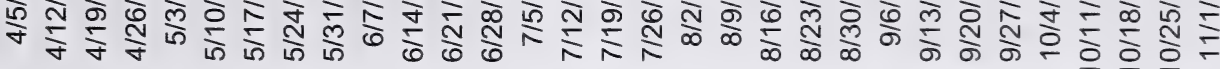

Figure 71. Daily water temperature (Thermograph), air temperature and flow in the Oldman River upstream of Lethbridge. April-October 1999. 


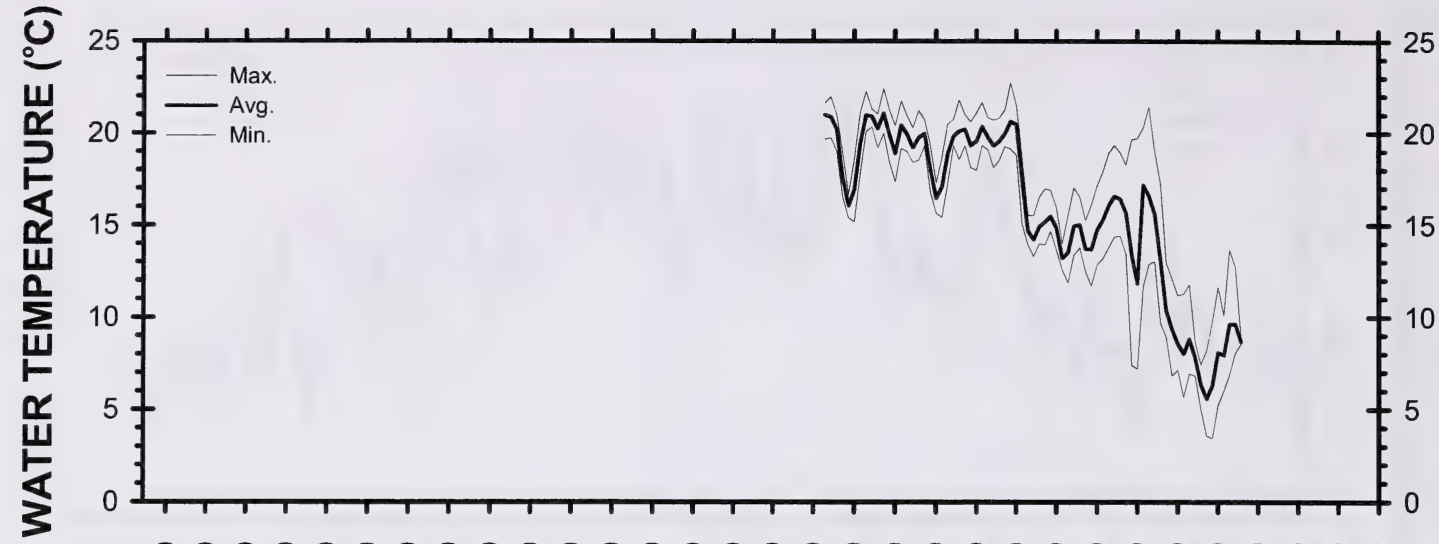

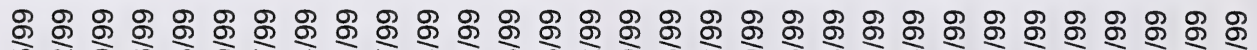

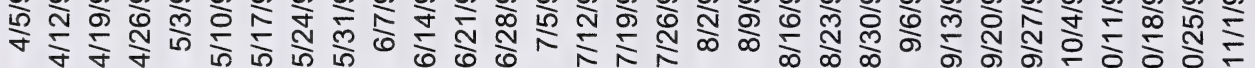

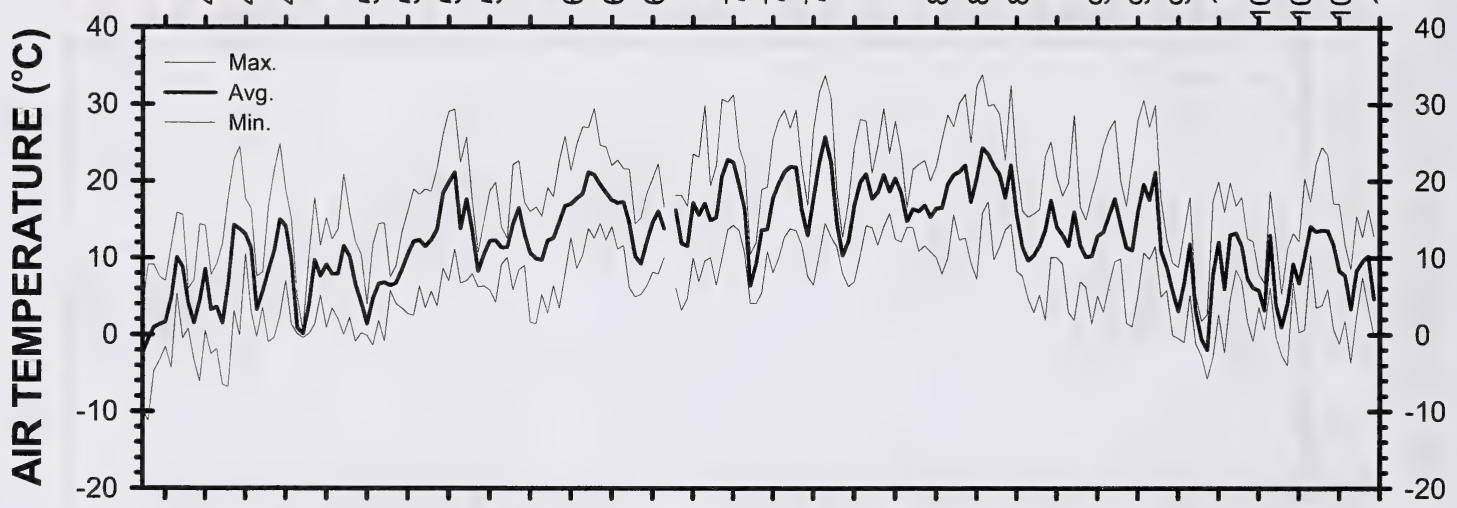

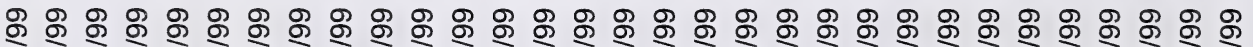

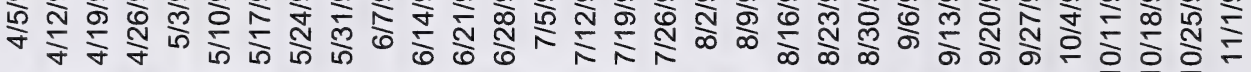

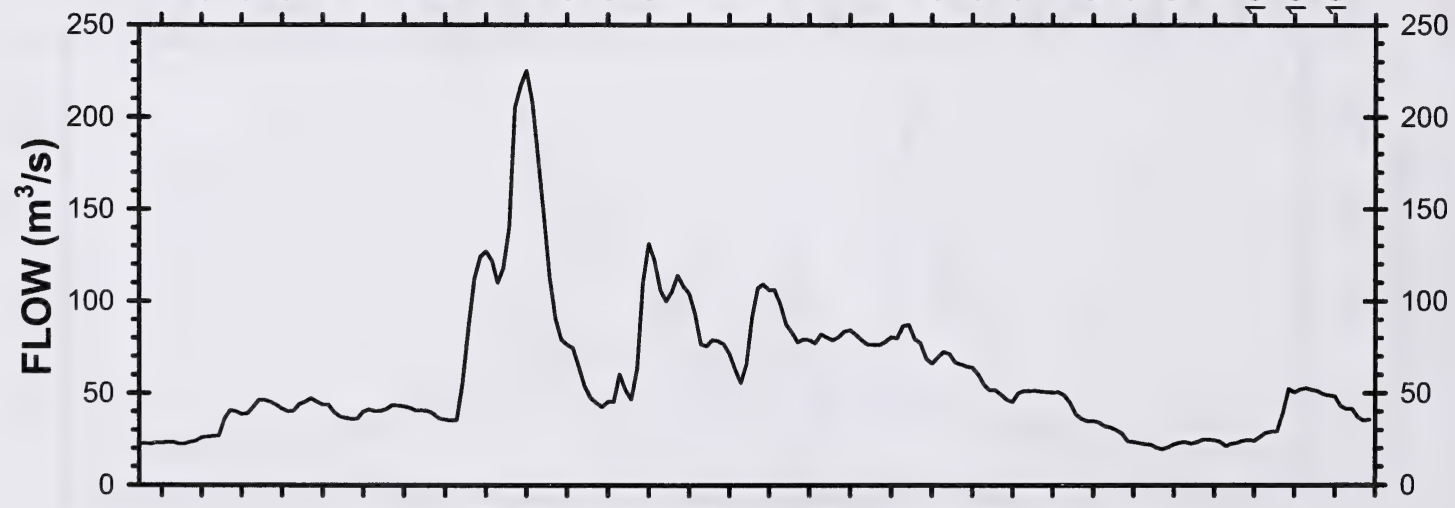

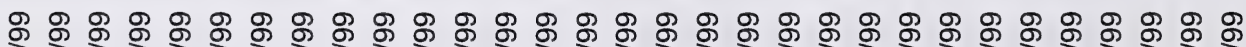
负

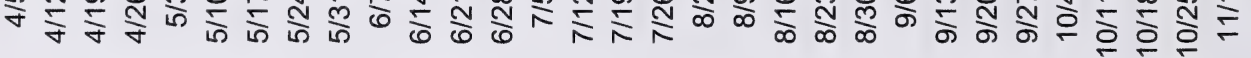

Figure 72. Daily water temperature (Datasonde), air temperature and flow in the Oldman River downstream of Lethbridge. April-October 1999. 


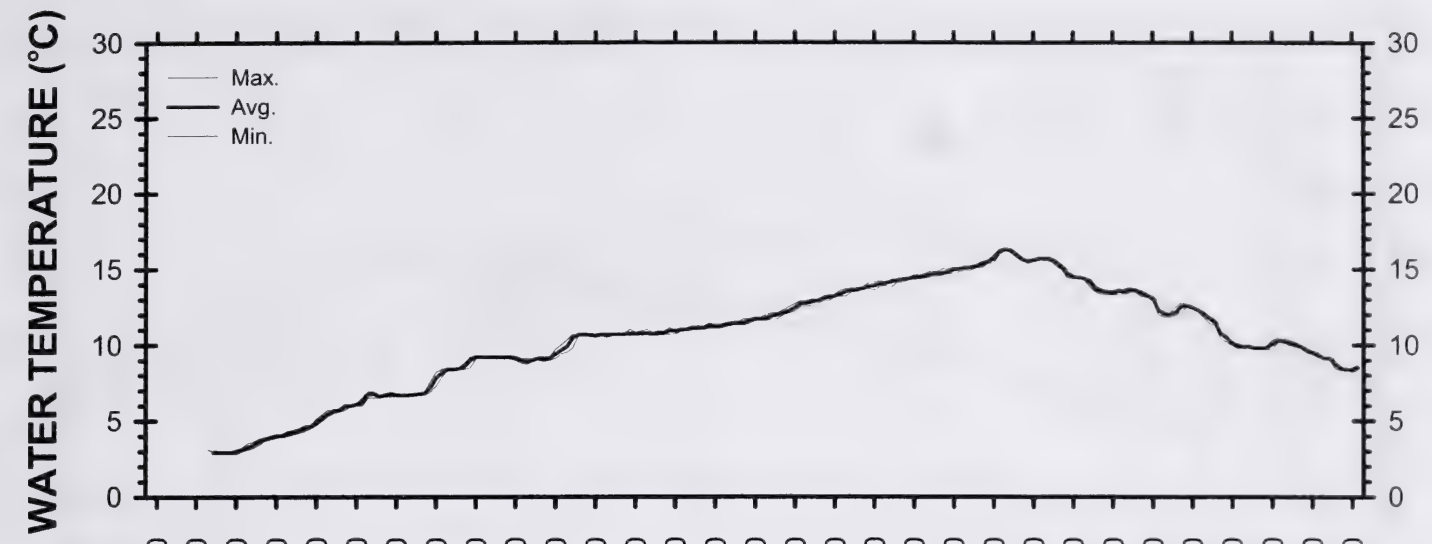

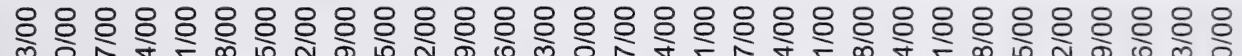

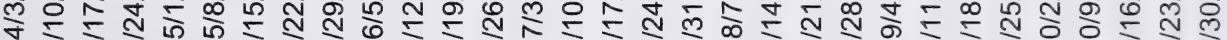

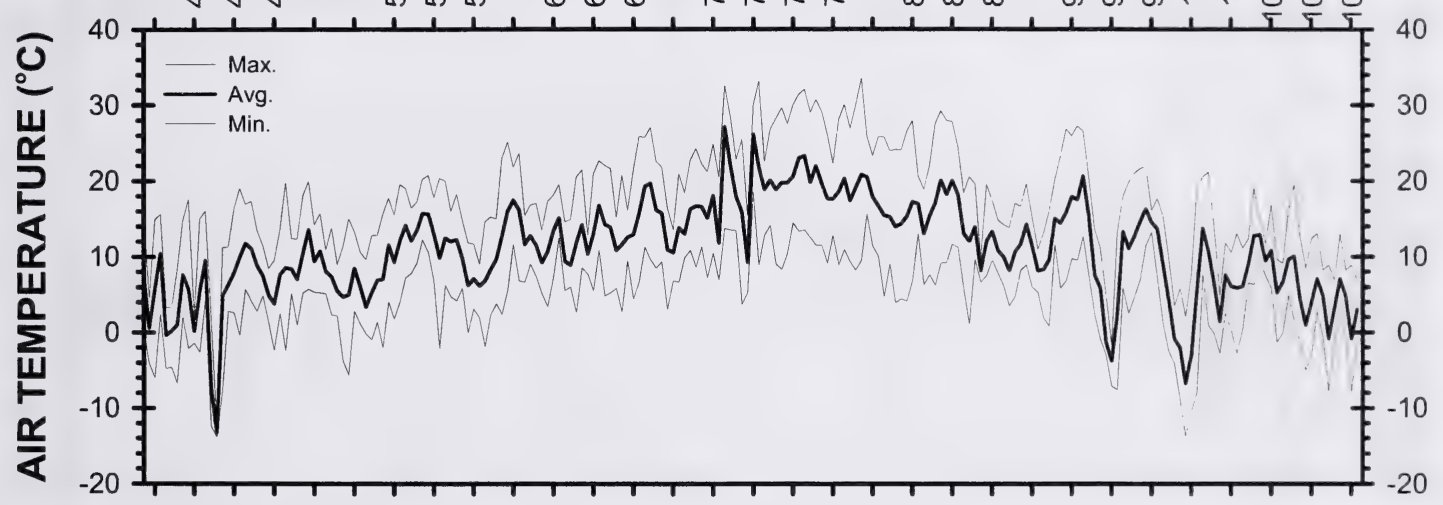

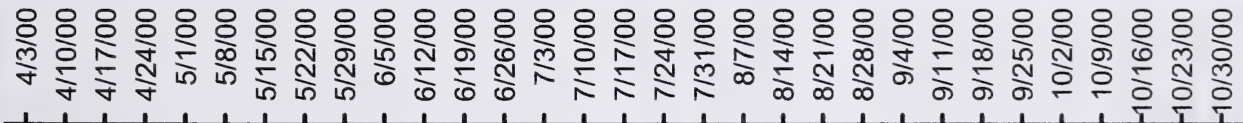

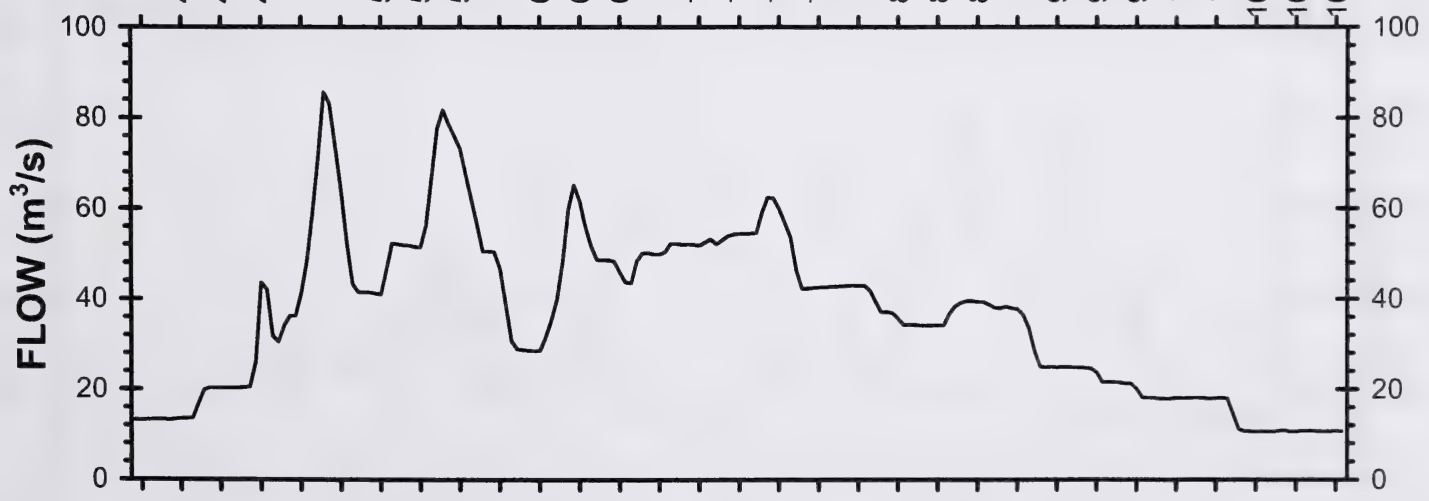

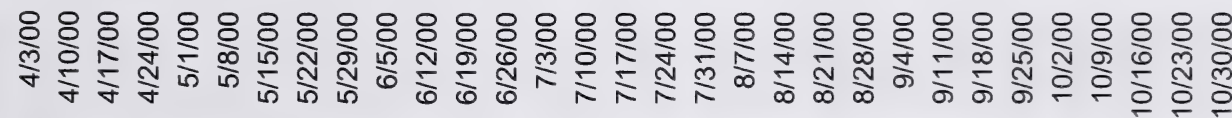

Figure 73. Daily water temperature (Thermograph), air temperature and flow in the Oldman River $100 \mathrm{~m} \mathrm{d/s}$ of the Oldman Reservoir. April-October 2000. 


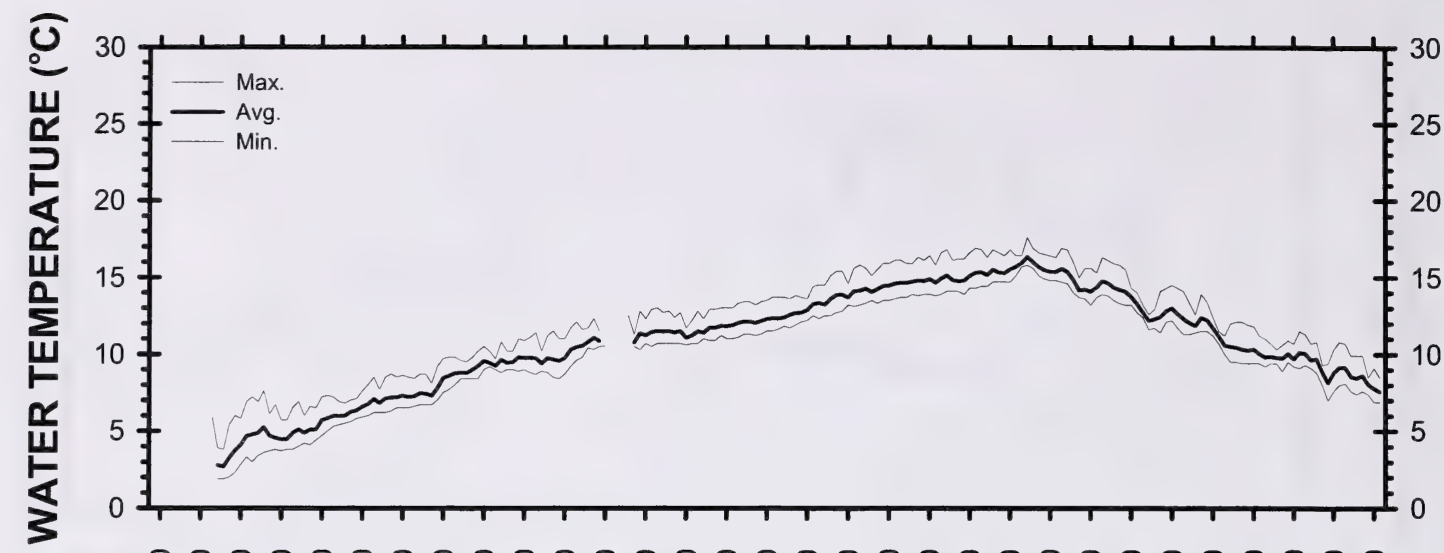

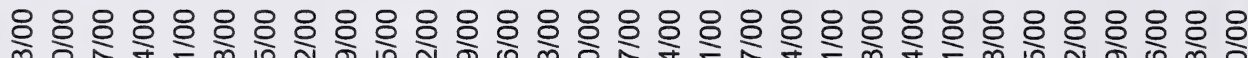

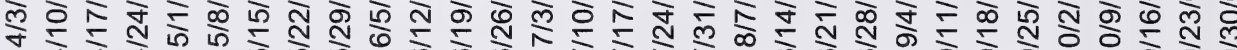

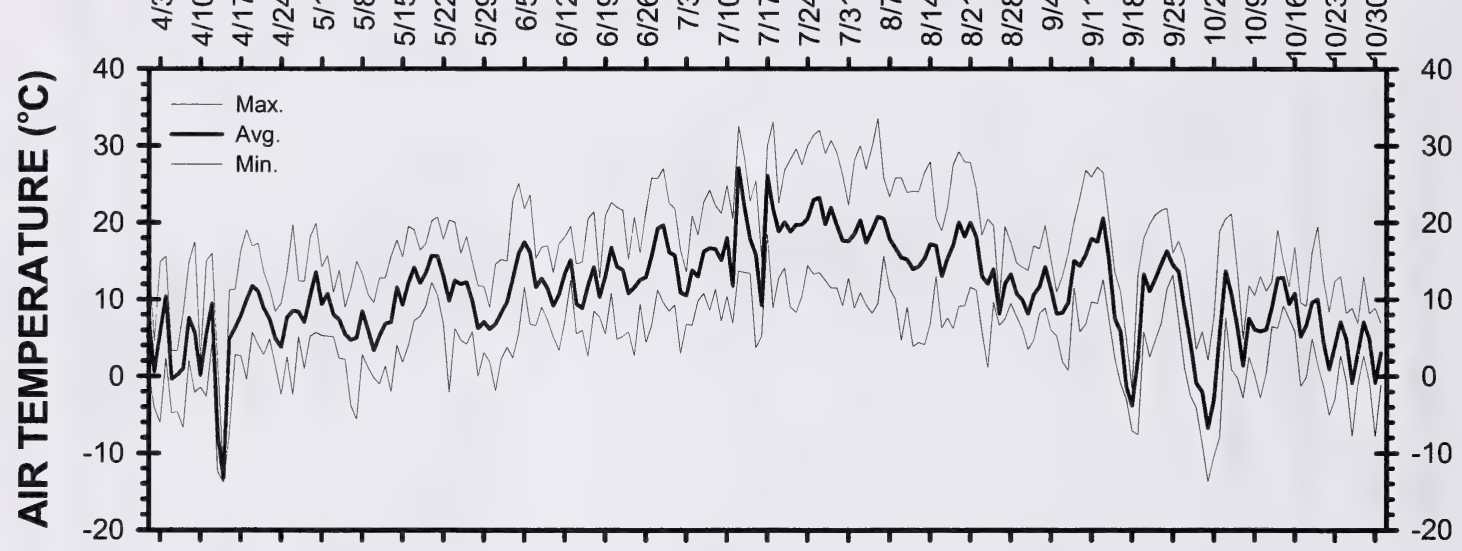

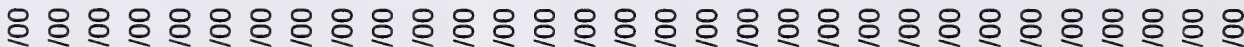

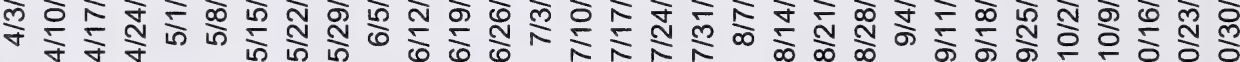

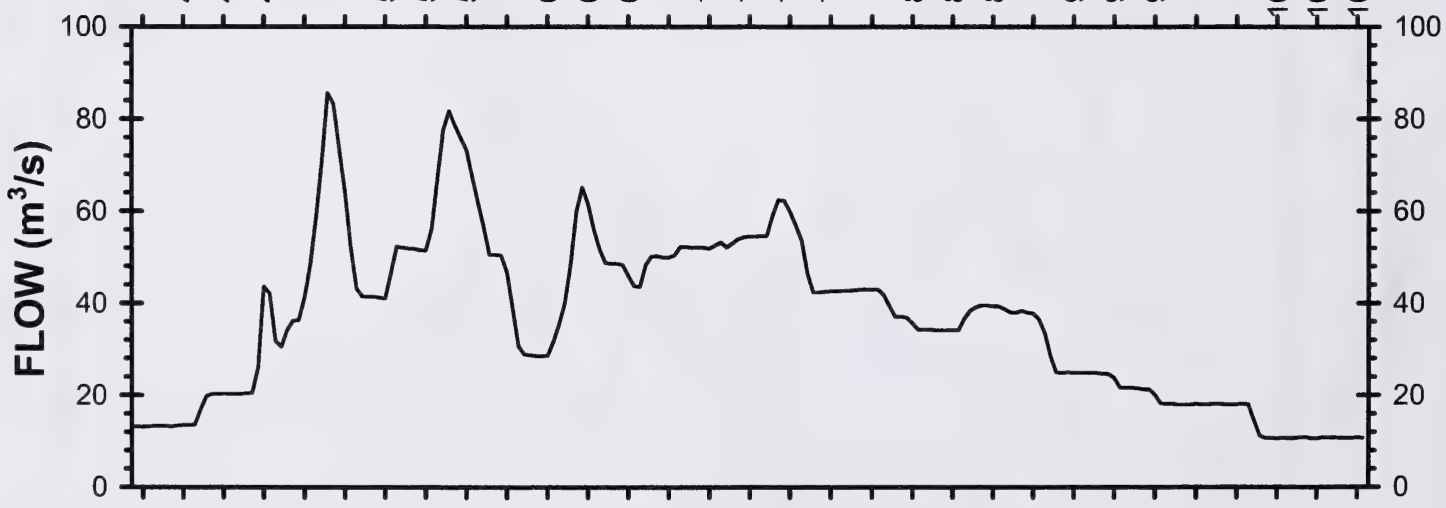

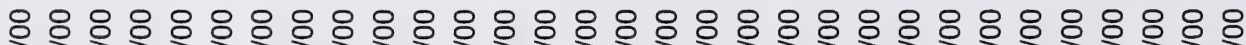

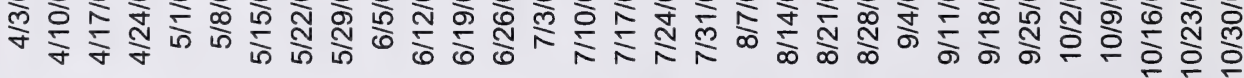

Figure 74. Daily water temperature (Thermograph), air temperature and flow in the Oldman River near Brocket. April-October 2000. 


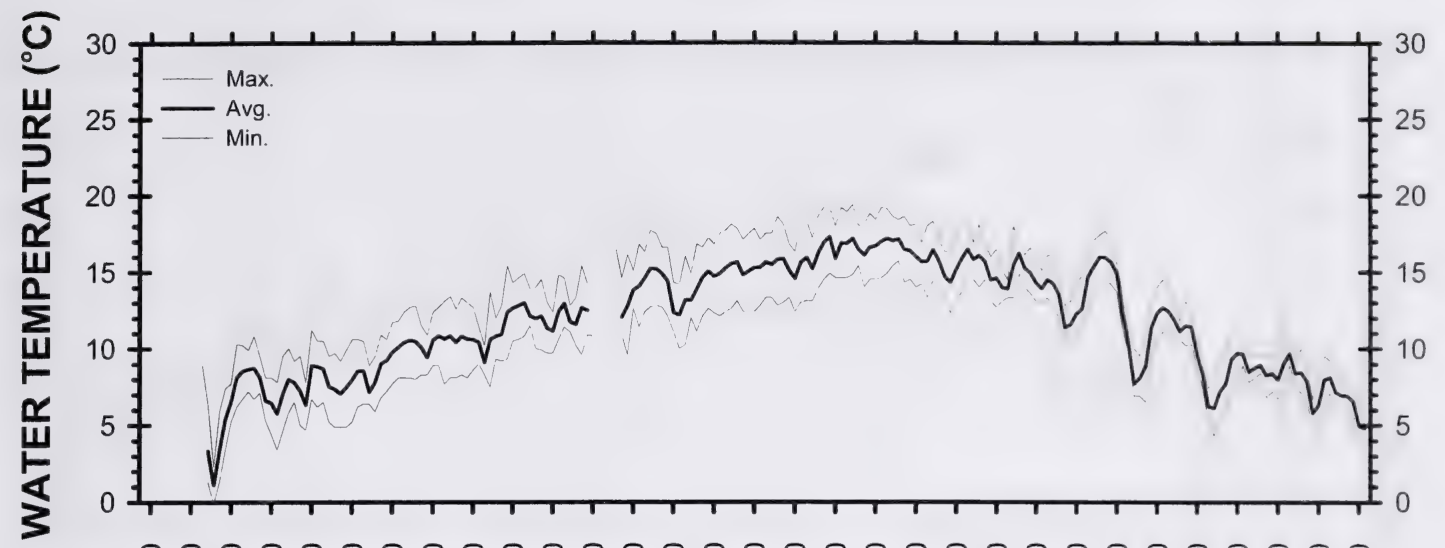

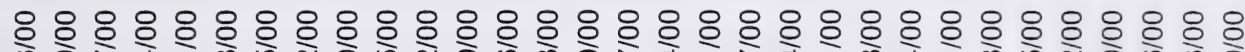

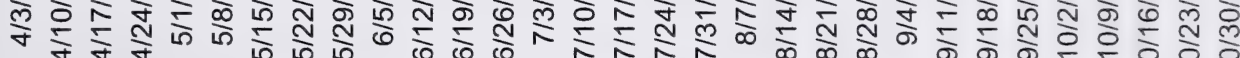

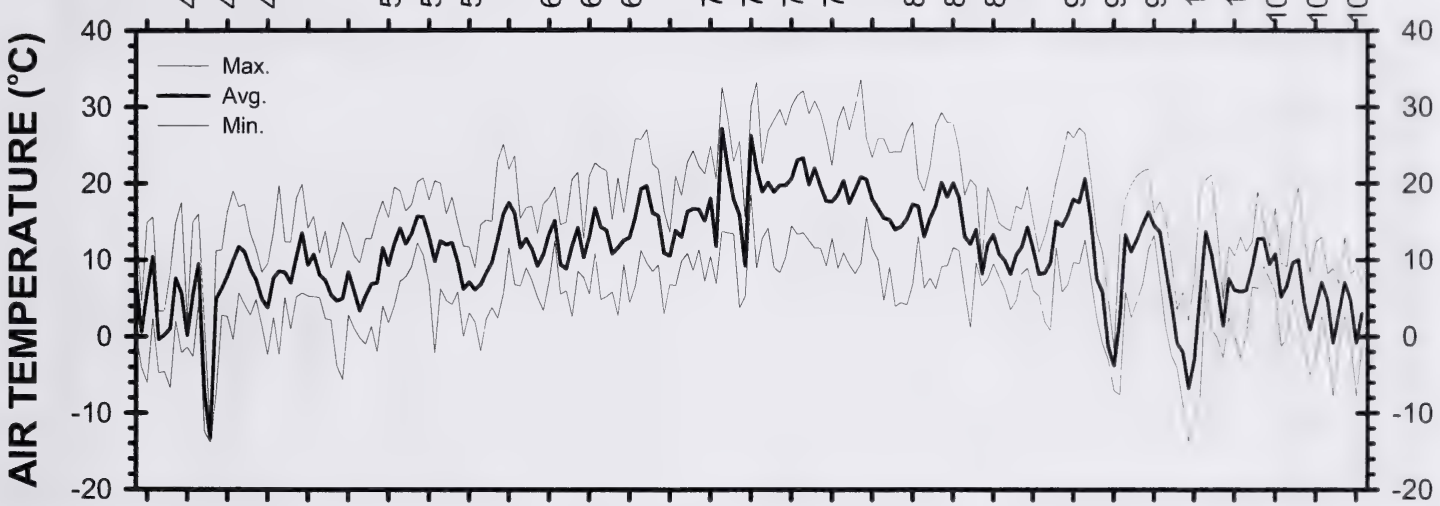

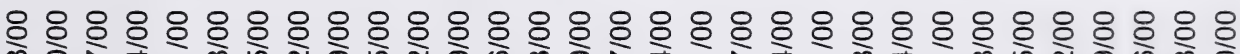

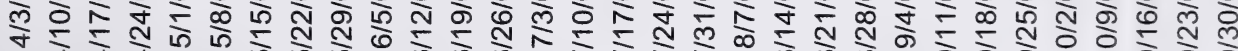

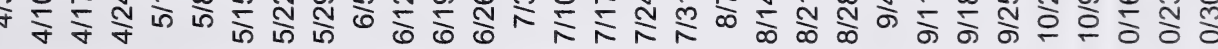

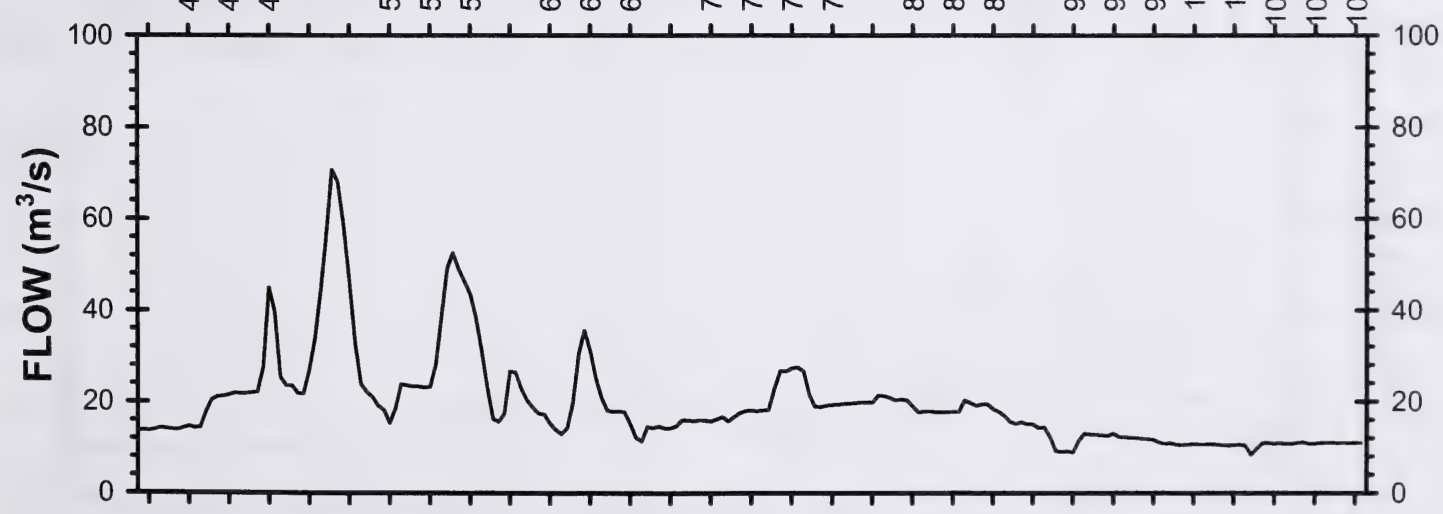

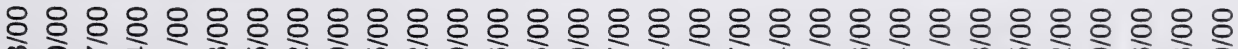

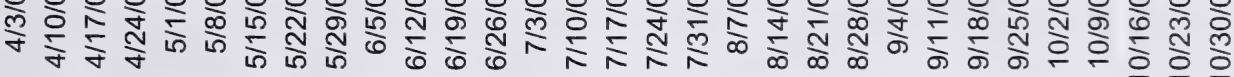

Figure 75. Daily water temperature (Thermograph), air temperature and flow in the Oldman River downstream of the LNHD. April-October 2000. 


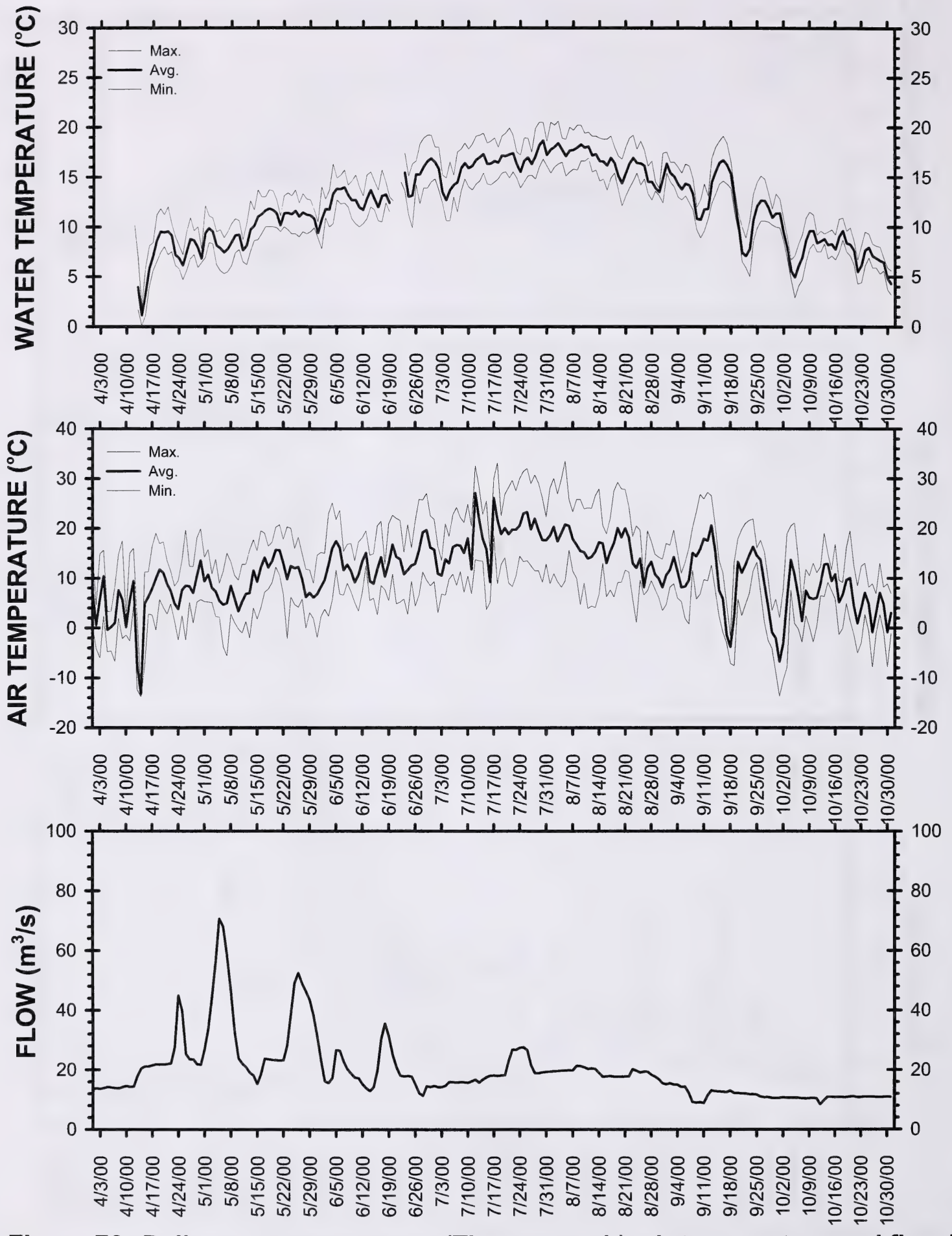

Figure 76. Daily water temperature (Thermograph), air temperature and flow in the Oldman River near Fort Macleod. April-October 2000. 


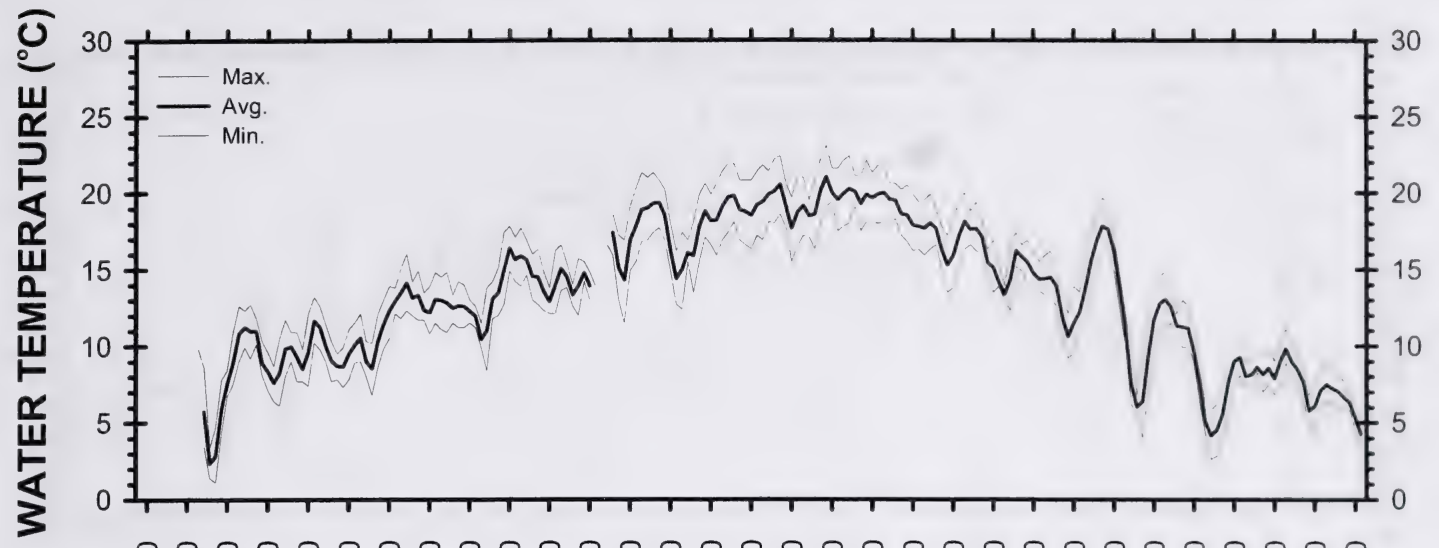

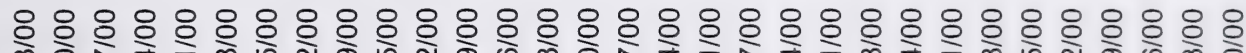

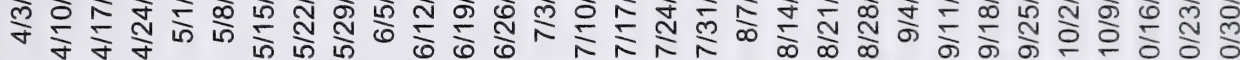

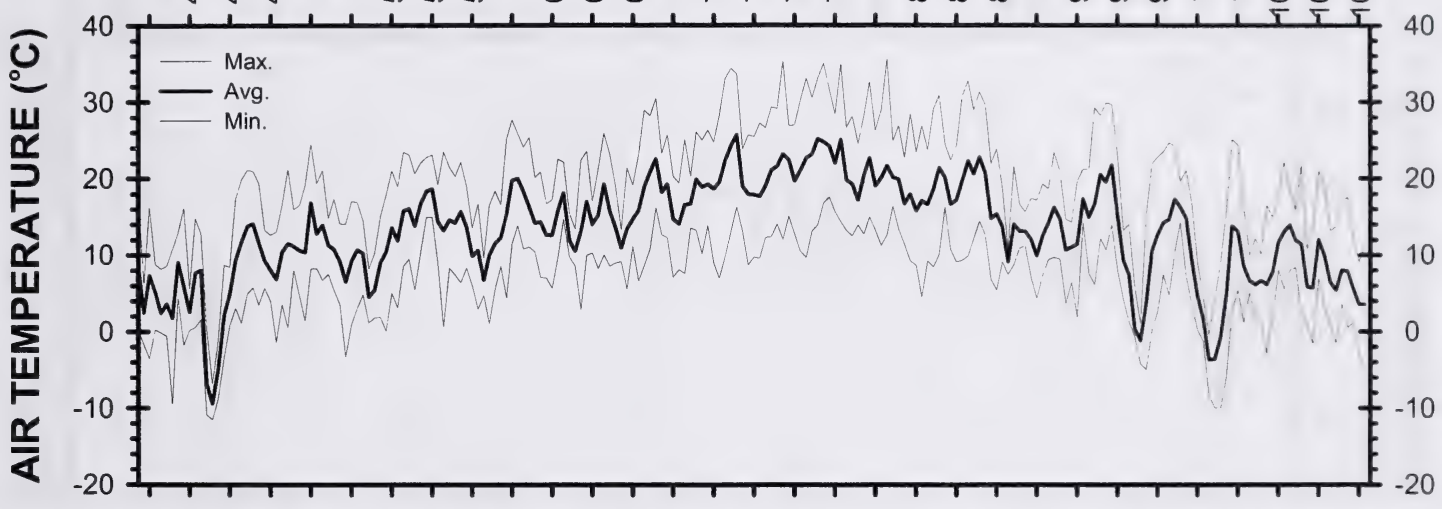

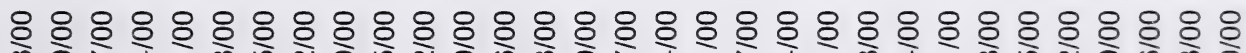

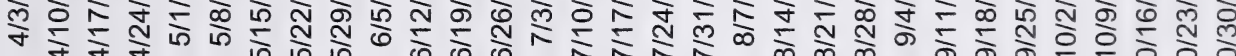

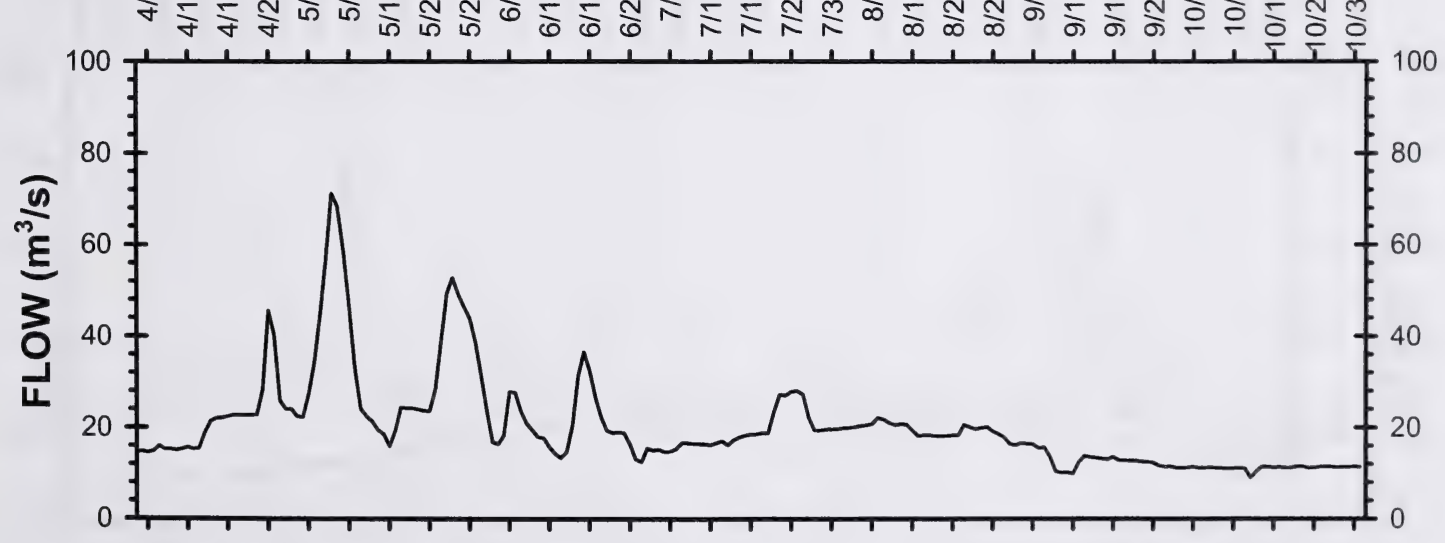

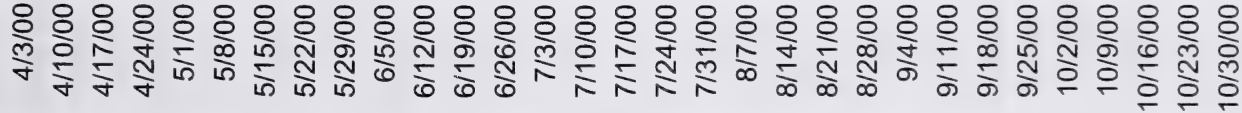

Figure 77. Daily water temperature (Thermograph), air temperature and flow in the Oldman River near Rocky Coulee. April-October 2000. 


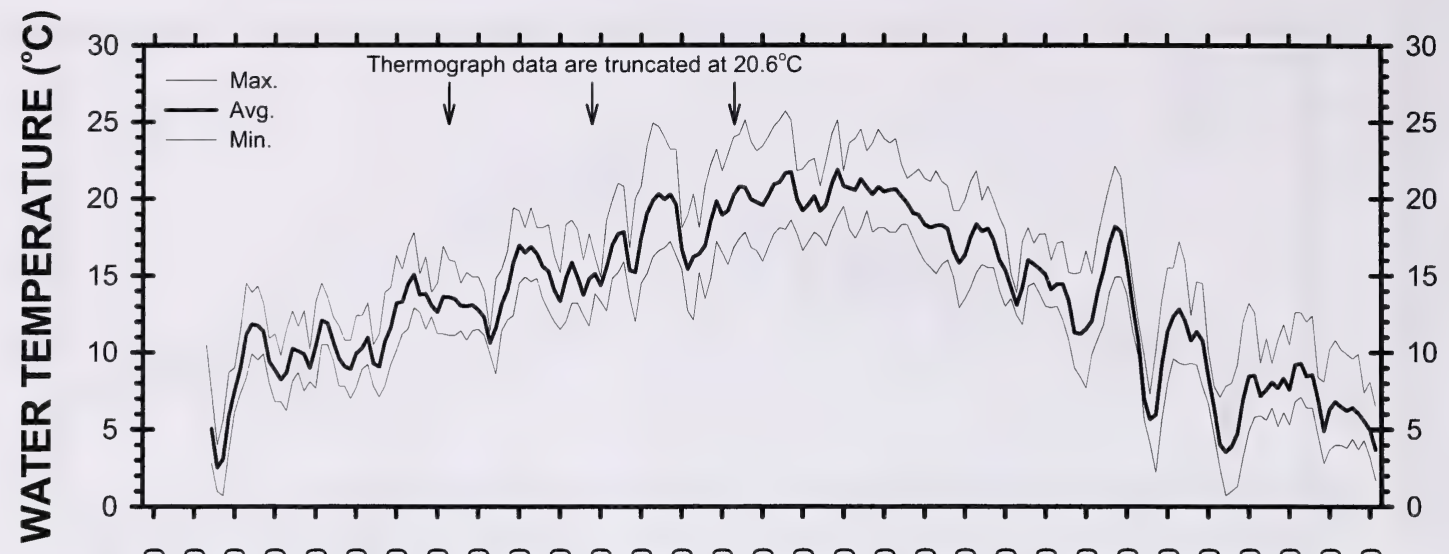

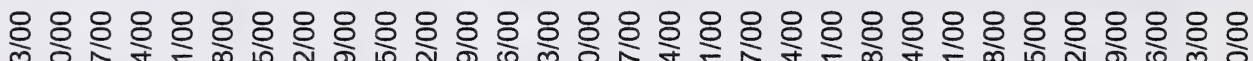

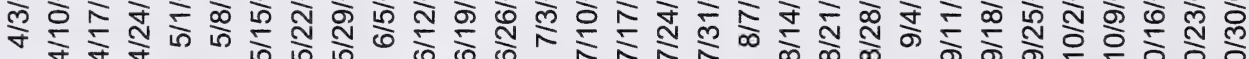

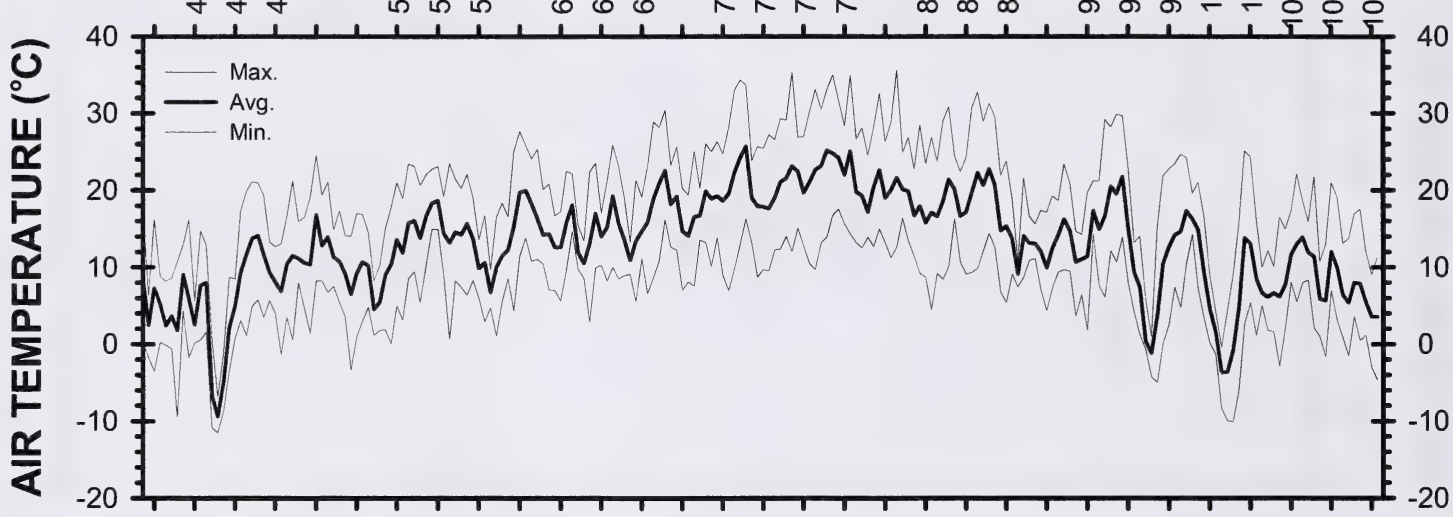

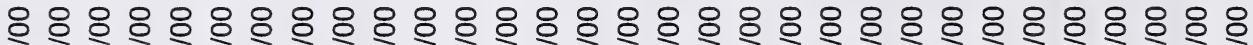

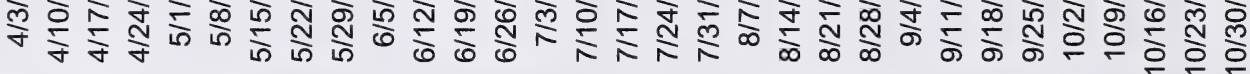

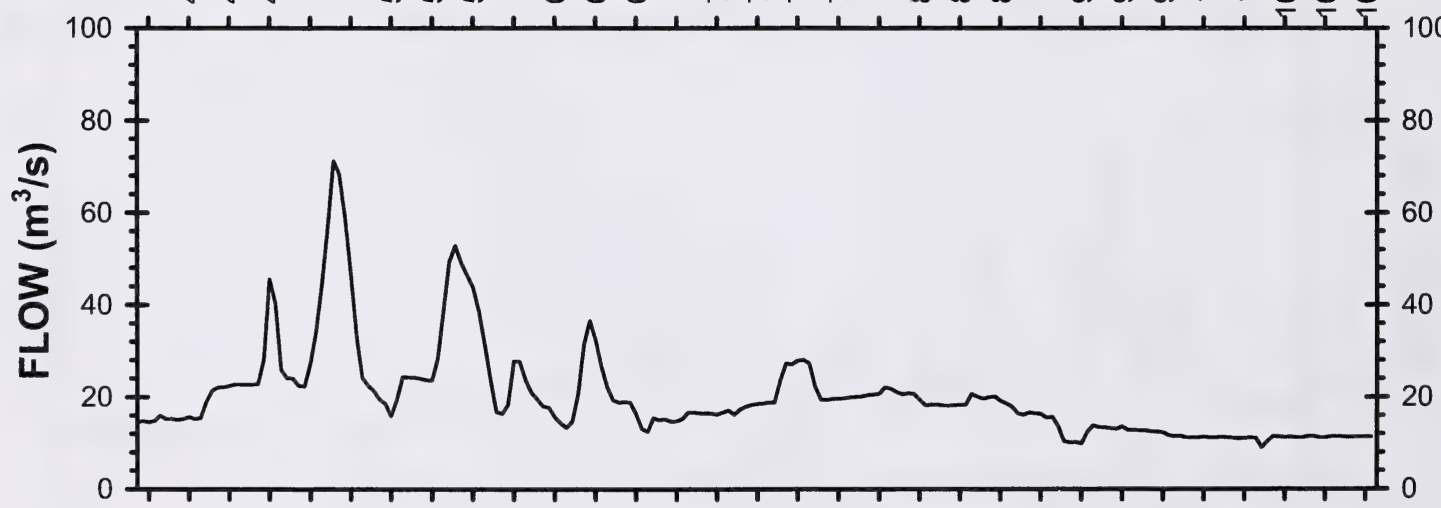

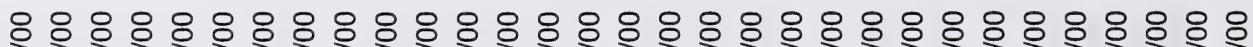

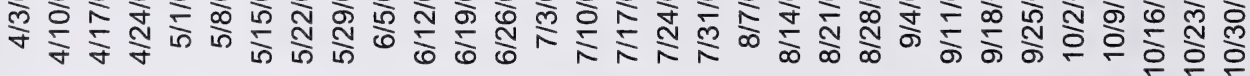

Figure 78. Daily water temperature (Thermograph/Datasonde), air temperature and flow in the Oldman River near Monarch. April-October 2000. 


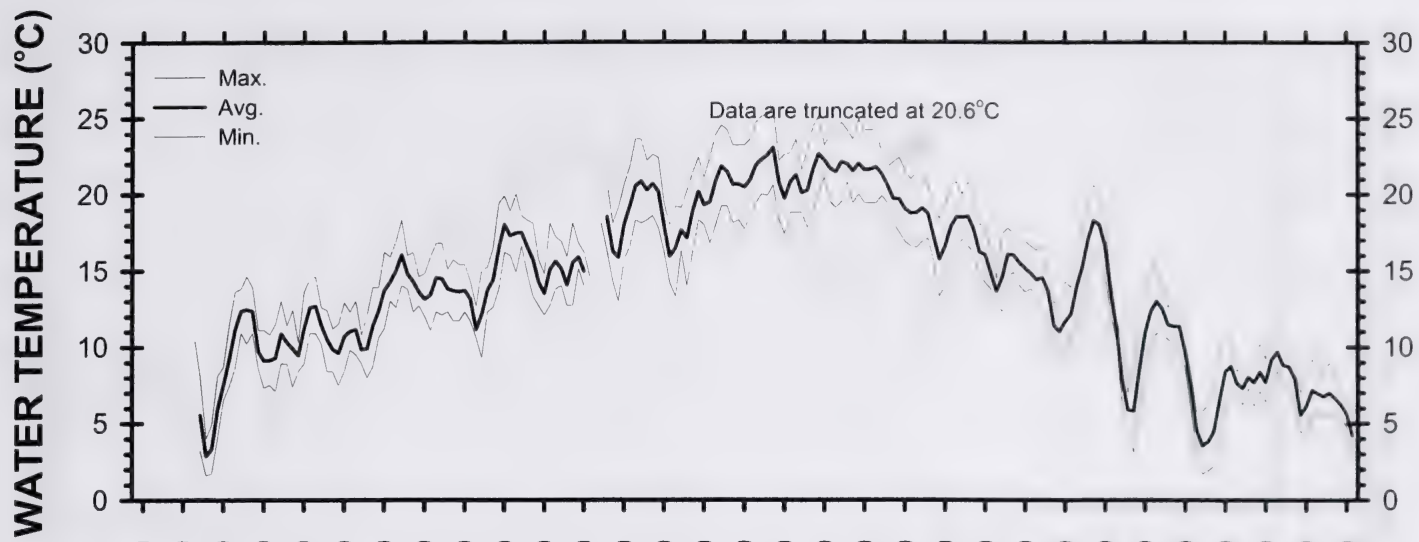

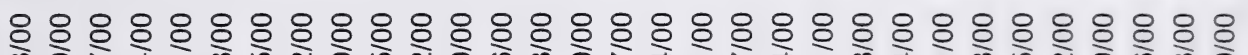

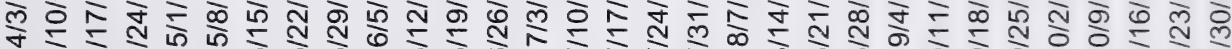

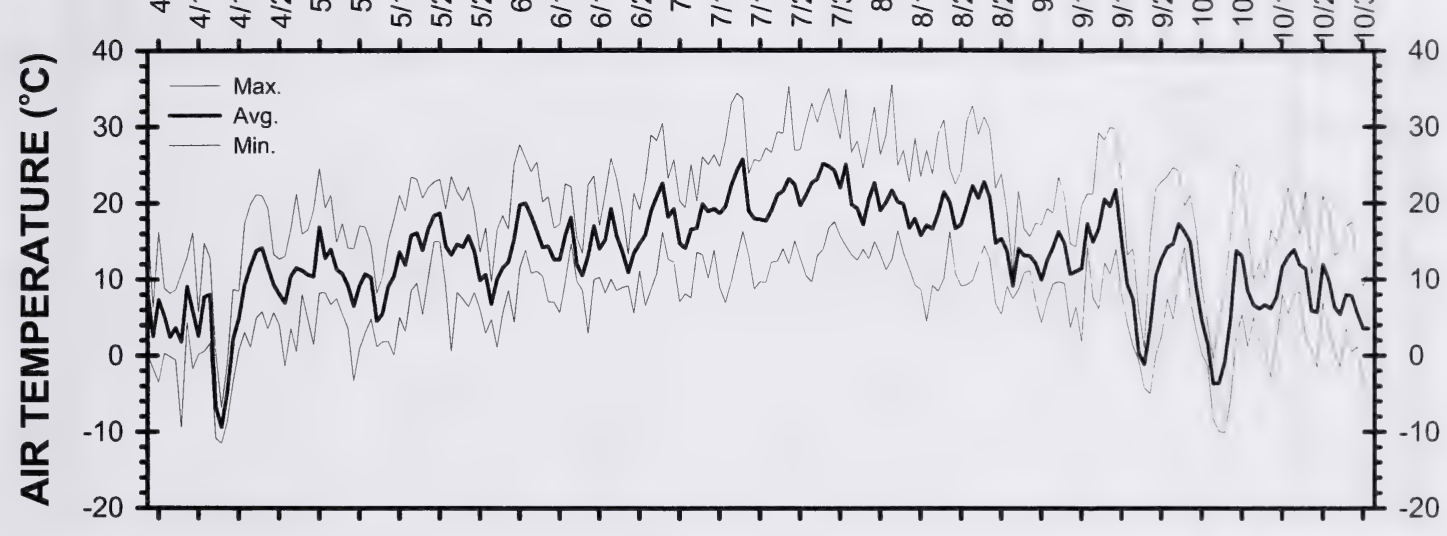

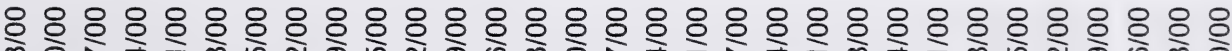

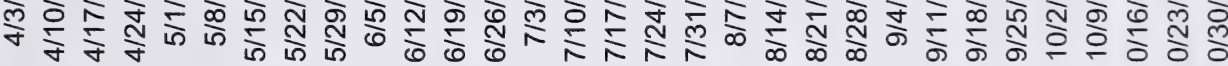

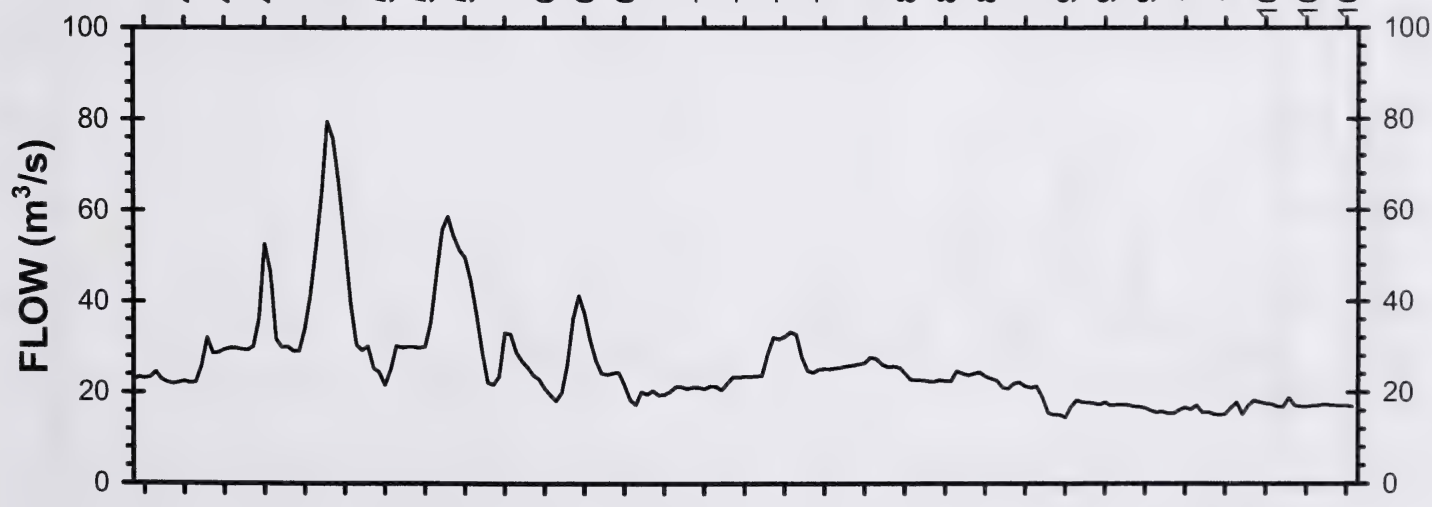

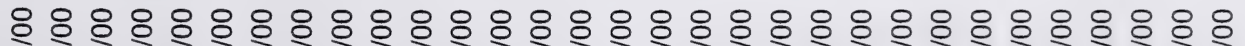

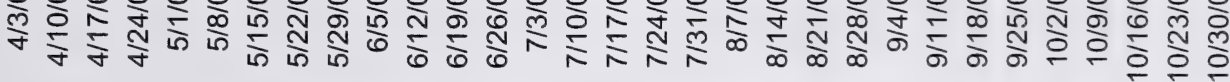

Figure 79. Daily water temperature (Thermograph), air temperature and flow in the Oldman River downstream of the Belly River. April-October 2000. 


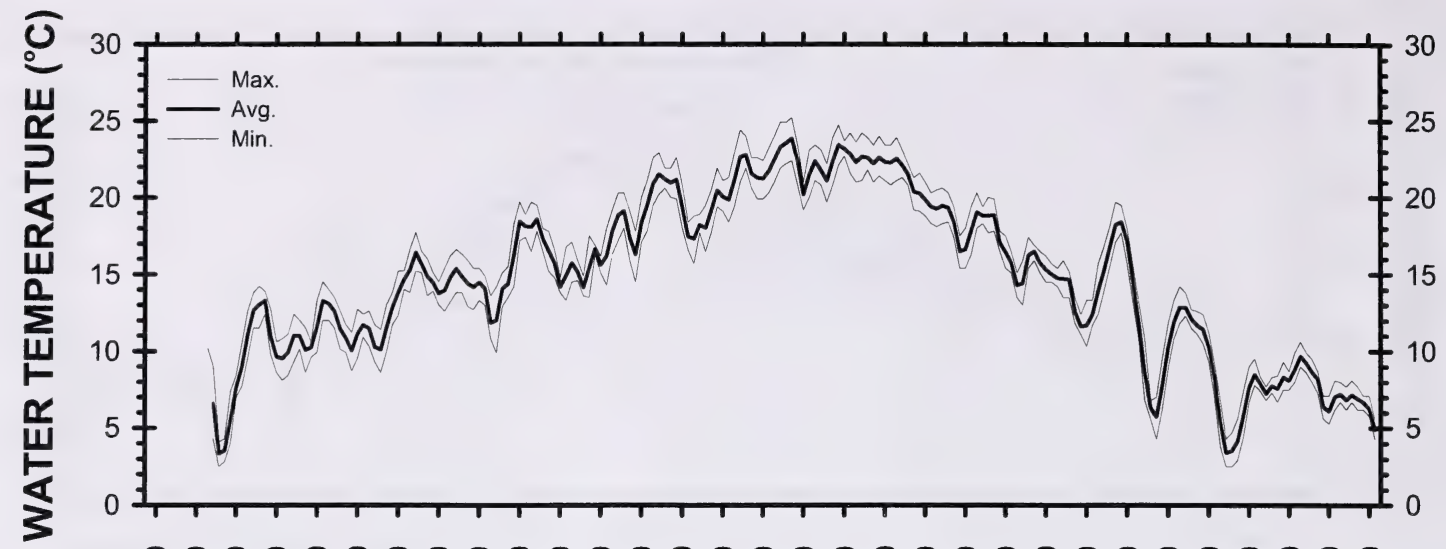

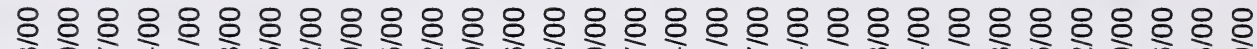

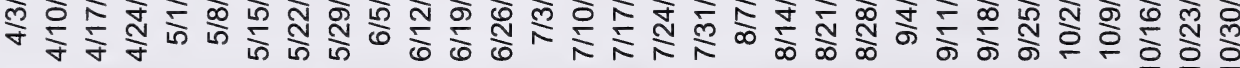

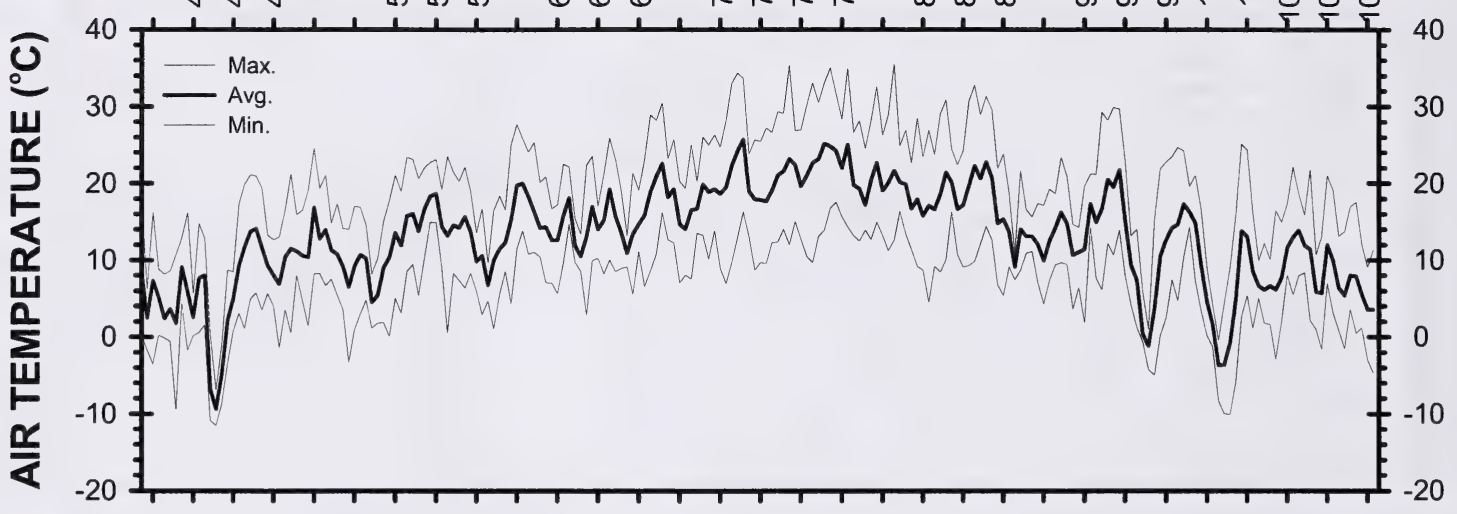

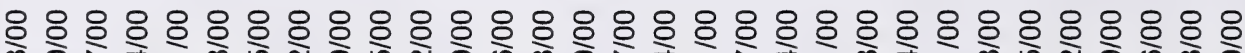

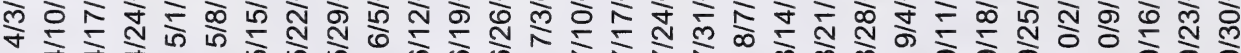

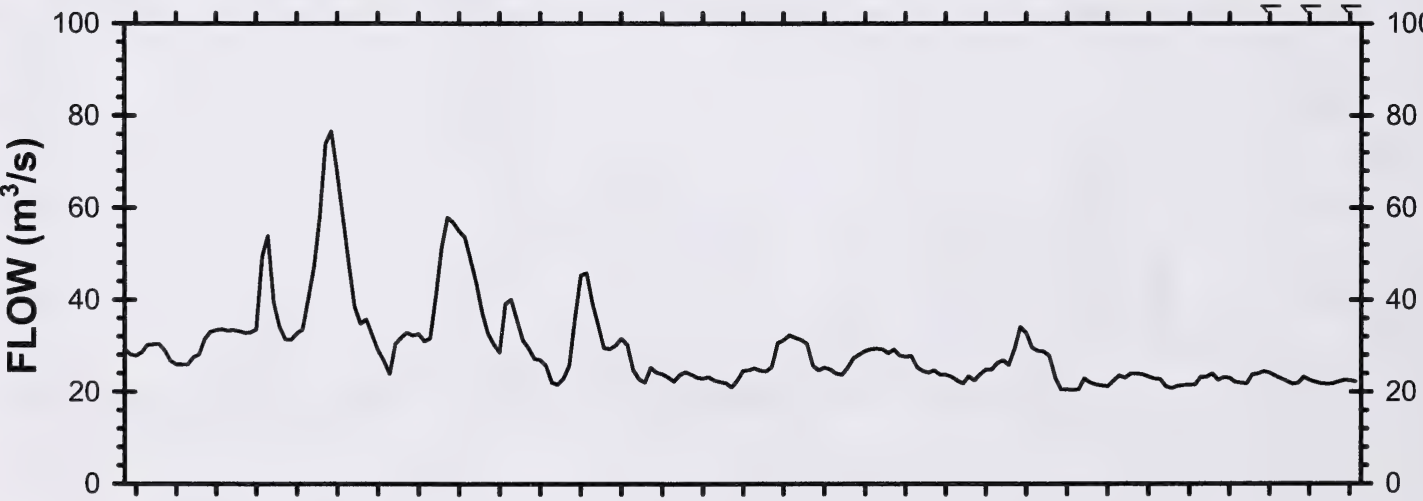

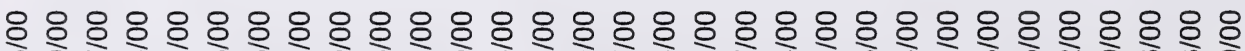

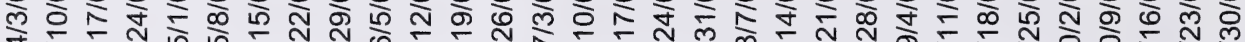

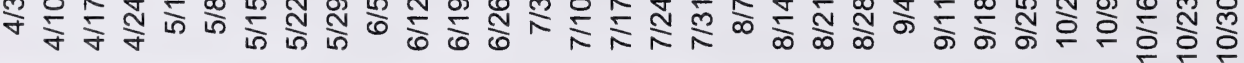

Figure 80. Daily water temperature (Thermograph), air temperature and flow in the Oldman River upstream of Lethbridge. April-October 2000. 


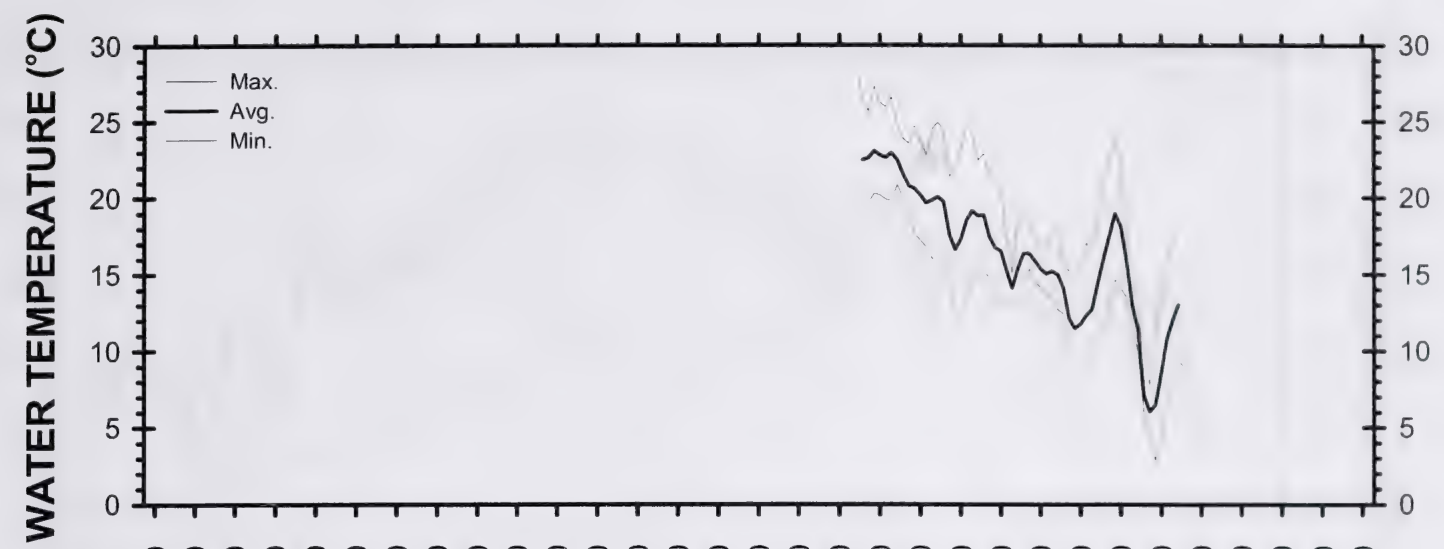

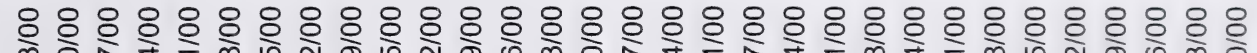

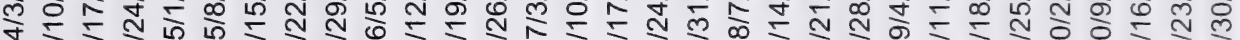

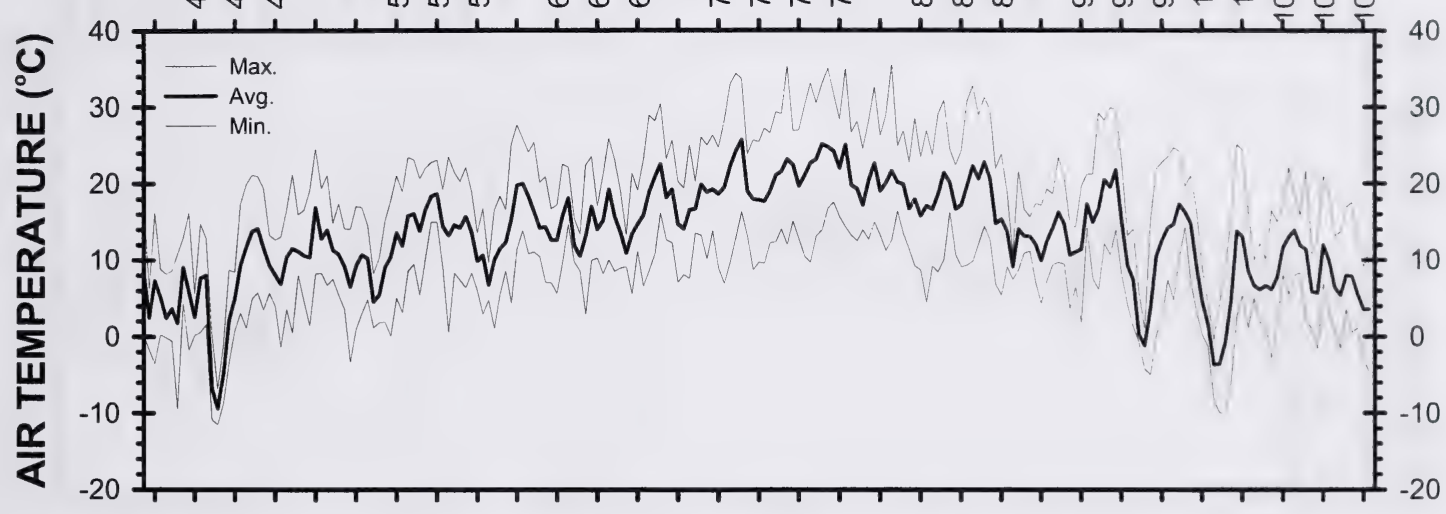

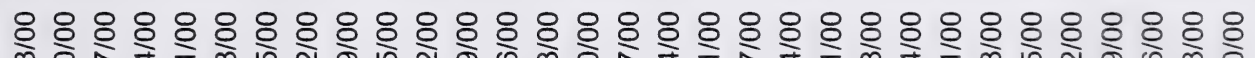

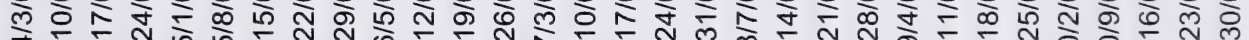

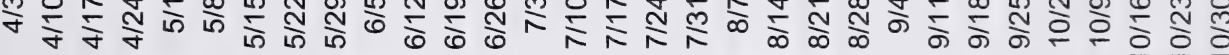

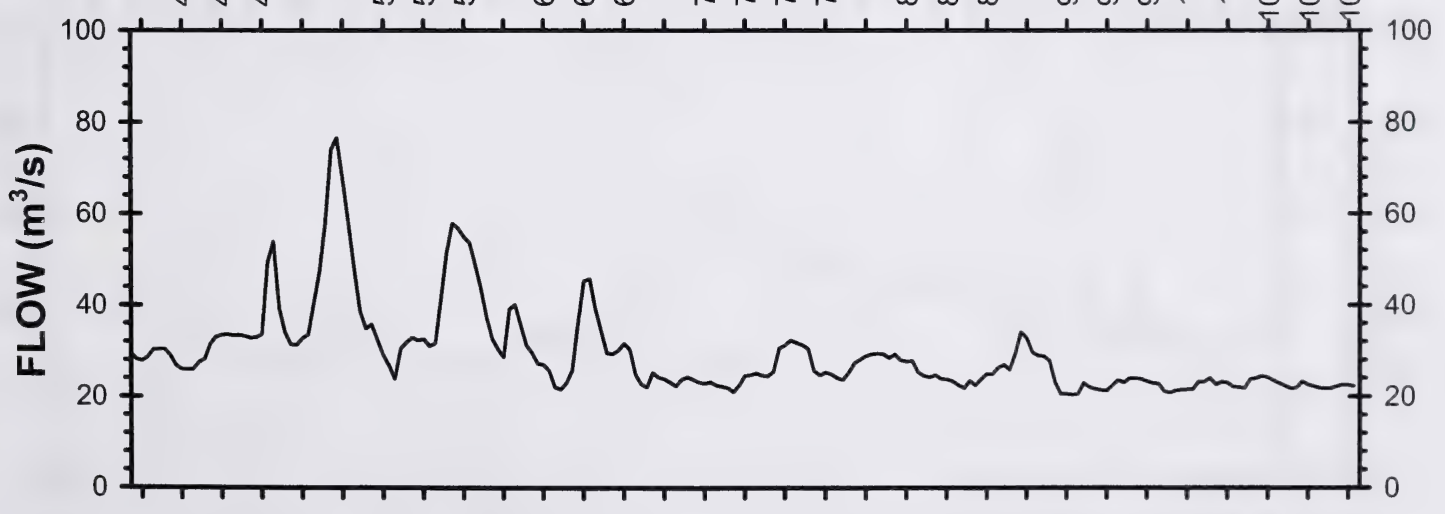

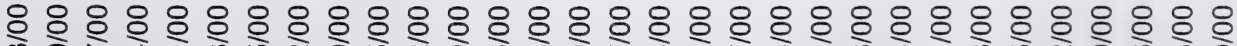

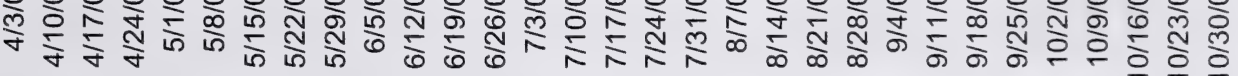

Figure 81. Daily water temperature (Datasonde), air temperature and flow in the Oldman River downstream of Lethbridge. April-October 2000. 


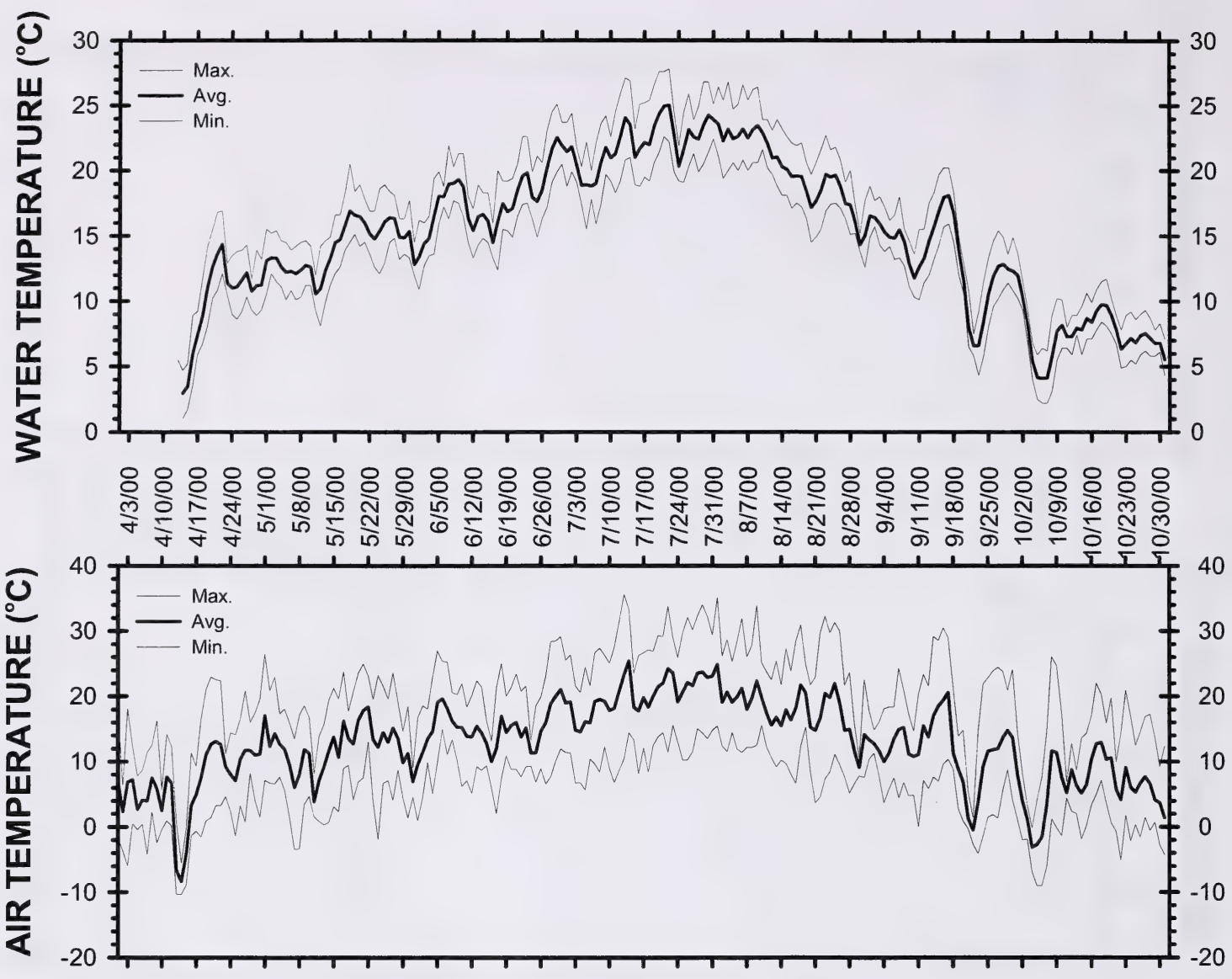

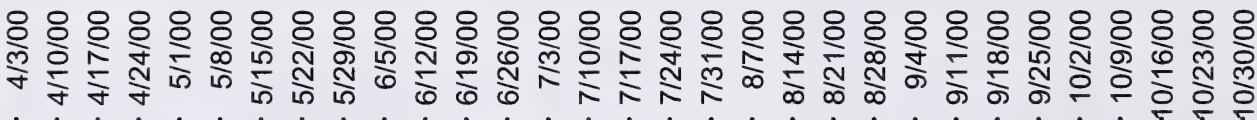

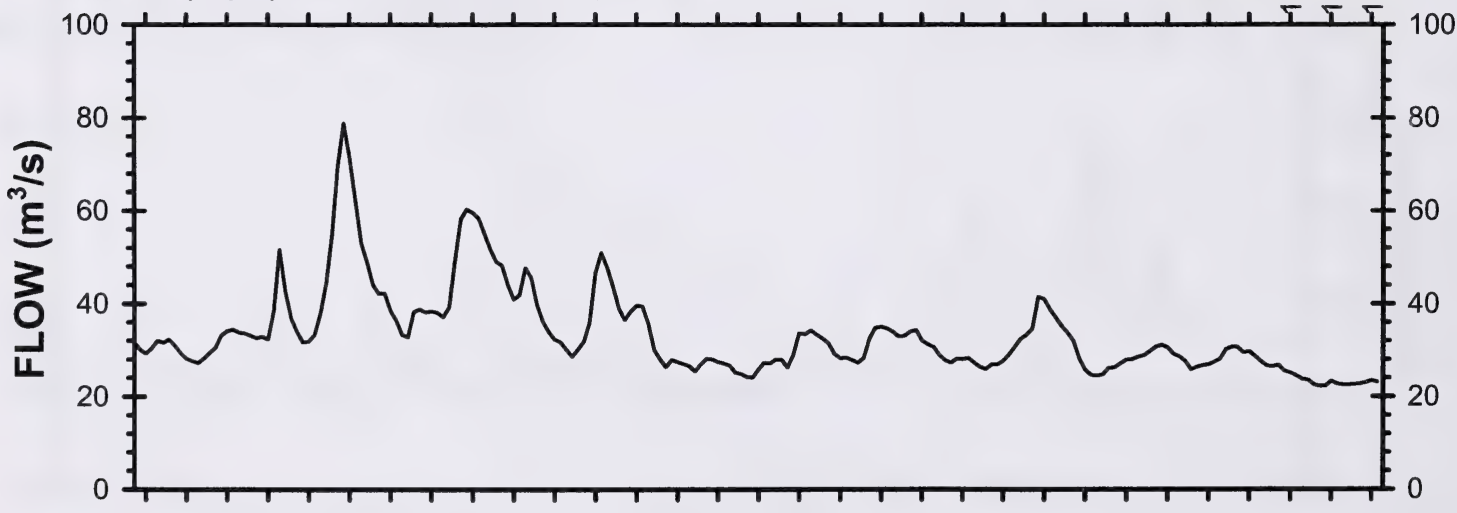

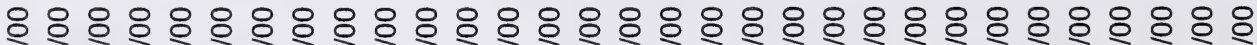

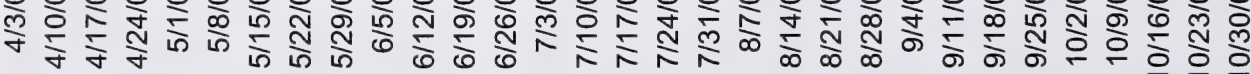

Figure 82. Daily water temperature (Datasonde), air temperature and flow in the Oldman River at Highway 36. April-October 2000. 


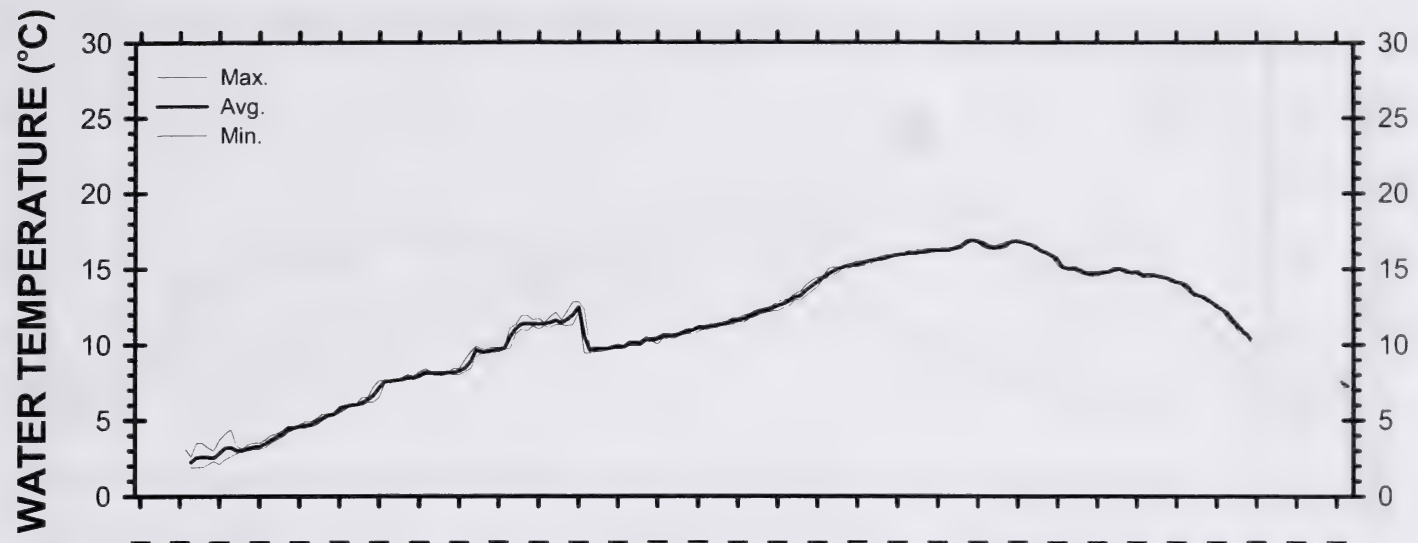

б

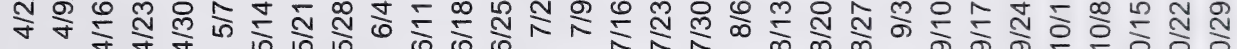

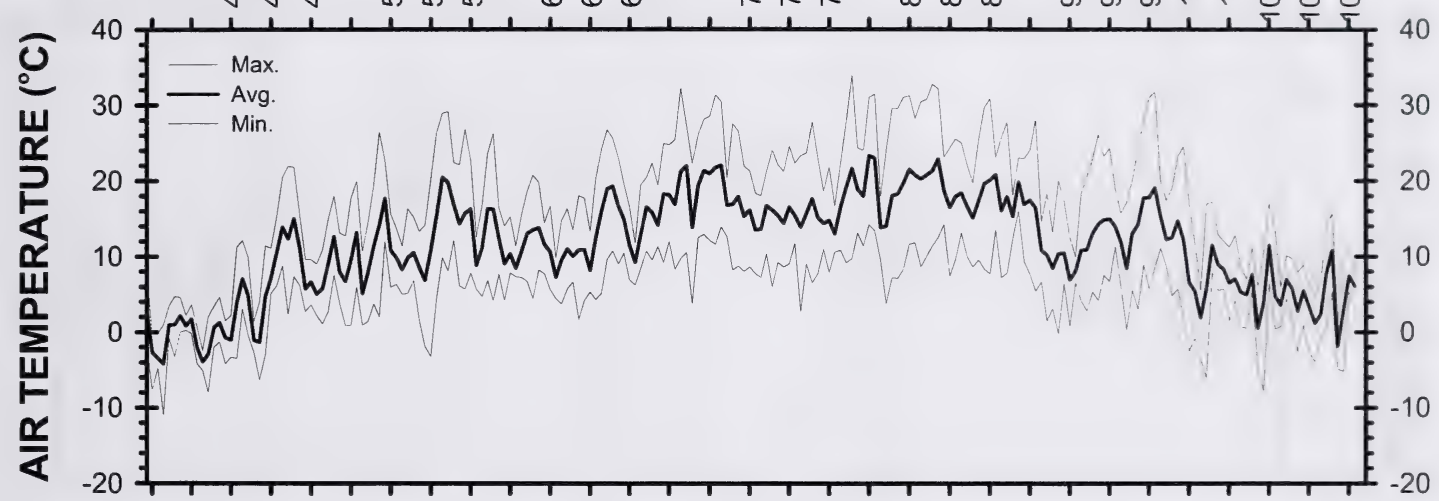

б

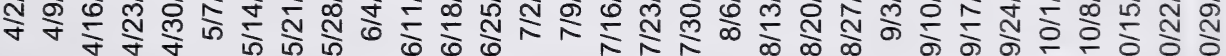

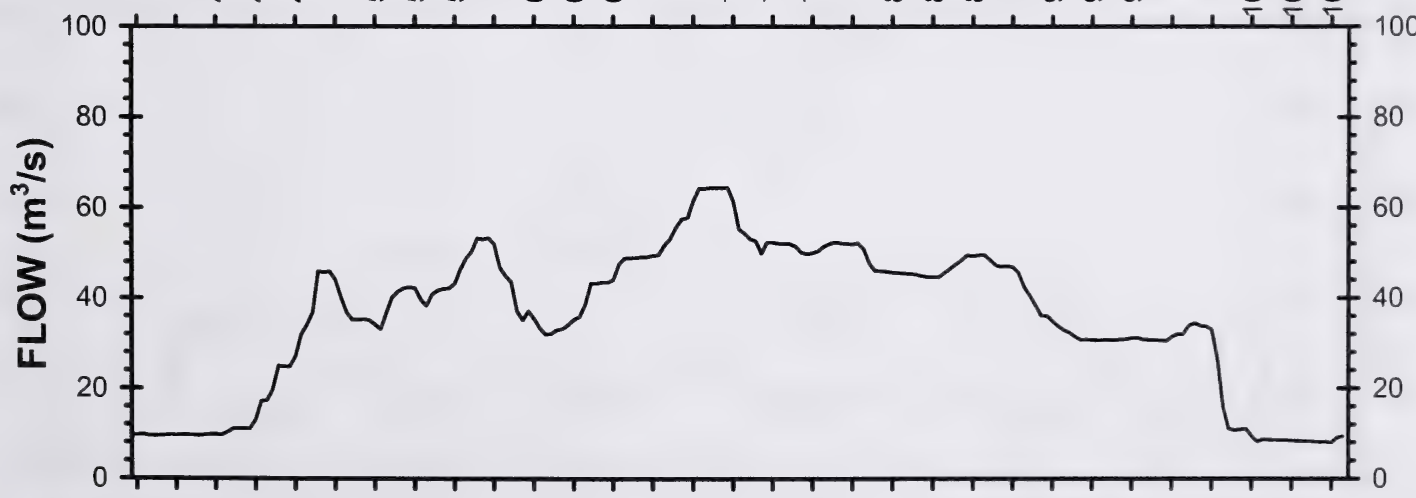

ธ

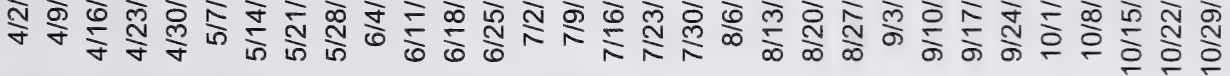

Figure 83. Daily water temperature (Thermograph), air temperature and flow in the Oldman River $100 \mathrm{~m} \mathrm{~d} / \mathrm{s}$ of the Oldman Reservoir. April-October 2001. 


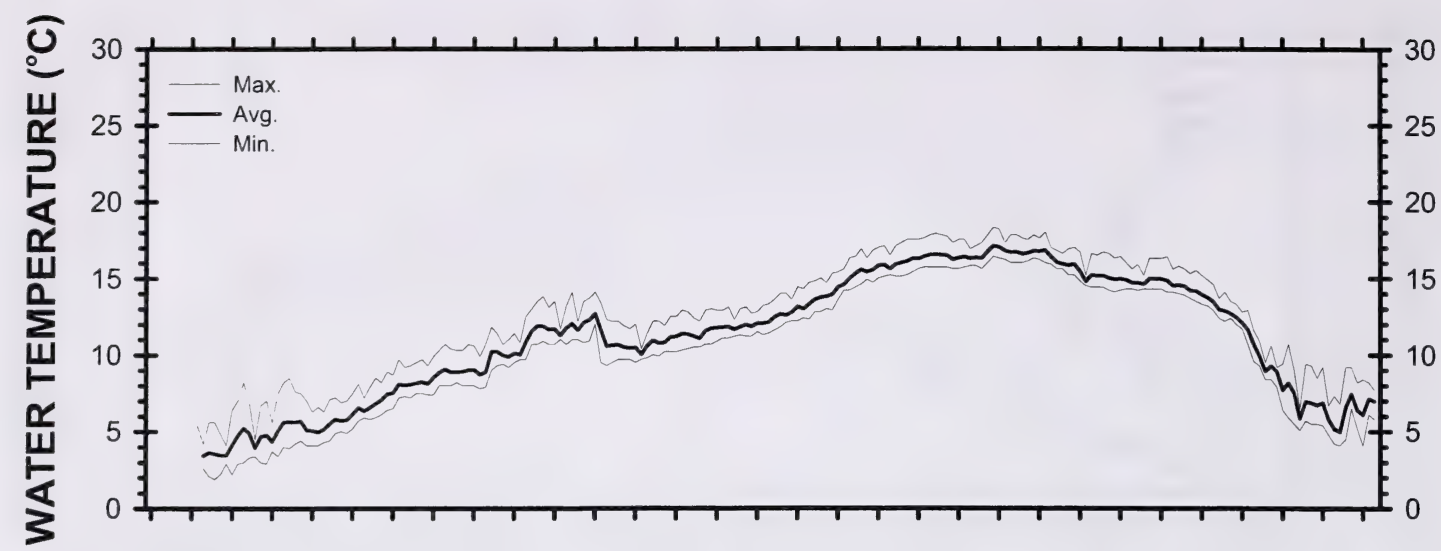

ড্ণ

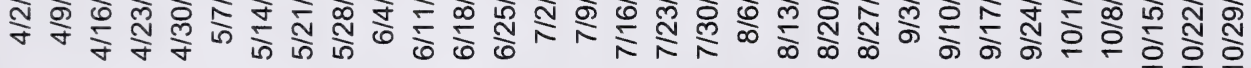

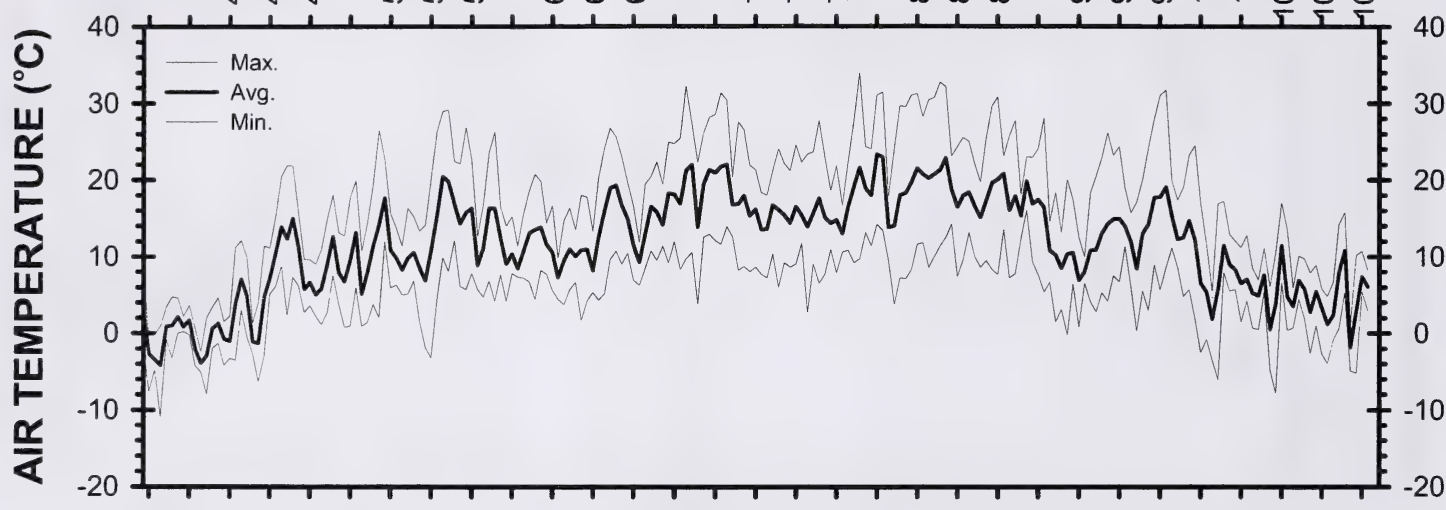

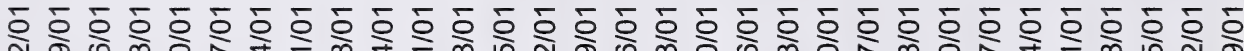

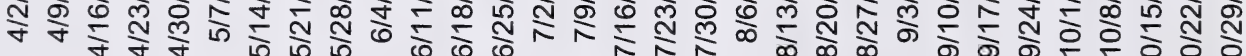

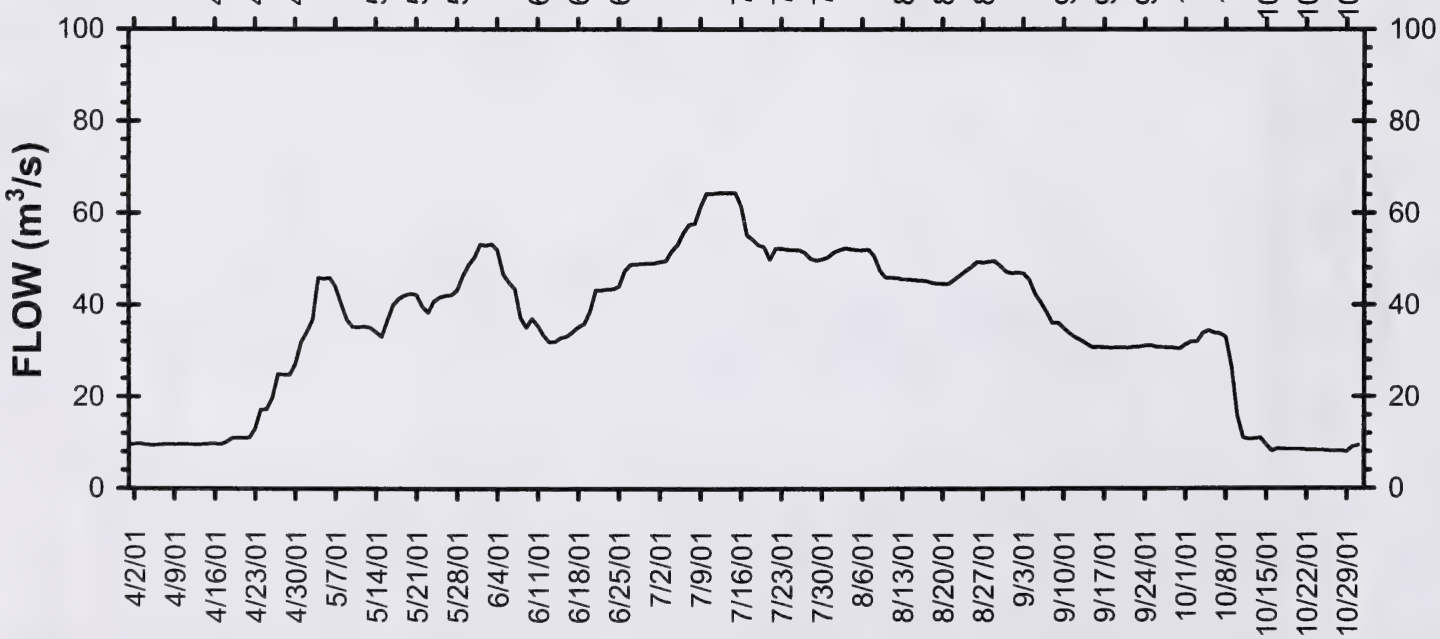

Figure 84. Daily water temperature (Thermograph), air temperature and flow in the Oldman River near Brocket. April-October 2001. 


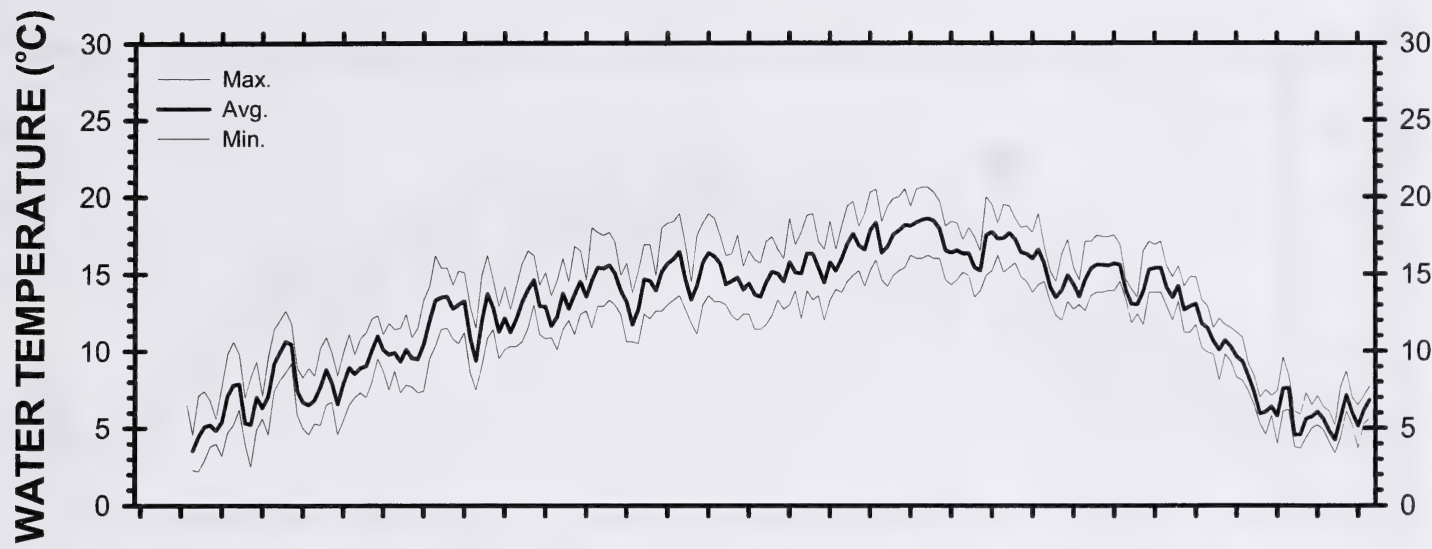

¿্র

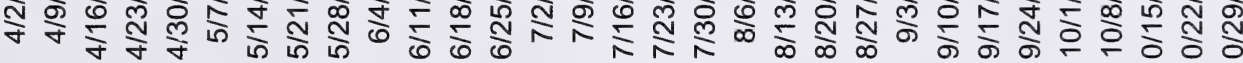

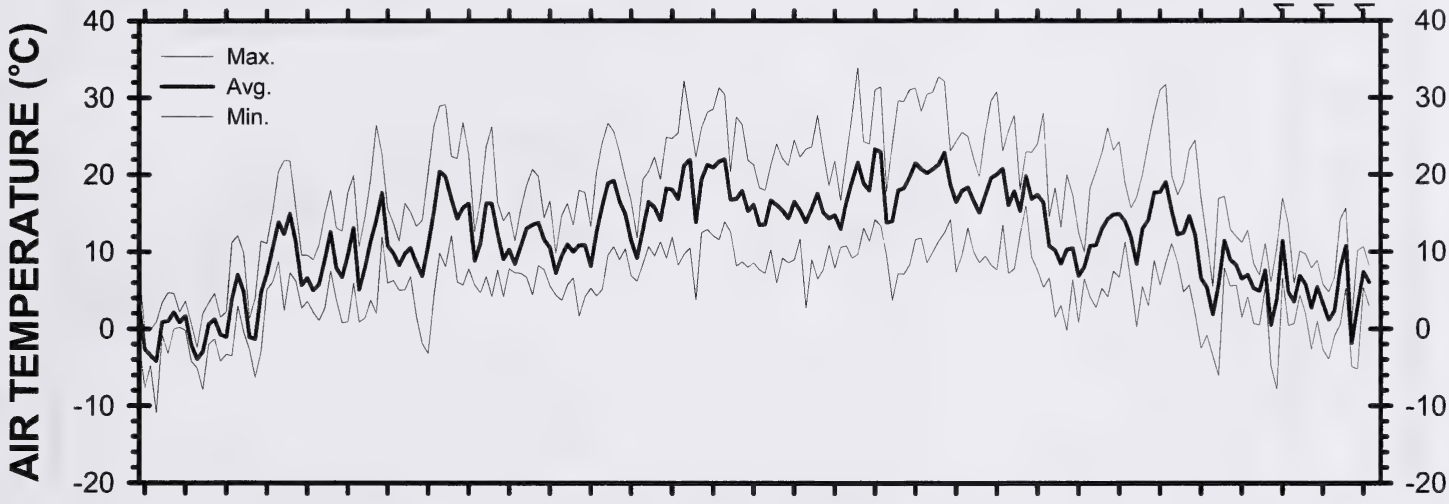

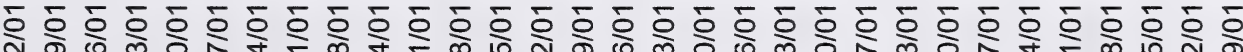

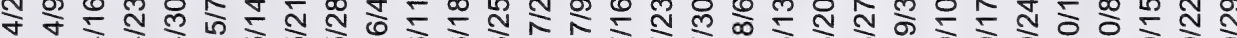

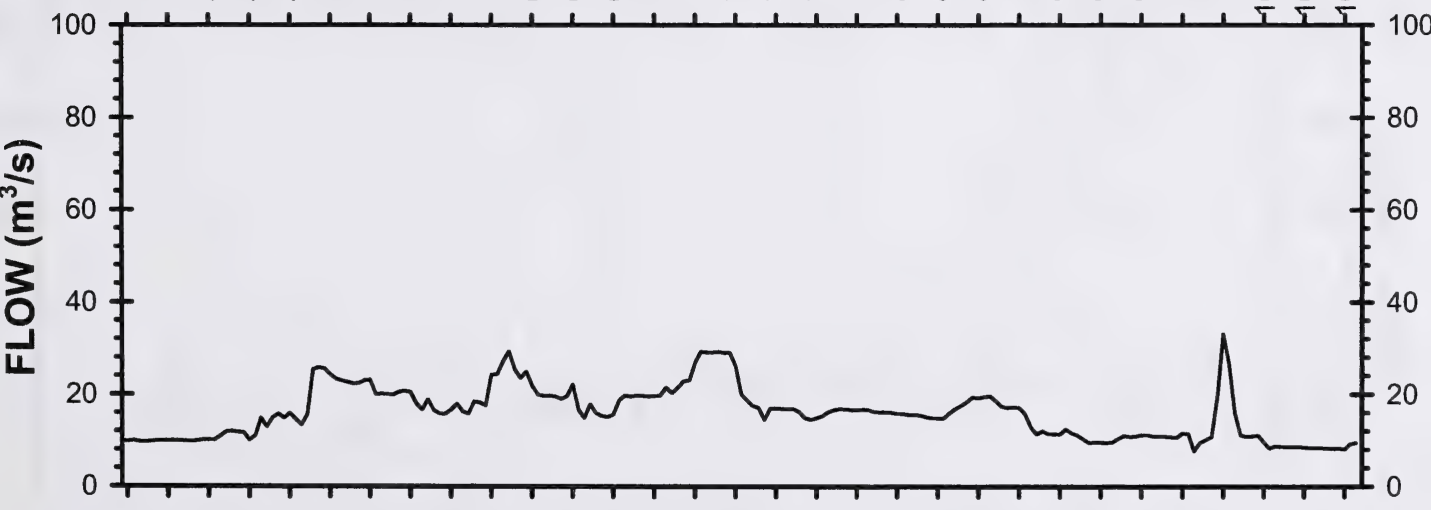

б

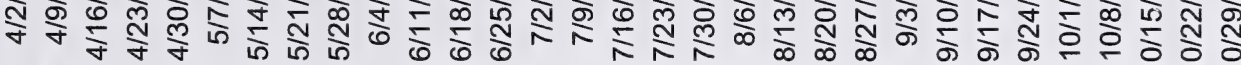

Figure 85. Daily water temperature (Thermograph), air temperature and flow in the Oldman River downstream of the LNHD. April-October 2001. 


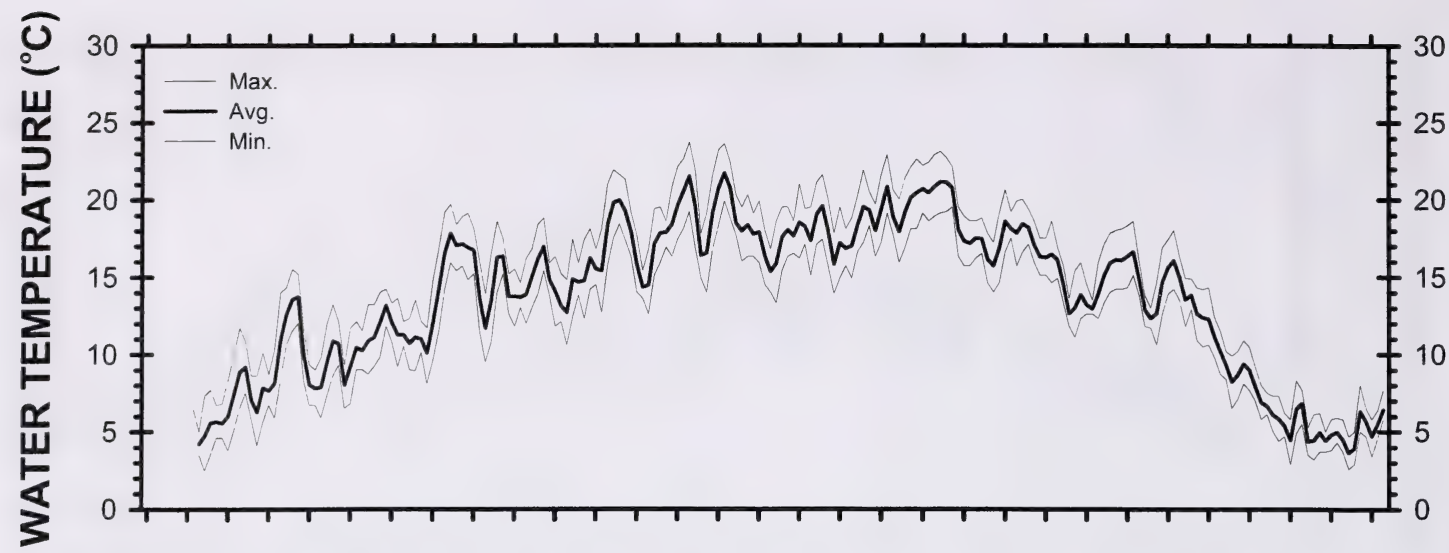

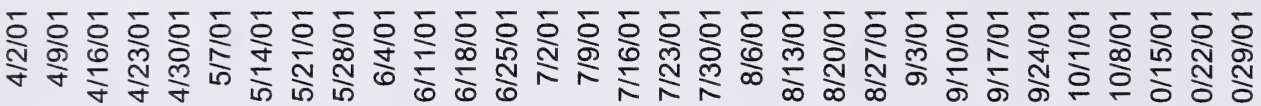

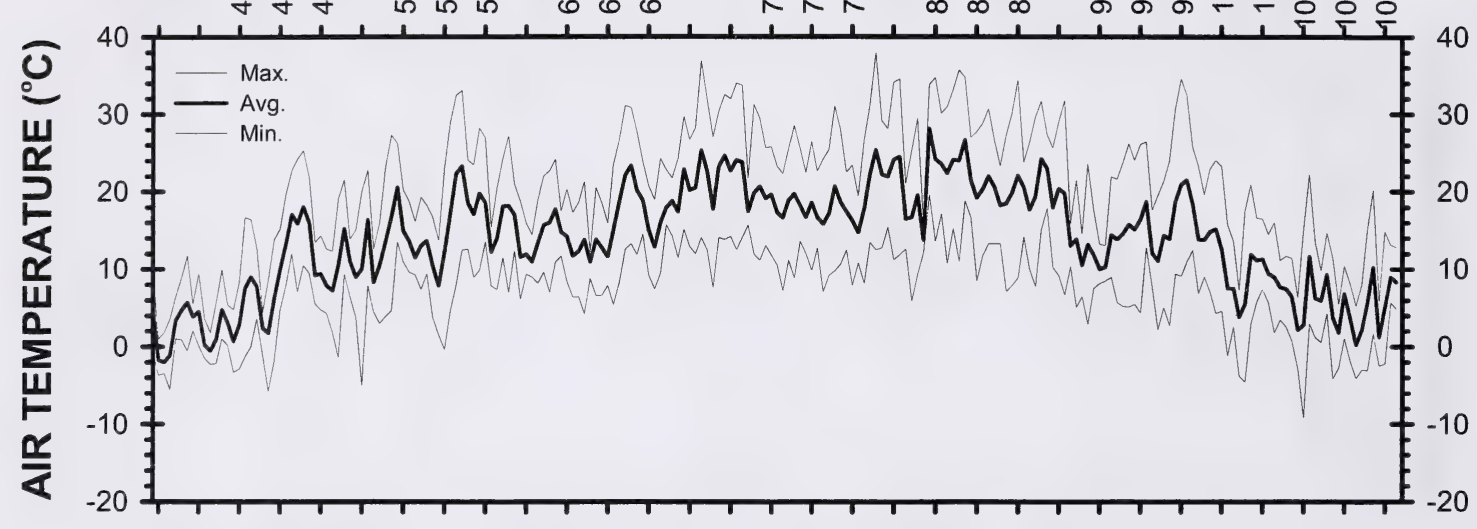

б

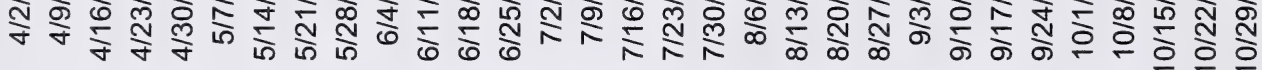

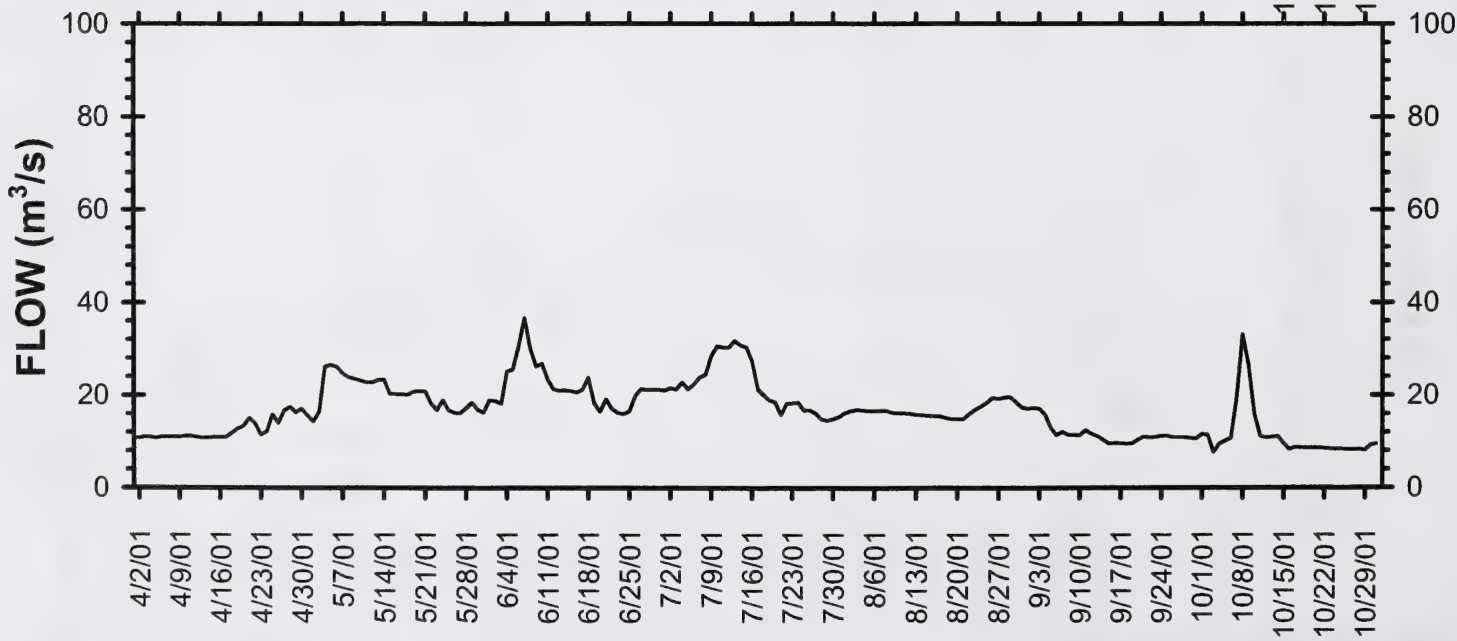

Figure 86. Daily water temperature (Thermograph), air temperature and flow in the Oldman River near Rocky Coulee. April-October 2001. 


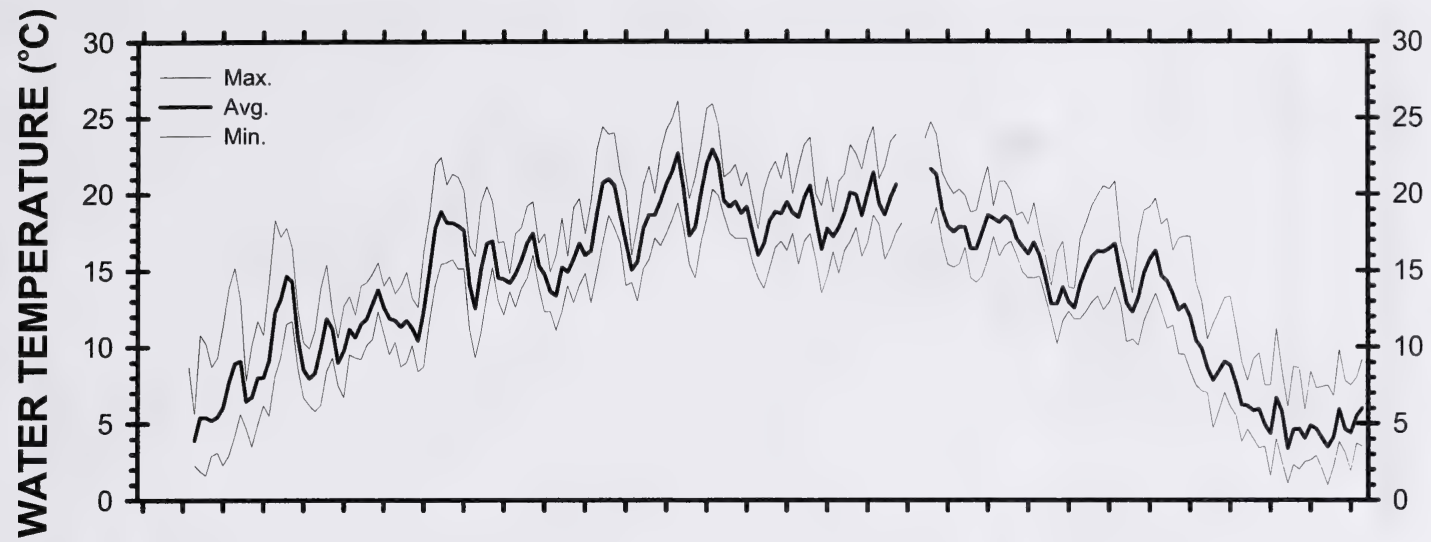

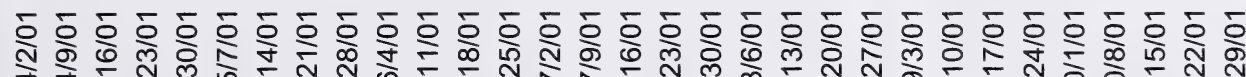

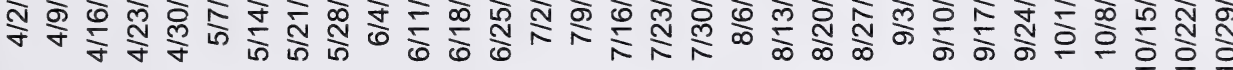

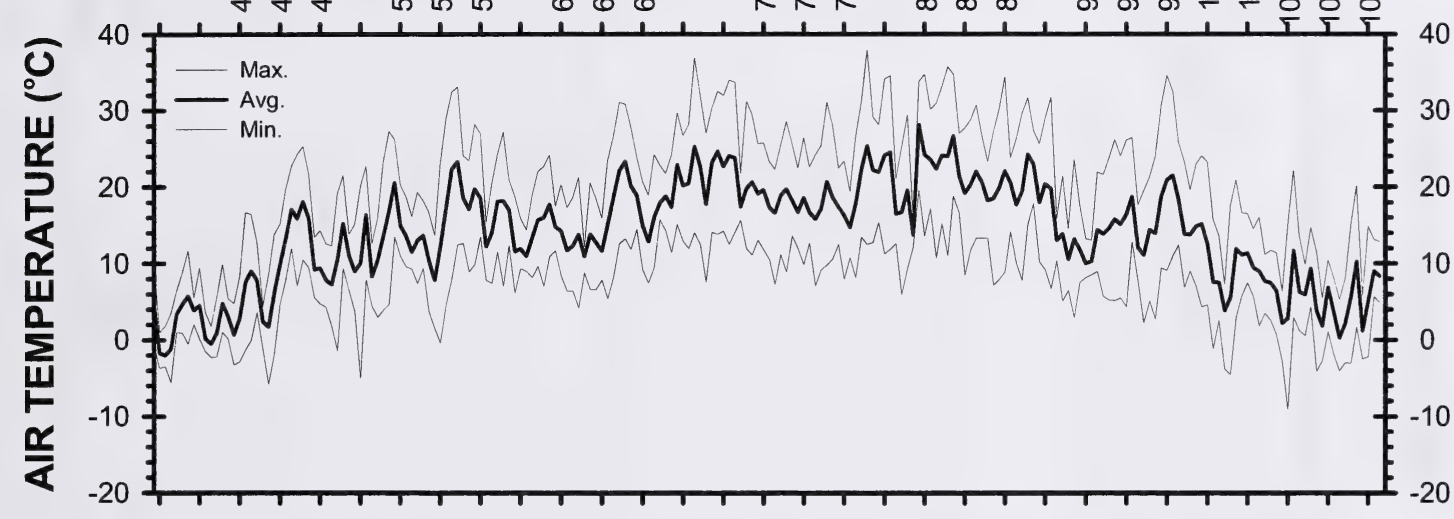

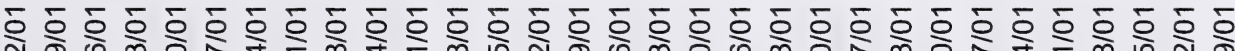

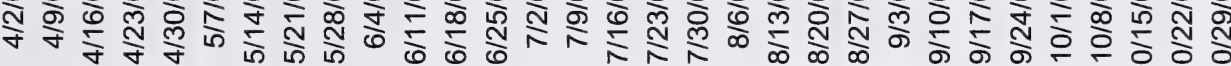

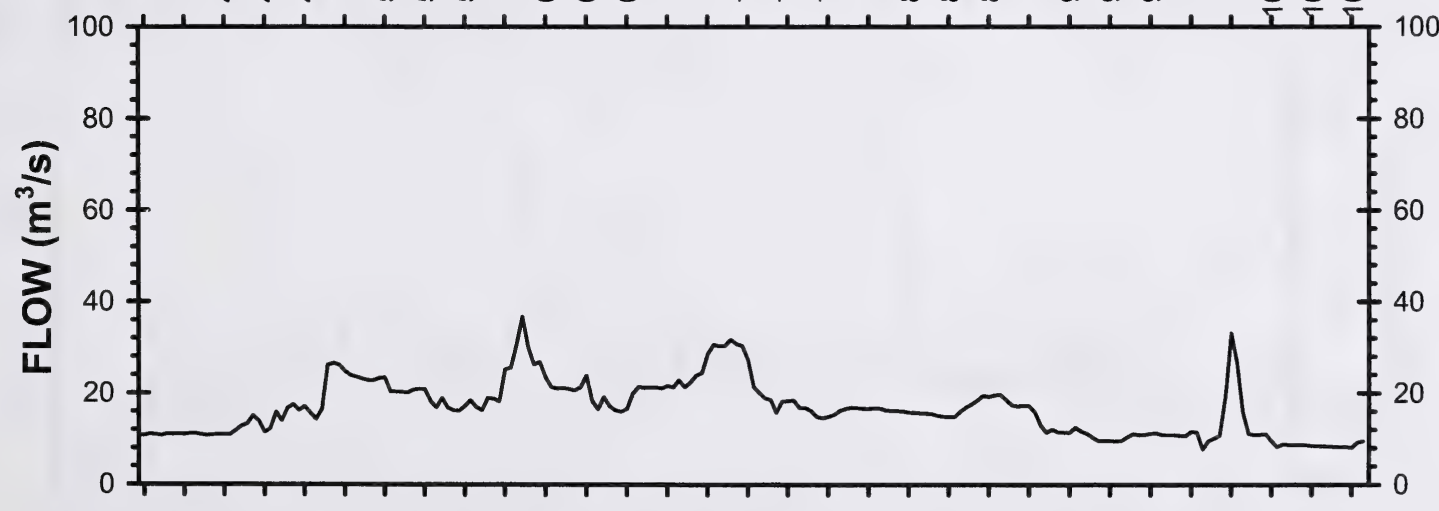

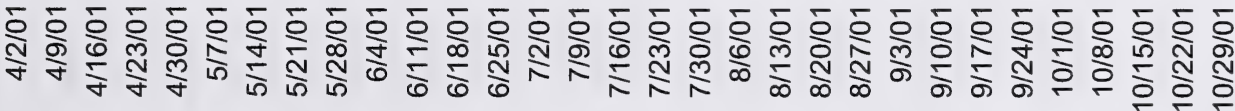

Figure 87. Daily water temperature (Thermograph/Datasonde), air temperature and flow in the Oldman River near Monarch. April-October 2001. 


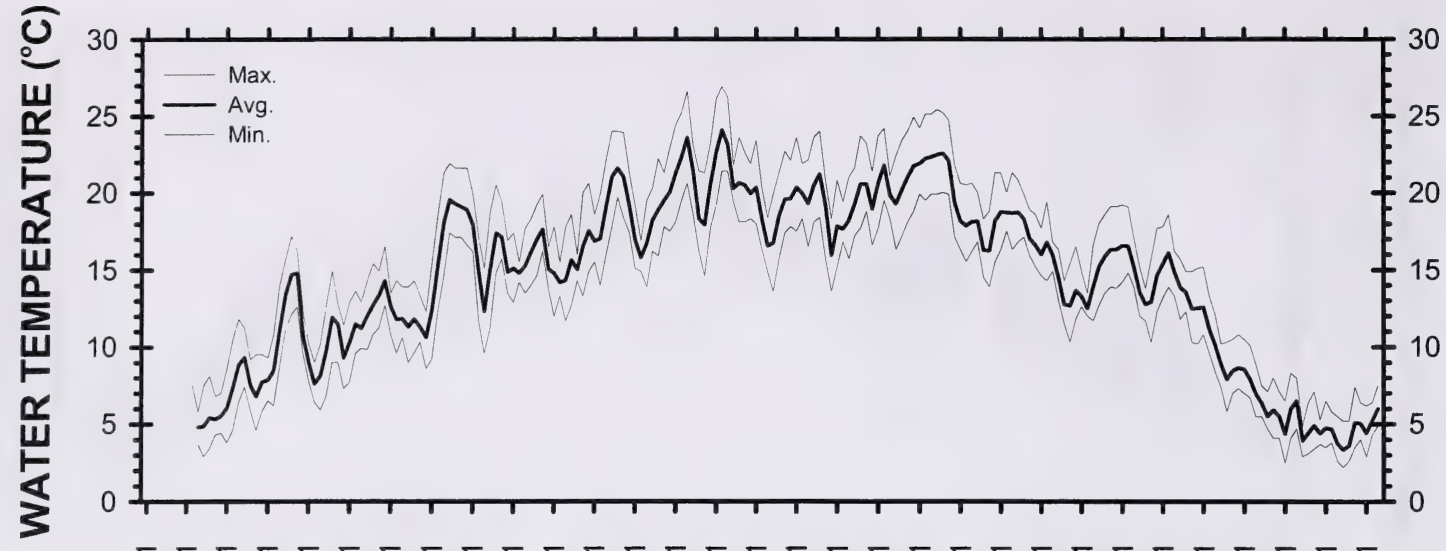

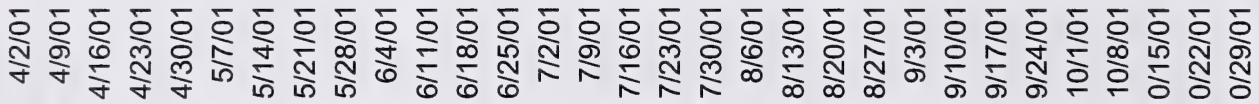

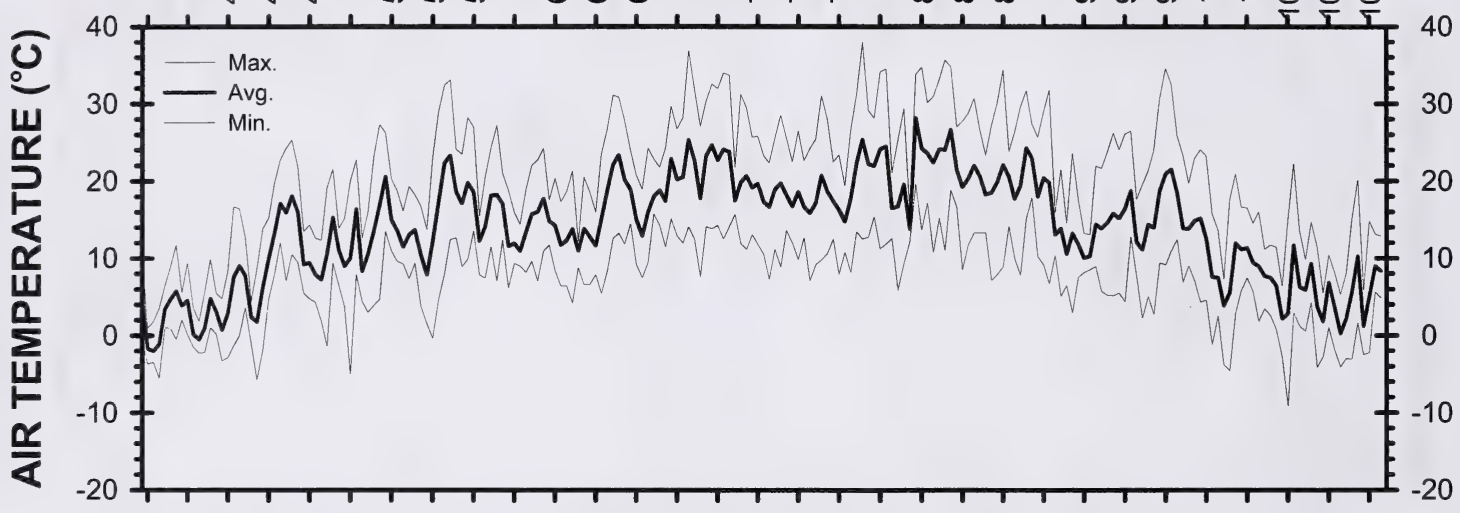

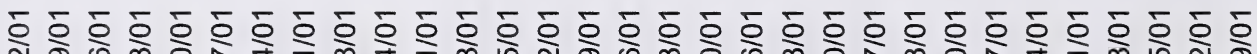

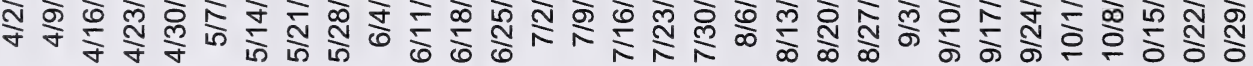

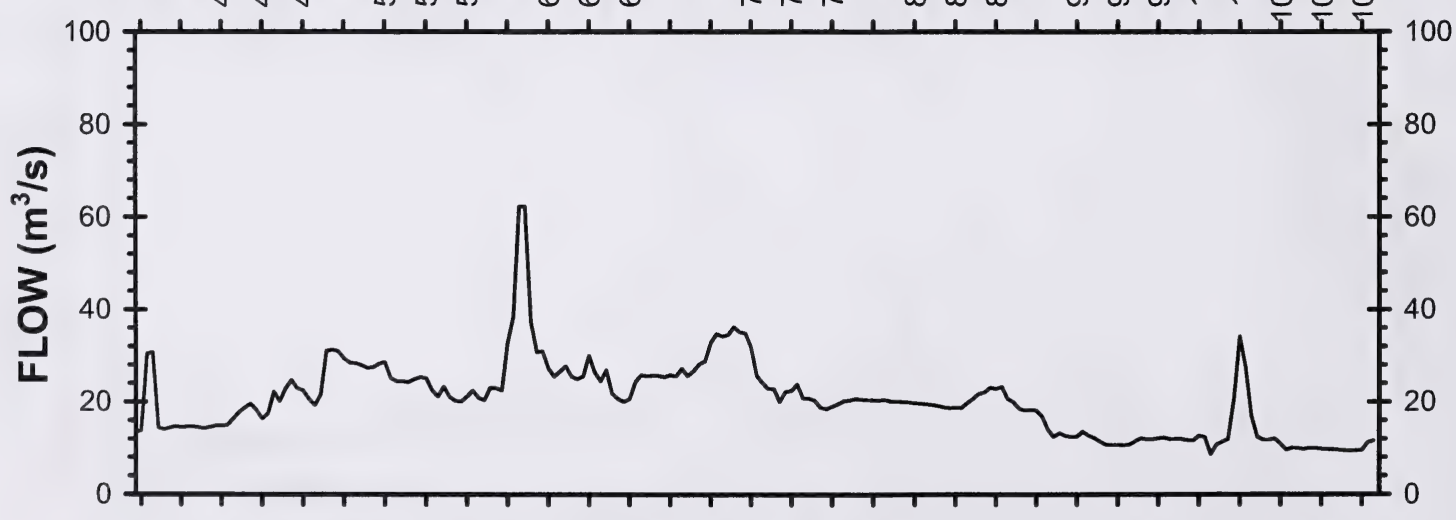

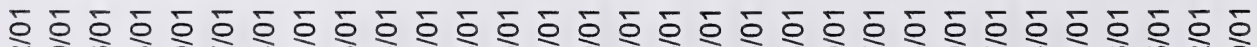

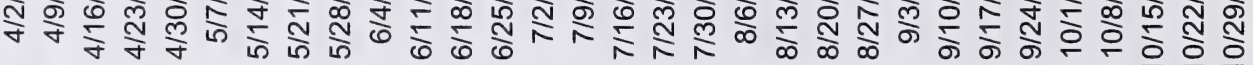

Figure 88. Daily water temperature (Thermograph), air temperature and flow in the Oldman River downstream of the Belly River. April-October 2001. 


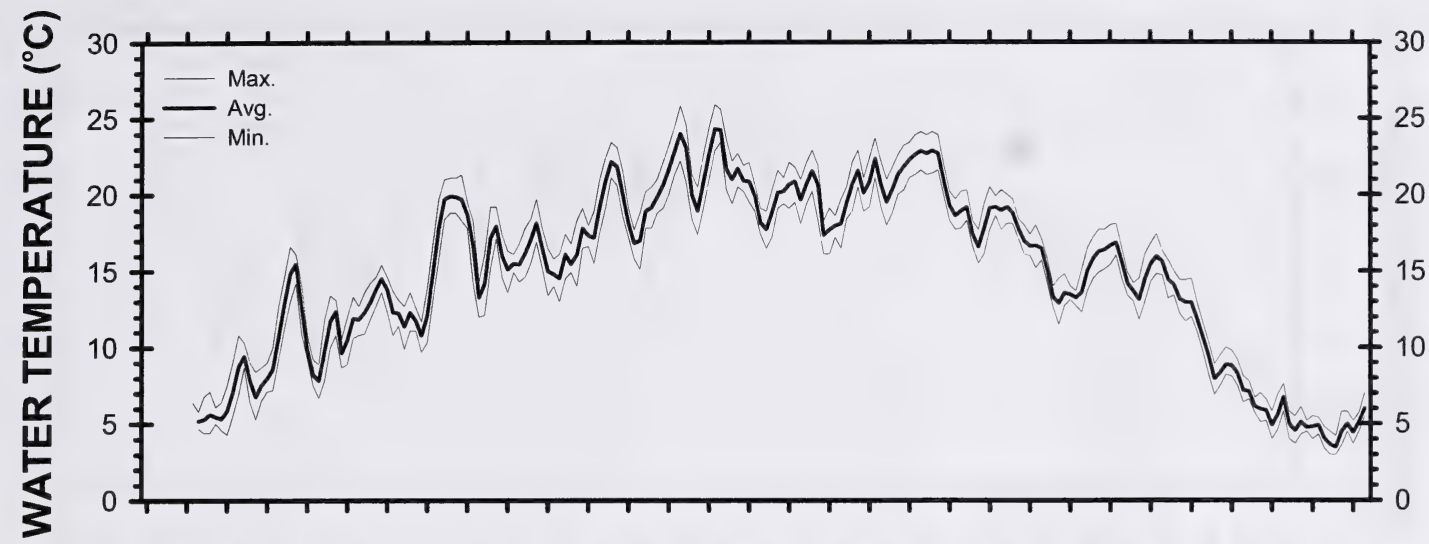

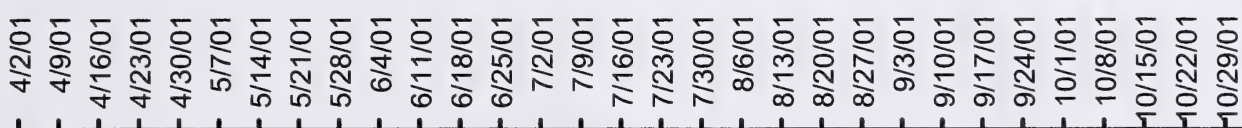

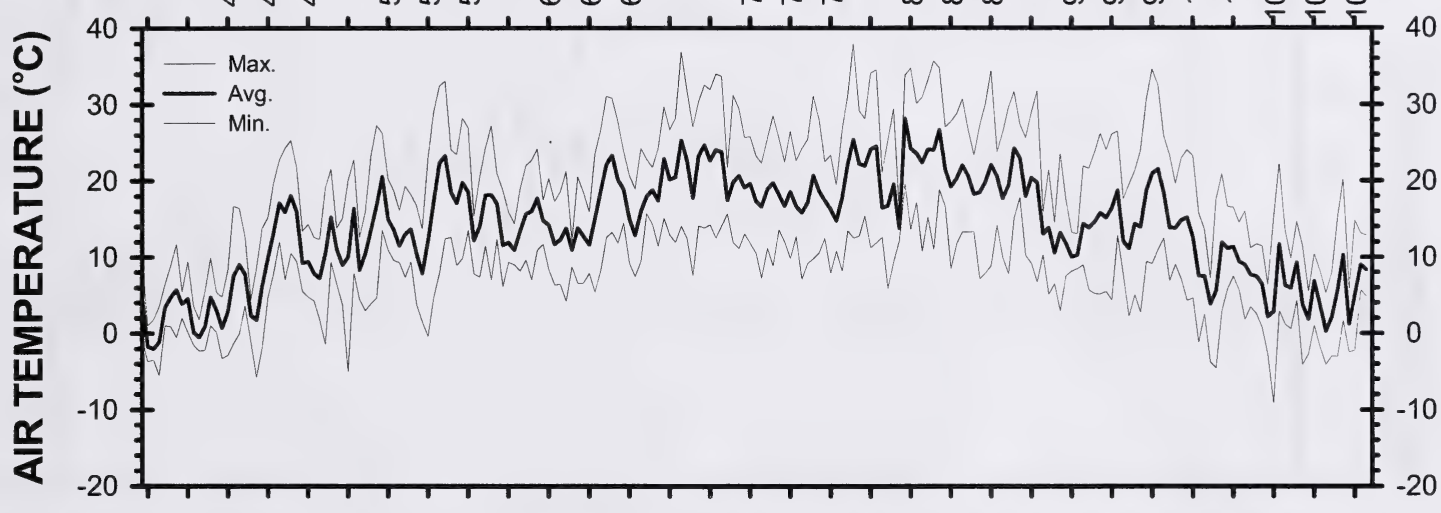

б 公 के

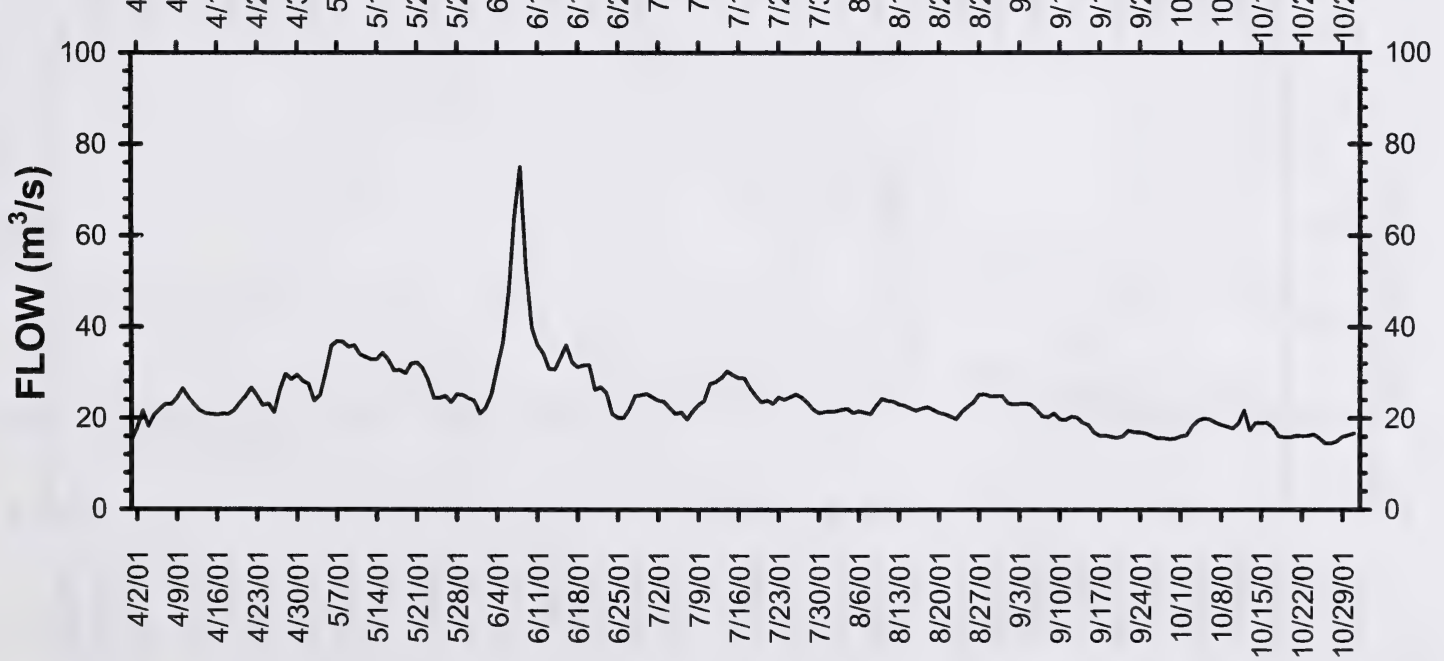

Figure 89. Daily water temperature (Thermograph), air temperature and flow in the Oldman River upstream of Lethbridge. April-October 2001. 


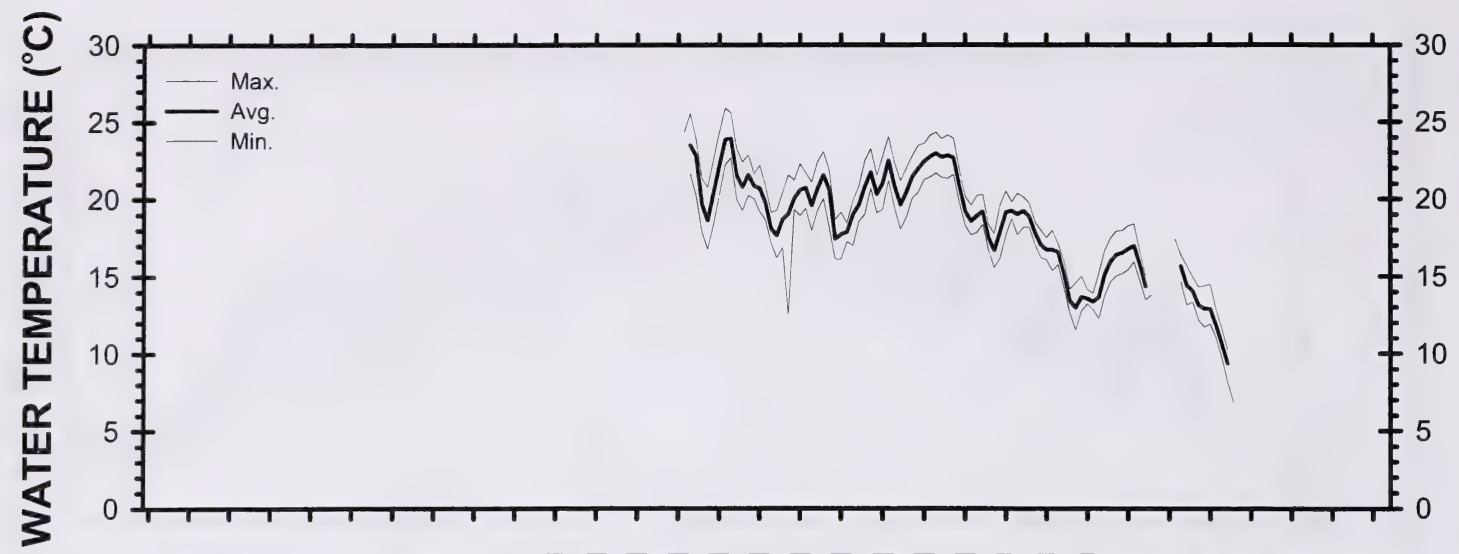

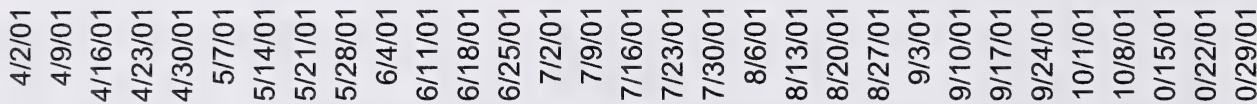

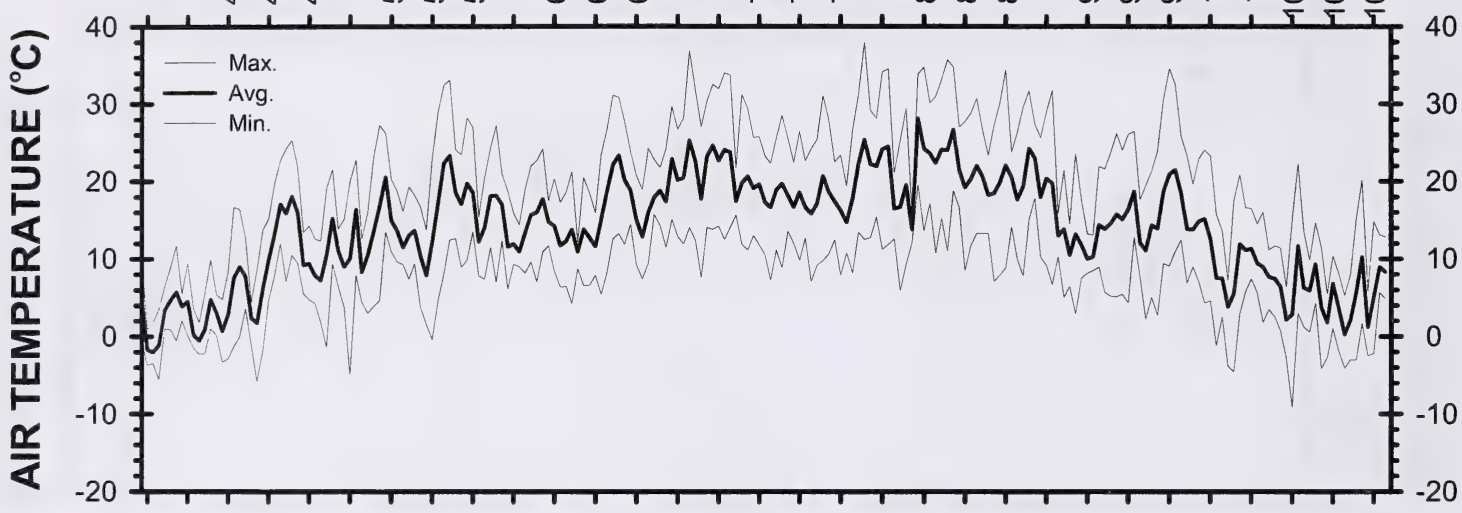

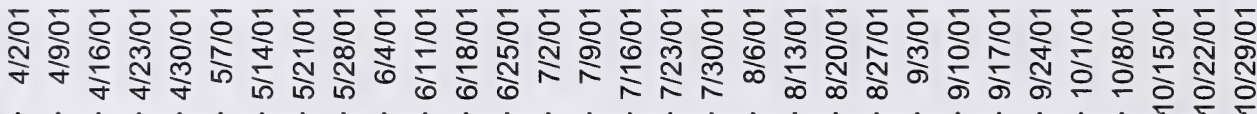

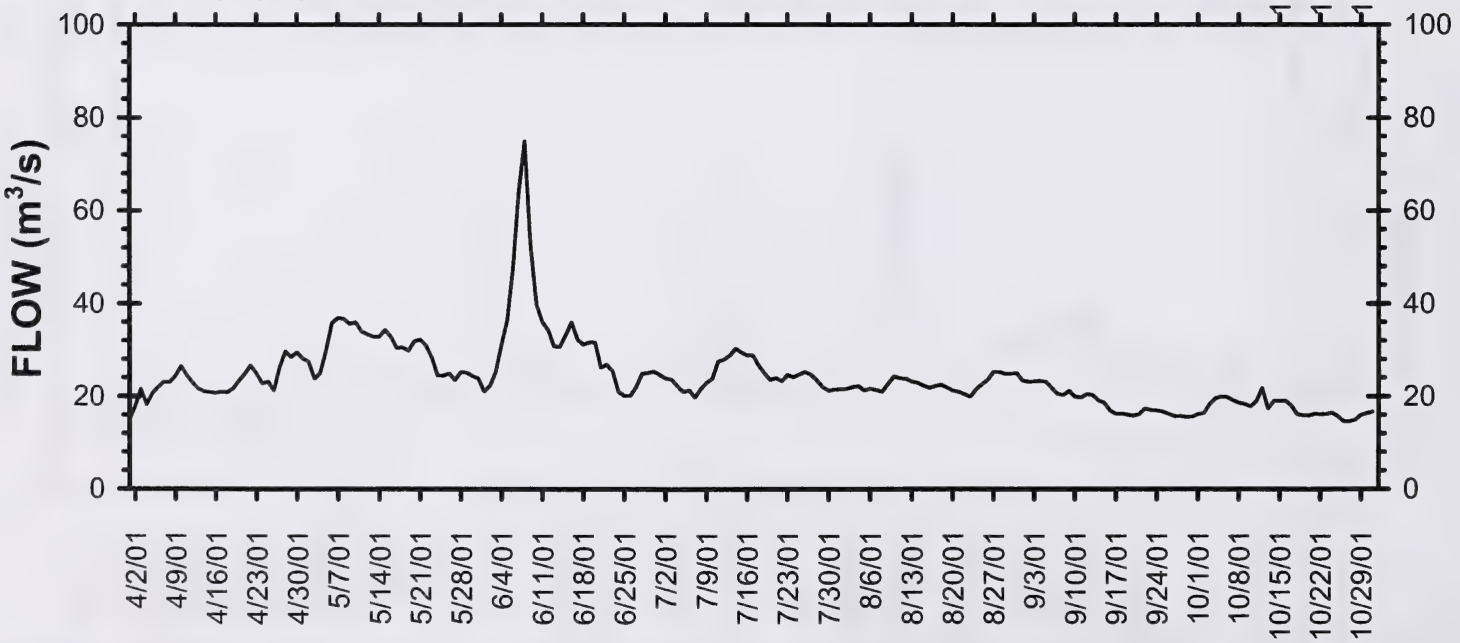

Figure 90. Daily water temperature (Datasonde), air temperature and flow in the Oldman River downstream of Lethbridge. April-October 2001. 


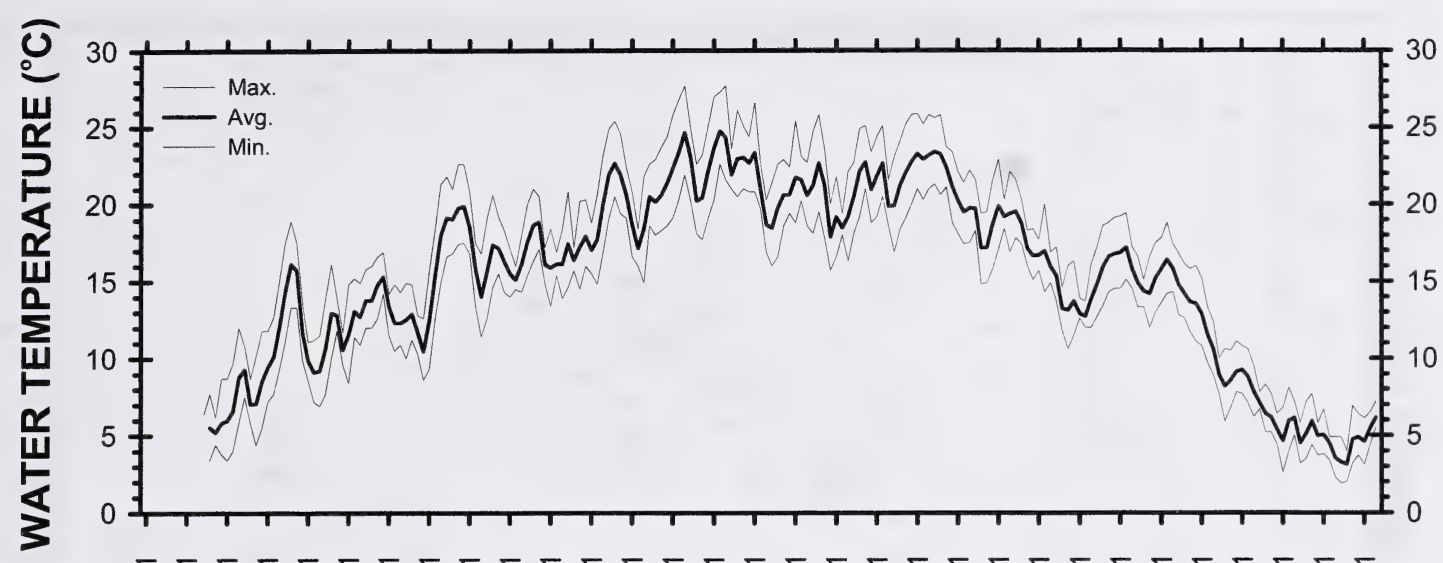

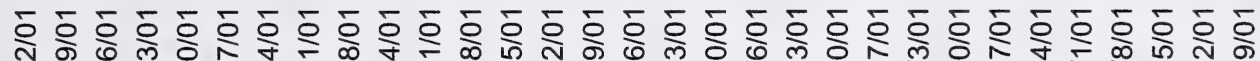

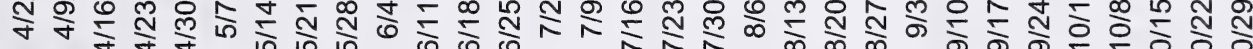

일

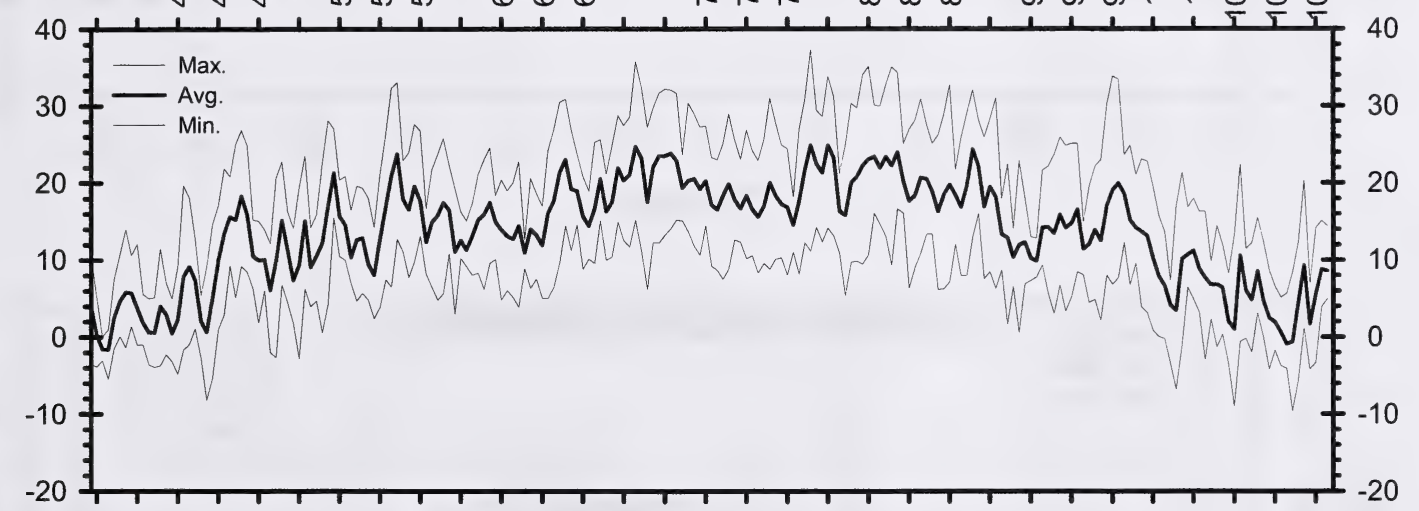

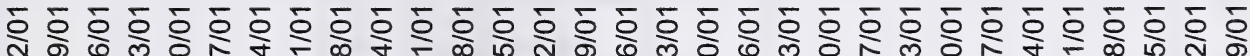
公

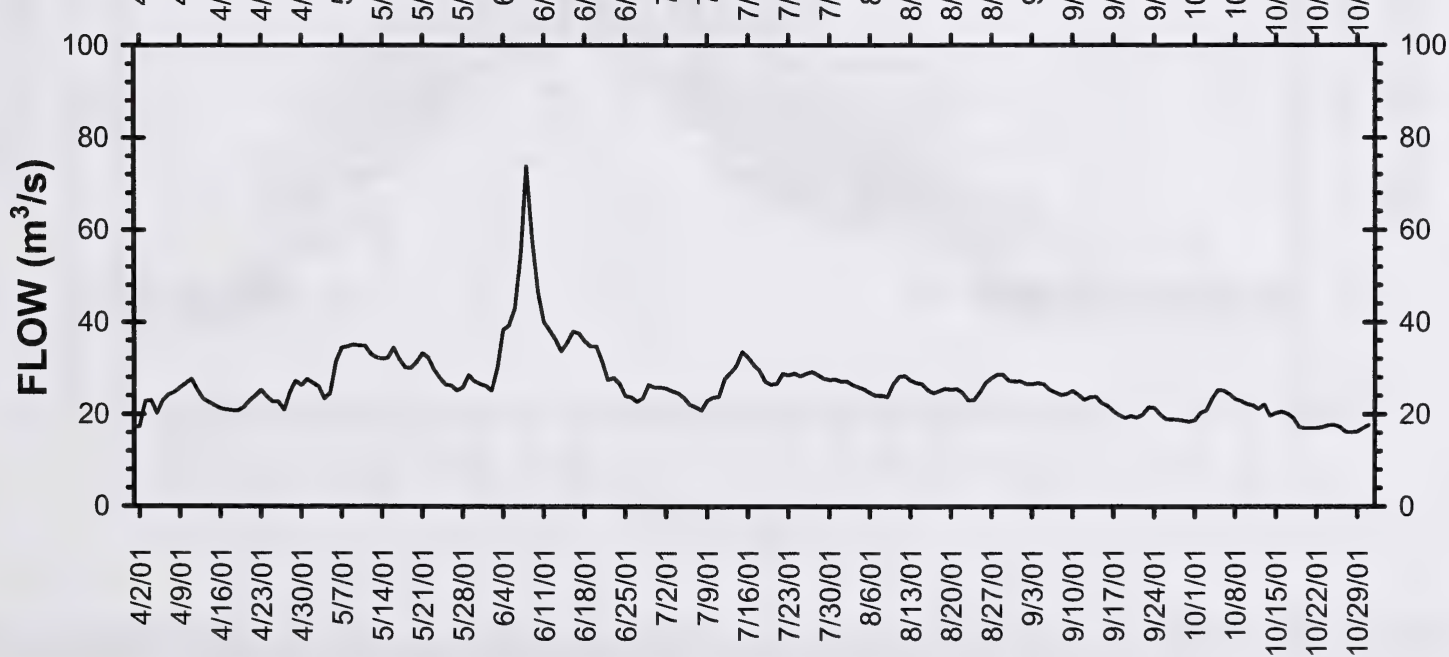

Figure 91. Daily water temperature (Datasonde), air temperature and flow in the Oldman River at Highway 36. April-October 2001. 

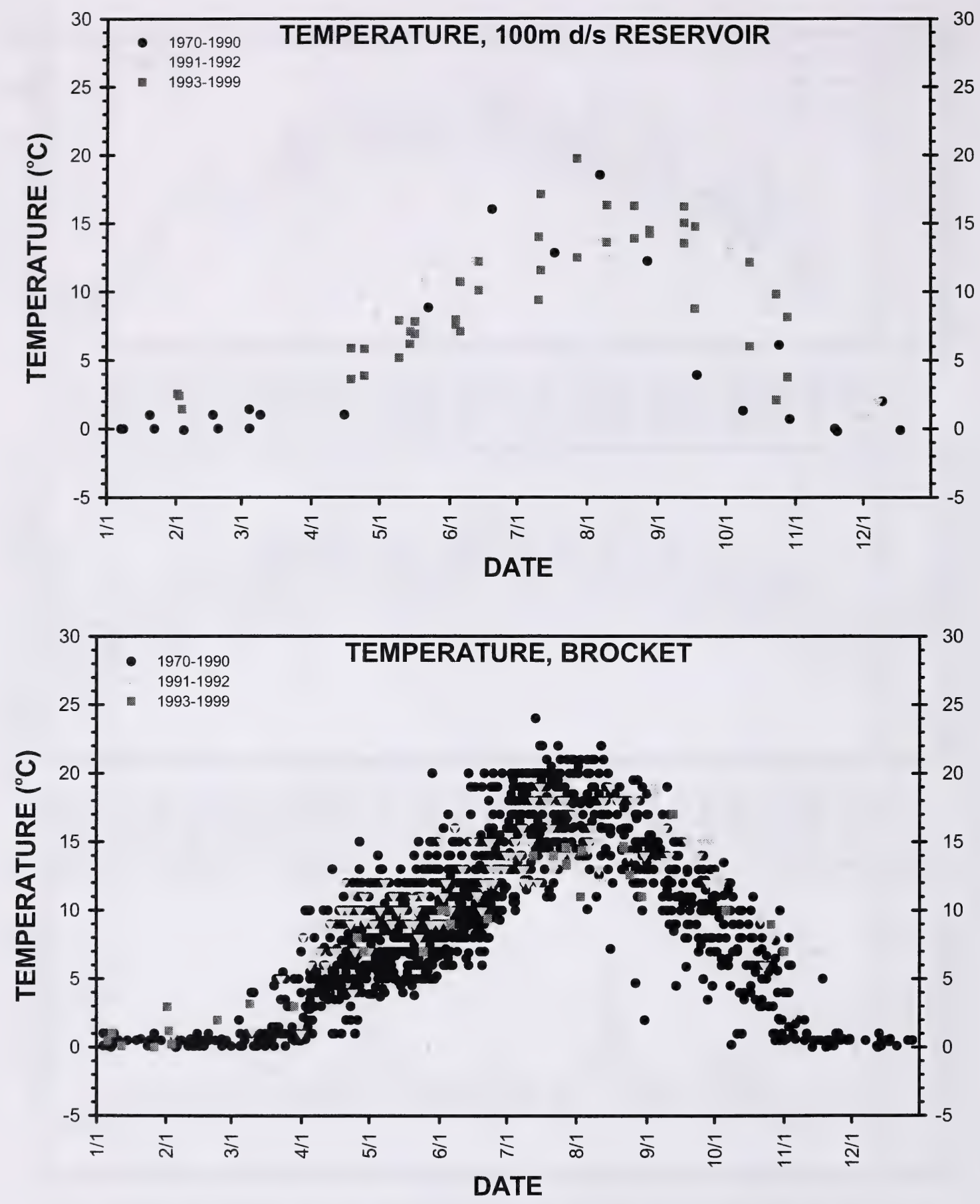

Figure 92. Water temperature (spot measurements) in the Oldman River $100 \mathrm{~m}$ downstream of the reservoir and near Brocket for pre-impoundment, transition, and post-impoundment years. 

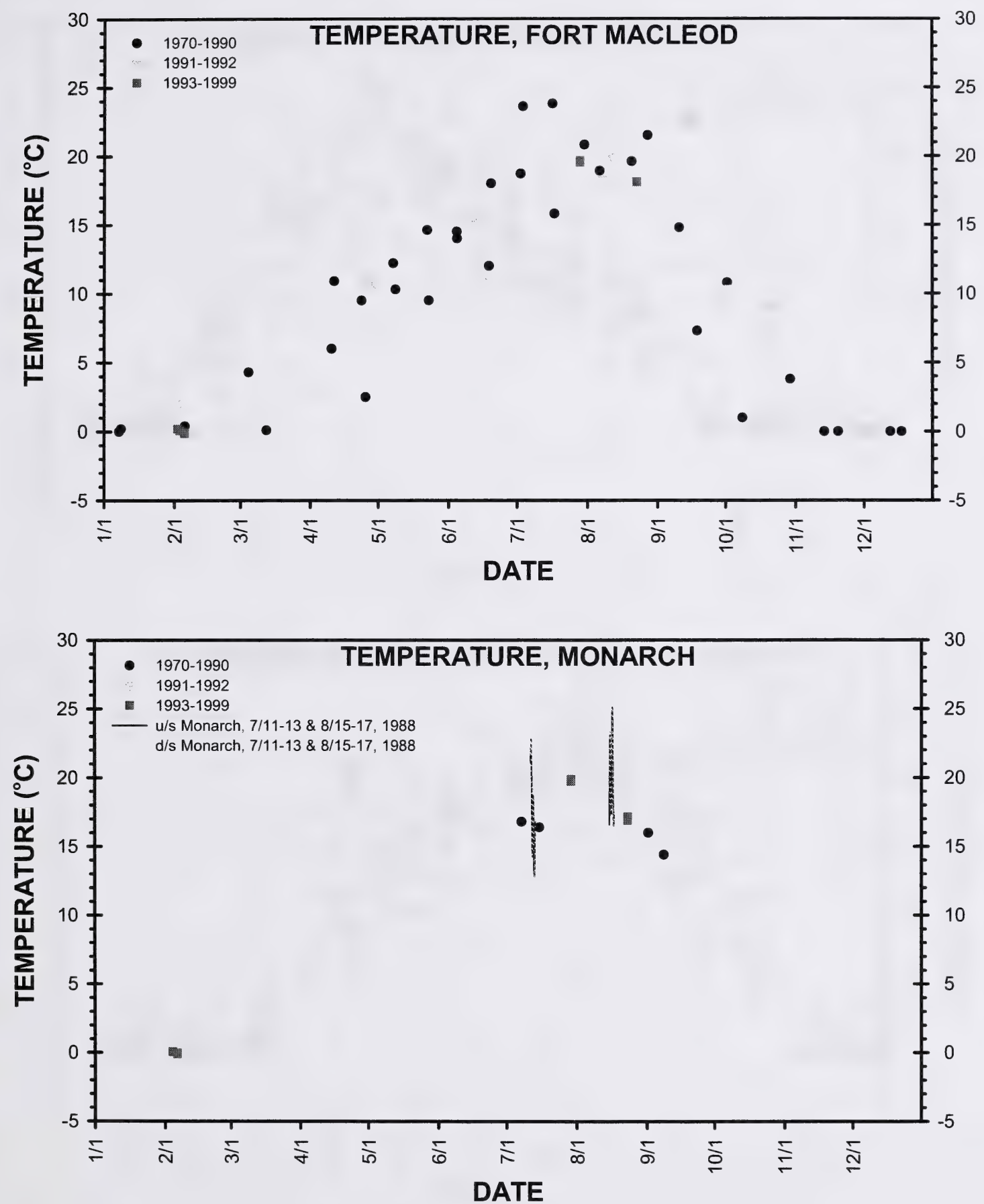

Figure 93. Water temperature (spot measurements) in the Oldman River near Fort macleod and Monarch for pre-impoundment, transition, and post-impoundment years. 

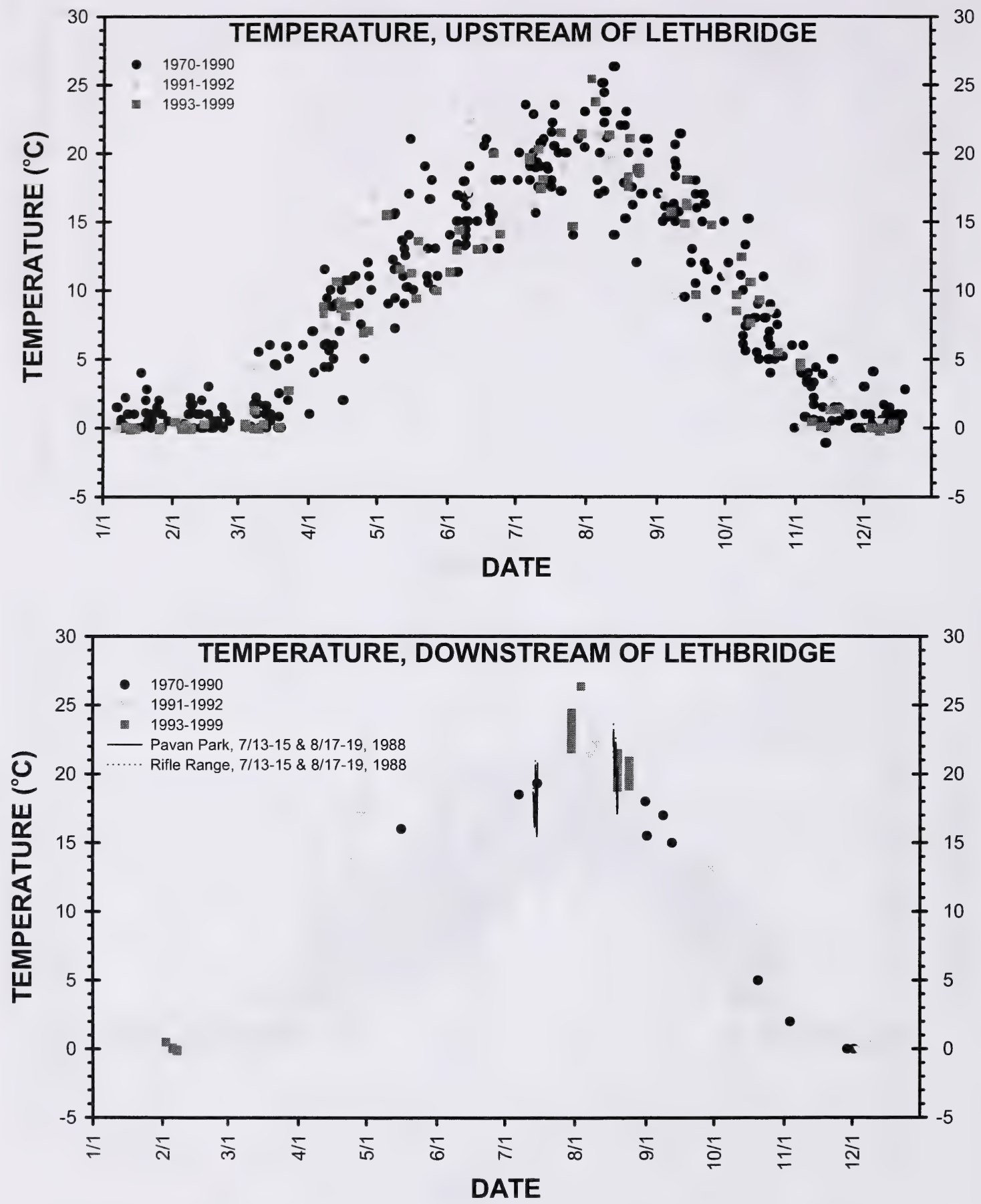

Figure 94. Water temperature (spot measurements) in the Oldman River upstream and downstream of Lethbridge for pre-impoundment, transition, and post-impoundment years. 

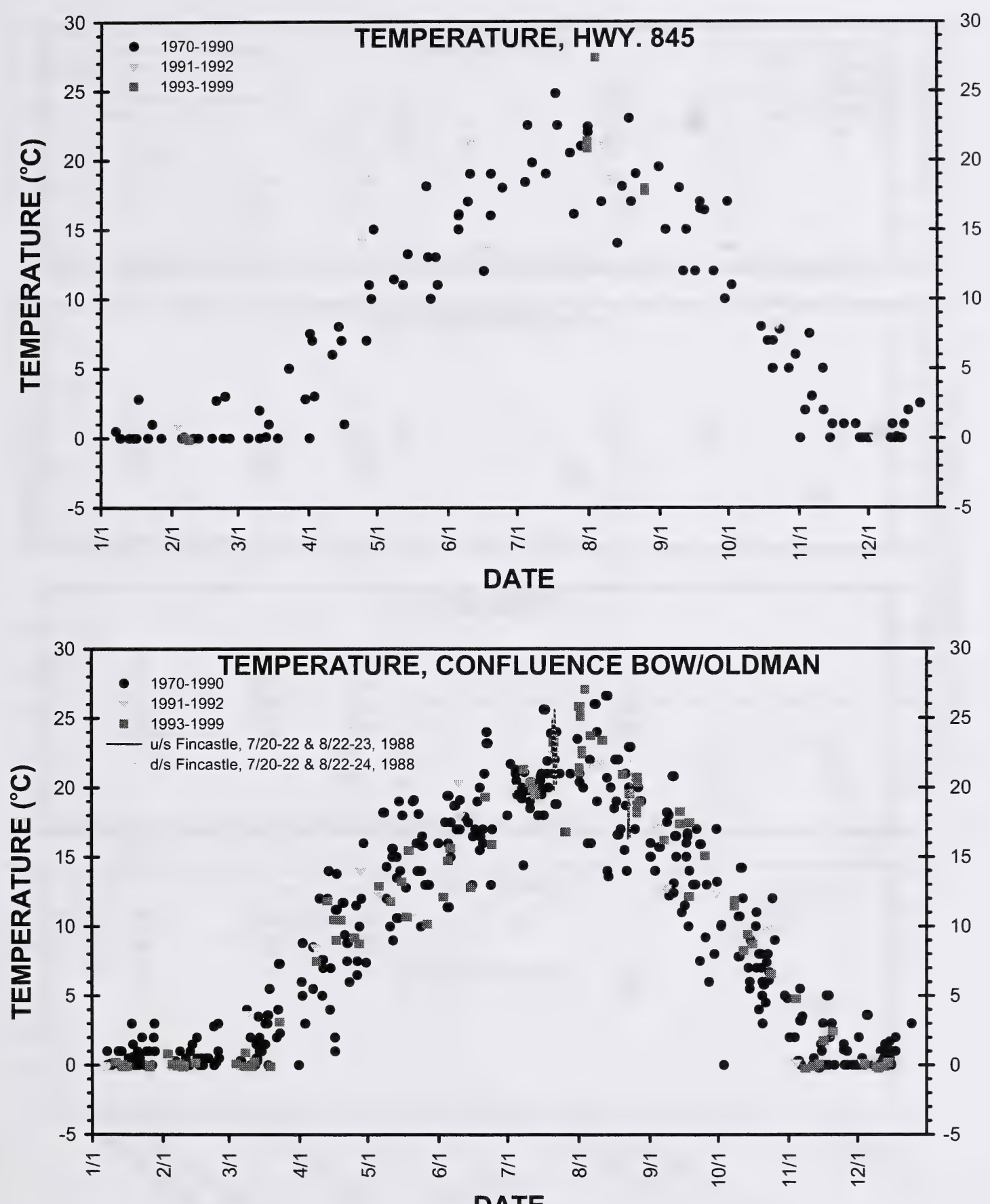

DATE

Figure 95. Water temperature (spot measurements) in the Oldman River near Hwy. 845 and the confluence of the Bow and Oldman rivers for pre-impoundment, transition, and post-impoundment years. 

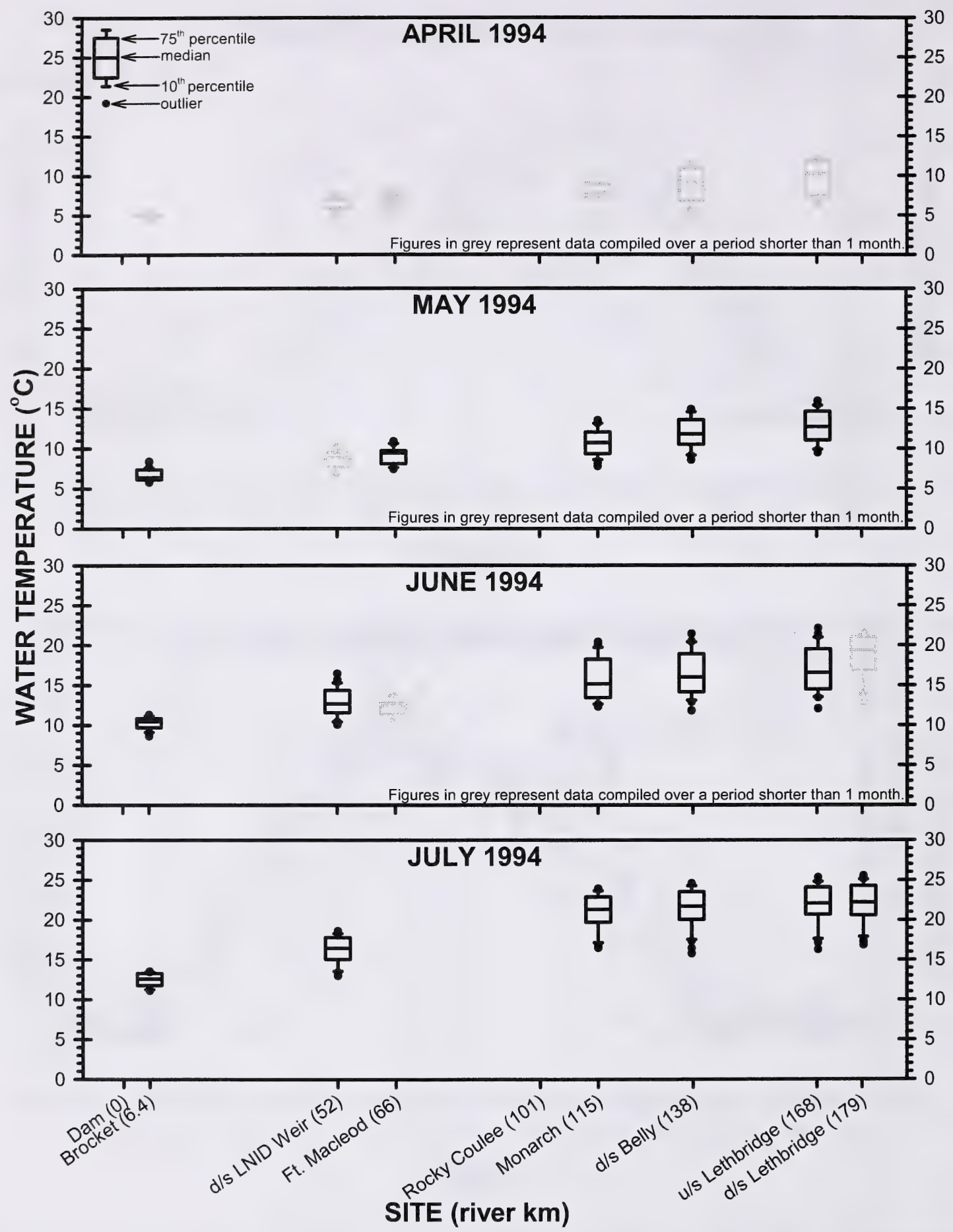

Figure 96. Range in daily mean water temperatures based on Thermograph and Datasonde data*. April-July 1994.

*Where data from both monitoring devices exist, Thermograph data have been used. 

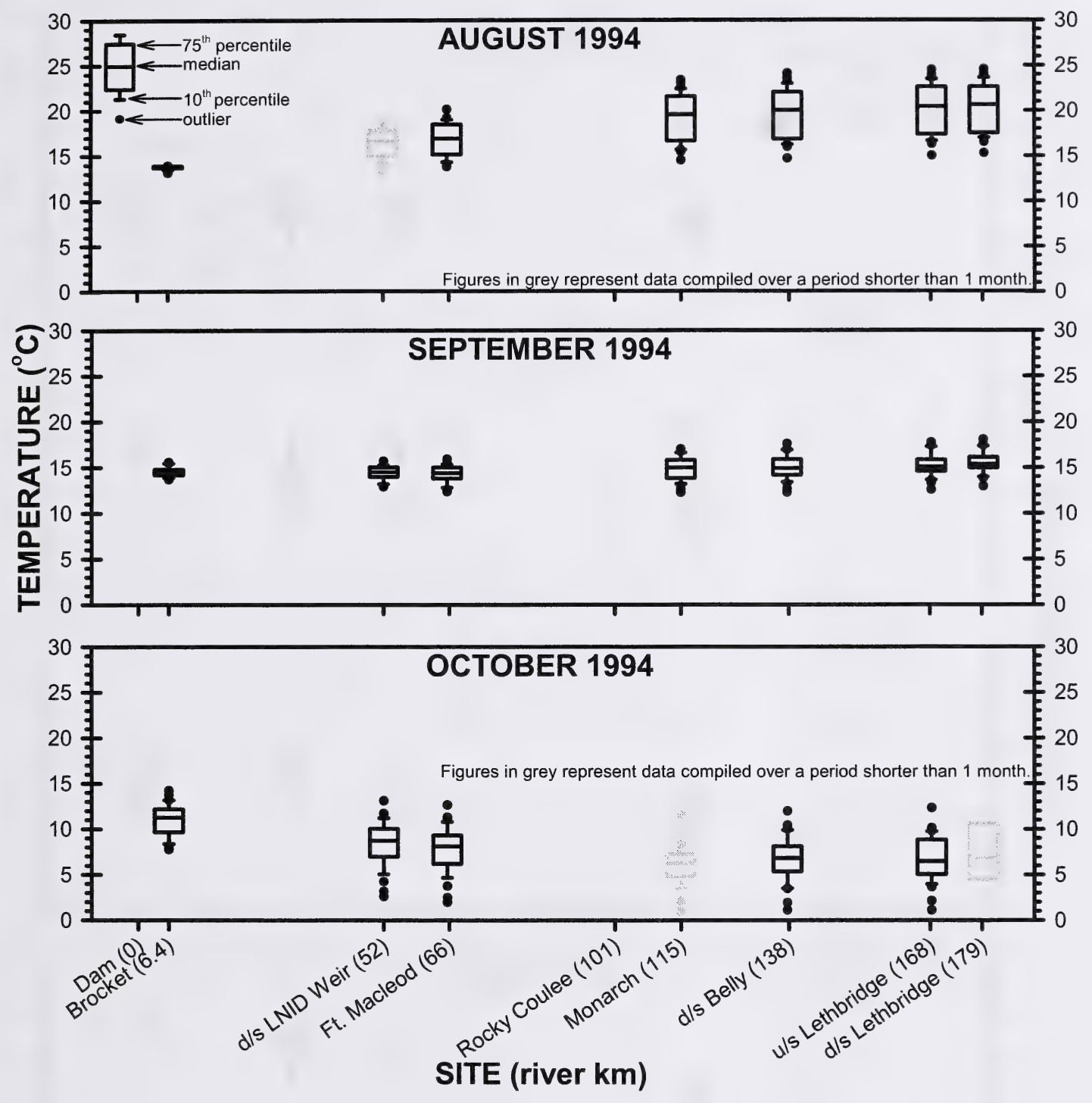

Figure 97. Range in daily mean water temperatures based on Thermograph and Datasonde data*. August-October 1994.

*Where data from both monitoring devices exist, Thermograph data have been used. 

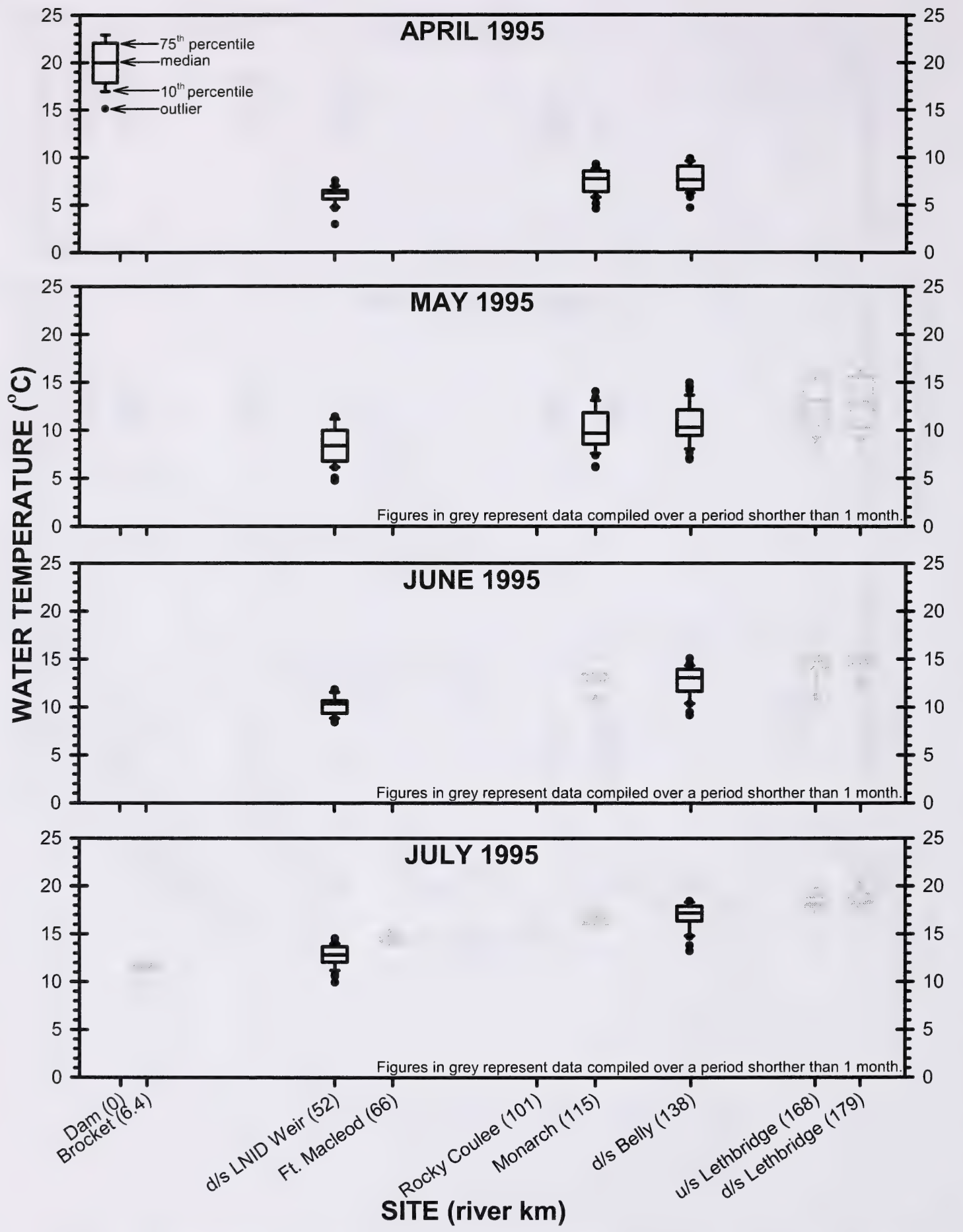

Figure 98. Range in daily mean water temperatures based on Thermograph and Datasonde data*. April-July 1995.

*Where data from both monitoring devices exist, Thermograph data have been used 

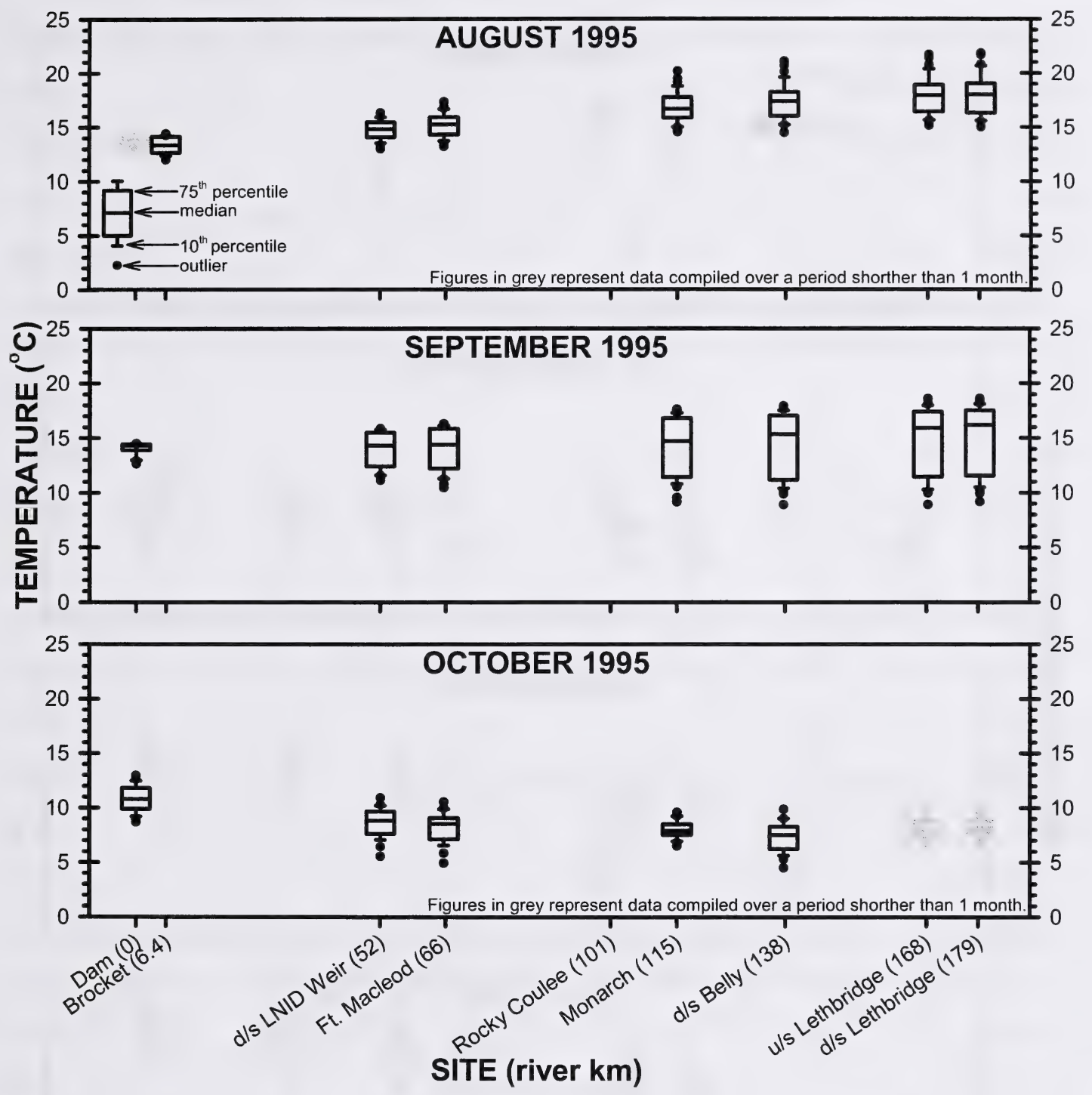

Figure 99. Range in daily mean water temperatures based on Thermograph and Datasonde data*. August-October 1995.

*Where data from both monitoring devices exist, Thermograph data have been used. 

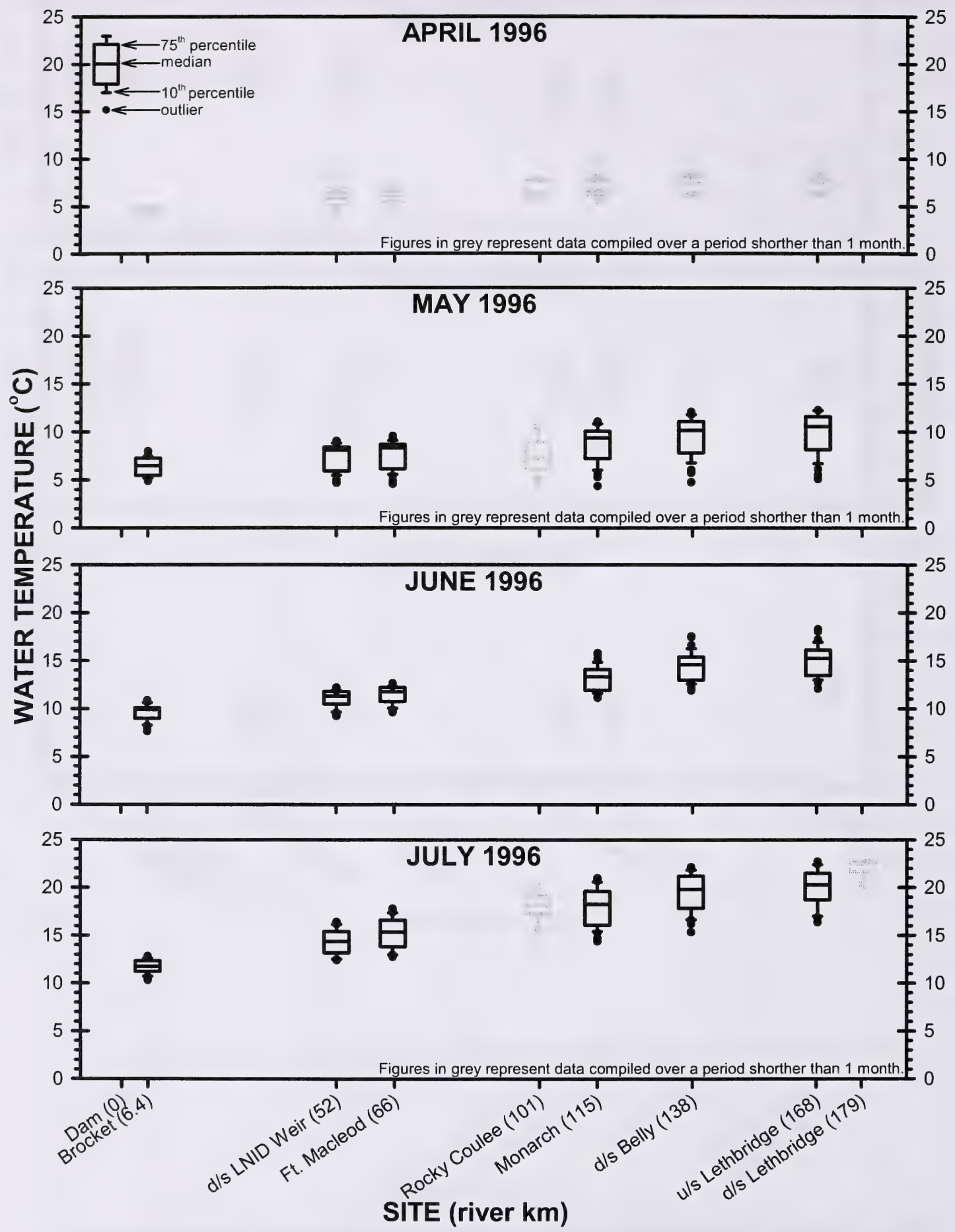

Figure 100. Range in daily mean water temperatures based on Thermograph and Datasonde data*. April-July 1996.

*Where data from both monitoring devices exist, Thermograph data have been used. 

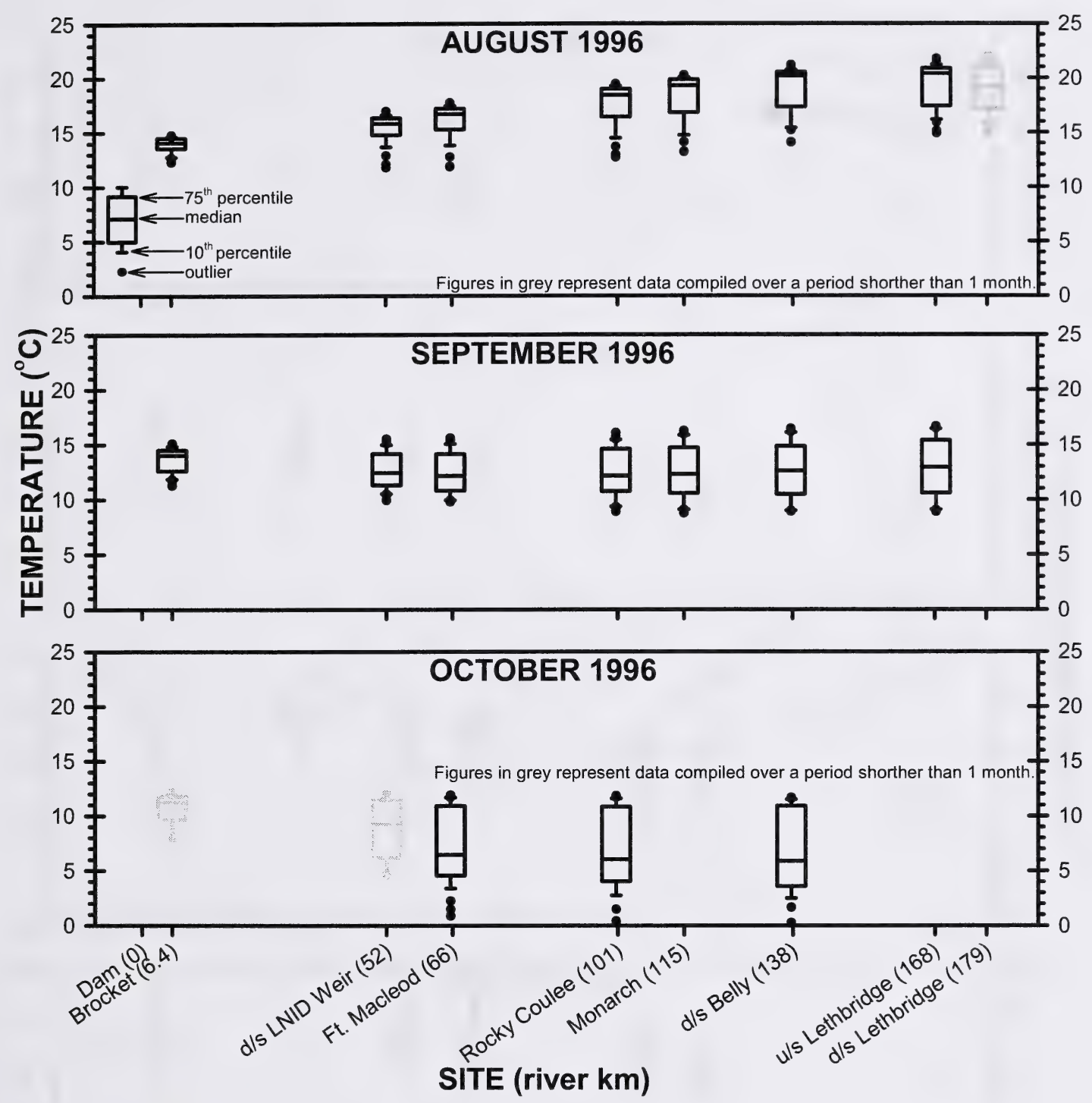

Figure 101. Range in daily mean water temperatures based on Thermograph and Datasonde data*. August-October 1996.

*Where data from both monitoring devices exist, Thermograph data have been used. 

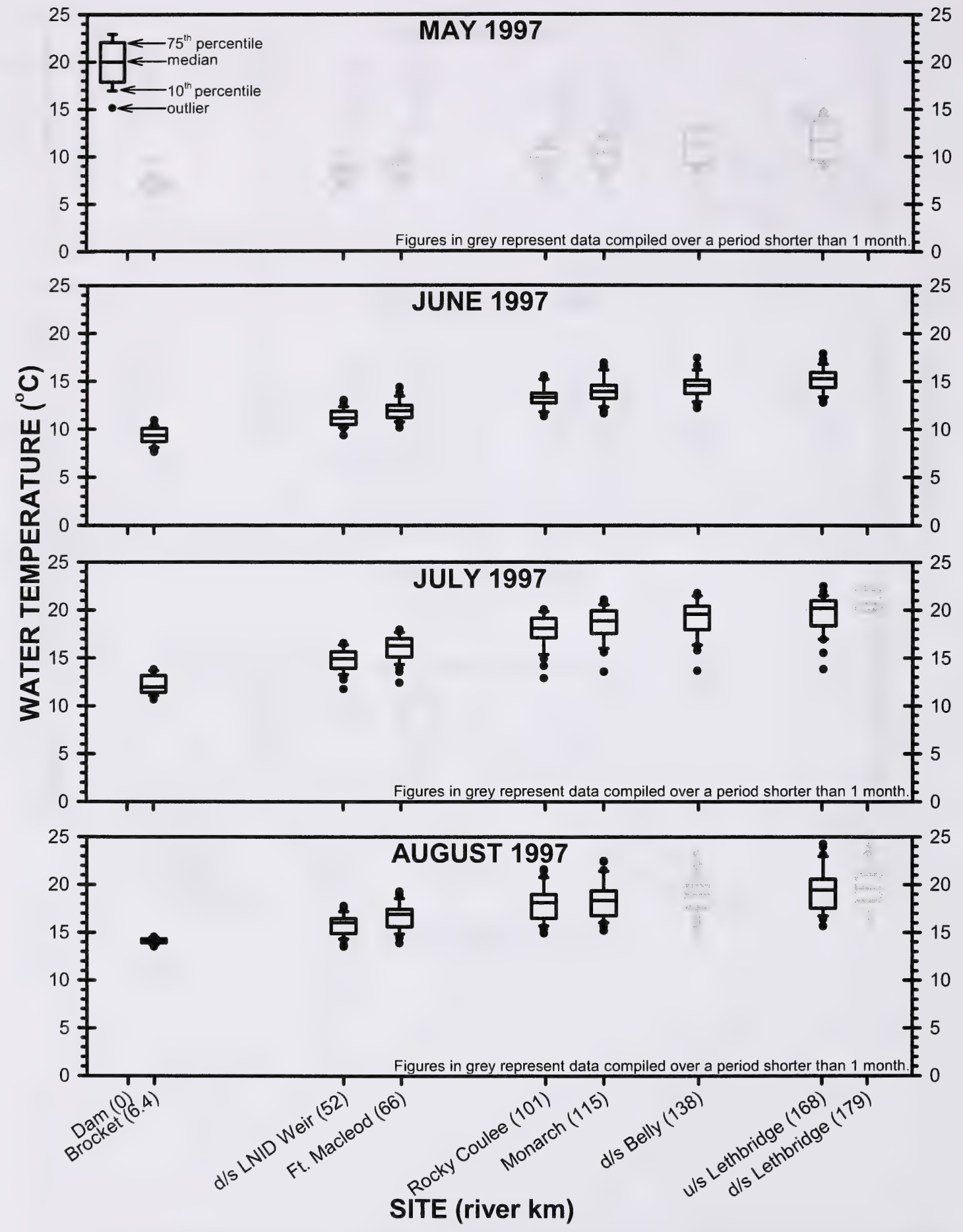

Figure 102. Range in daily mean water temperatures based on Thermograph and Datasonde data*. May-August 1997.

*Where data from both monitoring devices exist, Thermograph data have been used. 


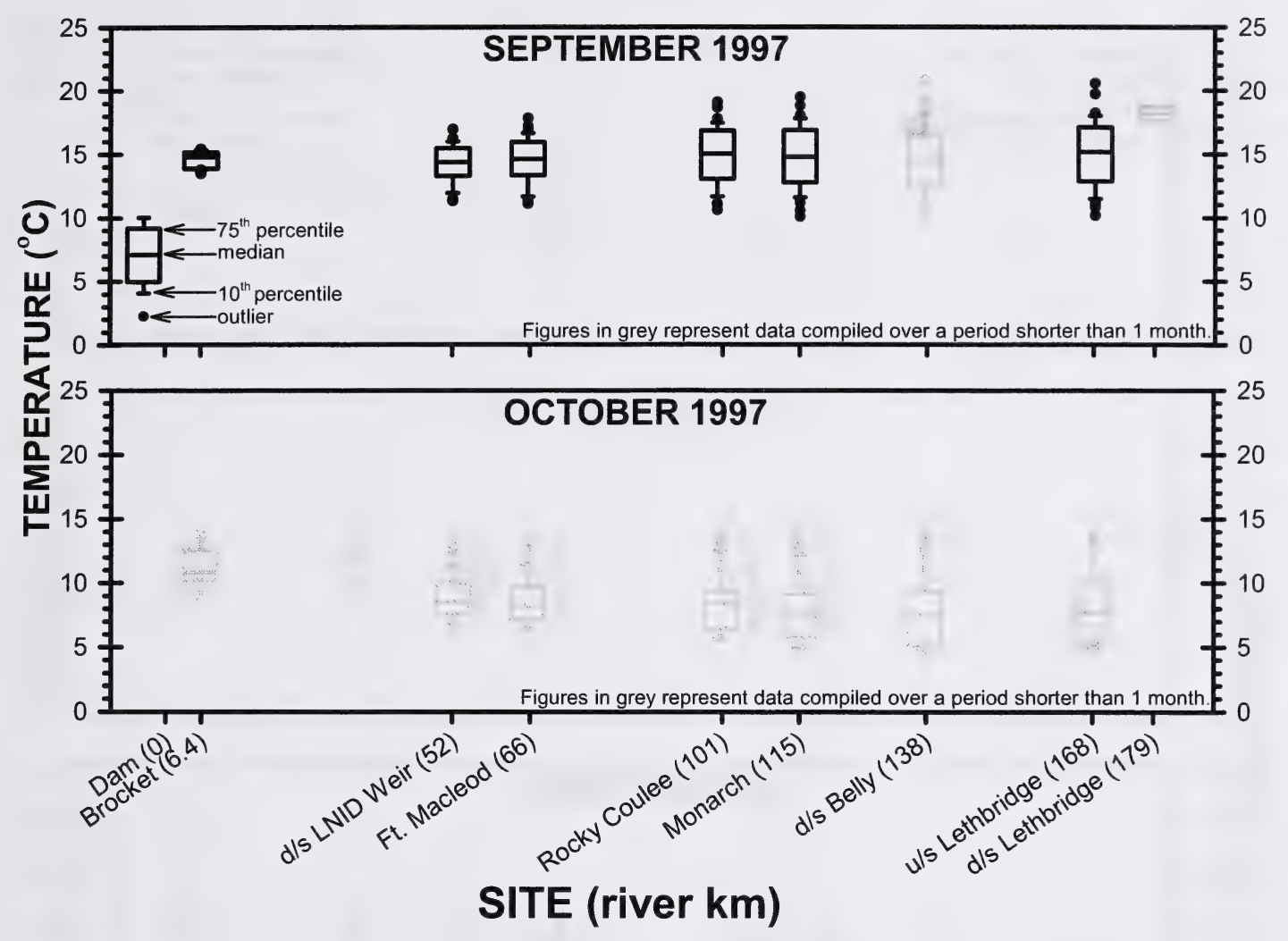

Figure 103. Range in daily mean water temperatures based on Thermograph and Datasonde data*. September-October 1997. *Where data from both monitoring devices exist, Thermograph data have been used. 

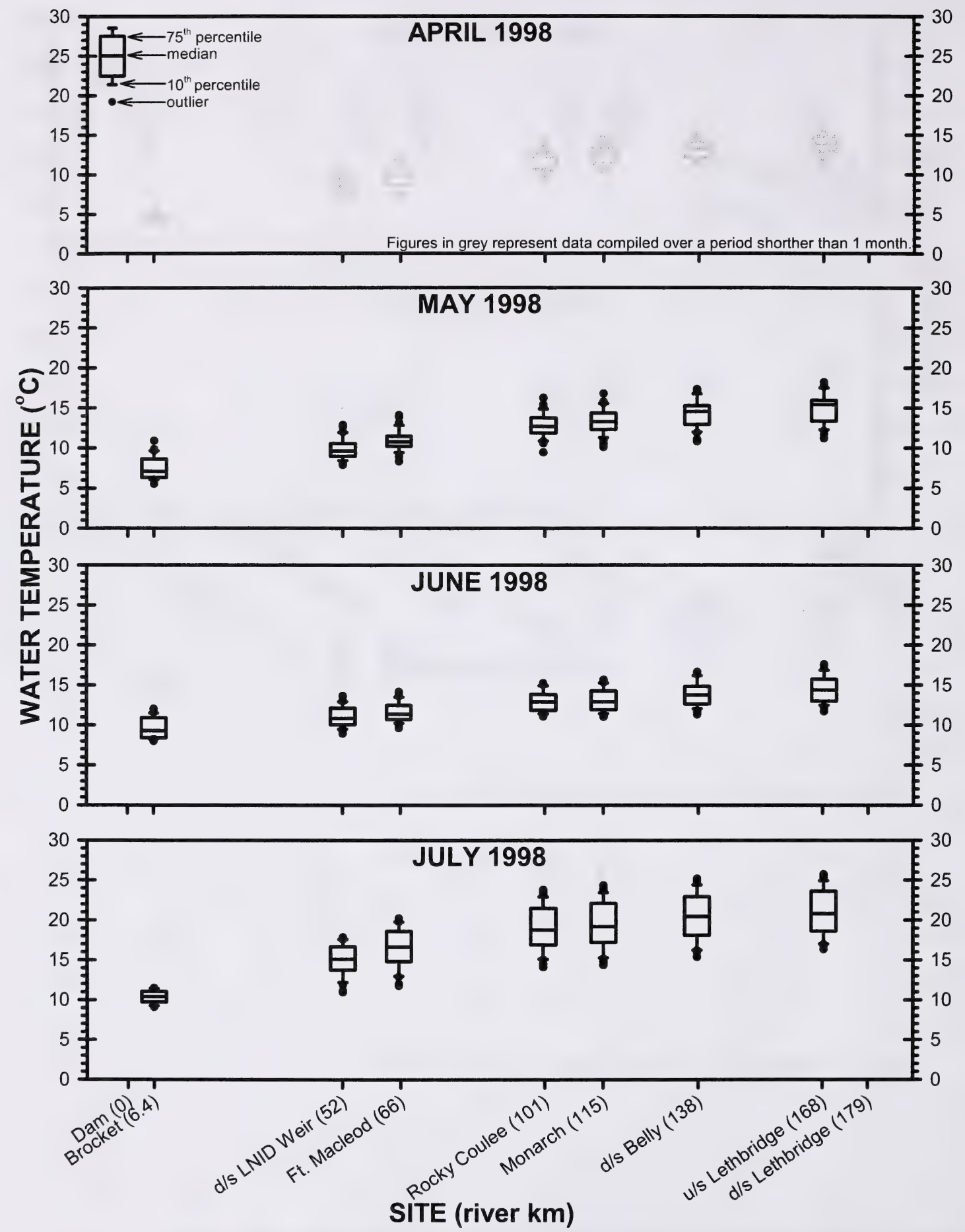

Figure 104. Range in daily mean water temperatures based on Thermograph and Datasonde data*. April-July 1998.

*Where data from both monitoring devices exist, Thermograph data have been used. 


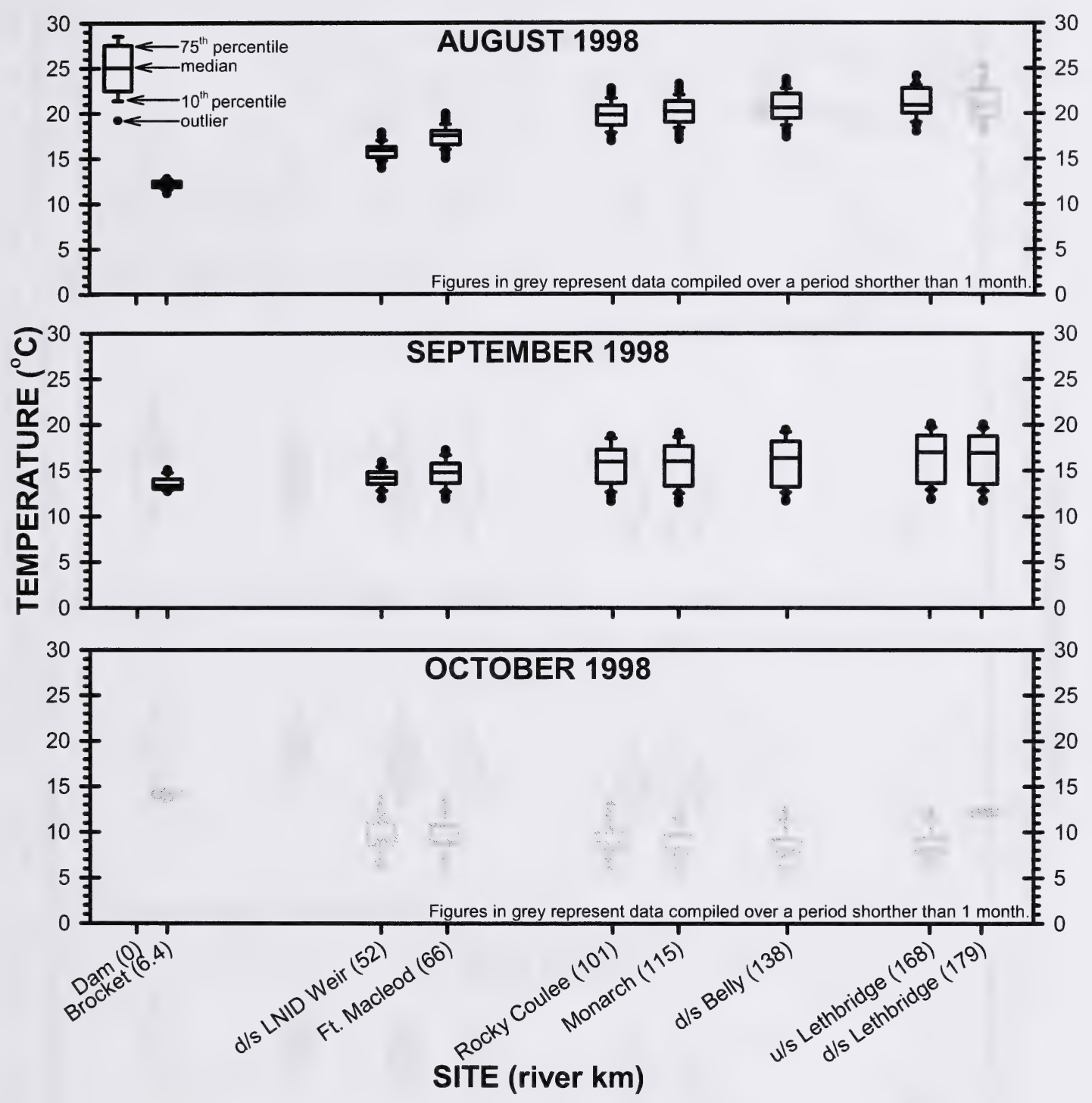

Figure 105. Range in daily mean water temperatures based on Thermograph and Datasonde data*. August-October 1998. *Where data from both monitoring devices exist, Thermograph data have been used. 

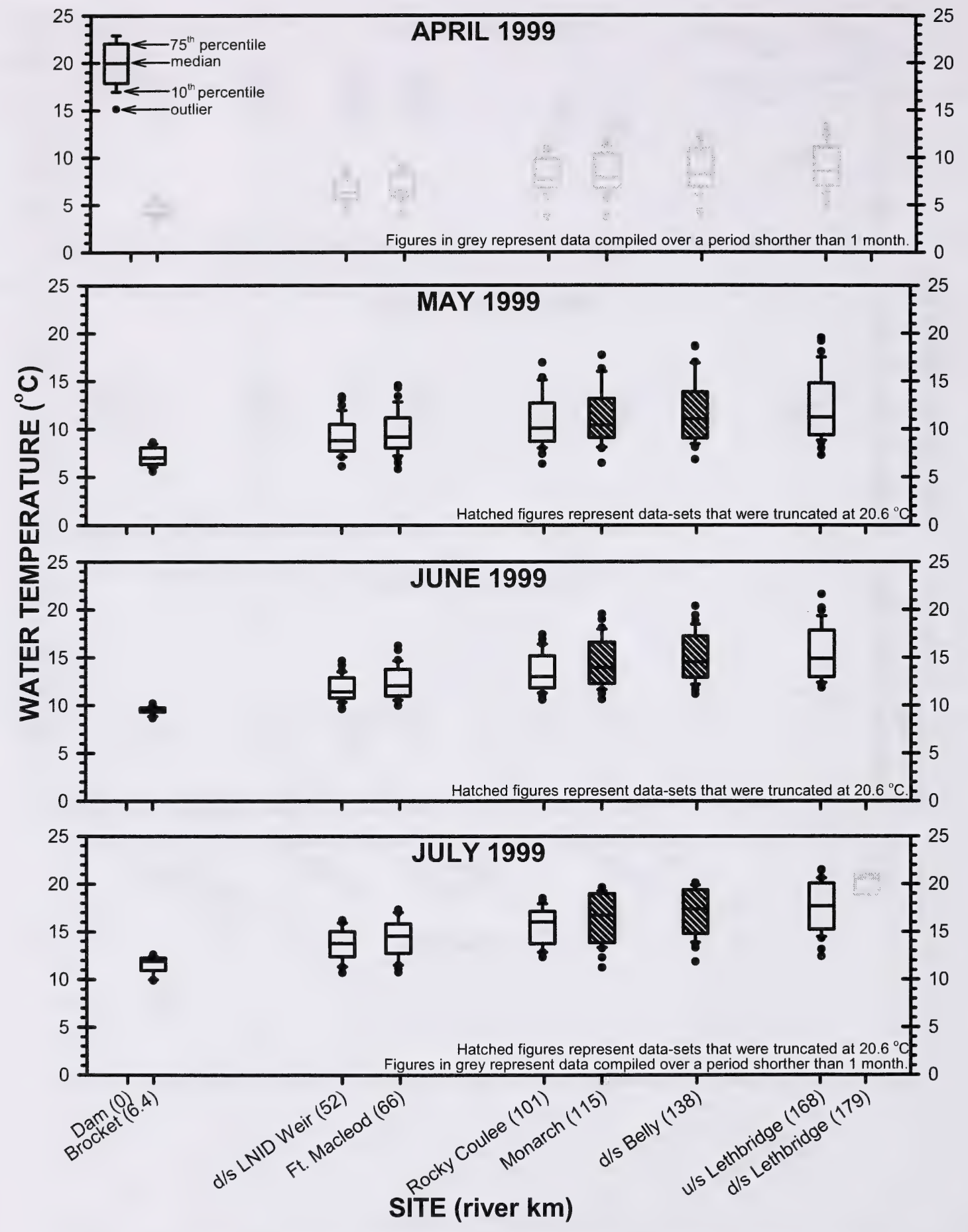

Figure 106. Range in daily mean water temperatures based on Thermograph and Datasonde data*. April-July 1999.

*Where data from both monitoring devices exist, Thermograph data have been used. 


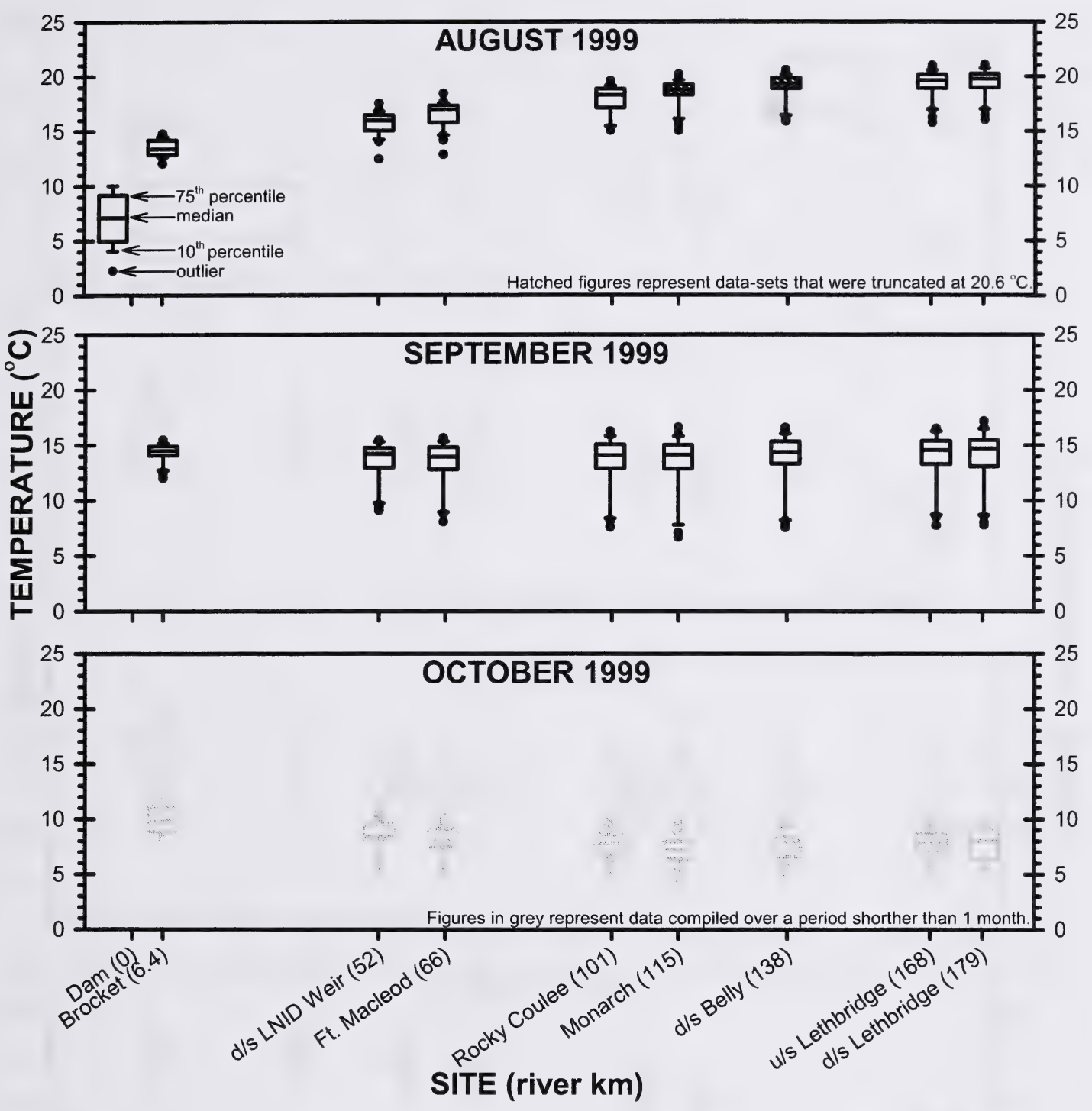

Figure 107. Range in daily mean water temperatures based on Thermograph and Datasonde data*. August-October 1999. *Where data from both monitoring devices exist, Thermograph data have been used. 

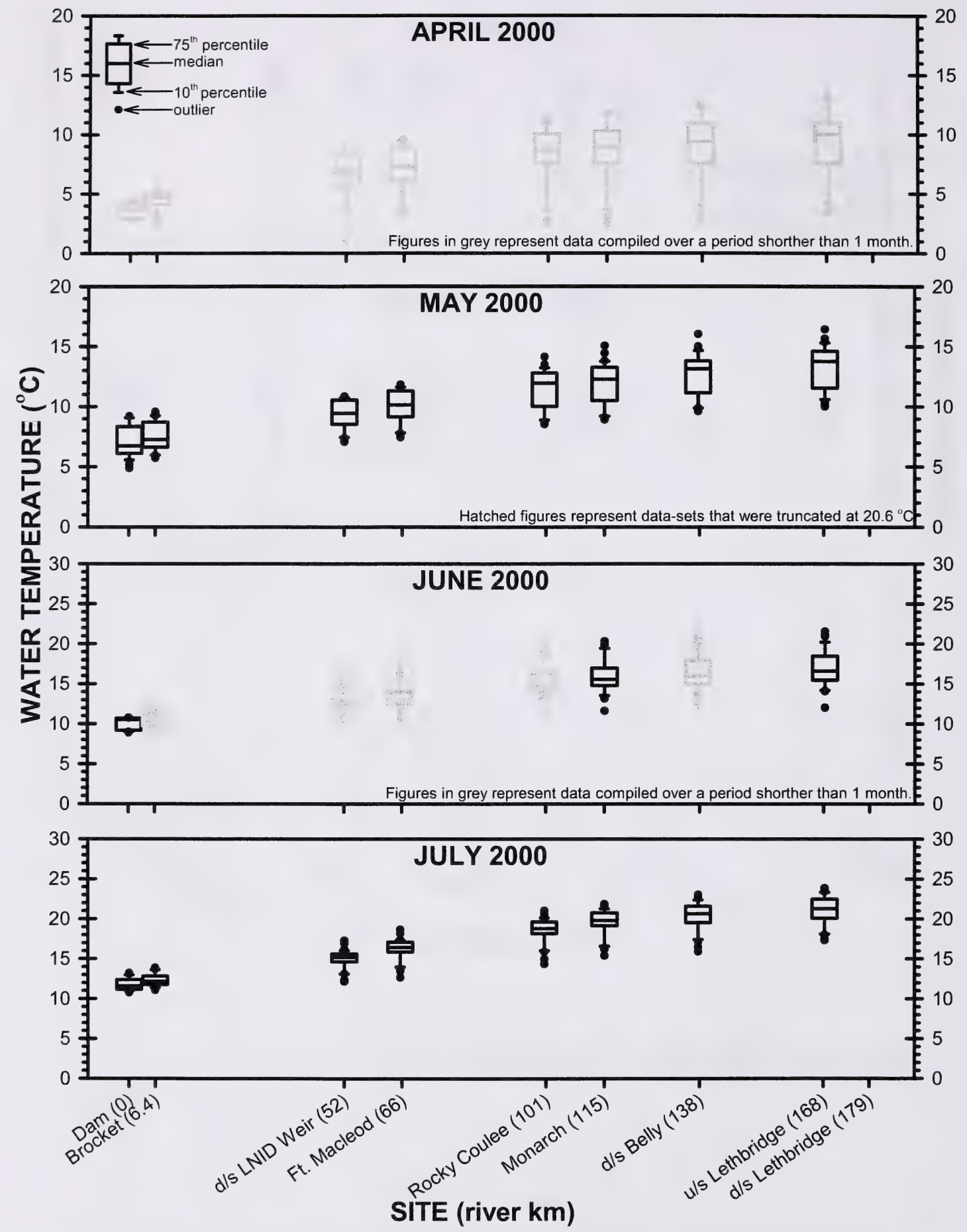

Figure 108. Range in daily mean water temperatures based on Thermograph and Datasonde data*. April-July 2000.

*Where data from both monitoring devices exist, Thermograph data have been used. 


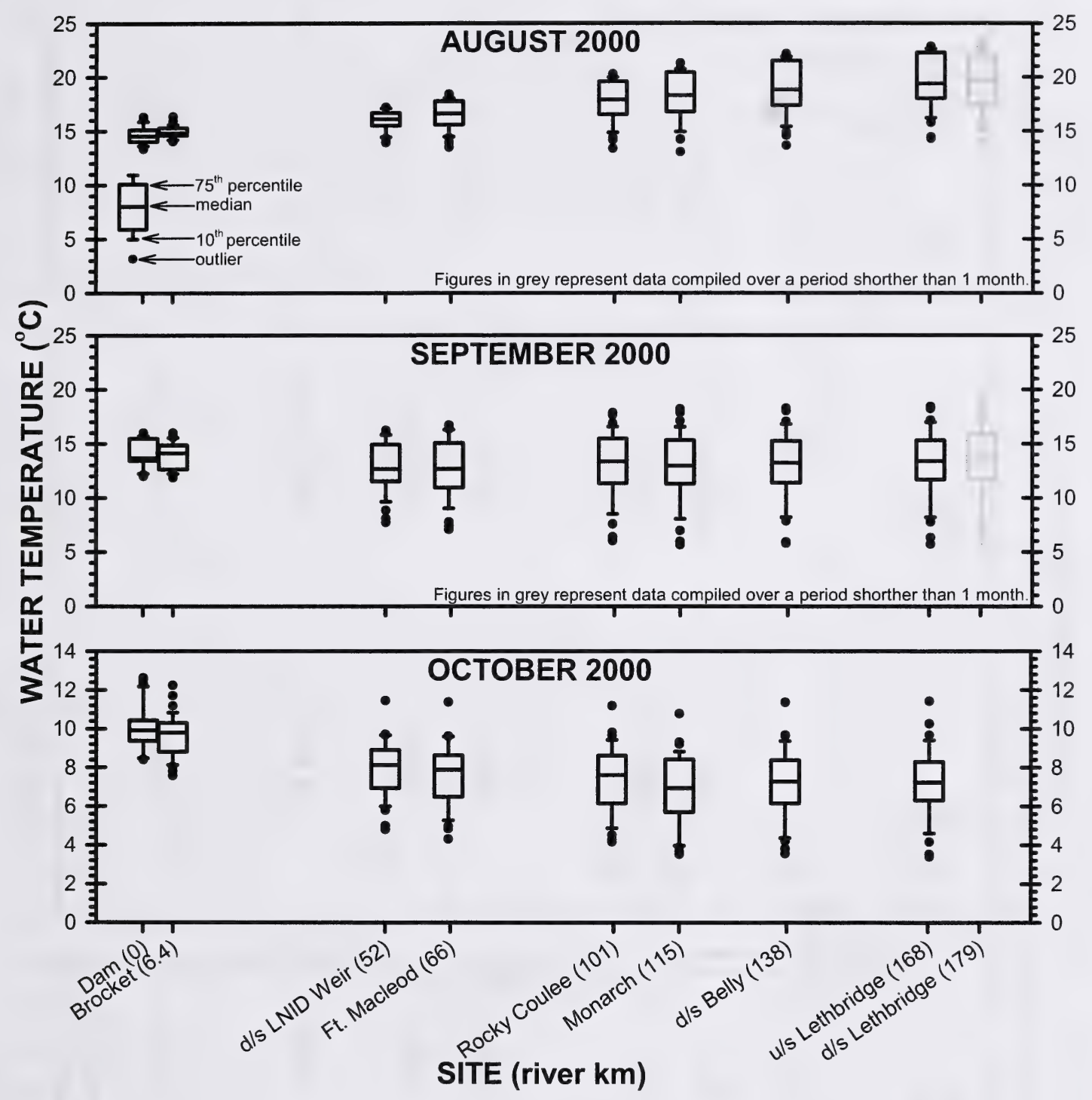

Figure 109. Range in daily mean water temperatures based on Thermograph and Datasonde data*. August-October 2000.

*Where data from both monitoring devices exist, Thermograph data have been used. 


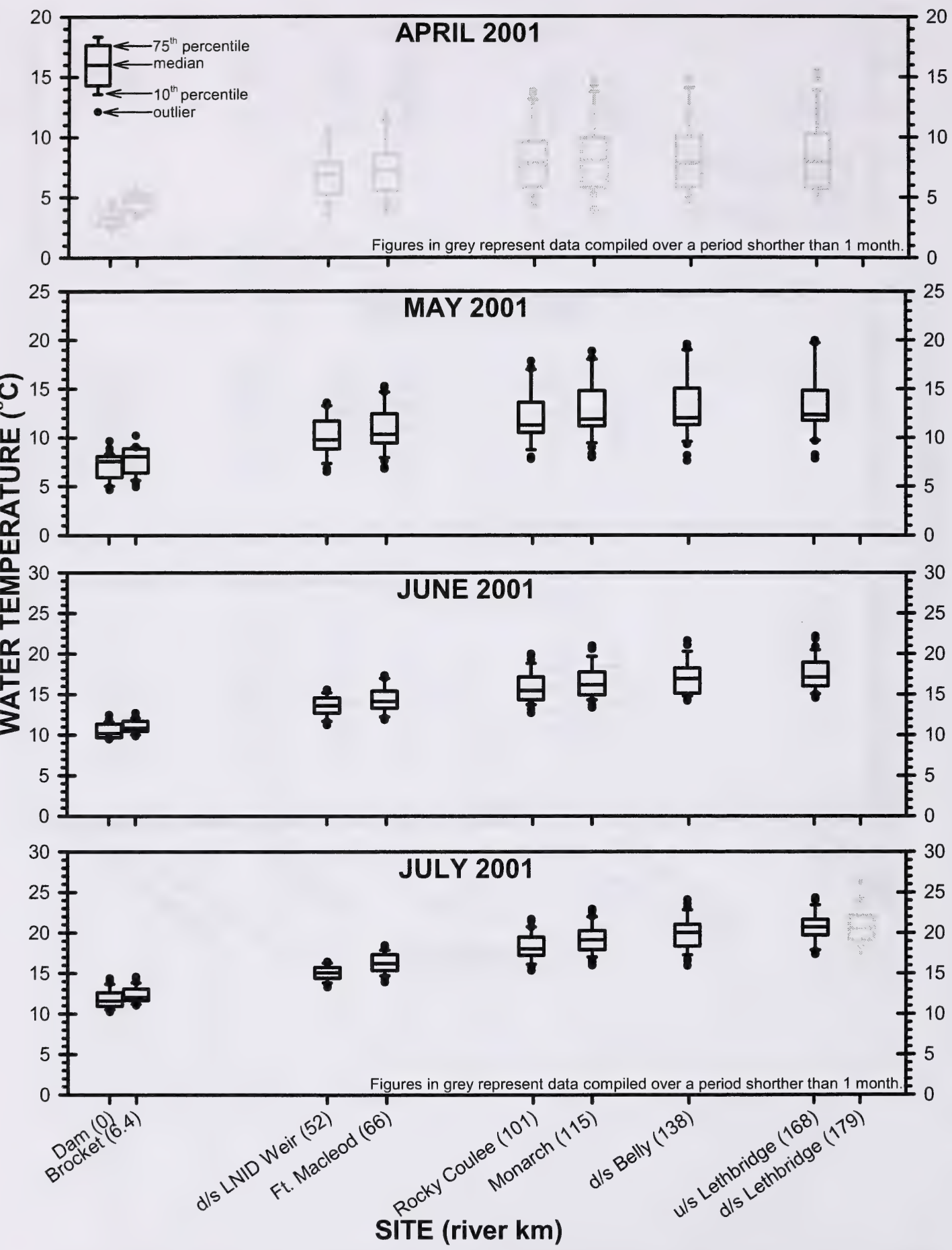

Figure 110. Range in daily mean water temperatures based on Thermograph and Datasonde data*. April-July 2001.

*Where data from both monitoring devices exist, Thermograph data have been used. 

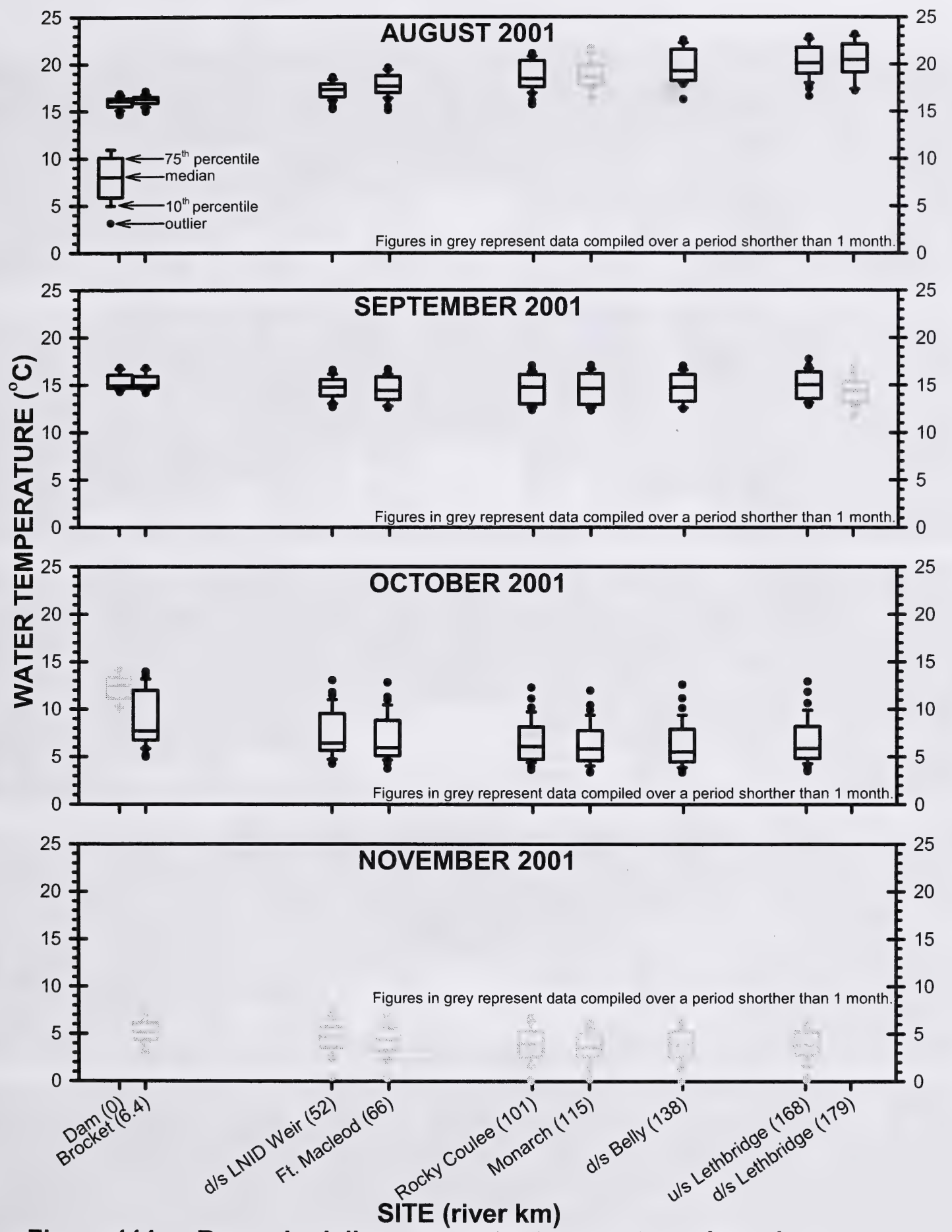

Figure 111. Range in daily mean water temperatures based on Thermograph and Datasonde data*. August-October 2001.

*Where data from both monitoring devices exist, Thermograph data have been used. 
Table 1. Matrix of Tukey pairwise mean comparisons for mean monthly water temperature, April 1994.

\begin{tabular}{|c|c|c|c|c|c|c|c|}
\hline SITE & Brocket & LNHD & Ft. Macleod R. Coulee & Monarch & d/s Belly & u/s Leth. & d/s Leth. \\
\hline Brocket & & & & \multicolumn{4}{|c|}{ Bold type indicates significance at the $95 \%$ level. } \\
\hline LNHD & 0.114 & & & \multicolumn{4}{|c|}{ Grey type indicates that data do not exist for the entire month. } \\
\hline Ft. Macleod & 0.036 & 0.997 & & & & & \\
\hline $\begin{array}{l}\text { R. Coulee } \\
\text { Monarch }\end{array}$ & 0.007 & 0.457 & 0.674 & & & & \\
\hline $\begin{array}{l}\text { Monarch } \\
\text { d/s Belly }\end{array}$ & 0.000 & 0.004 & 0.016 & 0.931 & & & \\
\hline $\begin{array}{l}\text { u/s Leth. } \\
\text { d/s Leth. }\end{array}$ & 0.000 & 0.000 & 0.000 & 0.507 & 0.883 & & \\
\hline
\end{tabular}

Table 2. Matrix of Tukey pairwise mean comparisons for mean monthly water temperature, May 1994.

\begin{tabular}{|c|c|c|c|c|c|c|c|c|}
\hline SITE & Brocket & LNHD & Ft. Macleod & R. Coulee & Monarch & d/s Belly & u/s Leth. & d/s Leth. \\
\hline Brocket & & & & & & & & \\
\hline LNHD & 0.000 & & & & & & & \\
\hline Ft. Macleod & 0.000 & 0.886 & & & & & & \\
\hline Monarch & 0.000 & 0.000 & 0.000 & & & & & \\
\hline d/s Belly & 0.000 & 0.000 & 0.000 & & 0.021 & & & \\
\hline $\begin{array}{l}\text { u/s Leth. } \\
\text { d/s Leth. }\end{array}$ & 0.000 & 0.000 & 0.000 & & 0.000 & 0.286 & & \\
\hline
\end{tabular}

Table 3. Matrix of Tukey pairwise mean comparisons for mean monthly water temperature, June 1994.

\begin{tabular}{|c|c|c|c|c|c|c|c|c|}
\hline SITE & Brocket & LNHD & Ft. Macleod & R. Coulee & Monarch & d/s Belly & u/s Leth. & d/s Leth. \\
\hline Brocket & & & & & & & & \\
\hline LNHD & 0.000 & & & & & & & \\
\hline Ft. Macleod & 0.084 & 0.955 & & & & & & \\
\hline R. Coulee & & & & & & & & \\
\hline Monarch & 0.000 & 0.531 & 0.191 & & & & & \\
\hline d/s Belly & 0.000 & 0.000 & 0.000 & & 0.018 & & & \\
\hline u/s Leth. & 0.000 & 0.000 & 0.000 & & 0.002 & 0.981 & & \\
\hline d/s Leth. & 0.000 & 0.000 & 0.000 & & 0.000 & 0.037 & 0.208 & \\
\hline
\end{tabular}

Table 4. Matrix of Tukey pairwise mean comparisons for mean monthly water temperature, July 1994.

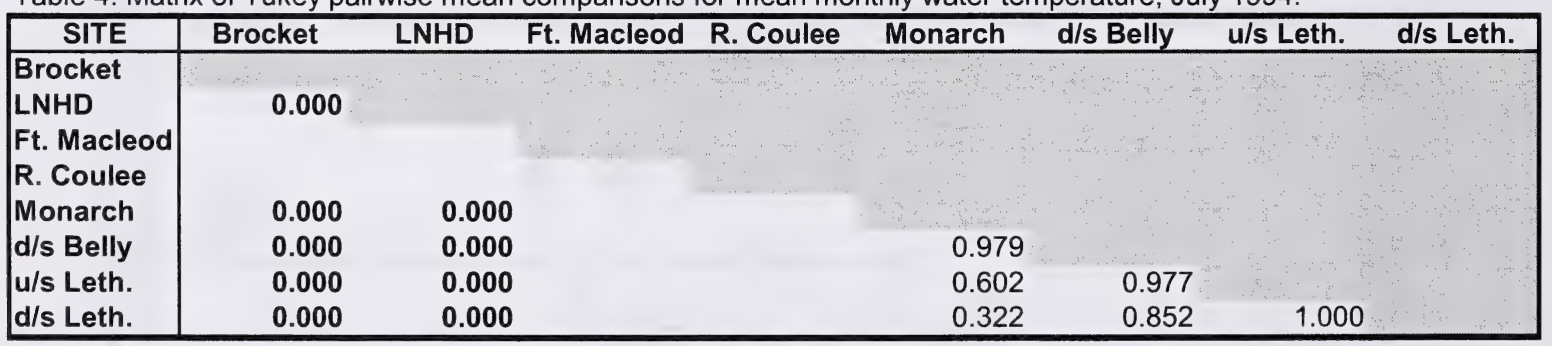

Table 5. Matrix of Tukey pairwise mean comparisons for mean monthly water temperature, August 1994.

\begin{tabular}{|c|c|c|c|c|c|c|c|c|}
\hline \multirow{2}{*}{\multicolumn{9}{|c|}{ Ft. Macleod R. Coulee }} \\
\hline & & & & & & & & \\
\hline LNHD & 0.000 & & & & & & & \\
\hline Ft. Macleod & 0.000 & 0.987 & & & & & & \\
\hline $\begin{array}{l}\text { R. Coulee } \\
\text { Monarch }\end{array}$ & 0.000 & 0.000 & 0.003 & & & & & \\
\hline d/s Belly & 0.000 & 0.004 & 0.000 & & 0.979 & & & \\
\hline u/s Leth. & 0.000 & 0.000 & 0.000 & & 0.680 & 0.991 & & \\
\hline d/s Leth. & 0.000 & 0.000 & 0.000 & & 0.481 & 0.944 & 1.000 & \\
\hline
\end{tabular}

Temperature and Dissolved Oxygen in the Oldman River Following Construction of the Oldman River Dam 204 
Table 6. Matrix of Tukey pairwise mean comparisons for mean monthly water temperature, September 1994.

\begin{tabular}{|c|c|c|c|c|c|c|c|}
\hline SITE & Brocket & LNHD & Ft. Macleod & R. Coulee & Monarch & d/s Belly & u/s Leth. \\
\hline Brocket & & & & & \multirow{2}{*}{\multicolumn{3}{|c|}{$\begin{array}{l}\text { Bold type indicates significance at the } 95 \% \text { level. } \\
\text { Grey type indicates that data do not exist for the entire month. }\end{array}$}} \\
\hline LNHD & 0.999 & & & & & & \\
\hline Ft. Macleod & 0.920 & 0.996 & & & & & \\
\hline R. Coulee & & & & & & & \\
\hline Monarch & 0.966 & 0.772 & 0.373 & & & & \\
\hline d/s Belly & 0.578 & 0.259 & 0.060 & & 0.983 & & \\
\hline u/s Leth. & 0.127 & 0.031 & 0.004 & & 0.646 & 0.981 & \\
\hline d/s Leth. & 0.006 & 0.001 & 0.000 & & 0.110 & 0.520 & 0.954 \\
\hline
\end{tabular}

Table 7. Matrix of Tukey pairwise mean comparisons for mean monthly water temperature, October 1994.

\begin{tabular}{|c|c|c|c|c|c|c|c|}
\hline SITE & Brocket & LNHD & Ft. Macleod R. Coulee & Monarch & d/s Belly & u/s Leth. & d/s Leth. \\
\hline Brocket & & & & & & & \\
\hline LNHD & 0.000 & & & & & & \\
\hline Ft. Macleod & 0.000 & 0.969 & & & & & \\
\hline R. Coulee & & & & & & & \\
\hline Monarch & 0.000 & 0.003 & 0.051 & & & & \\
\hline d/s Belly & 0.000 & 0.081 & 0.513 & 0.851 & & & \\
\hline u/s Leth. & 0.000 & 0.067 & 0.464 & 0.879 & 1.000 & & \\
\hline d/s Leth. & 0.090 & 0.996 & 1.000 & 0.817 & 0.992 & 0.990 & \\
\hline
\end{tabular}

Table 8. Matrix of Tukey pairwise mean comparisons for mean monthly water temperature, April 1995.

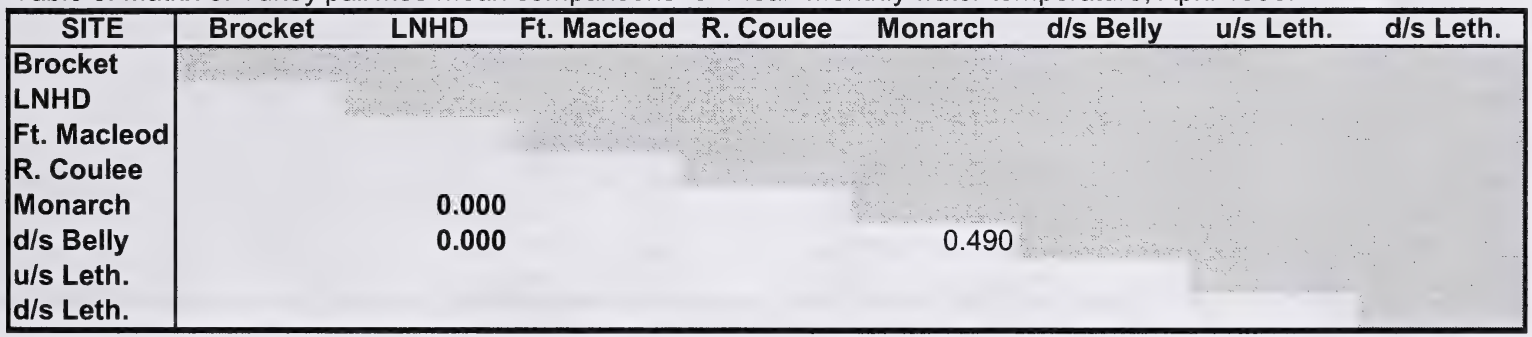

Table 9. Matrix of Tukey pairwise mean comparisons for mean monthly water temperature, May 1995.

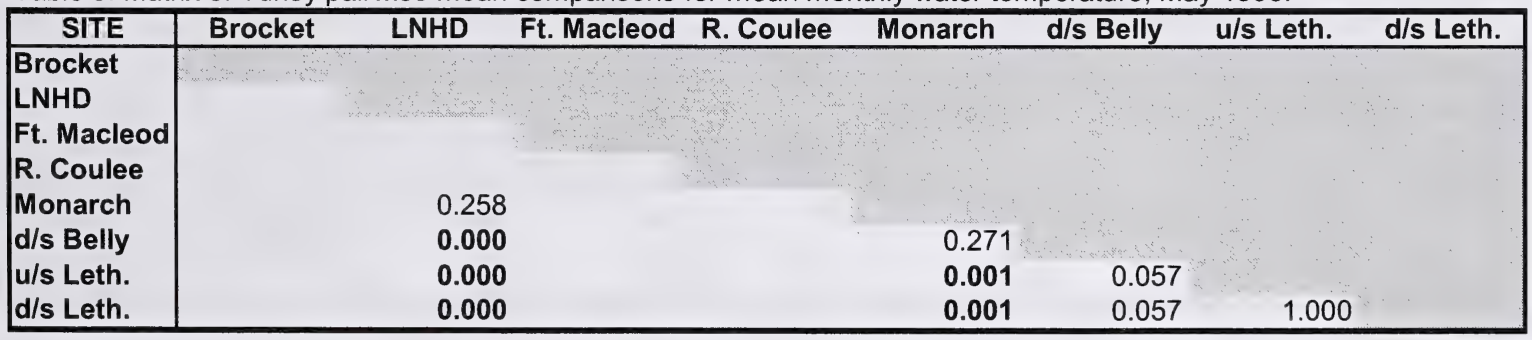

Table 10. Matrix of Tukey pairwise mean comparisons for mean monthly water temperature, June 1995.

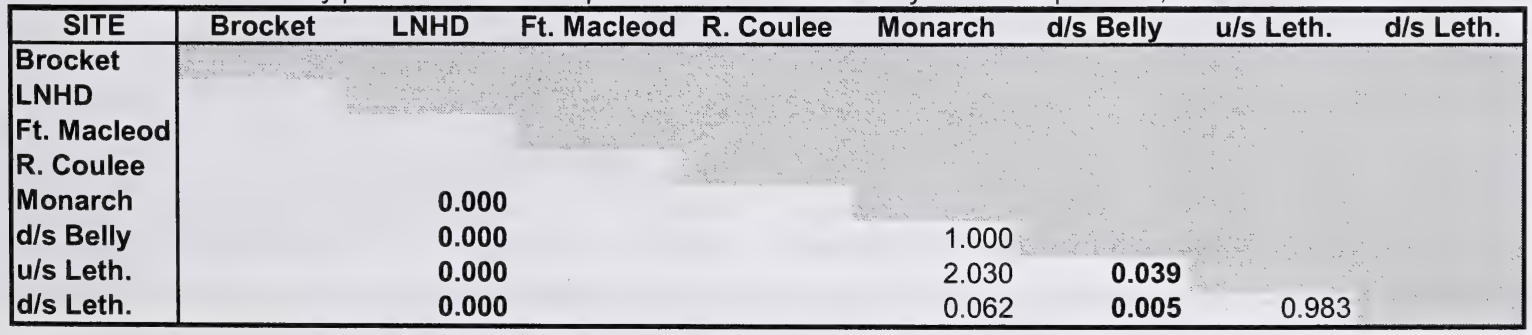

Temperature and Dissolved Oxygen in the Oldman River Following Construction of the Oldman River Dam 205 
Table 11. Matrix of Tukey pairwise mean comparisons for mean monthly water temperature, July 1995.

\begin{tabular}{|c|c|c|c|c|c|c|}
\hline SITE & Brocket & LNHD & Ft. Macleod R. Coulee & Monarch & d/s Belly & u/s Leth. \\
\hline Brocket & & & & \multirow{2}{*}{\multicolumn{3}{|c|}{$\begin{array}{l}\text { Bold type indicates significance at the } 95 \% \text { level. } \\
\text { Grey type indicates that data do not exist for the entire month. }\end{array}$}} \\
\hline LNHD & 0.105 & & & & & \\
\hline Ft. Macleod & 0.000 & 0.001 & & & & \\
\hline R. Coulee & & & & & & \\
\hline Monarch & 0.000 & 0.000 & 0.006 & & & \\
\hline d/s Belly & 0.000 & 0.000 & 0.000 & 0.997 & & \\
\hline u/s Leth. & 0.000 & 0.000 & 0.000 & 0.011 & 0.000 & \\
\hline d/s Leth. & 0.000 & 0.000 & 0.000 & 0.002 & 0.000 & 0.996 \\
\hline
\end{tabular}

Table 12. Matrix of Tukey pairwise mean comparisons for mean monthly water temperature, August 1995.

\begin{tabular}{|c|c|c|c|c|c|c|c|}
\hline \multirow{2}{*}{\multicolumn{8}{|c|}{ Ft. Macleod R. Coulee }} \\
\hline & & & & & & & \\
\hline LNHD & 0.018 & & & & & & \\
\hline Ft. Macleod & 0.000 & 0.880 & & & & & \\
\hline $\begin{array}{l}\text { R. Coulee } \\
\text { Monarch }\end{array}$ & 0.000 & 0.000 & 0.000 & & & & \\
\hline d/s Belly & 0.000 & 0.000 & 0.000 & 0.935 & & & \\
\hline u/s Leth. & 0.000 & 0.000 & 0.000 & 0.055 & 0.616 & & \\
\hline d/s Leth. & 0.000 & 0.000 & 0.000 & 0.026 & 0.449 & 1.000 & \\
\hline
\end{tabular}

Table 13. Matrix of Tukey pairwise mean comparisons for mean monthly water temperature, September 1995.

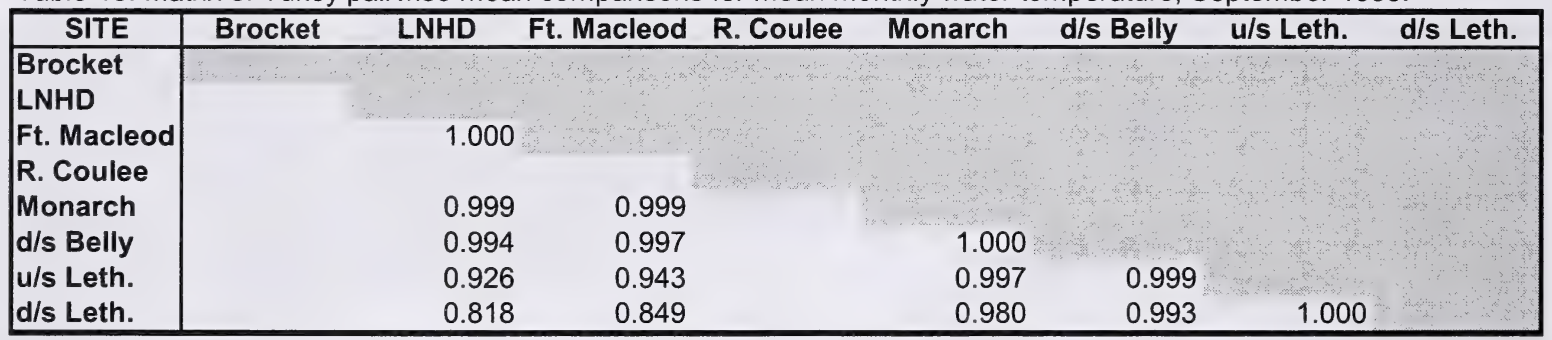

Table 14. Matrix of Tukey pairwise mean comparisons for mean monthly water temperature, October 1995.

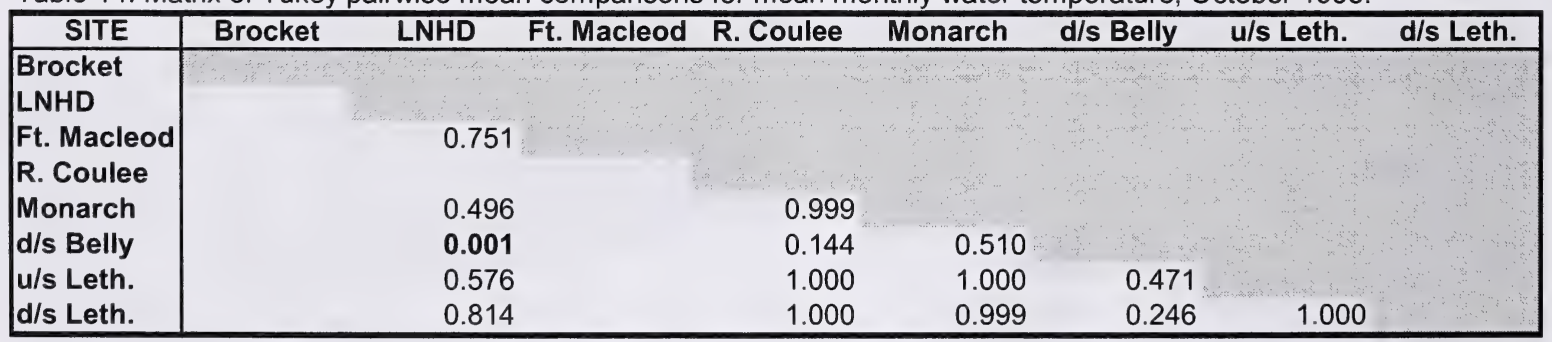

Table 15. Matrix of Tukey pairwise mean comparisons for mean monthly water temperature, April 1996.

\begin{tabular}{|c|c|c|c|c|c|c|c|c|}
\hline \multirow{2}{*}{$\frac{\text { SITE }}{\text { Brocket }}$} & Brocket & LNHD & Ft. Macleod & R. Coulee & Monarch & d/s Belly & $u / s$ Leth. & d/s Leth. \\
\hline & & & & & & & & \\
\hline LNHD & 0.025 & & & & & & & \\
\hline Ft. Macleod & 0.005 & 0.998 & & & & & & \\
\hline R. Coulee & 0.000 & 0.179 & 0.441 & & & & & \\
\hline Monarch & 0.000 & 0.138 & 0.365 & 1.000 & & & & \\
\hline d/s Belly & 0.000 & 0.009 & 0.034 & 0.846 & 0.896 & & & \\
\hline $\begin{array}{l}\text { u/s Leth. } \\
\text { d/s Leth. }\end{array}$ & 0.000 & 0.006 & 0.026 & 0.792 & 0.852 & 1.000 & & \\
\hline
\end{tabular}


Table 16. Matrix of Tukey pairwise mean comparisons for mean monthly water temperature, May 1996.

\begin{tabular}{|c|c|c|c|c|c|c|c|c|}
\hline SITE & Brocket & LNHD & Ft. Macleod & R. Coulee & Monarch & d/s Belly & u/s Leth. & d/s Leth \\
\hline Brocket & & & & & \multicolumn{4}{|c|}{ Bold type indicates significance at the $95 \%$ level. } \\
\hline LNHD & 0.213 & & & & \multicolumn{4}{|c|}{ Grey type indicates that data do not exist for the entire month. } \\
\hline Ft. Macleod & 0.059 & 0.999 & & & & & & \\
\hline R. Coulee & 0.262 & 1.000 & 1.000 & & & & & \\
\hline Monarch & 0.000 & 0.039 & 0.157 & 0.302 & & & & \\
\hline d/s Belly & 0.000 & 0.000 & 0.000 & 0.003 & 0.487 & & & \\
\hline $\begin{array}{l}\text { u/s Leth. } \\
\text { d/s Leth. }\end{array}$ & 0.000 & 0.000 & 0.000 & 0.000 & 0.114 & 0.985 & & \\
\hline
\end{tabular}

Table 17. Matrix of Tukey pairwise mean comparisons for mean monthly water temperature, June 1996.

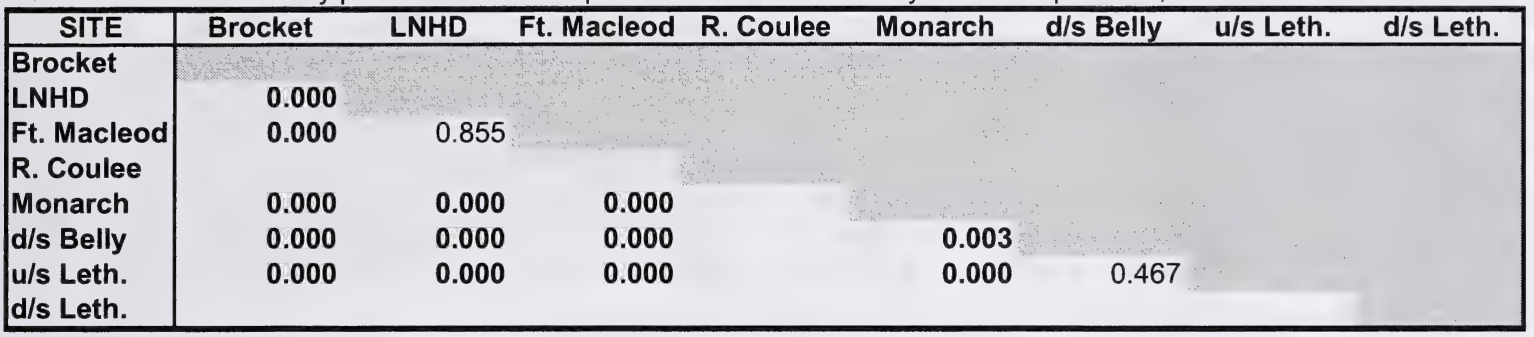

Table 18. Matrix of Tukey pairwise mean comparisons for mean monthly water temperature, July 1996.

\begin{tabular}{|c|c|c|c|c|c|c|c|c|}
\hline \multirow{2}{*}{\begin{tabular}{|r|} 
SITE \\
Brocket
\end{tabular}} & Brocket & LNHD & Ft. Macleod & R. Coulee & Monarch & d/s Belly & u/s Leth. & d/s Leth. \\
\hline & & & & & & & & \\
\hline LNHD & 0.000 & & & & & & & \\
\hline Ft. Macleod & 0.000 & 0.511 & & & & & & \\
\hline R. Coulee & 0.000 & 0.000 & 0.000 & & & & & \\
\hline Monarch & 0.000 & 0.000 & 0.000 & 1.000 & & & & \\
\hline d/s Belly & 0.000 & 0.000 & 0.000 & 0.026 & 0.013 & & & \\
\hline u/s Leth. & 0.000 & 0.000 & 0.000 & 0.000 & 0.000 & 0.890 & & \\
\hline d/s Leth. & 0.000 & 0.000 & 0.000 & 0.000 & 0.000 & 0.003 & 0.068 & \\
\hline
\end{tabular}

Table 19. Matrix of Tukey pairwise mean comparisons for mean monthly water temperature, August 1996.

\begin{tabular}{|c|c|c|c|c|c|c|c|c|}
\hline \multirow{2}{*}{\begin{tabular}{|r|} 
SITE \\
Brocket
\end{tabular}} & Brocket & LNHD & Ft. Macleod & R. Coulee & Monarch & d/s Belly & u/s Leth. & d/s Leth. \\
\hline & & & & & & & & \\
\hline LNHD & 0.198 & & & & & & & \\
\hline Ft. Macleod & 0.005 & 0.939 & & & & & & \\
\hline R. Coulee & 0.000 & 0.000 & 0.030 & & & & & \\
\hline Monarch & 0.000 & 0.000 & 0.000 & 0.891 & & & & \\
\hline d/s Belly & 0.000 & 0.000 & 0.000 & 0.091 & 0.869 & & & \\
\hline u/s Leth. & 0.000 & 0.000 & 0.000 & 0.004 & 0.273 & 0.990 & & \\
\hline d/s Leth. & 0.000 & 0.000 & 0.000 & 0.056 & 0.722 & 1.000 & 1.000 & \\
\hline
\end{tabular}

Table 20. Matrix of Tukey pairwise mean comparisons for mean monthly water temperature, September 1996.

\begin{tabular}{|c|c|c|c|c|c|c|c|c|}
\hline SITE & Brocket & LNHD & Ft. Macleod & R. Coulee & Monarch & d/s Belly & u/s Leth. & $\mathrm{d} / \mathrm{s}$ Leth. \\
\hline Brocket & & & & & & & & \\
\hline LNHD & 0.458 & & & & & & & \\
\hline Ft. Macleod & 0.295 & 1.000 & & & & & & \\
\hline R. Coulee & 0.217 & 0.998 & 1.000 & & & & & \\
\hline Monarch & 0.241 & 0.999 & 1.000 & 1.000 & & & & \\
\hline d/s Belly & 0.426 & 1.000 & 1.000 & 1.000 & 1.000 & & & \\
\hline $\begin{array}{l}\text { u/s Leth. } \\
\text { d/s Leth. }\end{array}$ & 0.719 & 1.000 & 0.995 & 0.984 & 0.988 & 0.999 & & \\
\hline
\end{tabular}


Table 21. Matrix of Tukey pairwise mean comparisons for mean monthly water temperature, October 1996.

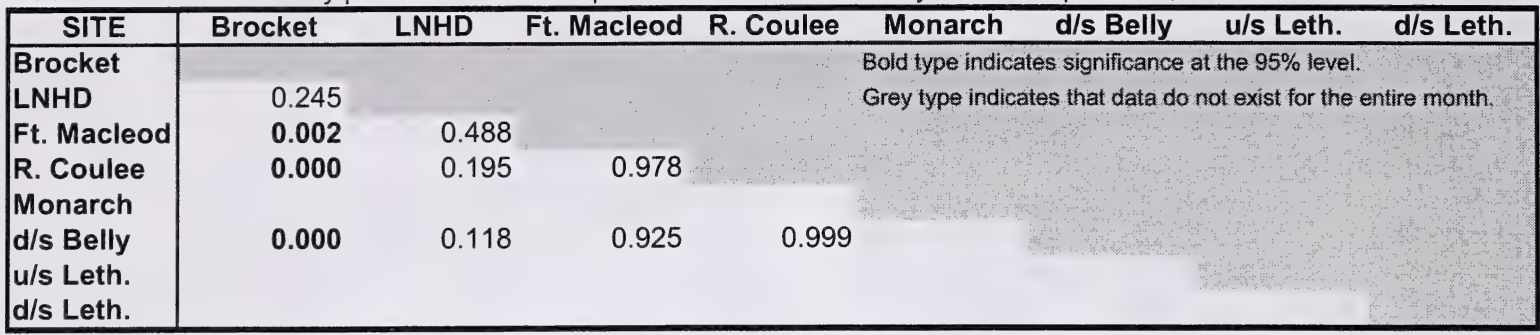

Table 22. Matrix of Tukey pairwise mean comparisons for mean monthly water temperature, May 1997.

\begin{tabular}{|c|c|c|c|c|c|c|c|c|}
\hline \multirow{2}{*}{\multicolumn{9}{|c|}{ Ft. Macleod R. Coulee }} \\
\hline & & & & & & & & \\
\hline LNHD & 0.043 & & & & & & & \\
\hline Ft. Macleod & 0.000 & 0.734 & & & & & & \\
\hline R. Coulee & 0.000 & 0.002 & 0.190 & & & & & \\
\hline Monarch & 0.000 & 0.000 & 0.031 & 0.993 & & & & \\
\hline d/s Belly & 0.000 & 0.000 & 0.000 & 0.055 & 0.279 & & & \\
\hline $\begin{array}{l}\text { u/s Leth. } \\
\text { d/s Leth. }\end{array}$ & 0.000 & 0.000 & 0.000 & 0.000 & 0.001 & 0.583 & & \\
\hline
\end{tabular}

Table 23. Matrix of Tukey pairwise mean comparisons for mean monthly water temperature, June 1997.

\begin{tabular}{|c|c|c|c|c|c|c|c|c|}
\hline \multirow{2}{*}{\begin{tabular}{|r|} 
SITE \\
Brocket
\end{tabular}} & Brocket & LNHD & Ft. Macleod & R. Coulee & Monarch & d/s Belly & u/s Leth. & d/s Leth. \\
\hline & & & & & & & & \\
\hline LNHD & 0.000 & & & & & & & \\
\hline Ft. Macleod & 0.000 & 0.097 & & & & & & \\
\hline R. Coulee & 0.000 & 0.000 & 0.000 & & & & & \\
\hline Monarch & 0.000 & 0.000 & 0.000 & 0.355 & & & & \\
\hline d/s Belly & 0.000 & 0.000 & 0.000 & 0.002 & 0.570 & & & \\
\hline $\begin{array}{l}\text { u/s Leth. } \\
\text { d/s Leth. }\end{array}$ & 0.000 & 0.000 & 0.000 & 0.000 & 0.000 & 0.164 & & \\
\hline
\end{tabular}

Table 24. Matrix of Tukey pairwise mean comparisons for mean monthly water temperature, July 1997.

\begin{tabular}{|c|c|c|c|c|c|c|c|c|}
\hline SITE & Brocket & LNHD & Ft. Macleod & R. Coulee & Monarch & d/s Belly & u/s Leth. & d/s Leth. \\
\hline Brocket & & & & & & & & \\
\hline LNHD & 0.000 & & & & & & & \\
\hline Ft. Macleod & 0.000 & 0.054 & & & & & & \\
\hline R. Coulee & 0.000 & 0.000 & 0.000 & & & & & \\
\hline Monarch & 0.000 & 0.000 & 0.000 & 0.583 & & & & \\
\hline d/s Belly & 0.000 & 0.000 & 0.000 & 0.026 & 0.862 & & & \\
\hline u/s Leth. & 0.000 & 0.000 & 0.000 & 0.000 & 0.226 & 0.968 & & \\
\hline d/s Leth. & 0.000 & 0.000 & 0.000 & 0.001 & 0.033 & 0.223 & 0.559 & \\
\hline
\end{tabular}

Table 25. Matrix of Tukey pairwise mean comparisons for mean monthly water temperature, August 1997.

\begin{tabular}{|c|c|c|c|c|c|c|c|c|}
\hline SITE & Brocket & LNHD & Ft. Macleod & R. Coulee & Monarch & d/s Belly & u/s Leth. & d/s Leth. \\
\hline Brocket & & & & & & & & \\
\hline LNHD & 0.003 & & & & & & & \\
\hline Ft. Macleod & 0.000 & 0.501 & & & & & & \\
\hline R. Coulee & 0.000 & 0.000 & 0.060 & & & & & \\
\hline Monarch & 0.000 & 0.000 & 0.002 & 0.982 & & & & \\
\hline d/s Belly & 0.000 & 0.000 & 0.000 & 0.283 & 0.863 & & & \\
\hline u/s Leth. & 0.000 & 0.000 & 0.000 & 0.015 & 0.214 & 0.971 & & \\
\hline d/s Leth. & 0.000 & 0.000 & 0.000 & 0.001 & 0.032 & 0.631 & 0.993 & \\
\hline
\end{tabular}


Table 26. Matrix of Tukey pairwise mean comparisons for mean monthly water temperature, September 1997.

\begin{tabular}{|c|c|c|c|c|c|c|c|}
\hline SITE & Brocket & LNHD & Ft. Macleod & R. Coulee & Monarch & d/s Belly & u/s Leth. \\
\hline Brocket & & & & & \multicolumn{3}{|c|}{ Bold type indicates significance at the $95 \%$ level. } \\
\hline LNHD & 0.992 & & & & \multicolumn{3}{|c|}{ Grey type indicates that data do not exist for the entire month. } \\
\hline Ft. Macleod & 1.000 & 1.000 & & & & & \\
\hline R. Coulee & 1.000 & 0.927 & 0.997 & & & & \\
\hline Monarch & 1.000 & 0.960 & 0.999 & 1.000 & & & \\
\hline d/s Belly & 1.000 & 0.980 & 1.000 & 1.000 & 1.000 & & \\
\hline u/s Leth. & 0.993 & 0.729 & 0.949 & 1.000 & 0.999 & 0.998 & \\
\hline d/s Leth. & 0.098 & 0.036 & 0.068 & 0.149 & 0.130 & 0.119 & 0.222 \\
\hline
\end{tabular}

Table 27. Matrix of Tukey pairwise mean comparisons for mean monthly water temperature, October 1997.

\begin{tabular}{|c|c|c|c|c|c|c|c|c|}
\hline SITE & Brocket & LNHD & Ft. Macleod & R. Coulee & Monarch & d/s Belly & u/s Leth. & d/s Leth. \\
\hline Brocket & & & & & & & & \\
\hline LNHD & 0.019 & & & & & & & \\
\hline Ft. Macleod & 0.007 & 1.000 & & & & & & \\
\hline R. Coulee & 0.004 & 0.997 & 1.000 & & & & & \\
\hline Monarch & 0.000 & 0.873 & 0.962 & 0.996 & & & & \\
\hline d/s Belly & 0.000 & 0.806 & 0.927 & 0.987 & 1.000 & & & \\
\hline $\begin{array}{l}\text { u/s Leth. } \\
\text { d/s Leth. }\end{array}$ & 0.000 & 0.960 & 0.994 & 1.000 & 1.000 & 1.000 & & \\
\hline
\end{tabular}

Table 28. Matrix of Tukey pairwise mean comparisons for mean monthly water temperature, April 1998.

\begin{tabular}{|c|c|c|c|c|c|c|c|c|}
\hline SITE & Brocket & LNHD & Ft. Macleod & R. Coulee & Monarch & d/s Belly & u/s Leth. & d/s Leth. \\
\hline Brocket & & & & & & & & \\
\hline LNHD & 0.000 & & & & & & & \\
\hline Ft. Macleod & 0.000 & 0.141 & & & & & & \\
\hline R. Coulee & 0.000 & 0.000 & 0.003 & & & & & \\
\hline Monarch & 0.000 & 0.000 & 0.000 & 0.943 & & & & \\
\hline d/s Belly & 0.000 & 0.000 & 0.000 & 0.249 & 0.858 & & & \\
\hline $\begin{array}{l}\text { u/s Leth. } \\
\text { d/s Leth. }\end{array}$ & 0.000 & 0.000 & 0.000 & 0.020 & 0.242 & 0.938 & & \\
\hline
\end{tabular}

Table 29. Matrix of Tukey pairwise mean comparisons for mean monthly water temperature, May 1998.

\begin{tabular}{|c|c|c|c|c|c|c|c|c|}
\hline SITE & Brocket & LNHD & Ft. Macleod & R. Coulee & Monarch & d/s Belly & u/s Leth. & d/s Leth. \\
\hline Brocket & & & & & & & & \\
\hline LNHD & 0.000 & & & & & & & \\
\hline Ft. Macleod & 0.000 & 0.106 & & & & & & \\
\hline R. Coulee & 0.000 & 0.000 & 0.000 & & & & & \\
\hline Monarch & 0.000 & 0.000 & 0.000 & 0.877 & & & & \\
\hline d/s Belly & 0.000 & 0.000 & 0.000 & 0.005 & 0.207 & & " & \\
\hline $\begin{array}{l}\text { u/s Leth. } \\
\text { d/s Leth. }\end{array}$ & 0.000 & 0.000 & 0.000 & 0.000 & 0.001 & 0.532 & & \\
\hline
\end{tabular}

Table 30. Matrix of Tukey pairwise mean comparisons for mean monthly water temperature, June 1998.

\begin{tabular}{|c|c|c|c|c|c|c|c|c|}
\hline SITE & Brocket & LNHD & Ft. Macleod & R. Coulee & Monarch & d/s Belly & u/s Leth. & d/s Leth. \\
\hline Brocket & & & & & & & & \\
\hline LNHD & 0.002 & & & & & & & \\
\hline Ft. Macleod & 0.000 & 0.583 & & & & & & \\
\hline R. Coulee & 0.000 & 0.002 & 0.006 & & & & & \\
\hline Monarch & 0.000 & 0.000 & 0.000 & 0.999 & & & & \\
\hline d/s Belly & 0.000 & 0.000 & 0.000 & 0.163 & 0.400 & & & \\
\hline $\begin{array}{l}\text { u/s Leth. } \\
\text { d/s Leth. }\end{array}$ & 0.000 & 0.000 & 0.000 & 0.000 & 0.003 & 0.583 & & \\
\hline
\end{tabular}


Table 31. Matrix of Tukey pairwise mean comparisons for mean monthly water temperature, July 1998.

\begin{tabular}{|c|c|c|c|c|c|c|c|c|}
\hline SITE & Brocket & LNHD & Ft. Macleod & R. Coulee & Monarch & d/s Belly & u/s Leth. & d/s Leth. \\
\hline Brocket & & & & & \multicolumn{4}{|c|}{ Bold type indicates significance at the $95 \%$ level. } \\
\hline LNHD & 0.000 & & & & \multicolumn{4}{|c|}{ Grey type indicates that data do not exist for the entire month. } \\
\hline Ft. Macleod & 0.000 & 0.220 & & & & & & \\
\hline R. Coulee & 0.000 & 0.000 & 0.000 & & & & & \\
\hline Monarch & 0.000 & 0.000 & 0.000 & 0.997 & & & & \\
\hline d/s Belly & 0.000 & 0.000 & 0.000 & 0.346 & 0.742 & & & \\
\hline $\begin{array}{l}\text { u/s Leth. } \\
\text { d/s Leth. }\end{array}$ & 0.000 & 0.000 & 0.000 & 0.040 & 0.190 & 0.970 & & \\
\hline
\end{tabular}

Table 32. Matrix of Tukey pairwise mean comparisons for mean monthly water temperature, August 1998.

\begin{tabular}{|c|c|c|c|c|c|c|c|c|}
\hline \multirow{2}{*}{\multicolumn{9}{|c|}{ Ft. Macleod R. Coulee }} \\
\hline & & & & & & & & \\
\hline LNHD & 0.000 & & & & & & & \\
\hline Ft. Macleod & 0.000 & 0.000 & & & & & & \\
\hline R. Coulee & 0.000 & 0.000 & 0.000 & & & & & \\
\hline Monarch & 0.000 & 0.000 & 0.000 & 0.963 & & & & \\
\hline d/s Belly & 0.000 & 0.000 & 0.000 & 0.169 & 0.812 & & & \\
\hline u/s Leth. & 0.000 & 0.000 & 0.000 & 0.002 & 0.066 & 0.839 & & \\
\hline d/s Leth. & 0.000 & 0.000 & 0.000 & 0.003 & 0.094 & 0.873 & 1.000 & \\
\hline
\end{tabular}

Table 33. Matrix of Tukey pairwise mean comparisons for mean monthly water temperature, September 1998.

\begin{tabular}{|c|c|c|c|c|c|c|c|c|}
\hline \multirow{2}{*}{\multicolumn{9}{|c|}{ Ft. Macleod R. Coulee }} \\
\hline & & & & & & & & \\
\hline LNHD & 0.970 & & & & & & & \\
\hline Ft. Macleod & 0.407 & 0.960 & & & & & & \\
\hline R. Coulee & 0.009 & 0.189 & 0.843 & & & & & \\
\hline Monarch & 0.008 & 0.172 & 0.822 & 1.000 & & & & \\
\hline d/s Belly & 0.001 & 0.035 & 0.437 & 0.998 & 0.999 & & & \\
\hline u/s Leth. & 0.000 & 0.002 & 0.073 & 0.825 & 0.847 & 0.991 & & \\
\hline d/s Leth. & 0.000 & 0.003 & 0.113 & 0.899 & 0.914 & 0.998 & 1.000 & \\
\hline
\end{tabular}

Table 34. Matrix of Tukey pairwise mean comparisons for mean monthly water temperature, October 1998.

\begin{tabular}{|c|c|c|c|c|c|c|c|c|}
\hline \multirow{2}{*}{\multicolumn{9}{|c|}{ Ft. Macleod R. Coulee }} \\
\hline & & & & & & & & \\
\hline LNHD & 0.000 & & & & & & & \\
\hline Ft. Macleod & 0.000 & 1.000 & & & & & & \\
\hline R. Coulee & 0.000 & 0.978 & 0.992 & & & & & \\
\hline Monarch & 0.000 & 0.418 & 0.524 & 0.952 & & & & \\
\hline d/s Belly & 0.000 & 0.210 & 0.289 & 0.812 & 1.000 & & & \\
\hline u/s Leth. & 0.000 & 0.466 & 0.574 & 0.967 & 1.000 & 1.000 & & \\
\hline d/s Leth. & 0.899 & 0.461 & 0.423 & 0.251 & 0.099 & 0.069 & 0.106 & \\
\hline
\end{tabular}

Table 35. Matrix of Tukey pairwise mean comparisons for mean monthly water temperature, April 1999.

\begin{tabular}{|c|c|c|c|c|c|c|c|c|}
\hline \multirow{2}{*}{\multicolumn{9}{|c|}{ Ft. Macleod R. Coulee }} \\
\hline & & & & & & & & \\
\hline LNHD & 0.002 & & & & & & & \\
\hline Ft. Macleod & 0.000 & 0.996 & & & & & & \\
\hline R. Coulee & 0.000 & 0.056 & 0.240 & & & & & \\
\hline Monarch & 0.000 & 0.008 & 0.054 & 0.997 & & & & \\
\hline d/s Belly & 0.000 & 0.000 & 0.004 & 0.827 & 0.990 & & & \\
\hline $\begin{array}{l}\text { u/s Leth. } \\
\text { d/s Leth. }\end{array}$ & 0.000 & 0.000 & 0.000 & 0.439 & 0.825 & 0.997 & & \\
\hline
\end{tabular}

Temperature and Dissolved Oxygen in the Oldman River Following Construction of the Oldman River Dam 
Table 36. Matrix of Tukey pairwise mean comparisons for mean monthly water temperature, May 1999.

\begin{tabular}{|l|ccccccc|}
\hline \multicolumn{1}{|c|}{ SITE } & Brocket & LNHD & Ft. Macleod & R. Coulee & Monarch & d/s Belly u/s Leth. & d/s Leth. \\
\hline Brocket & & & & & Bold type indicates significance at the $95 \%$ level. \\
LNHD & $\mathbf{0 . 0 4 0}$ & & & & Grey type indicates that data do not exist for the entire month. \\
Ft. Macleod & $\mathbf{0 . 0 0 4}$ & 0.993 & & & & \\
R. Coulee & $\mathbf{0 . 0 0 0}$ & 0.172 & 0.573 & & & \\
Monarch & $\mathbf{0 . 0 0 0}$ & $\mathbf{0 . 0 4 1}$ & 0.238 & 0.998 & & \\
d/s Belly & $\mathbf{0 . 0 0 0}$ & $\mathbf{0 . 0 0 3}$ & $\mathbf{0 . 0 3 3}$ & 0.841 & 0.987 & \\
u/s Leth. & $\mathbf{0 . 0 0 0}$ & $\mathbf{0 . 0 0 0}$ & $\mathbf{0 . 0 0 3}$ & 0.382 & 0.743 & 0.991 & \\
d/s Leth. & & & & & & & \\
\hline
\end{tabular}

Table 37. Matrix of Tukey pairwise mean comparisons for mean monthly water temperature, June 1999.

\begin{tabular}{|c|c|c|c|c|c|c|c|c|}
\hline \multirow{2}{*}{\begin{tabular}{|r|} 
SITE \\
Brocket
\end{tabular}} & Brocket & LNHD & Ft. Macleod & R. Coulee & Monarch & d/s Belly & u/s Leth. & d/s Leth. \\
\hline & & & & & & & & \\
\hline LNHD & 0.000 & & & & & & & \\
\hline Ft. Macleod & 0.000 & 0.900 & & & & & & \\
\hline R. Coulee & 0.000 & 0.018 & 0.357 & & & & & \\
\hline Monarch & 0.000 & 0.000 & 0.002 & 0.578 & & & & \\
\hline d/s Belly & 0.000 & 0.000 & 0.000 & 0.062 & 0.924 & & & \\
\hline $\begin{array}{l}\text { u/s Leth. } \\
\text { d/s Leth. }\end{array}$ & 0.000 & 0.000 & 0.000 & 0.005 & 0.476 & 0.986 & & = \\
\hline
\end{tabular}

Table 38. Matrix of Tukey pairwise mean comparisons for mean monthly water temperature, July 1999.

\begin{tabular}{|l|cccccccc|}
\hline \multicolumn{1}{|c|}{ SITE } & Brocket & LNHD & Ft. Macleod & R. Coulee & Monarch & d/s Belly & u/s Leth. & d/s Leth. \\
\hline Brocket & & & & & & & & \\
LNHD & $\mathbf{0 . 0 0 1}$ & & & & & & & \\
Ft. Macleod & $\mathbf{0 . 0 0 0}$ & 0.928 & & & & & \\
R. Coulee & $\mathbf{0 . 0 0 0}$ & $\mathbf{0 . 0 1 9}$ & 0.394 & & & & \\
Monarch & $\mathbf{0 . 0 0 0}$ & $\mathbf{0 . 0 0 0}$ & $\mathbf{0 . 0 0 2}$ & 0.583 & & & \\
d/s Belly & $\mathbf{0 . 0 0 0}$ & $\mathbf{0 . 0 0 0}$ & $\mathbf{0 . 0 0 0}$ & $\mathbf{0 . 0 4 3}$ & 0.924 & & \\
u/s Leth. & $\mathbf{0 . 0 0 0}$ & $\mathbf{0 . 0 0 0}$ & $\mathbf{0 . 0 0 0}$ & $\mathbf{0 . 0 0 2}$ & 0.435 & 0.991 & \\
d/s Leth. & $\mathbf{0 . 0 0 0}$ & $\mathbf{0 . 0 0 0}$ & $\mathbf{0 . 0 0 0}$ & $\mathbf{0 . 0 0 2}$ & $\mathbf{0 . 0 3 8}$ & $\mathbf{0 . 1 8 0}$ & 0.393 \\
\hline
\end{tabular}

Table 39. Matrix of Tukey pairwise mean comparisons for mean monthly water temperature, August 1999.

\begin{tabular}{|c|c|c|c|c|c|c|c|c|}
\hline SITE & Brocket & LNHD & Ft. Macleod & R. Coulee & Monarch & d/s Belly & u/s Leth. & d/s Leth. \\
\hline Brocket & & & & & & & & \\
\hline LNHD & 0.000 & & & & & & & \\
\hline Ft. Macleod & 0.000 & 0.316 & & & & & & \\
\hline R. Coulee & 0.000 & 0.000 & 0.000 & & & & & \\
\hline Monarch & 0.000 & 0.000 & 0.000 & 0.572 & & & & \\
\hline d/s Belly & 0.000 & 0.000 & 0.000 & 0.011 & 0.727 & & & \\
\hline u/s Leth. & 0.000 & 0.000 & 0.000 & 0.000 & 0.192 & 0.989 & & \\
\hline d/s Leth. & 0.000 & 0.000 & 0.000 & 0.000 & 0.060 & 0.888 & 1.000 & \\
\hline
\end{tabular}

Table 40. Matrix of Tukey pairwise mean comparisons for mean monthly water temperature, September 1999.

\begin{tabular}{|l|cccccccc|}
\hline \multicolumn{1}{|c|}{ SITE } & Brocket & LNHD & Ft. Macleod & R. Coulee & Monarch & d/s Belly & u/s Leth. & d/s Leth. \\
\hline Brocket & & & & & & & & \\
LNHD & 0.832 & & & & & & & \\
Ft. Macleod & 0.648 & 1.000 & & & & & \\
R. Coulee & 0.792 & 1.000 & 1.000 & & & & \\
Monarch & 0.615 & 1.000 & 1.000 & 1.000 & & & \\
d/s Belly & 0.932 & 1.000 & 0.999 & 1.000 & 0.999 & 1.000 & \\
u/s Leth. & 0.990 & 0.999 & 0.986 & 0.998 & 0.981 & 1.000 & 1.000 \\
d/s Leth. & 0.948 & 1.000 & 0.999 & 1.000 & 0.998 & 1.000 \\
\hline
\end{tabular}


Table 41. Matrix of Tukey pairwise mean comparisons for mean monthly water temperature, October 1999.

\begin{tabular}{|c|c|c|c|c|c|c|c|}
\hline SITE & Brocket & LNHD & Ft. Macleod & R. Coulee & Monarch & d/s Belly & u/s Leth. \\
\hline Brocket & & & & & \multicolumn{3}{|c|}{ Bold type indicates significance at the $95 \%$ level. } \\
\hline LNHD & 0.001 & & & & \multicolumn{3}{|c|}{ Grey type indicates that data do not exist for the entire month. } \\
\hline Ft. Macleod & 0.000 & 0.934 & & & & & \\
\hline R. Coulee & 0.000 & 0.342 & 0.971 & & & & \\
\hline Monarch & 0.000 & 0.003 & 0.122 & 0.701 & & & \\
\hline d/s Belly & 0.000 & 0.103 & 0.765 & 0.999 & 0.951 & & \\
\hline u/s Leth. & 0.000 & 0.191 & 0.892 & 1.000 & 0.865 & 1.000 & \\
\hline d/s Leth. & 0.000 & 0.819 & 0.998 & 1.000 & 0.935 & 1.000 & 1.000 \\
\hline
\end{tabular}

Table 42. Matrix of Tukey pairwise mean comparisons for mean monthly water temperature, April 2000.

\begin{tabular}{|c|c|c|c|c|c|c|c|c|}
\hline SITE & Brocket & LNHD & Ft. Macleod & R. Coulee & Monarch & d/s Belly & u/s Leth. & $\mathrm{d} / \mathrm{s}$ Leth. \\
\hline Brocket & & & & & & & & \\
\hline LNHD & 0.107 & & & & & & & \\
\hline Ft. Macleod & 0.012 & 0.996 & & & & & & \\
\hline R. Coulee & 0.000 & 0.335 & 0.805 & & & & & \\
\hline Monarch & 0.000 & 0.147 & 0.548 & 1.000 & & & & \\
\hline d/s Belly & 0.000 & 0.037 & 0.237 & 0.986 & 1.000 & & & \\
\hline $\begin{array}{l}\text { u/s Leth. } \\
\text { d/s Leth. }\end{array}$ & 0.000 & 0.006 & 0.062 & 0.832 & 0.966 & 0.999 & & \\
\hline
\end{tabular}

Table 43. Matrix of Tukey pairwise mean comparisons for mean monthly water temperature, May 2000.

\begin{tabular}{|c|c|c|c|c|c|c|c|c|}
\hline SITE & Brocket & LNHD & Ft. Macleod & R. Coulee & Monarch & d/s Belly & u/s Leth. & d/s Leth. \\
\hline Brocket & & & & & & & & \\
\hline LNHD & 0.000 & & & & & & & \\
\hline Ft. Macleod & 0.000 & 0.614 & & & & & & \\
\hline R. Coulee & 0.000 & 0.000 & 0.014 & & & & & \\
\hline Monarch & 0.000 & 0.000 & 0.000 & 0.901 & & & & \\
\hline d/s Belly & 0.000 & 0.000 & 0.000 & 0.043 & 0.632 & & & \\
\hline $\begin{array}{l}\text { u/s Leth. } \\
\text { d/s Leth. }\end{array}$ & 0.000 & 0.000 & 0.000 & 0.000 & 0.025 & 0.819 & & \\
\hline
\end{tabular}

Table 44. Matrix of Tukey pairwise mean comparisons for mean monthly water temperature, June 2000.

\begin{tabular}{|c|c|c|c|c|c|c|c|c|}
\hline SITE & Brocket & LNHD & Ft. Macleod & R. Coulee & Monarch & d/s Belly & u/s Leth. & d/s Leth. \\
\hline Brocket & & & & & & & & \\
\hline LNHD & 0.000 & & & & & & & \\
\hline Ft. Macleod & 0.000 & 0.563 & & & & & & \\
\hline R. Coulee & 0.000 & 0.000 & 0.006 & & & & & \\
\hline Monarch & 0.000 & 0.000 & 0.000 & 0.713 & & & & \\
\hline d/s Belly & 0.000 & 0.000 & 0.000 & 0.162 & 0.976 & & & \\
\hline $\begin{array}{l}\text { u/s Leth. } \\
\text { d/s Leth. }\end{array}$ & 0.000 & 0.000 & 0.000 & 0.003 & 0.324 & 0.933 & & \\
\hline
\end{tabular}

Table 45. Matrix of Tukey pairwise mean comparisons for mean monthly water temperature, July 2000.

\begin{tabular}{|c|c|c|c|c|c|c|c|c|}
\hline SITE & Brocket & LNHD & Ft. Macleod & R. Coulee & Monarch & d/s Belly & u/s Leth. & d/s Leth. \\
\hline Brocket & & & & & & & & \\
\hline LNHD & 0.000 & & & & & & & \\
\hline Ft. Macleod & 0.000 & 0.015 & & & & & & \\
\hline R. Coulee & 0.000 & 0.000 & 0.000 & & & & & \\
\hline Monarch & 0.000 & 0.000 & 0.000 & 0.110 & & & & \\
\hline d/s Belly & 0.000 & 0.000 & 0.000 & 0.000 & 0.378 & & & \\
\hline $\begin{array}{l}\text { u/s Leth. } \\
\text { d/s Leth. }\end{array}$ & 0.000 & 0.000 & 0.000 & 0.000 & 0.000 & 0.283 & & \\
\hline
\end{tabular}


Table 46. Matrix of Tukey pairwise mean comparisons for mean monthly water temperature, August 2000.

\begin{tabular}{|c|c|c|c|c|c|c|c|}
\hline SITE & Brocket & LNHD & Ft. Macleod & R. Coulee & Monarch & d/s Belly & u/s Leth. \\
\hline Brocket & & & & & \multicolumn{3}{|c|}{ Bold type indicates significance at the $95 \%$ level. } \\
\hline LNHD & 0.438 & & & & \multicolumn{3}{|c|}{ Grey type indicates that data do not exist for the entire month. } \\
\hline Ft. Macleod & 0.022 & 0.953 & & & & & \\
\hline R. Coulee & 0.000 & 0.003 & 0.156 & & & & \\
\hline Monarch & 0.000 & 0.000 & 0.010 & 0.992 & & & \\
\hline d/s Belly & 0.000 & 0.000 & 0.000 & 0.262 & 0.846 & & \\
\hline u/s Leth. & 0.000 & 0.000 & 0.000 & 0.006 & 0.111 & 0.933 & \\
\hline d/s Leth. & 0.000 & 0.000 & 0.000 & 0.024 & 0.262 & 0.989 & 1.000 \\
\hline
\end{tabular}

Table 47. Matrix of Tukey pairwise mean comparisons for mean monthly water temperature, September 2000.

\begin{tabular}{|l|cccccccc|}
\hline \multicolumn{1}{|c|}{ SITE } & Brocket & LNHD & Ft. Macleod & R. Coulee & Monarch & d/s Belly & u/s Leth. & d/s Leth. \\
\hline Brocket & & & & & & & & \\
LNHD & 0.924 & & & & & & & \\
Ft. Macleod & 0.847 & 1.000 & & & & & \\
R. Coulee & 0.952 & 1.000 & 1.000 & & & & \\
Monarch & 0.870 & 1.000 & 1.000 & 1.000 & & & \\
d/s Belly & 0.847 & 1.000 & 1.000 & 1.000 & 1.000 & 1.000 & 1.000 \\
u/s Leth. & 0.994 & 1.000 & 0.999 & 1.000 & 1.000 & 1.000 & 1.000 \\
d/s Leth. & 0.998 & 1.000 & 0.998 & 1.000 & 0.999 & \\
\hline
\end{tabular}

Table 48. Matrix of Tukey pairwise mean comparisons for mean monthly water temperature, October 2000.

\begin{tabular}{|c|c|c|c|c|c|c|c|c|}
\hline SITE & Brocket & LNHD & Ft. Macleod & R. Coulee & Monarch & d/s Belly & u/s Leth. & d/s Leth. \\
\hline Brocket & & & & & & & & \\
\hline LNHD & 0.000 & & & & & & & \\
\hline Ft. Macleod & 0.000 & 0.997 & & & & & $\therefore$ & \\
\hline R. Coulee & 0.000 & 0.937 & 1.000 & & & & & \\
\hline Monarch & 0.000 & 0.148 & 0.535 & 0.839 & & & 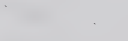 & \\
\hline d/s Belly & 0.000 & 0.580 & 0.943 & 0.998 & 0.995 & & & \\
\hline $\begin{array}{l}\text { u/s Leth. } \\
\text { d/s Leth. }\end{array}$ & 0.000 & 0.763 & 0.988 & 1.000 & 0.968 & 1.000 & & \\
\hline
\end{tabular}

Table 49. Matrix of Tukey pairwise mean comparisons for mean monthly water temperature, April 2001.

\begin{tabular}{|c|c|c|c|c|c|c|c|c|}
\hline SITE & Brocket & LNHD & Ft. Macleod & R. Coulee & Monarch & d/s Belly & u/s Leth. & d/s Leth. \\
\hline Brocket & & & & & & & & \\
\hline LNHD & 0.100 & & & & & & & \\
\hline Ft. Macleod & 0.017 & 0.997 & & & & & & \\
\hline R. Coulee & 0.000 & 0.699 & 0.691 & & & & & \\
\hline Monarch & 0.000 & 0.444 & 0.831 & 1.000 & & & & \\
\hline d/s Belly & 0.000 & 0.419 & 0.811 & 1.000 & 1.000 & & & \\
\hline $\begin{array}{l}\text { u/s Leth. } \\
\text { d } / \mathrm{s} \text { Leth. }\end{array}$ & 0.000 & 0.295 & 0.688 & 0.996 & 1.000 & 1.000 & & \\
\hline
\end{tabular}

Table 50. Matrix of Tukey pairwise mean comparisons for mean monthly water temperature, May 2001.

\begin{tabular}{|c|c|c|c|c|c|c|c|c|}
\hline \multirow{2}{*}{\multicolumn{9}{|c|}{ Ft. Macleod R. Coulee }} \\
\hline & & & & & & & & \\
\hline LNHD & 0.008 & & & & & & & \\
\hline Ft. Macleod & 0.000 & 0.917 & & & & & & \\
\hline R. Coulee & 0.000 & 0.038 & 0.477 & & & & & \\
\hline Monarch & 0.000 & 0.001 & 0.057 & 0.955 & & & & \\
\hline d/s Belly & 0.000 & 0.000 & 0.014 & 0.778 & 0.999 & & & \\
\hline $\begin{array}{l}\text { u/s Leth. } \\
\text { d/s Leth. }\end{array}$ & 0.000 & 0.000 & 0.002 & 0.440 & 0.962 & 0.999 & & \\
\hline
\end{tabular}


Table 51. Matrix of Tukey pairwise mean comparisons for mean monthly water temperature, June 2001.

\begin{tabular}{|c|c|c|c|c|c|c|c|}
\hline SITE & Brocket & LNHD & Ft. Macleod & R. Coulee & Monarch & d/s Belly & $u / s$ Leth. \\
\hline Brocket & & & & & \multicolumn{3}{|c|}{ Bold type indicates significance at the $95 \%$ level. } \\
\hline LNHD & 0.000 & & & & \multicolumn{3}{|c|}{ Grey type indicates that data do not exist for the entire month. } \\
\hline Ft. Macleod & 0.000 & 0.441 & & & & & \\
\hline R. Coulee & 0.000 & 0.000 & 0.018 & & & & \\
\hline Monarch & 0.000 & 0.000 & 0.000 & 0.726 & & & \\
\hline d/s Belly & 0.000 & 0.000 & 0.000 & 0.116 & 0.924 & & \\
\hline $\begin{array}{l}\text { u/s Leth. } \\
\text { d/s Leth. }\end{array}$ & 0.000 & 0.000 & 0.000 & 0.006 & 0.380 & 0.966 & \\
\hline
\end{tabular}

Table 52. Matrix of Tukey pairwise mean comparisons for mean monthly water temperature, July 2001.

\begin{tabular}{|c|c|c|c|c|c|c|c|c|}
\hline SITE & Brocket & LNHD & Ft. Macleod & R. Coulee & Monarch & d/s Belly & u/s Leth. & d/s Leth. \\
\hline Brocket & & & & & & & & \\
\hline LNHD & 0.000 & & & & & & & \\
\hline Ft. Macleod & 0.000 & 0.072 & & & & & & \\
\hline R. Coulee & 0.000 & 0.000 & 0.000 & & & & & \\
\hline Monarch & 0.000 & 0.000 & 0.000 & 0.276 & & & & \\
\hline d/s Belly & 0.000 & 0.000 & 0.000 & 0.001 & 0.593 & & & \\
\hline u/s Leth. & 0.000 & 0.000 & 0.000 & 0.000 & 0.005 & 0.563 & & \\
\hline d/s Leth. & 0.000 & 0.000 & 0.000 & 0.000 & 0.006 & 0.529 & 1.000 & \\
\hline
\end{tabular}

Table 53. Matrix of Tukey pairwise mean comparisons for mean monthly water temperature, August 2001.

\begin{tabular}{|c|c|c|c|c|c|c|c|c|}
\hline SITE & Brocket & LNHD & Ft. Macleod & R. Coulee & Monarch & d/s Belly & u/s Leth. & d/s Leth. \\
\hline Brocket & & & & & & & & \\
\hline LNHD & 0.092 & & & & & & & \\
\hline Ft. Macleod & 0.000 & 0.790 & & & & & & \\
\hline R. Coulee & 0.000 & 0.001 & 0.149 & & & & & \\
\hline Monarch & 0.000 & 0.001 & 0.098 & 1.000 & & & & \\
\hline d/s Belly & 0.000 & 0.000 & 0.000 & 0.136 & 0.320 & & & \\
\hline u/s Leth. & 0.000 & 0.000 & 0.000 & 0.001 & 0.008 & 0.861 & & \\
\hline $\mathrm{d} / \mathrm{s}$ Leth. & 0.000 & 0.000 & 0.000 & 0.000 & 0.000 & 0.401 & 0.996 & \\
\hline
\end{tabular}

Table 54. Matrix of Tukey pairwise mean comparisons for mean monthly water temperature, September 2001.

\begin{tabular}{|c|c|c|c|c|c|c|c|c|}
\hline \multirow{2}{*}{\multicolumn{9}{|c|}{ Ft. Macleod R. Coulee }} \\
\hline & & & & & & & & \\
\hline LNHD & 0.696 & & & & & & & \\
\hline Ft. Macleod & 0.618 & 1.000 & & & & & & \\
\hline R. Coulee & 0.569 & 1.000 & 1.000 & & & & & \\
\hline Monarch & 0.662 & 1.000 & 1.000 & 1.000 & & & & \\
\hline d/s Belly & 0.682 & 1.000 & 1.000 & 1.000 & 1.000 & & & \\
\hline u/s Leth. & 0.989 & 0.992 & 0.982 & 0.973 & 0.988 & 0.991 & & \\
\hline d/s Leth. & 0.847 & 1.000 & 1.000 & 1.000 & 1.000 & 1.000 & 0.999 & \\
\hline
\end{tabular}

Table 55. Matrix of Tukey pairwise mean comparisons for mean monthly water temperature, October 2001.

\begin{tabular}{|c|c|c|c|c|c|c|c|c|}
\hline \multirow{2}{*}{\multicolumn{9}{|c|}{ Ft. Macleod R. Coulee }} \\
\hline & & & & & & & & \\
\hline LNHD & 0.173 & & & & & & & \\
\hline Ft. Macleod & 0.023 & 0.990 & & & & & & \\
\hline R. Coulee & 0.002 & 0.791 & 0.994 & & & & & \\
\hline Monarch & 0.000 & 0.417 & 0.874 & 0.998 & & & & \\
\hline d/s Belly & 0.000 & 0.505 & 0.922 & 0.999 & 1.000 & & & \\
\hline $\begin{array}{l}\text { u/s Leth. } \\
\text { d/s Leth. }\end{array}$ & 0.001 & 0.742 & 0.989 & 1.000 & 0.999 & 1.000 & & \\
\hline
\end{tabular}

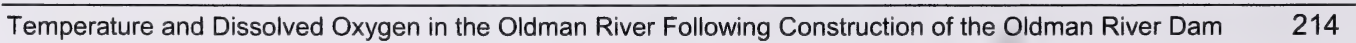


Table 56. Matrix of Tukey pairwise mean comparisons for mean monthly water temperature, November 2001.

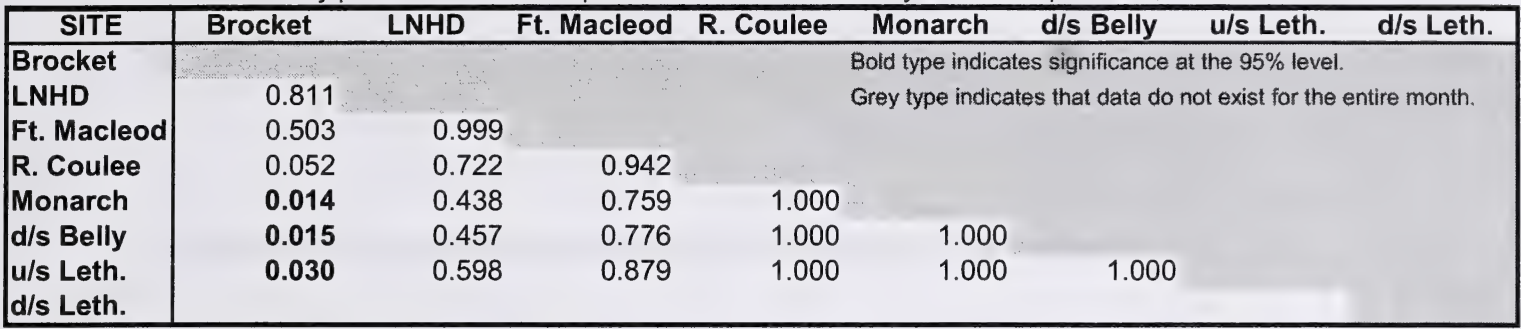


APPENDIX C

OBSERVED WATER TEMPERATURE AND DISSOLVED OXYGEN LEVELS EVALUATED AGAINST SPORT FISH CRITERIA (Taylor and Barton 1992) 

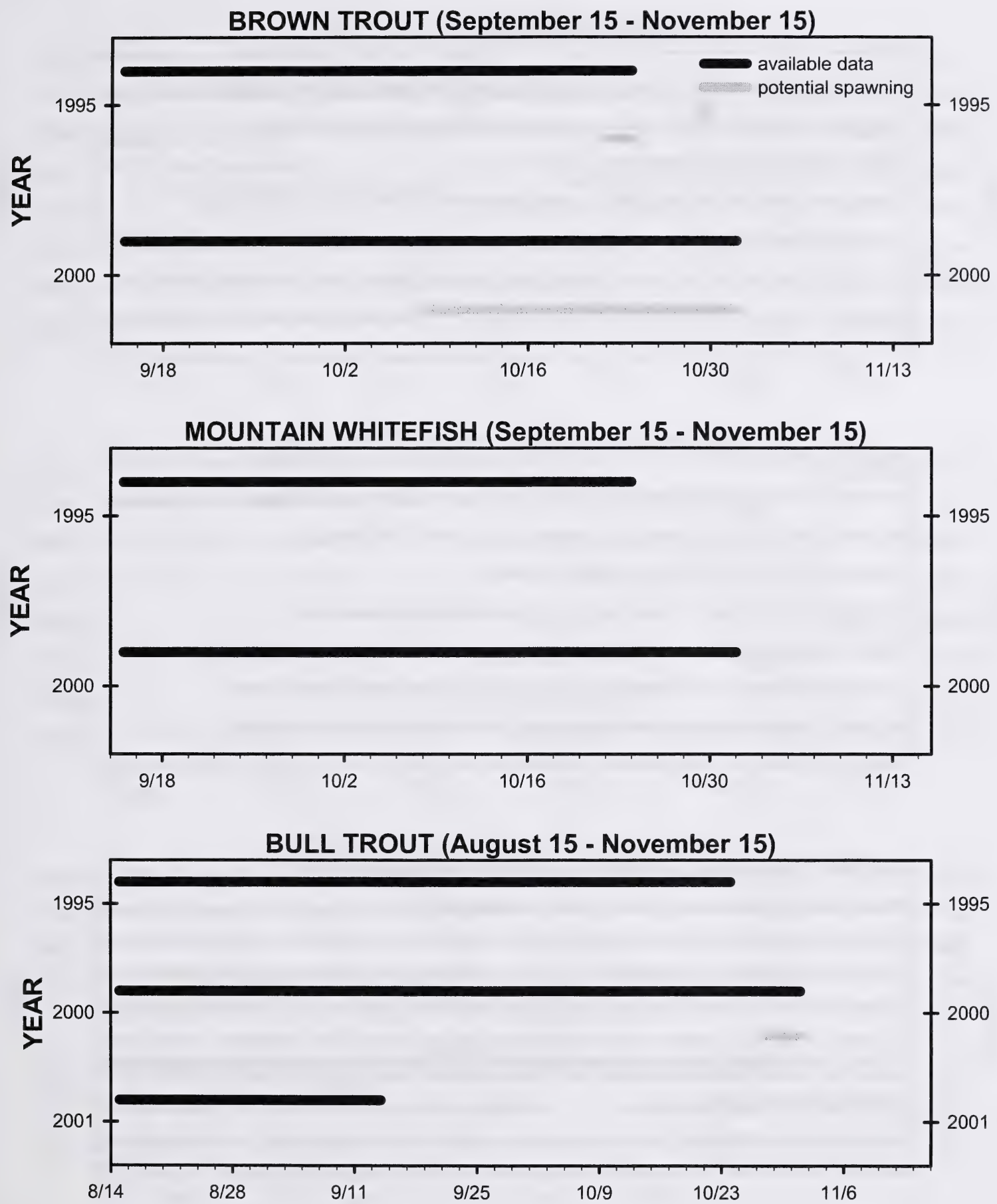

Figure 1. Suitability of water temperatures $100 \mathrm{~m} \mathrm{~d} / \mathrm{s}$ of the Oldman Dam for spawning of brown trout, mountain whitefish, and bull trout. 

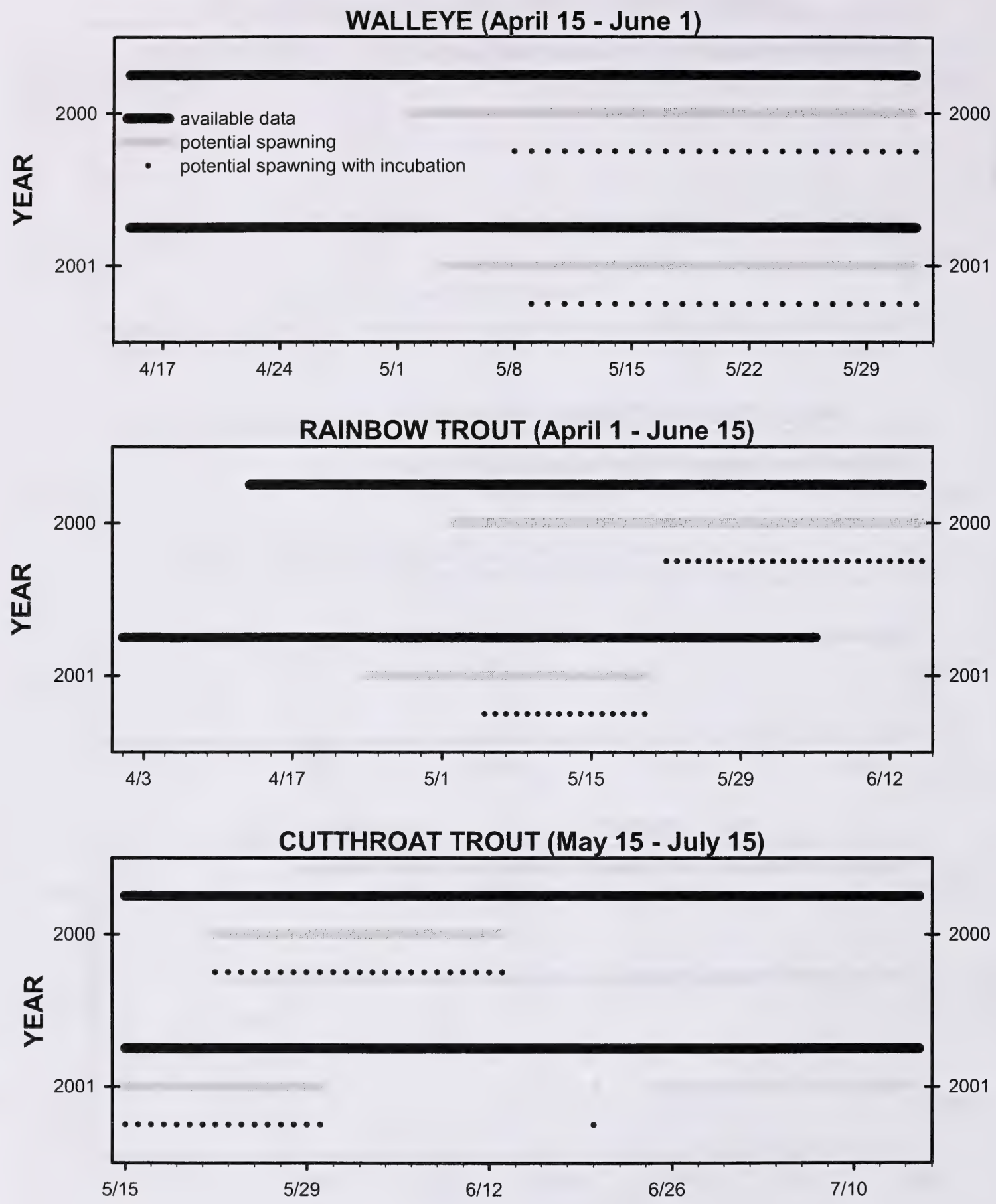

Figure 2. Suitability of water temperatures $100 \mathrm{~m} \mathrm{~d} / \mathrm{s}$ of the Oldman Dam for spawning and incubation of walleye, rainbow trout, and cutthroat trout. 
WALLEYE (April 15 - June 1)

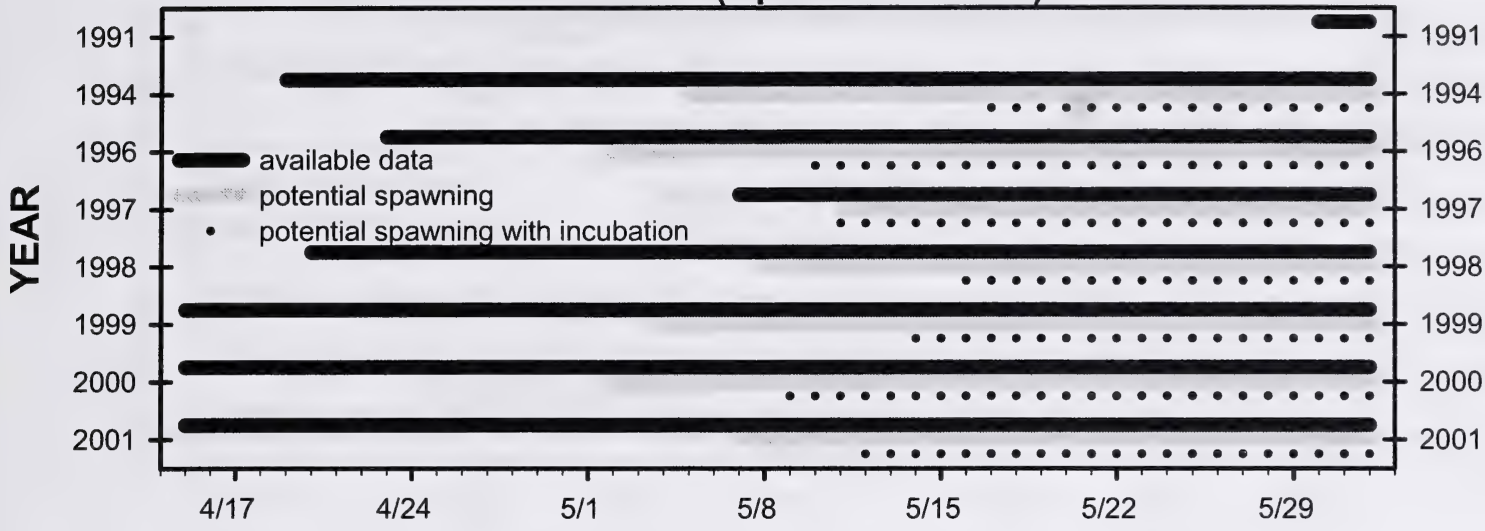

RAINBOW TROUT (April 1 - June 15)

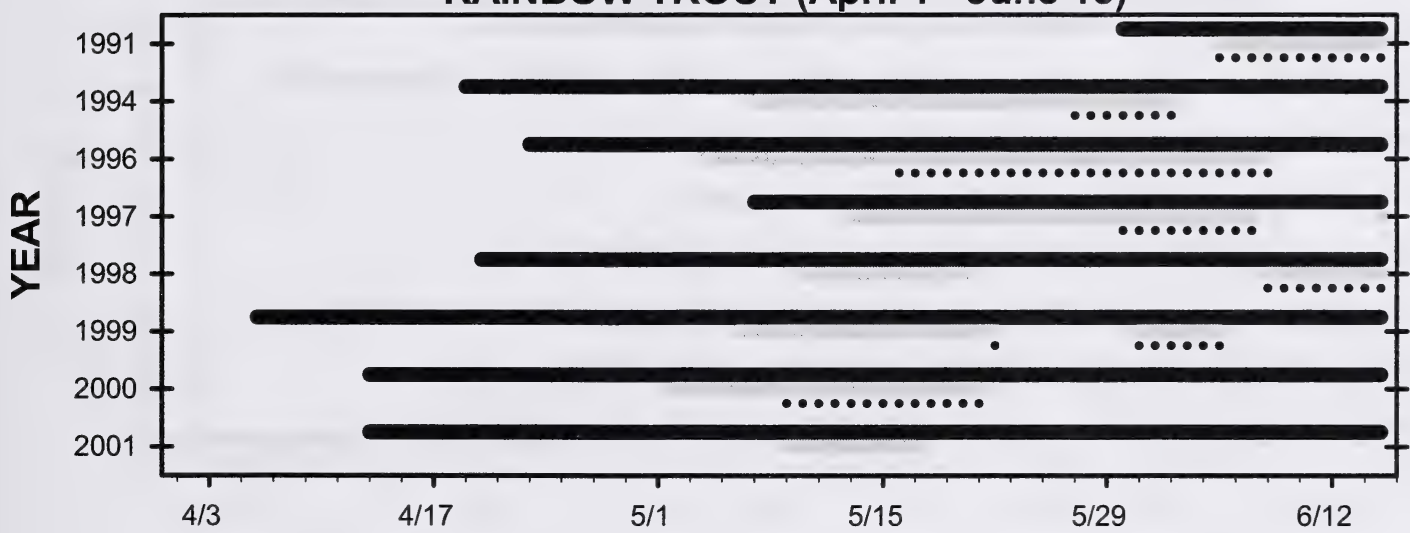

CUTTHROAT TROUT (May 15 - July 15)

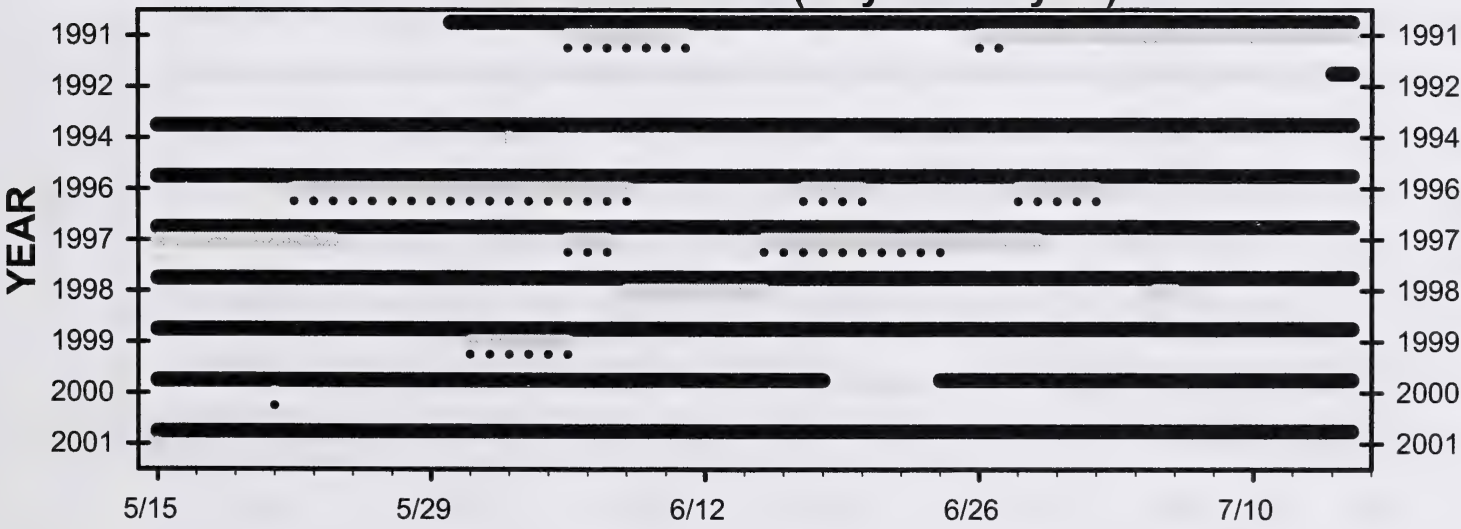

Figure 3. Suitability of water temperatures near Brocket for spawning and incubation of walleye, rainbow trout, and cutthroat trout. 

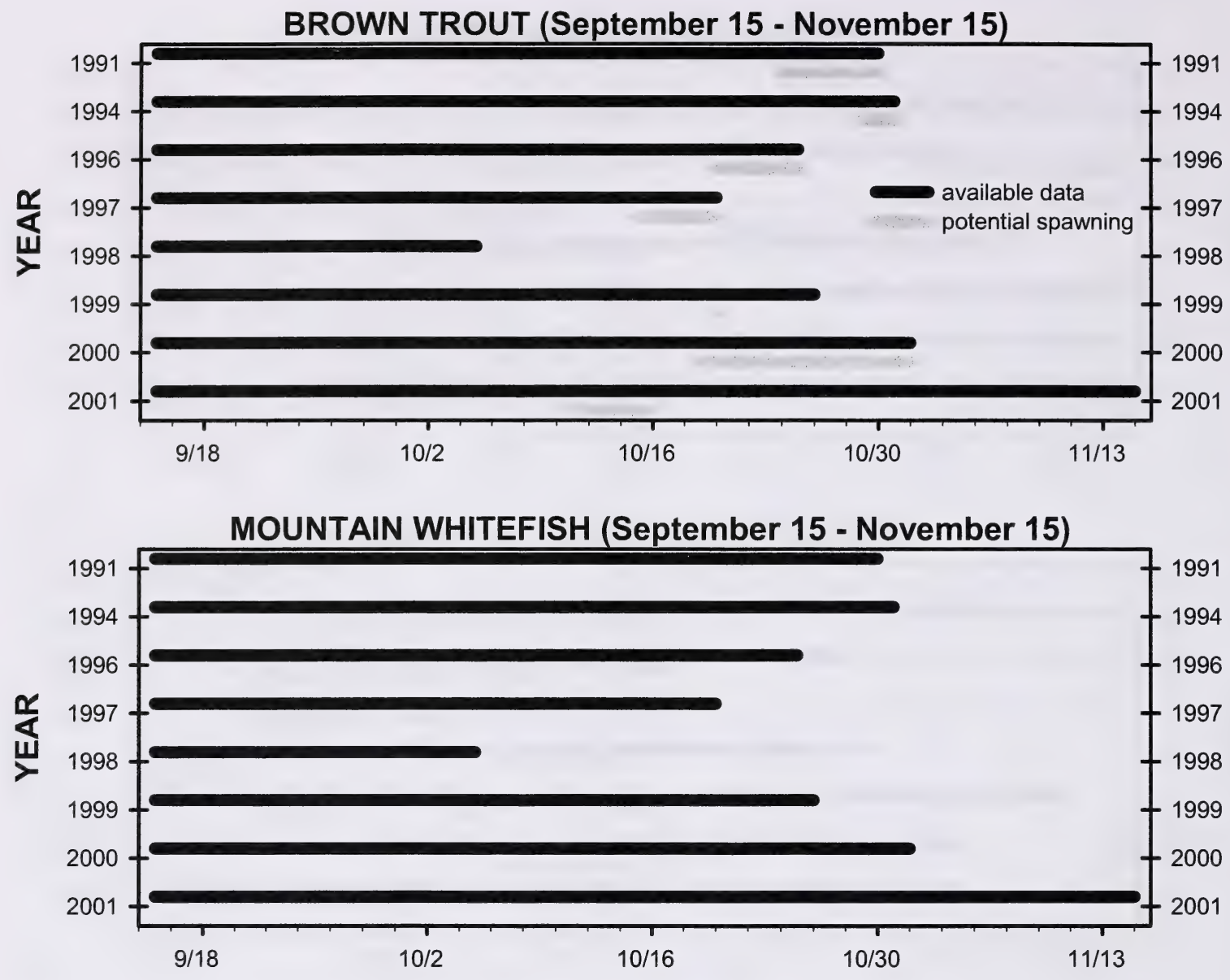

BULL TROUT (August 15 - November 15)

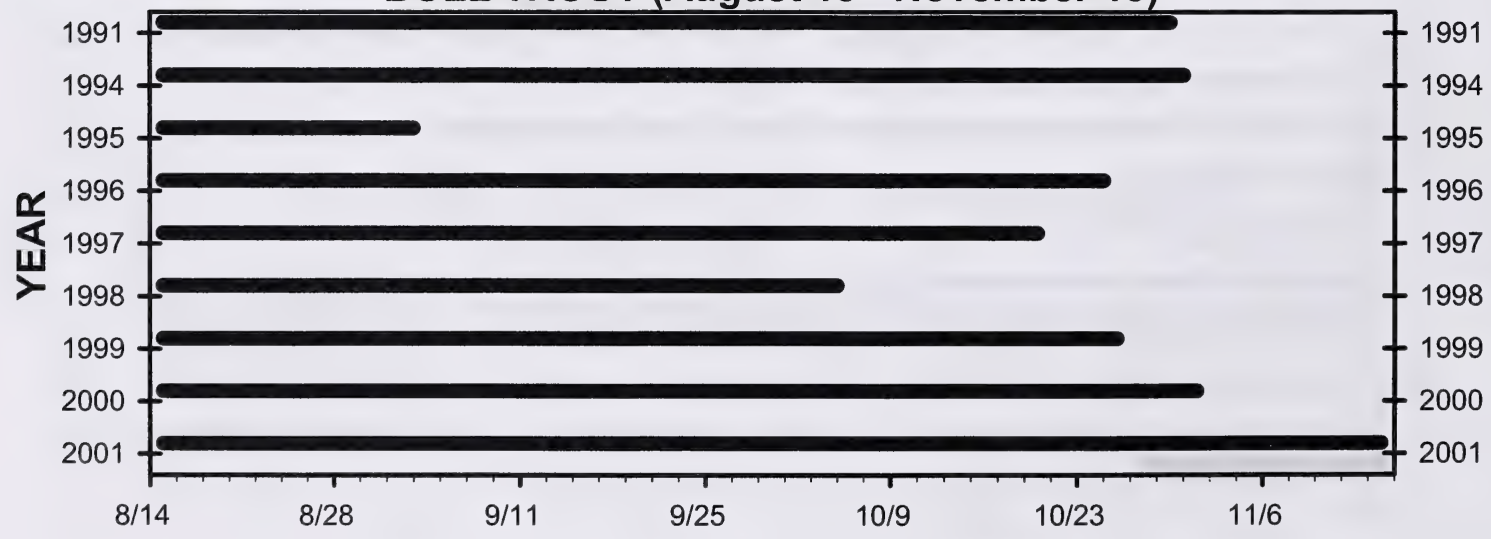

Figure 4. Suitability of water temperatures near Brocket for spawning of brown trout, mountain whitefish, and bull trout. 
WALLEYE (April 15 - June 1)

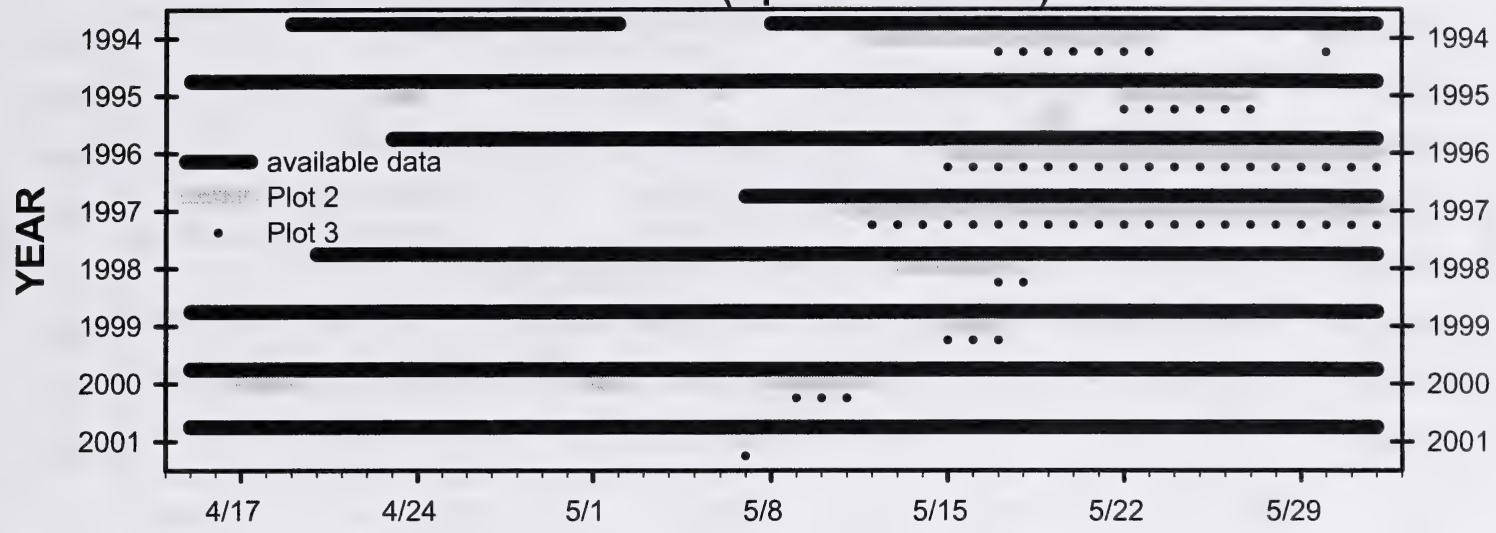

RAINBOW TROUT (April 1 - June 15)
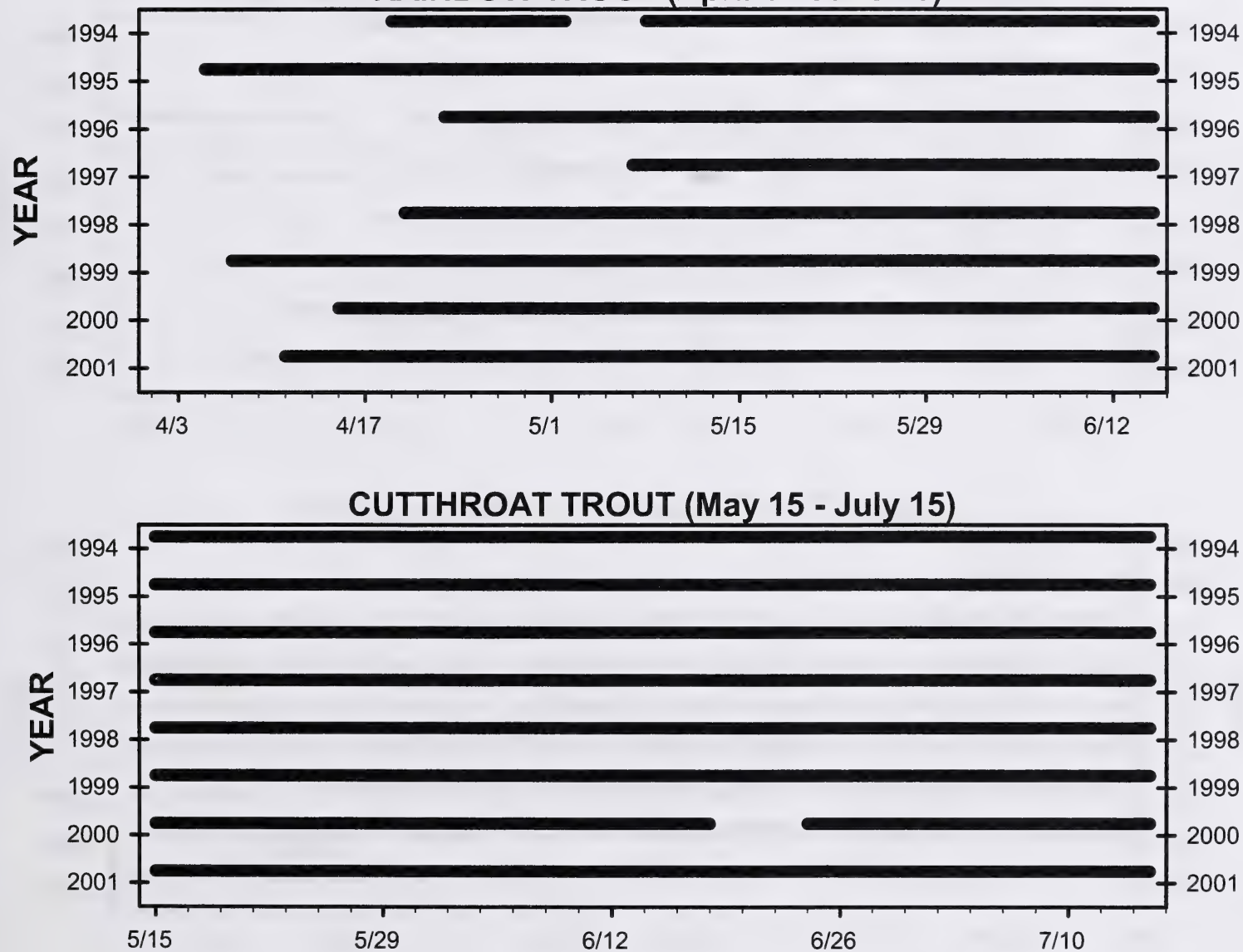

Figure 5. Suitability of water temperatures $\mathrm{d} / \mathrm{s}$ of the LNHD for spawning and incubation of walleye, rainbow trout, and cutthroat trout. 
BROWN TROUT (September 15 - November 15)

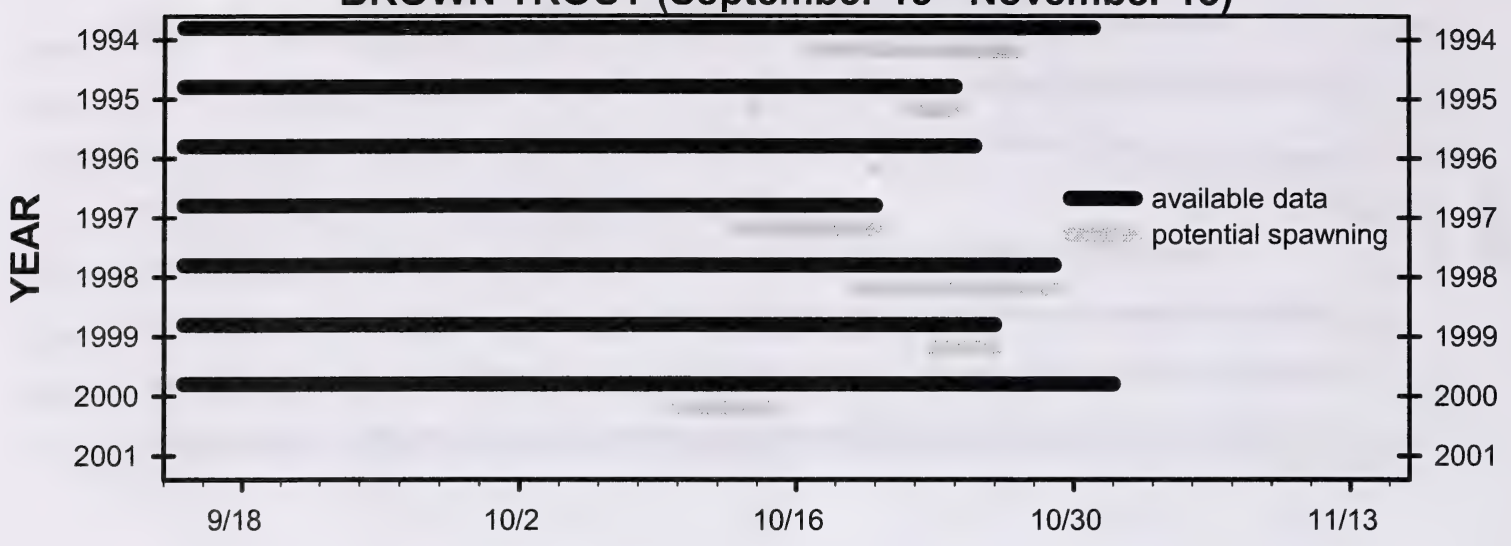

MOUNTAIN WHITEFISH (September 15 - November 15)

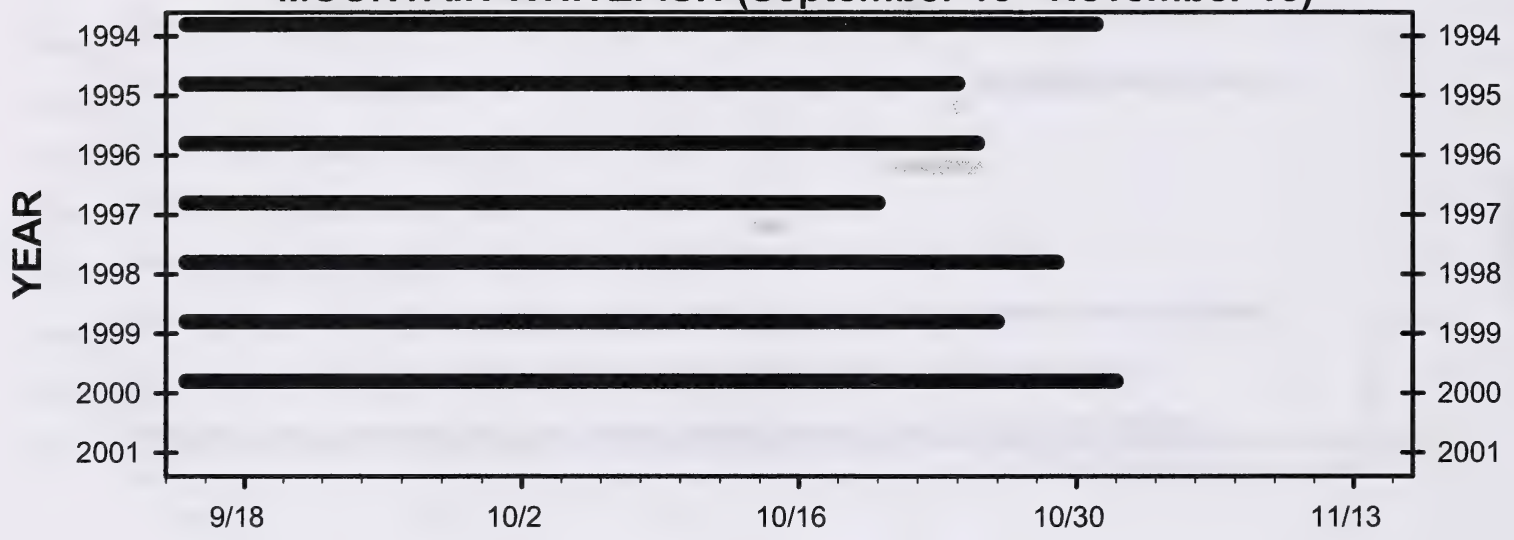

BULL TROUT (August 15 - November 15)

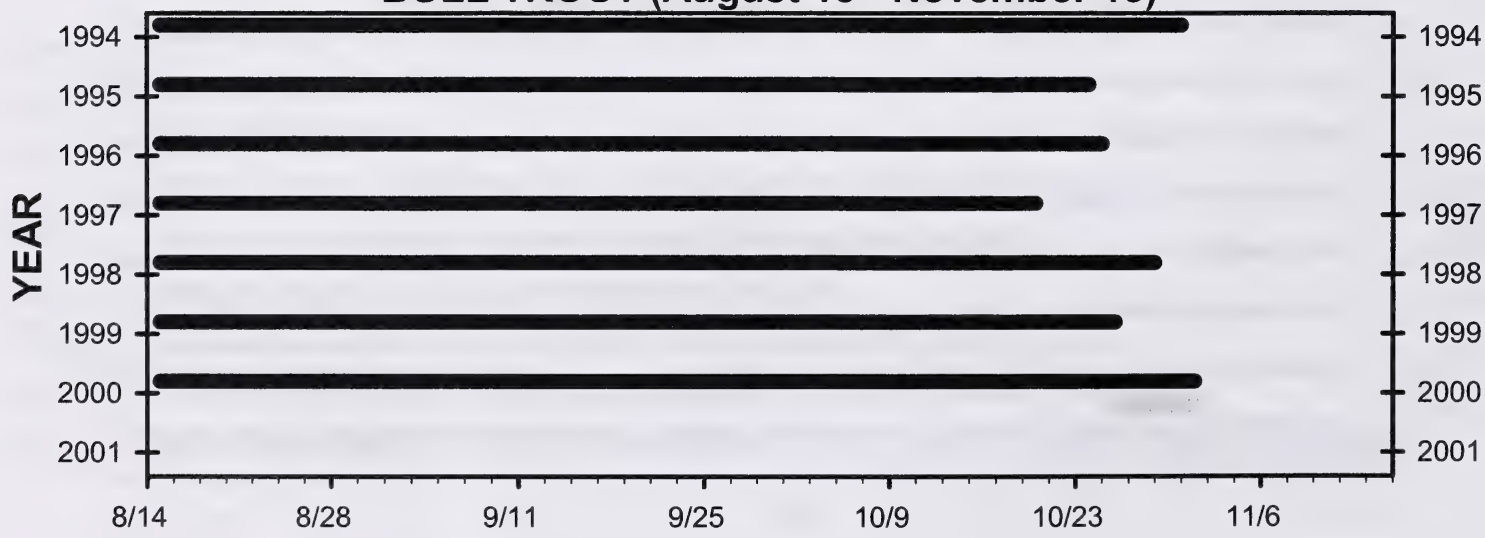

Figure 6. Suitability of water temperatures $\mathrm{d} / \mathrm{s}$ of the LNHD for spawning of brown trout, mountain whitefish, and bull trout. 
WALLEYE (April 15 - June 1)

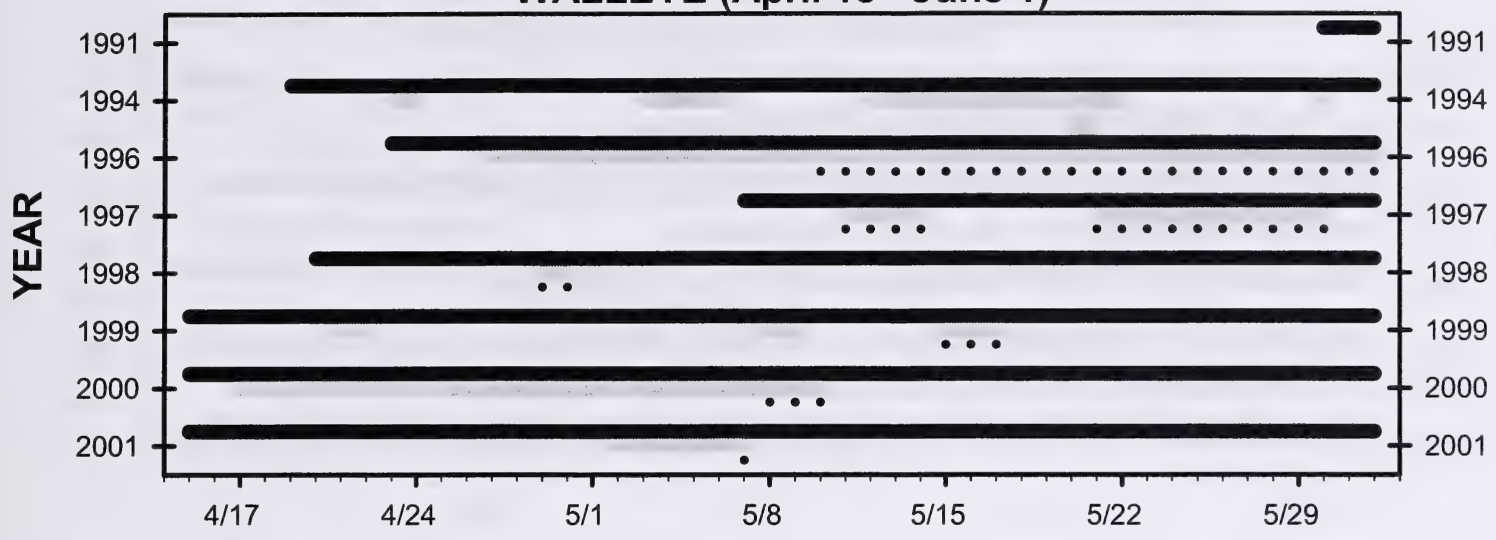

RAINBOW TROUT (April 1 - June 15)

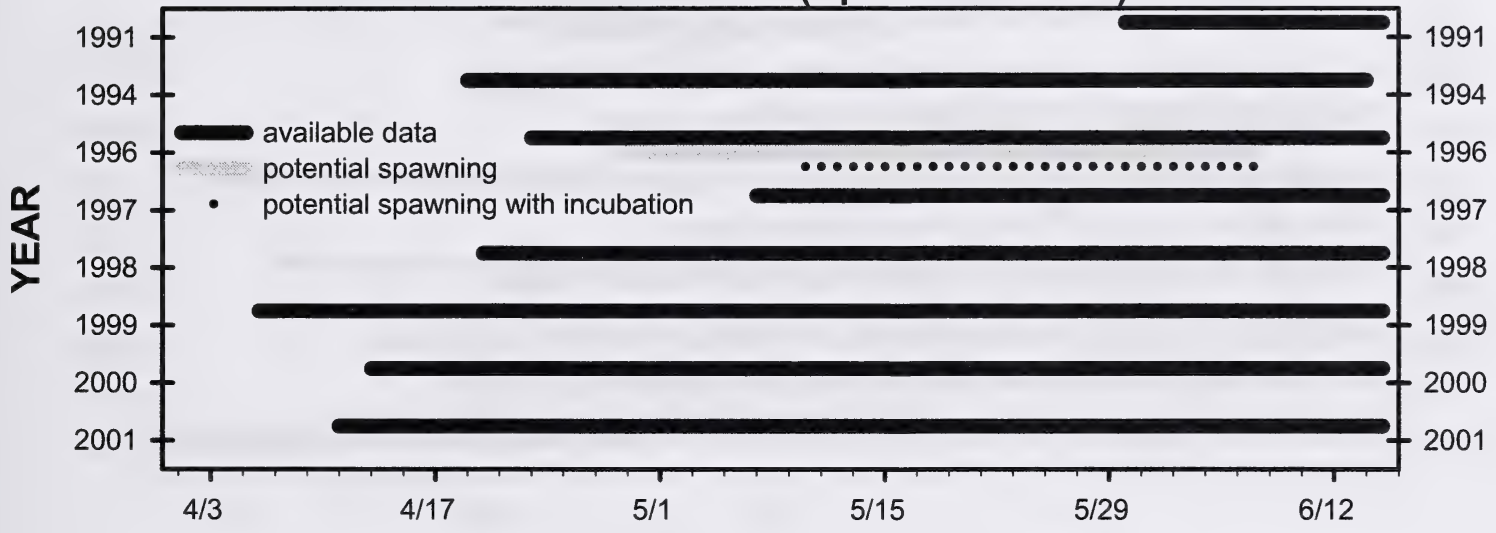

CUTTHROAT TROUT (May 15 - July 15)

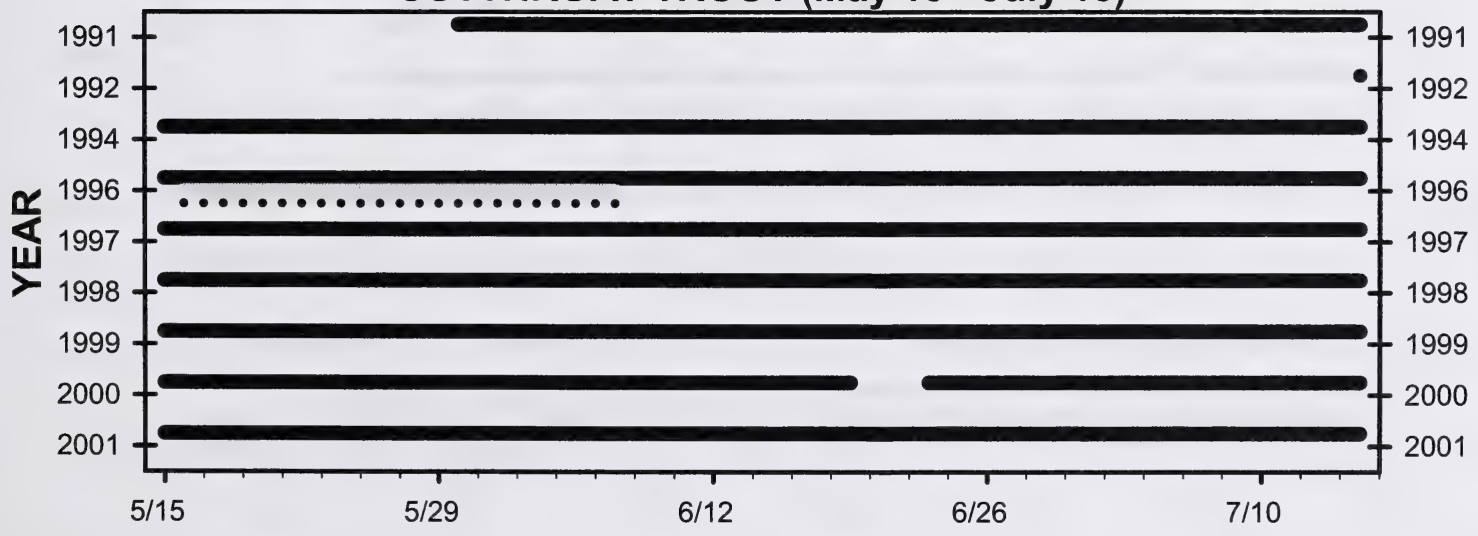

Figure 7. Suitability of water temperatures near Fort Macleod for spawning and incubation of walleye, rainbow trout, and cutthroat trout. 
BROWN TROUT (September 15 - November 15)

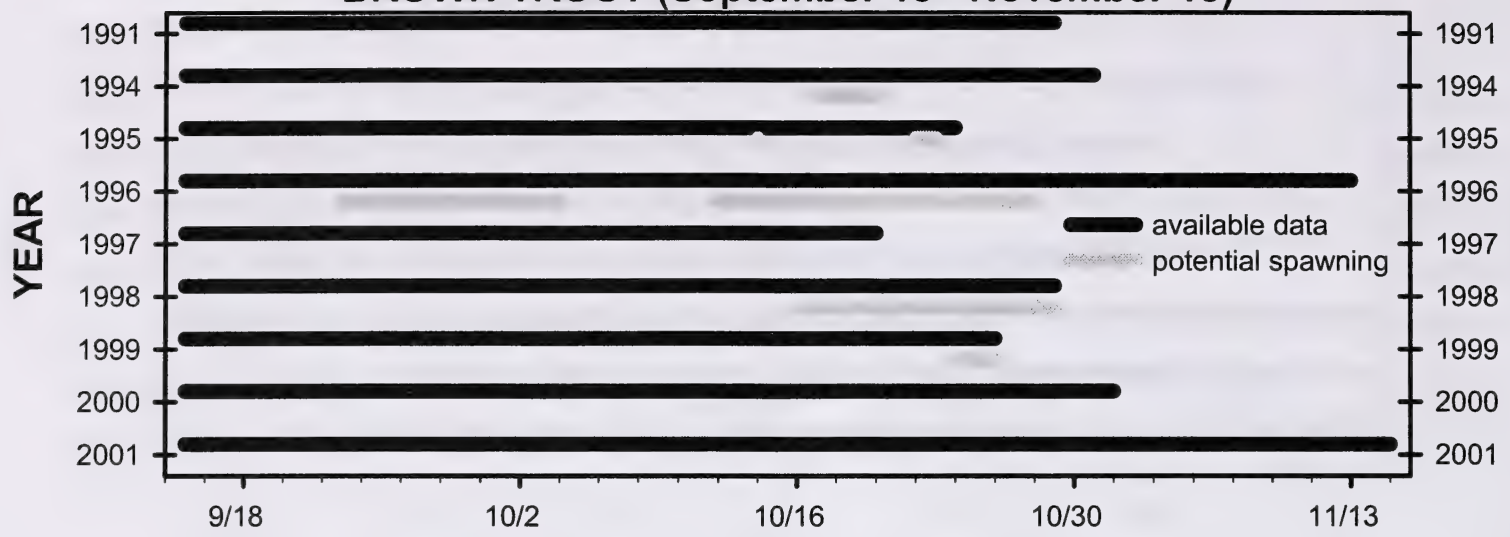

MOUNTAIN WHITEFISH (September 15 - November 15)

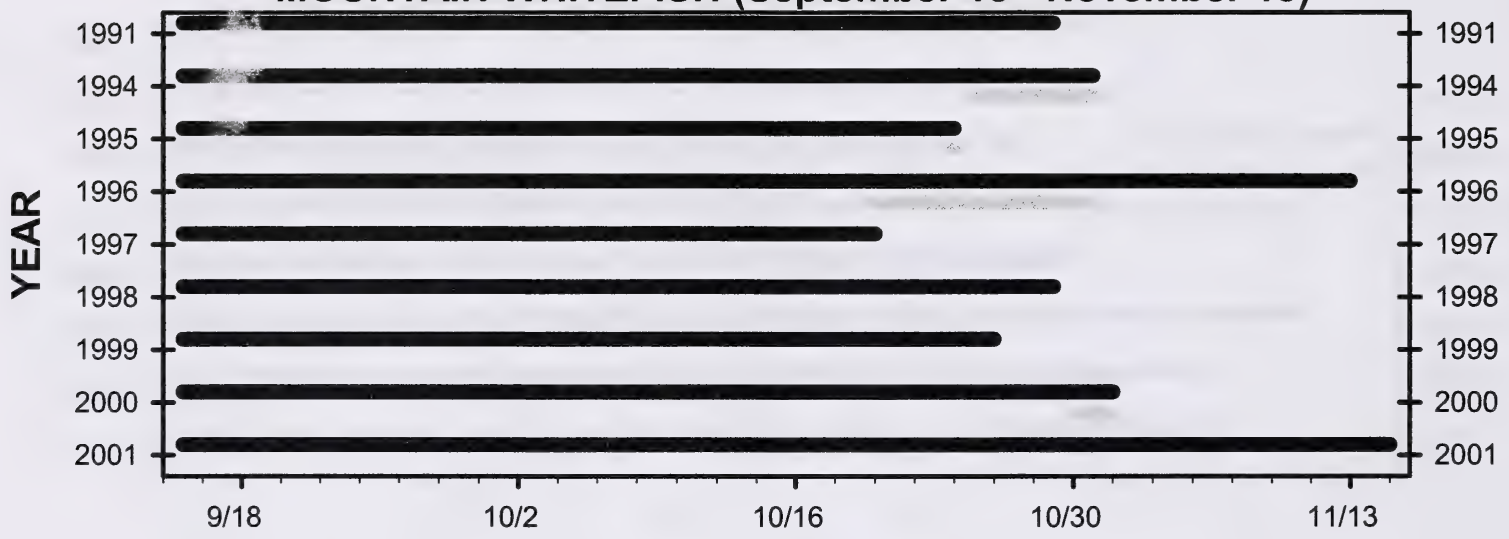

BULL TROUT (August 15 - November 15)

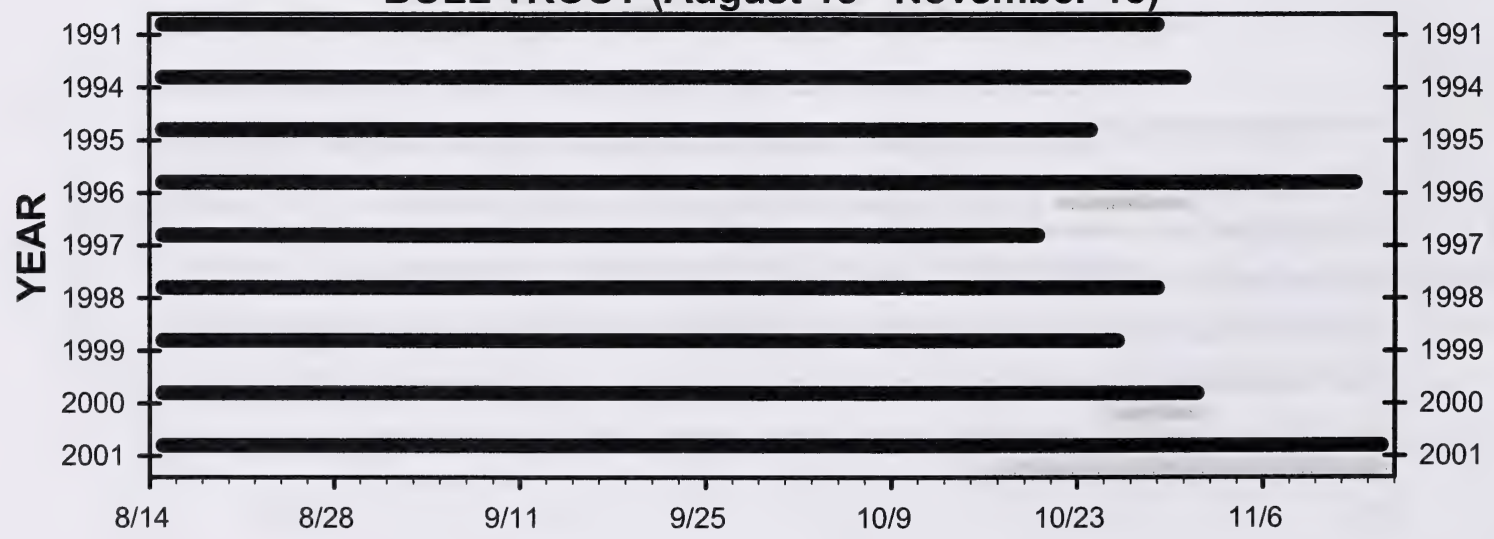

Figure 8. Suitability of water temperatures near Fort Macleod for spawning of brown trout, mountain whitefish, and bull trout. 
WALLEYE (April 15 - June 1)

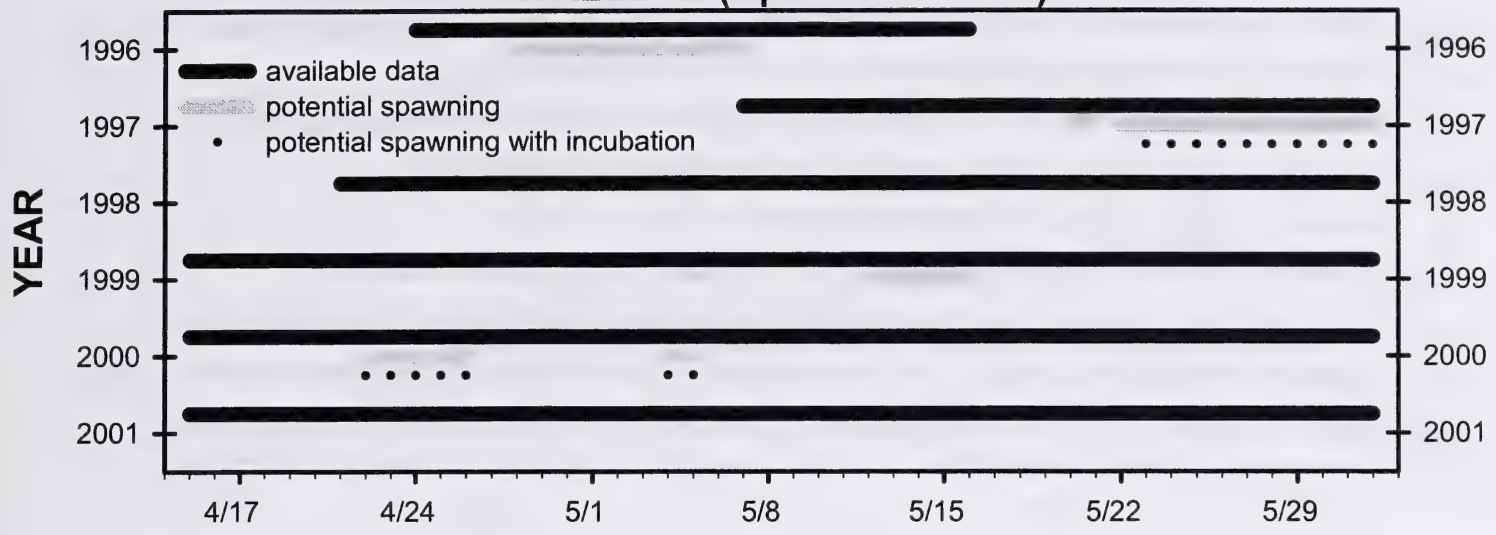

RAINBOW TROUT (April 1 - June 15)

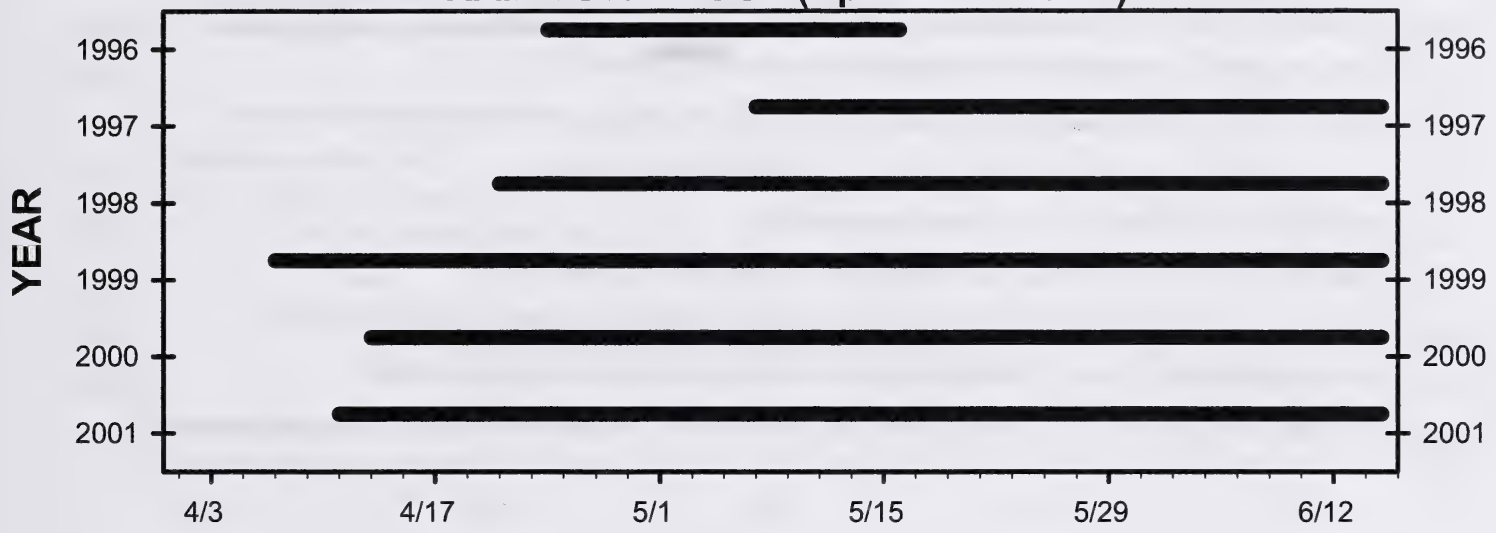

CUTTHROAT TROUT (May 15 - July 15)

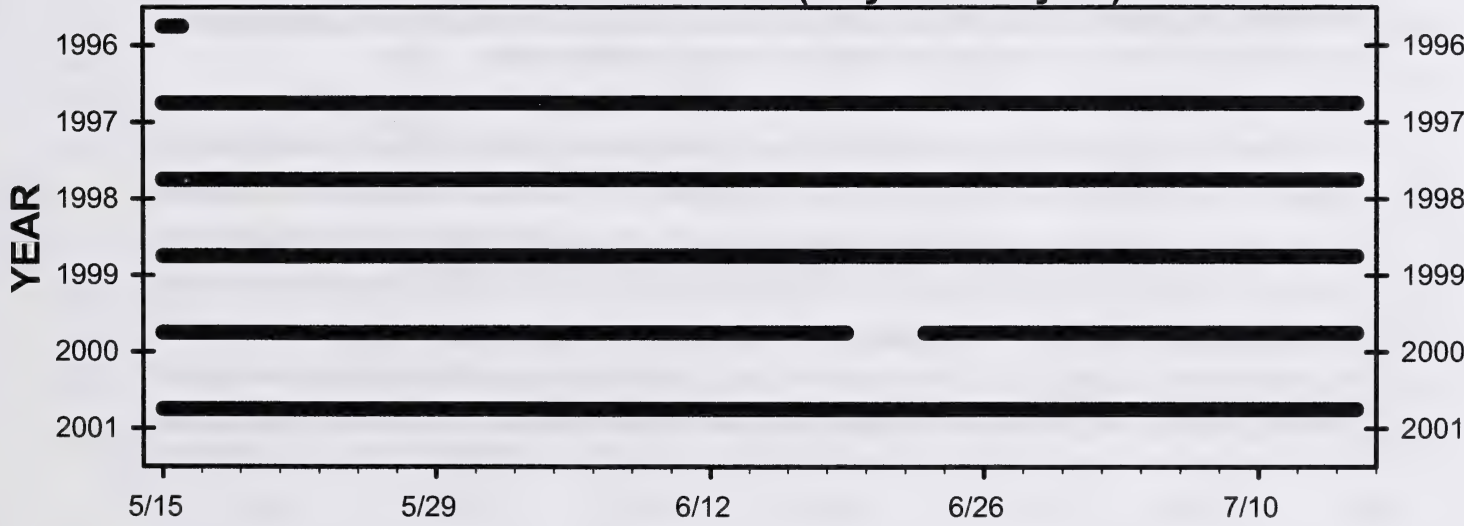

Figure 9. Suitability of water temperatures near Rocky Coulee for spawning and incubation of walleye, rainbow trout, and cutthroat trout. 
BROWN TROUT (September 15 - November 15)

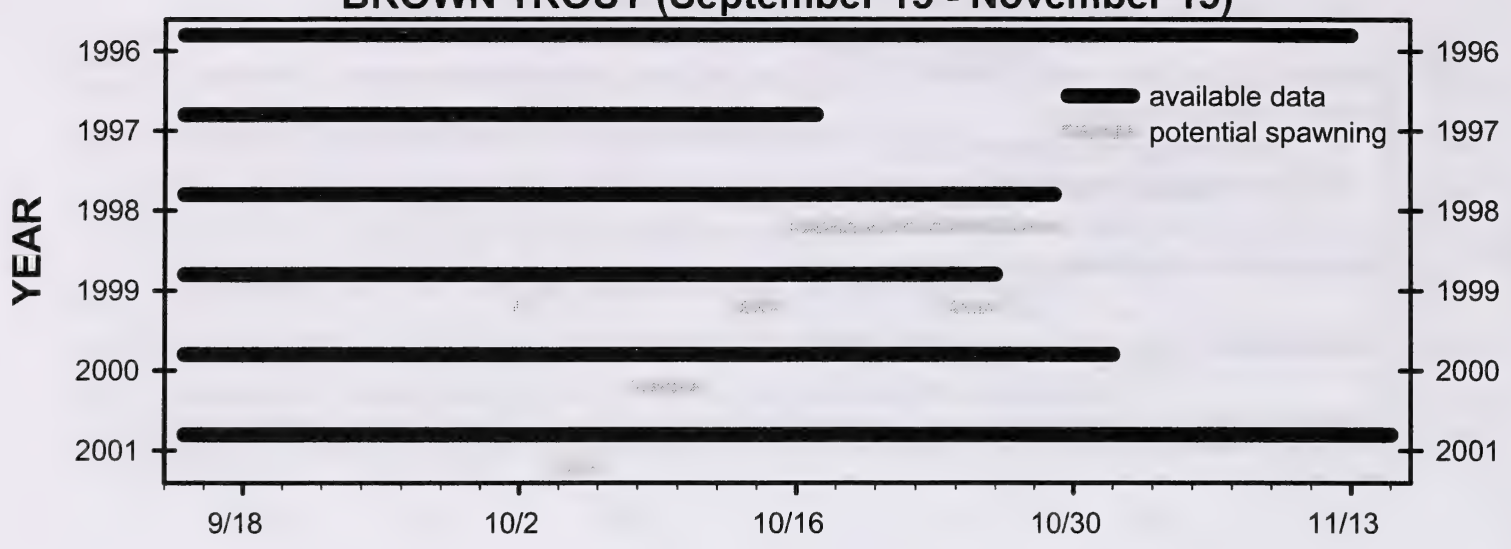

MOUNTAIN WHITEFISH (September 15 - November 15)

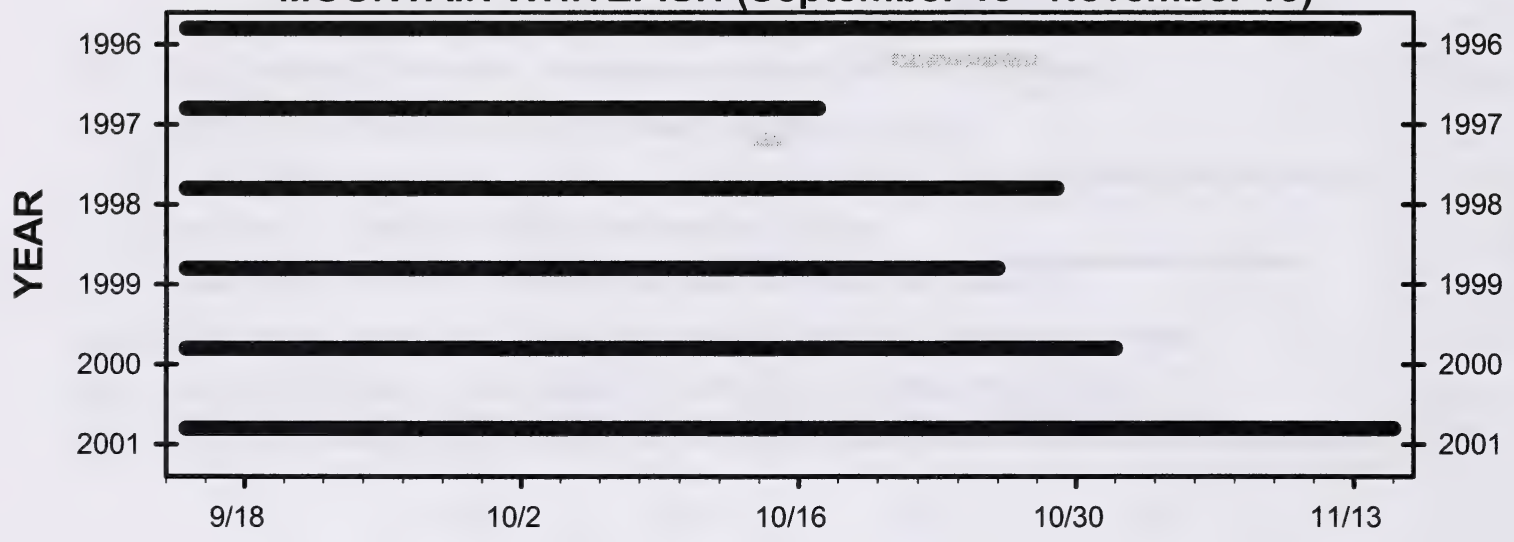

BULL TROUT (August 15 - November 15)

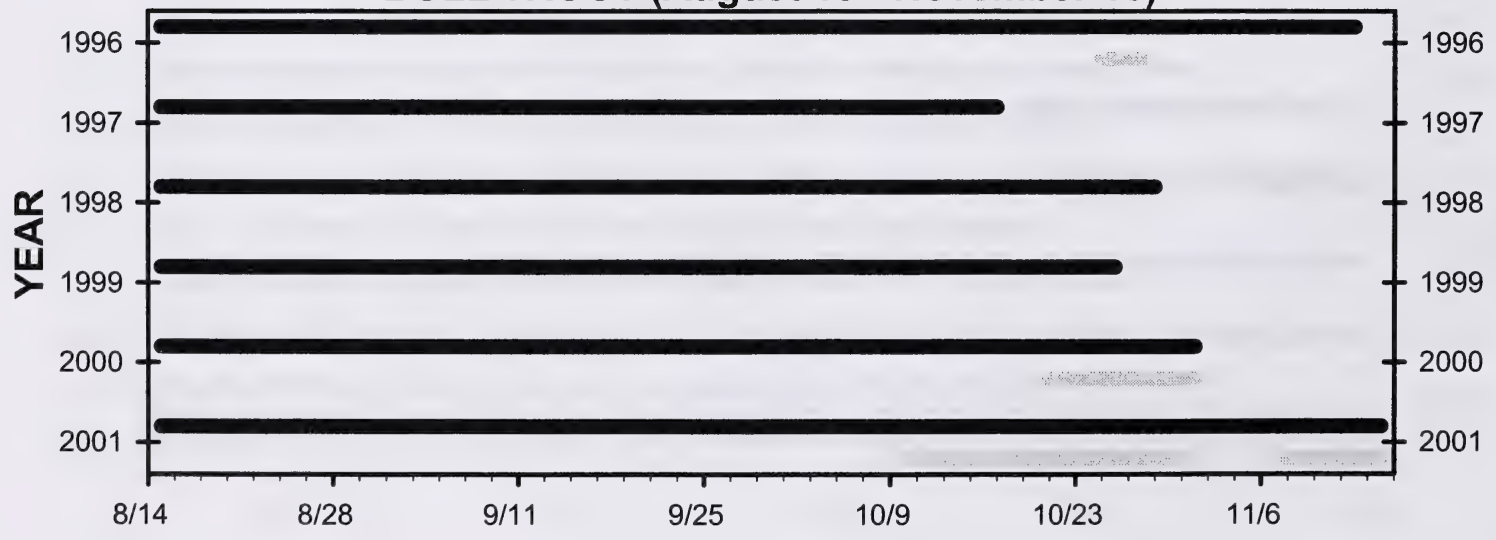

Figure 10. Suitability of water temperatures near Rocky Coulee for spawning of brown trout, mountain whitefish, and bull trout. 
WALLEYE (April 15 - June 1)

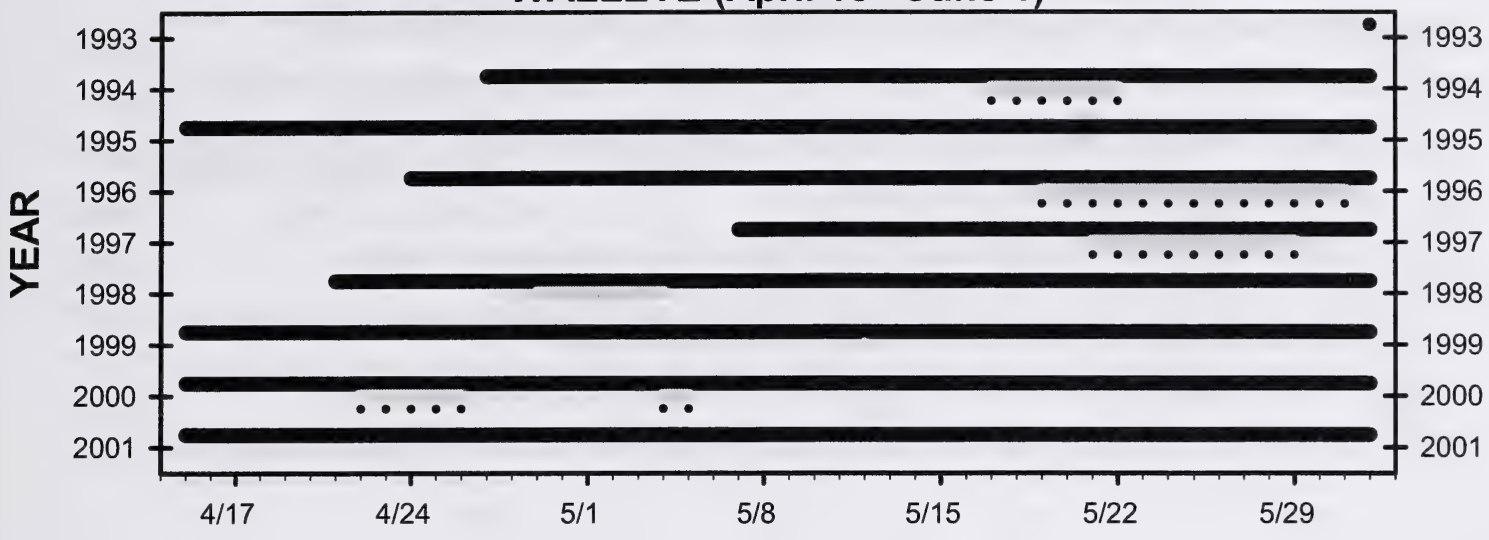

RAINBOW TROUT (April 1 - June 15)

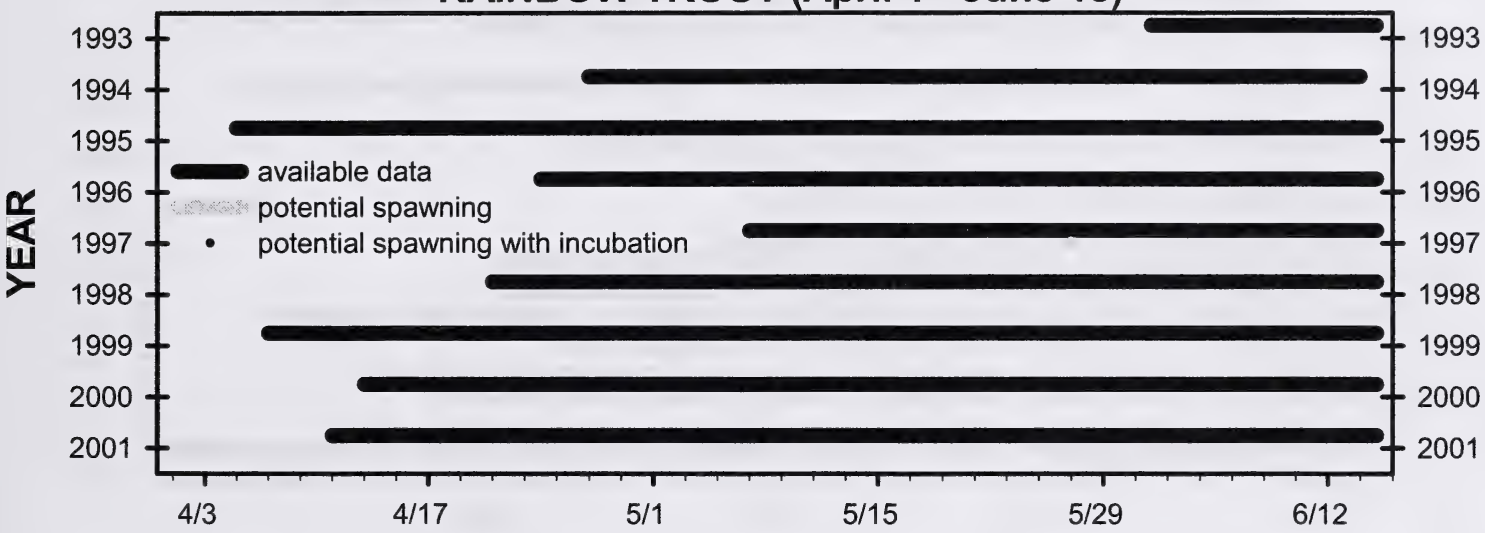

CUTTHROAT TROUT (May 15 - July 15)

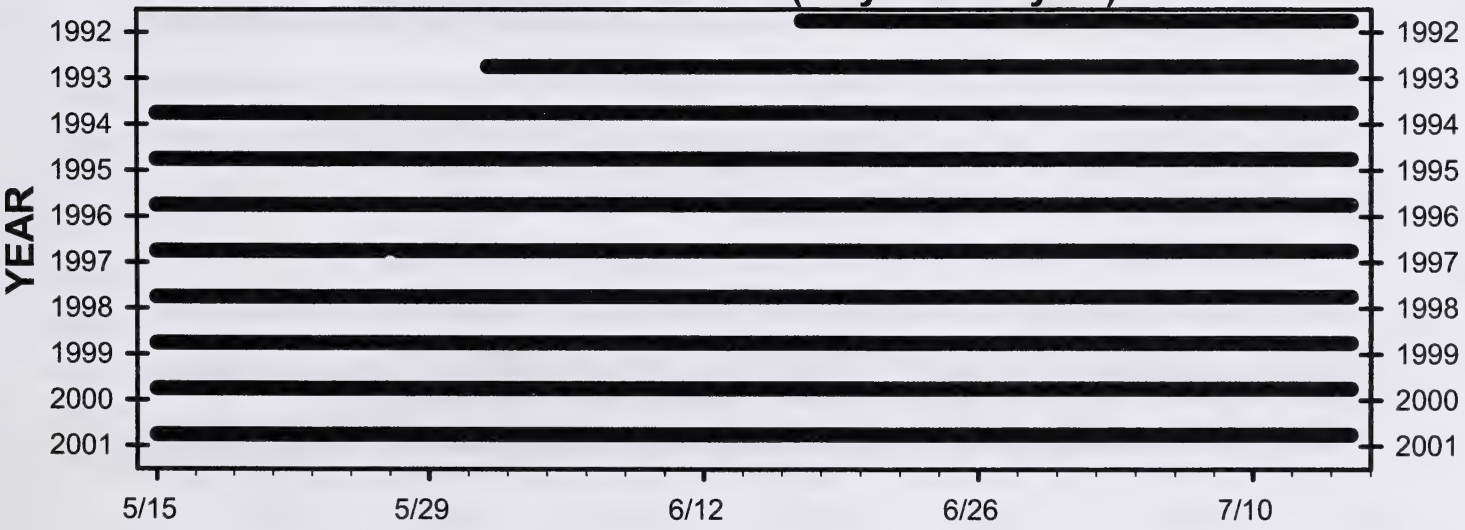

Figure 11. Suitability of water temperatures near Monarch for spawning and incubation of walleye, rainbow trout, and cutthroat trout. 
BROWN TROUT (September 15 - November 15)

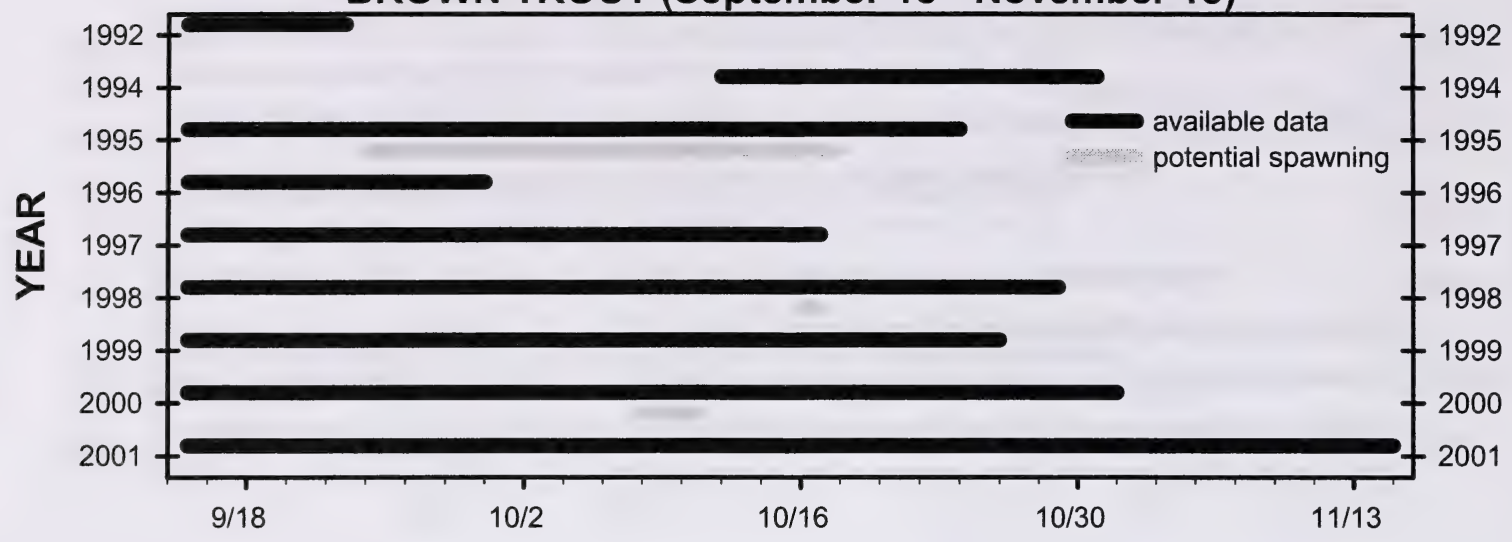

MOUNTAIN WHITEFISH (September 15 - November 15)

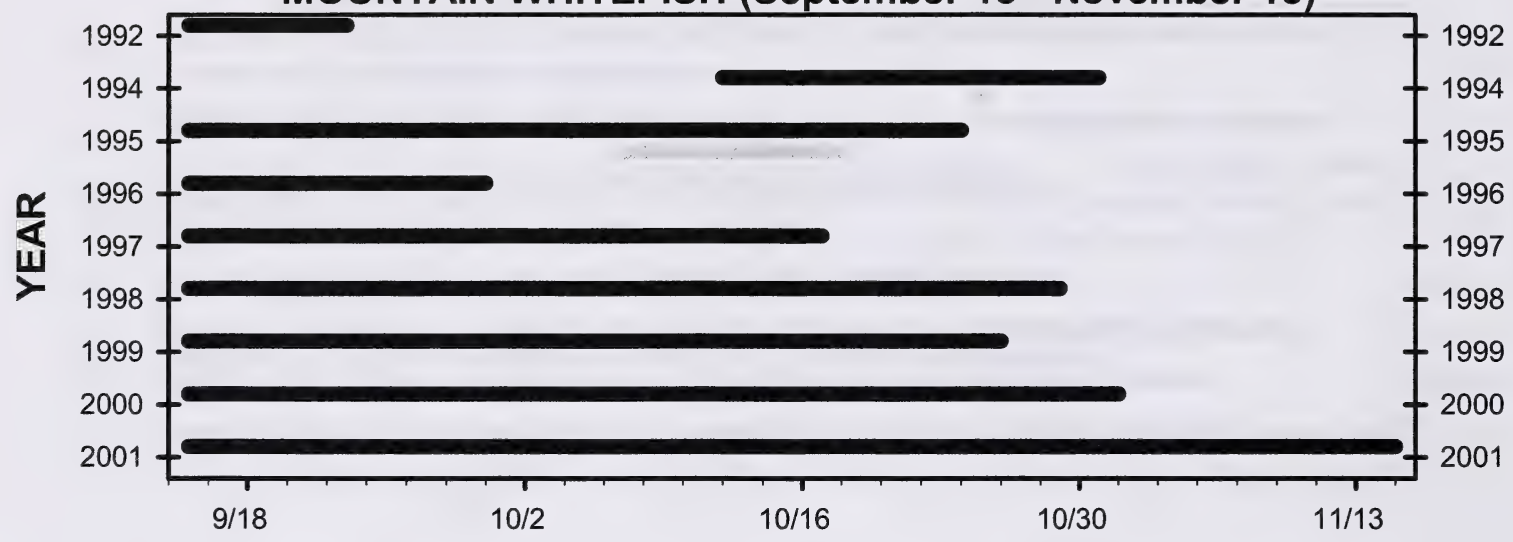

BULL TROUT (August 15 - November 15)

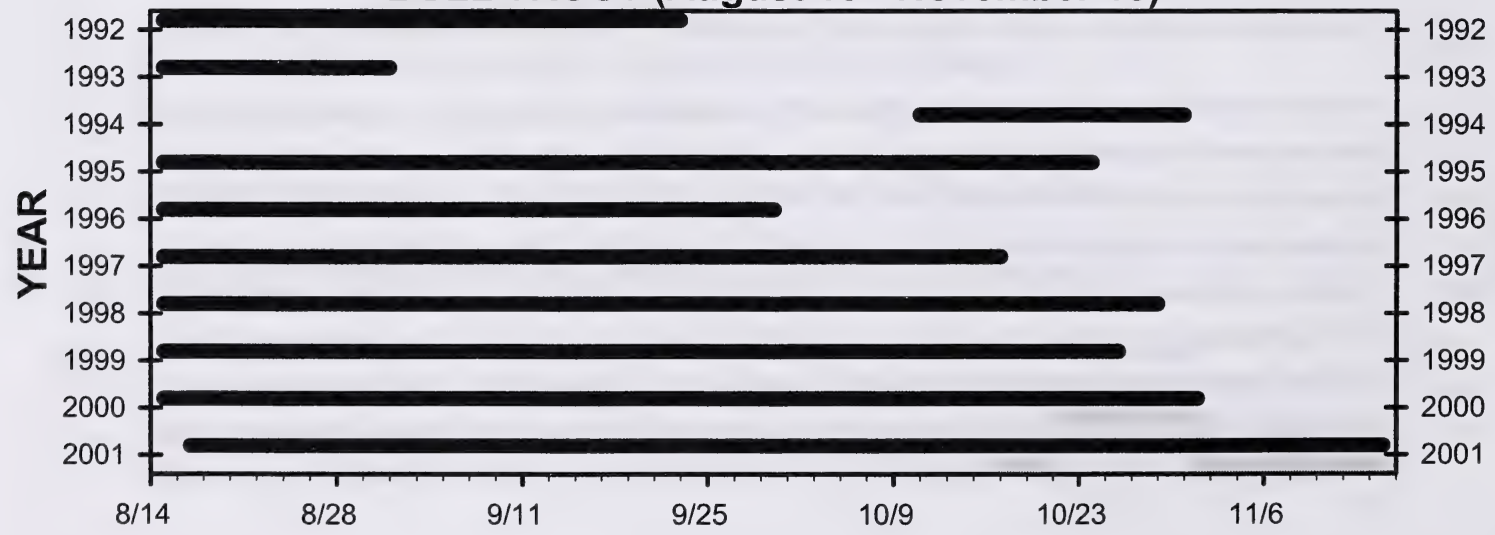

Figure 12. Suitability of water temperatures near Monarch for spawning of brown trout, mountain whitefish, and bull trout. 
WALLEYE (April 15 - June 1)

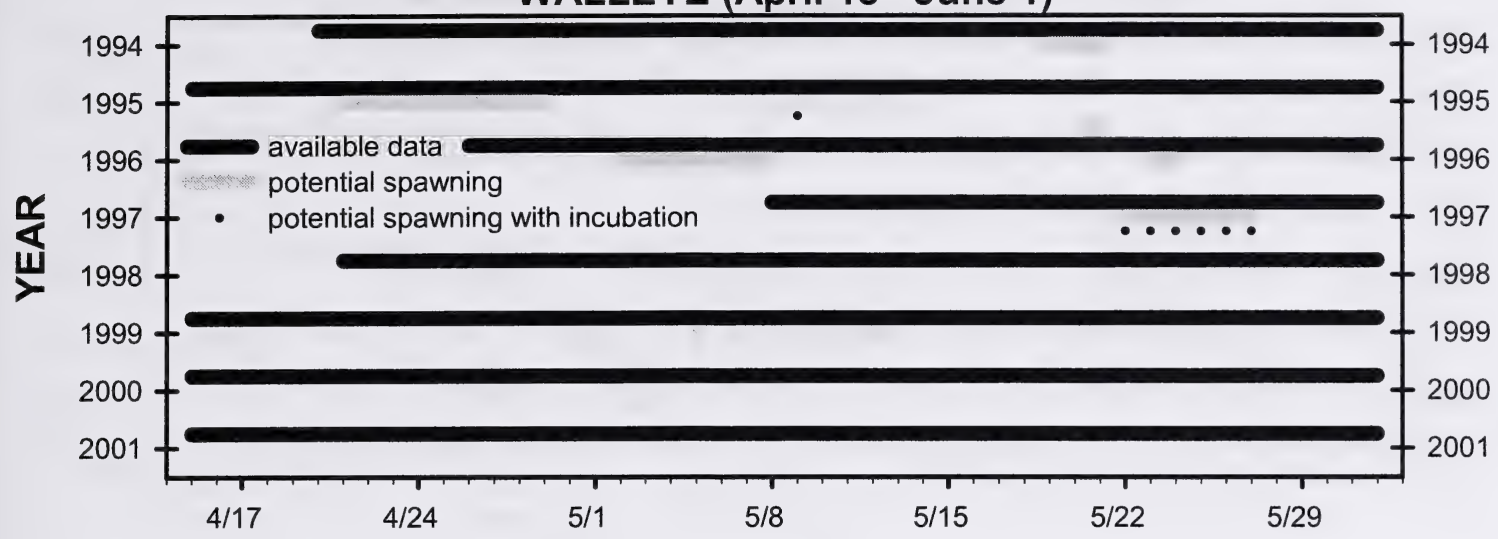

RAINBOW TROUT (April 1 - June 15)

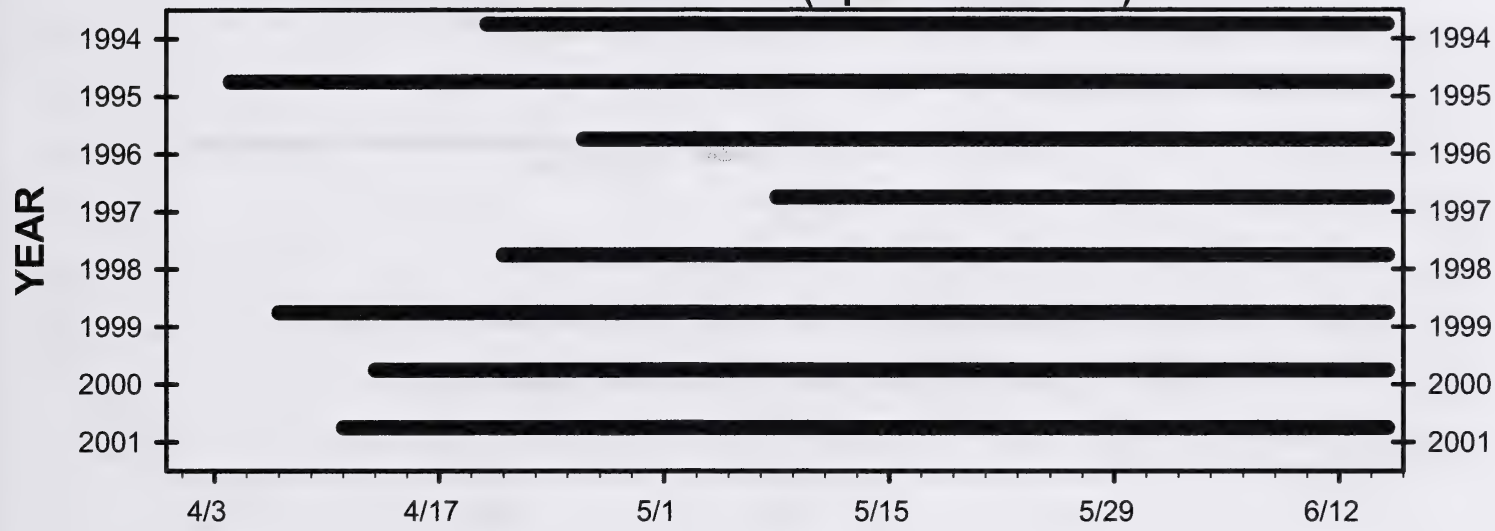

CUTTHROAT TROUT (May 15 - July 15)

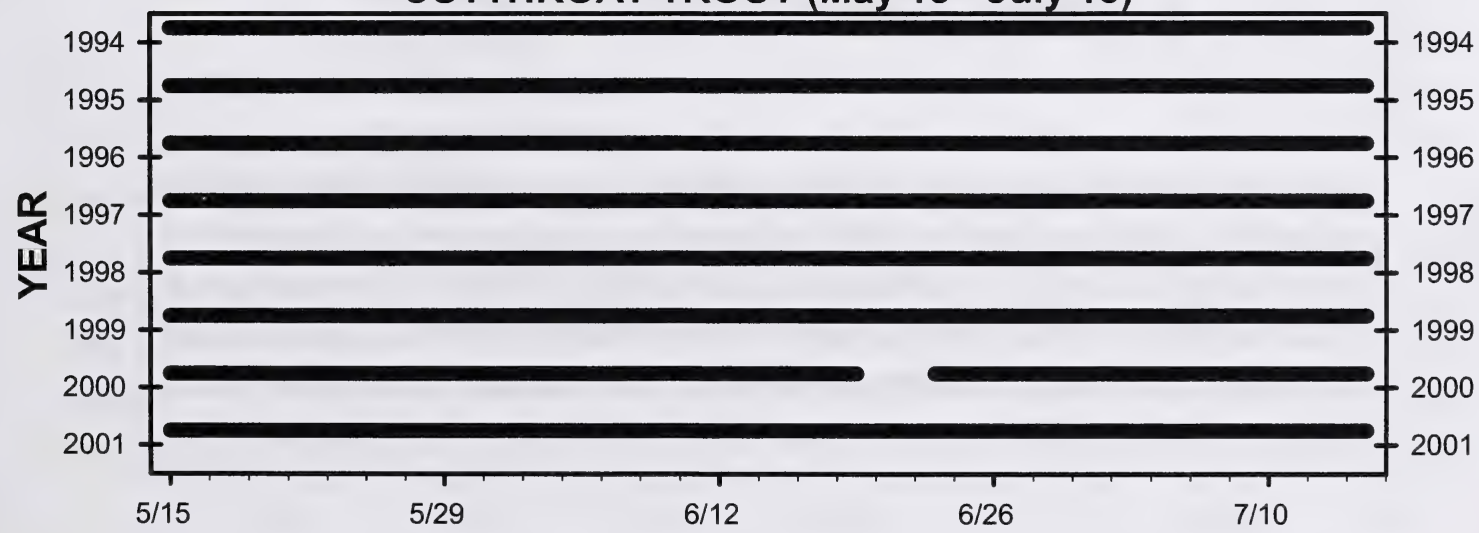

Figure 13. Suitability of water temperatures d/s of the Belly River for spawning and incubation of walleye, rainbow trout, and cutthroat trout. 
BROWN TROUT (September 15 - November 15)

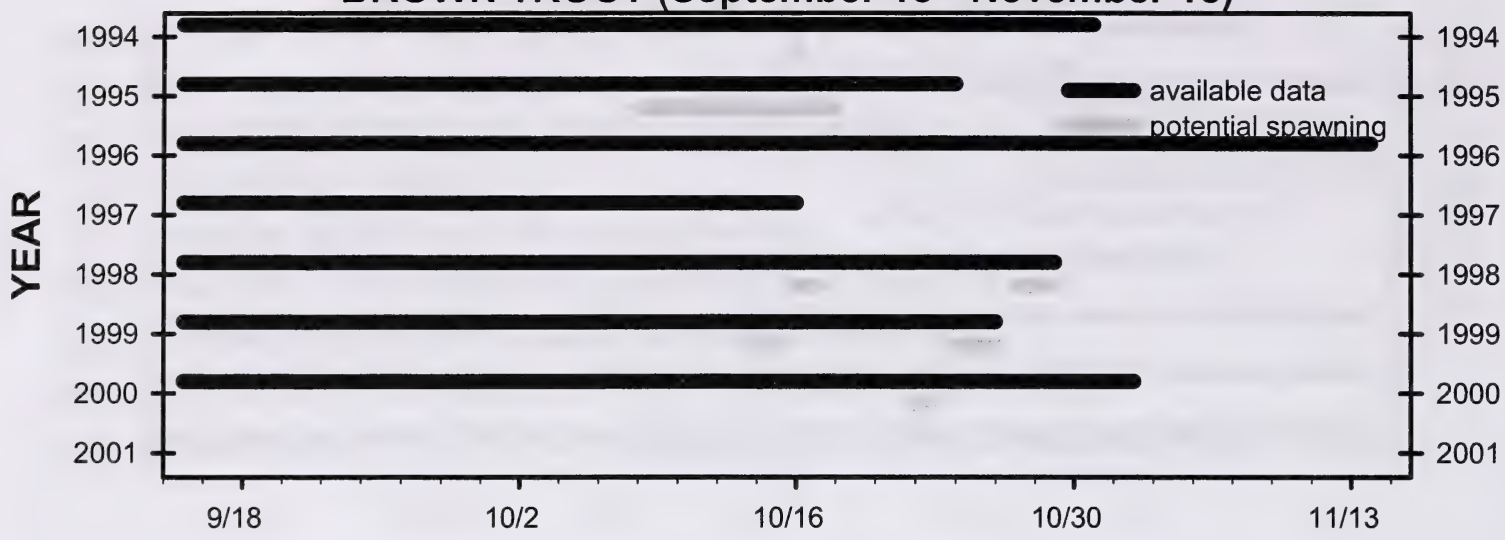

MOUNTAIN WHITEFISH (September 15 - November 15)

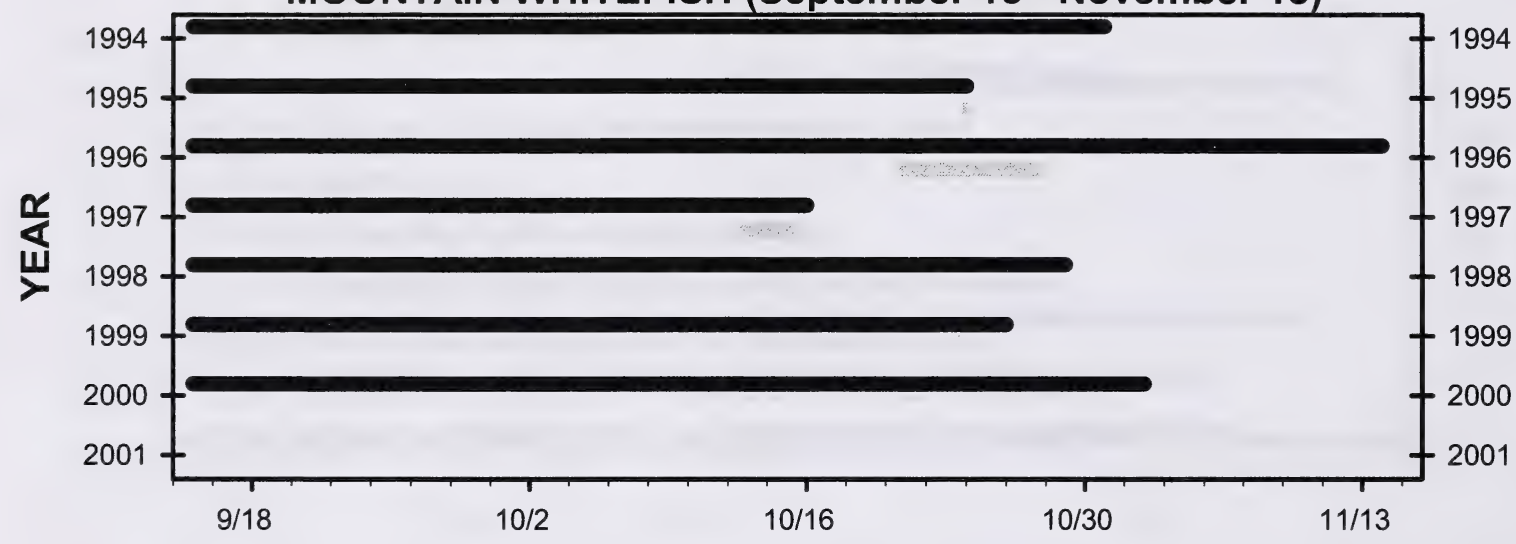

BULL TROUT (August 15 - November 15)

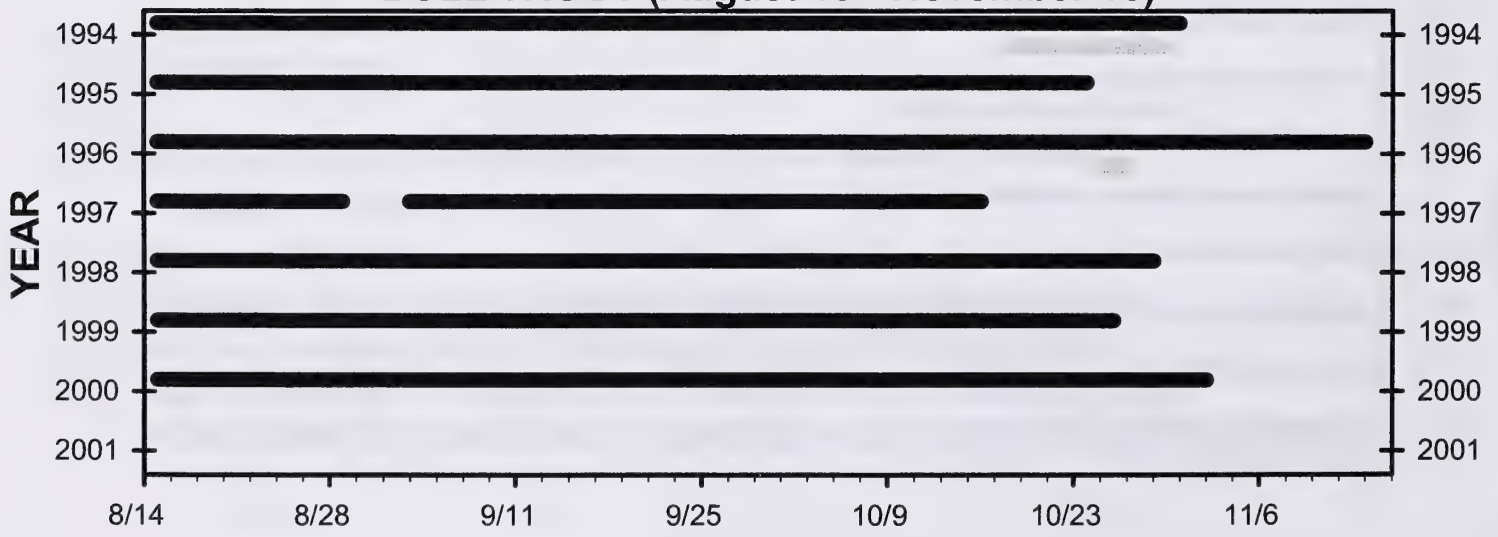

Figure 14. Suitability of water temperatures $d / s$ of the Belly River for spawning of brown trout, mountain whitefish, and bull trout. 
WALLEYE (April 15 - June 1)

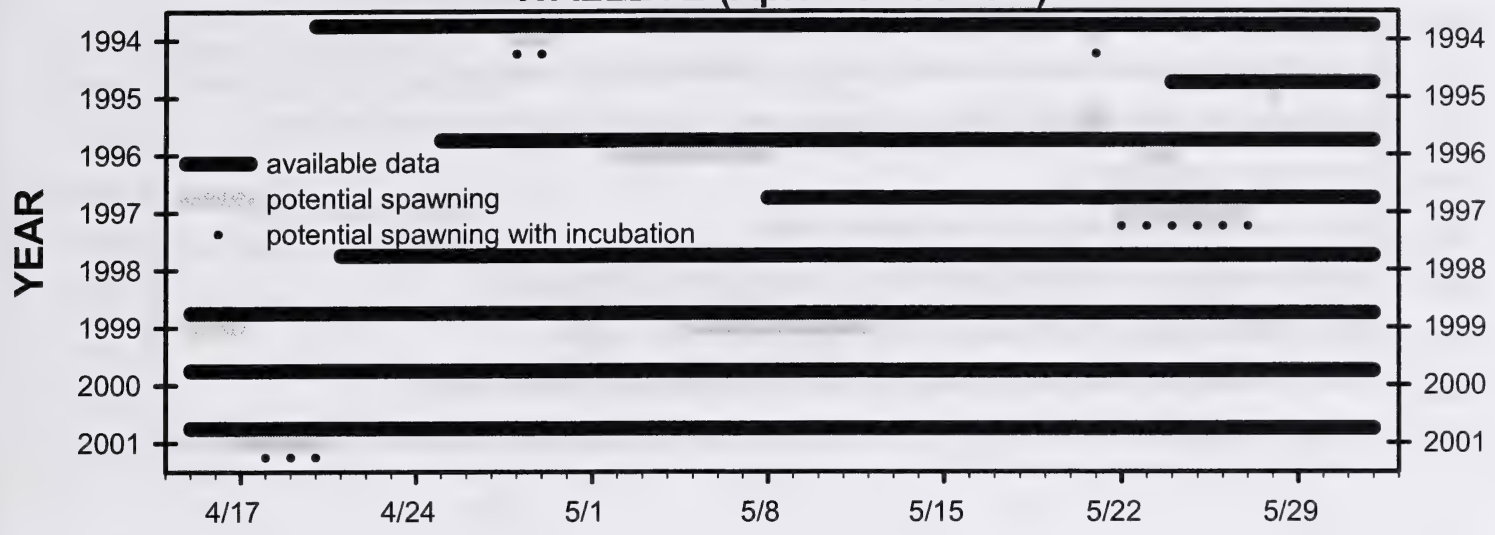

RAINBOW TROUT (April 1 - June 15)

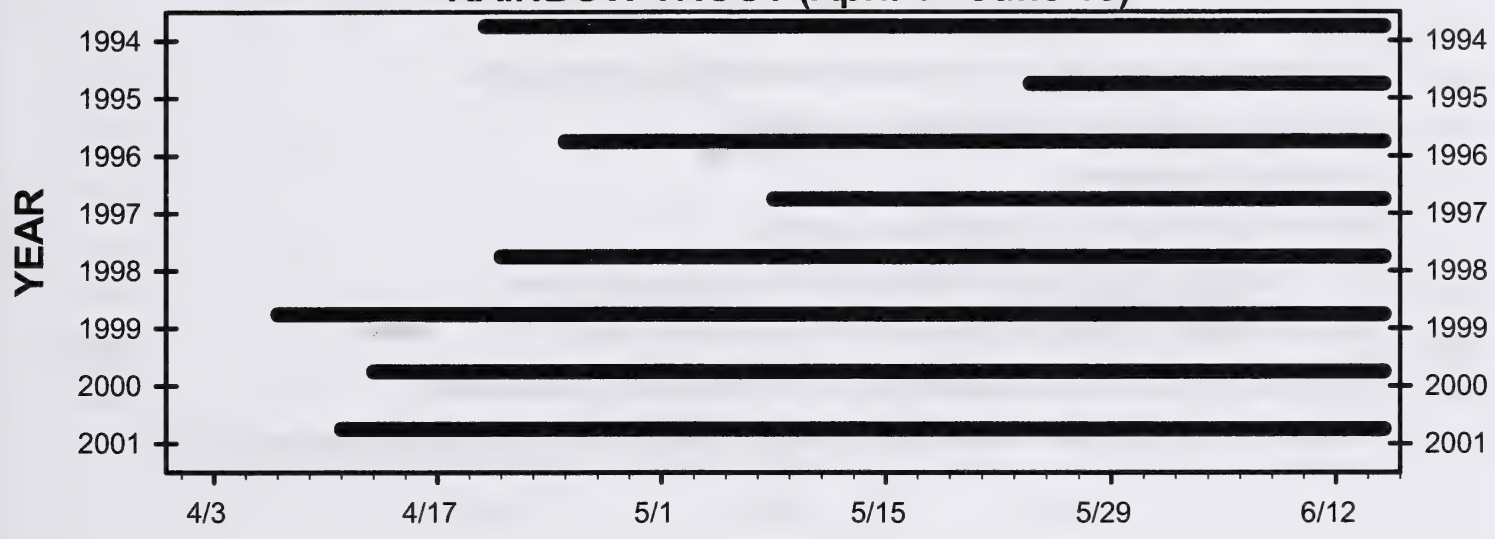

CUTTHROAT TROUT (May 15 - July 15)

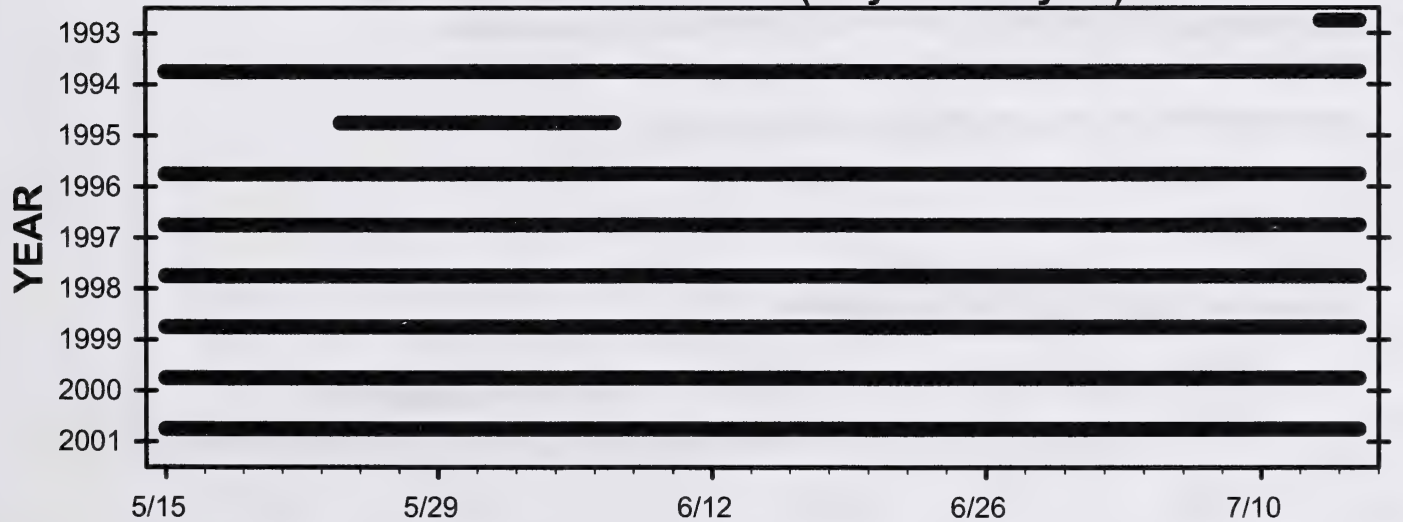

Figure 15. Suitability of water temperatures $\mathrm{u} / \mathrm{s}$ of Lethbridge for spawning and incubation of walleye, rainbow trout, and cutthroat trout. 
BROWN TROUT (September 15 - November 15)

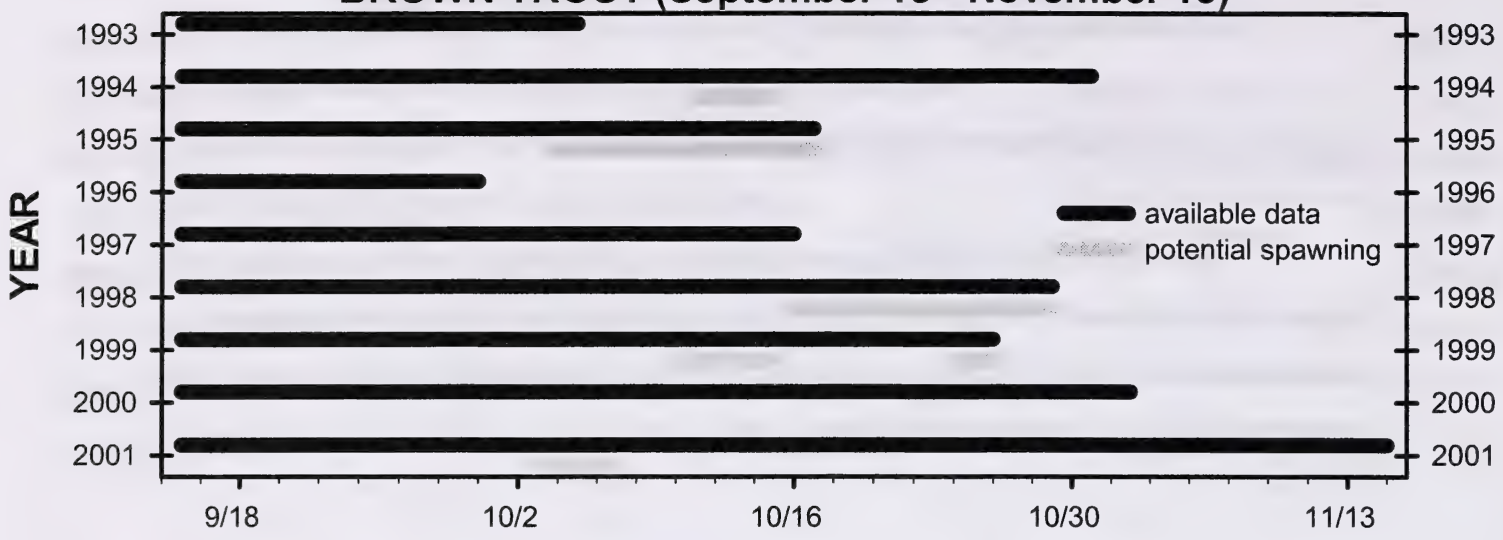

MOUNTAIN WHITEFISH (September 15 - November 15)

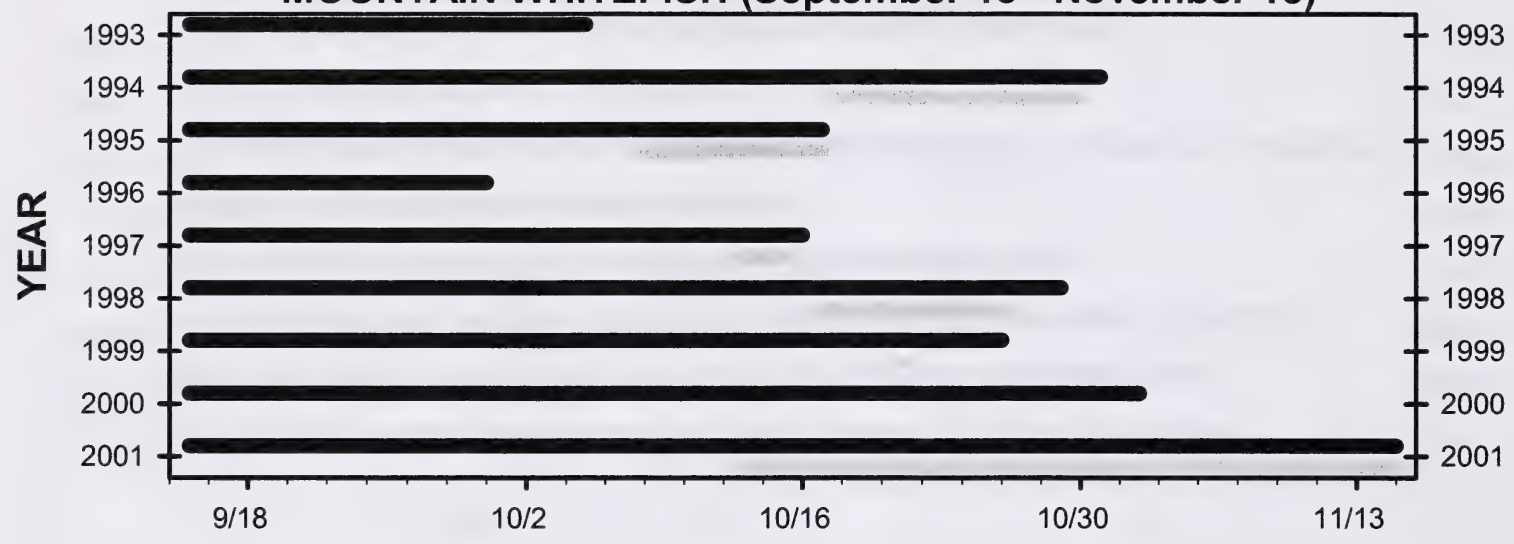

BULL TROUT (August 15 - November 15)

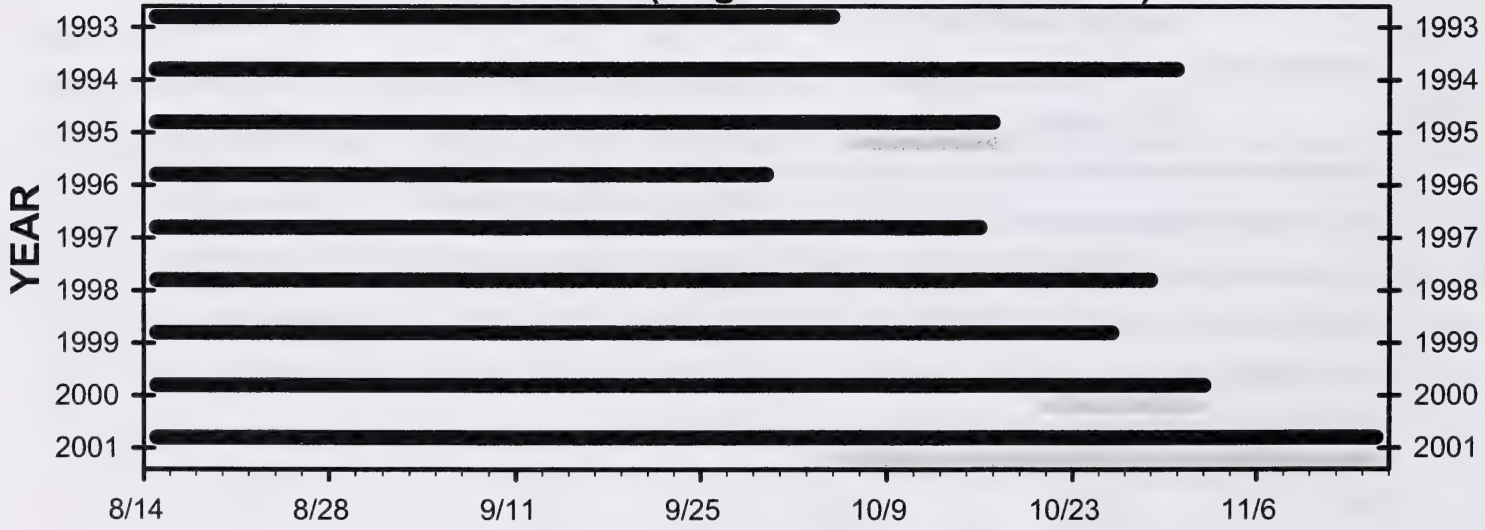

Figure 16. Suitability of water temperatures $u / s$ of Lethbridge for spawning of brown trout, mountain whitefish, and bull trout. 
WALLEYE (April 15 - June 1)

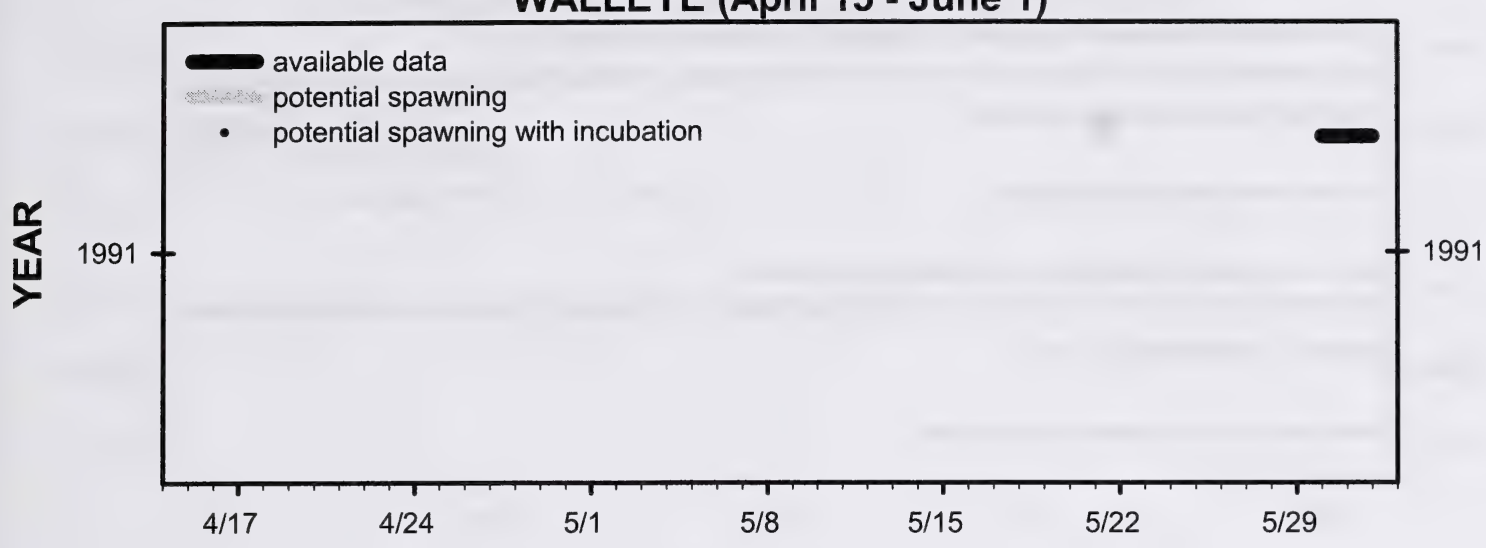

RAINBOW TROUT (April 1 - June 15)

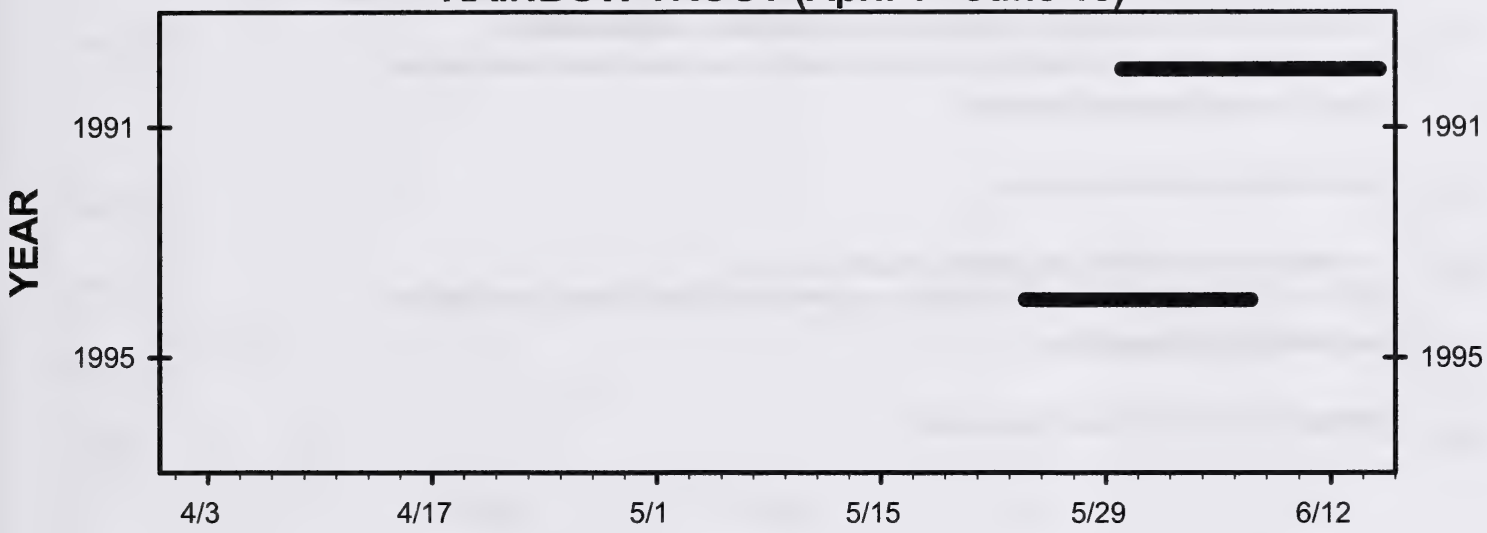

CUTTHROAT TROUT (15 May - July 15)

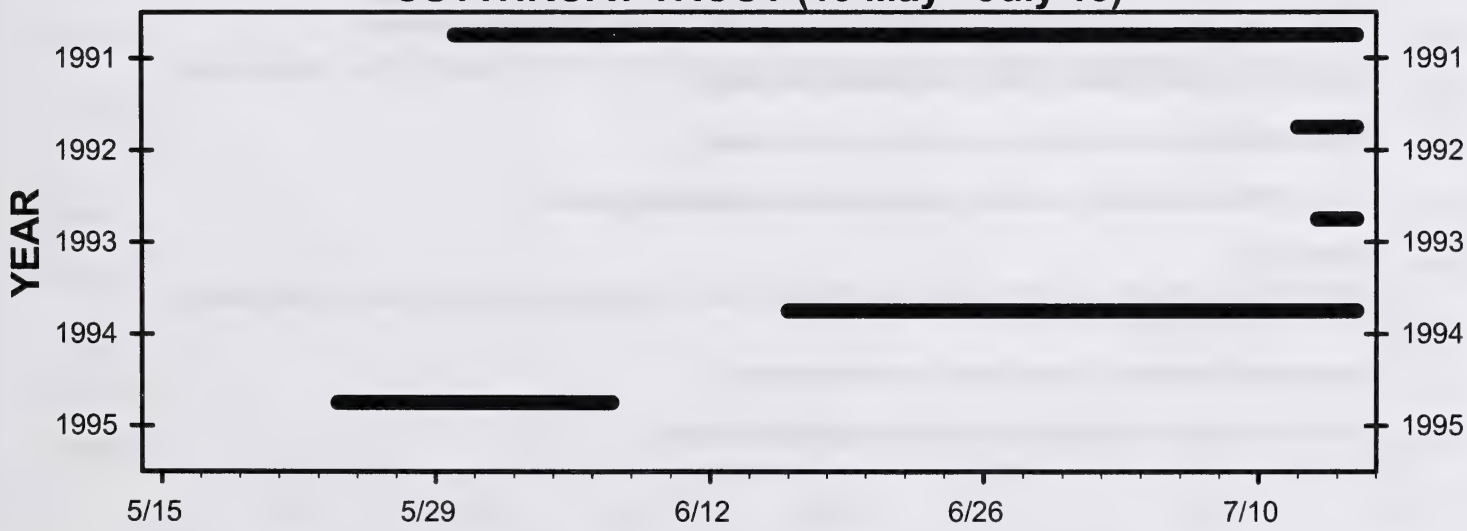

Figure 17. Suitability of water temperatures $\mathrm{d} / \mathrm{s}$ of Lethbridge for spawning and incubation of walleye, rainbow trout, and cutthroat trout. 
BROWN TROUT (September 15 - November 15)

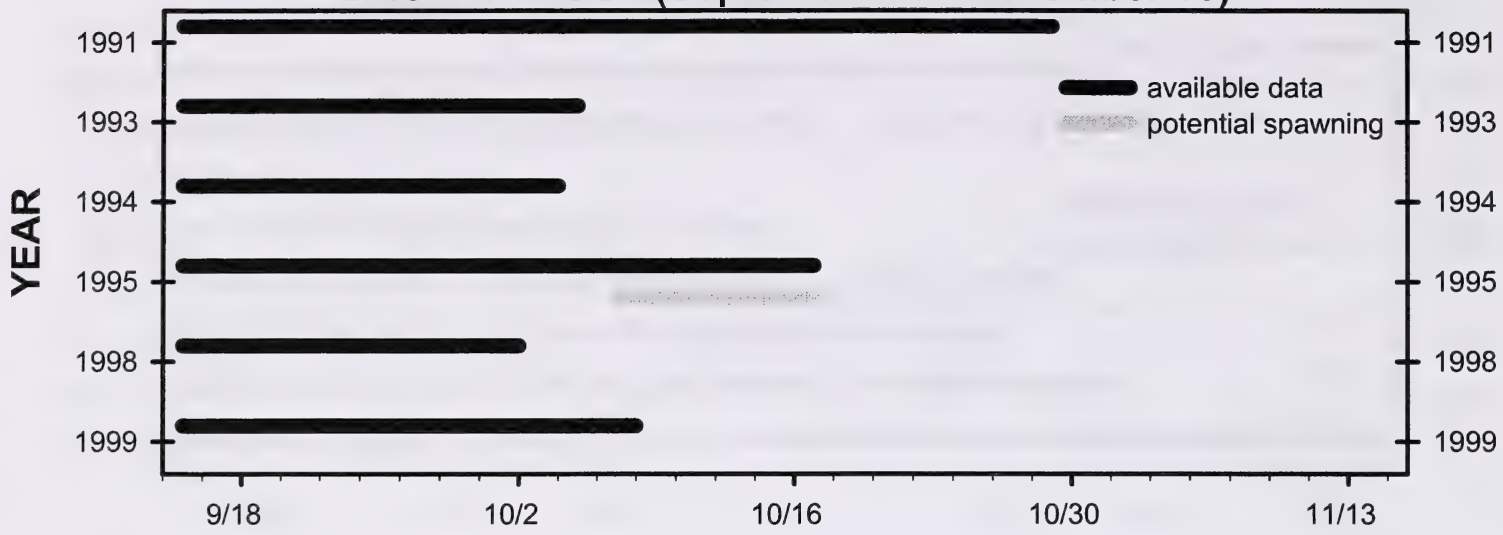

MOUNTAIN WHITEFISH (September 15 - November 15)

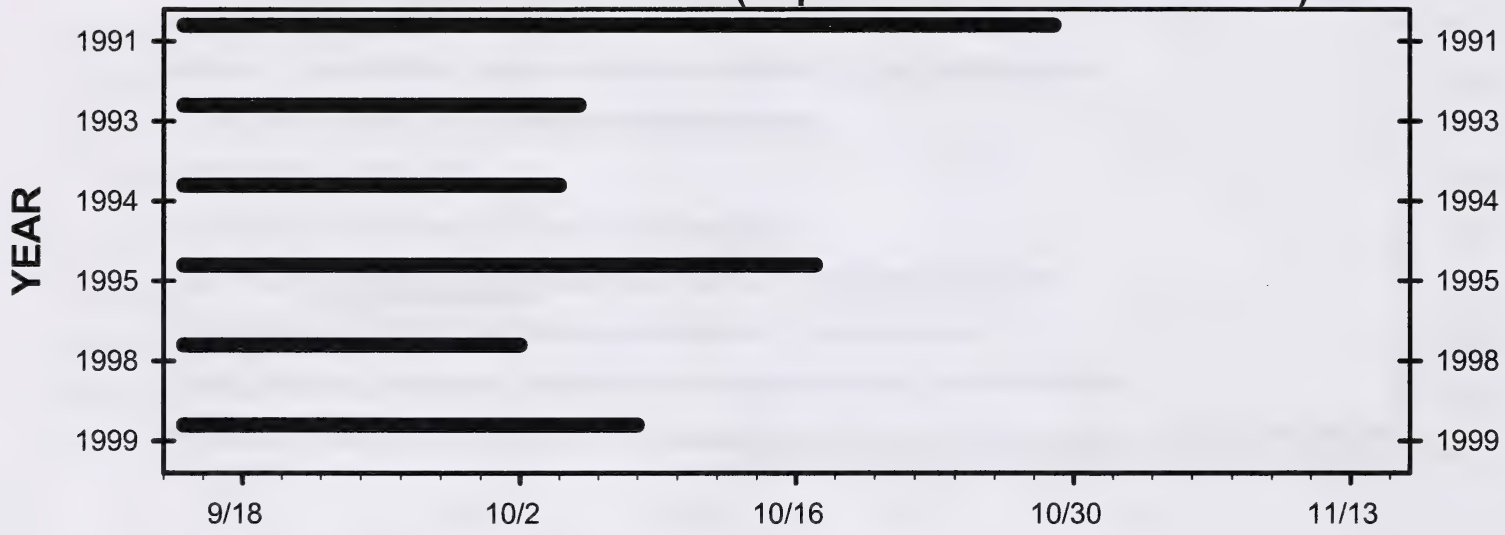

BULL TROUT (August 15 - November 15)

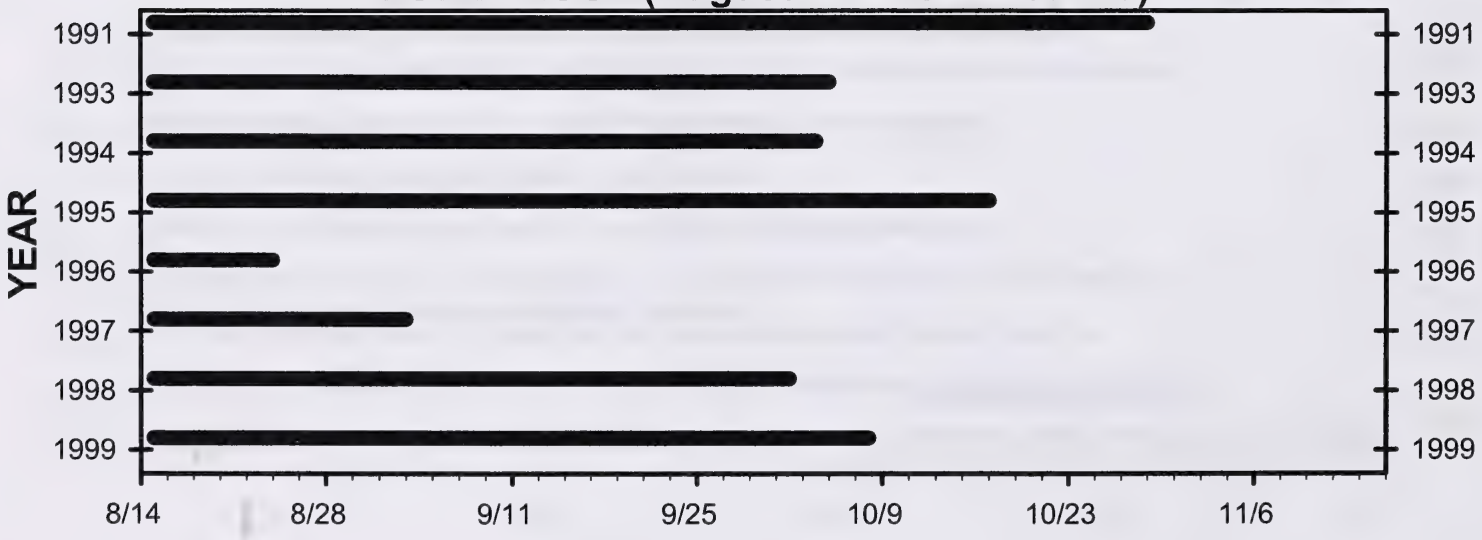

Figure 18. Suitability of water temperatures $\mathrm{d} / \mathrm{s}$ of Lethbridge for spawning of brown trout, mountain whitefish, and bull trout. 

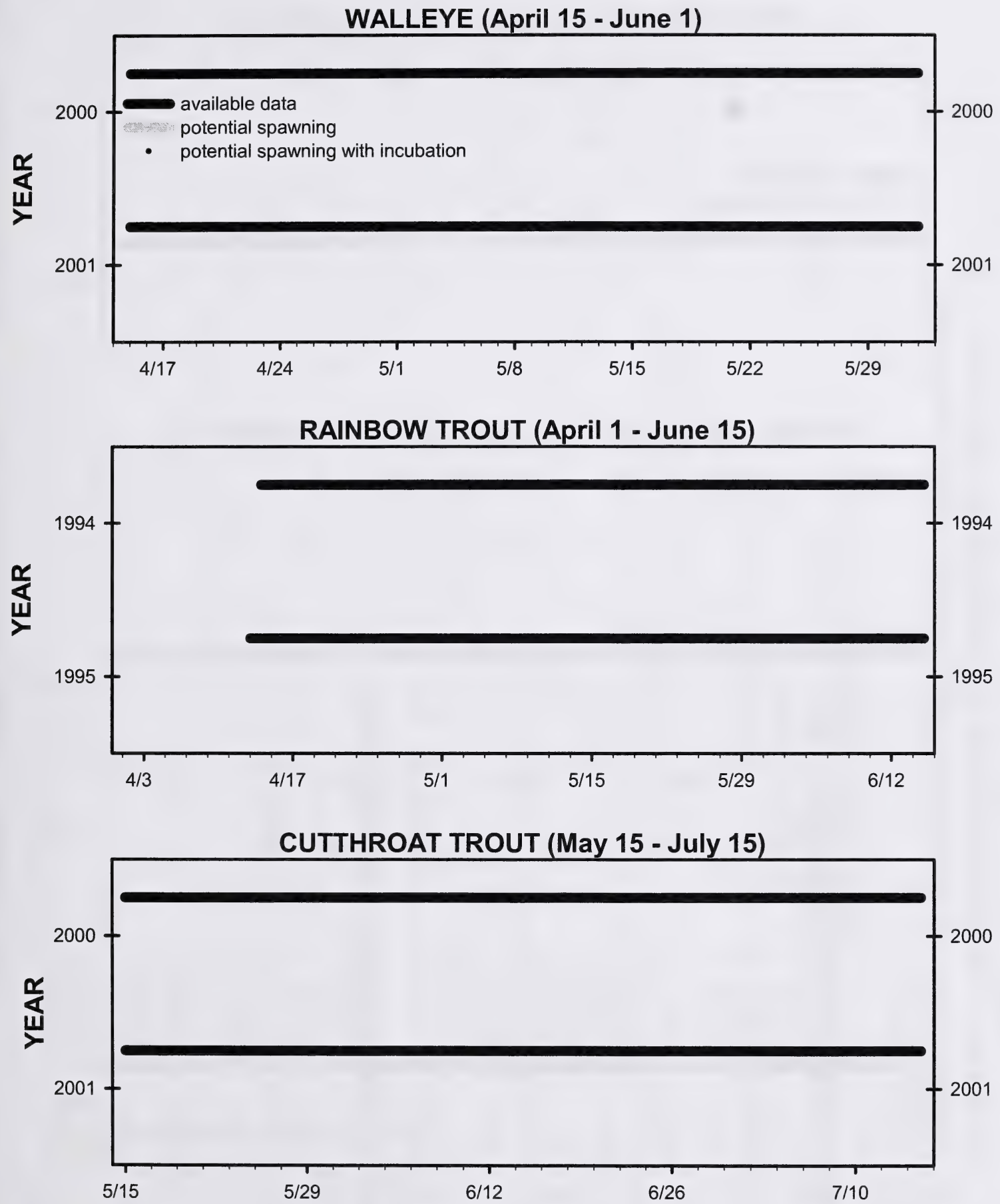

Figure 19. Suitability of water temperatures at Highway 36 for spawning and incubation of walleye, rainbow trout, and cutthroat trout. 

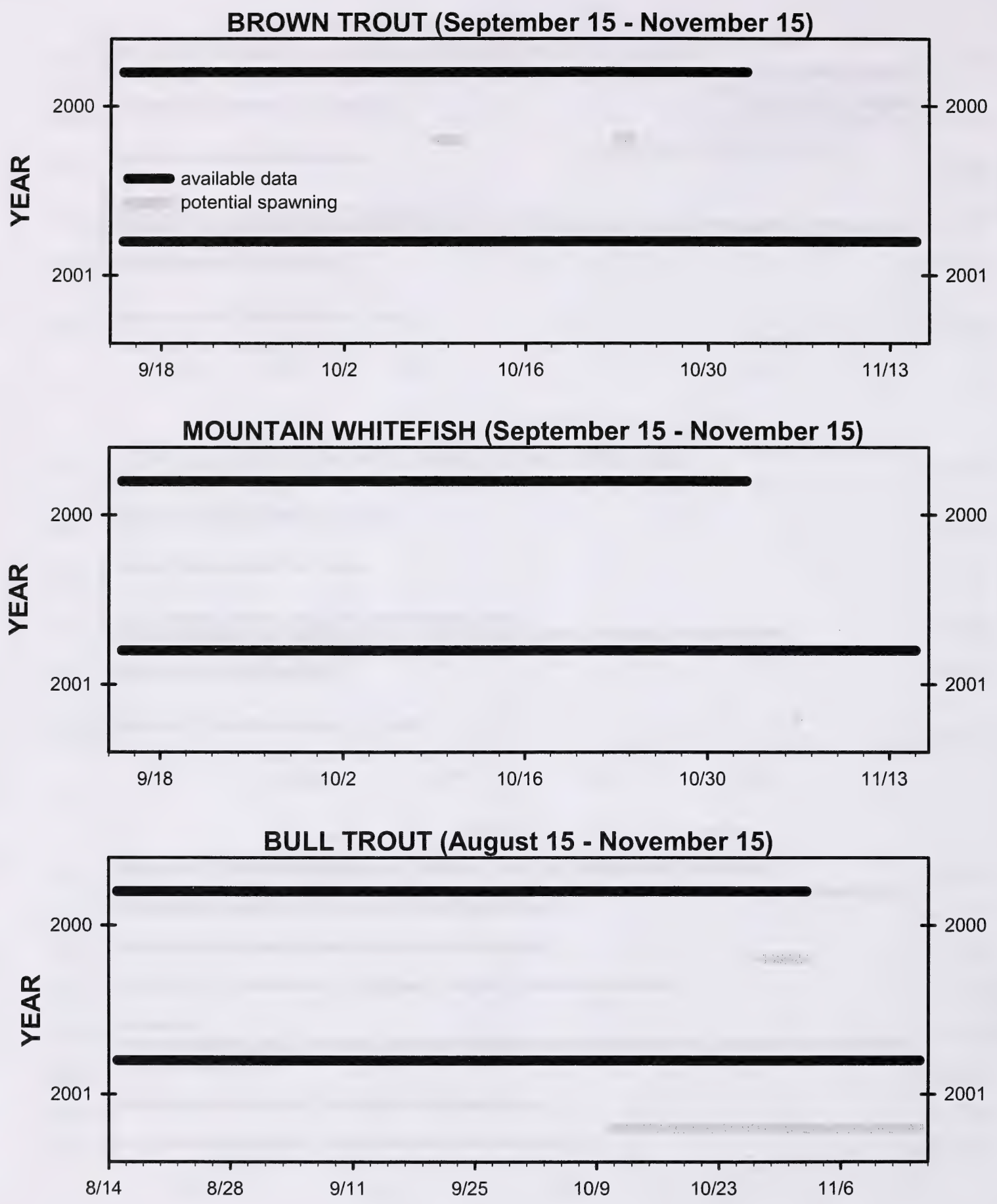

Figure 20. Suitability of water temperatures at Highway 36 for spawning of brown trout, mountain whitefish, and bull trout. 


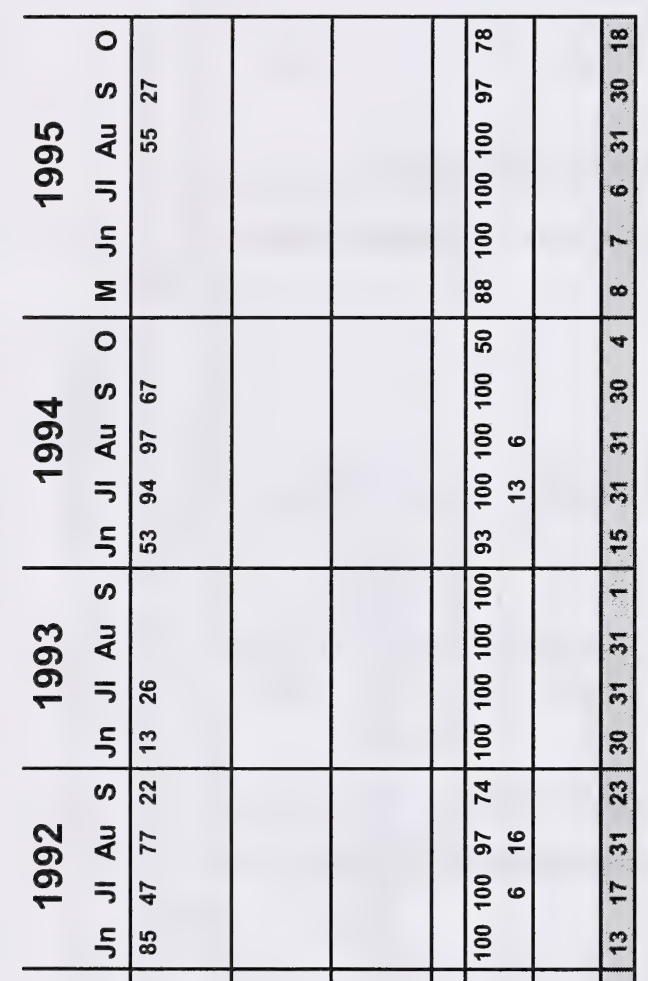

के के की के के की है है है है है है है है है है है है है है

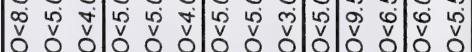
일

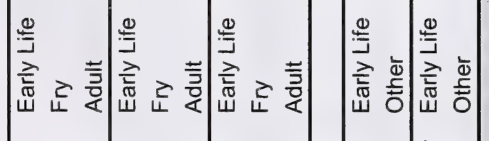

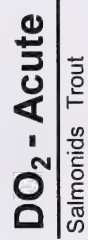

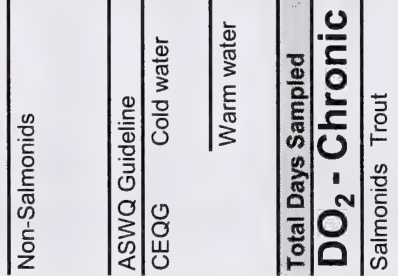

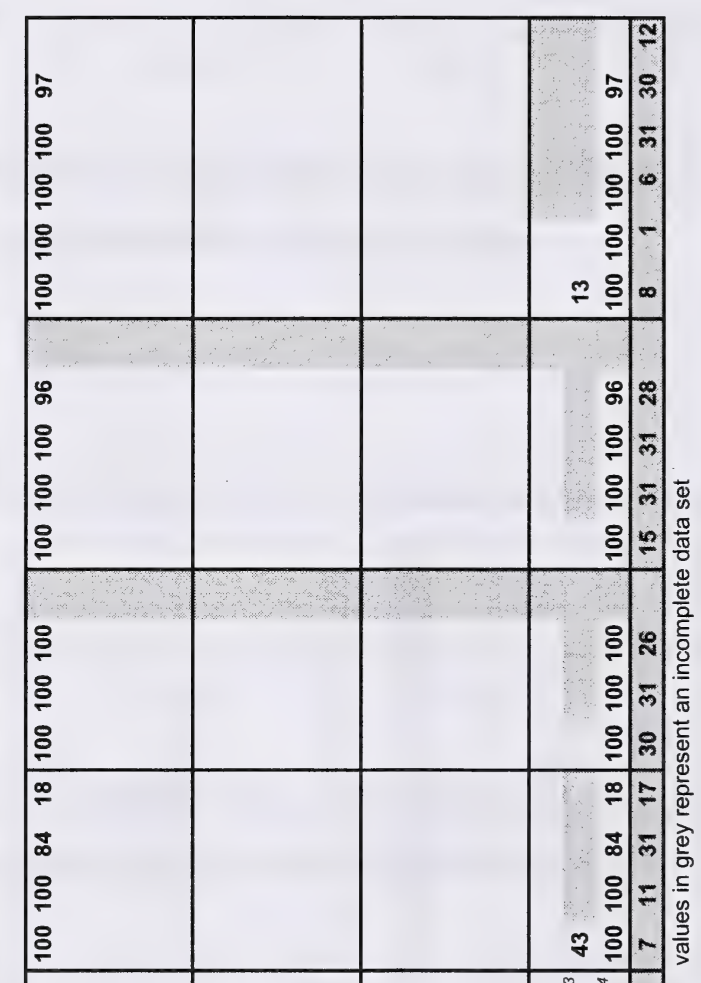

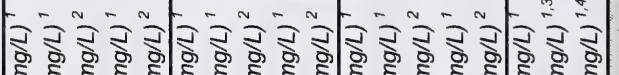
है है है है है है है है है हैं है है है है है है है है

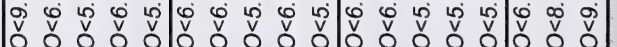

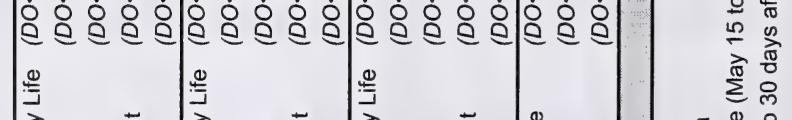

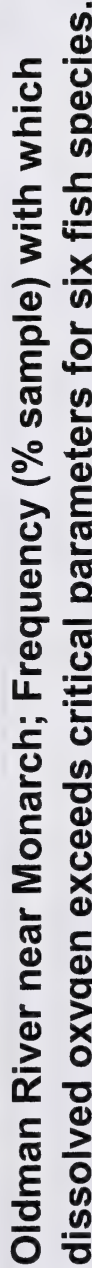
$\stackrel{\infty}{\text { N }}$ E $\frac{2}{\circ}$ ळ $\sum_{x}^{\infty}$ 뜸

. 둥 (

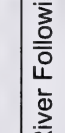
产 हू $\stackrel{0}{5}$

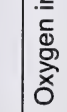




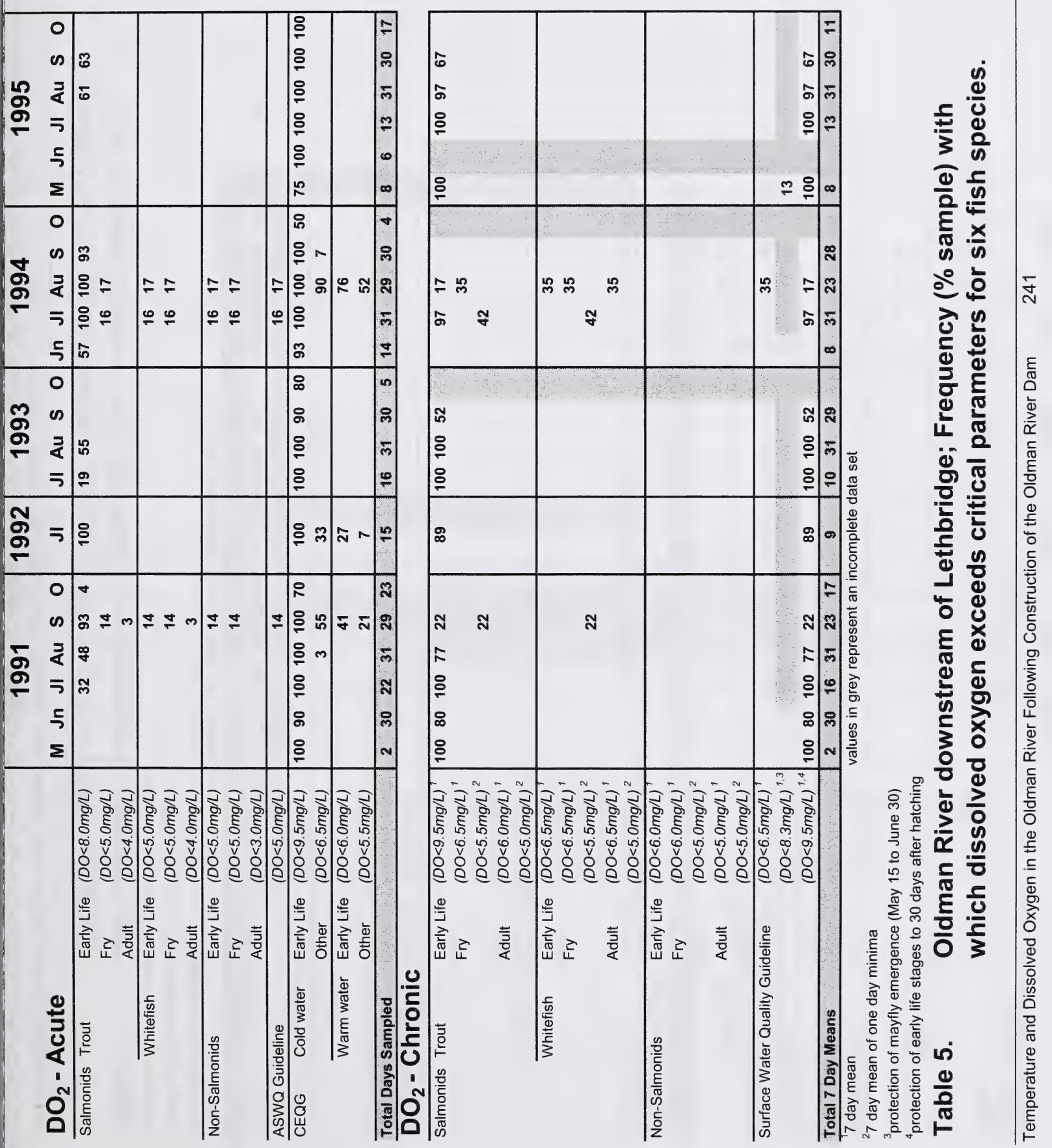




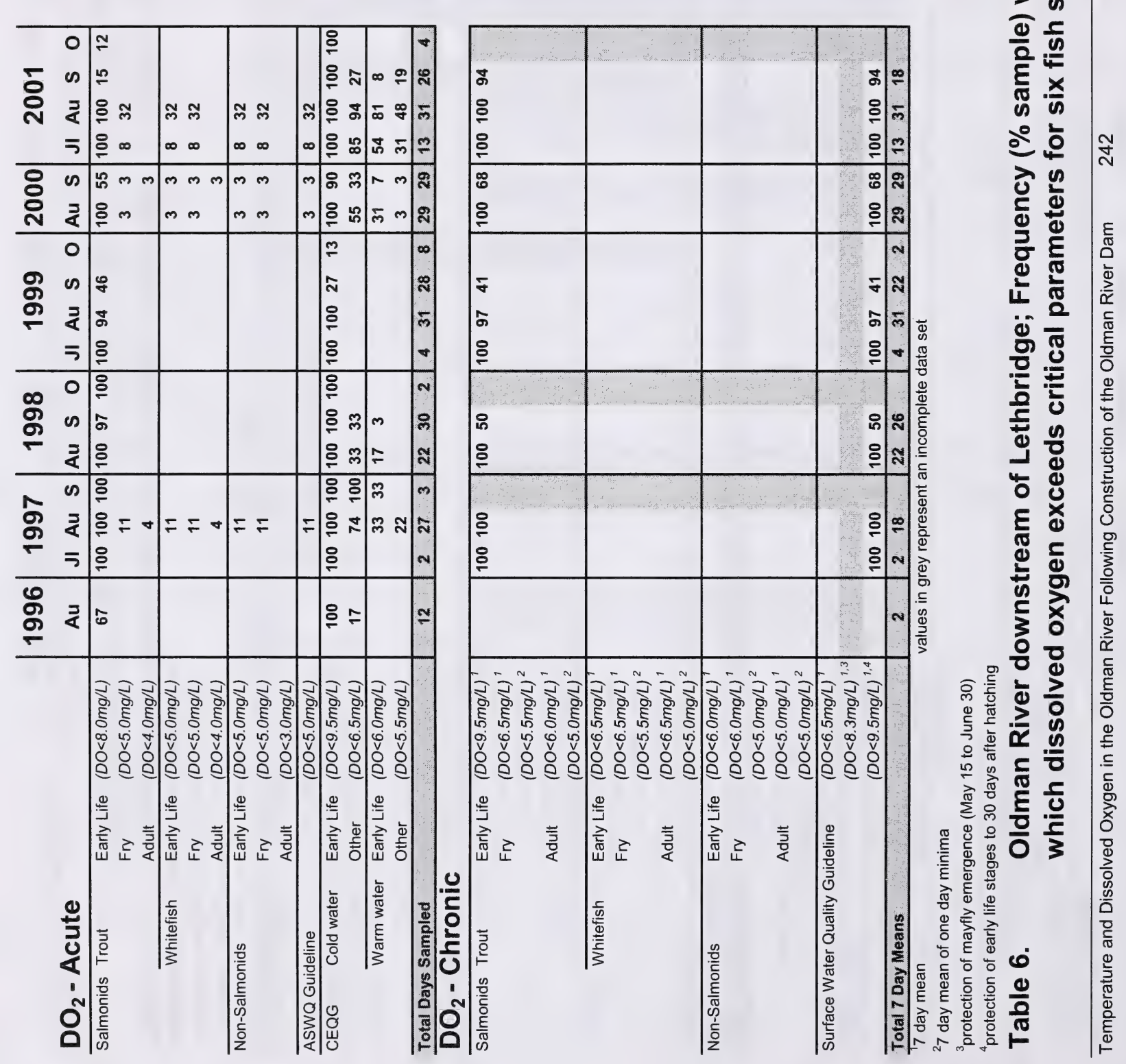




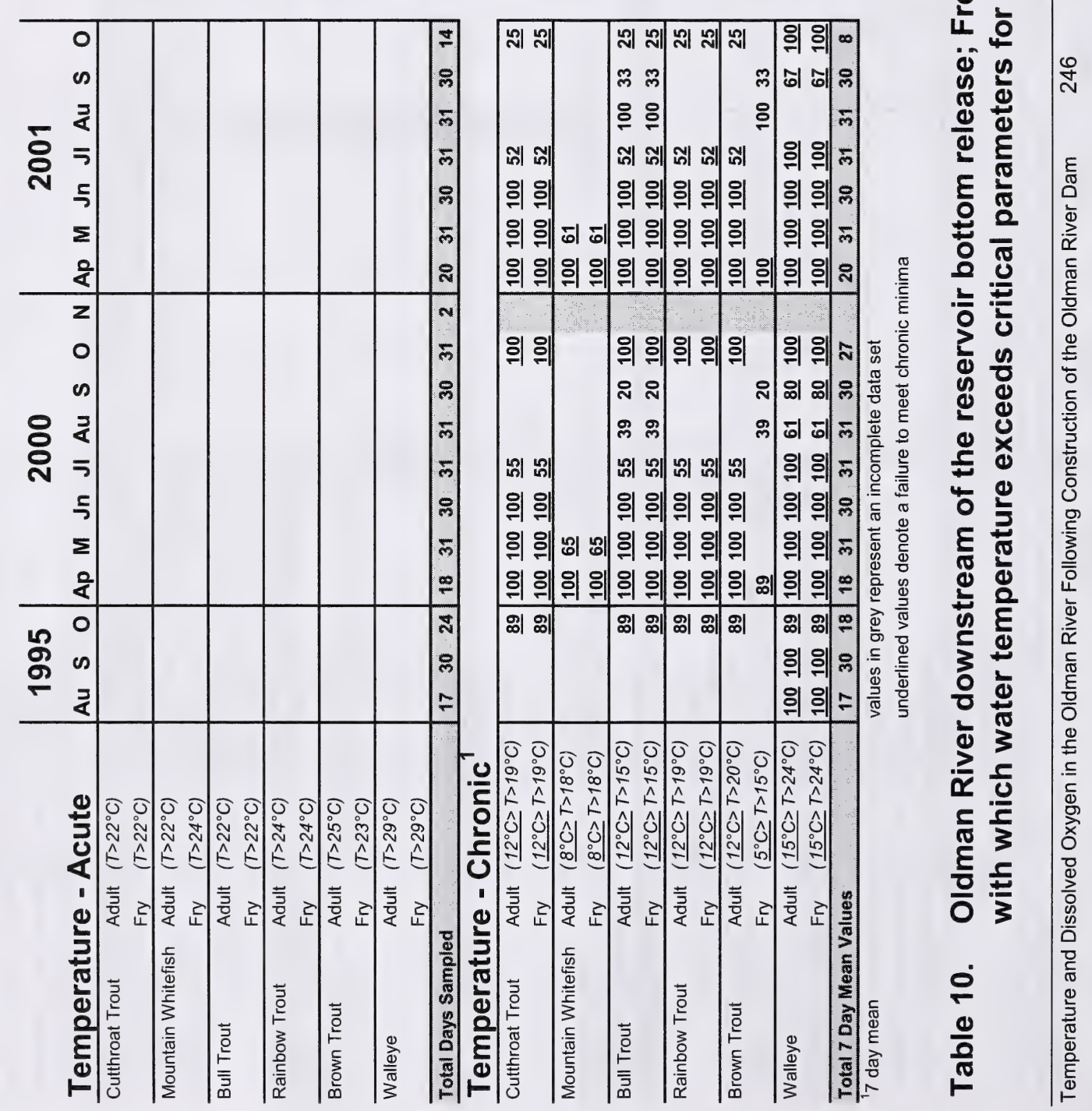




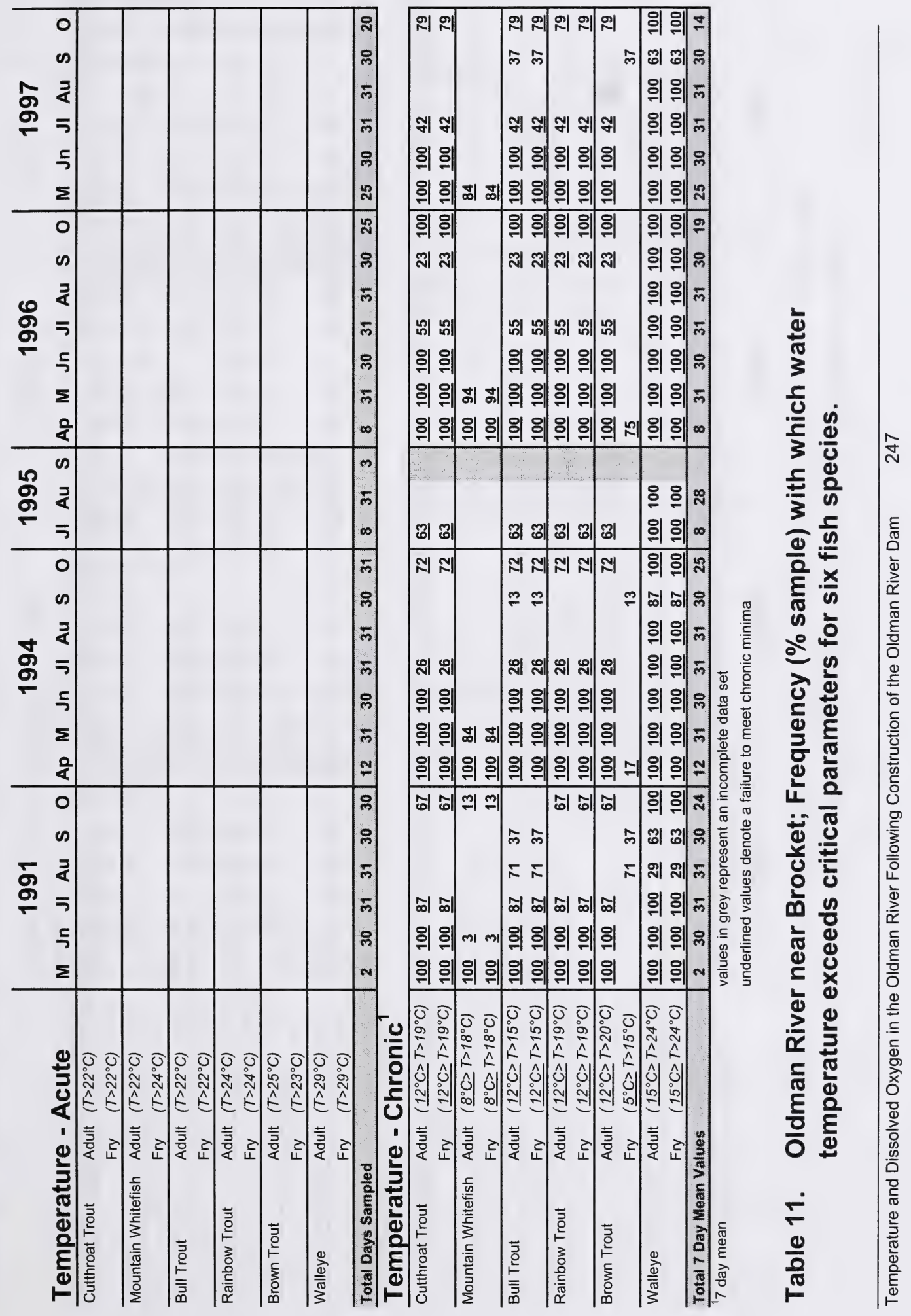




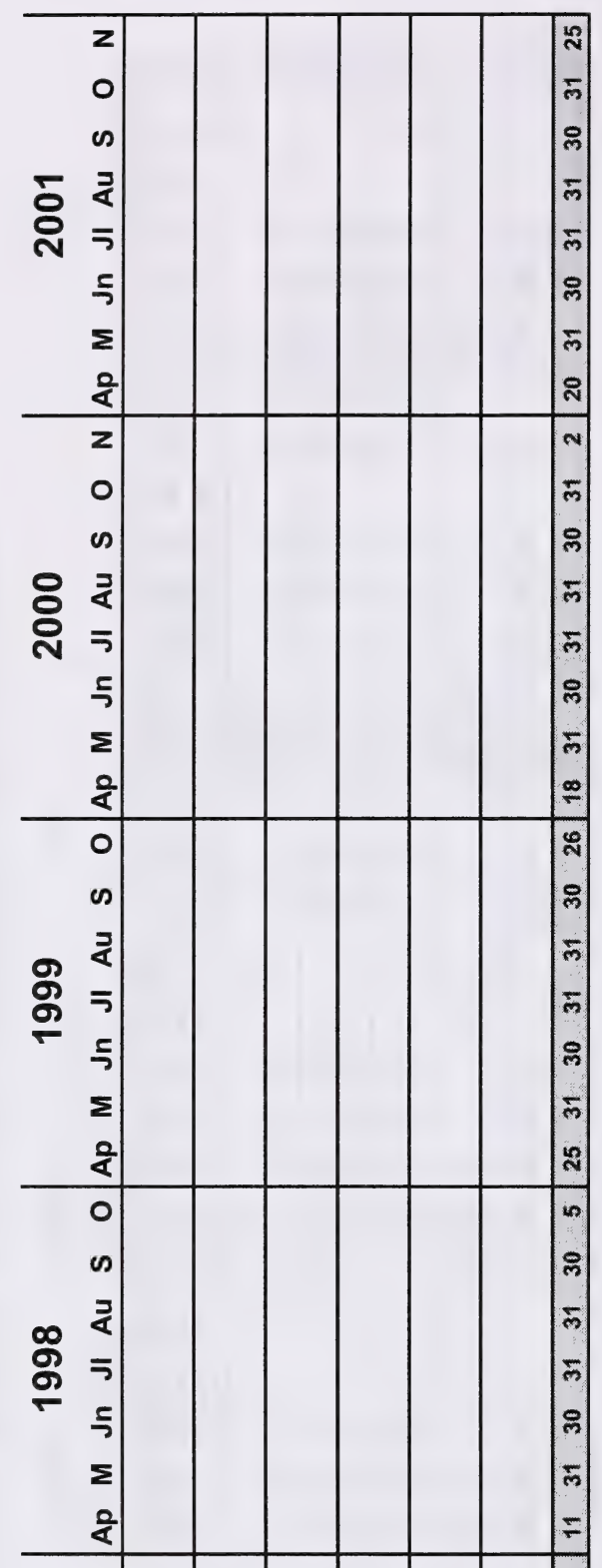

의 위의 위의 위의 위의 에의 의우

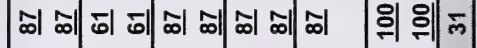
이 아 아 이 에을

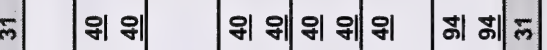

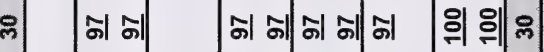
ㄷ 의 위 귀 궤의 의의 의의 의 의

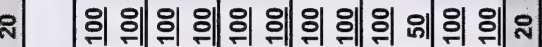
의 의 의 의의 의의 의 위서

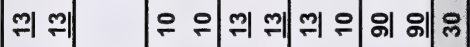

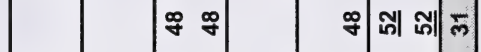
이 에 기 에 이 에 이 의웨 의 의 의 의의 의의 의 의으 의 위잉 에의 의 의 의의 의 의드 의 의의 의의 의의 의의 이 의 의으 의의 의의의의의 의의스

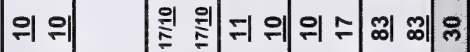
है ह

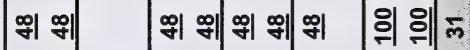
의 위 위위의 위의 위의을 의의 니 네 의 의의 의의 의 의드 의 의의 의의 의의 의의 의 위노

의 에 이 에 이 에이 의 의드 의 윈
의 위
의 의 음 의 의 의 의의 웨의 의 웨 의 위의 위의 의 의을 의 에 뙤 뙤의 의의 의의 의 의드 의 의 의 의의 의 의 의의 히의 웨 $=$

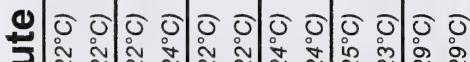

는

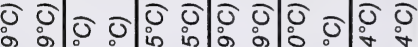
离 $\frac{10}{10}$ 要 


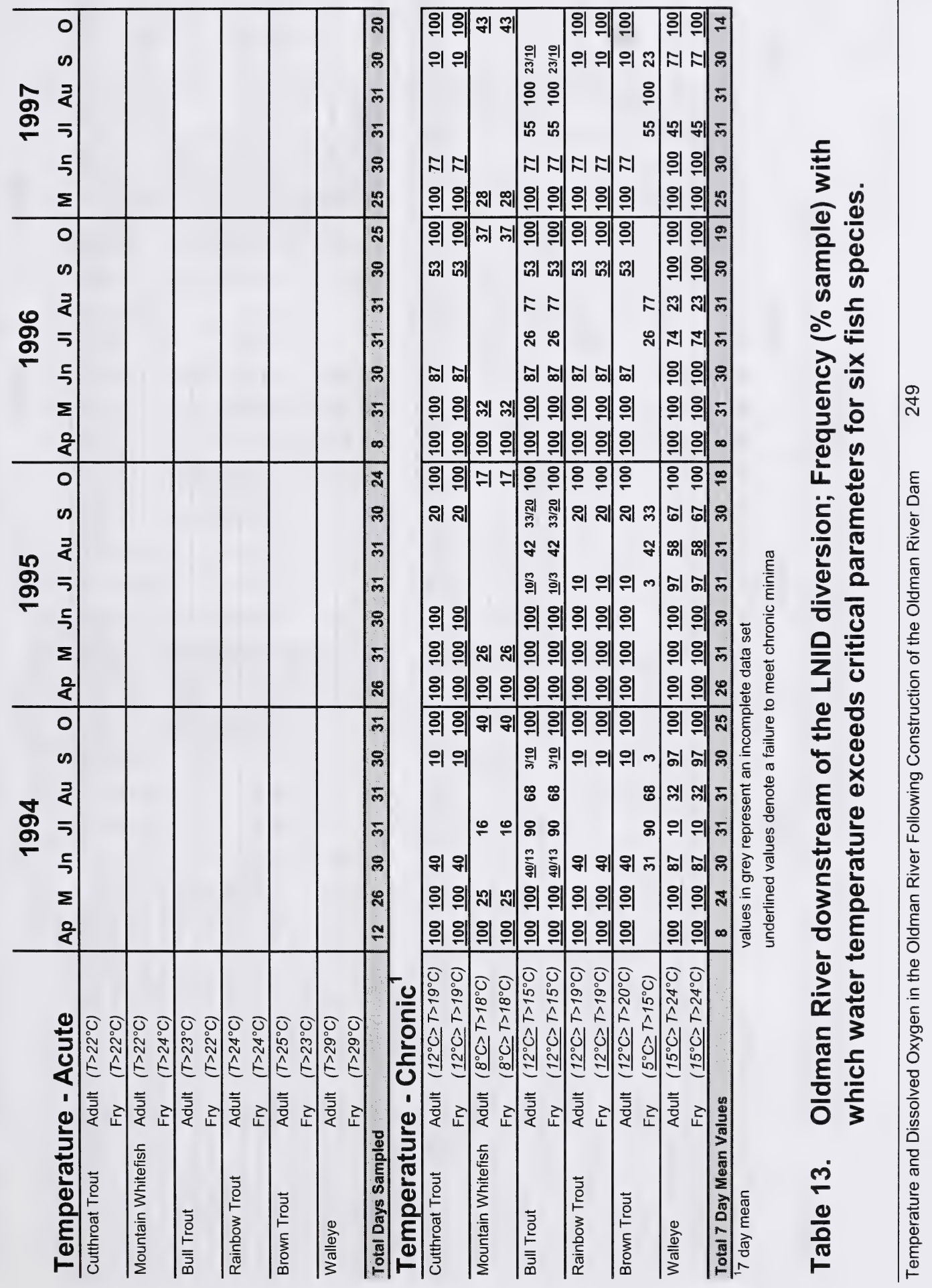




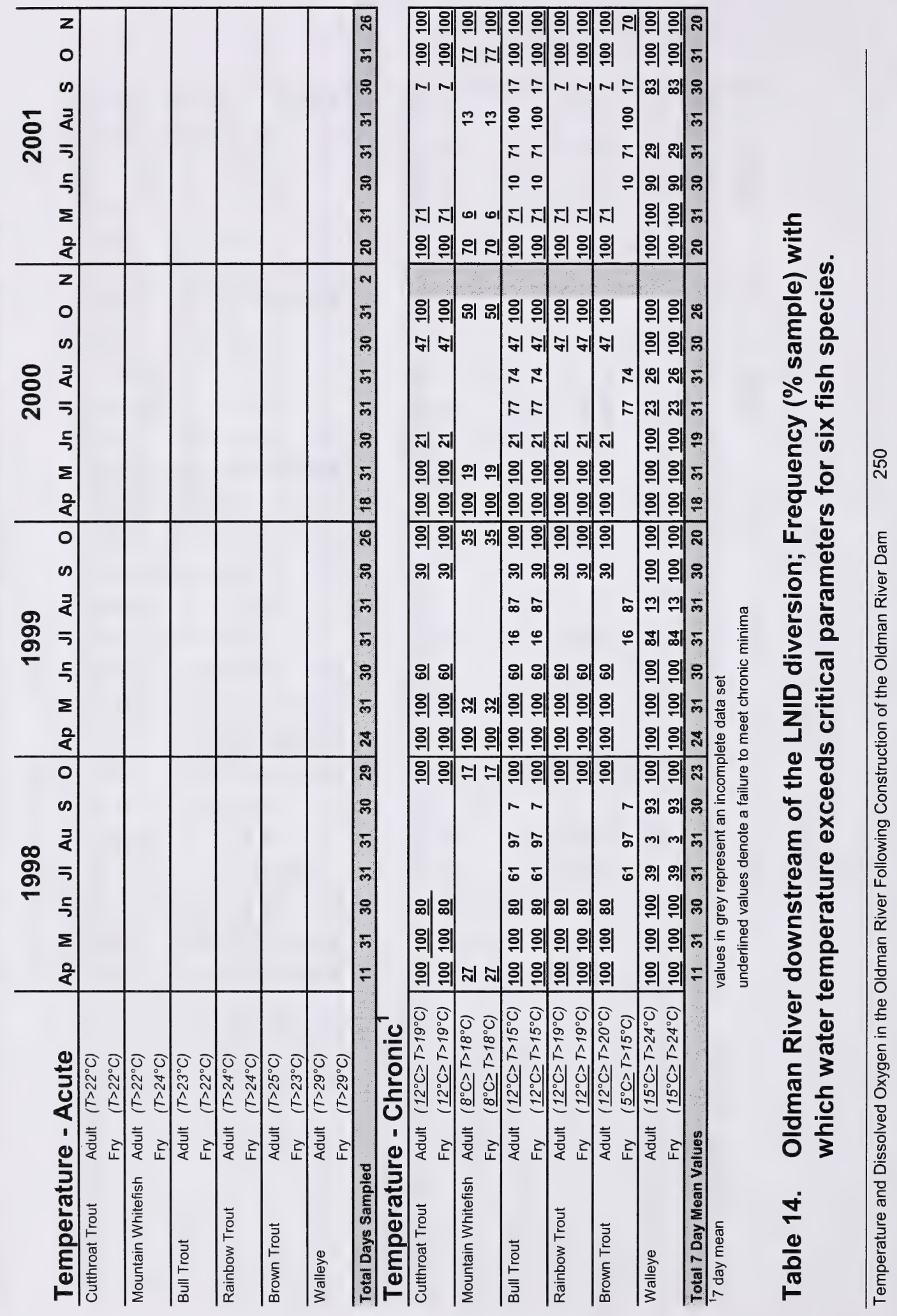




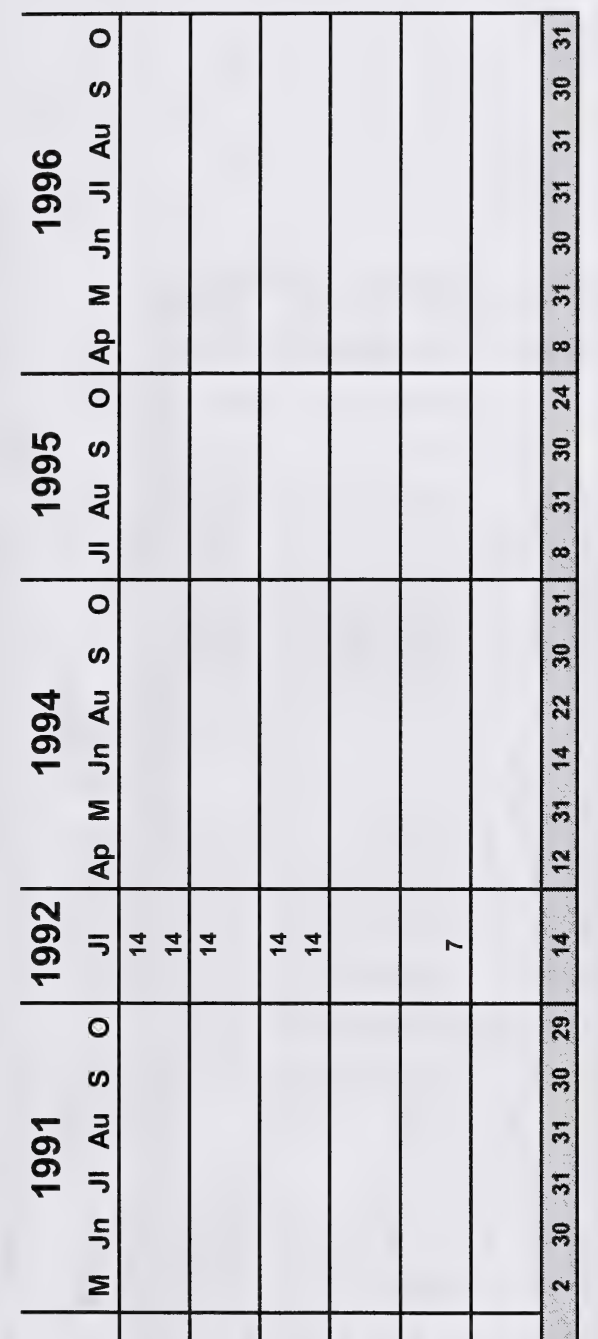

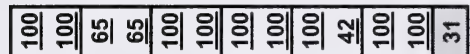

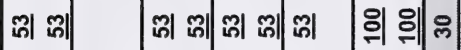
- $\bar{\infty}$ ธक 의 위드 이 에 이 에이 에 이 의 위응 의 위 이 이의 위의 의의 의 의의 의의 의의 의의 의의 의 의 의 위 ㄱ 싀의 위의의의 의위

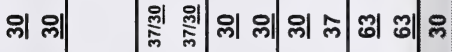

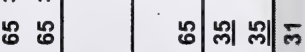

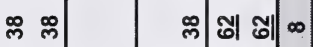
의의 하 혜의 의의 의의 의의노 의 의 끠 에의 의의 의 의을

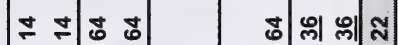
의 에 의 의의 위의 의 위 $\infty$ 의 웨 의 의의 의의 의의 의 의 의 웨 ळ이의 의 의 의의 의 윅 ల

$\frac{0}{\frac{1}{0}}$

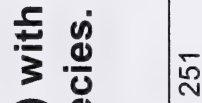
() 응 ह 들

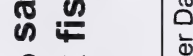
อำ $\frac{x}{\vec{n}}$ 츨 은 윙의 위 위의의의의의 에의 의소

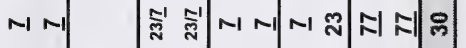

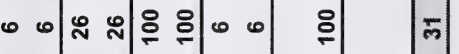

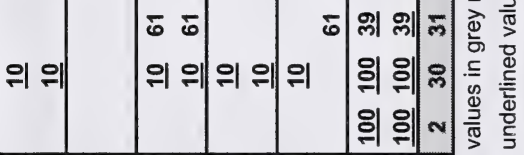

O 0 o

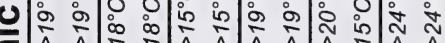

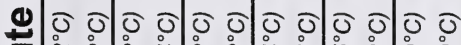

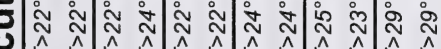
인

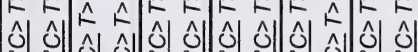

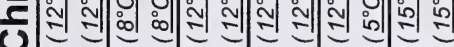

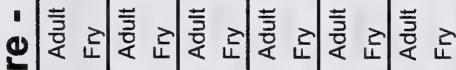

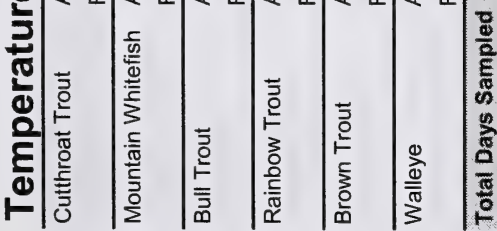

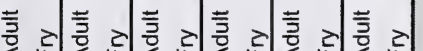




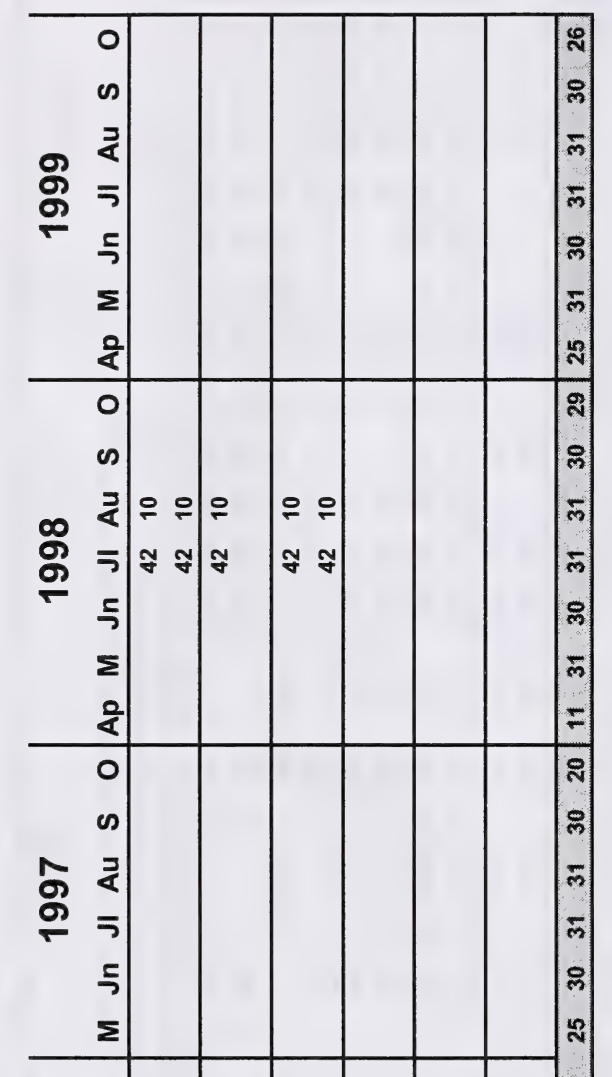

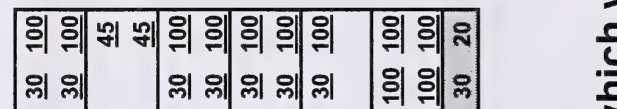

సั.

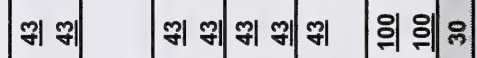

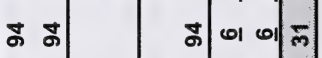

$\frac{1}{3}$

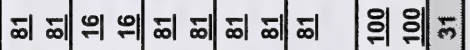

의 의 의 의의 의의 의의 의 의노

의의 제 제의의의의의 의 위요

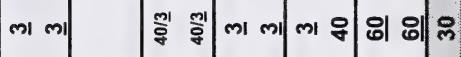

워 워응 응

:

$\bar{m}$

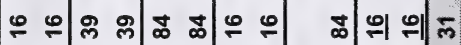

-

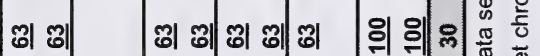

का का का की की की

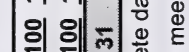

의 의

의 의의 의응

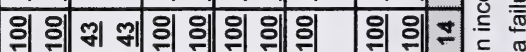

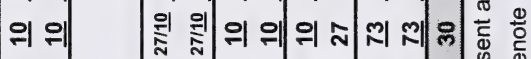

岳

ㅎํㅇ

क म

$\frac{\varepsilon}{\pi} \frac{1}{0}$

क)

de $\frac{x}{n}$

वे के

ฮั

둥

น"

ชั

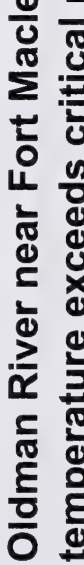

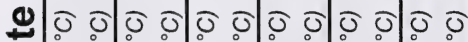

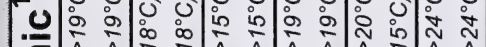

- 0 응 의 ल-

- 0 ธิ ผ

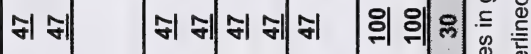

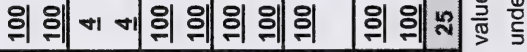

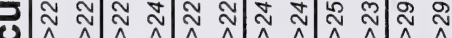

의

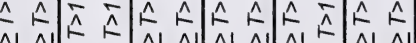

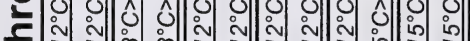

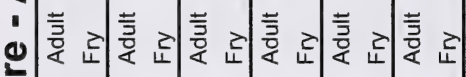

1 ए

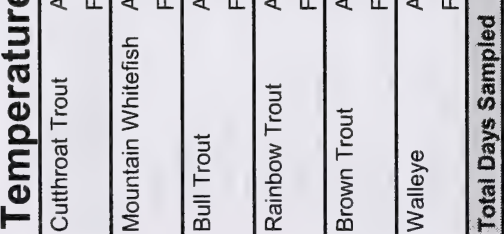

| 


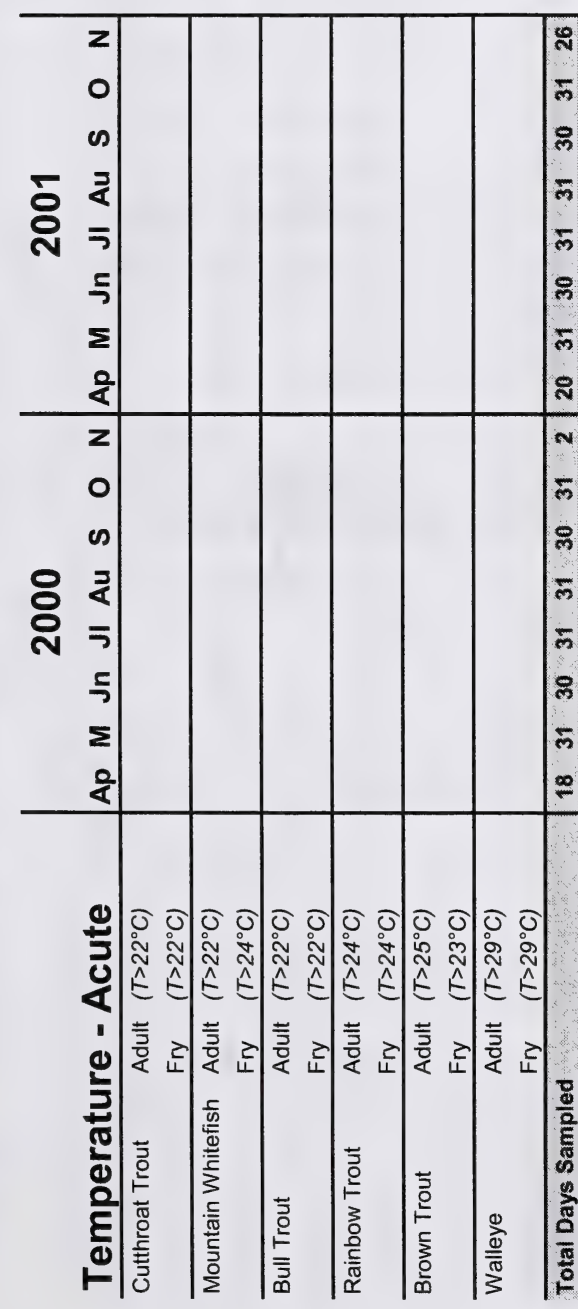

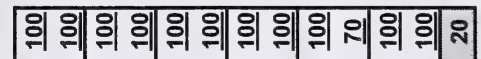

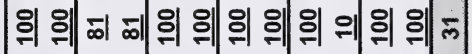

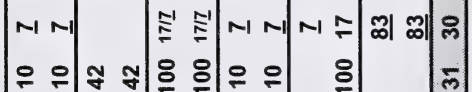

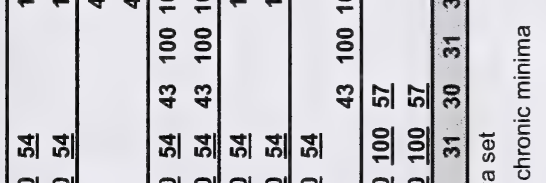

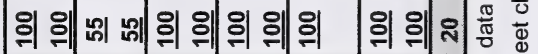

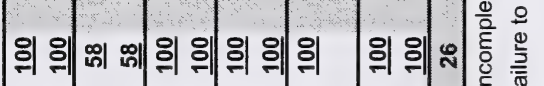

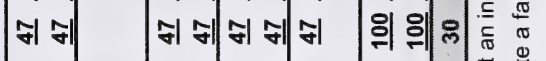

$\frac{1}{\pi}$
$\frac{\pi}{3}$
$\frac{2}{0}$
$\frac{1}{3}$

兵

$\stackrel{\infty}{\sim}$

흔 은

突

อ $\frac{x}{0}$

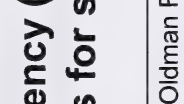

कृष

बै 屯

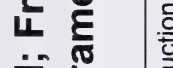

ชั

을

정

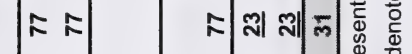

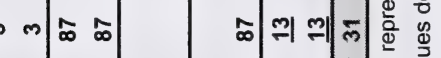

-

हి

है

ज新

의 의이 에의 의의 의의 의 의 $\infty$ 홍 훅

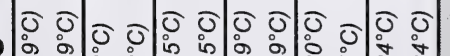

- 0 -

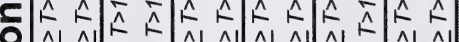

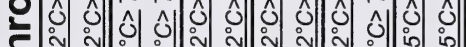

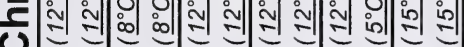

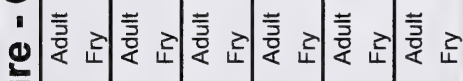

$\frac{\mathrm{g}}{\frac{\mathrm{s}}{\mathrm{s}}}$

는

인

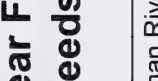

ฮ્犬

㐫

ฉ约

ट तั

흥 ह

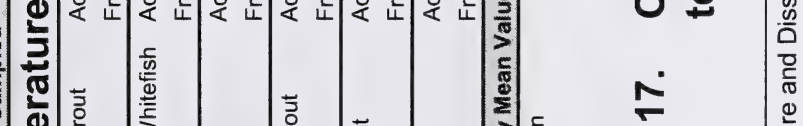




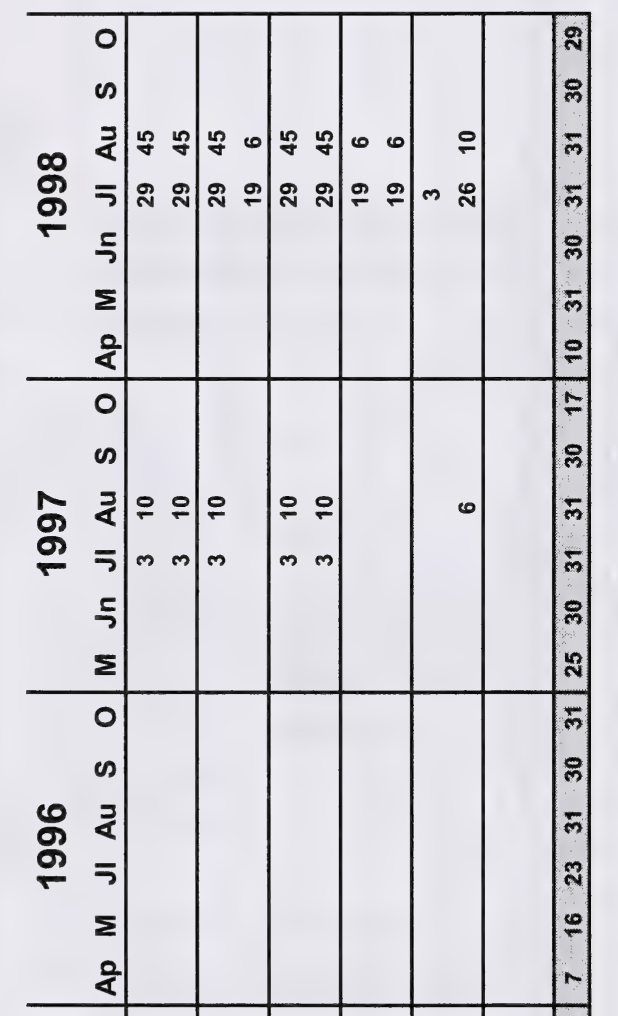

의 위이이의의의의의의 의의요

战

M M m

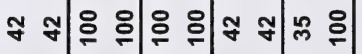

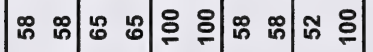

의 의

휘위의 의의 $\mathrm{m}$ 회 회을

이 에

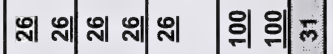

이 에

이 에 이 에이 의 위으

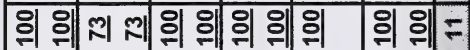

의 의 윟 윟의 의의 응위 에을

는

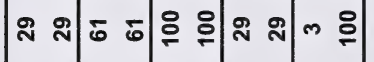

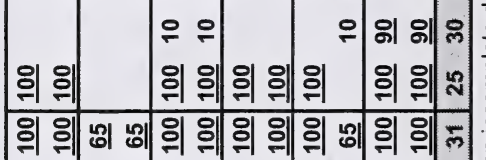

จิ

의 의 이 에의 의의 의의 의 의의 든

의 웨의 의의 위의 의의 의 웨 $-\frac{5}{3}$ 돋

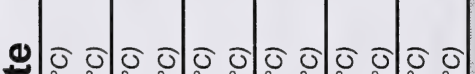

- ou 0 o

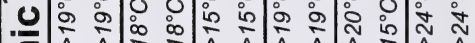

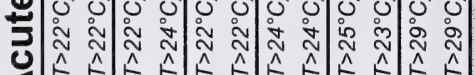

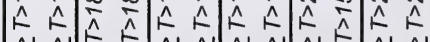

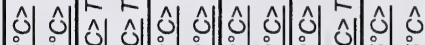

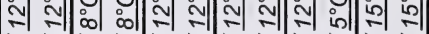

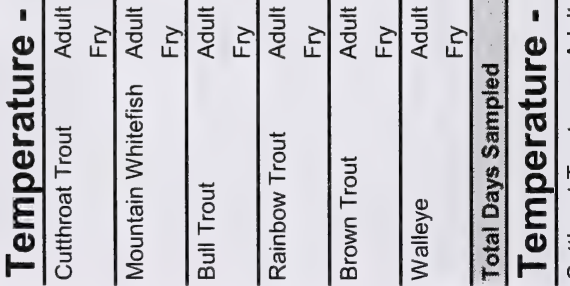

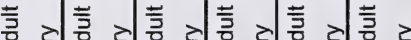




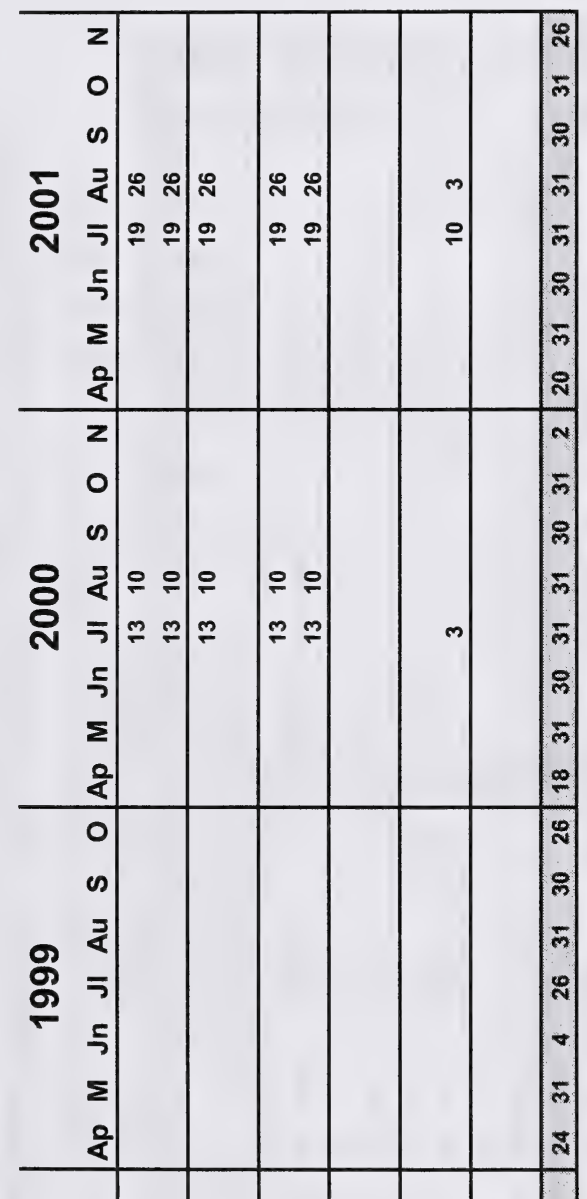

의 위의의의의의 의의 외의 위으 의 의히 헤의 의 의 의 의 에 의 의 항 의 의 윌 윌 의 의의 에 지 세을

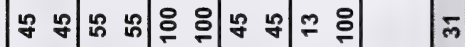

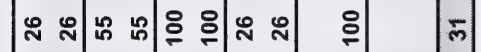

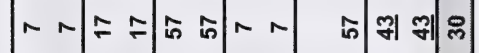

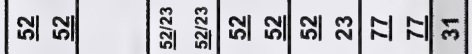
의 의 이 위의 의의 의의 의 의워

의 의 이 이의 의의 의의 의 의 서

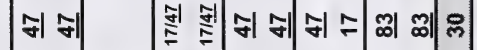

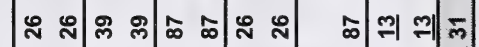

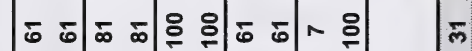

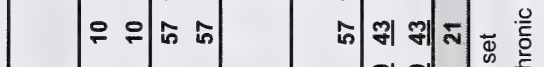

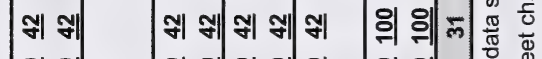

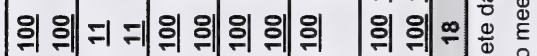

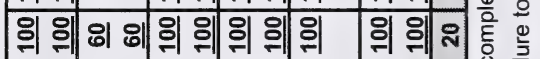

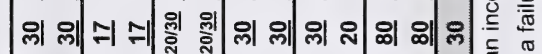

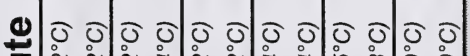

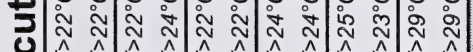

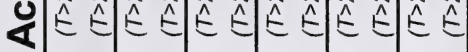

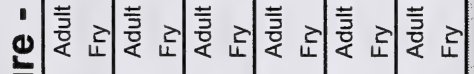

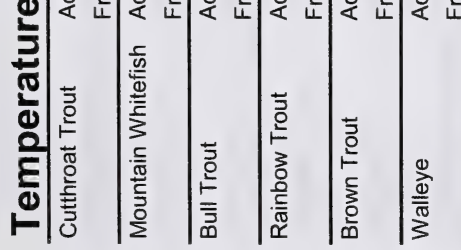

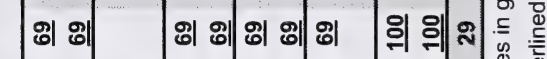

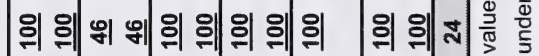

- o o . 0 -

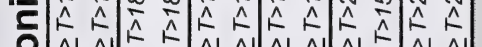

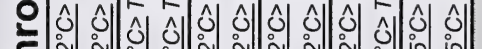

ט

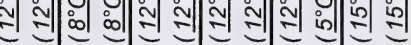

\pm 立 


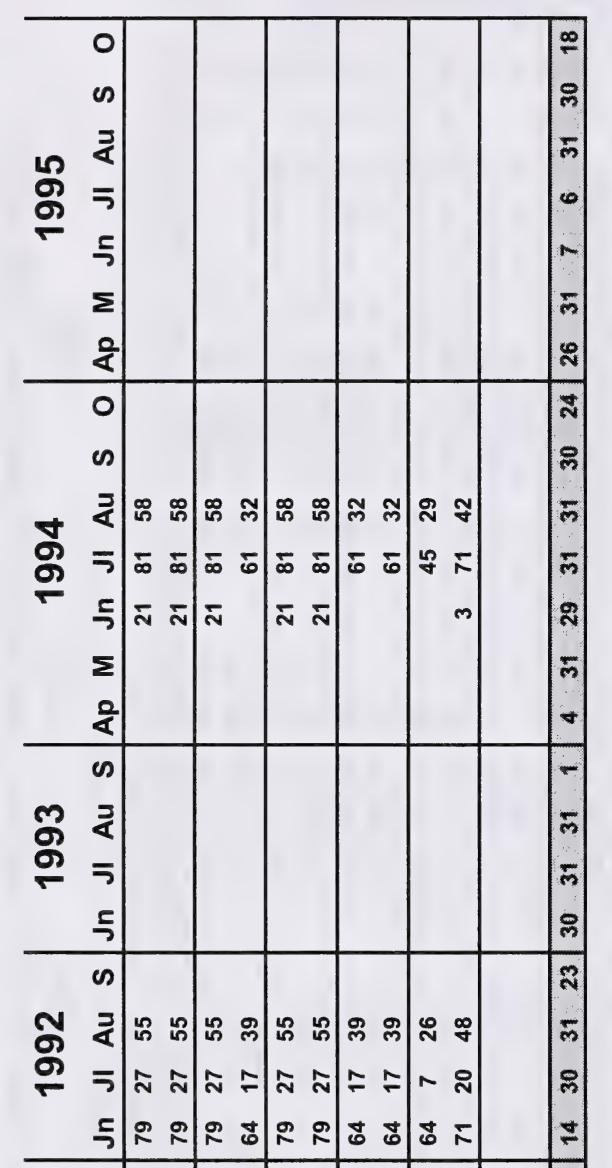

위웨뇌 에의 위의 웨의 의윅

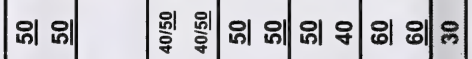
$\begin{array}{llllll}0 & 0 & 0 & 0 & 0 & 0\end{array}$ 의 ₹

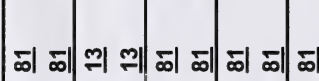
은 의 의 이 뇌의 의의 의의 의 의

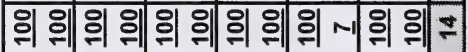

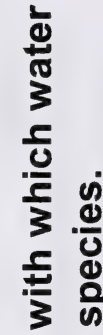

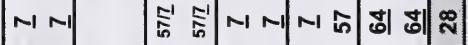

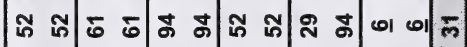

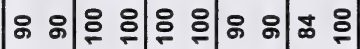

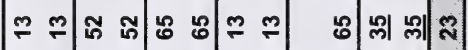
Nㅔ NNNN제 의의 의 의 의 의의 의의 의 의

बํㅡㅇ

हैํㅡㄹ

की

อㅇำ

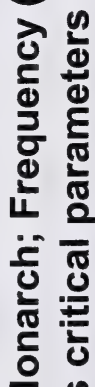

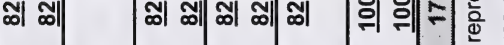

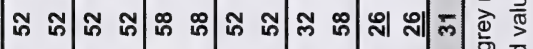

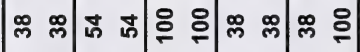

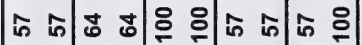

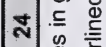
$\pm \frac{2}{\frac{2}{2}}$

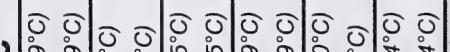

\$

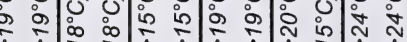

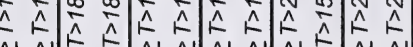

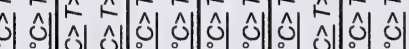

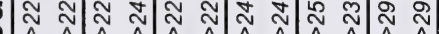
Q $\hat{E} \hat{E} \hat{E} \hat{E} \hat{E} \hat{E} \hat{E} \hat{E} \hat{E} \hat{E} \hat{E} \hat{E} \hat{E}$

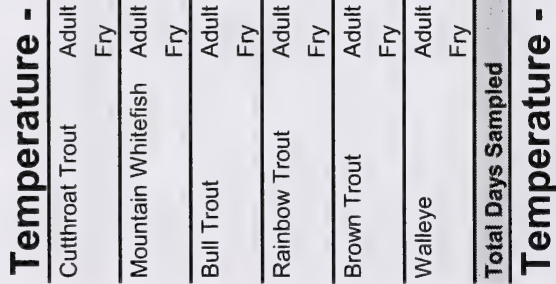

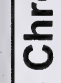

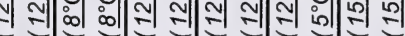

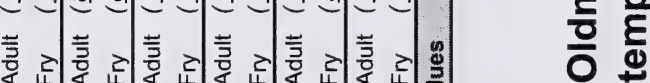
엉

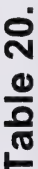




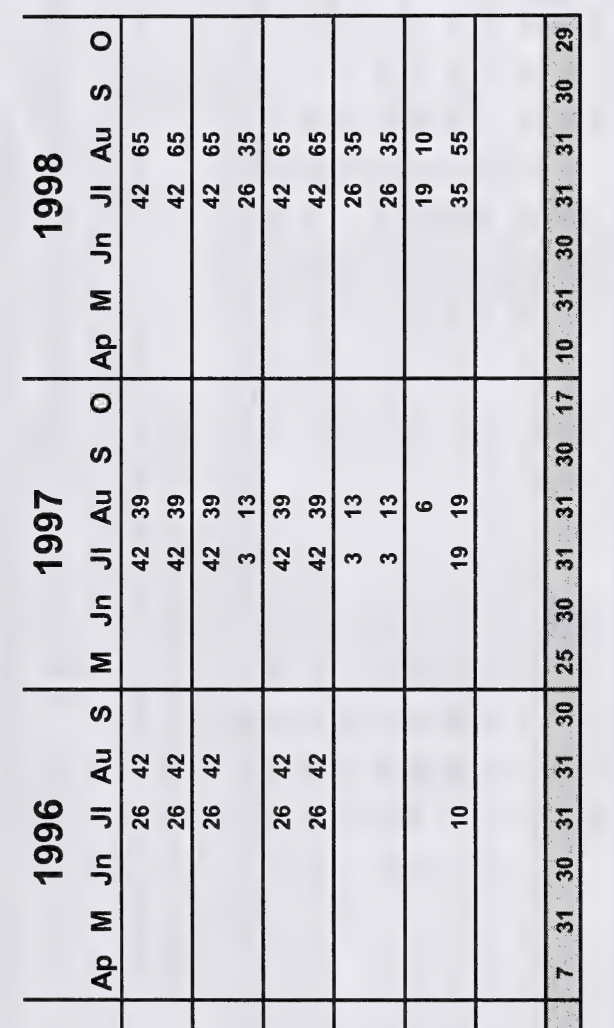

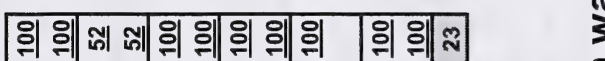

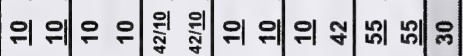

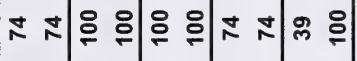

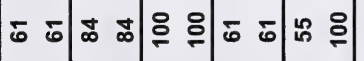

m mा

의 이

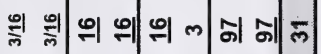

이 에 지 에에 에리 의 의응

의 ㅇㅟㄸ 의 의의의 위의 의 윙=

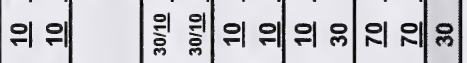

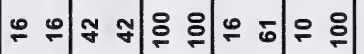

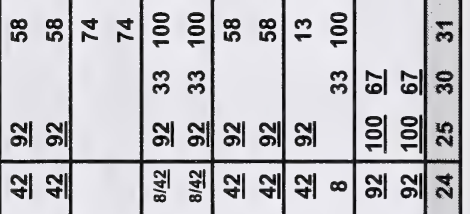

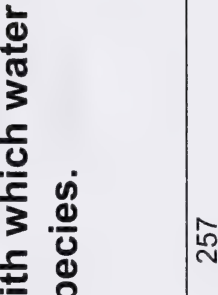

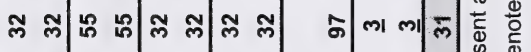

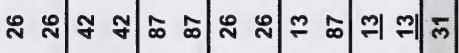

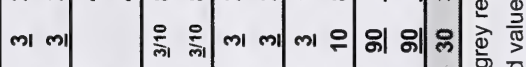

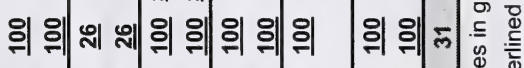

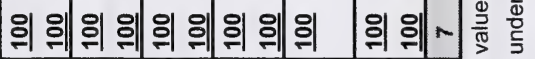

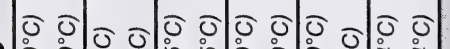

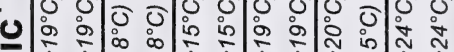

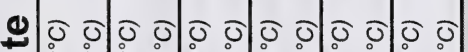

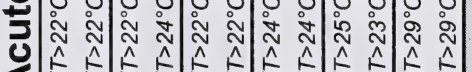

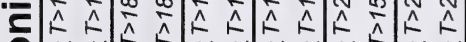

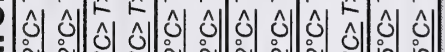

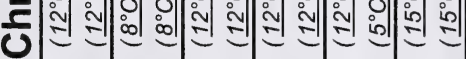

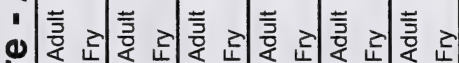

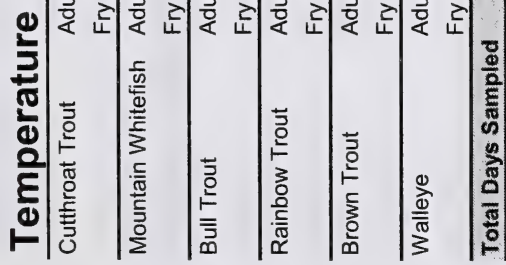

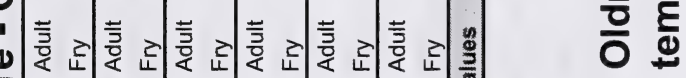

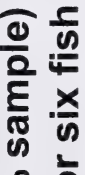

ఏㅎํㄴ

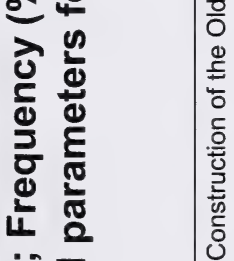

它

$\sum \frac{8}{8}$

要

ᄃ

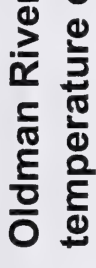

$\stackrel{Ð 0}{\underline{\underline{E}}}$

这 


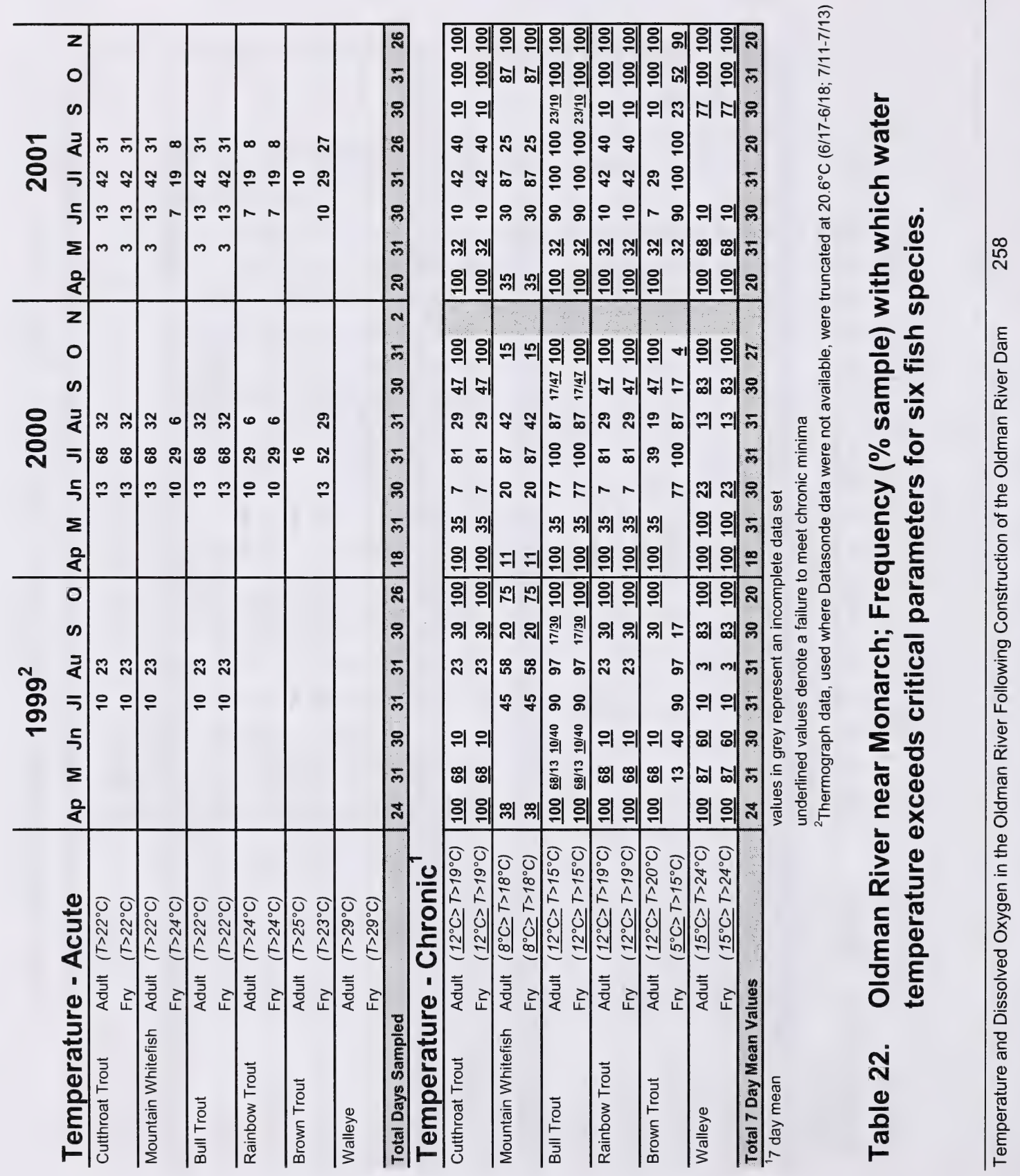




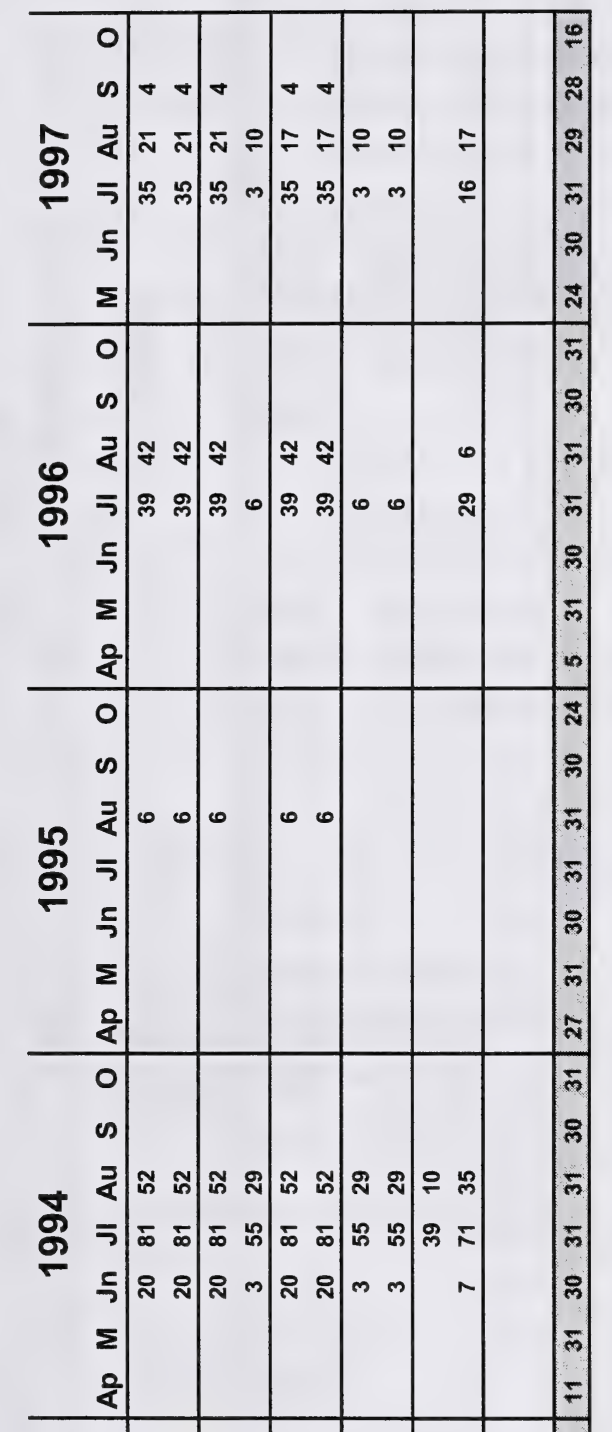

의 위이 에의 위의 의의 의 의 웨우

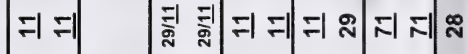

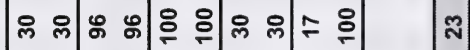
Б こ Б

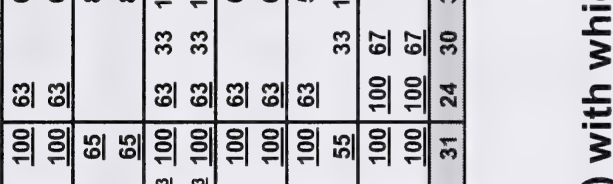

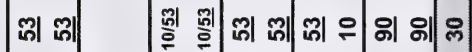

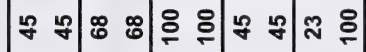

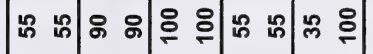

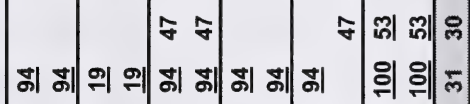

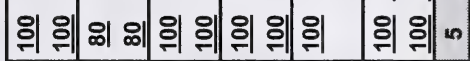

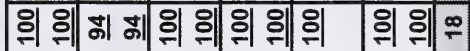

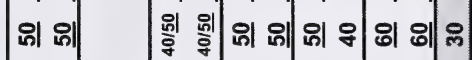
- $\circ$ ก $\approx$ 은 으으응

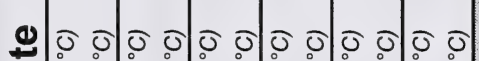

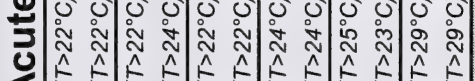

r

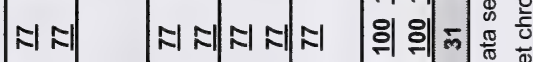

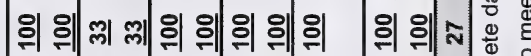

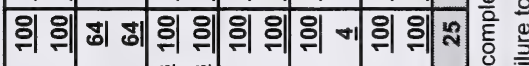

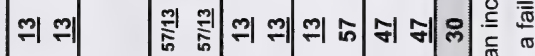

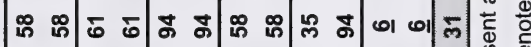

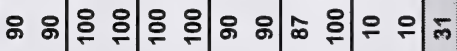

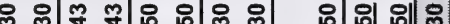
్ㅣ 씨

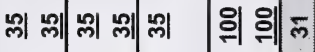

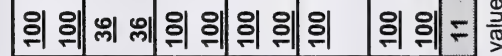

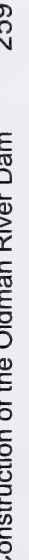




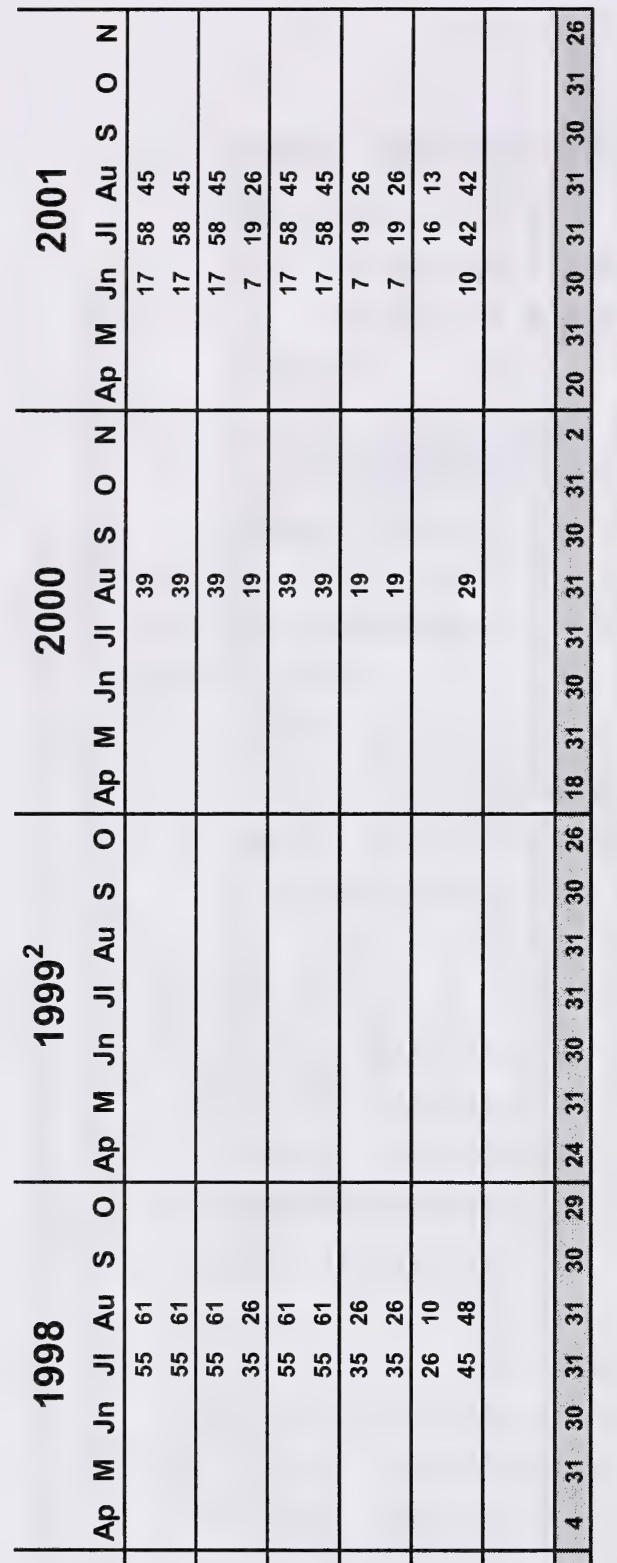

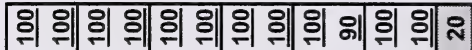
의 의 띠 헤의 위의 의의 웨의 웨

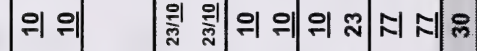

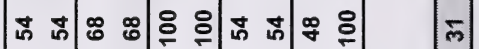
๕ ล ลิว

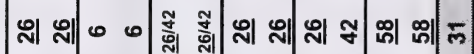
의 의닜 있의 위의 의의 의 위우

의 의 지 체의 의의 의의 의 웨소

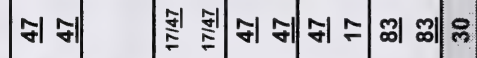

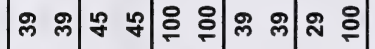

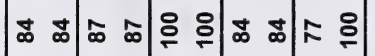
I

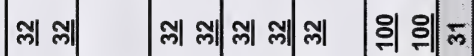
의 에기 페의 의의 의의 의 위 $\infty$ 의 위니 메의 위의 의의 의의 즈

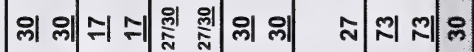

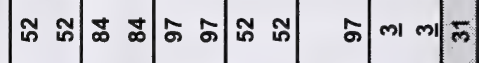

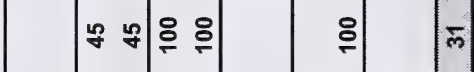

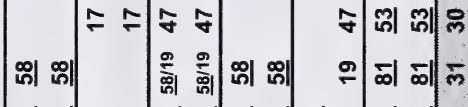
의 의씨 씨의 의 의 의의 이 의 의 저

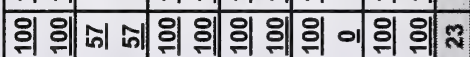

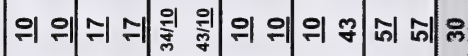

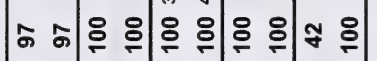
$\frac{\frac{5}{0}}{\frac{1}{3}}$ 흘 ㅇำ তे 항 인 $\div$ 는

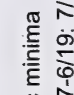
ब。

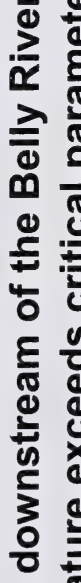
의 의 $\rightarrow$ 造 할

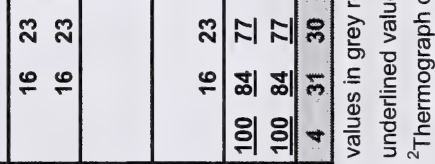

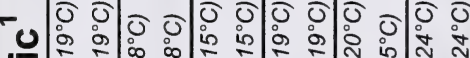
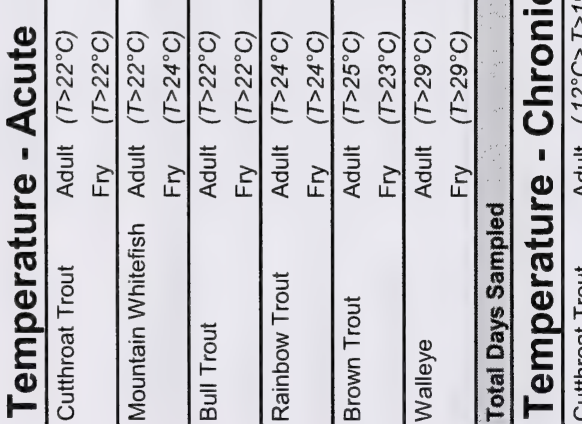
it $\hat{A}$ A

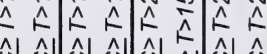

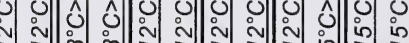

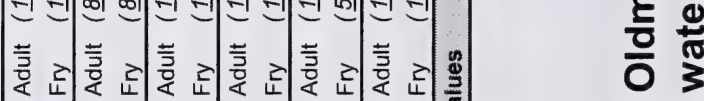

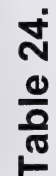




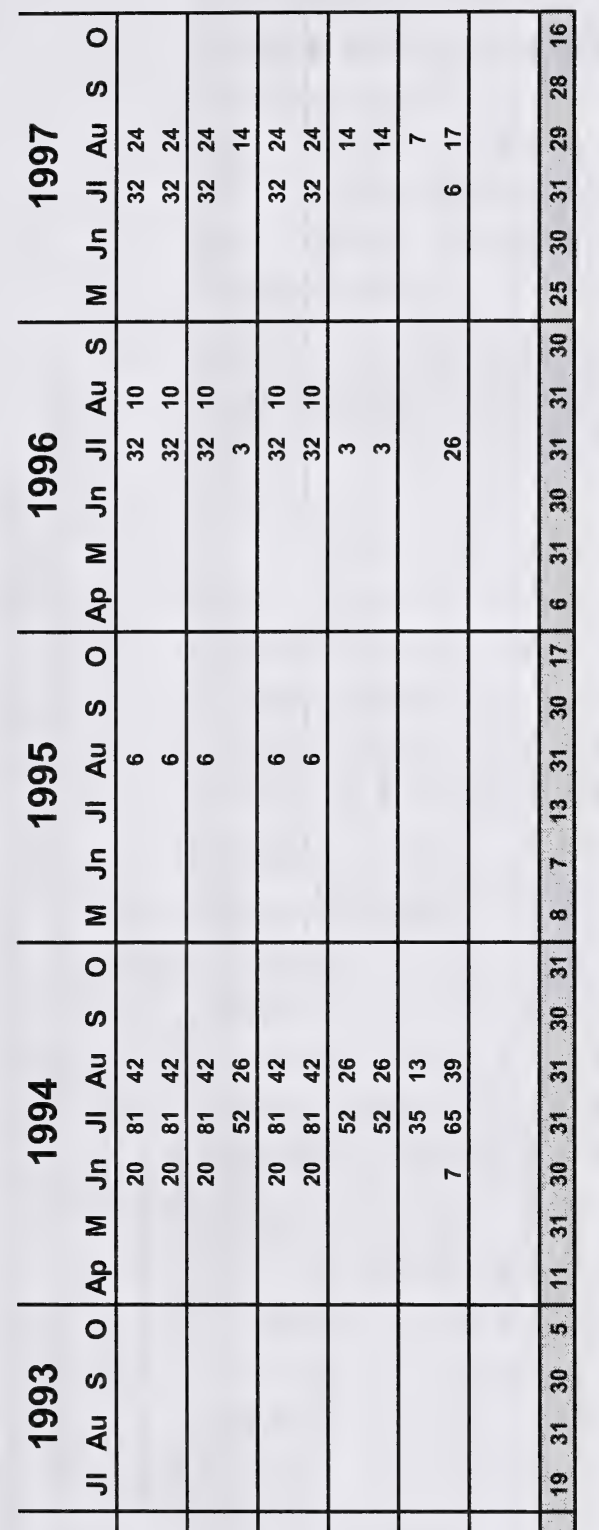

의 위이 에의 의의 웨의 의 웨으

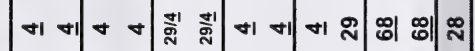

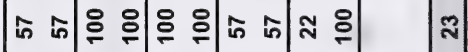

辛

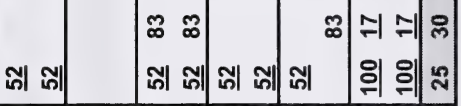

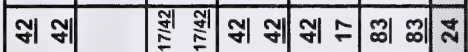

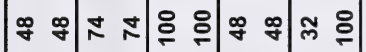

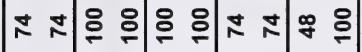

N 8 의위 위유

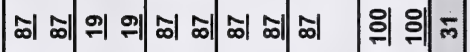

의 의 이 에의 위의 위의 의 에

위의 에의 위의 의의 위의 $=$

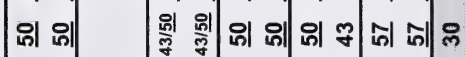

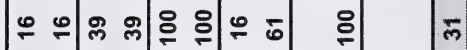

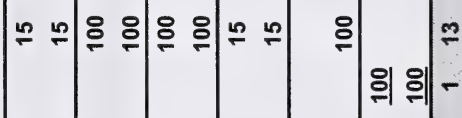

$\frac{\frac{1}{u}}{\frac{1}{3}}$

至 $\frac{1}{3}$

(1) 음

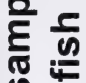

ธัธ

巳e $\frac{x}{n}$

의 웨쇠 세의 의의 웨의 $\infty$ 의 에

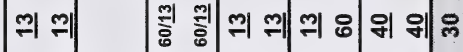

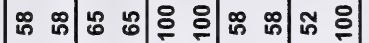

-

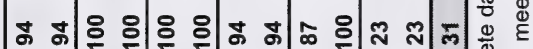

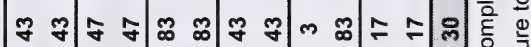

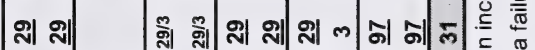

의 의 의 에의 의의 의 웨 $=$ 등

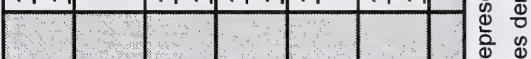

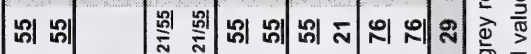

웅유

ธ ลำ ลิโ

ฌ

: 디 데우

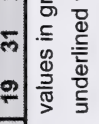

ত व

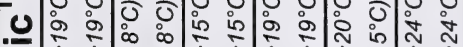

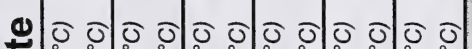
J

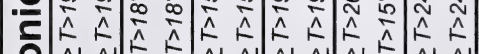
$<\hat{E} \hat{E}|\hat{E} \hat{E}| \hat{E} \hat{E}|\hat{E} \hat{E}| \hat{E} \hat{E} \mid \hat{E} \hat{E}$

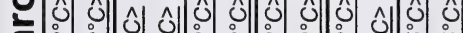

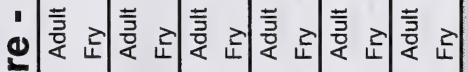

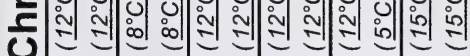

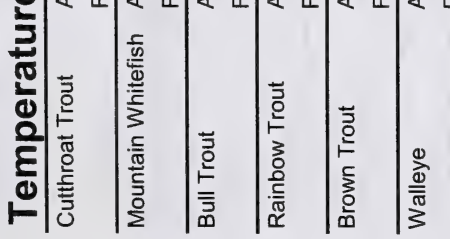

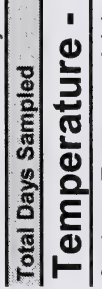

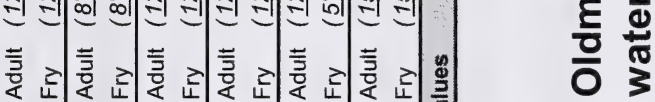

ำ 


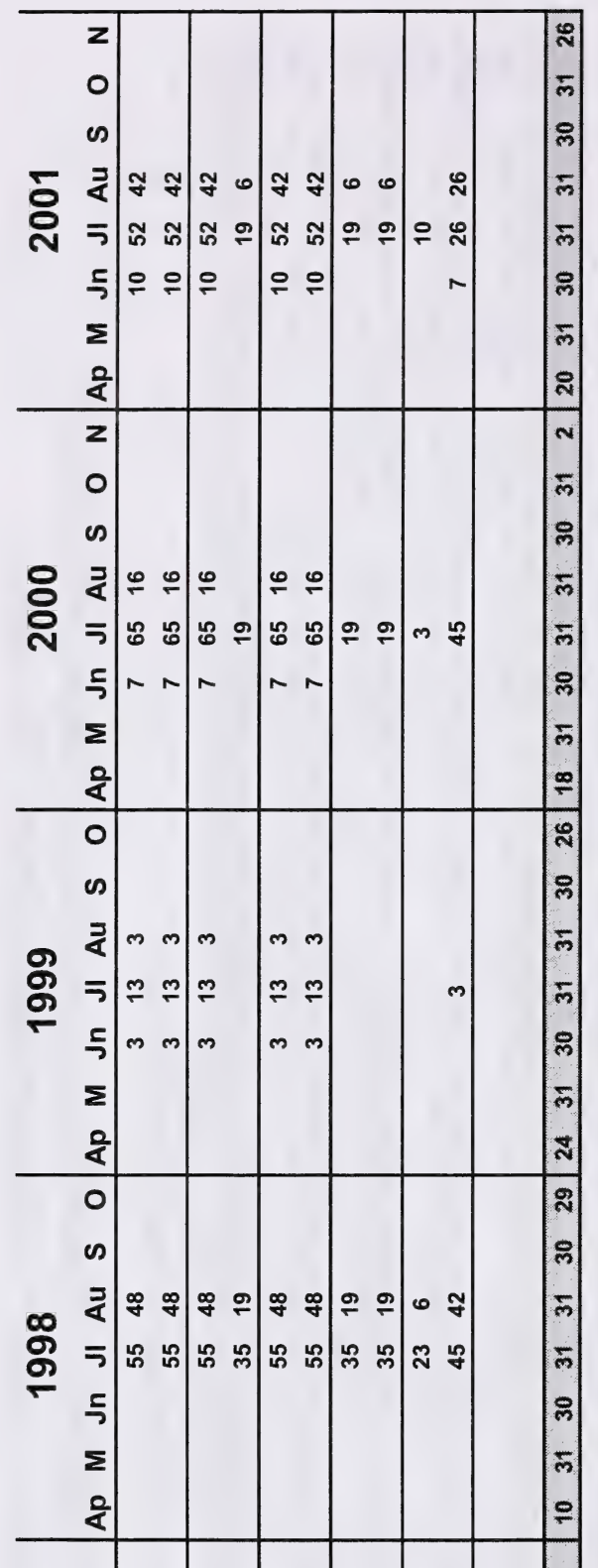

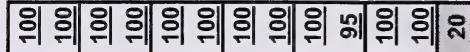

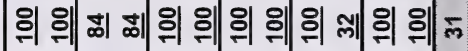

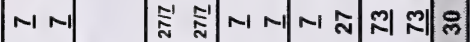

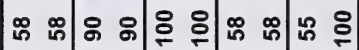

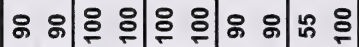

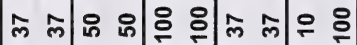

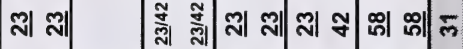
이 에씨 쎄이 에이 에이 의 웨죠

위 웨 이 에의 에의 웨의 의 의 그

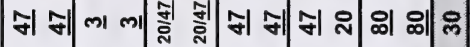

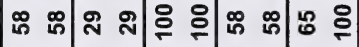
ఓ

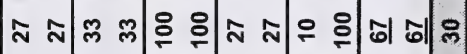

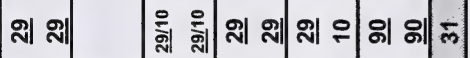
의 위디 데의 에의 위의 의 휘 $\infty$

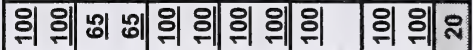

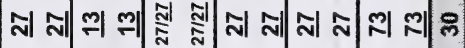

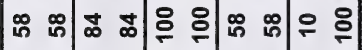
- 0 品 m $m$ ก ก โ

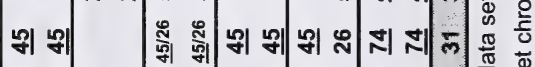
의 위거 게의 위의 의의 의 에고 의 웨 위 위의 의의 위의 휘의 의 의흥

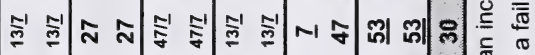

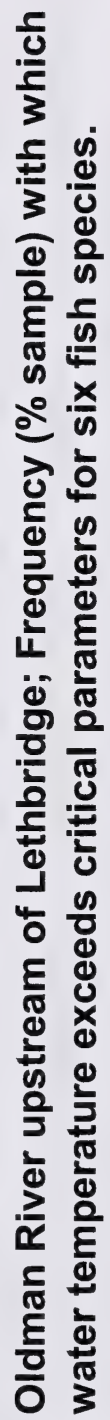

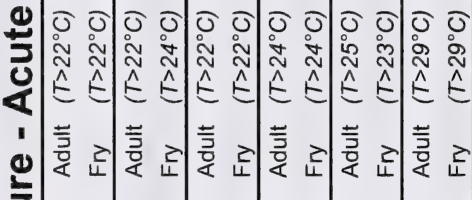

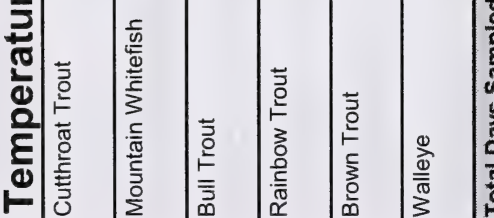
응 위응 위응 휘응 휟ㅇ 우

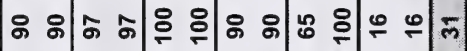
ำ 오 กี สี ำ 요

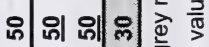

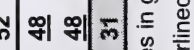

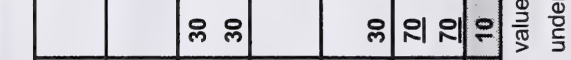

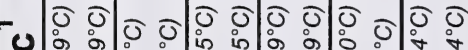
0

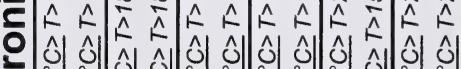

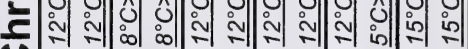

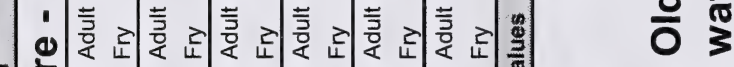

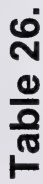




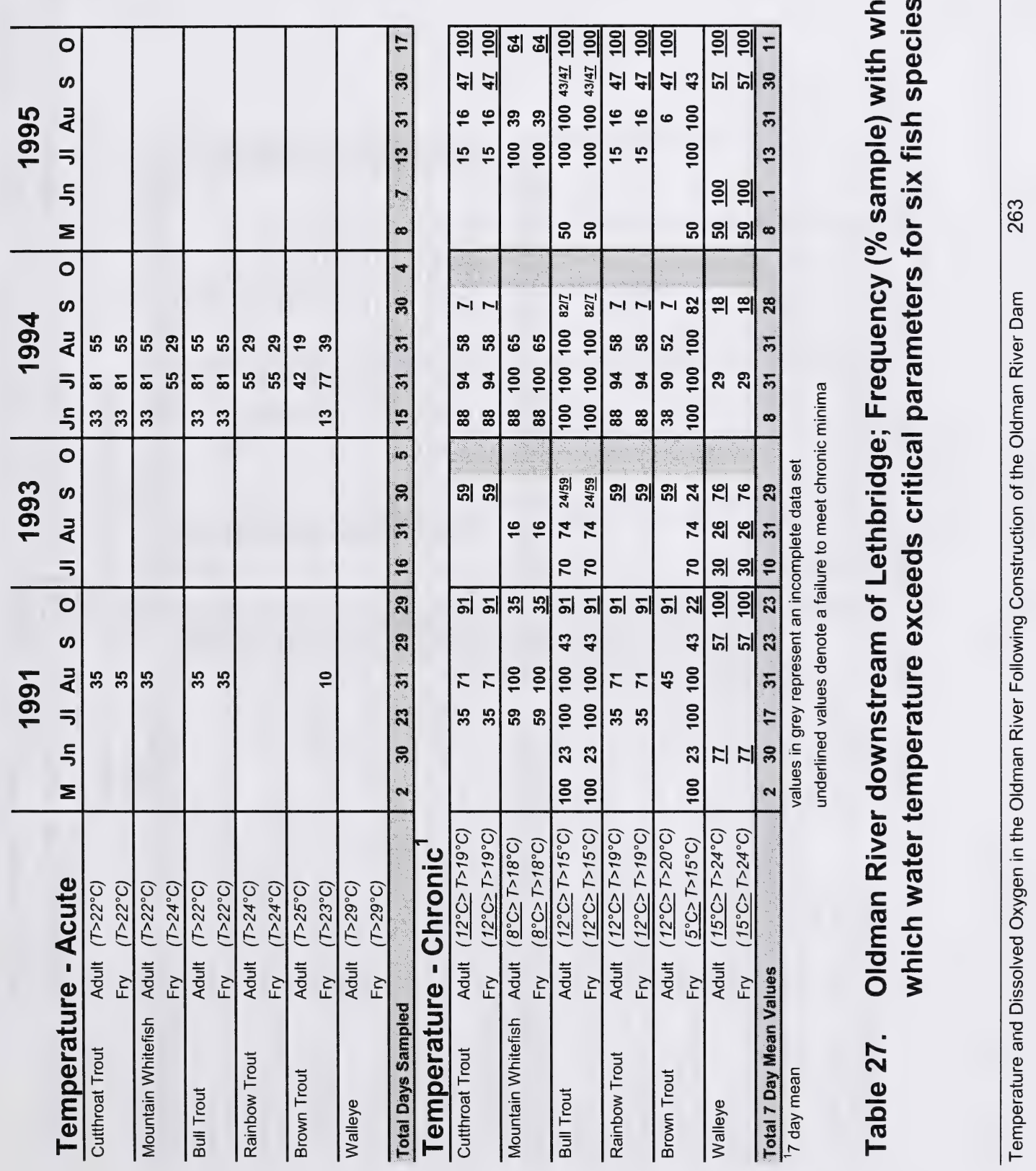



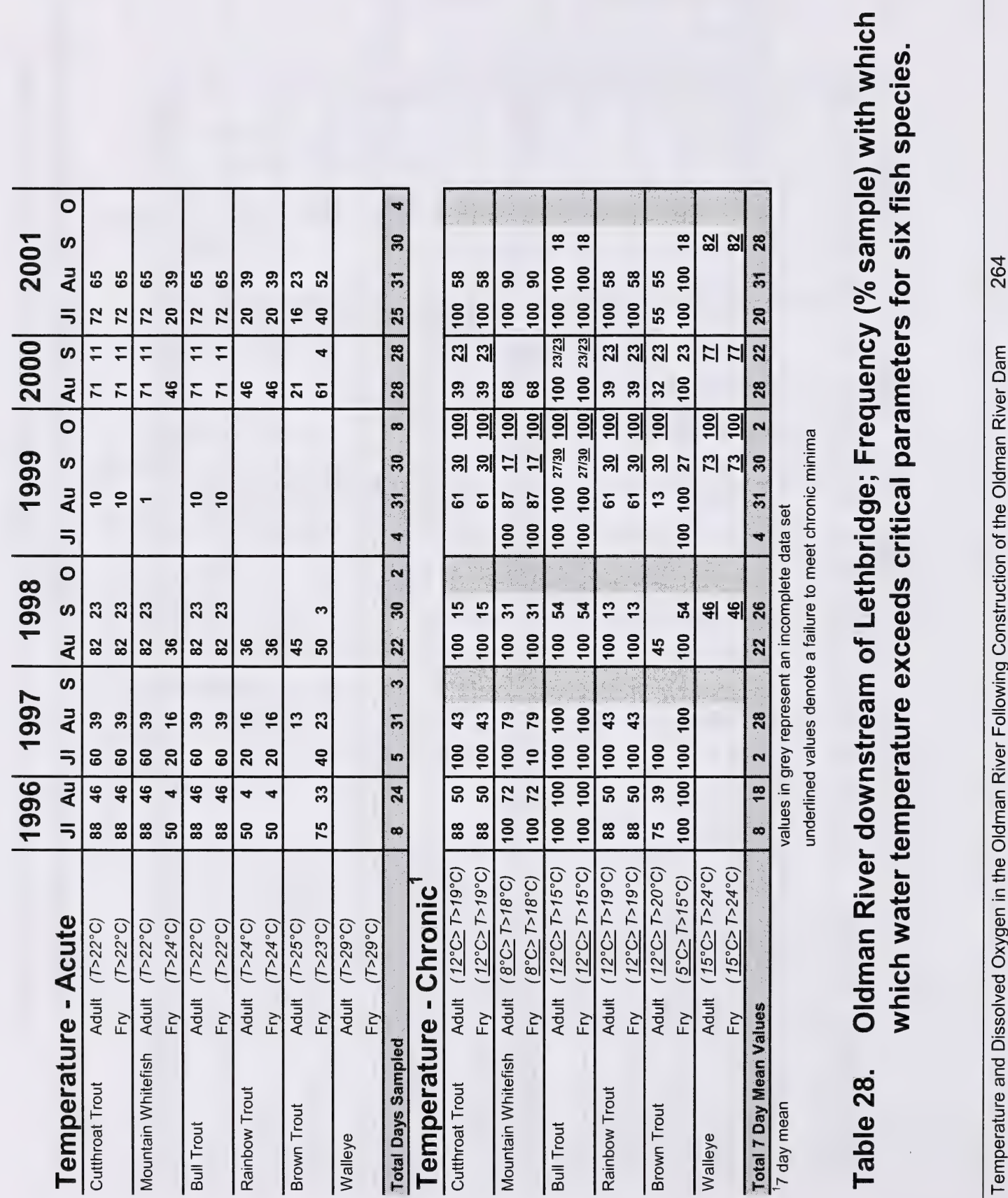


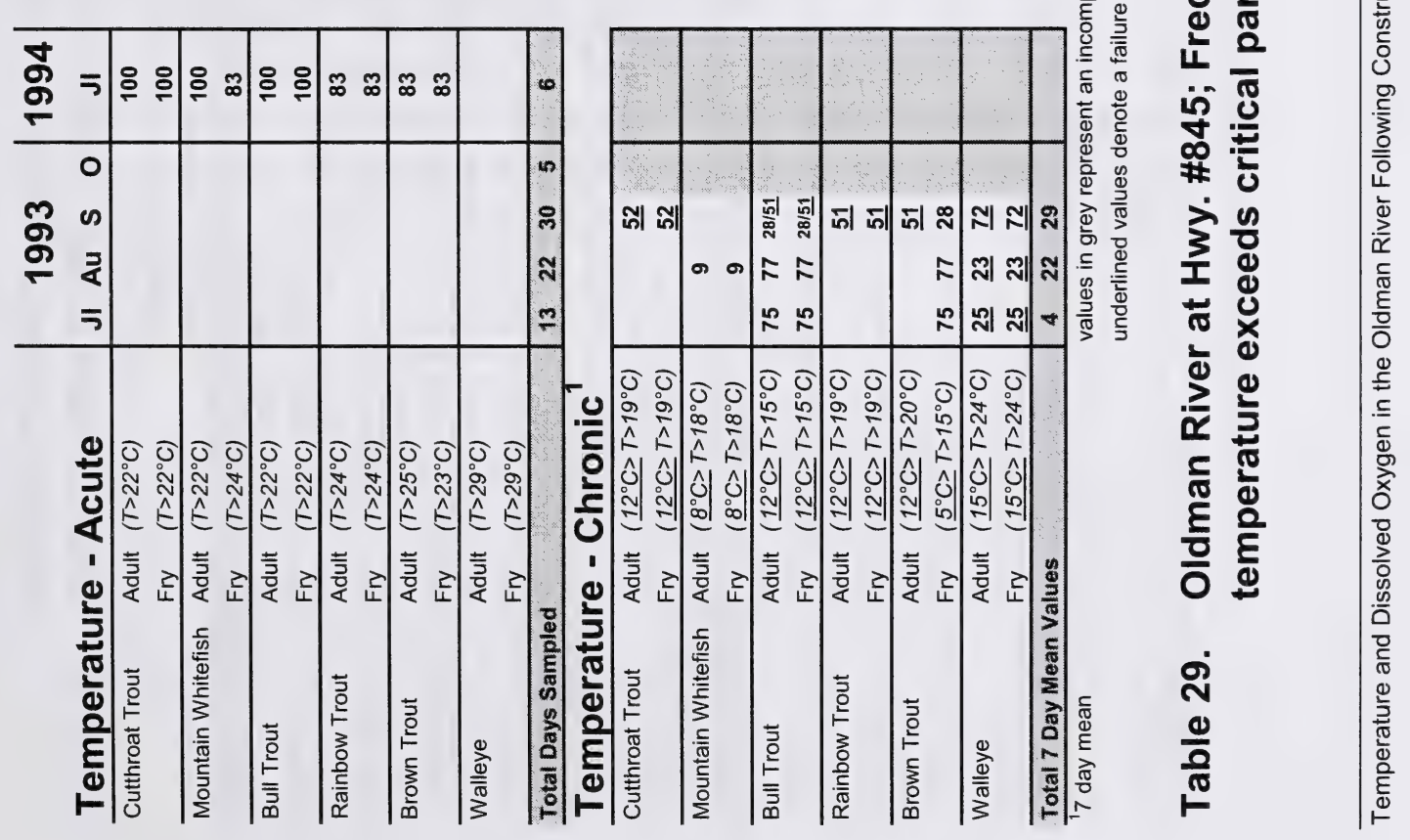




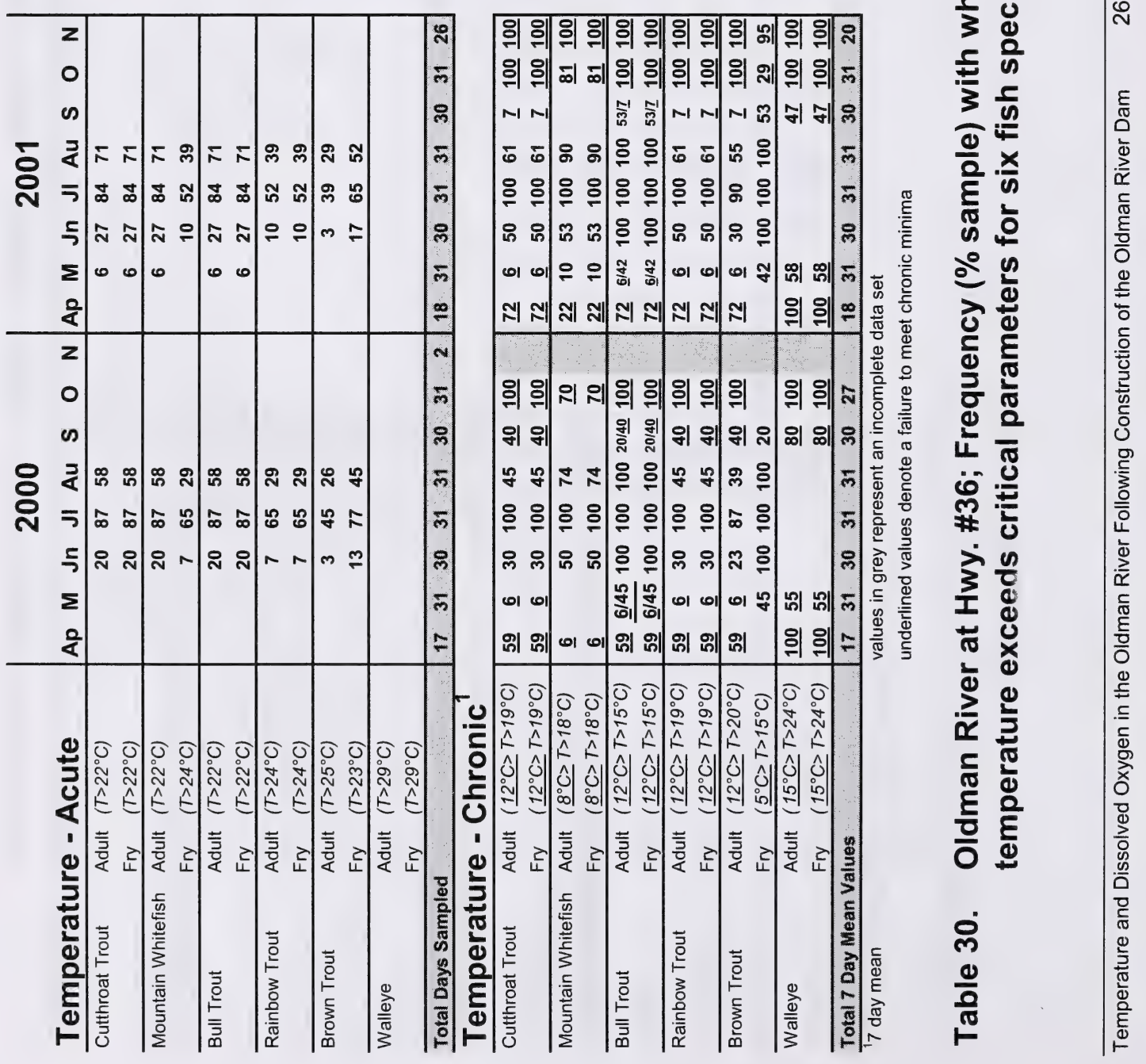



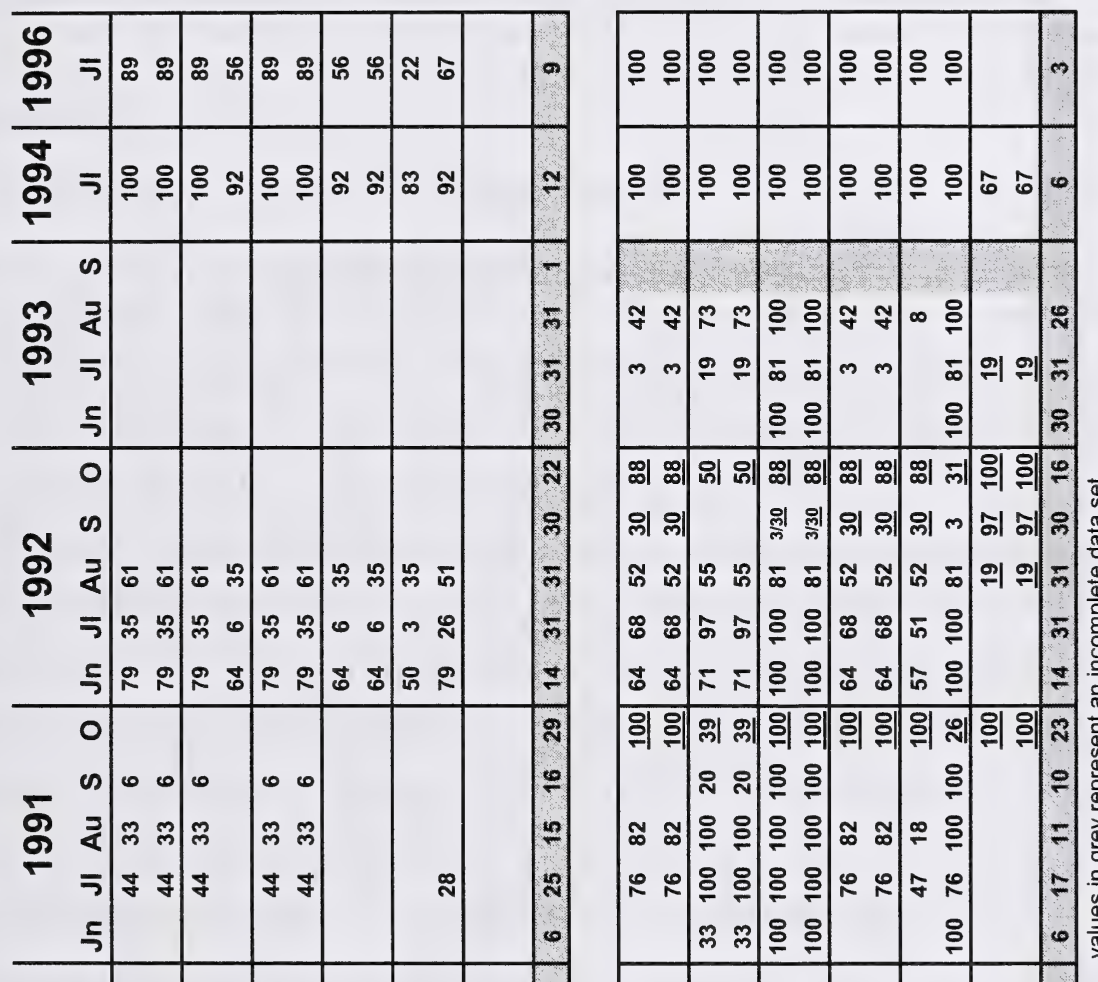

$\frac{\frac{1}{3}}{\frac{1}{3}}$

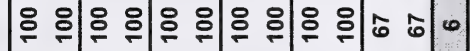

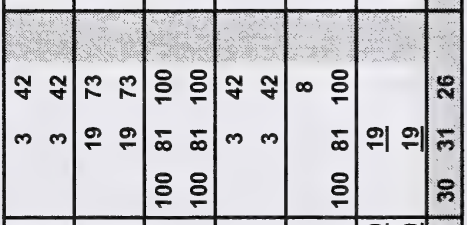

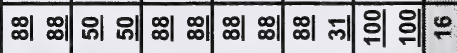

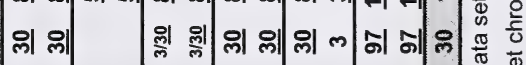

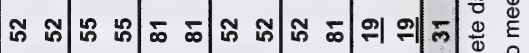

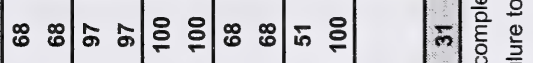

む t

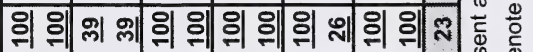

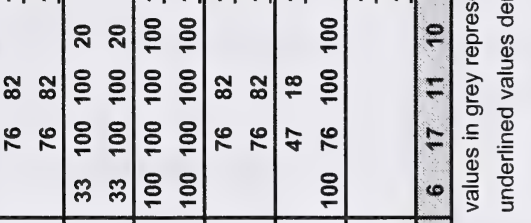

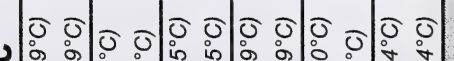

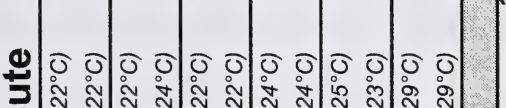

U.

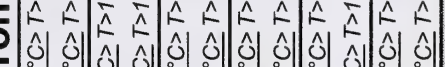

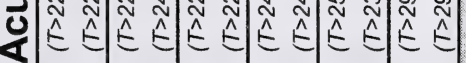

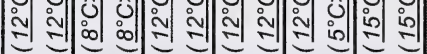

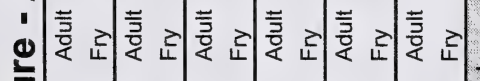

:

亲

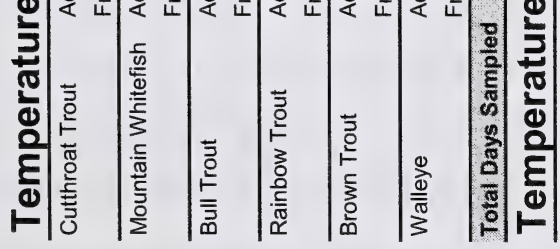

ए 
APPENDIX D

TEMPERATURE-FLOW RELATIONS 


\section{Introduction}

This section provides a technical discussion of heat exchange processes, followed by an exploration of heat exchange processes in the Oldman River via an empirical model. The intent of this section is to explore alternatives to simple linear air temperature and flow-based predictors of water temperature, and to explore in detail the water temperature to flow relation.

Changes in water temperature are controlled by the rate with which heat is exchanged across the boundaries of the water body, and by the rate with which heat is advected in and out of the water body. The influence of these factors on water temperatures has been well characterised through theoretical and statistical analysis, and many models of varying complexity have been developed as a result. The most important of the many interrelated components that determine the magnitude and relative contribution of these factors are explored here, with application to conditions in the Oldman River.

\section{Heat Exchange and Equilibrium Temperature}

Boundary heat exchange takes place across the air-water interface, and across the water-channel bed boundary. While the relative significance of streambed heat flux is a matter of some debate, it is generally agreed that surface heat exchange is the predominant factor in the heat balance. Heat is dissipated from the water surface through back radiation, evaporation, and conduction, and is acquired primarily through incident solar and atmospheric radiation (Edinger et al. 1974, Webb and Zhang 1997). The relative importance of these factors in relation to heat exchange is highly variable. The intensity of incident solar (short wave) radiation varies daily and seasonally, and depends on the extent to which it is depleted by reflection, absorption, and scattering in the atmosphere. The daily variability in solar radiation drives diel water temperature fluctuations directly through short wave solar radiation and indirectly through long wave atmospheric radiation (Sinokrot and Stefan 1993). Atmospheric radiation is solar radiation (primarily) and re-radiated long wave radiation that is absorbed in the atmosphere and emitted in the form of long wave radiation. Atmospheric radiation constitutes the primary thermal input at night, and on cloudy days (Edinger et al. 1974). Canopy and topographic shading affect both short and long wave radiative thermal inputs (Webb and Zhang 1997). While conduction and condensation can both constitute thermal inputs, the magnitude of these inputs relative to solar and atmospheric radiation is often negligible (Web and Zhang 1997).

The relative contribution of heat exchange processes varies in relation to water temperature. While the rate of radiative thermal input is independent of water temperature, the rates of back radiation, evaporation, and conduction are temperature dependent. The rate with which long wave radiation is emitted from the water body varies predominantly as a function of water temperature. Long-wave back radiation typically constitutes the dominant process by which heat is dissipated from a water body (Webb and Zhang 1997, Evans et al. 1998). The rate of heat dissipation through evaporation and conduction is dependent on the difference between air temperature and water temperature. While the rate of conductive heat dissipation is directly proportional to the difference between air temperature and water temperature, the evaporation rate is vapour-pressure dependent and is proportional to the difference between dew-point temperature and water temperature (Edinger et al. 1974). 
It is helpful to discuss factors that affect changes in water temperature in terms of equilibrium temperature. The equilibrium temperature is a concept that describes a condition where the net rate of surface heat exchange is zero (Edinger et al. 1968, 1974). Discounting all other factors, it is the temperature to which the water would equilibrate if all elements of surface heat exchange (meteorological variables) were constant in time. The equilibrium concept was originally conceived to explain heat exchange in lakes, so its strict definition does not account for any element of the heat balance other than surface heat exchange. However, any factor that enters into the gross heat balance can be considered to contribute to equilibrium temperature.

The key feature of the water temperature-equilibrium temperature relationship is that water temperature is continually driven toward equilibrium temperature. The water body gains heat when equilibrium temperature is greater than water temperature, and loses heat when equilibrium temperature is less than water temperature. The rate at which water temperature is driven toward equilibrium temperature is proportional to the difference between water and equilibrium temperatures. This difference is referred to as heat flux, a variable that can be positive or negative. When heat flux at the water surface is positive, the water body is gaining heat, and vice-versa. It follows that mean daily water temperature will tend to approach mean daily equilibrium temperature. If mean daily water temperature is less than mean daily equilibrium temperature, then the net daily heat flux will be positive, driving mean daily water temperature towards mean daily equilibrium temperature. The same is true if net daily heat flux is negative. When net daily heat flux is zero, water temperature has attained a steady state relative to equilibrium temperature.

Equilibrium temperature varies as a function of changing meteorological variables, and therefore describes a cyclic diurnal pattern. This cyclic pattern is reflected in daily water temperature. Water temperature will achieve a relative maximum or minimum value when water temperature is equal to equilibrium temperature. At this point heat flux is zero, and water temperature is neither increasing nor decreasing. In the hypothetical case, where equilibrium temperature describes a more-or-less sinusoidal curve with a relatively constant amplitude and mean value, and water temperature is within the equilibrium temperature range, this point occurs twice daily. Water temperature will achieve a relative minimum at the intersection with the increasing portion of the equilibrium temperature curve, after which point heat flux will be positive. It will achieve a relative maximum at the intersection with the decreasing portion of the equilibrium temperature curve, after which point heat flux will be negative. Depending on the amplitude of the water temperature cycle, this point of intersection can approach the local maximum or minimum of the equilibrium temperature curve or can be delayed such that it approaches the mean value for the equilibrium temperature curve.

\section{Influence of Flow and Air Temperature}

The amplitude of the diel water temperature cycle, relative to that of the equilibrium temperature cycle, is governed in part by the thermal inertia of the water body (Edinger et al. 1968). The thermal inertia of a water body is in turn a function of the volume (mass) of the water body. The thermal inertia of a water body increases as the volume of the water body increases. With increased thermal inertia, the heat flux at the water surface that is required to cause a given 
change in temperature also increases. Therefore, an increase in volume, connected with an increase in flow, will cause water temperature cycles to be damped.

It is important to note that the amplitude of diel temperature cycles measured at a fixed point along a stream is not necessarily equivalent to the amplitude of diel cycles measured for a parcel of water travelling downstream. This is significant where the relative contribution of advected heat exchange is large, as in the segment of the Oldman extending from the reservoir to Rocky Coulee. However, downstream of the Belly River the difference between diel cycles as measured at a fixed point, and those measured for a discreet parcel of water can largely be ignored.

Increased flow also damps the response of water temperature to shifts in the equilibrium curve. This is again a function of the increased thermal inertia under higher flows. This, along with the attenuation of diel cycles, has important implications for water management in regulated rivers, in that high diurnal water temperature can be mitigated to a certain extent by increased instream flows.

The capacity of increased flows to attenuate the amplitude of diel temperature cycles and to damp the response of water temperature to equilibrium shifts makes flow a suitable means by which water management strategies can be implemented to protect aquatic life from high water temperatures. Although many models have been devised, the most practicable solution usually involves a model that comprises relatively few, readily available parameters. By far the most common parameters used in modelling water temperature for the purpose of resource management strategies are flow and air temperature.

Air temperature does not directly influence water temperature. Many studies have shown that conductive heat exchange is a minor component of net surface heat flux, relative to radiative heat flux and evaporative heat loss (Evans et al. 1998, Webb and Zhang 1997, 1999). Air temperature does however provide a reasonable index of equilibrium temperature, and as such is the basis of the vast majority of water temperature models and analyses. The utility of water temperature as an index of equilibrium temperature appears to be limited to a range that extends to a maximum of $20^{\circ} \mathrm{C}$ to $25^{\circ} \mathrm{C}$. This is due to a change in the relative contributions of various heat exchangerelated processes to equilibrium temperature with changing water temperature (Mohseni and Stefan 1999). As air temperature rises, surface heat flux becomes increasingly dominated by evaporative cooling (Mohseni et al. 1998). Evaporative cooling will offset the effects of heat influx, resulting in a weakening of the air temperature-water temperature relationship.

At near-freezing temperatures, the specific heat capacity of water increases, and advective heat inputs (such as the Oldman Reservoir) have a more significant role in moderating downstream temperatures. As a result, the correlation between air temperature and water temperature is very weak. The apparent lag in the response of water temperature to a given change in air temperature becomes more pronounced at cold temperatures, with the result that a given change in air temperature can appear to effect little or no change in water temperature. This does not necessarily imply a change in the air temperature-equilibrium temperature relationship, but is nonetheless an important consideration if spring or autumn data are used in deriving water temperature-air temperature models. 


\section{Framework for a Temperature-Flow Model for the Oldman River}

In view of the nature of this relationship between flow and water temperature, it is clear that to derive a linear model that relates water temperature directly to flow would be inappropriate. In particular, as higher flows typically occur in late spring to early summer, the cooler water temperatures associated with these flows would be attributable as much to lower early season heat influx as to increased flow. A model so derived would be under-protective at high air temperatures.

Gu et al. (1999) proposed a regression model that more accurately addresses the nature of the flow-water temperature relationship. This model first sorts water temperature data and associated flows based on maximum daily heat flux (the difference between equilibrium temperature and water temperature). A non-linear regression equation is then applied to the sorted data, such that a curve is derived for each set of reference parameters. This model permits the uncoupling of weather from the water temperature-flow relationship, avoiding the limitations of linear flow to water temperature to air temperature models.

We have applied the regression model derived by Gu et al. (1999), with some modification, to post-impoundment (1993-1999) data from the Oldman River in order to illustrate its potential applicability to water management in the Oldman Basin. Data for 2000 and 2001 were not available until following the completion of model calculations, and are therefore not included in the model. For each monitoring site, daily maximum water temperature and daily mean discharge are sorted by daily maximum air temperature, in $5^{\circ} \mathrm{C}$ increments. The data used are for the period of June 1 to September 15. This period was chosen to minimise the lag inherent to the early- and late-season air temperature-water temperature relationship, and to capture a period of relative uniformity in the temperature at the reservoir outflow. This is not ideal, as the outflow temperature can vary by as much as $5^{\circ} \mathrm{C}$ during this period. However, as the reservoir exerts little influence downstream of Lethbridge, the problem of outflow variability is less significant there.

The regression equation applied to the sorted data is of the form $T_{\max }=a Q^{b}$, where $T_{\max }$ is maximum daily water temperature and $\mathrm{Q}$ is the corresponding mean daily discharge. This function does not strictly describe the temperature-flow relationship, which would probably be more aptly described by an S-shaped function (at least at higher temperature ranges; e.g., Mohseni and Stefan 1999). However, because of the considerable scatter in the data and because of the lack of data in the area of critically low flow, it provides the best fit. The model was estimated using a Gauss-Newton algorithm in SYSTAT 10.

The substitution of maximum daily heat flux with maximum daily air temperature is not ideal. The equivalence of heat flux with air temperature should not be inferred from this substitution. Heat flux is intrinsically coupled to water temperature; while air temperature is functionally related to water temperature, the relationship is not intrinsic. Nor should the difference between air temperature and water temperature be taken to be equivalent to heat flux; this would imply that air temperature and equilibrium temperature could be applied interchangeably, which they should not be (Edinger et al. 1968). However, as discussed, air temperature can provide a 
reasonable index of equilibrium temperature, and its application is more practical in that a reasonably reliable forecast of maximum daily air temperature can be obtained several days in advance.

The model is illustrated in Figures 1-4, along with data used in its derivation. Model statistics, and the values of the model coefficients, are given in Table 1 . The Wald 95\% confidence interval (WCI) is given for each model coefficient. The $\mathrm{r}^{2}$ value shown is for observed vs. predicted values. Regressions with $r^{2}$ values that are less than 0.150 are not included in figures 1-4.

The tendency of the regression lines illustrates the moderating effect of flow on water temperature that becomes apparent when the confounding effect of weather is uncoupled from the relationship. Near Brocket the slope is more illustrative of the error that is introduced by seasonal temperature fluctuations at the reservoir outlet, as surface heat flux probably has little influence on water temperature at this site. To some degree, the same is true for the sites downstream of the LNHD and near Fort Macleod, as higher flows tend to occur when reservoir temperatures are relatively cool, resulting in downward sloping regression lines. Farther downstream, there is a very general tendency for the slope of the regression lines to increase with increasing air temperature (slope coefficient $b$ becomes more negative). This is the expected pattern, as the regression lines should intersect with the Y-axis (zero flow) at a point that approximately corresponds with the heat input, here approximated by air temperature. While in theory the regression lines should converge at some very high flow, this would be unlikely to occur in practice, as the warmer air temperatures typically coincide with warmer reservoir temperatures. Diversion from the expected pattern is primarily a result of a lack of data at low flows, again compounded by the variability in the data. It must be noted that in the lowest temperature ranges for the sites near Rocky Coulee, upstream of Lethbridge, and near the mouth, the upper confidence interval for the slope coefficient $b$ is positive. This is again an attribute of the tendency of the regression lines to become steeper with increasing air temperature. It is expected that at progressively lower temperatures, the regression lines would attain a positive slope (slope coefficient $b$ becomes more positive).

Another feature of the slope of the regression line is that it indicates the sensitivity of river temperatures to meteorological variables (air temperature) at a given flow. Below flows of approximately $40 \mathrm{~m}^{3} \mathrm{~s}^{-1}$ the regression line becomes steeper, signifying a stronger influence of meteorological variables (air temperature) over water temperatures.

The relatedness of the regression models to actual data $\left(r^{2}\right)$ tends to be weak. Several factors probably account for the low $\mathrm{r}^{2}$ values:

- The large variation reflects the lag in the response of water temperature to a change in air temperature. Large, short-term changes in air temperature that probably have little effect on water temperature are still reflected in the model. While this is moderated by the exclusion of data from the spring and autumn, it still results in considerable scatter. Presumably, this could be addressed by sorting the water temperature data based on air temperature from the previous few days; however, the failure of the model to account for the 'history' of water temperatures presents a major shortfall. 
- $\quad$ Reservoir outflow temperatures, which increase steadily over the period from June 1 through September 15, further contribute to the scatter of water temperature data relative to discharge. As a result, higher flows in June will depress downstream temperatures substantially more than higher flows in August. This is most true at sites directly downstream of the reservoir; downstream of Lethbridge, the contribution of reservoir temperature to low $r^{2}$ values is minimal.

- $\quad$ Because the data are sorted in increments of $5^{\circ} \mathrm{C}$, further scatter of a comparable order should be expected.

- $\quad$ Because post-impoundment flows used in deriving the model rarely approach the critically low values that define the portion of the curve where it is inflected strongly upwards, the fit of the regression curve to the available data is not optimal.

- Data points that coincide with the release of water over the spillway were not excluded from the model; however, this shortfall is again of little significance downstream of Lethbridge.

As it is presented, the model is not sufficiently robust to permit its application to water management in the Oldman River. The error that results from the considerable scatter in the data is too great to permit much confidence in the slope coefficient $(b)$. It does, however, indicate that the effect of flow on water temperature is more pronounced at flows below approximately $20-30 \mathrm{~m}^{3} \mathrm{~s}^{-1}$, while flows in excess of $40 \mathrm{~m}^{3} \mathrm{~s}^{-1}$ have a negligible effect on water temperature (cf. Gu et al., 1999). It may be worthwhile to further explore the possibilities of isolating stream flow from meteorological effects, in an effort to control maximum stream temperatures. The error may be reduced if data were sorted based on heat input from the previous two or three days, by either averaging or summing these values. The suitability of air temperature as an index of equilibrium temperature should also be explored.

\section{Conclusions}

By sorting maximum water temperature data into categories of maximum air temperature, it is possible to isolate the effect of flow on water temperature variability from that of heat flux. This permits an assessment of the effect of flow regulation on downstream water temperature, showing that (a) the moderating influence of the reservoir outflow temperature persists to Monarch and possibly to Lethbridge, and (b) the influence of flow regulation on water temperature is most pronounced at flows below approximately $20-30 \mathrm{~m}^{3} \mathrm{~s}^{-1}$. While this model illustrates the extent of the effect of flow regulation by the Oldman River Reservoir on downstream water temperature, it is not sufficiently robust as to be a reliable predictive tool for water managers. 
Table 1 Non-linear regression of flow on maximum water temperature $\left(T_{w} m a x=a Q^{b}\right)$, sorted by maximum air temperature for the period of June 1 to September 15

\begin{tabular}{|c|c|c|c|c|c|c|c|c|}
\hline SITE & $\begin{array}{c}\text { Air } \\
\text { Temperature } \\
\text { Range }\left({ }^{\circ} \mathrm{C}\right)\end{array}$ & a & $\begin{array}{r}\text { Wald } \\
\text { Confidenc } \\
\text { upper }\end{array}$ & $\begin{array}{l}5 \% \\
\text { Interval } \\
\text { lower }\end{array}$ & b & $\begin{array}{r}\text { Walo } \\
\text { Confiden } \\
\text { upper }\end{array}$ & $\begin{array}{l}5 \% \\
\text { Interval } \\
\text { lower }\end{array}$ & $r^{2}$ \\
\hline \multirow{5}{*}{ Brocket } & $10-15$ & 27.470 & 35.468 & 19.472 & -0.209 & -0.139 & -0.279 & 0.503 \\
\hline & $15-20$ & 29.374 & 35.521 & 23.227 & -0.231 & -0.179 & -0.283 & 0.452 \\
\hline & $20-25$ & 38.963 & 44.678 & 33.249 & -0.297 & -0.258 & -0.335 & 0.618 \\
\hline & $25-30$ & 37.041 & 43.966 & 30.115 & -0.283 & -0.232 & -0.334 & 0.546 \\
\hline & $30-35$ & 23.968 & 37.522 & 10.414 & -0.157 & 0.002 & -0.315 & 0.107 \\
\hline \multirow{4}{*}{ LNHD } & $10-15$ & 20.063 & 22.009 & 18.116 & -0.111 & -0.087 & -0.135 & 0.678 \\
\hline & $15-20$ & 20.735 & 22.132 & 19.339 & -0.100 & -0.083 & -0.118 & 0.539 \\
\hline & $20-25$ & 22.864 & 23.769 & 21.959 & -0.105 & -0.095 & -0.116 & 0.670 \\
\hline & $25-30$ & 25.378 & 26.836 & 23.919 & -0.118 & -0.100 & -0.136 & 0.602 \\
\hline \multirow{5}{*}{ Fort Macleod } & $10-15$ & 15.577 & 17.886 & 13.268 & -0.051 & -0.018 & -0.084 & 0.340 \\
\hline & $15-20$ & 19.672 & 21.562 & 17.781 & -0.085 & -0.058 & -0.111 & 0.358 \\
\hline & $20-25$ & 25.472 & 26.818 & 24.125 & -0.130 & -0.115 & -0.145 & 0.648 \\
\hline & $25-30$ & 31.038 & 33.548 & 28.527 & -0.164 & -0.139 & -0.189 & 0.617 \\
\hline & $30-35$ & 30.322 & 34.270 & 26.374 & -0.144 & -0.102 & -0.185 & 0.569 \\
\hline \multirow{4}{*}{ Rocky Coulee } & $10-15$ & 17.009 & 21.775 & 12.242 & -0.053 & 0.008 & -0.114 & 0.371 \\
\hline & $15-20$ & 19.925 & 22.793 & 17.056 & -0.072 & -0.036 & -0.108 & 0.306 \\
\hline & $20-25$ & 25.231 & 27.875 & 22.587 & -0.107 & -0.079 & -0.134 & 0.437 \\
\hline & $25-30$ & 26.234 & 29.070 & 23.399 & -0.084 & -0.053 & -0.115 & 0.259 \\
\hline \multirow{5}{*}{ Monarch } & $10-15$ & 22.009 & 27.103 & 16.915 & -0.104 & -0.044 & -0.164 & 0.391 \\
\hline & $15-20$ & 23.526 & 26.005 & 21.047 & -0.101 & -0.073 & -0.130 & 0.358 \\
\hline & $20-25$ & 30.315 & 32.498 & 28.131 & -0.133 & -0.113 & -0.154 & 0.466 \\
\hline & $25-30$ & 36.435 & 39.652 & 33.219 & -0.158 & -0.131 & -0.184 & 0.500 \\
\hline & $30-35$ & 39.130 & 45.054 & 33.205 & -0.159 & -0.110 & -0.207 & 0.377 \\
\hline \multirow{5}{*}{ Belly } & $10-15$ & 20.573 & 25.316 & 15.830 & -0.081 & -0.036 & -0.126 & 0.493 \\
\hline & $15-20$ & 24.871 & 27.233 & 22.509 & -0.102 & -0.081 & -0.123 & 0.555 \\
\hline & $20-25$ & 26.719 & 28.626 & 24.811 & -0.094 & -0.078 & -0.111 & 0.431 \\
\hline & $25-30$ & 29.838 & 32.326 & 27.350 & -0.098 & -0.077 & -0.119 & 0.345 \\
\hline & $30-35$ & 29.143 & 33.541 & 24.744 & -0.067 & -0.025 & -0.109 & 0.134 \\
\hline \multirow{5}{*}{ u/s Lethbridge } & $10-15$ & 21.136 & 29.731 & 12.540 & -0.071 & 0.015 & -0.156 & 0.152 \\
\hline & $15-20$ & 22.372 & 25.448 & 19.295 & -0.068 & -0.038 & -0.099 & 0.185 \\
\hline & $20-25$ & 23.256 & 25.075 & 21.436 & -0.054 & -0.037 & -0.071 & 0.167 \\
\hline & $25-30$ & 26.048 & 28.457 & 23.638 & -0.062 & -0.039 & -0.084 & 0.150 \\
\hline & $30-35$ & 28.488 & 31.995 & 24.902 & -0.065 & -0.032 & -0.098 & 0.192 \\
\hline \multirow{4}{*}{ d/s Lethbridge } & $15-20$ & 23.293 & 27.322 & 19.263 & -0.070 & -0.031 & -0.110 & 0.217 \\
\hline & $20-25$ & 24.393 & 26.779 & 22.007 & -0.060 & -0.038 & -0.083 & 0.198 \\
\hline & $25-30$ & 28.798 & 31.886 & 25.710 & -0.080 & -0.053 & -0.107 & 0.228 \\
\hline & $30-35$ & 34.816 & 40.555 & 29.077 & -0.110 & -0.064 & -0.156 & 0.295 \\
\hline \multirow{5}{*}{ Mouth } & $10-15$ & 18.287 & 27.700 & 8.875 & -0.021 & 0.087 & -0.129 & 0.024 \\
\hline & $15-20$ & 19.078 & 23.092 & 15.064 & -0.025 & 0.016 & -0.067 & 0.034 \\
\hline & $20-25$ & 26.555 & 30.456 & 22.653 & -0.064 & -0.033 & -0.069 & 0.212 \\
\hline & $25-30$ & 35.408 & 40.044 & 30.773 & -0.102 & -0.071 & -0.134 & 0.567 \\
\hline & $30-35$ & 35.958 & 41.972 & 29.944 & -0.093 & -0.048 & -0.139 & 0.643 \\
\hline
\end{tabular}



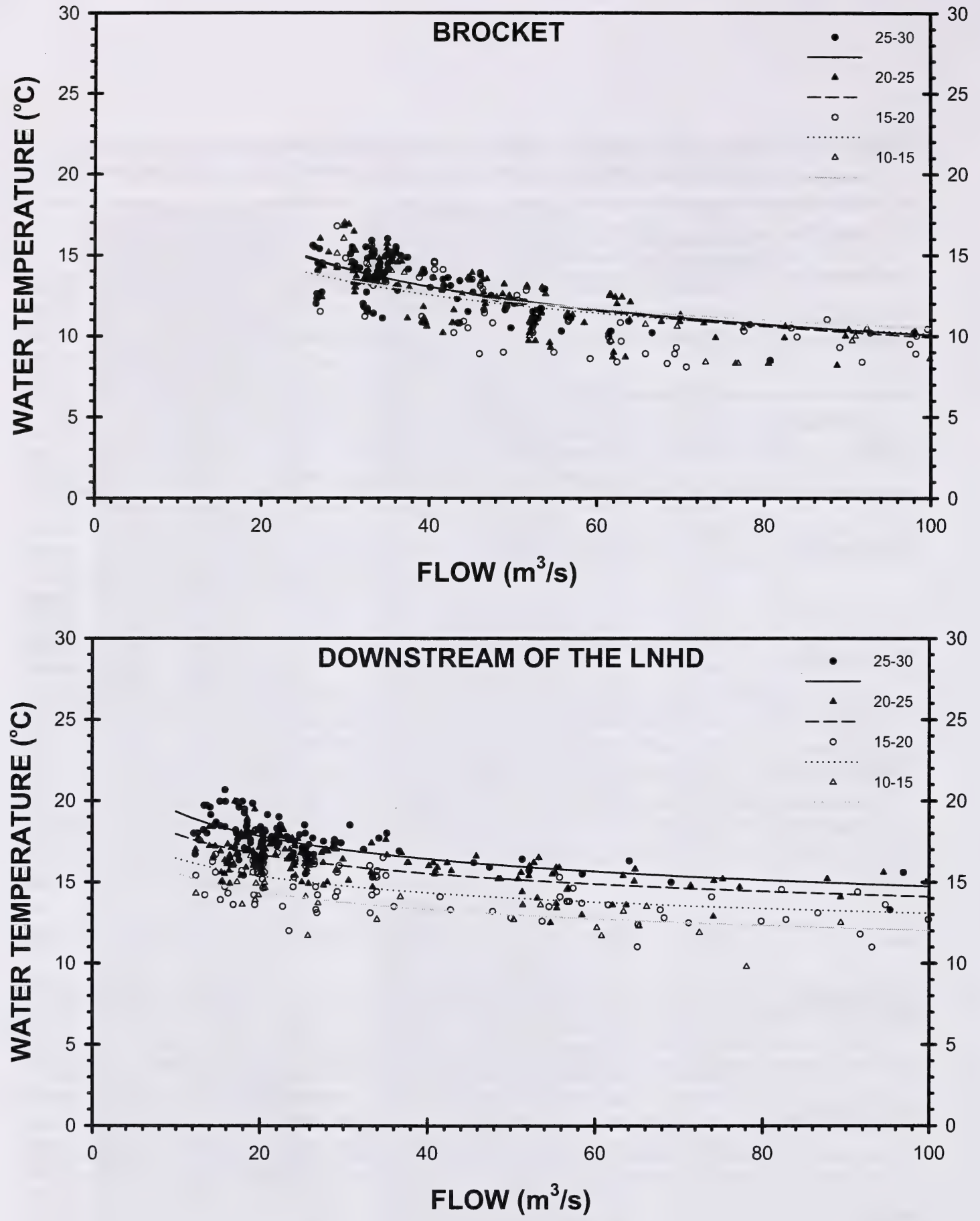

Figure 1. Water temperature vs. flow (nonlinear regression of the form $T=a Q^{b}$ ) in the Oldman River near Brocket and downstream of the LNHD, sorted for air temperature ranges of $5^{\circ} \mathrm{C}$ (post-imoundment). 

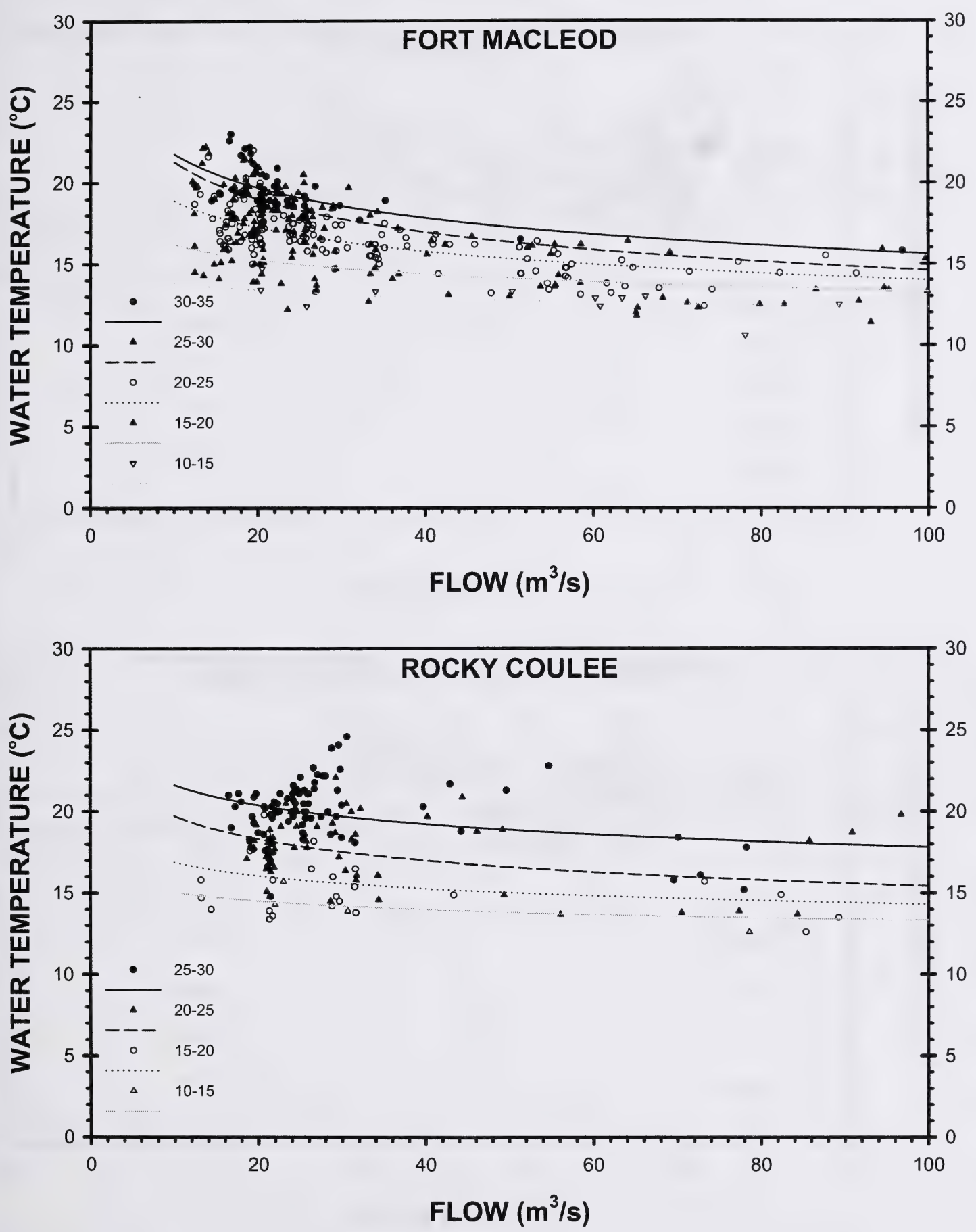

Figure 2. Water temperature vs. flow (nonlinear regression of the form $T=a^{b}$ ) in the Oldman River near Fort Macleod and Rocky Coulee, sorted for air temperature ranges of $5^{\circ} \mathrm{C}$ (post-imoundment). 

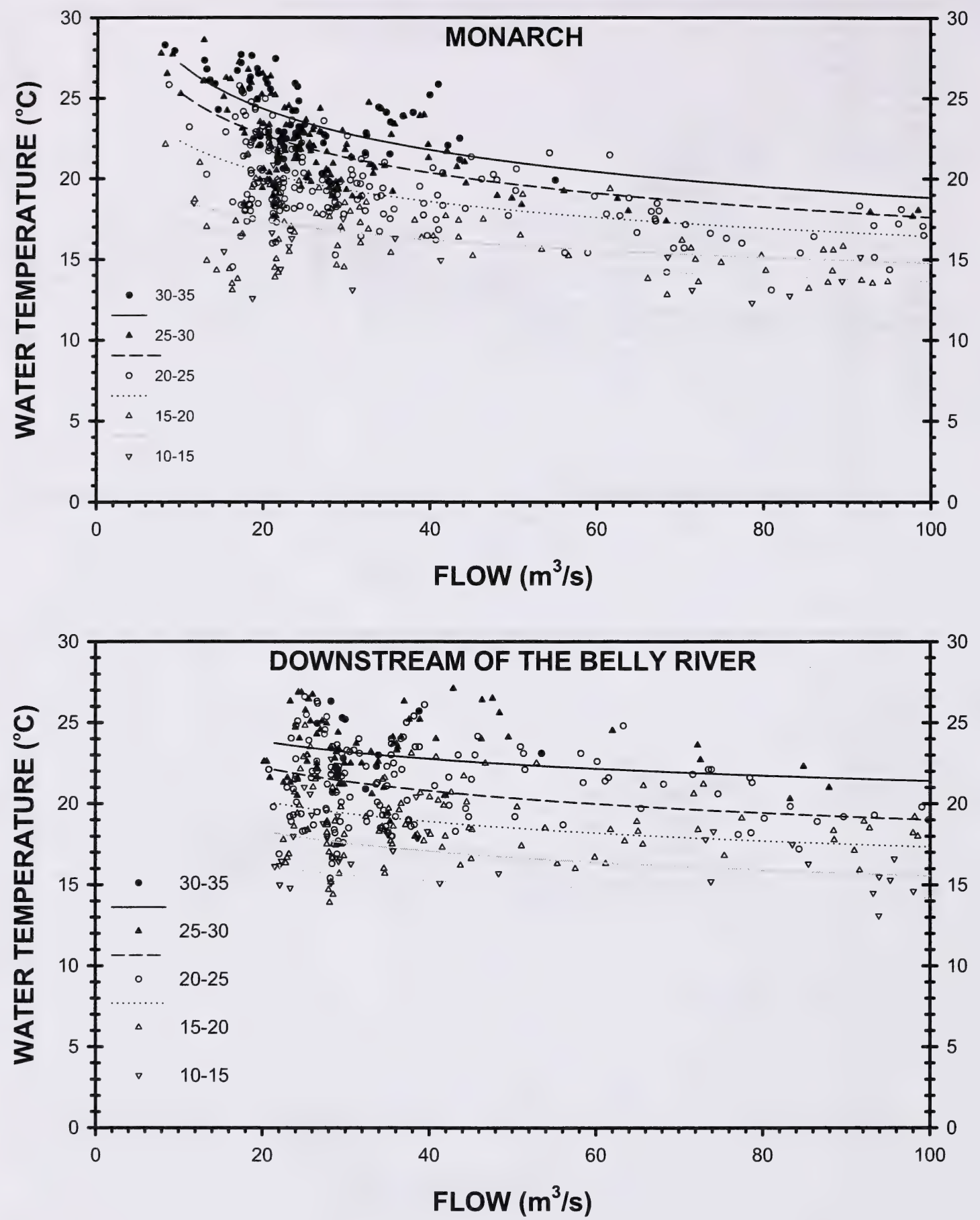

Figure 3. Water temperature vs. flow (nonlinear regression of the form $T=a Q^{b}$ ) in the Oldman River near Monarch and downstream of the Belly River, sorted for air temperature ranges of $5^{\circ} \mathrm{C}$ (post-imoundment). 


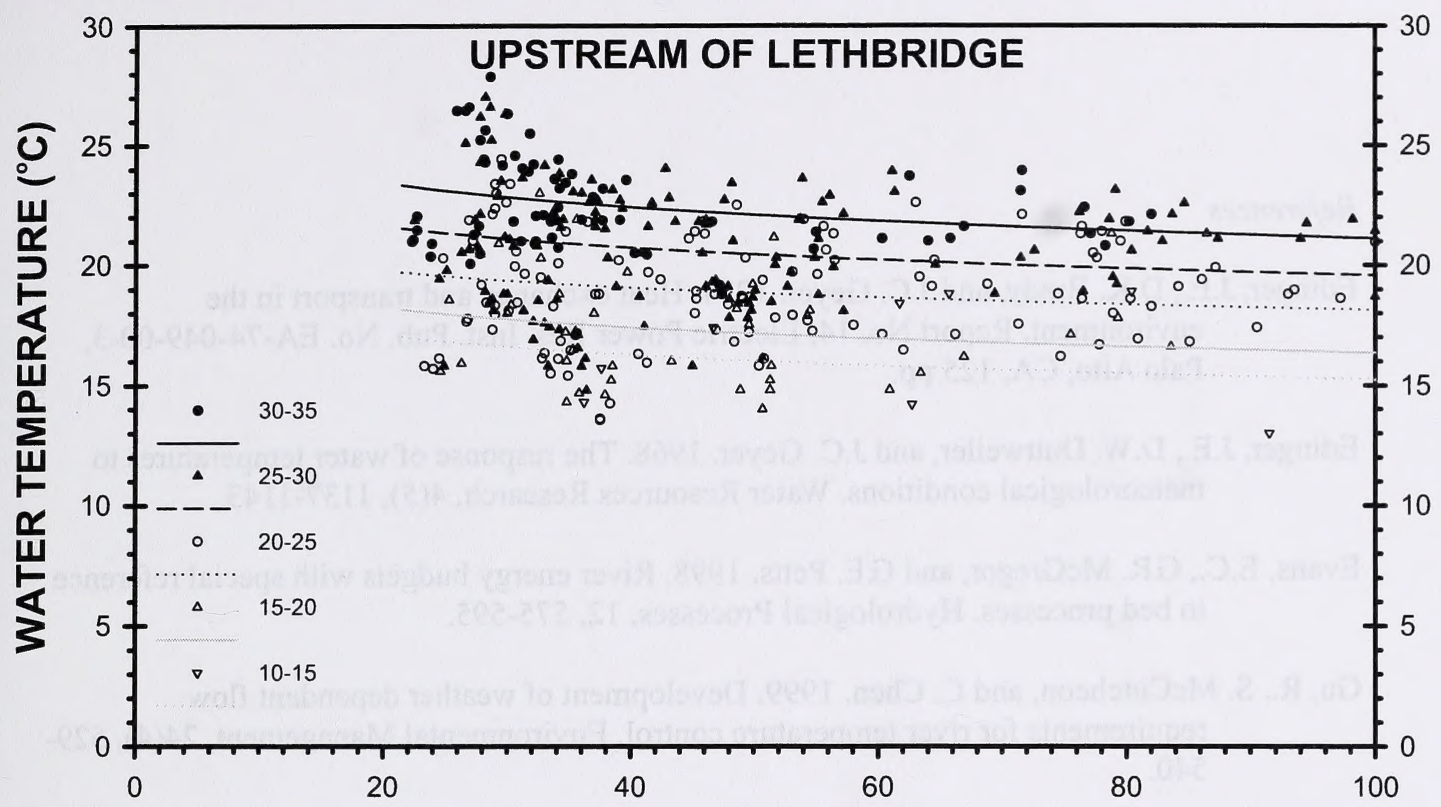

FLOW $\left(\mathrm{m}^{3} / \mathrm{s}\right)$

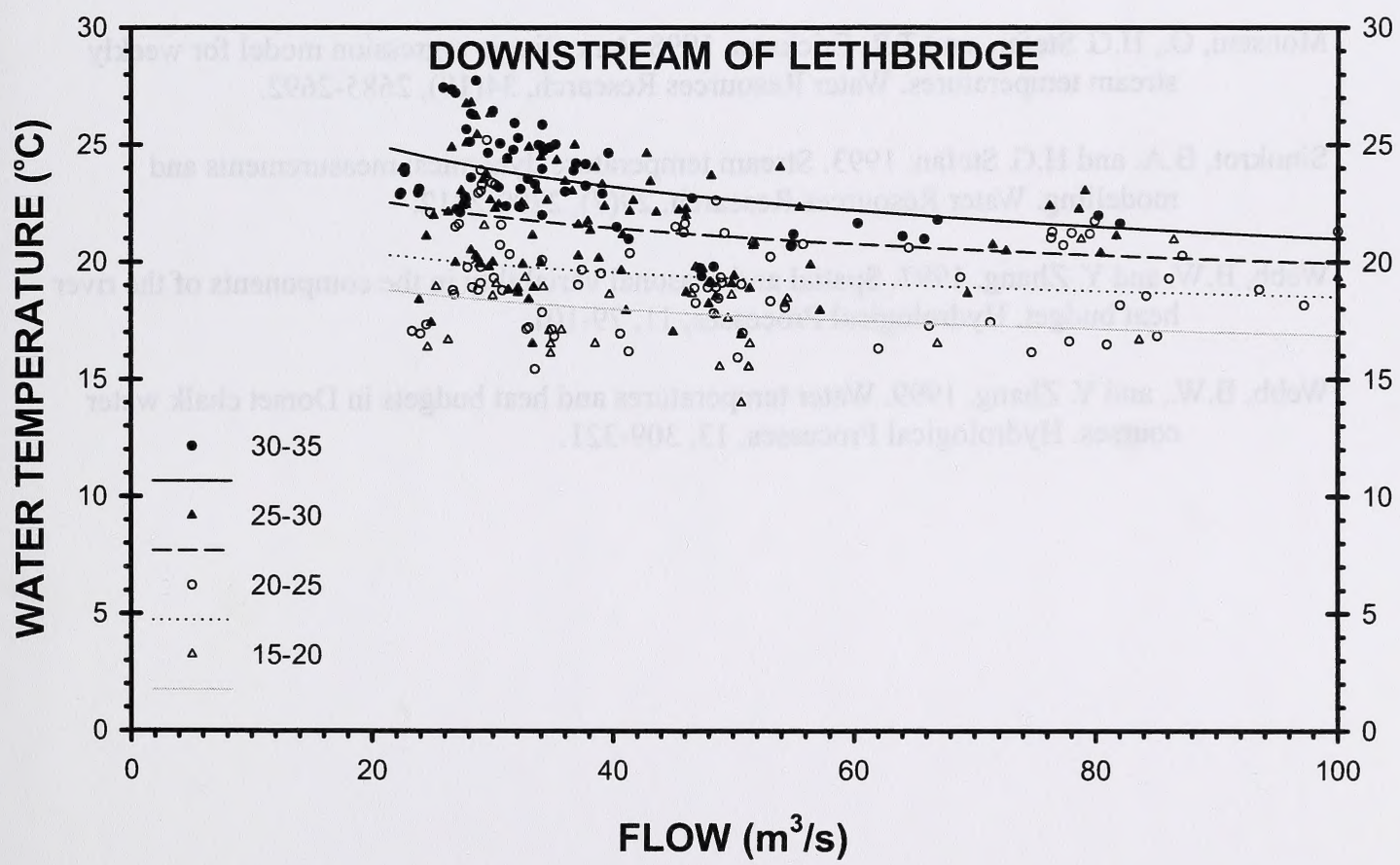

Figure 4. Water temperature vs. flow (nonlinear regression of the form $T=a^{b}$ ) in the Oldman River upstream and downstream of Lethbridge, sorted for air temperature ranges of $5^{\circ} \mathrm{C}$ (post-imoundment). 
References

Edinger, J.E., D.K. Brady, and J.C. Geyer. 1974. Heat exchange and transport in the environment. Report No. 14, Electric Power Res. Inst. Pub. No. EA-74-049-00-3, Palo Alto, CA, 125 pp.

Edinger, J.E., D.W. Duttweiler, and J.C. Geyer. 1968. The response of water temperatures to meteorological conditions. Water Resources Research, 4(5), 1137-1143.

Evans, E.C., G.R. McGregor, and G.E. Petts. 1998. River energy budgets with special reference to bed processes. Hydrological Processes, 12, 575-595.

Gu, R., S. McCutcheon, and C. Chen. 1999. Development of weather dependent flow requirements for river temperature control. Environmental Management, 24(4), 529540 .

Mohseni, O., and H.G. Stefan. 1999. Stream temperature/air temperature relationship: a physical interpretation. Journal of Hydrology. 218, 128-141.

Mohseni, O., H.G. Stefan, and T.R. Erickson. 1998. A nonlinear regression model for weekly stream temperatures. Water Resources Research, 34(10), 2685-2692.

Sinokrot, B.A. and H.G. Stefan. 1993. Stream temperature dynamics: measurements and modelling. Water Resources Research, 29(7), 2299-2312.

Webb, B.W. and Y. Zhang. 1997. Spatial and seasonal variability in the components of the river heat budget. Hydrological Processes, 11, 79-101.

Webb, B.W., and Y. Zhang. 1999. Water temperatures and heat budgets in Dorset chalk water courses. Hydrological Processes, 13, 309-321. 

LIBRARY AND ARCHIVES CANADA

Bibliothèque et Archives CANADA

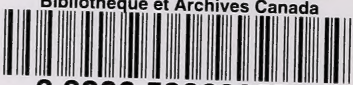

33286538602570 